\title{
Experimental investigations for the modelling of anhydritic swelling claystones
}

\section{Monograph}

\section{Author(s):}

Wanninger (-Huber), Tara

Publication date:

2020-06

\section{Permanent link:}

https://doi.org/10.3929/ethz-b-000424076

\section{Rights / license:}

In Copyright - Non-Commercial Use Permitted

\section{Originally published in:}

Veröffentlichungen des Instituts für Geotechnik (IGT) der ETH Zürich 255, https://doi.org/10.3218/4012-8 


\section{Experimental investigations for the modelling of anhydritic swelling claystones}

Tara Wanninger (-Huber) 
Weitere aktuelle vdf-Publikationen finden Sie in unserem Webshop:

\section{vdf.ch}

, Bauwesen

, Naturwissenschaften, Umwelt und Technik

, Informatik, Wirtschaftsinformatik und Mathematik
, Wirtschaft

, Geistes- und Sozialwissenschaften, Interdisziplinäres, Militärwissenschaft, Politik, Recht

\section{Gerne informieren wir Sie regelmässig per E-Mail über unsere Neuerscheinungen.}

\section{Newsletter abonnieren}

Anmeldung auf vdf.ch 


\section{Experimental investigations for the modelling of anhydritic swelling claystones}

Tara Wanninger (-Huber)

Veröffentlichungen des Instituts für Geotechnik (IGT) der ETH Zürich

Band 255, Juni 2020 
ETH-Dissertation Nr. 25879

(C) 2020, vdf Hochschulverlag AG an der ETH Zürich

ISBN: 978-3-7281-4011-1 (Printversion)

ISBN: 978-3-7281-4012-8 (E-Book)

Bibliografische Information der Deutschen Nationalbibliothek Die Deutsche Nationalbibliothek verzeichnet diese Publikation in der Deutschen Nationalbibliografie; detaillierte bibliografische Daten sind im Internet über http://dnb.d-nb.de abrufbar. 
Anhydritführende Tonsteine sind stark quellfähig. Sie erfahren unter Wasseraufnahme eine Volumenvergrösserung von bis zu 30-40\%. Im Tunnelbau äussert sich das Quellen der Gesteine durch eine Hebung der Tunnelsohle, welche für die Gebrauchstauglichkeit problematisch ist oder - beim Vorhandensein eines Sohlgewölbes - durch die Entwicklung des sogenannten Quelldrucks, welcher das Gewölbe zerstören oder sogar als Ganzes anheben kann. Anhydritführende Tonsteine werden in der Schweiz in der geologischen Formation des Gipskeupers angetroffen. Sie haben oft grosse Schäden verursacht, deren Behebung war äusserst kostspielig, zeitaufwendig und mit Betriebsunterbrechungen verbunden. Der Tunnelbau im Gipskeuper ist heute noch mit grossen Unsicherheiten behaftet, da weder die makroskopischen Gesetzmässigkeiten des Quellens (insbesondere die für den konzeptuellen Entwurf von Tunnelgewölben sehr wichtige Beziehung zwischen Quelldehnung und Quelldruck) noch die zugrundeliegenden chemischen Prozesse (Lösung von Anhydritkristallen ins Porenwasser und anschliessend Bildung von Gipskristallen) gut verstanden sind.

Im Rahmen eines langjährigen Forschungsprojekts der Professur für Untertagbau wird die Wechselwirkung zwischen den chemischen Reaktions- und Transportvorgängen und den makroskopisch beobachteten Quelldehnungen und -drücken theoretisch und experimentell untersucht mit dem Ziel, die Quellvorgänge im Gipskeuper besser zu verstehen und wissenschaftlich fundierte Grundlagen für die Planung von Tunnels in solchem Gebirge zu erarbeiten. Die Wissenslücken bezüglich des Quellverhaltens anhydritführender Tonsteine sind grösstenteils durch das Fehlen systematischer experimenteller Untersuchungen zu den chemisch-mechanischen Prozessen bedingt, die dem Quellvorgang zugrunde liegen. Solche Untersuchungen werden durch die Heterogenität natürlicher Proben, die sehr lange Dauer des Quellvorgangs (mehrere Jahre selbst unter Laborbedingungen) und die Überlappung von zwei grundsätzlich unterschiedlichen Prozessen (osmotisches Quellen der Tonphase, chemisches Quellen des Anhydrits) erschwert. Hier setzt die vorgelegte Dissertationsschrift an.

Frau Wanninger hat auf der Grundlage von umfangreichen, zeitaufwendigen und sorgfältig geplanten und interpretierten Experimenten an künstlichen Proben und natürlichen anhydritführenden Tonsteinen Grundlagenkenntnisse über mehrere Aspekte des Quellvorgangs gewonnen. Das Thema ist wissenschaftlich anspruchsvoll und für die Praxis relevant. Die von Frau Wanninger erarbeiteten Grundlagenkenntnisse sind für weiterführende Untersuchungen, insbesondere für die kontinuumsmechanische Modellierung des Quellens anhydritführender Tonsteine, sehr wertvoll.

Prof. Dr. G. Anagnostou 

I would like to express my gratitude to Prof. Dr. Georg Anagnostou (ETH Zurich) for offering me to be a part of this challenging research project and giving me the opportunity to write this thesis in his group. I appreciate his guidance and support during this work.

I would also like to thank Prof. Dr. Peter Huggenberger and Prof. Dr. Flatt for agreeing to be coexaminers of this $\mathrm{PhD}$ thesis and offering their comments on this work.

I am grateful to Dr. Erich Pimentel, who co-supervised this work, planned and designed most of the apparatuses for the experimental investigations and supported me with the interpretations and the discussions of the results. Furthermore, I would like to thank our technician, T. Heierli, for manufacturing many of the apparatuses and helping with carrying out the experiments.

This $\mathrm{PhD}$ thesis is part of the research project "Modelling of Anhydritic Swelling Claystones" which is financed by the Swiss National Science Foundation (SNF) and the Swiss Federal Roads Office (FEDRO). Their support is greatly acknowledged. I am furthermore thankful to my co-workers whose PhD theses are also a part of this research project: Dr. K. Serafeimidis for his theoretical groundwork and the thematical exchanges we have had, and A. Nousiou, whose motivation for her future research on this topic and implementation of my results is very uplifting.

For the experiments presented herein, we were allowed to collect and use sample materials from different sites in Switzerland and I would like to thank the people and companies who enabled this: T. Zieger, SBB, and B. Rick, Dr. von Moos AG (Bözberg samples); F. Amann, ETH (1 ${ }^{\text {st }}$ series Belchen samples); Pfirter, Nyfeler + Partner AG ( $2^{\text {nd }}$ series Belchen samples); the engineering association IG BL-STB ( $3^{\text {rd }}$ series Belchen samples); G. Frey, Rigips (Leissigen samples); L. Maret, Fixit AG (Bex samples).

Furthermore, I would like to thank my colleagues at ETH Zurich for their generous help, valuable inputs and interesting discussions. Particularly the support of Dr. M. Plötze and his technical assistants at the Clay Lab of the ETH, A. Röthlisberger and M. Rothaupt, is greatly appreciated. A great number of analyses (such as mineralogical and structural investigations) were conducted at the Clay Lab. Special thanks also go to researchers within the group of Prof. Dr. Flatt: A. M. Aguilar Sanchez for her help with the microscopic investigations, Dr. S. Mantellato for her help with the ICP measurements and Dr. T. Wangler for his appreciated continuous interest in our work and the numerous and very insightful discussions and advice he offered over the past years.

I would also like to thank M. Kunz (2014 and 2016), D. Werlen (2015), C. Jost (2016), V. Rogenmoser (2016) and A. Kaiser (2017) for their contribution in carrying out experimental investigations within this project during their Bachelor's theses and later as part-time assistants.

Finally, I would like to thank my family and friends for their unwavering support. Particularly my father, Thomas, for proof-reading parts of my thesis and my brother, Thomas, for helping me with countless grammatical crises. I dedicate this thesis to my husband, Flavio, who also proof-read my thesis and had the patience to stand by me and encourage me throughout the entire dissertation, and to our son Liam, who provides me simultaneously with restless nights and with balance in life. 

Anhydritic claystones are highly problematic for underground construction because of their swelling ability: When the rock comes into contact with water, the rock volume expands due to swelling of both clay as well as anhydrite. When the expansion is restricted, e.g., by an invert arch in tunneling, the swelling rocks can exert high pressures on the lining and damage the structure. The swelling behavior of purely argillaceous rock (containing solely swelling clays and no anhydrite) can be attributed mainly to osmotic processes and is well understood for the conceptual design of tunnels, as opposed to the swelling of anhydrite where considerable knowledge gaps exist.

Swelling of anhydrite is caused by chemical processes: The anhydrite dissolves when it comes into contact with water, and gypsum precipitates from the dissolved ions in the pore water. The volume of gypsum is greater than that of anhydrite by $61 \%$. During Anhydrite to $\underline{\text { Gypsum }}$ Transformation (hereafter denoted as AGT) the rock mass expands and the pore volume can also increase, for example due to cracking of the rock induced by the pressure exerted by the growing crystals upon a rigid rock structure ("crystallization pressure").

Although AGT-induced problems in tunneling have been known since 150 years, the current state of research concerning the swelling behavior of anhydritic rock still contains many knowledge gaps. These gaps exist due to the fact that only very few systematic experimental investigations were carried out on a fundamental basis, which examine and quantify the chemo-mechanical processes during AGT - a consequence of the long duration of the swelling process which can take several years to complete.

This $\mathrm{PhD}$ thesis seeks to establish a better understanding and quantification of the coupled chemomechanical swelling processes due to AGT and creates a basis for developing chemo-mechanical models of the swelling of anhydritic claystones. Fundamental experiments were performed to verify existing kinetic models concerning AGT and systematic swelling experiments were conducted to support the formulation of a constitutive chemo-mechanical model that considers the strains and stresses resulting from anhydrite dissolution and gypsum precipitation. Furthermore, swelling experiments with anhydritic claystones were carried out to investigate simultaneous swelling of anhydrite and clay and to quantify their respective contributions to the observed swelling of the rock.

The kinetics of AGT was investigated by dissolving anhydrite powder in water and indirectly determining the amount of calcium and sulfate ions in the water through conductivity measurements. This led to the following observations: (i) the equilibrium concentration of gypsum as calculated from a theoretical model could be verified; (ii) the calculated equilibrium concentration of anhydrite is higher than the measured concentrations and could not be reached due to the consumption of ions during gypsum precipitation; (iii) a higher initial mass of anhydrite in water causes a higher peak in ion concentration and accelerates the process of AGT; (iv) the reaction takes longer than expected and thus the assumed reaction rate constants and kinetic model could not be confirmed; (v) an addition of "foreign" minerals to the solution influences the timedevelopment of calcium and sulfate ion concentration in the water.

When pure, massive anhydritic rock comes in contact with water, a porous gypsum surface coating on the anhydrite surface forms, which impedes further hydration (so-called "self-sealing" of anhydrite). With the aim of verifying an existing mathematical model which quantifies said effect, multiple anhydritic platelets were immersed in water and the developing gypsum surface coating 
was observed qualitatively with photography over a span of up to three years, as well as quantitatively with microscopic investigations. The shape and spatial distribution of the gypsum varied depending on the testing temperature and the texture of the initial rock. However, the thickness of the developing gypsum layers was well within the theoretically predicted values.

The relationship between swelling stress and swelling strain is of great conceptual importance for the design of underground structures in anhydritic rock. Therefore, a major part of this thesis focuses on quantifying the strains and stresses resulting from anhydrite dissolution and gypsum precipitation and relating them to the respective mass changes.

In mathematical chemo-mechanical models, also described in this work, the relationship between the AGT-induced macroscopically observed strains and the mass of transformed anhydrite is expressed by a material parameter $\chi$ (which is a material tensor and is hereafter referred to as coupling parameter). After a qualitative discussion of the meaning of this parameter on the basis of conceptual models, an extensive, systematic experimental campaign was undertaken to quantify $\chi$ for powdered rock specimens experiencing swelling under the following mechanical boundary conditions: (i) oedometric conditions under a constant axial stress; (ii) complete volume constraint; (iii) isotropic compression by a constant stress; (iv) and so-called "flexible" oedometer tests introduced here, where the radial stresses and strains are additionally determined, which is not possible in conventional oedometer cells. By using artificially created, powdered and highly compressed rock-like specimens (with an average density of $1.9 \mathrm{~g} / \mathrm{cm}^{3}$ ), it was possible to study the chemically induced swelling on reproducible specimens without the interference of clay swelling and by excluding the uncertainties associated with the heterogeneity of natural rock specimens. In most cases the relationship between the dissolving mass of anhydrite and the occurring stresses, respectively strains, could be approximated by a linear function. In other words: The coupling parameter $\chi$ is constant for a given stress acting on the specimen (assuming the Young's modulus and the Poisson ratio to remain constant). Furthermore, the tests showed a practically linear dependency between the strains and the logarithm of the applied stress, which - in spite of the very different mechanisms underlying the macroscopically observed swelling - is similar to the wellknown semilogarithmic swelling law of purely argillaceous rocks, which implies that the deformation of the rock can be significantly reduced by applying a counter pressure or, alternatively, that the swelling pressure can be reduced by allowing a heave to occur. Therefore, the observed strong non-linearity of the stress-strain relationship has great practical relevance for future modelling of swelling anhydritic claystones and thus for the conceptual design of underground structures in anhydritic rock.

Simultaneous swelling of anhydrite and clay was investigated by performing a series of free swelling tests on natural rock specimens as well as specimens of powdered and compacted anhydritic claystones. Upon watering, a rapid increase in volume occurs nearly instantaneously, which can be attributed to water intake due to capillary effects and to osmotic swelling of the clay minerals. The initial increase in volume is then followed by a slow swelling which can be attributed to AGT. This extends over several years and in some cases was not completed after more than five years of observation. In order to prove that this subdivision of strains is adequate for the evaluation of the experiments, additional tests were run under higher temperatures: At $50{ }^{\circ} \mathrm{C}$ the equilibrium concentration of gypsum is higher than that of anhydrite and thus - as opposed to swelling at $20^{\circ} \mathrm{C}$ - swelling due to AGT does not occur. These tests prove that the strains occurring after the initial rapid heave at $20^{\circ} \mathrm{C}$ can be attributed to swelling due to AGT. Furthermore, swelling can be inhibited by raising the temperature of an actively swelling rock specimen from $20^{\circ} \mathrm{C}$ to 
$50{ }^{\circ} \mathrm{C}$. However, contrary to expectations, changing the testing conditions from $50{ }^{\circ} \mathrm{C}$ to $20^{\circ} \mathrm{C}$, did not always immediately trigger swelling due to AGT. This peculiarity occurred solely with natural rock specimens while powdered specimens swelled as expected. This phenomenon was investigated by varying the experimental conditions (e.g., the duration of the exposition at $50^{\circ} \mathrm{C}$ ), by performing further analyses of the water used, and by microscopic inspections of the rock prior and post swelling. However, in spite of these additional investigations, no conclusive explanation was found as to why the rock specimens did not swell immediately after lowering the temperature from $50{ }^{\circ} \mathrm{C}$ to $20^{\circ} \mathrm{C}$.

The findings from the experiments performed in the context of this thesis verified kinetic models and assumptions related to AGT. Moreover, the systematic experimental investigations regarding the swelling behavior of anhydrite give an indication of a stress-strain relationship which can be implemented and used as a fundamental basis for future modelling of swelling due to AGT. This is necessary for practicing engineers in order to design underground structures in anhydritic rock. Furthermore, it was seen that the swelling due to anhydrite and clay can be de-coupled by varying the testing temperatures, which changes the equilibrium concentrations. 

Anhydrithaltige Tonsteine stellen aufgrund ihrer Quellfähigkeit erhebliche Probleme im Untertagebau dar: Kommt das Gestein in Kontakt mit Wasser, so nimmt das Gesteinsvolumen infolge Wasseraufnahme durch die Tonmineralien sowie durch Hydratation des Anhydrits zu. Wird diese Volumenzunahme begrenzt, beispielsweise durch ein Sohlgewölbe im Tunnelbau, entwickelt sich ein hoher Druck auf das Gewölbe, der dieses sogar zerstören kann. Beim Quellverhalten reiner, anhydritfreier, quellfähiger Tonsteine handelt es sich vor allem um osmotische Prozesse, welche im Hinblick auf die Dimensionierung von Tunneln gut verstanden sind, im Gegensatz zum Quellverhalten des Anhydrits, welches erhebliche Wissenslücken aufweist.

Das Quellen des Anhydrits ist auf chemische Prozesse zurückzuführen: Der Anhydrit löst sich im Porenwasser auf und aus der Lösung wachsen Gipskristalle. Gips hat ein um $61 \%$ grösseres Volumen als Anhydrit. Während der Umwandlung von Anhydrit zu Gips (nachfolgend als "AGT" bezeichnet; Anhydrite-Gypsum-Iransformation) nimmt folglich das Volumen der Festsubstanz zu. Das Porenvolumen kann dabei abnehmen (wenn die Kristalle innerhalb der Poren wachsen), konstant bleiben oder sich vergrössern, beispielsweise durch eine Rissbildung im Gestein, welche durch den Kristallisationsdruck bei der Kristallbildung hervorgerufen wird.

Obwohl quellbedingte Probleme im Tunnelbau durch anhydritführende Tonsteine seit 150 Jahren bekannt sind, weist die aktuelle Kenntnis über das Quellverhalten anhydrithaltiger Gesteine immer noch viele Wissenslücken auf. Letztere bestehen aufgrund der Tatsache, dass nur sehr wenige systematische experimentelle Untersuchungen auf fundamentaler Ebene durchgeführt wurden, welche die chemisch-mechanischen Prozesse während der AGT untersuchen und quantifizieren. Der Grund hierfür ist die lange Dauer des Quellprozesses, die mehrere Jahre betragen kann.

Das Ziel dieser Dissertation ist es, ein besseres Verständnis und eine bessere Quantifizierung der gekoppelten chemo-mechanischen Quellprozesse durch die AGT zu gewinnen und eine Grundlage für die Entwicklung chemo-mechanischer Modelle für das Quellverhalten anhydrithaltiger Tonsteine zu erschaffen. Grundlegende Experimente wurden durchgeführt, um bestehende kinetische Modelle bezüglich der AGT zu verifizieren, und systematische Quellversuche wurden ausgeführt, um die Formulierung eines chemo-mechanischen Stoffgesetzes zu unterstützen, welches die Spannungen und Dehnung berücksichtigt, die aufgrund der Anhydritlösung und Gipsbildung entstehen. Des Weiteren wurden Quellversuche mit anhydrithaltigen Tonsteinen durchgeführt, um das gleichzeitige Quellen von Anhydrit und Ton zu untersuchen und ihren jeweiligen Beitrag zur beobachteten Quellung des Gesteins zu quantifizieren.

Die Kinetik der AGT wurde untersucht, indem Anhydritpulver in Wasser gelöst und die Menge an Calcium- und Sulfationen im Wasser durch Leitfähigkeitsmessungen indirekt bestimmt wurde. Dies führte zu den folgenden Beobachtungen: (i) die Gleichgewichtskonzentration von Gips, wie sie aus einem theoretischen Modell berechnet wurde, konnte verifiziert werden; (ii) die berechnete Gleichgewichtskonzentration von Anhydrit ist höher als die gemessenen Konzentrationen, weil letztere aufgrund des lonenverbrauchs während der Gipsausfällung die Sättigungskonzentration in Bezug auf den Anhydrit nicht erreichen konnten; (iii) eine höhere Anfangsmasse von Anhydrit in Wasser verursacht einen höheren Peak in der lonenkonzentration und beschleunigt den Prozess der AGT; (iv) die Reaktion dauert länger als erwartet und somit konnten die angenommenen Reaktionsratenkonstanten und das kinetische Modell nicht bestätigt werden; (v) eine Zugabe von 
"fremden" Mineralien in der Lösung beeinflusst die zeitliche Entwicklung der Calcium- und Sulfationenkonzentration im Wasser.

Wenn reiner, massiger Anhydrit mit Wasser in Kontakt kommt, bildet sich eine poröse Gipsschicht auf der Anhydritoberfläche, die eine weitere Hydratation verlangsamt. Dies wird als die sogenannte "Selbstversiegelung" des Anhydrits bezeichnet. Mit dem Ziel, ein bestehendes mathematisches Modell zu überprüfen, welches diesen Effekt quantifiziert, wurden mehrere Anhydritplättchen in Wasser eingetaucht und die sich entwickelnde Gipsschicht qualitativ mit Fotografie über einen Zeitraum von bis zu drei Jahren beobachtet sowie quantitativ mit Mikroskopie untersucht. Die Form und räumliche Verteilung des Gipses variierte in Abhängigkeit von der Prüftemperatur und der Struktur des Ausgangsgesteins. Die Dicke der entstehenden Gipsschichten lag jedoch im Bereich der theoretisch prognostizierten Werte.

Der Zusammenhang zwischen Quelldehnung und Quelldruck ist von sehr grosser Bedeutung für das Entwurfskonzept des Tunnelausbaus in quellfähigem Gebirge. Deshalb befasst sich ein grosser Teil dieser Forschungsarbeit mit der Quantifizierung der Dehnungen und Spannungen, die infolge der Auflösung von Anhydrit und der Ausfällung von Gips entstehen.

In mathematischen chemo-mechanischen Modellen, die ebenfalls in dieser Arbeit beschrieben werden, wird das Verhältnis zwischen den makroskopisch beobachtbaren Dehnungen und der Masse des in Gips umgewandelten Anhydrits durch einen Materialparameter ausgedrückt. Die Bedeutung dieses sogenannten Kopplungsparameters wurde in der Arbeit vorerst qualitativ auf der Grundlage von konzeptuellen Modellen diskutiert. Anschliessend wurde eine umfangreiche, systematische experimentelle Studie durchgeführt, um den Kopplungsparameter von gemahlenen und verdichteten Gesteinsproben unter verschiedenen mechanischen Randbedingungen zu quantifizieren: (i) ödometrische Bedingungen unter konstanter Axialspannung; (ii) vollständige Verhinderung von Volumendehnung; (iii) isotrope Kompression durch eine konstante Spannung (iv) und sogenannte "flexible" Ödometerversuche welche in dieser Arbeit eingeführt werden, bei denen zusätzlich die radialen Spannungen und Dehnungen bestimmt werden, was bei herkömmlichen Ödometerzellen nicht möglich ist. Durch die Verwendung von künstlich hergestellten, pulverförmigen und komprimierten gesteinsähnlichen Proben (mit einer hohen durchschnittlichen Dichte von $1.9 \mathrm{~g} / \mathrm{cm}^{3}$ ) war es möglich, das chemisch induzierte Quellverhalten an reproduzierbaren Proben ohne die Beeinflussung des Tonquellens und unter Vermeidung der mit der Heterogenität von natürlichen Gesteinsproben verbundenen Unsicherheiten zu untersuchen. In den meisten Fällen konnte das Verhältnis zwischen der Masse des sich lösenden Anhydrits und den auftretenden Spannungen bzw. Dehnungen durch eine lineare Funktion angenähert werden. Mit anderen Worten: Der Kopplungsparameter ist konstant für eine gegebene Spannung, die auf die Probe wirkt (unter der Annahme, dass der E-Modul und die Poissonzahl konstant bleiben). Darüber hinaus zeigten die Versuche eine praktisch lineare Abhängigkeit zwischen den Dehnungen und dem Logarithmus der aufgebrachten Spannungen, was - trotz der gänzlich unterschiedlichen, dem Quellvorgang zugrundeliegenden Mechanismen - mit dem bekannten halblogarithmischen Quellgesetz von quellfähigen Tonen vergleichbar ist. Dies weist darauf hin, dass die Quellhebung durch das Aufbringen eines Gegendrucks deutlich reduziert werden kann oder - umgekehrt - dass der Quelldruck durch das Zulassen einer Quellhebung erheblich reduziert werden kann. Dieses Ergebnis hat daher eine grosse praktische Relevanz für die zukünftige Modellierung des Quellverhaltens und somit für den konzeptionellen Entwurf der Tunnelverkleidung in anhydrithaltigem Gestein. 
Das gleichzeitige Quellen von Anhydrit und Ton wurde durch eine Serie von Freiquellversuchen an natürlichen Gesteinsproben sowie an Proben aus pulverförmigem und verdichtetem anhydrithaltigem Tonstein untersucht. Unmittelbar nach der Bewässerung der Probe tritt eine sehr rasche Volumenvergrösserung ein, welche auf die Wasseraufnahme durch kapillare Effekte und das osmotische Quellen des Tons zurückzuführen ist. Diesem anfänglichen Volumenanstieg folgt ein langsameres Quellen, welches auf die AGT zurückzuführen ist. Dies erstreckt sich über mehrere Jahre und ist in einigen Fällen nach mehr als fünf Jahren Beobachtung nicht abgeschlossen. Durch das Durchführen einiger Versuche unter höheren Temperaturen ist es möglich zu beweisen, dass diese Aufteilung der Dehnungen in Bezug auf die Quellprozesse adäquat ist: Bei $50{ }^{\circ} \mathrm{C}$ ist die Gleichgewichtskonzentration von Gips höher als die von Anhydrit und somit kommt es - im Gegensatz zum Quellen bei $20^{\circ} \mathrm{C}$ - nicht zu einem Quellen durch AGT. Demzufolge sind die nach der ersten raschen Hebung bei $20^{\circ} \mathrm{C}$ auftretenden Dehnungen auf das Quellen durch AGT zurückzuführen. Darüber hinaus kann das Quellen unterbunden werden, indem die Temperatur einer aktiv quellenden Gesteinsprobe von $20^{\circ} \mathrm{C}$ auf $50{ }^{\circ} \mathrm{C}$ erhöht wird. Entgegen den Erwartungen führte die Änderung der Versuchsbedingungen von $50^{\circ} \mathrm{C}$ auf $20^{\circ} \mathrm{C}$ jedoch nicht immer sofort zu Quellerscheinungen durch AGT. Diese Besonderheit trat nur bei natürlichen Gesteinsproben auf, während pulverförmige Proben nach der Abkühlung wie erwartet quollen. Dieses Phänomen wurde durch Variation der Versuchsbedingungen (z.B. die Dauer der Bewässerung unter $50^{\circ} \mathrm{C}$ ), durch Analysen des verwendeten Wassers und durch mikroskopische Untersuchungen des Gesteins vor und nach dem Quellen weiter untersucht. Trotz diesen zusätzlichen Untersuchungen wurde jedoch keine schlüssige Erklärung dafür gefunden, warum die Gesteinsproben nicht unmittelbar nach der Senkung der Temperatur von $50^{\circ} \mathrm{C}$ auf $20^{\circ} \mathrm{C}$ quellen.

Die Ergebnisse der Experimente, die im Rahmen dieser Arbeit durchgeführt wurden, bestätigen kinetische Modelle und Annahmen im Zusammenhang mit der AGT. Die systematischen experimentellen Untersuchungen zum Quellverhalten von Anhydrit geben zudem Hinweise auf eine Spannungs-Dehnungsbeziehung, die als fundamentale Grundlage für die zukünftige Modellierung des Quellverhaltens durch AGT implementiert und verwendet werden kann. Dies ist erforderlich für die Planung und den Bau von Untertagebauten durch praktizierende Ingenieure. Darüber hinaus zeigte sich, dass das Quellen von Anhydrit und Ton durch das Variieren der Prüftemperaturen und der damit verbundenen Änderung der Gleichgewichtskonzentrationen entkoppelt werden können. 



\section{TABLE OF CONTENTS}

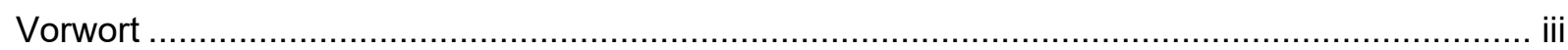

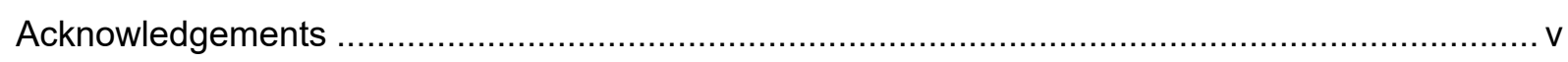

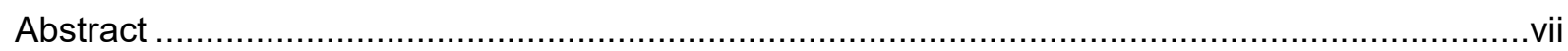

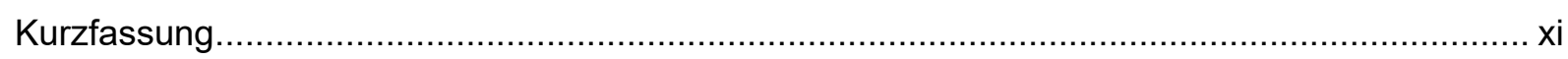

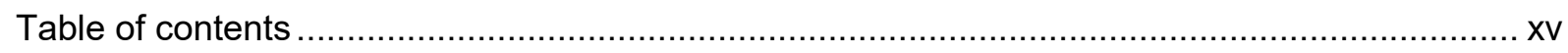

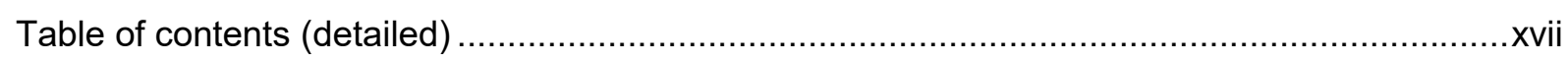

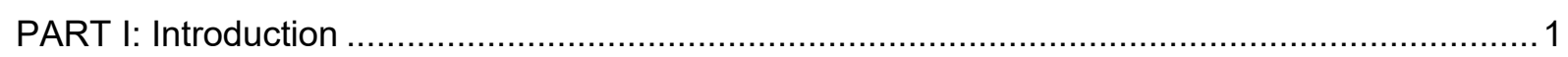

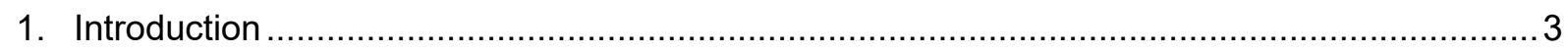

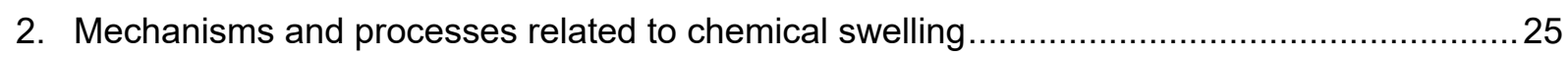

3. Description of standard analytical testing techniques used .............................................. 41

PART II: Anhydrite dissolution and gypsum precipitation in a solution ..................................... 45

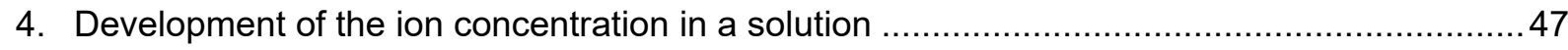

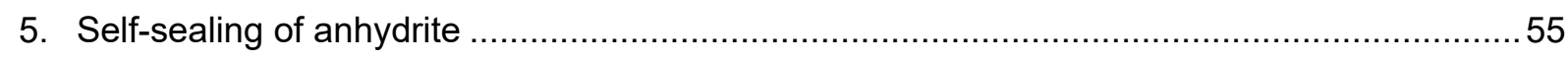

PART III: Coupled chemo-mechanical processes (C-M) ................................................... 75

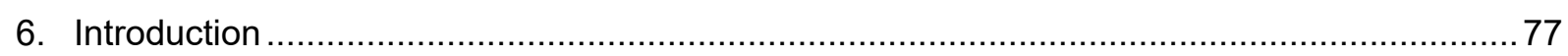

7. Constitutive and conceptual models for the description of the C-M coupling ........................79

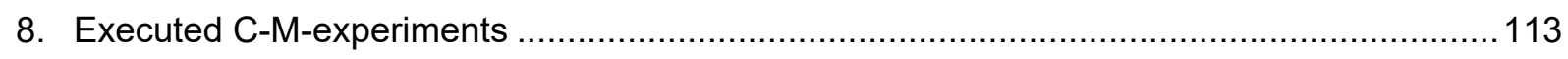

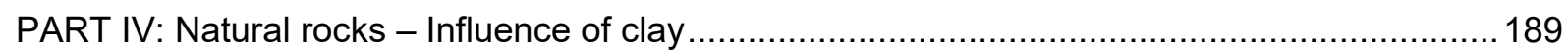

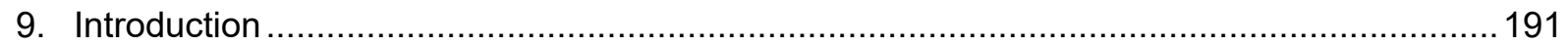

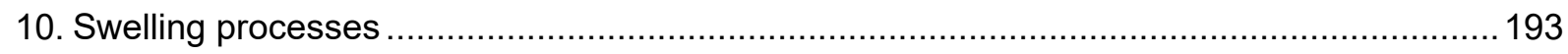

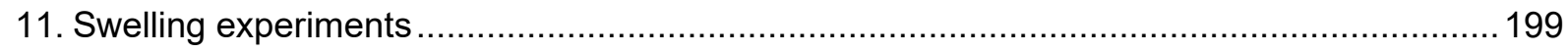

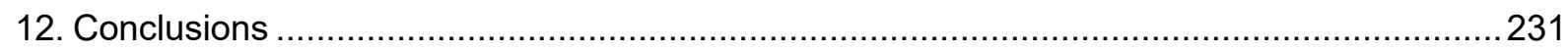

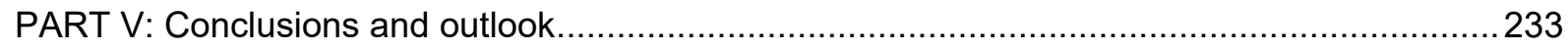

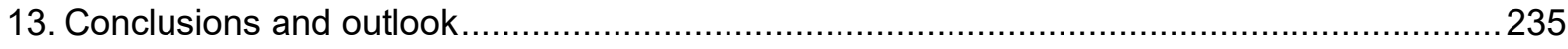

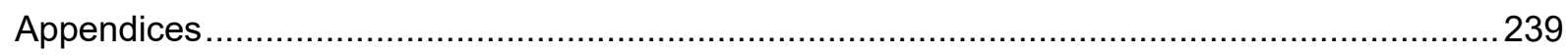

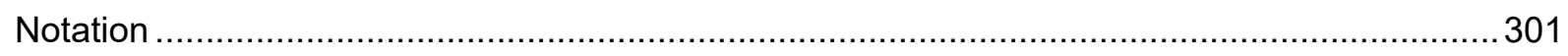

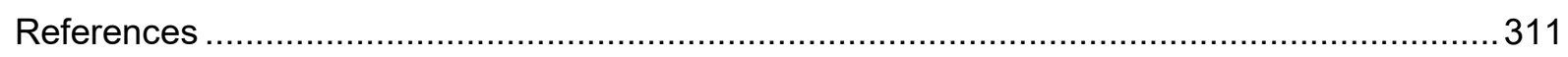





\section{TABLE OF CONTENTS (DETAILED)}

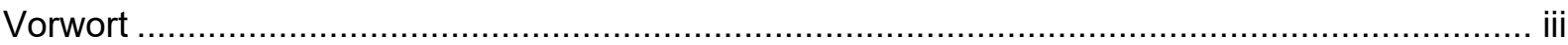

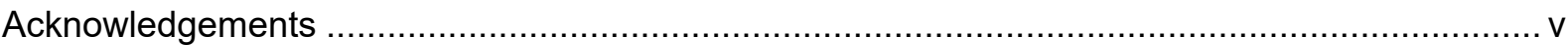

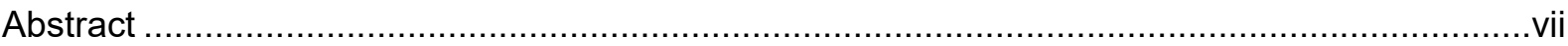

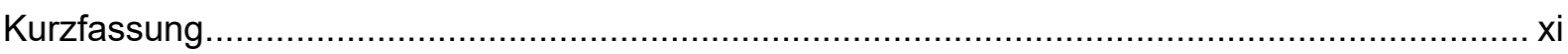

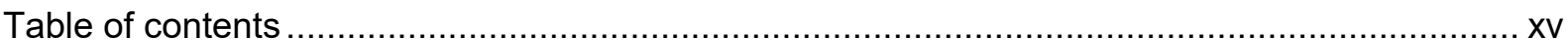

Table of contents (detailed) ......................................................................................................

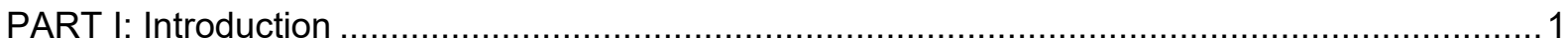

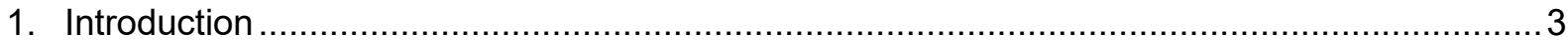

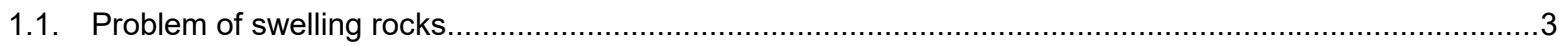

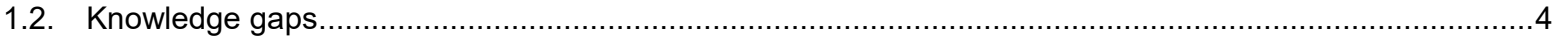

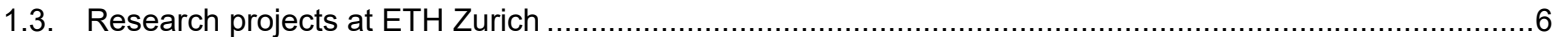

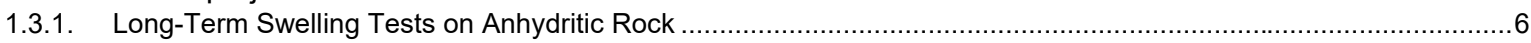

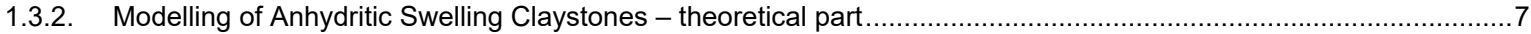

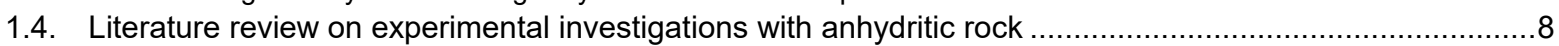

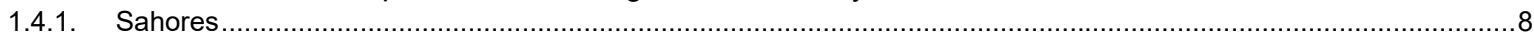

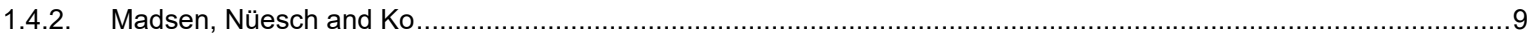

1.4.3. Long-term experiments on specimens from the Freudensteintunnel............................................................ 12

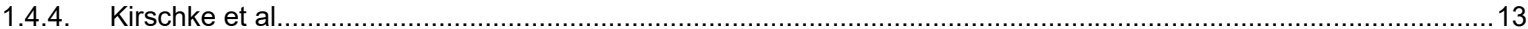

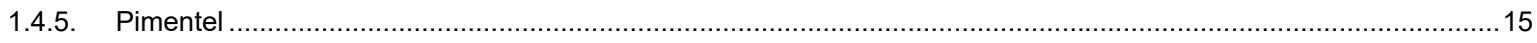

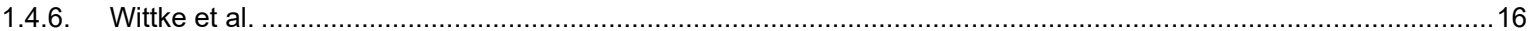

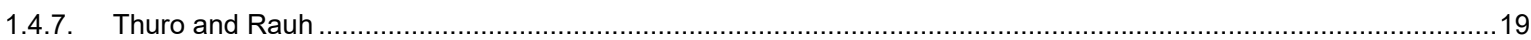

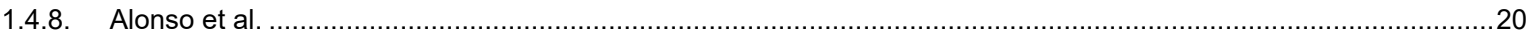

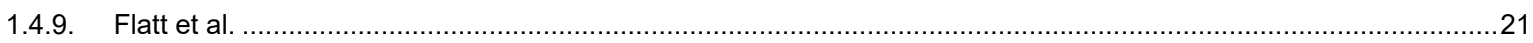

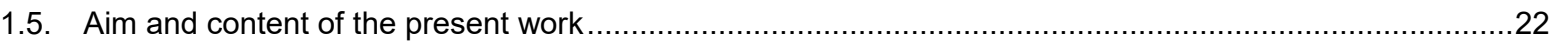

2. Mechanisms and processes related to chemical swelling ............................................25

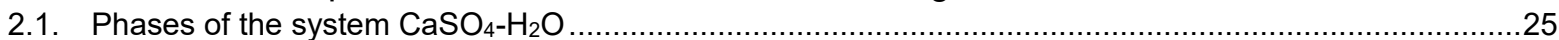

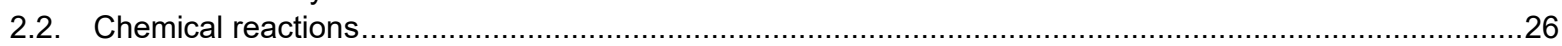

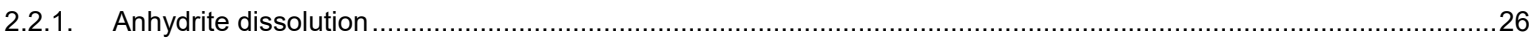

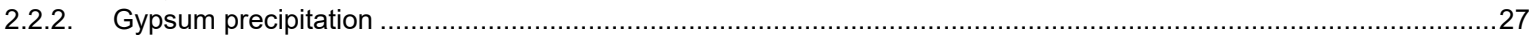

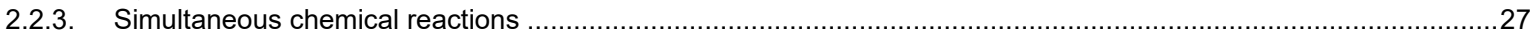

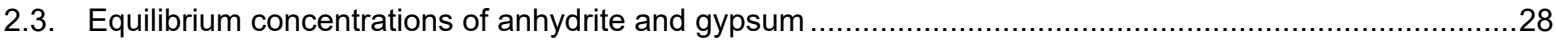

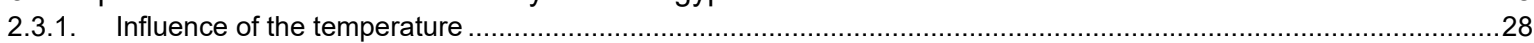

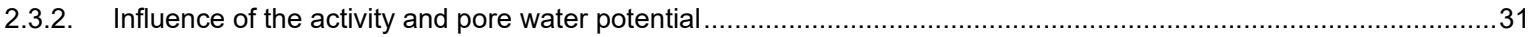

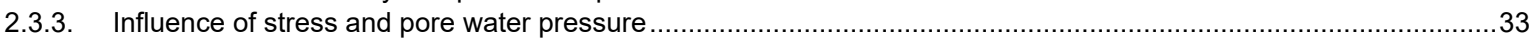

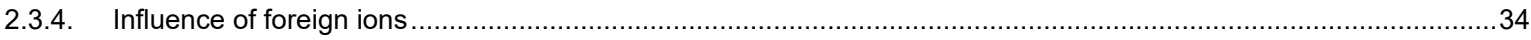

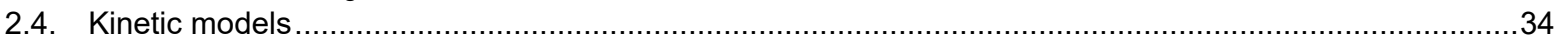

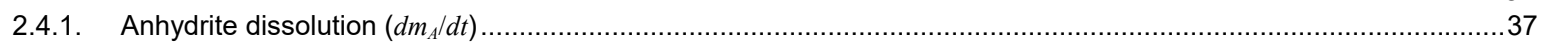

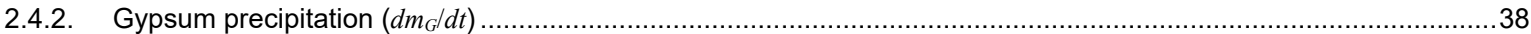

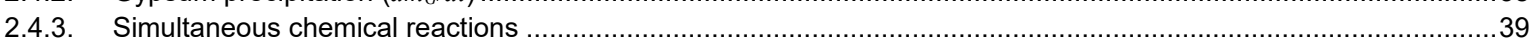

3. Description of standard analytical testing techniques used .......................................... 41

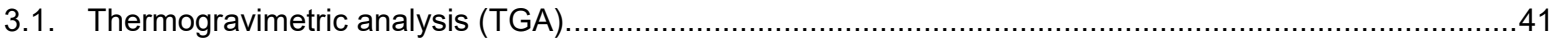

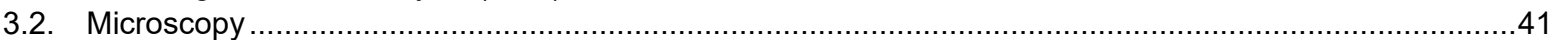

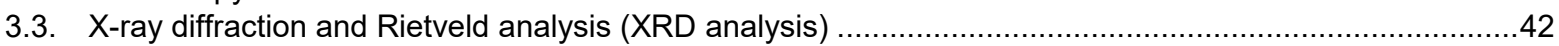

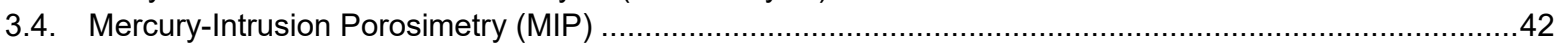

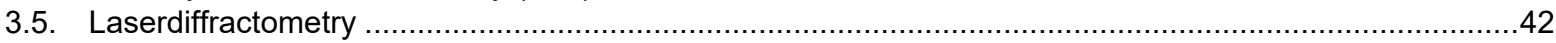

3.6. Surface area measurements based on the theory of Brunauer, Emmett and Teller (BET) ....................43

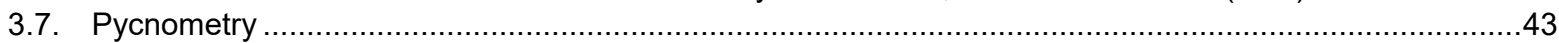

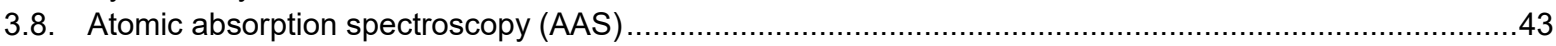

3.9. Inductively coupled plasma - Optical emission spectrometry (ICP-OES) …...................................44

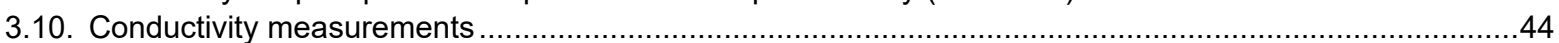




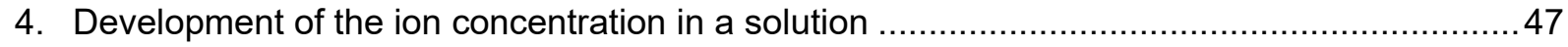

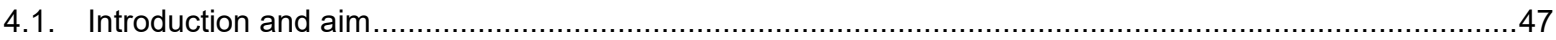

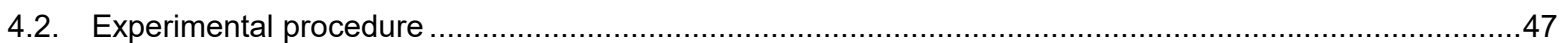

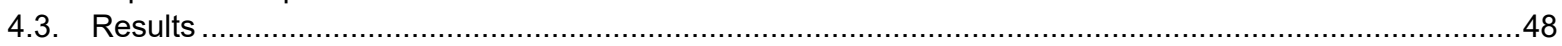

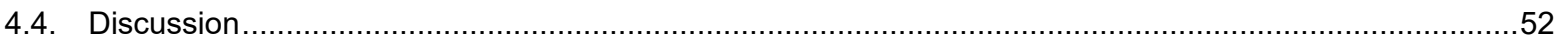

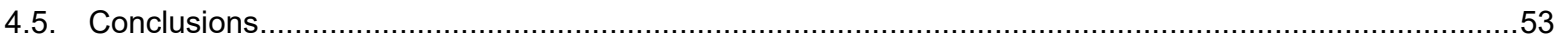

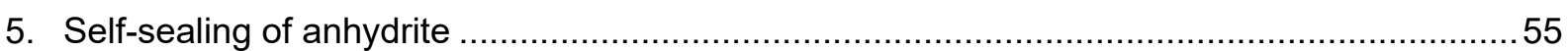

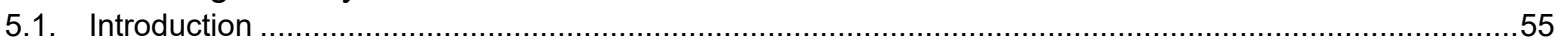

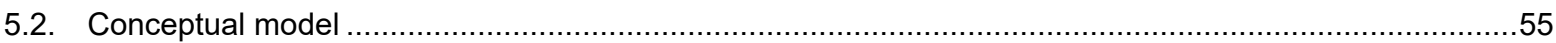

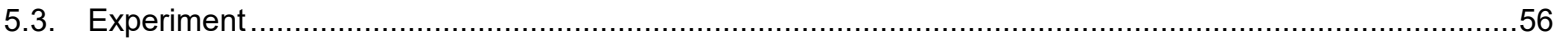

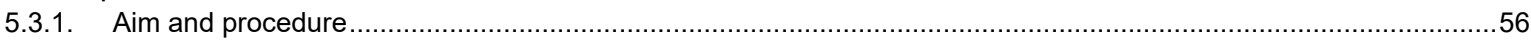

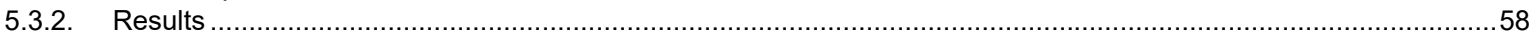

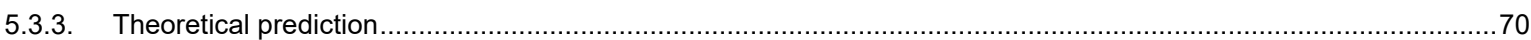

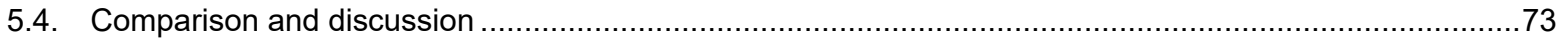

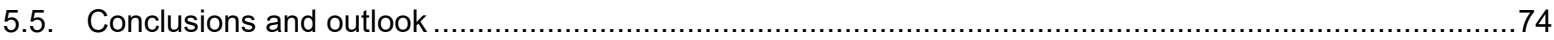

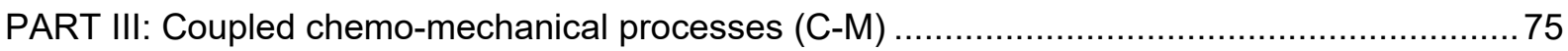

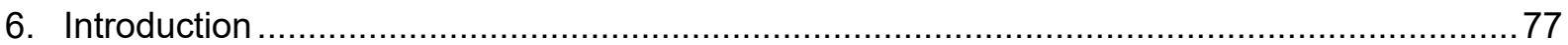

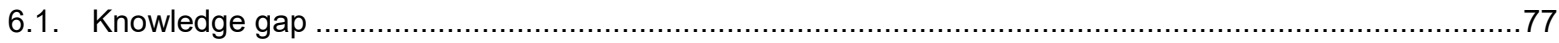

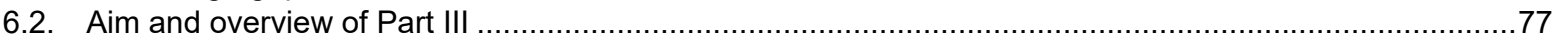

7. Constitutive and conceptual models for the description of the C-M coupling ........................79

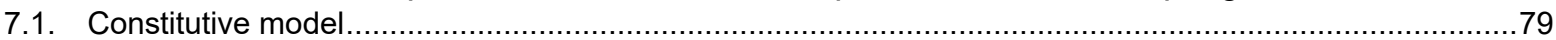

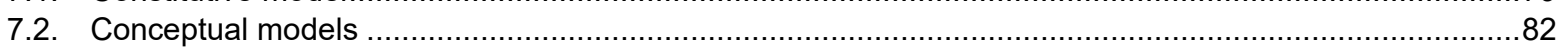

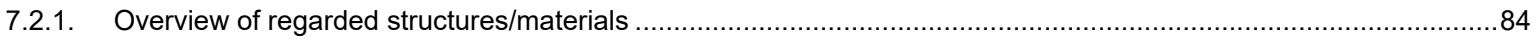

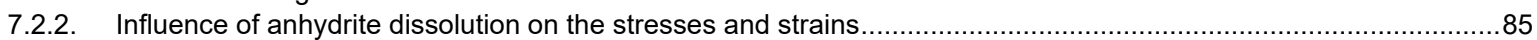

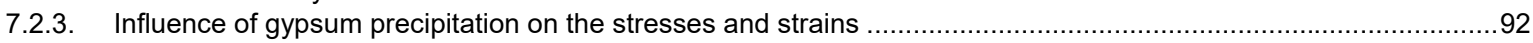

7.2.4. Influence of simultaneous anhydrite dissolution and gypsum precipitation on the stresses and strains ..................97

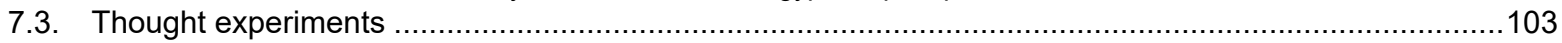

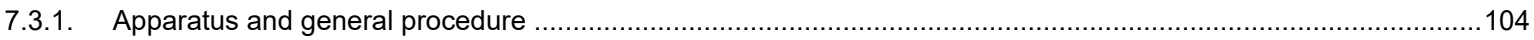

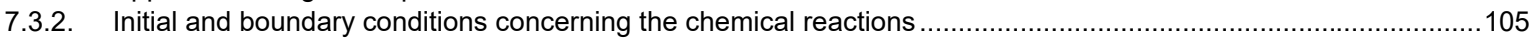

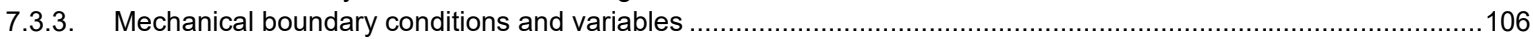

7.3.4. Evaluation of thought experiments for simultaneous anhydrite dissolution and gypsum precipitation .....................108

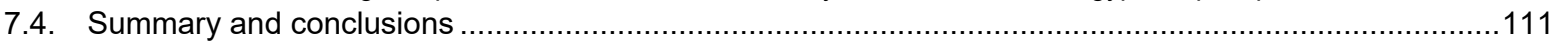

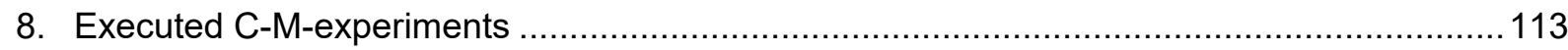

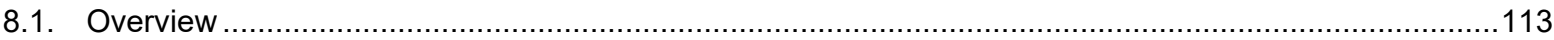

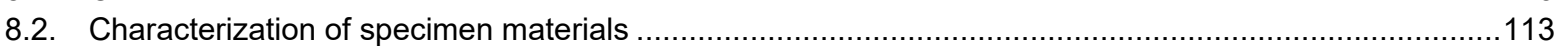

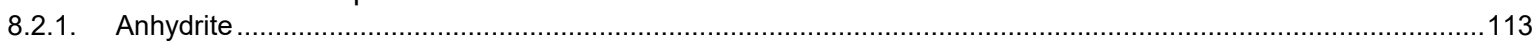

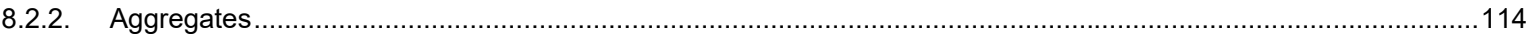

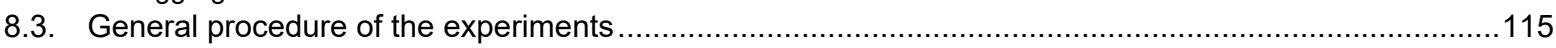

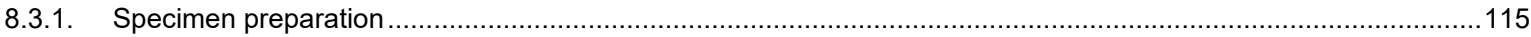

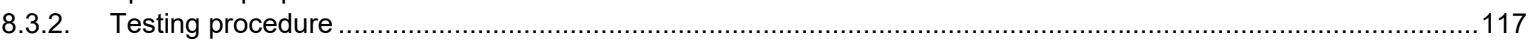

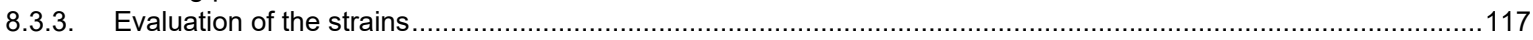

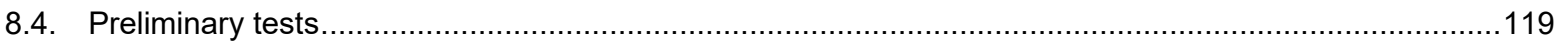

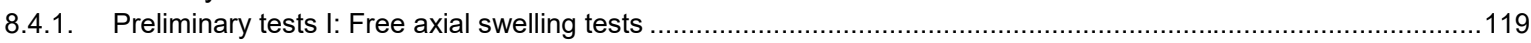

8.4.2. Preliminary tests II: Comparison milled natural anhydrite - commercial anhydrite .............................................124

8.4.3. Preliminary tests III: Comparison different commercial anhydrite powders .....................................................127

8.4.4. Preliminary tests IV: Determination of Young's modulus and Poisson ratio .............................................131

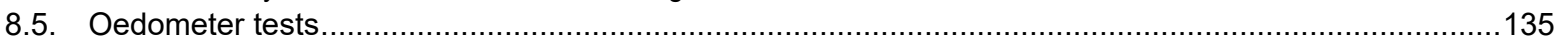

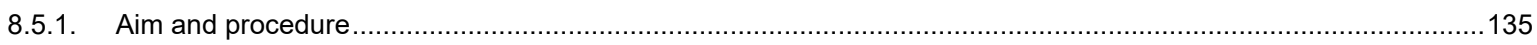

8.5.2. Results of the first series (various axial loads - swelling until strain reaches steady state) ................................135

8.5.3. Results of the second series (axial loads of $3 \mathrm{kPa}$ and $800 \mathrm{kPa}-$ swelling until various degrees of AGT) ...............139

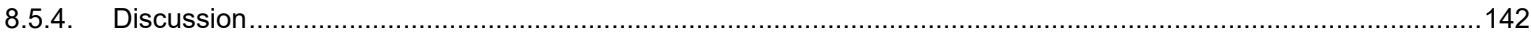

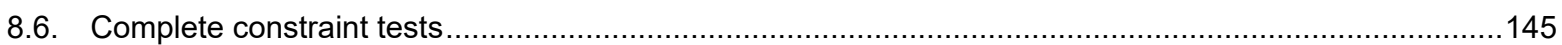

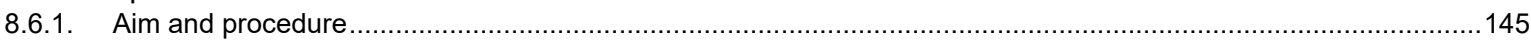

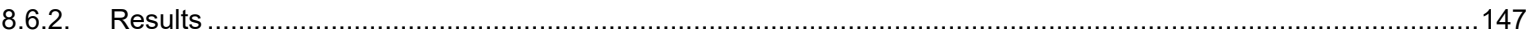

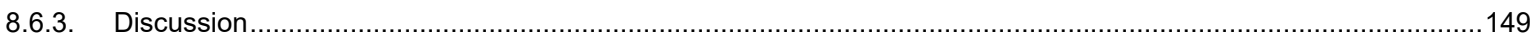

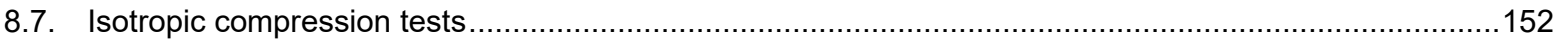

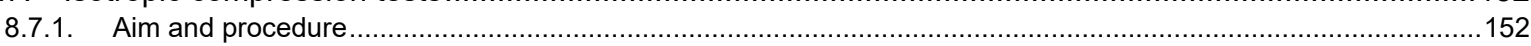

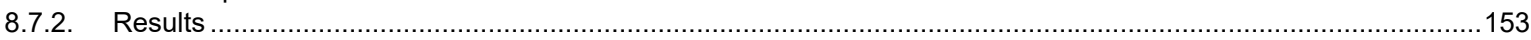

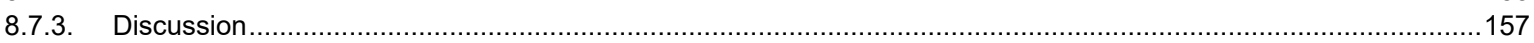




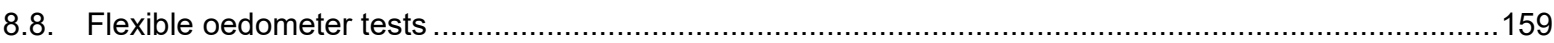

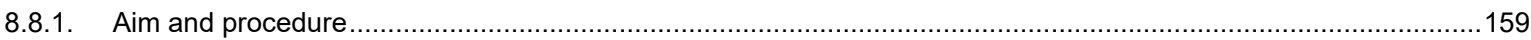

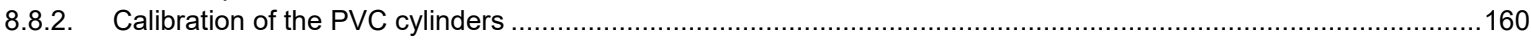

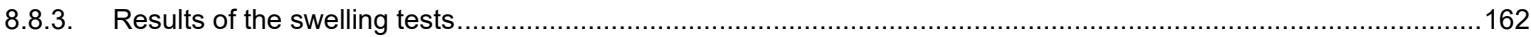

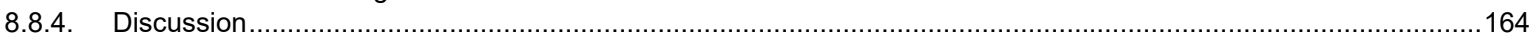

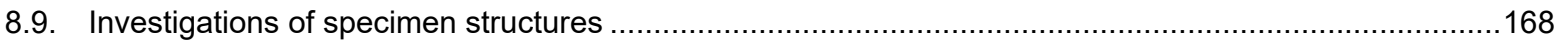

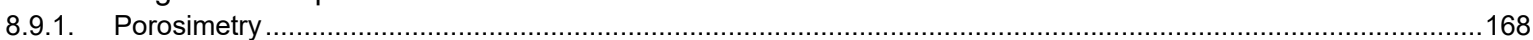

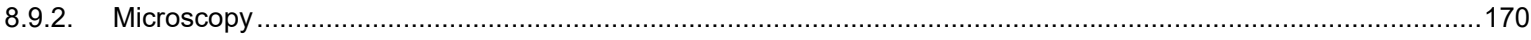

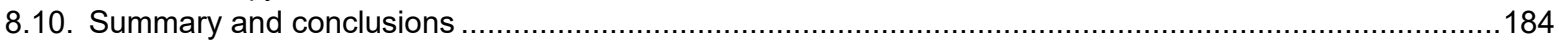

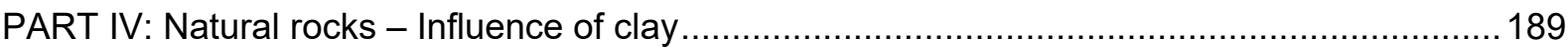

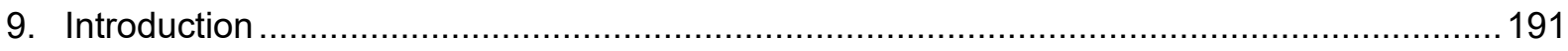

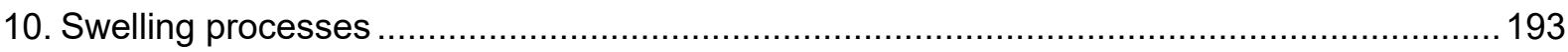

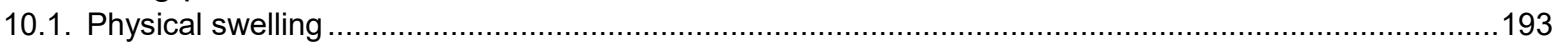

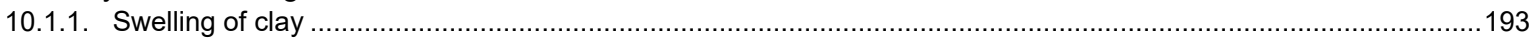

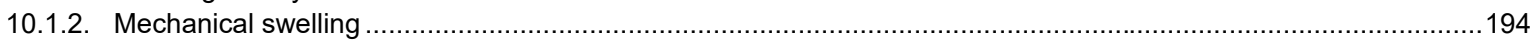

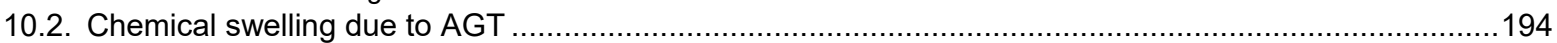

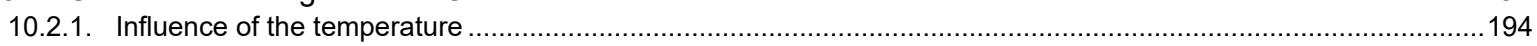

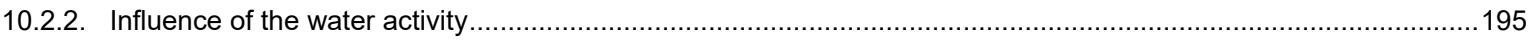

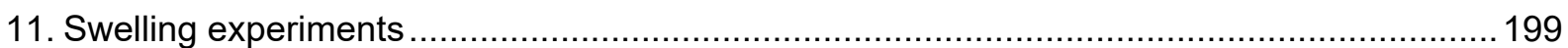

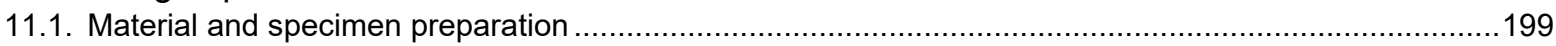

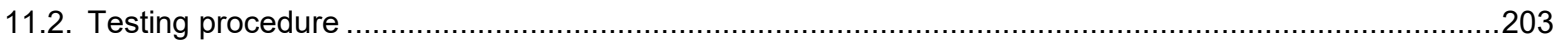

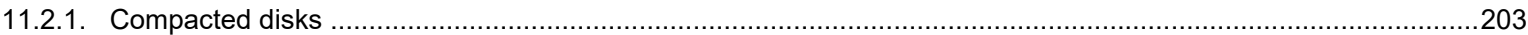

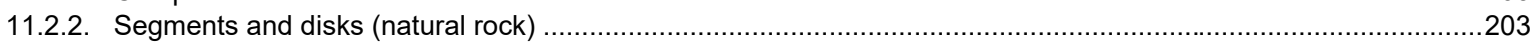

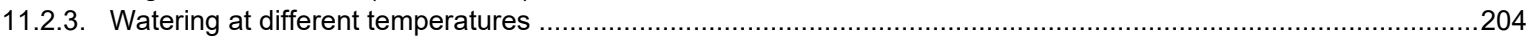

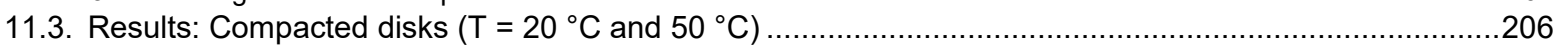

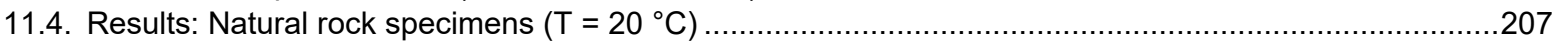

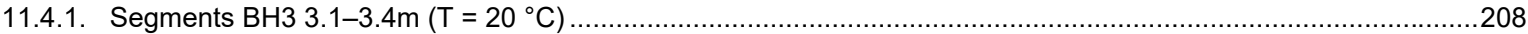

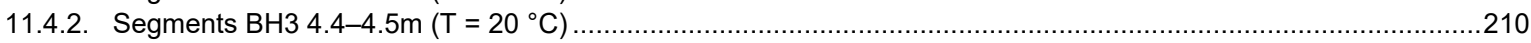

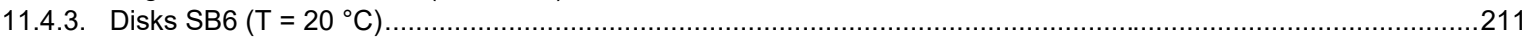

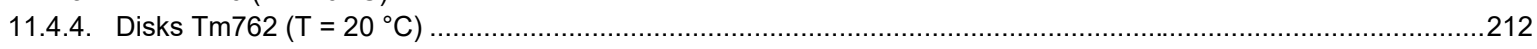

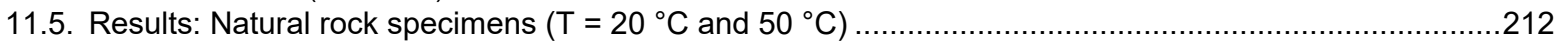

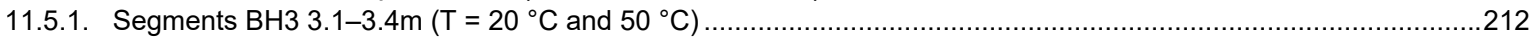

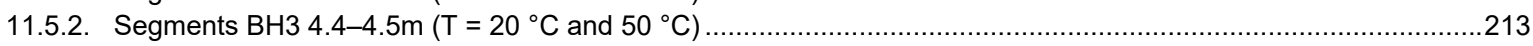

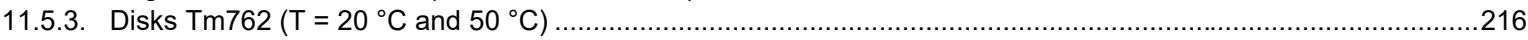

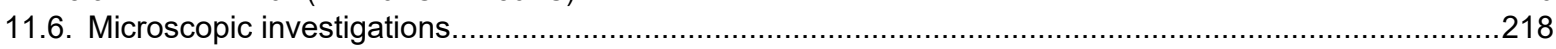

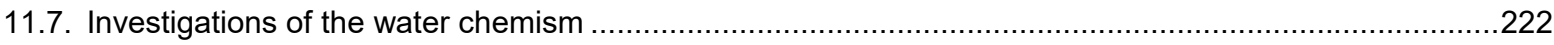

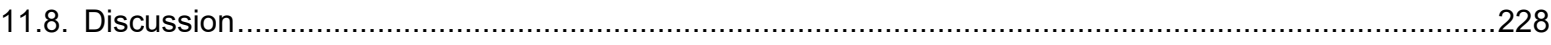

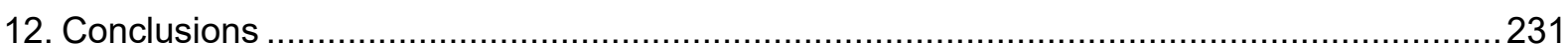

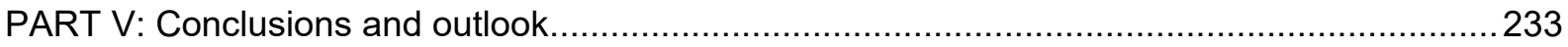

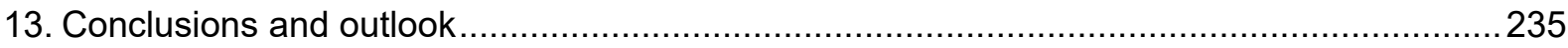

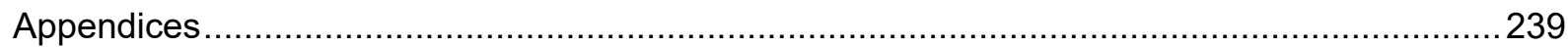

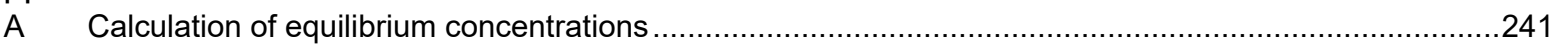

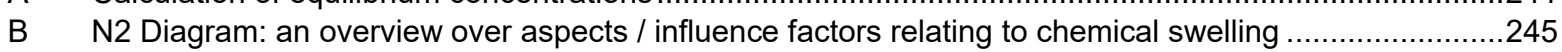

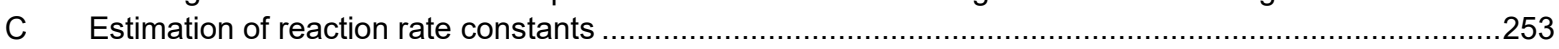

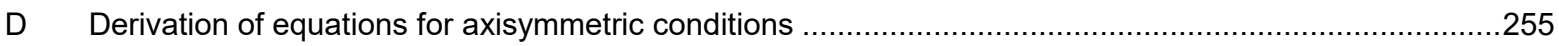

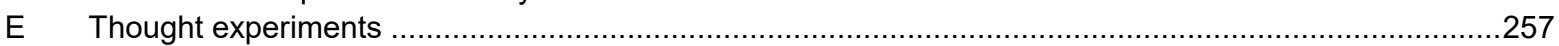

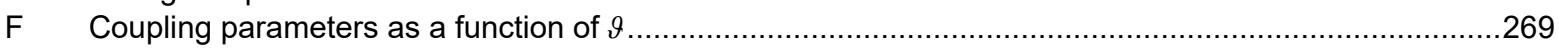

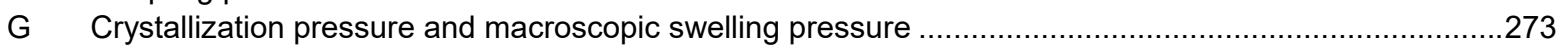

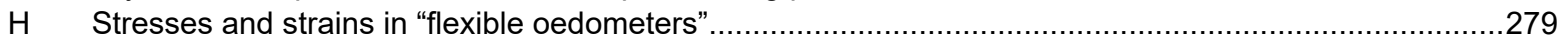

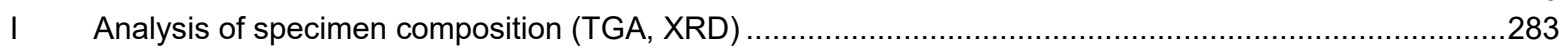

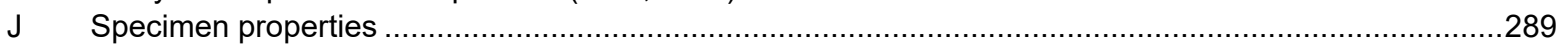

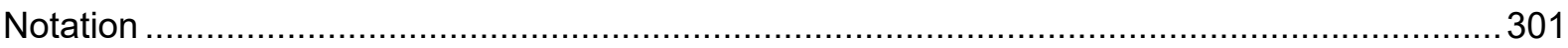

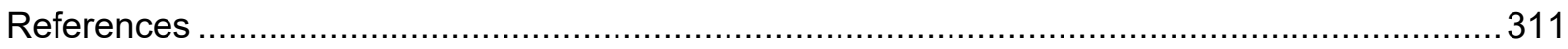



PART I

INTRODUCTION 



\section{Introduction}

\subsection{Problem of swelling rocks}

Swelling rocks experience an increase in volume when they come into contact with water. This is especially pronounced for rocks containing clay and / or anhydrite: When so-called swelling clays are wetted, water gets attracted between the clay platelets due to electric forces, increasing the distance between them, and thus expanding the volume of the clay. When anhydrite comes into contact with water, it can dissolve under certain conditions and due to supersaturation of dissolved ions in the pore water, gypsum can precipitate. Since gypsum has a greater molar volume than the dissolving anhydrite, the Anhydrite to Gypsum Iransformation (hereafter referred to as "AGT") leads to an increase in solid volume of $61 \%$. AGT may result in a decrease of the pore volume (if gypsum-crystals grow within the pore space) or also in a higher pore volume, e.g., because growing crystals push the surrounding grains apart or, in a cemented material, when the pressure generated by the crystals that grow from a supersaturated solution in the pores suffices to create new cracks.

Anhydritic swelling rocks are often encountered in Switzerland, in France (Elsace), the Southern part of Germany and in Spain and can cause massive problems in tunneling: The increase in volume of swelling rocks due to the chemical reactions can cause the tunnel floor to heave upon excavation (Figure 1-1a). For example, in an exploratory adit of the Wagenburgtunnel, Germany, a heave of the unsupported tunnel floor of $1.1 \mathrm{~m}$ was measured over a span of 25 years (Götz, 1972; see Figure 1-2a). When these swelling strains of the rock are restricted (e.g., by an invert arch in tunneling), a swelling pressure (or swelling stress) builds up on the confining boundary and, if an invert arch is in place, the pressure acting from the rock may overstress and damage the invert (Figure 1-1b and example of damages to the invert of the Belchentunnel in Figure 1-2b) or even cause a heave of the entire tunnel (Figure 1-1c), which occurred at the Chienberg tunnel prior to the remedation measures.

a

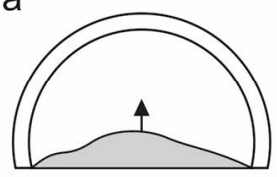

b

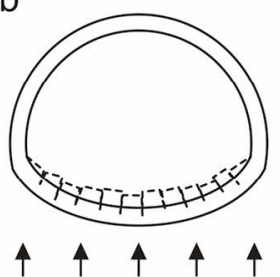

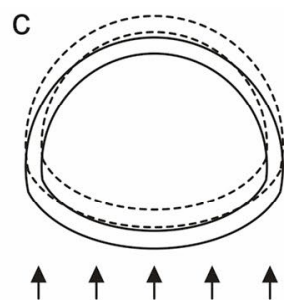

Figure 1-1: $\quad$ Problems in tunneling caused by swelling rock, after Anagnostou (1992).
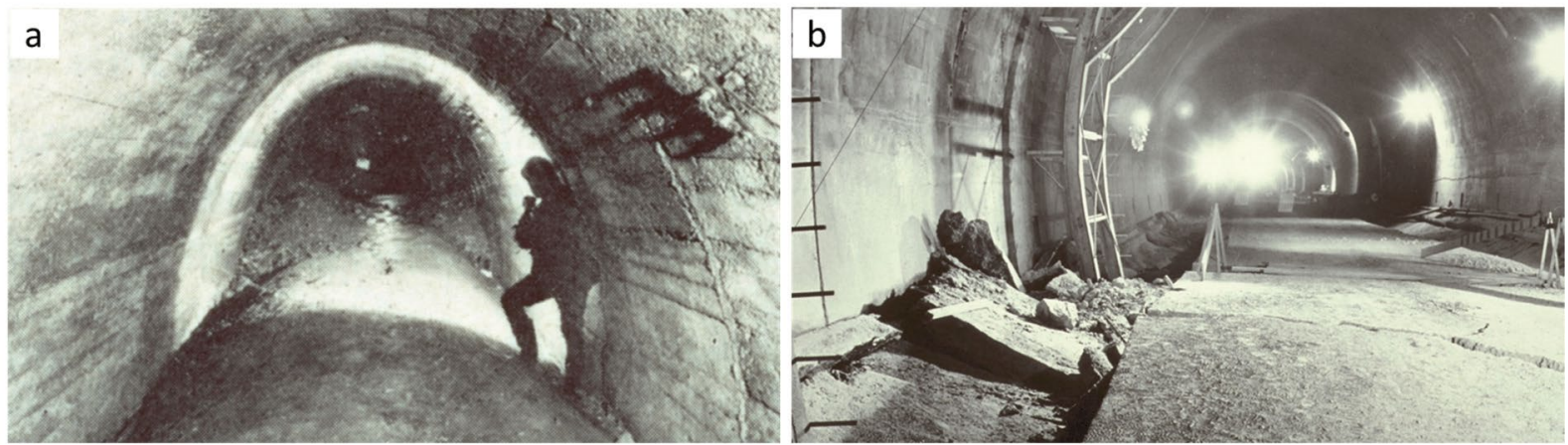

Figure 1-2: $\quad$ Examples for problems in tunneling caused by swelling rock: (a) heave of the unsupported floor in an adit of the Wagenburgtunnel (Spaun, 1974), (b) damage to the concrete slab (thickness of $45 \mathrm{~cm}$ ) in the invert arch of the Belchentunnel (Amstad and Kovári, 2001). 
Furthermore, swelling due to AGT has become cause for massive damages to bridges and buildings as well. For example, two central pillars of the Pont de Candí railway bridge (ES) which was constructed on claystone with gypsum and anhydrite ("red formation" of the lower-medium Eocene, cf. Alonso and Ramon, 2013) experienced a heave of nearly $250 \mathrm{~mm}$ within five years after construction of the bridge. Also, with the increasing number of geothermal borings in the recent years, in the well-publicized cases of Lochwiller, FR (Pimentel and Wanninger, 2016) and Staufen, DE (Engesser et al., 2010), the geothermal borings punctured lower artesian aquifers which led to water infiltration in the above lying Gypsum Keuper containing anhydrite. AGT within the Gypsum Keuper is now causing uneven heaves of the surface which leads to massive damage in the structures above.

\subsection{Knowledge gaps}

Despite the phenomenon being known for over 150 years in tunneling, there are still considerable knowledge gaps concerning the swelling of anhydritic claystones. Between 2006 and 2010, the existing knowledge gaps were identified at the Chair for Underground Construction of the ETH Zurich for the basis of two research projects: "Long-Term Swelling Tests on Anhydritic Rock" (initiated in 2006 and financed by the Swiss Federal Roads Office "FEDRO", FGU 2006/001) and "Modelling of Anhydritic Swelling Claystones" (initiated in 2010 and financed by the Swiss National Science Foundation "SNF" and the FEDRO, FGU 2010/07), which the research presented in this thesis is a part of.

The identified knowledge gaps were grouped into the following four topics (Anagnostou et al., 2010) prior to the initiation of the research projects:

- The role of transport processes: The dissolved ions may circulate in the pore water by advection or diffusion (due to a concentration gradient). As a result of ion transport it is possible for anhydrite or gypsum to leach in one rock mass region, and gypsum to precipitate in another. It was, however, not known to which extent which transport process becomes relevant and influences the macroscopically observed swelling behavior.

- The role of hydraulic boundary conditions: The hydraulic conditions in the macroscale, i.e., in the wider surroundings as well as in the immediate vicinity of an underground construction, influence the transport processes via the seepage flow and can cause unsaturated zones due to water depression. This may lead to a supersaturation of ions and thus crystal growth. A better understanding of the hydraulic processes and boundary conditions at the scale of underground constructions is important for the structural design of tunnels.

- The role of the clay matrix: Upon excavation of some tunnels in anhydritic claystone (e.g., the Chienberg tunnel near Basel or the Engelberg tunnel near Stuttgart), a rapid heave of the tunnel floor was observed. This rapid heave is most likely caused by swelling of clay rather than chemical swelling due to AGT, which is a comparably slow process. The influence of the clay matrix on the chemical swelling is, however, unknown as is the distinction between the two swelling processes and identification of the dominant process. Furthermore, the clay matrix governs the water transport in the absence of cracks and fissures and the clay minerals can influence the thermodynamic equilibrium of the anhydrite and gypsum in water. 
- The swelling law: In the case of swelling claystones without anhydrite, a distinct relationship between the swelling strains $\varepsilon$ and swelling stresses $\sigma$ has been established and is widely known as the so-called "Grob's law" (Grob, 1972), a semilogarithmic swelling law which states that the swelling strains decrease linearly with the logarithm of the confining stress (see black line in Figure 1-3, where $\sigma_{\max }$ denotes the maximal stress which occurs under complete confinement and above which the rock does not swell, and $\varepsilon_{0}$ denotes the strain which occurs at a minimal confining stress). From a structural design point of view, the knowledge of such a swelling law is of great importance, since it implies that the heave of a tunnel floor can be significantly reduced by applying a counter pressure to the floor, or alternatively, the swelling pressure acting on the invert can be decreased by allowing a limited floor heave to occur (Anagnostou, 2007 and 2010). Based on this behavior different design concepts for the tunnel support exist. In extreme cases, the swelling is prevented by means of a stiff closed tunnel lining of high bearing capacity or with systematic heavy anchoring of the invert (so-called resistance principle), or the tunnel floor is allowed to heave unhindered in a designated space under the roadway without affecting the operation of the tunnel. In practice, a structural solution between these two extreme cases is often carried out, the so-called yielding principle, where a yielding support of the tunnel floor allows a limited heave with a simultaneous reduction of the swelling pressure (cf., e.g., Amstad and Kovári, 2001).

However, for anhydritic rock the relation of swelling strains to stresses (indicated by the green lines in Figure 1-3) is unknown so far, and, especially, which amount of stresses and strains are caused by AGT. Although swelling of anhydritic claystones have been known to cause problems for underground constructions for over a century, the stress-strain relationship and the coupling to the chemical processes are unknown for anhydritic rock. Systematic experimental investigations of these coupled chemo-mechanical processes are rare, because they must be of very long duration since AGT in rock can take multiple years to complete. Some authors have addressed this problem in the past and give hypotheses for stress-strain relationships (e.g., Pimentel 2003, 2007a and 2007b, and Kirschke, 1996, see Figure 1-3). Their experimental research is described in Chapter 1.4.

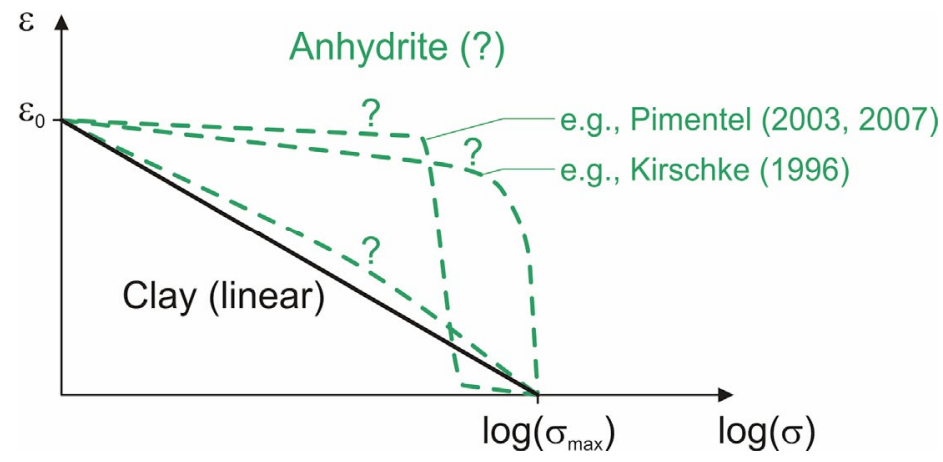

Figure 1-3: Hypotheses about the relationship between swelling pressure and swelling strain.

In the meantime, some of the open questions listed above have been investigated by Anagnostou, Pimentel and Serafeimidis at ETH Zurich within the scope of the above mentioned research projects (see Chapter 1.3). Further investigations related to the knowledge gaps have independently also been performed by other research groups (e.g., Alonso et al., Huggenberger et al.). 
The research project "Modelling of Anhydritic Swelling Claystones" was split into a theoretical and an experimental part. While the theoretical part was the focus of the work of Anagnostou and Serafeimidis, where they established thermodynamic fundamentals governing the AGT process and investigated AGT in anhydritic rocks computationally (see summary in Chapter 1.3.2), the present thesis addresses the above mentioned knowledge gaps mainly from an experimental point of view, with a special focus on establishing a swelling law. The literature review on the experimental investigations concerning the swelling of anhydritic rock is summarized in Chapter 1.4 and the aim and content of the present thesis is described in Chapter 1.5.

The research projects at ETH Zurich focus on the role of the transport processes, the clay matrix, and the swelling law (the so far published research is summarized in Chapter 1.3). Questions concerning the role of the hydraulic boundary conditions were not investigated in depth at ETH Zurich (see Anagnostou et al., 2015, and Chapter 1.3.2). Relevant research on the role of the hydraulic boundary conditions can be found, e.g., with the research groups of Huggenberger (2012, 2012, 2016) and Butscher et al. (2011a, 2011b, 2011c, 2015, 2016), who study the impact of tunneling on groundwater flow systems and the implications for the swelling of anhydritic claystones, or with Alonso and Olivella (2008), who investigated the effect of evaporation at the tunnel boundaries.

\subsection{Research projects at ETH Zurich}

\subsubsection{Long-Term Swelling Tests on Anhydritic Rock}

With the main aim of determining a swelling law, the research project FGU 2006/001 was launched at ETH Zurich. The investigations comprise of the execution of 25 simultaneous long-term swelling tests with anhydritic rock from the Gypsum Keuper under different constant loads (the axial stresses on specimens with a diameter of $70 \mathrm{~mm}$ range from $0.5 \mathrm{MPa}$ to $2 \mathrm{MPa}$ ). For this purpose, apparatuses with the similar type of load frame as used for the swelling tests of the specimens from the Freudensteintunnel (see Chapter 1.4.3) were constructed but with several improvements, especially regarding the load application and the axial deformation measurement (Pimentel and Anagnostou, 2010 and 2013).

First results from these long-term tests are published in Pimentel and Anagnostou (2010 and 2013) after a duration of 300 days. In a later report to ASTRA (Pimentel and Anagnostou, 2016) the measurements are shown up to a duration of 6.5 years. Exemplarily, the results of five specimens from the same bore core in the Chienberg tunnel, Switzerland, are shown in Figure 1-4. The specimens were loaded with $0.5,0.8,1,1.3$ and $2 \mathrm{MPa}$. On the left, the axial strains are shown in dependence of the time. The right diagram shows the development of the relationship between the strains and the applied axial stress for different points in time of the same specimens. Though these results may give a first indication of a swelling law, it needs to be born in mind that the tests are obviously still far from completion (swelling is still in progress). Furthermore, the results of tests on other bore cores did not produce the same results concerning the stress-strain relationship. 

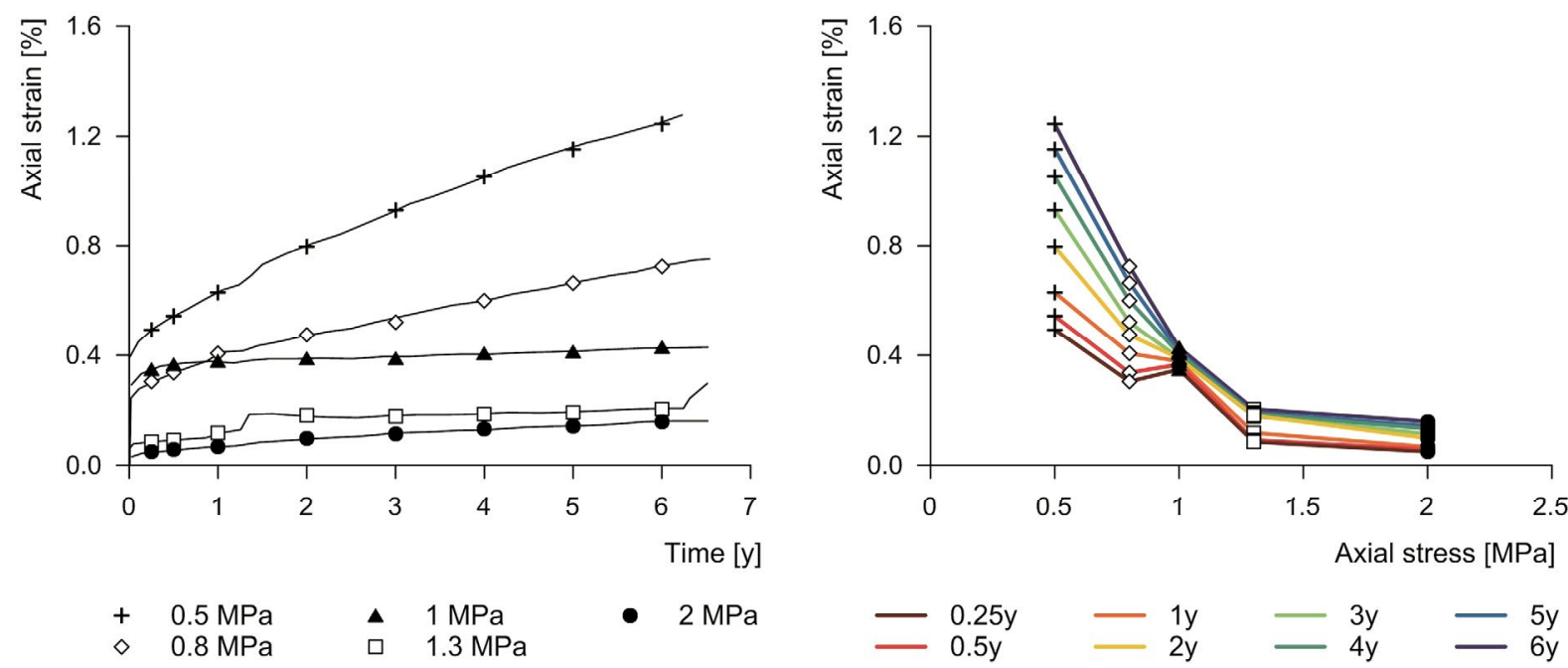

Figure 1-4: $\quad$ Results of the swelling tests with different axial stresses, data taken from Pimentel and Anagnostou (2016).

\subsubsection{Modelling of Anhydritic Swelling Claystones - theoretical part}

Within the scope of the theoretical part of the research project "Modelling of Anhydritic Swelling Claystones", Anagnostou and Serafeimidis identified and investigated key mechanisms behind the macroscopic swelling of anhydritic claystones:

Serafeimidis and Anagnostou (2012b, 2012a, 2013a) examined the dissolution rate of anhydrite and precipitation rate of gypsum by studying the reaction kinetics. They calibrated their model with experimental results found in literature and performed a parametric study of the kinetics in dependence of the anhydrite fraction. They concluded that anhydrite dissolution is in most relevant cases the governing factor during the AGT process (e.g., when the surface area of anhydrite in contact with water is smaller than roughly $10 \mathrm{~m}^{2}$ per $\mathrm{m}^{3}$ of rock according to Serafeimidis and Anagnostou, 2013a). They also studied the effect of so-called "self-sealing" of anhydrite with a gypsum layer by formulating a computational model. Since existing studies on the anhydritegypsum-water equilibrium appeared to be contradictory and did not provide sufficient information, Serafeimidis and Anagnostou (2013b) formulated a thermodynamic model for the prediction of the solubilities, taking the contact stresses between the minerals into account and comparing their results to values found in literature. Serafeimidis and Anagnostou (2014b) additionally investigated the influence of pore water activity, clay minerals, and pore size (especially the case of small pores as is commonly found in anhydritic claystones of the Gypsum Keuper) on the equilibrium concentrations. They found the solubility of gypsum to increase in the presence of clays and in the case of small pores. Anagnostou et al. (2014) then investigated, why anhydrite rather than gypsum is found at small depths of cover, which is usually the case in tunneling and came to the conclusion that the clay minerals and thus the low water activity are most likely responsible for the anhydrite to be the thermodynamically stable phase, rather than gypsum, thus preventing AGT prior to the excavation of tunnels. They used thermodynamic computations to determine the crystallization pressure of gypsum and found that the pressures are considerably lower in the case of low water activities (Serafeimidis and Anagnostou, 2014a). Serafeimidis and Anagnostou (2014a) furthermore show that the crystallization pressure is dependent on a number of factors, such as pore radius, temperature, water activity, and presence of foreign ions. Serafeimidis et al. (2015) expanded their investigations to the macroscopic and the mega scale using a cavity expansion model for the interaction between the growing crystal and the surrounding clay matrix to explain 
why swelling pressures in the laboratory are far lower than the crystallization pressure of gypsum, yet higher than the swelling pressures in situ. Serafeimidis (2014) furthermore investigated the role of the transport processes relative to the rate of the chemical reactions, considering also that gypsum precipitation occurs faster than anhydrite dissolution. He came to the conclusion that diffusion can be neglected in most cases, as can advective transport of ions in the case of very low seepage flow velocities which are usually encountered in the Gypsum Keuper formation and depend on the rock permeability and hydraulic boundary conditions. Serafeimidis therefore concludes that gypsum precipitates in the vicinity of the dissolving anhydrite in most cases. This is additionally supported by in situ observations which show a decrease in the gypsum fraction and an increase in the anhydrite fraction with the distance underneath the floor of tunnels (see, e.g., Hauber et al., 2005). On the other hand, observations also exist that indicate sulfate transport in the drainage pipes, showing that at least a part of the dissolved sulfate is transported away by the flowing water (e.g., Amstad and Kovári, 2001).

\subsection{Literature review on experimental investigations with anhydritic rock}

\subsubsection{Sahores}

Sahores (1962) was the first researcher to study the swelling of anhydritic rock and perform experiments to further the understanding of developing swelling strains and pressures due to the chemical reactions. However, Sahores mainly performed the experiments with calcium sulfate hemihydrate (also known as bassanite, see Chapter 2.1) instead of anhydrite, in order to accelerate the swelling process and induce higher swelling stresses. Some specimens contained up to $15 \%$ of anhydrite as well. He performed swelling tests at atmospheric pressure as well as under constant or variable stresses (ranging from 0.1 to $20 \mathrm{MPa}$ ) and measured the change in volume. He also performed tests where he kept the volume nearly constant and measured the stresses. The hemihydrate was mixed with water at various ratios to a paste, inserted in water-tight rubber testing tubes which were attached to a scale and immersed in a tank of water. Under atmospheric pressure, he determined the volume change of the paste as it transformed to gypsum by measuring the weight change and applying the principle of Archimedes. For the tests with increased stress, he placed the test tubes in dilatometric chambers which were filled with water and applied (or measured) the respective pressure for the tests above the liquid level.

In the case of swelling tests at atmospheric pressure, he registered a decrease in volumetric strains during hydration especially of the hemihydrate within the first 15 minutes, followed by a rapid increase within approximately 2 hours, after which he considered the reaction of hemihydrate to gypsum to be completed. The specimens containing anhydrite additionally were seen to swell for a longer duration, up to 30 days. Sahores was therefore able to assign the changes in volume to different swelling processes (i.e., transformation of hemihydrate to gypsum and hydration of anhydrite). Furthermore, he investigated different ratios of hemihydrate to water and has seen that a higher ratio causes less decrease in volume at first, and higher swelling strains in total. In the experiments where he additionally investigated the pressure acting on the specimen (i.e., pressures higher than atmospheric), he has seen that the first contraction increases with increasing pressure, while the swelling strains following the settlement decrease with increasing pressure. 
Sahores found that the minimal stress to prohibit any swelling of the hemihydrate at all, is $12 \mathrm{MPa}$, whereas $1.5 \mathrm{MPa}$ suffice for the swelling to be less than the first settlement (i.e., the volume remains smaller than the initial volume before hydration). In the case of few tests with anhydritic rocks, he has seen that values of 0.3 to $0.8 \mathrm{MPa}$ prohibit any swelling at all, whereas 0.1 to $0.3 \mathrm{MPa}$ suffice for the swelling to be less than the first settlement.

Since his research was performed mainly with a plaster containing hemihydrate (whereas the material properties such as the density of the plaster are unknown), the results concerning the rate and amount of swelling, as well as the influence of the applied pressure, cannot be adopted for the case of anhydritic rock (or even powdered anhydrite).

\subsubsection{Madsen, Nüesch and Ko}

Madsen and Nüesch (1990) and (1991) have performed four free swelling tests with rock specimens from anhydritic claystones (whereas absolutely no radial confinement was used), as well as 15 (nearly) completely constrained tests. Their rock specimens originate from borings in the Muschelkalk ("Anhydritgruppe") in Weiach (canton of Zurich, Switzerland) and from borings from a tunnel in Raibler Gypsum at the Walgau hydro power station in Austria.

Their results are depicted in Figure 1-5: In the left diagram, the swelling stresses over time are shown with an indication of the amount of anhydrite, gypsum and clay in each specimen post test (by the numbers following the letters " $A$ ", " $G$ " and "T"), and right, the strains over time are shown with an indication of the clay content (denoted by "T"). For some specimens the amount of gypsum was determined prior to the tests as well and can be considered negligibly small (it is therefore assumed here that all gypsum post test stems from AGT during the tests). In the discussion of their results, they postulate that the swelling stresses and swelling strains are strongly dependent on the clay content, and that the swelling stress reaches a maximum at a clay content of about $20 \%$. This, however, is deemed an unreasonable conclusion, since none of the swelling tests have reached full conversion of anhydrite to gypsum (in the case of the swelling stress tests, the specimens still contained roughly $70 \%$ of anhydrite on average) and the swelling stresses are clearly still increasing in most cases (see Figure 1-5, left diagram). Therefore, due to the uncompleted state of the swelling tests, no conclusions should be drawn about the maximal swelling stress. In a later publication, Madsen et al. (1995) also state that by allowing a heave, the swelling stress will be smaller only in the beginning (analogue to clays), however that as long as anhydrite is present in the rock, the swelling stress will build up due to AGT.

The swelling strains obtained during the free swelling tests ranged from nearly zero to more than $120 \%$ (see Figure 1-5, right). While the specimens all contained little clay (1-5\%), the amount of gypsum detected in the specimens post test varied from 0 to $71.3 \%$ (determined via TGA; cf. Chapter 3.1). 

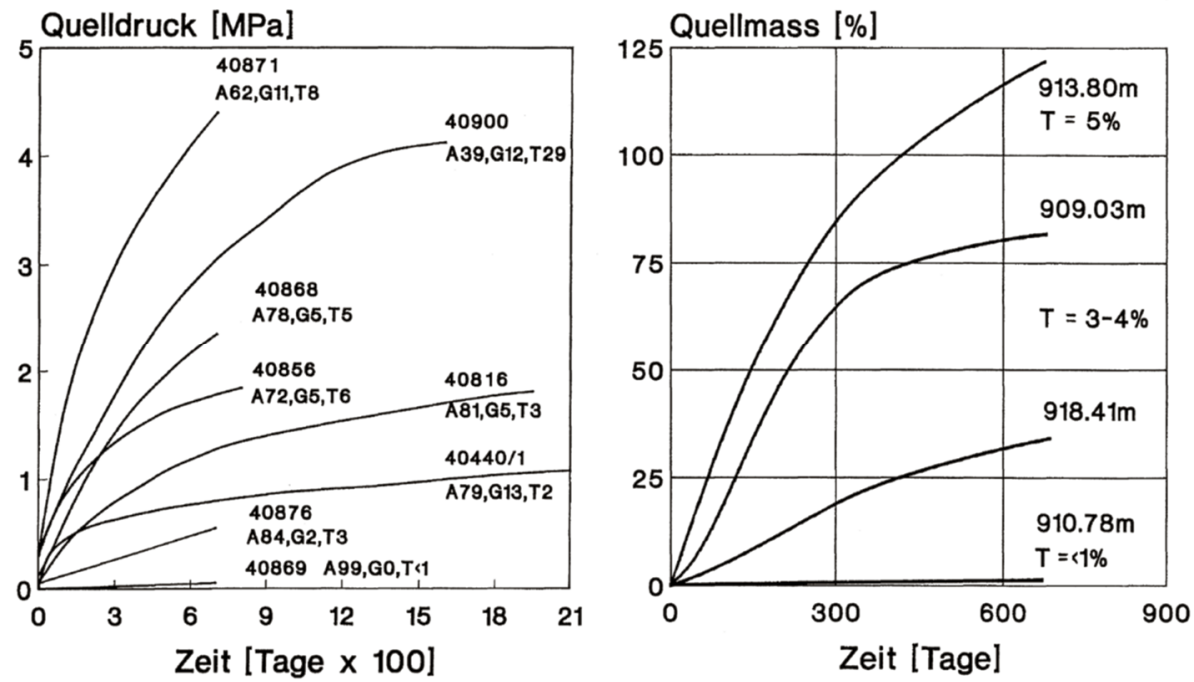

Figure 1-5: $\quad$ Swelling stresses (left) and swelling strains (right) vs. time (after Madsen and Nüesch, 1990).

From their results, the author was able to see a relationship between the swelling stresses resp. swelling strains and the amount of precipitated gypsum in the specimens post test (indicated in Figure 1-5, left, by the value following "G"):

In the following Figure 1-6, the author compiled the end-values of the stresses and strains along with the gypsum contents from Figure 1-5 and further data the author found in the work of Madsen and Nüesch (1990). Here, the amount of precipitated gypsum post test is used to indicate the influence of the sulfates on the swelling stresses and strains rather than the amount of anhydrite, since the latter varied strongly among the specimens.

With the exception of two specimens in Figure 1-6, left, a clear trend is visible: The swelling stresses increased nearly linearly with the amount of precipitated gypsum, independently of the duration of the tests. It may very well be that the swelling stress would increase further with continuous AGT in most cases (which may, however, take decades).

The relationship between the reached swelling strain and the amount of gypsum post test was seen to be nearly linear as well (see Figure 1-6, right). It is, however, not certain, whether the amount of gypsum really was negligibly small prior to the tests and the amount of anhydrite prior to the tests is not known. Furthermore, the swelling due to clay was not distinguished from AGT-swelling (no rapid increase in strains can be seen in Figure 1-5). 

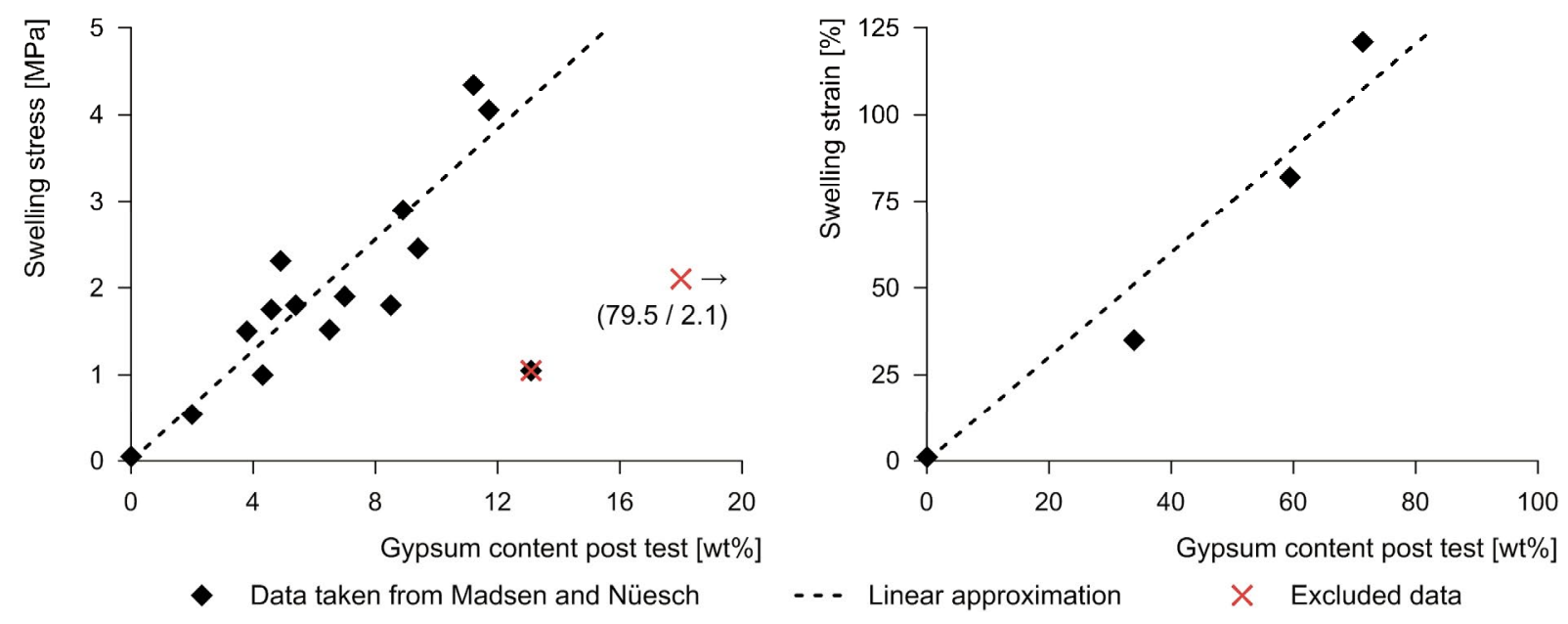

Figure 1-6: $\quad$ Swelling stresses and swelling strains vs. gypsum content post test; evaluation of the data presented by Madsen and Nüesch (1990).

Madsen and Nüesch investigated the structures of some specimens post test by cutting them and examining the sections optically and microscopically. They observed a gypsification of the specimens both within the structures and along the edge of the specimens. In the case of free swelling tests they saw large gypsum needles (with lengths up to $1 \mathrm{~cm}$ ). The gypsum crystals grew preferentially between the marl layers and created a porous structure. On some specimens, Madsen and Nüesch also saw a coating of gypsum, especially of the massive specimens. This is accompanied by a reduction in water supply of the anhydrite with increasing gypsum precipitation and thus slows down the AGT process. This can be conceived as so called "self-sealing" of anhydrite, as described, e.g., in Serafeimidis and Anagnostou (2013a) and Wanninger et al. (2017) and which is the topic of Chapter 5.

Nüesch and Ko (2000) performed swelling strain and swelling stress tests on specimens from Belchen, Adler and Sissach (presumably Chienberg-)tunnel. They have seen that most free swelling strain tests were completed after one year, whereas some of the swelling stress tests reached a steady stress state after 600 to 700 days while some did not reach a final value even after 1100 days at which point the tests were terminated. They have seen that in all cases anhydrite still remained in the specimens at the end of the tests and, therefore, AGT was not completed. From the comparison of stresses, strains and mineralogical compositions they conclude that swelling rocks have the highest swelling potential when they contain 5-15 wt\% (weight percentage) clay and $40-80 \mathrm{wt} \%$ anhydrite. However, the results they obtained with the samples from Belchen, Adler and Sissach showed different correlations compared to the data from Madsen and Nüesch (1990) compiled in Figure 1-6 (these are also shown in Nüesch and Ko, 2000): In some cases, even experiments where $>60 \%$ of gypsum was found in the specimens post test the strains and stresses were very low compared to the other data. Since Nüesch and Ko (2000) state that the samples contained less than $5 \%$ of gypsum prior to the tests, it must be questioned why AGT did not cause swelling in those cases or if they actually contained more gypsum to start with.

Nüesch and Ko (2000) have also seen that during the evolution of the swelling stress over time, the clay and anhydrite swelling can be distinguished from one another (see Figure 1-7): A specimen containing only clay swells rapidly within one day (curve A), while the specimen containing only anhydrite (curve E) showed no stress increase during the first days. Specimens containing both anhydrite and clay (curves B-D) showed both a small stress increase after one day, followed by a 
continuous increase due to anhydrite swelling. These results indicate that the swelling of clay occurs much faster than the swelling of anhydrite.

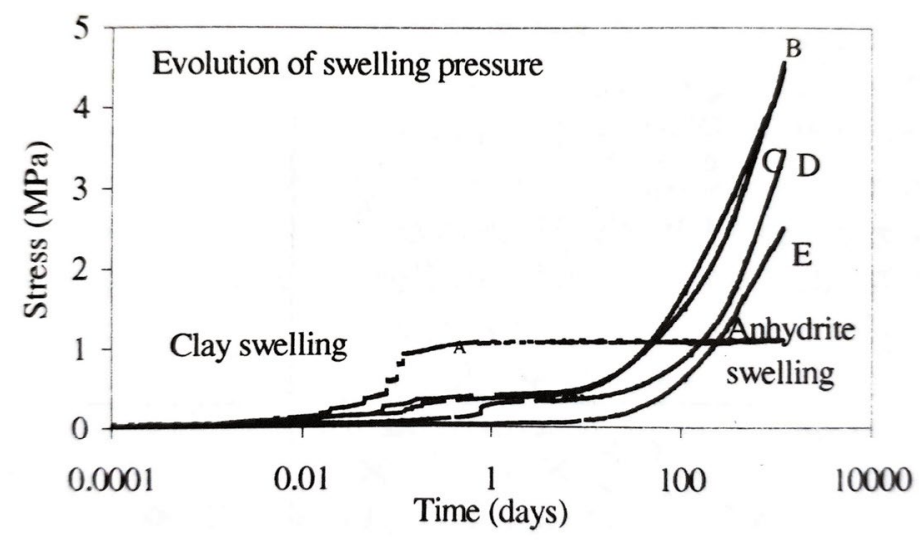

Figure 1-7: $\quad$ Swelling stress over time (after Nüesch and Ko, 2000).

\subsubsection{Long-term experiments on specimens from the Freudensteintunnel}

Arguably the longest and most elaborate experimental investigation campaign concerning the swelling of anhydritic claystones (specifically of the Gypsum Keuper) was undertaken within the scope of the construction of the Freudenstein railway tunnel. Here, the so far only systematic in situ tests were performed in a specially constructed test adit and long-term swelling tests on specimens from the Freudensteintunnel were undertaken at the University of Karlsruhe and at the TU Darmstadt.

For the in situ tests, different design principles (as described in Chapter 1.2) were applied over a tunnel length of roughly 100 m, which was divided in 15 blocks (e.g., Kirschke, 1987, Fecker, 1996, Pimentel and Anagnostou, 2013): The sections were constructed with linings of varying strength (up to $850 \mathrm{~mm}$ ), some with a yielding layer of puffed up burned clay in the invert below the lining, and the invert of four blocks was anchored by pre-stressed anchors ranging from $0.1 \mathrm{MPa}$ to $0.75 \mathrm{MPa}$. The heave of the tunnel lining as well as the developing pressure on it was measured. Pimentel and Anagnostou (2013) discussed the measurements of the pre-stressed blocks (see Figure 1-8) and concluded that the semilogarithmic relationship between the deformation and the applied stress cannot be confirmed due to the fact that it changes with the course of time (the originally observed semilogarithmic relationship changed to a nearly linear one after 17 years, see Figure 1-8b). 

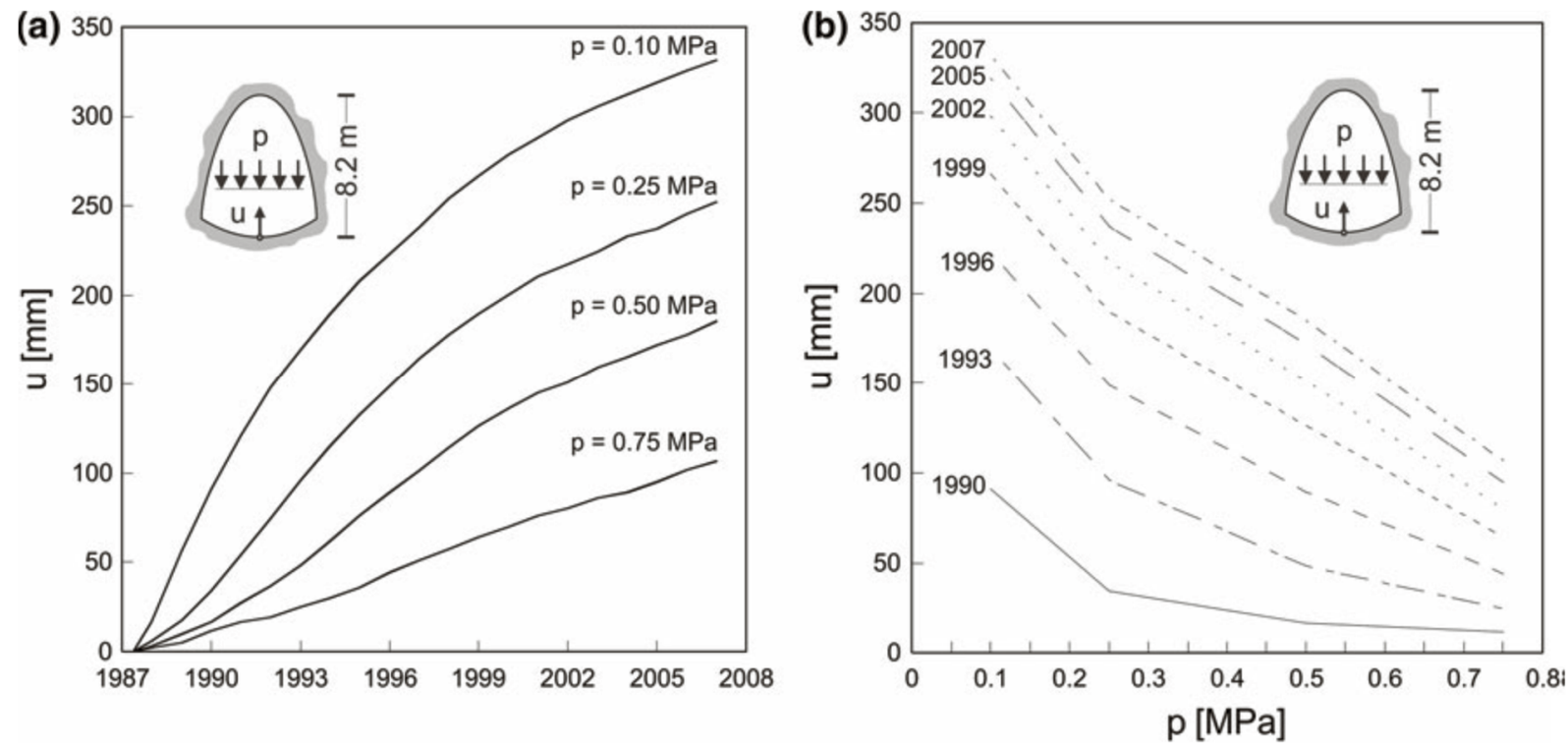

Figure 1-8: $\quad$ Results from field tests in the test adit of the Freudenstein tunnel, after Pimentel and Anagnostou (2013). (a) Measured heave of pre-stressed blocks X1-XIV vs. time, (b) development of relationship between heave and applied stress over the span of 20 years.

The laboratory experiments on specimens from the Freudenstein tunnel were begun roughly 36 years ago and some are (to the author's knowledge) still on-going. According to Pimentel (2019, personal communication), who supervised the experiments at the University of Karlsruhe between 1986 and 2003, the apparatuses used for the swelling tests were designed for a maximal load of $4 \mathrm{MPa}$, since they originally expected maximal swelling pressures of 2 to $3 \mathrm{MPa}$. However, the nominal load of the cells was reached after only 2 years, which necessitated several unloading cycles in order to avoid damages to the apparatuses. In some cases, the specimens were unloaded and new load cells were installed which could withstand stresses up to $8 \mathrm{MPa}$ and stiffer apparatuses were built for the subsequent tests. For this reason, the experiments were conducted under varying mechanical boundary conditions (as described, e.g., in Kirschke, 1987), and to the author's knowledge, none of the tests were performed under constant boundary conditions until an equilibrium was achieved (e.g., tests were begun under nearly completely constrained boundary conditions and the developing axial stress was measured, however, the specimens were unloaded after a certain time and the developing axial strain was measured, then the axial deformation was prohibited again and the developing stress was measured). A few results to these experiments are published and analyzed by a number of authors (e.g., Kirschke, 1987, Kirschke et al., 1991, Wittke et al., 2004, Pimentel, 2007b, Katzenbach et al., 2010). In the following (Chapters 1.4.4 to 1.4.6) some of these results and corresponding interpretations concerning the swelling law are summarized and discussed.

\subsubsection{Kirschke et al.}

Kirschke (1987) and Kirschke et al. (1991) observed the developing swelling strains of rock specimens from the Gypsum Keuper of the Freudensteintunnel (see Chapter 1.4.3) in free swelling tests as well as oedometer tests with an axial load or axial constraint. They saw a retardation of the developing strains with increasing axial stress and that the axial stress influences the extent of the swelling strains after a test duration of five years (however, the strains have not reached a steady state prior to the publication of their article). Furthermore, no indication is given as to which extent the swelling process is progressed (e.g., by determining the amount of remaining anhydrite 
in the specimens). In later publications, Kirschke (1996 and 2010) states that the swelling behavior of anhydritic rock specimens from the Freudensteintunnel appeared to follow Grob's law at first (without specifying the time frame), but then began to change after the first years and - as opposed to the argumentation of Wittke et al. (2004) - that the final relationship between swelling strain and swelling stress of anhydritic claystones does not follow Grob's law. He postulates that this is caused by the fact that the rate at which the specimens swell depends strongly on the stress acting on the specimen and the strain-stress relationship may very well take on a different shape than a semilogarithmic relationship. Therefore, he rightfully suggests that typical swelling tests according to Huder and Amberg (1970, see Chapter 1.4.6) in combination with Grob's law are unsuitable for investigating anhydritic swelling rocks.

Kirschke (1992 and 1996) presents a hypothetical stress-strain relationship (see Figure 1-9) with which he emphasizes that although the stress-strain relationship of many experimental investigations show a semilogarithmic dependency at first, the final shape of the relationship may be very different (and also not necessarily the shape he presents in the diagram). However, he does not present the experimental results to confirm this. It is presumed unlikely that the maximal stress reached by all stress-strain curves does not change over time, as he presents in Figure 1-9. Kirschke appears to assume this based on the experiments described in Chapter 1.4.3 and he states that the swelling stress of long-term swelling tests does not exceed a certain value, but he neglects the fact that the repeatedly measured "maximal swelling stress" after each unloading actually corresponded to the nominal load of the cell (i.e., it was technically not even possible to measure any stress increase above that stress).

Kirschke (1992 and 1996) argues that any results from experiments that were not completed are wrong by definition, since no equilibrium between swelling strain and swelling stress was reached. While the author agrees that the stress-strain relationship cannot be ascertained unless an equilibrium is indeed reached and AGT fully completed, intermediary results should not be considered as wrong, but the conclusions (interpretations or extrapolations) drawn from these results need to take this into account accordingly.

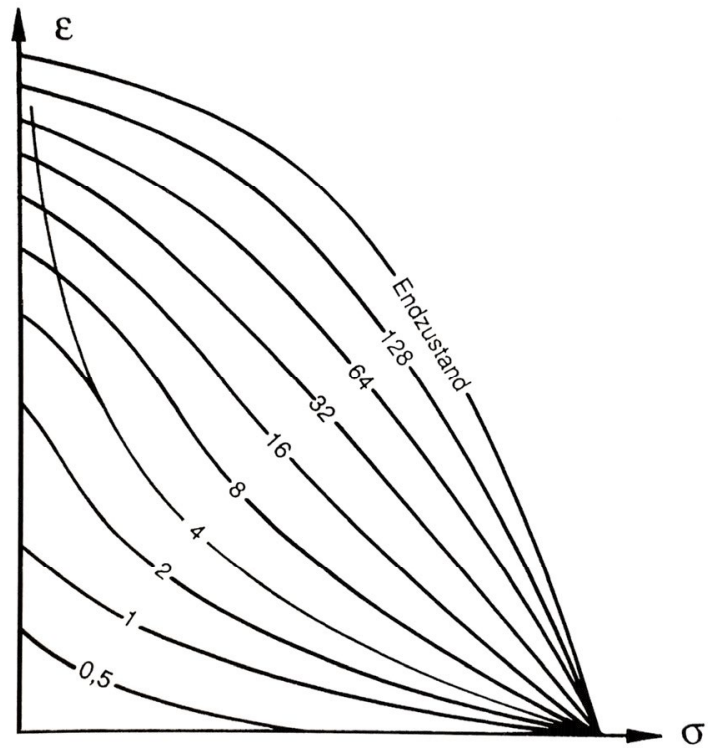

Figure 1-9: Hypothetical development (in years) of the stress-strain relationship according to Kirschke (1992 and 1996). 


\subsubsection{Pimentel}

Pimentel $(2003,2007 a, 2007 b)$ evaluated results of tests described in Chapter 1.4.3, i.e., swelling tests where either the stress or the strain was held constant (the conditions were also alternated, e.g., first the swelling stress at constant strains was measured, then some strains were allowed and kept constant again). Since none of the tests reached a steady state, Pimentel estimated different end-values via extrapolation and therefore obtained multiple values for the stress-strain dependency from the results of one single specimen. An example for this is shown in Figure 1-10 (a to c) for the specimen Abl 2: At the beginning of the test, the strains were held constant (at level "A" in Figure 1-10b) and the developing stress was measured (Figure 1-10a). Due to the fact that the stress reached the capacity load of the used testing frame (see Chapter 1.4.3), the specimen was repeatedly unloaded (i.e., the strains increased slightly). Since the first development of the stress did not reach a steady state, Pimentel estimated the maximal stress value ("A" in Figure 110a) via extrapolation (based on the indirect least squares method, see Pimentel, 2007b and 2007a). By doing this for each strain level (e.g., "B" in Figure 1-10a and b), he obtained pairs of values for the stress-strain relationship (Figure 1-10c). By gathering these results for multiple specimens (see Figure 1-10d), he identified three "swelling-phases":

- Phase I: In the range of high pressures (i.e., above ca. $6 \mathrm{MPa}$ ), the strains are very small. Pimentel concludes that, while some anhydrite dissolution occurs, this stress suffices to restrict gypsum crystallization and thus limit the increase in volume.

- Phase II (indicated by the grey area in Figure 1-10d): Around the value of 4-5 MPa a small reduction of the stress causes a strong increase of the strain. Pimentel postulates that the stress is low enough to allow gypsum crystal growth, which breaks the structure of the rock between the layers and leads to the formation of new macropores. This change in structure represents an irreversible process and the stiffness of the specimen is strongly reduced.

- Phase III: Further reduction of the stress barely leads to additional strain. According to Pimentel, most of the gypsum precipitates within the macropores during this phase. It is, nevertheless, also possible that - with increasing time - gypsum-dissolution and leaching will take place in this phase, leading to a loss of mass.

Pimentel therefore introduces the concept of cracking of anhydritic rock and the formation of macropores below a certain stress. This explains why the volume increase of the solids during AGT (i.e., 61\%) does not suffice as an explanation for the observed swelling strains and, therefore, the strains occurring due to AGT in natural rock cannot be estimated theoretically and need to be determined experimentally. As a further conclusion of his analysis, he postulates that the semilogarithmic swelling law is not applicable for anhydritic claystones.

The uncertainties of this analysis lie, however, in the fact that no end-values were obtained during the experiments (which lasted from 3 to over 20 years), and it is thus difficult to say whether, e.g., the same value for the stress at certain strain would be obtained as the extrapolations deliver. Due to the heterogeneity of the specimens, it was not possible to compare real end-values of the stresses at different strains to one another. 
(a)

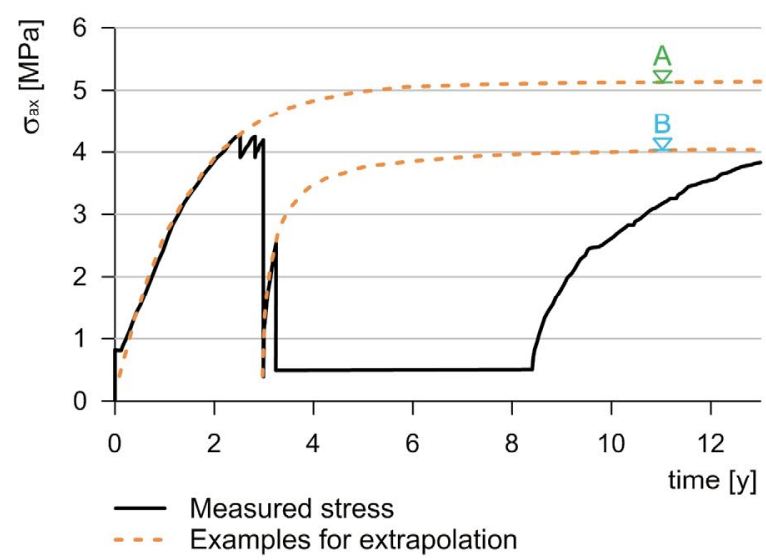

(c)

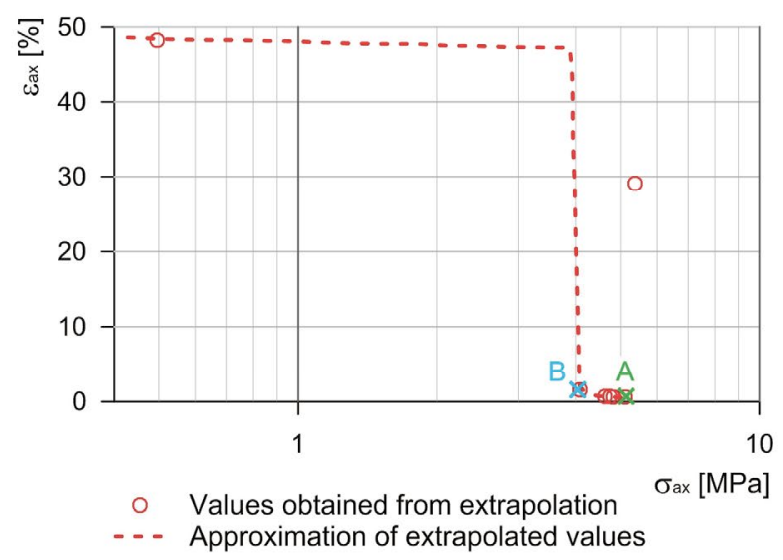

(b)

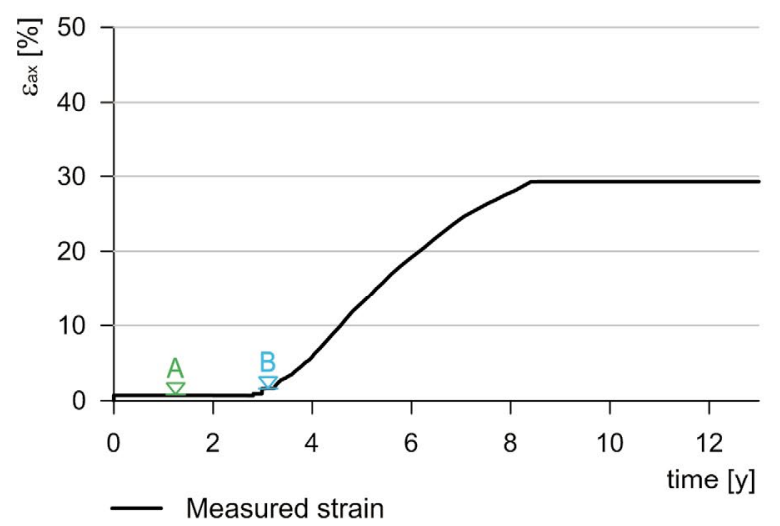

(d)

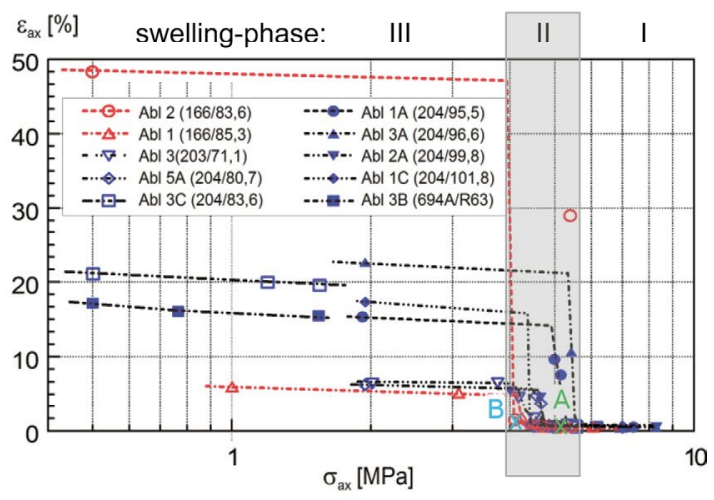

Figure 1-10: Extrapolation of data for the determination of a swelling stress - swelling strain relationship by Pimentel (2003, 2007a, 2007b). (a) Measured stress for the specimen Abl 2 and example for two extrapolations. (b) Measured strain for the specimen Abl 2. (c) Compilation of extrapolated stresses and strains of the specimen Abl 2 and approximation of those values. (d) Compilation of extrapolated stresses and strains of 10 specimens. The data in images (a)-(c) was copied from Pimentel (2007a), and image (d) was copied and modified after Pimentel (2007b).

\subsubsection{Wittke et al.}

Wittke and Rissler (1976) and Wittke (1978) consider the swelling law by Grob (1972) to be generally applicable also to anhydritic claystones. They base this assumption primarily on swelling tests performed by Huder and Amberg (1970). However, the stress-strain relationship in question published by Huder and Amberg (1970) was obtained with marlstone specimens (which did not contain any anhydrite). Concerning their tests on specimens containing anhydrite, Huder and Amberg (1970) clearly state that they have seen no significant reduction of the swelling stress due to a small heave, as was the case in their tests with marlstone and opalinus clay, and that swelling (and a corresponding increase in stress) is caused by chemical reactions. In their results of tests on bore cores from Gipskeuper (containing anhydrite), Huder and Amberg (1970) show the development of the swelling stress over time (up to 600 days and without any unloading-steps) and reached swelling stresses of 1.3-3.8 MPa.

However, Wittke and Rissler (1976) and Wittke (1978) did not take the time-dependency of the developing swelling stresses into consideration and did not present sufficient results from laboratory tests to support their assumption that the swelling law of anhydritic rock follows Grob's law. In the only results from a swelling test they show, the unloading steps lasted merely 10 to 
40 days each, stresses up to only $0.52 \mathrm{MPa}$ were measured and the stress-strain relationship containing the measured data is not explicitly shown. This test is considered inadequate by the author, since it is not clear how much anhydrite was in the specimen prior to the test, whether AGT occurred at all during each unloading step, and whether the corresponding final swelling strain was really reached and delivers a semilogarithmic relationship. In any case, Wittke and Rissler (1976) and Wittke (1978) consider the semilogarithmic swelling law to be valid not only for the case of osmotic but also for the case of chemical swelling, and they expand the one-dimensional swelling law to a three-dimensional swelling law.

The above mentioned results from swelling tests are later also used by Kiehl (1990) and WittkeGattermann (1998), who then expand the three-dimensional swelling law to also consider timedependency. However, they base the validation of the three-dimensional swelling law on experimental results published by Pregl et al. (1980), which were performed on compacted clays, without any anhydrite.

Wittke (2004b) argues that it is not sensible to distinguish between swelling due to AGT and swelling due to clay, since both swelling mechanisms appear in rocks of the Gypsum Keuper formation. As already in 1976, he claims that both swelling mechanisms abide by the same swelling law, though a physical explanation for this statement is not given. As already indicated above, this assumption that Grob's law can be applied not only to clays but also when anhydrite is present (and thus when chemical swelling occurs) has been made in in a number of publications of the group of Wittke (e.g., Kiehl, 1990, Wittke-Gattermann, 1998). However, a conclusive validation of this assumption with numerous long-term experiments is not presented.

As previously done by Pimentel (2003), Wittke et al. (2004) analyzed the results from a number of swelling experiments on specimens from the Freudensteintunnel as well. As mentioned in Chapter 1.4 .3 , the specimens were tested under a variety of boundary conditions, whereas in none of the cases the boundary conditions were kept constant over the entire duration of the tests. From the results, Wittke et al. (2004) estimated multiple maximal stresses with the same stress-time curves by extrapolating individual segments and plotted them against the corresponding axial strain held during the respective segment. This way, they obtained two to four strain/stress points for each specimen, which they considered to represent the maximally reached stress that develops at a certain maximal value of strain (see Figure 1-11a). With an interpolation between those points (Figure 1-11b), they consider the swelling law by Grob (1972) to be valid also for sulfatic rock. However, when plotting the curves from Figure 1-11b in a semilogarithmic diagram (Figure 1-11c) and extrapolating their data linearly to zero strain (as is exemplarily indicated for three data sets, $A 2, A 3 d$ and A4d, where "A" stands for "Ablesung") the author obtains unrealistically high maximal stresses (in the case of $\mathrm{A} 2$ more than $100 \mathrm{MPa}$, which even exceeds the expected crystallization pressure of gypsum, see Serafeimidis and Anagnostou, 2014a, who consider a range up to about $50 \mathrm{MPa}$ for the crystallization pressure in a closed system). Since in none of the cases the maximal swelling stress under constant volume was actually measured and not all load-steps were considered for the generation of the interpolated curves, these interpretations are considered questionable.

Wittke et al. (2004, 2004a, 2016) then describe the swelling law of anhydritic claystones to be dependent on the parameter $\omega$, which is referred to as a dimensionless water content in most publications, but also as the degree of transformation from gypsum to anhydrite in Wittke et al. (2016) (which is assumed to correspond to $\vartheta$ used in this report, cf. Equation (7 - 12)), see Figure 1-12. According to Wittke et al. (2004), they base their assumptions on the findings of Gattermann (1998), 
who investigated the maximal swelling stress that occurs while gradually adding water to pure, highly compacted bentonite specimens (i.e., without anhydrite). Gattermann has observed that the maximal swelling stress of the bentonite specimens is nearly linear dependent on their degree of saturation.

(a)

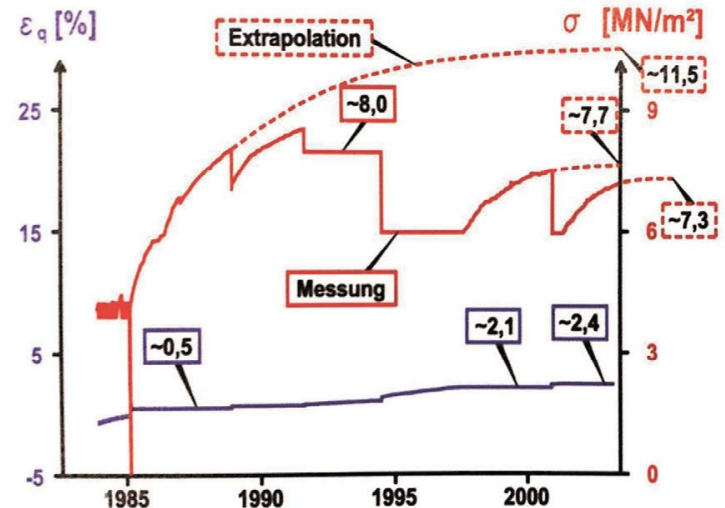

(b)

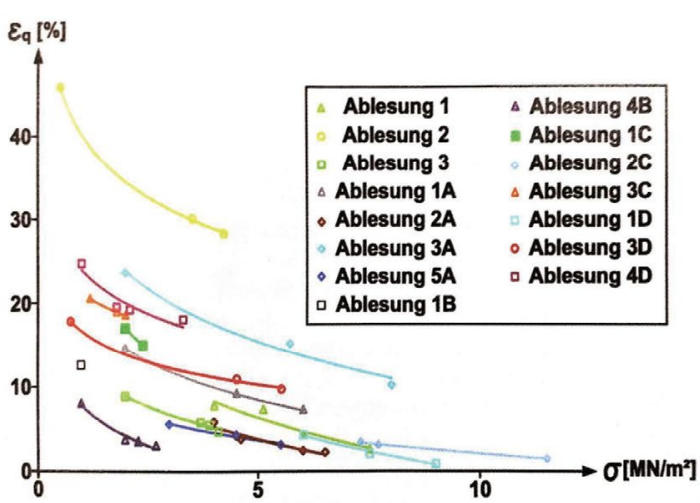

(c)

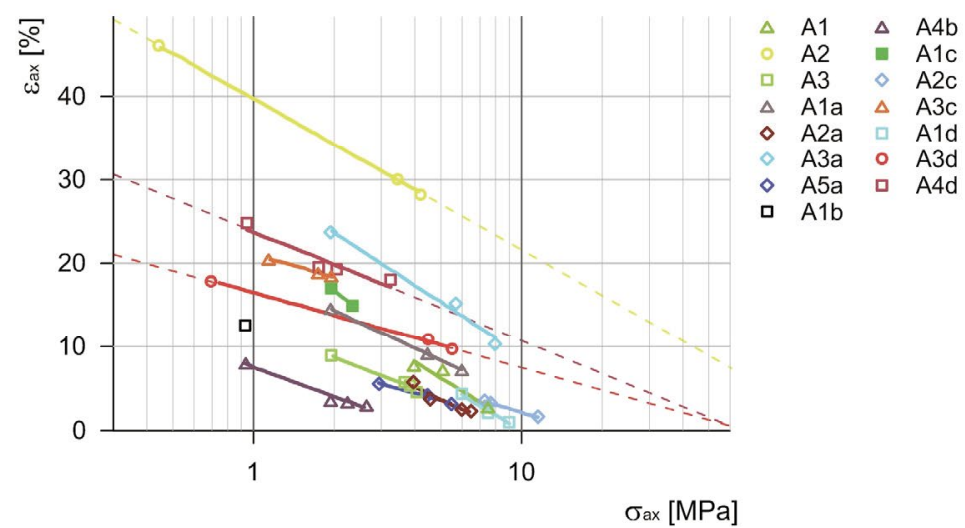

Figure 1-11: (a) Extrapolation of swelling strain and swelling stress experiments, (b) Interpretation of the relationship between swelling strain and stress, according to Wittke et al. (2004) (images (a) and (b) copied from Wittke et al., 2004); (c) Data from Figure (b) presented in a semilogarithmic diagram with exemplary linear extrapolations indicated by the dashed lines.

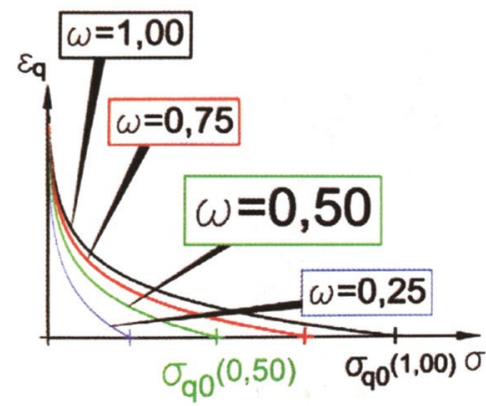

linear

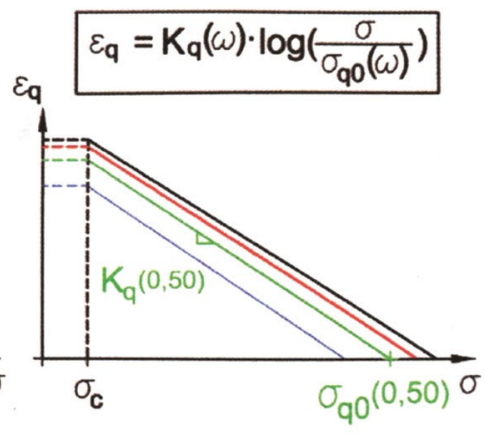

halblogarithmisch

$\omega:$ normierter dilmensionsloser Wassergehalt

Figure 1-12: $\quad$ The swelling law and its dependence on the dimensionless water content, according to Wittke et al.; image copied from Wittke et al. (2004).

Based on an analysis of Gattermann's data, the author was not able to determine curves similar to those in Figure 1-12 and could thus not reproduce the semilogarithmic dependency between stresses and strains for varying degrees of saturation for these experiments. It is, therefore, 
questionable, whether the semilogarithmic swelling law according to Grob is applicable for partly saturated specimens, even in the case of pure bentonite specimens. Assuming this swelling law also to be true for the case of anhydritic specimens, as Wittke et al. (2004) present (see Figure 1-12), is even more doubtful. It appears that they did not further consider the porosity of the rock, its anhydrite content or the distribution of the anhydrite within. Furthermore, the stiffness of the rock-matrix plays a role on the maximal swelling pressure. Wittke et al. (2016) use the same term $\omega$ for the dimensionless water content as for the degree of transformation from anhydrite to gypsum and claim that the maximal swelling stress is linearly dependent on it. This may, however, only be the case when one assumes that the entire volume of water in the specimen is indeed used for gypsum precipitation and thus - due to stoichiometry - the consumption of water is linearly related to the amount of gypsum in the specimen.

In the author's opinion, there is insufficient foundation to the general assumption made by the group of Wittke that the semi-logarithmic swelling law is applicable also to anhydritic rock. It is indispensable to distinguish between the different swelling processes (due to clay and AGT) when investigating swelling of anhydritic claystones (e.g., the stress-strain relationships) and also to consider the long duration of chemical swelling, therefore keeping in mind that in most cases the end-values for strains or stresses are not reached.

\subsubsection{Thuro and Rauh}

In order to determine the swelling capacity of argillaceous rock, Thuro (1993) proposes the usage of powdered swelling tests. By drying, crushing and milling the rock to roughly the size of silt, then manually compacting the powder to disks (with a proposed density of $1.5 \mathrm{~g} / \mathrm{cm}^{3}$ ), reproducible specimens can be obtained for the swelling tests. They consider this advantageous, since the original rock may be heterogeneous and since the specimens may be disturbed by the boring process and thus do not represent the rock in situ according to Thuro (1993). By applying the same specimen preparation procedure for each powdered specimen, the results of the swelling tests can thus be reliably compared to one another.

Rauh and Thuro (2006) and (2007) have then investigated the swelling behavior of anhydrite bearing rock from the Haselgebirge, Reichenhall and Gypsum Keuper formations by performing powdered swelling tests as mentioned above (see Figure 1-13). They evaluated their tests after 1.5 years and claim that the measurements have gone below the accuracy of measurement after that duration. In a later publication, Rauh (2009) shows the swelling strain vs. time curves for these experiments, and it appears questionable, whether the swelling process was indeed completed. Rauh and Thuro (2007) list furthermore the anhydrite and gypsum contents before and after the powdered swelling tests and it can be seen that the specimens from the Reichenhall Formation and the Haselgebirge still contained anhydrite after the tests (see Figure 1-13, right), thus the anhydrite to gypsum transformation process was not completed. However, they find a linear correlation between (a) the reached swelling strain after 1.5 years and the estimated former rock cover, (b) the Blaine value (specific surface) of the powdered rocks prior to swelling and the swelling strain after 1.5 years, (c) the relative gypsum contents in the specimens after 1.5 years of swelling and the estimated former rock cover. In summary, after 1.5 years of swelling, the reached swelling strain was smaller for the rocks with higher former overburden and lower Blaine-values, while less gypsum precipitated. 

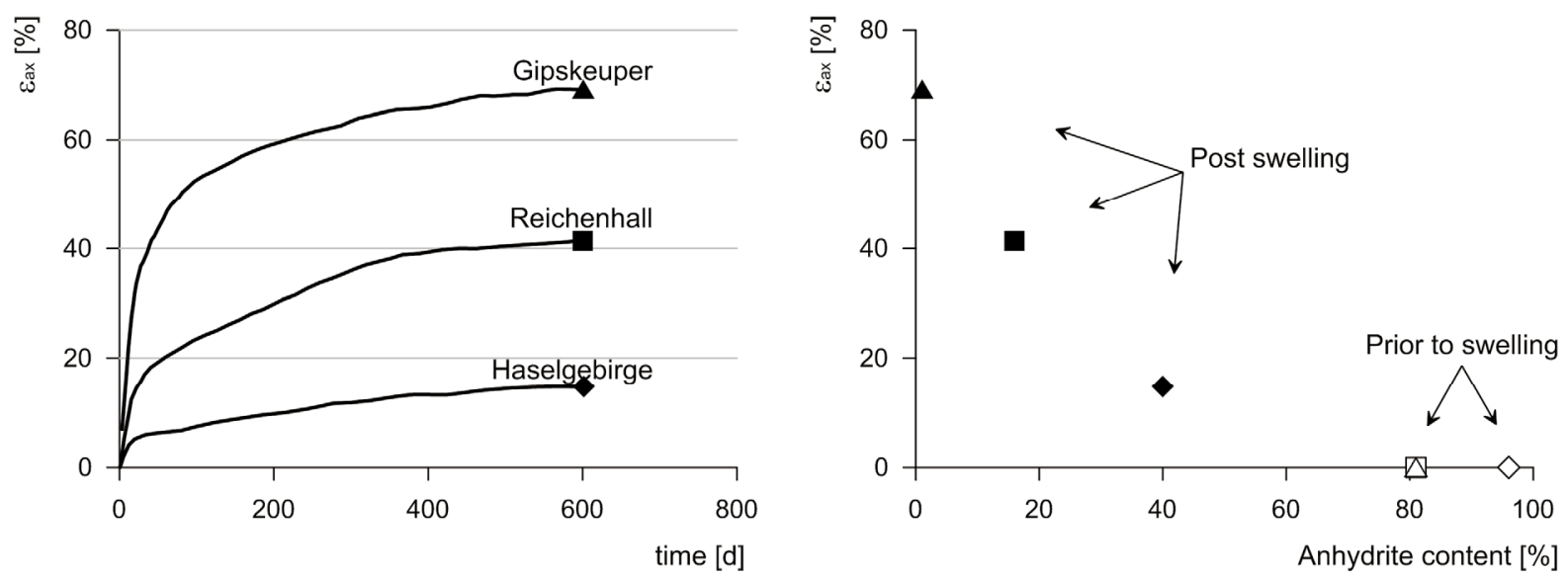

Figure 1-13: Results of free powder swelling tests, data taken from Rauh and Thuro (2007) and Rauh (2009). Left: axial swelling strains vs. time; right: maximally reached swelling strains vs. remaining anhydrite content in the specimens and corresponding anhydrite content prior to the swelling tests. The same symbols indicate the same specimens in both images.

Additionally, they crushed the rock of the Haselgebirge to different grain sizes from which they produced specimens for powdered swelling tests. They have seen that specimens containing larger grain sizes of anhydrite swelled less after a duration of 1.5 years, than those with smaller grain sizes. However, they do not specify the amount of gypsum or anhydrite remaining in the specimens after the swelling test. Since the processes of anhydrite dissolution and gypsum precipitation are dependent on the specific surface area of the grains (cf., e.g., Serafeimidis and Anagnostou, 2012a), it is strongly assumed that AGT was less progressed in the case of the larger grains and that the swelling strains may have reached higher values, had the swelling tests gone longer.

A major disadvantage of powdered swelling tests is, however, that the structure of the rock cannot be represented (the cementation of natural rock is lost, i.e., the crushed and compacted rock cannot exhibit any tensile strength and its swelling behavior will be more pronounced than in the case of the original rock; furthermore, anisotropic behavior is neglected in the case of powdered swelling tests). While the proposed powdered swelling tests may give an indication of whether the rock can swell based on its mineralogy, its real swelling behavior will still remain unknown. For example, crushing, milling and compacting massive anhydrite and subjecting the powdered specimen to a swelling tests will result in a comparatively fast development of swelling strains (which depends also on the grain size of the anhydrite), whereas the original massive anhydrite may show a very slow swelling behavior which may not be problematic during the lifetime of an underground construction. It is, therefore, questionable, whether the proposed swelling tests are applicable for practical purposes.

\subsubsection{Alonso et al.}

The research group of Prof. Alonso at UPC Barcelona has been investigating possible causes and mechanisms relating to swelling due to AGT for nearly 20 years.

Starting from the "classical" distinction between the rapid "physical swelling", which they attribute to clay minerals (as will be seen in this thesis, physical swelling can also occur in the absence of swelling clays), and the far slower "chemical swelling" due to AGT, which is attributed to the change in solid volume, they indicate that the latter is a slow, isovolumetric process, during which anhydrite is dissolved as fast as gypsum precipitates. The excess of dissolved ions could either be 
transported in the water or lead to gypsum precipitation in discontinuities (Alonso et al., 2007, Berdugo et al., 2009, Berdugo, 2007).

In their early publications (e.g., Alonso et al., 2007, Alonso and Olivella, 2008, Berdugo, 2007), they consider swelling induced by crystal growth to be a consequence of drying. However, in later publications (e.g., Oldecop and Alonso, 2012, Alonso et al., 2013) they take several possible mechanisms into account which are responsible for swelling: evaporation, water inflow by seepage, stress changes and dissolution of anhydrite. They acknowledge that evaporation is not necessary in order for swelling due to AGT to occur (Ramon and Alonso, 2013).

Oldecop and Alonso (2012) investigated the free swelling of rock specimens from the Lilla tunnel (Spain) under various hydraulic boundary conditions, i.e., with or without evaporation, as well as for different aqueous solutions. They saw that swelling occurred similarly when distilled water or water from the Lilla tunnel was used and that the boundary conditions did not show a definite change in the swelling behavior. The swelling strains with distilled water and water from the Lilla tunnel reached $11-18 \%$ in vertical direction after 5 months of swelling. Post swelling they broke pieces off the specimens and investigated the specimen structure optically. They observed large gypsum needles (up to $10 \mathrm{~mm}$ ) mainly at the base of the specimens. In the interior of the specimens they saw cracks which were partially filled with gypsum. They concluded that the major fraction of the volume increase is due to increasing voids. It is unknown which amount of swelling was caused by the clay resp. by the anhydrite.

In the research of Oldecop and Alonso (2012), Ramon and Alonso (2013) and Ramon (2014), they relate the strain rates $\dot{\varepsilon}$ to the mass change of gypsum $\dot{m}_{G}$ via a - so far unknown - bulking parameter, $\gamma$ :

$$
\dot{\varepsilon}=\gamma \frac{\dot{m}_{G}}{\rho_{G}}
$$

This implies that new crystals may either occupy part of the volume of an already existing open discontinuity, or generate additional porosity (Ramon and Alonso, 2013). The magnitude of $\gamma$ is, however, so far unknown and needs to be further determined by experiments or field observations (Ramon et al., 2017).

\subsubsection{Flatt et al.}

The group of Prof. Flatt at the Chair of Physical Chemistry of Building Materials at ETH Zurich studied the use of swelling inhibitors in a recent research project (Flatt, 2012 and Flatt et al., 2017), parallel to the research project of the group of Prof. Anagnostou (introduced in Chapter 1.2). They investigated the decoupling of the swelling processes due to clay and AGT and the efficacy of swelling inhibitors with respect to the two swelling processes.

They propose to decouple the swelling processes by making use of the fact that AGT does not occur at temperatures above about $50^{\circ} \mathrm{C}$ due to changing thermodynamic conditions (this is explained in Chapter 2.3.1). Flatt et al. (2017) introduce the term "thermodynamic switch" for the process of changing the temperature in order to prevent or trigger AGT. With previous experiments, Flatt et al. (2014) have already investigated and confirmed the influence of the temperature on the crystallization pressure of mirabilite forming in a solution saturated with respect to thenardite. They indicate that the crystallization pressure increases from $0 \mathrm{MPa}$ at $32.4^{\circ} \mathrm{C}$ to $32 \mathrm{MPa}$ at $3{ }^{\circ} \mathrm{C}$. By exposing portland limestone samples to cycles of impregnation and drying, whereas impregnation 
occurred at varying temperatures, they show experimentally that damage of the stone (i.e., when the tensile strength of the stone is reached due to crystallization) occurs faster at lower temperatures.

Within the scope of their research project, Flatt et al., 2017 performed oedometer tests with compacted specimens containing milled anhydritic claystone from the Belchen tunnel, Switzerland. The specimen preparation followed the same procedure as described later in this thesis, i.e., the specimens were compacted with a pressure up to $100 \mathrm{MPa}$ (also at the Rock Lab of the Institute for Geotechnical Engineering at ETH Zurich).

In order to determine the efficacy of the used inhibitors, they first conducted three swelling tests with different solutions: AGT inhibitor $(0.1 \%$ Sika Retardan $L$ in water), clay inhibitor $(5 \%$ diaminobutane dihydrochloride) and water saturated with respect to gypsum. While the clay inhibitor did not impede the swelling in this test, the specimen saturated with the AGT inhibitor swelled slightly less than the other two and by analyzing the specimen post test they have seen that roughly half as much gypsum had precipitated.

In order to study the efficacy of the AGT inhibitor closer, Flatt et al. then performed two further oedometer tests with the same specimen material, but loaded the specimens with a slight axial stress $(5 \mathrm{kPa})$ and used the proposed thermodynamic switch: They started the tests in an oven at $60{ }^{\circ} \mathrm{C}$ by watering the specimens with a saturated calcium sulfate solution and observed a rapid initial swelling which they allocated to clay swelling and they did not measure further swelling after the initial heave. After four weeks, they moved one specimen to $20^{\circ} \mathrm{C}$ and observed an increase in swelling strains which they allocated to AGT swelling, thus confirming the effectivity of the thermodynamic switch. After an additional four weeks, they moved the second test to $20{ }^{\circ} \mathrm{C}$ as well, but replaced the water with AGT-inhibitor (1\% Sika Retardan L in water, i.e., a higher concentration than in the first series of oedometer tests). In contrast to the first specimen, they measured nearly no swelling in this case and thus concluded the AGT-inhibitor to have reacted successfully. This may be very lucrative in regard to the problems faced in underground constructions; for example, AGT inhibitors could be added to the water used for drilling in tunneling.

\subsection{Aim and content of the present work}

The aim of this thesis is to resolve knowledge gaps related to the "swelling law" and "role of clay" as described in Chapter 1.2 with the aid of experimental investigations. This work is part of the larger research project "Modelling of Anhydritic Swelling Claystones" at ETH Zurich (cf. Chapter 1.3.2) and contains the following sets of experimental investigations:

1. Experimental testing of some theoretical aspects in the work of Anagnostou and Serafeimidis (see Chapter 1.3.2) was performed with the aim of verifying assumptions and models presented therein.

2. Systematic swelling experiments were conducted with the goal of quantifying the relationship between swelling strains, swelling stresses, and the mass (or volume) change during AGT and using the obtained information to establish a swelling law. The quantitative understanding of such a relationship provides a basis for the modelling of chemo-mechanical processes and has great practical relevance for future modelling of swelling of anhydritic claystones and thus for the conceptual design of underground structures in anhydritic rock. 
3. Experiments were performed which aim at separating the swelling due to AGT from swelling of clay.

The role of hydraulic boundary conditions was not investigated in this work. Their relevance was reviewed early on and found to be limited to special cases, such as high seepage flow or evaporation. Serafeimidis (2014) also concludes that transport processes are in most cases not relevant (cf. Chapter 1.3.2). Therefore, they are only considered marginally on a conceptual basis for specific cases (e.g., when solely anhydrite dissolution without gypsum precipitation is discussed). Furthermore, gypsum dissolution and thus leaching of the rock, which is assumed to occur after AGT, is not a topic of this thesis.

The thesis is structured in five parts:

- The introductory Part I continues with a description of the different phases of calcium sulfate and features the relevant chemical reactions of anhydrite dissolution and gypsum precipitation in Chapter 2. Furthermore, factors are discussed, which influence the equilibrium concentrations of anhydrite and gypsum, such as temperature, pore water potential, stress, and foreign ions, which may define whether anhydrite or gypsum is stable in a system. The kinetics of the processes of anhydrite dissolution and gypsum precipitation are then described, along with factors which may accelerate or decelerate the processes.

In Chapter 3 all standard analytical testing techniques used for the experimental investigations are listed and described.

- Part II deals with the simultaneous anhydrite dissolution and gypsum precipitation over time. The kinetics of AGT in a solution were investigated for different amounts of dissolved anhydrite with conductivity measurements, an indirect observation of the development of the concentration of a solution. Additionally, the impact of foreign ions on the process was tested (Chapter 4). In Chapter 5 another set of experiments is described, where the selfsealing of anhydritic rock was tested. In particular, the development of a gypsum coating on anhydrite is measured and compared to the theoretical prediction obtained with the model by Serafeimidis and Anagnostou (2013a).

- Part III investigates the coupling of chemical and mechanical processes and presents the majority of experiments performed within this work. After an introduction and overview (Chapter 6), constitutive and conceptual models are presented in Chapter 7 which describe

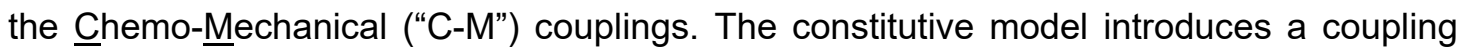
parameter $\chi$ which relates the occurring swelling strains and/or swelling stresses to the mass changes of anhydrite respectively gypsum (i.e., the chemical processes) and represents a material-specific tensor. On a conceptual basis, various structures and possible experimental conditions are considered in order to understand how to quantify the so far unknown relationship $\chi$. For the experiments, artificially created powdered specimens of high density $\left(1.9 \mathrm{~g} / \mathrm{cm}^{3}\right)$ containing solely anhydrite and kaolin were used (kaolin is considered to be a so-called non-swelling clay). The development of stresses and strains caused by watering the specimens was measured for four different sets of mechanical boundary conditions: (1) oedometer tests, (2) complete constraint tests, (3) isotropic compression tests and (4) so-called "flexible oedometer"-tests, which allowed measurement of radial as well as axial strain and indirect determination of radial stress. All of these C-M-experiments are presented and discussed in Chapter 8. 
- Through these experiments, it was possible to obtain an indication for the coupling parameter $\chi$, relating the mass change of anhydrite and the resulting stresses and/or strains for each set of boundary conditions. Understanding of this relationship is of great practical relevance and high significance for future modelling of swelling of anhydritic claystones.

- Part IV deals with swelling of natural rocks containing both swelling clay minerals and anhydrite (as opposed to Part III where only chemical swelling on artificial specimens is investigated). After a short introduction in Chapter 9, Chapter 10 describes the swelling processes observed in anhydritic claystones: physical swelling (osmotic swelling of clay and water intake due to capillary effects, here referred to as mechanical swelling) and chemical swelling due to AGT. Chapter 11 features the performed swelling experiments, where rock specimens of anhydritic claystones as well as powdered and compacted specimens of the same rock were immersed in water and their deformation measured. The fact that anhydrite rather than gypsum becomes the stable phase at temperatures above roughly $50{ }^{\circ} \mathrm{C}$ (where the equilibrium concentration of anhydrite is lower than that of gypsum), was used to separate the physical swelling of the clay from swelling due to AGT. Therefore, the tests were performed both at room temperature, where AGT occurs, as well as in an oven at $50{ }^{\circ} \mathrm{C}$, where AGT does not occur. The conclusions to these experiments are drawn in Chapter 12.

- Part $\mathrm{V}$ summarizes and highlights the main conclusions of this work and provides an outlook for future research. 


\section{Mechanisms and processes related to chemical swelling}

As introduced in the previous chapter, chemical swelling is caused by the transformation of anhydrite to gypsum, which are both phases of the calcium-sulfate system. In the following, an overview of these phases is given (Chapter 2.1) and the underlying chemical reactions for AGT are listed (Chapter 2.2). Whether or not AGT occurs depends on the equilibrium concentrations of anhydrite and gypsum, which are influenced by a number of factors and are discussed in Chapter 2.3., while the rates at which anhydrite dissolution or gypsum precipitation occur can be determined with existing kinetic models described in Chapter 2.4 .

\subsection{Phases of the system $\mathrm{CaSO}_{4}-\mathrm{H}_{2} \mathrm{O}$}

As described, e.g., in Wirsching (2000), the system $\mathrm{CaSO}_{4}-\mathrm{H}_{2} \mathrm{O}$ is characterized by a dihydrate phase (gypsum, $\mathrm{CaSO}_{4} \cdot 2 \mathrm{H}_{2} \mathrm{O}$ ), a hemihydrate phase (bassanite, $\mathrm{CaSO}_{4} \cdot 0.5 \mathrm{H}_{2} \mathrm{O}$ ) and three anhydrite phases (anhydrite I, II and III, $\mathrm{CaSO}_{4}$ ), whereas anhydrite I only exists at temperatures above $1180^{\circ} \mathrm{C}$ and will not be further discussed within the framework of this thesis.

Gypsum is considered stable below $40^{\circ} \mathrm{C}$ while anhydrite II is stable from $40^{\circ} \mathrm{C}$ to $1180{ }^{\circ} \mathrm{C}$ (see Table 2-1). Bassanite and anhydrite III are metastable under normal atmospheric conditions and will transform to gypsum when in contact with water or vapor below temperatures of $40^{\circ} \mathrm{C}$. In the case of anhydrite III (which is also known as "soluble" anhydrite), the transformation to gypsum begins via the bassanite phase.

Depending on the increasing burn temperature and duration during manufacturing, the phase anhydrite II is further categorized in three types: anhydrite II-s $\left(300^{\circ}-500^{\circ} \mathrm{C}\right)$, anhydrite II-u $(500$ $700^{\circ} \mathrm{C}$ ) and anhydrite II-E $\left(>700^{\circ} \mathrm{C}\right)$. The hydration rate to gypsum is the fastest for anhydrite II-s ("slowly soluble" anhydrite) and slowest for anhydrite II-u ("insoluble" anhydrite).

Bassanite and anhydrite III can be further categorized into $\alpha$ - and $\beta$ - forms or stages. These are, however, not further discussed here and can be found elsewhere (e.g., Wirsching, 2000). The structures of bassanite and anhydrite III are considered similar, whereas structural channels are empty in the latter case and filled with water molecules in the former (cf., e.g., Partridge and White, 1929, Ramsdell and Partridge, 1929, Seufert et al., 2009b and 2009a). As opposed to anhydrite II, the addition of water to anhydrite III will lead to the formation bassanite without dissolution of anhydrite (the structural channels are filled with water molecules). Anhydrite II will, however, dissolve directly and precipitate as gypsum in the aqueous solution (Seufert et al., 2009b).

Table 2-1: $\quad$ Gypsum, bassanite and anhydrite phases and some physical properties relevant to this research (source: Wirsching, 2000).

\begin{tabular}{|c|c|c|c|c|c|c|c|}
\hline & Gypsum & Bassanite & & & Anhydrite & & \\
\hline & (dihydrate) & (hemihydrate) & III & II-s & II-u & II-E & $\mathbf{I}$ \\
\hline Formula & $\mathrm{CaSO}_{4} \cdot 2 \mathrm{H}_{2} \mathrm{O}$ & $\mathrm{CaSO}_{4} \cdot 0.5 \mathrm{H}_{2} \mathrm{O}$ & & & $\mathrm{CaSO}_{4}$ & & \\
\hline Molar mass [g/mol] & 172.17 & 145.15 & & & 136.14 & & \\
\hline Density $\left[\mathrm{g} / \mathrm{cm}^{3}\right]$ & 2.310 & $2.619-2.757$ & 2.580 & & $2.93-2.97$ & & undetermined \\
\hline $\begin{array}{l}\text { Temperature of } \\
\text { thermodynamic stability }\left[{ }^{\circ} \mathrm{C}\right]\end{array}$ & $<40$ & $\begin{array}{l}\text { Metastable } \\
\text { in dry air }\end{array}$ & $\begin{array}{l}\text { Metastable } \\
\text { in dry air }\end{array}$ & & $40-1180$ & & $>1180$ \\
\hline Production temperature $\left[{ }^{\circ} \mathrm{C}\right]$ & $<40$ & $80-180$ & $110-290$ & $<500$ & $500-700$ & $>700$ & undetermined \\
\hline
\end{tabular}


Unless indicated otherwise, the densities are taken from Serafeimidis and Anagnostou (2012a):

Density of anhydrite:

$$
\rho_{A}=2960 \mathrm{~kg} / \mathrm{m}^{3}
$$

Density of gypsum:

$$
\rho_{G}=2320 \mathrm{~kg} / \mathrm{m}^{3}
$$

Density of water $\left(20^{\circ} \mathrm{C}\right)$ :

$$
\rho_{W}=998 \mathrm{~kg} / \mathrm{m}^{3}
$$

\subsection{Chemical reactions}

The underlying reactions for chemical swelling are anhydrite dissolution and gypsum precipitation, and are shown in the following sub-chapters.

\subsubsection{Anhydrite dissolution}

Anhydrite $\left(\mathrm{CaSO}_{4}\right)$ dissolves in water according to the following chemical reaction:

$$
\mathrm{CaSO}_{4} \rightarrow \mathrm{Ca}^{2+}+\mathrm{SO}_{4}^{2-}
$$

Anhydrite dissolution takes place as long as the ratio between the ionic product $Q$ and the solubility product $K$ is smaller than one. They are determined via the ionic activities $a$ of the calcium and sulfate ions at the respective concentrations ( $c$ or $c_{e q, A}$ at equilibrium) while the ionic activities of pure solids and liquids are equal to one (see, e.g., Mullin, 2001, Atkins and De Paula, 2006). Therefore:

$$
\frac{Q}{K}=\frac{a_{\mathrm{Ca}^{2+}, \mathrm{c}} \cdot a_{\mathrm{SO}_{4}^{2-}, \mathrm{c}}}{a_{\mathrm{Ca}^{2+}, \mathrm{ceqA} A} \cdot a_{\mathrm{SO}_{4}^{2-}, \mathrm{ceq}, A}}
$$

Dissolution takes place when $Q / K$ is smaller than one.

The activities can be expressed by the activity coefficients $\gamma_{i}$ (which are dependent on the concentrations and can determined according to the Davies equations, see Equations (A - 3 ) and (A - 4) in Appendix A) and the respective concentrations $c_{i}$ of the ions. In absence of other sources of calcium and sulfates, the concentrations of these ions in the solution are equal and their activity coefficients equal or at least very similar. Therefore, we can express Equation (2 - 5) as a function of the respective concentrations and the mean activity coefficients for the ions in solution and at equilibrium:

$$
\frac{Q}{K}=\frac{\left(c_{\mathrm{Ca}^{2+}} \cdot \gamma_{\mathrm{Ca}^{2+}, c}\right) \cdot\left(c_{\mathrm{SO}_{4}^{2-}} \cdot \gamma_{\mathrm{SO}_{4}^{2-}, \mathrm{c}}\right)}{\left(c_{C a^{2+}, c e q, A} \cdot \gamma_{\mathrm{Ca}^{2+}, c e q, A}\right) \cdot\left(c_{S O_{4}^{2-}, c e q, A} \cdot \gamma_{S O_{4}^{2-}, c e q, A}\right)}=\frac{c^{2} \cdot \gamma_{ \pm, c}^{2}}{c_{e q, A}^{2} \cdot \gamma_{ \pm, c e q, A}^{2}}
$$

For $c \leq c_{e q, A}$, the ratio $Q / K \leq 1$, therefore anhydrite dissolution takes place. 


\subsubsection{Gypsum precipitation}

Gypsum $\left(\mathrm{CaSO}_{4} \cdot 2 \mathrm{H}_{2} \mathrm{O}\right)$ precipitates according to the following chemical reaction:

$$
\mathrm{Ca}^{2+}+\mathrm{SO}_{4}^{2-}+2 \mathrm{H}_{2} \mathrm{O} \rightarrow \mathrm{CaSO}_{4} \cdot 2 \mathrm{H}_{2} \mathrm{O}
$$

Gypsum precipitation takes place, when $\mathrm{Q} / \mathrm{K}$ for the above reaction is larger than one. In terms of concentrations, the simplest case is when calcium and sulfate ions are in the same proportion in solution. Then, precipitation will take place if the molar concentration of either calcium or sulfate in the water exceeds the equilibrium concentration of gypsum (i.e., $c \geq c_{e q, G}$ ). Equation (2 - 8) first expresses the general situation, and then the specific one in which calcium and sulfate are present in the same amounts.

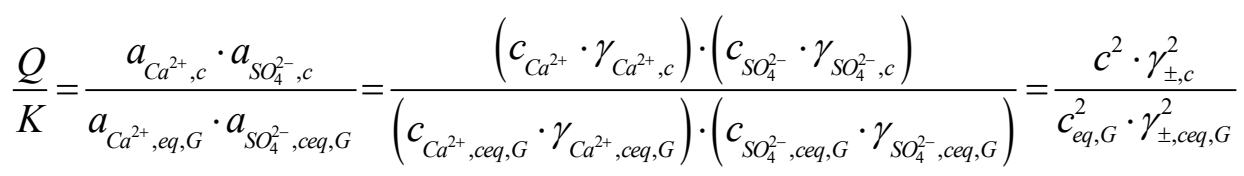

\subsubsection{Simultaneous chemical reactions}

Although both anhydrite dissolution and gypsum precipitation occur as individual processes over the solution phase, they occur simultaneously in most cases. Assuming that, (i), the ions are not transported by water (which, as was investigated by Serafeimidis, 2014, is insignificant in most cases in Gypsum Keuper, cf. Chapter 1.3.2), (ii), the gypsum nucleates locally and, (iii), all dissolved calcium and sulfate ions from the anhydrite are used for gypsum precipitation, the transformation from anhydrite to gypsum can be considered (from the mass balance viewpoint) as a single reaction (the rate of anhydrite dissolution is slower than that of gypsum precipitation at the relevant temperature ranges in Gypsum Keuper, as discussed by Serafeimidis and Anagnostou, 2012a). Therefore, leaching of the rock is not considered when simultaneous anhydrite dissolution and gypsum precipitation are taken into account. The following reaction (including the mass balance) is thus considered:

$$
\begin{array}{ccc}
\text { Anhydrite } & \text { Water } \\
\mathrm{CaSO}_{4} & 2 \mathrm{H}_{2} \mathrm{O} \\
0.136 \mathrm{~kg} / \mathrm{mol} & 0.036 \mathrm{~kg} / \mathrm{mol}
\end{array} \quad \begin{gathered}
\text { Gypsum } \\
\mathrm{CaSO}_{4} \cdot 2 \mathrm{H}_{2} \mathrm{O} \\
0.172 \mathrm{~kg} / \mathrm{mol}
\end{gathered}
$$

Therefore, all ions from anhydrite dissolution are considered to be used for gypsum precipitation (the amount of ions in the solution is low), and the changes in masses of anhydrite and gypsum per unit volume are coupled as follows:

$$
\frac{\dot{m}_{G}}{\dot{m}_{A}} \triangleq \frac{0.172[\mathrm{~kg} / \mathrm{mol}]}{-0.136[\mathrm{~kg} / \mathrm{mol}]}=-1.265,
$$

whereas the mass per unit volume $m_{i}$ of a substance $i$ is defined as the ratio between the total mass of the substance $M_{i}$ and the total volume of the system $V_{t o t}$ :

$$
m_{A}=\frac{M_{A}}{V_{\text {tot }}} \quad \text { and } \quad m_{G}=\frac{M_{G}}{V_{\text {tot }}}
$$

Note that for the total mass of a substance the capital notation $M_{i}$ is used here (as, e.g., in ASTM International, 2007a) and is not to be confused with the molar mass. 
In order to assess the change in volumes of anhydrite $\left(\Delta V_{A}\right)$, gypsum $\left(\Delta V_{G}\right)$ and water $\left(\Delta V_{W}\right)$ the mass balance from Equation (2 - 9) is combined with the densities of anhydrite, gypsum and water (Equations (2 - 1) to (2 - 3)):

$$
\Delta V_{A}=-\frac{0.136}{0.172} \cdot \frac{\rho_{G}}{\rho_{A}} \cdot \Delta V_{G}=-0.6198 \cdot \Delta V_{G} \quad \text { or } \quad \Delta V_{G}=-1.6135 \cdot \Delta V_{A} .
$$

Therefore, the volume increase of the solids during AGT is roughly $61 \%$.

When considering a closed system (i.e., no inflow or outflow of water), the change in volume of water due to the chemical reactions $\left(\Delta V_{W}\right)$ can be determined analogously to above:

$$
\begin{gathered}
\Delta V_{W}=\frac{0.036}{0.136} \cdot \frac{\rho_{A}}{\rho_{W}} \cdot \Delta V_{A}=0.7849 \cdot \Delta V_{A} \quad \text { or } \quad \Delta V_{A}=1.2740 \cdot \Delta V_{W} . \\
\Delta V_{W}=-\frac{0.036}{0.172} \cdot \frac{\rho_{G}}{\rho_{W}} \cdot \Delta V_{G}=-0.4865 \cdot \Delta V_{G} \quad \text { or } \quad \Delta V_{G}=-2.0556 \cdot \Delta V_{W} .
\end{gathered}
$$

For the exemplary case, where 1 gram of anhydrite (which corresponds to $338 \mathrm{~mm}^{3}$ of solid substance) dissolves and is bound again by gypsum precipitation, we get:

$$
1 \mathrm{~g} \text { Anhydrite }+0.265 \mathrm{~g} \text { Water } \rightarrow 1.265 \mathrm{~g} \text { Gypsum }
$$

which corresponds to:

$$
337.8 \mathrm{~mm}^{3} \text { Anhydrite }+264.7 \mathrm{~mm}^{3} \text { Water } \rightarrow 545.1 \mathrm{~mm}^{3} \text { Gypsum }
$$

Or, analogously, expressing Equation (2 - 16) for $1 \mathrm{~mm}^{3}$ of anhydrite:

$$
1 \mathrm{~mm}^{3} \text { Anhydrite }+0.785 \mathrm{~mm}^{3} \text { Water } \rightarrow 1.614 \mathrm{~mm}^{3} \text { Gypsum }
$$

As can be seen from Equations (2 - 16) and (2 - 17), the total volume (solids and water) shrinks by roughly $10 \%\left(1 \mathrm{~mm}^{3}+0.785 \mathrm{~mm}^{3}>1.614 \mathrm{~mm}^{3}\right)$ if the volume of the used water is considered as well, which is the case when regarding a closed system.

\subsection{Equilibrium concentrations of anhydrite and gypsum}

The equilibrium concentrations of anhydrite and gypsum are strongly dependent on the temperature, the activity of the pore water, the presence of foreign ions, the stress and on the pore water pressure acting on the rock, among other factors (cf. the work of Serafeimidis and Anagnostou described in Chapter 1.3.2, and, e.g., Anderson, 1996, Appelo and Postma, 2005). The equilibrium concentrations can be calculated with the thermodynamic relations described in Serafeimidis and Anagnostou (2014b), cf. Chapter 1.3.2, and their dependence on the above mentioned factors are discussed in the following sub-chapters. The main equations used in this work to calculate the equilibrium concentrations are summarized in Appendix A.

\subsubsection{Influence of the temperature}

Using the above mentioned thermodynamic equations, the equilibrium concentrations of anhydrite $\left(c_{e q, A}\right)$ and gypsum $\left(c_{e q, G}\right)$ were computed under the assumptions of distilled water (no foreign ions), atmospheric conditions, zero negative pore water potential and zero stress acting on the 
particles (see Appendix A). The results are shown in Figure 2-1 in dependence of the temperature for a temperature range relevant for the laboratory conditions used in this work (i.e., $5-50{ }^{\circ} \mathrm{C}$ ).

It can be seen that the equilibrium concentration of gypsum increases marginally between the temperatures of $0{ }^{\circ} \mathrm{C}$ and $60{ }^{\circ} \mathrm{C}$ (i.e., from $15.0 \mathrm{~mol} / \mathrm{m}^{3}$ to $16.1 \mathrm{~mol} / \mathrm{m}^{3}$ ), while the equilibrium concentration of anhydrite decreases from $32.7 \mathrm{~mol} / \mathrm{m}^{3}$ at $0{ }^{\circ} \mathrm{C}$ to $13.8 \mathrm{~mol} / \mathrm{m}^{3}$ at $60{ }^{\circ} \mathrm{C}$. Both equilibrium concentrations amount to $15.7 \mathrm{~mol} / \mathrm{m}^{3}$ at $48.8{ }^{\circ} \mathrm{C}$, which is considered to be the transition temperature for these conditions (i.e., the intersection between the two curves in Figure 2-1).

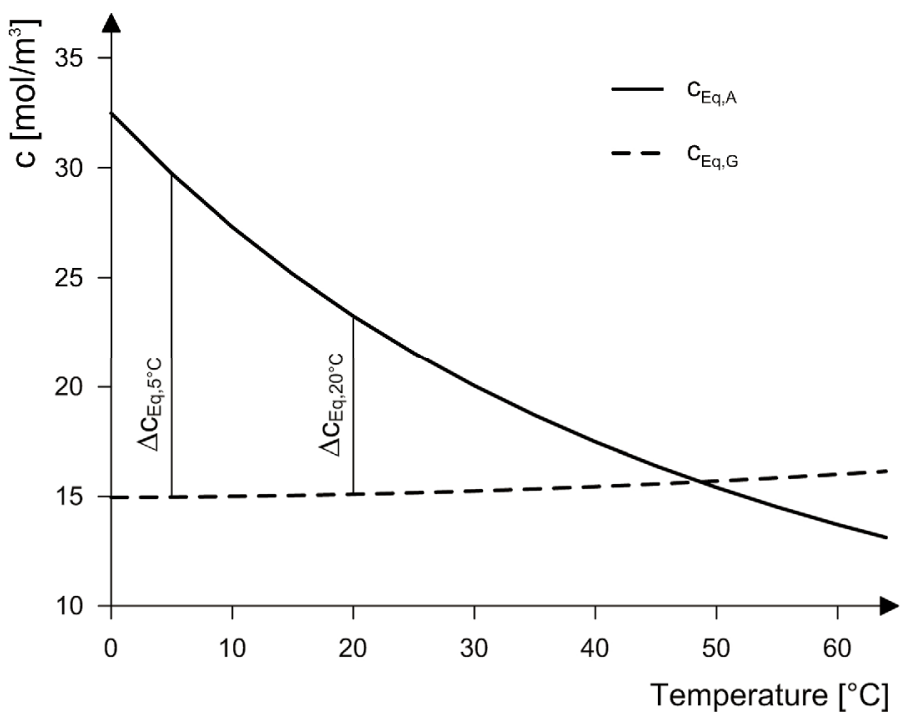

Figure 2-1: Equilibrium concentrations of anhydrite and gypsum as a function of the temperature (computed with the thermodynamic relations in Serafeimidis and Anagnostou, 2014b).

\section{Discussion and comparison to literature}

The change in equilibrium concentration over the temperature varies in literature and various values for the transition temperature (also referred to as equilibrium temperature) at which anhydrite rather than gypsum becomes the stable phase can be found. This was also thoroughly discussed most recently by van Driessche et al. (2017). In the following, the computed curves in Figure 2-1 are compared to some values stated by different authors for atmospheric pressure, absence of foreign ions in the solution and for the temperature range of relevance in this work (i.e., not higher than $100{ }^{\circ} \mathrm{C}$ ), see Figure 2-2.

Hill (1937) investigated the solubility of anhydrite by measuring the amount (\%) of calcium in a solvent in which anhydrite crystals were dissolved. In his experiments, he approached the equilibrium concentration via undersaturation and supersaturation at different temperatures. The equilibrium concentration of gypsum was taken from the "International Critical Tables" by Washburn (1926-1933). He determined the transition temperature to lie at $42^{\circ} \mathrm{C}$. This value was confirmed by Posnjak (1938), who investigated the conversion of gypsum, hemihydrate and anhydrite in solutions at different temperatures.

For the solubility measurements performed by Innorta et al. (1980), they placed gypsum or anhydrite in a container with bi-distilled water and stirred mechanically while the temperature was controlled. The solutions were diluted and the $\mathrm{Ca}^{2+}$ contents determined by atomic absorption spectrophotometry. According to their data, the transition temperature lies at $49.5 \pm 2.5^{\circ} \mathrm{C}$. 
Bock (1961) added gypsum and anhydrite to water (containing different amounts of sodium chloride) and stirred the solutions for up to 96 hours and determined the calcium concentrations by titration with standard EDTA. He discovered that the equilibrium concentration of the "less stable solid phase" decreased with longer periods of stirring. This can easily be explained: It appears that Bock assumed that the maximum concentration measured was the equilibrium concentration of the less stable phase (i.e., the phase with the higher equilibrium concentration, which is anhydrite at lower temperatures and gypsum at higher temperatures). The concentration in the solution increases during dissolution of the less stable phase and as soon as the concentration exceeds the equilibrium concentration of the stable phase, the latter begins to precipitate and thus reduces the concentration of the solution in return. His values for the equilibrium concentration of the less stable phase therefore need to be considered as a lower threshold for the true equilibrium concentration (this can be compared to the considerations made for the experiments described later in Chapter 4). For the comparison in Figure 2-2, merely values for the case of pure water (no sodium chloride) were taken from Bock (1961). With his experimental investigations he determined a transition temperature of $42{ }^{\circ} \mathrm{C}$.

Kontrec et al. (2002) investigated the kinetics of the transformation from anhydrite to gypsum by adding seed crystals to deionized water or calcium sulfate solution. They measured the change in concentration by monitoring the conductivity (see also Chapter 4.2), the calcium concentration (with a calcium ion selective electrode) and analyzed the solution by titration with EDTA. They determined the equilibrium concentrations for temperatures between $10-40{ }^{\circ} \mathrm{C}$, and similar to Bock, they assumed the maximal measured concentration of $\mathrm{CaSO}_{4}$ in the solution to correspond to the saturation concentration of anhydrite, thus most likely underestimating its actual value. They give no indication of the transition temperature, since the temperature range they investigated is lower.

Blount and Dickson (1973) measured the solubilities of anhydrite and gypsum for various temperatures, pressures and $\mathrm{NaCl}$ concentration in the solution, and established empirical equations for the equilibrium concentrations of gypsum and anhydrite as a function of temperature, pressure and $\mathrm{NaCl}$ content. These equations were used with 1 bar and pure water (no $\mathrm{NaCl}$ ) to compute the curves in Figure 2-2. However, since Blount and Dickson (1973) give values from $50^{\circ} \mathrm{C}$ on, the dashed green curve in Figure 2-2, which was determined with their empirical model, needs to be considered as an extrapolation for lower temperatures. The intersect (i.e., the transition temperature) lies at $56^{\circ} \mathrm{C}$, as is also indicated in their work.

Non-experimental values for the equilibrium concentrations were determined, e.g., by Marsal (1952), who set up equations to calculate the equilibrium concentrations and investigated the influence of pressure and temperature theoretically; by Ramon (2014) who computed the equilibrium concentrations with PHREEQC (a computer program which is designed to perform a wide variety of aqueous geochemical calculations; Parkhurst, 1995); and by Serafeimidis and Anagnostou (2013b and 2014b), who present thermodynamic fundamental equations in their work to calculate the equilibrium concentrations. As mentioned above, these equations were used to compute the equilibrium concentrations in this work.

Figure 2-2 compares the computed curves from Figure 2-1 with data found in the above mentioned literature, and shows the different values for the transition temperature (as gathered from the respective authors) in comparison to the assumptions made in this work for the equilibrium concentrations. As stated before, data for equilibrium concentrations determined in pure water and 
at ambient pressure were collected. Further data and additional references can also be found in the works of Serafeimidis and Anagnostou (2013b and 2014b) and van Driessche et al. (2017).
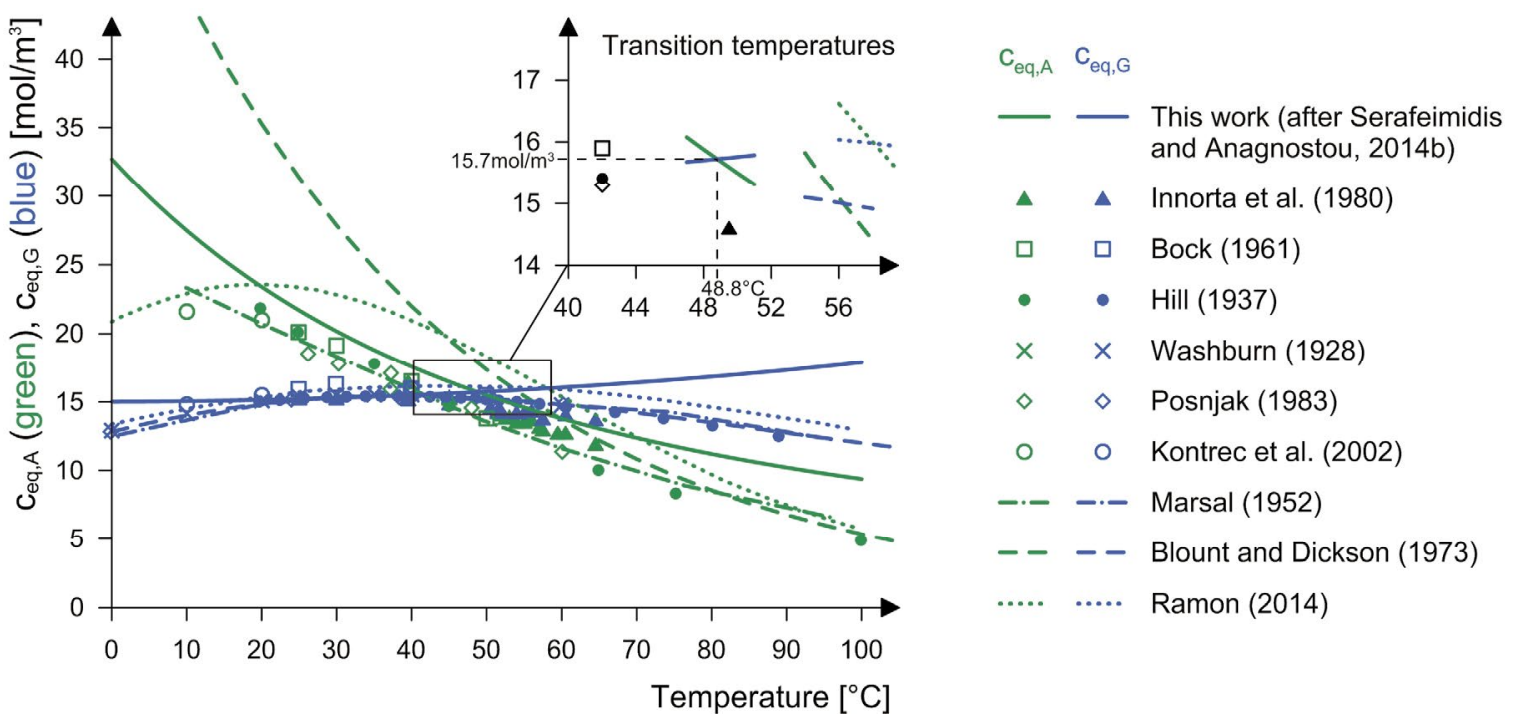

Figure 2-2: $\quad$ Comparison of equilibrium concentrations of anhydrite and gypsum by different authors, as a function of the temperature.

As can be seen in Figure 2-2 and as was also discussed by van Driessche et al. (2017), the equilibrium concentrations found in the literature vary, especially concerning that of anhydrite. One likely reason is that at these lower temperatures, it is very difficult to experimentally determine the equilibrium concentration of anhydrite accurately, since the ions in the solution precipitate to gypsum. It is furthermore challenging to find values for the equilibrium concentration of anhydrite at low temperatures in literature, as it is often only given for higher temperatures (cf., e.g., Blount and Dickson, 1973). Therefore, also the transition temperatures vary from author to author, according to van Driessche et al. (2017) between $38^{\circ}$ to $66^{\circ} \mathrm{C}$. As mentioned in the previous chapter, this work assumes a transition temperature of $48.8^{\circ} \mathrm{C}\left(15.7 \mathrm{~mol} / \mathrm{m}^{3}\right)$, as determined with the model by Serafeimidis and Anagnostou. This value corresponds well to experimentally determined (literature) values within the temperature range of $10^{\circ}$ to $60^{\circ} \mathrm{C}$. However, this model appears to slightly overestimate $c_{e q, G}$ at temperatures below $10^{\circ} \mathrm{C}$ and above approximately $60{ }^{\circ} \mathrm{C}$, as well as $c_{e q, A}$ above $60^{\circ} \mathrm{C}$.

\subsubsection{Influence of the activity and pore water potential}

As discussed, e.g., by Anagnostou et al. (2014), a low activity $a_{W}$ of the pore water can inhibit AGT. The water activity is defined as the ratio between the partial evaporation pressure in the vicinity of the pore $\left(p_{D}\right)$ to the saturated evaporation pressure over dilute water $\left(p_{S}\right)$. This ratio corresponds to the definition of relative humidity $R H$, see Equation (2 - 18). Already Lippmann (1976) stated that AGT occurs at high relative humidity (i.e., nearly $100 \%$ ).

$$
a_{W}=\frac{p_{D}}{p_{S}}=\frac{R H}{100 \%}
$$


The activity of the pore water is furthermore related to the pore water potential $(\psi)$ via the Kelvin equation (cf., e.g., Atkins and De Paula, 2006, Anagnostou et al., 2014, Blight, 2013, Fredlund and Rahardjo, 1993, Haynes, 1973, Dao et al., 2008 etc.):

$$
\ln \left(a_{W}\right) \cdot R \cdot T=\psi \cdot V_{W}
$$

With $R=8.314 \mathrm{~J} /(\mathrm{K} \cdot \mathrm{mol}), T=293 \mathrm{~K}, V_{W}=18 \mathrm{~cm}^{3} / \mathrm{mol}$ we can write:

$$
\psi[M P a]=135 \cdot \ln \left(a_{W}\right)=135 \cdot \ln (R H)=311 \cdot \log (R H)
$$

The pore water potential is the sum of the osmotic potential (which is associated with the ionic concentration in the water) and the matric potential (which is associated with adsorption and capillary forces, i.e., suction of the matrix). Therefore, the activity is smaller in rocks exhibiting low water potentials (i.e., high suction pressures and/ or dissolved salts), which is, e.g., the case for rocks in a nearly dry state.

Using the thermodynamic fundamentals described in Serafeimidis and Anagnostou (2013b and 2014b, see Appendix A) while considering the relationship in Equation (2 - 20), the equilibrium concentrations of anhydrite and gypsum can be calculated as a function of the soil-water potential within the rock (see Figure 2-3). In this case dilute water at room temperature $\left(20^{\circ} \mathrm{C}\right.$ ) was assumed, and the pore water pressure $p_{W}$ in Equations $(A-1)$ and $(A-2)$ equals the pore water potential $\psi$. It can be seen that for lower values of water potential in the rock matrix (i.e., for higher suction) the equilibrium concentration of gypsum exceeds that of anhydrite. In this case, AGT would not occur while the potential in the rock is lower than -20MPa, i.e., at an activity lower than 0.86 $($ RH $<86 \%)$.
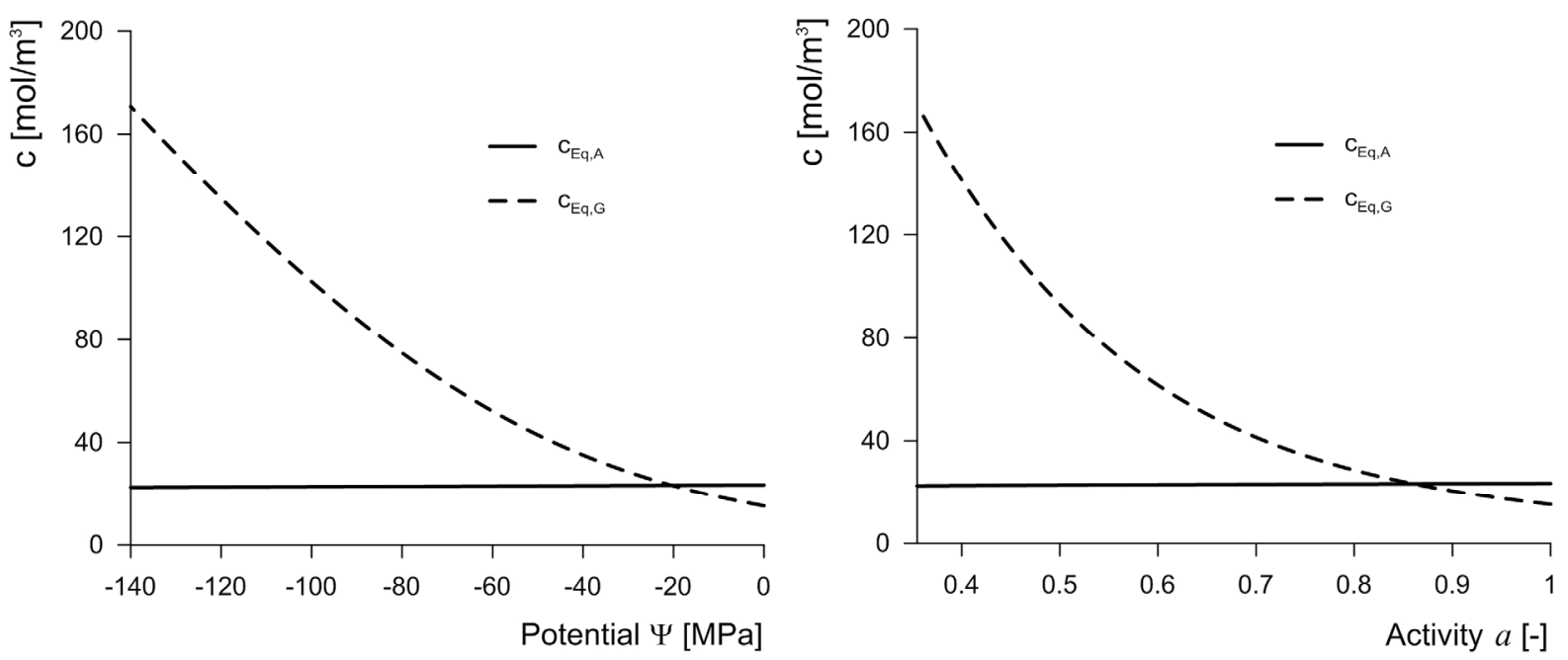

Figure 2-3: $\quad$ Influence of soil-water potential on the equilibrium concentrations.

The influence of the temperature on the equilibrium point (where $c_{e q, A}=c_{e q, G}$ ) for both the potential and the water activity is taken into account in the diagrams Figure 2-4 (for the relevant temperature range in this work). 

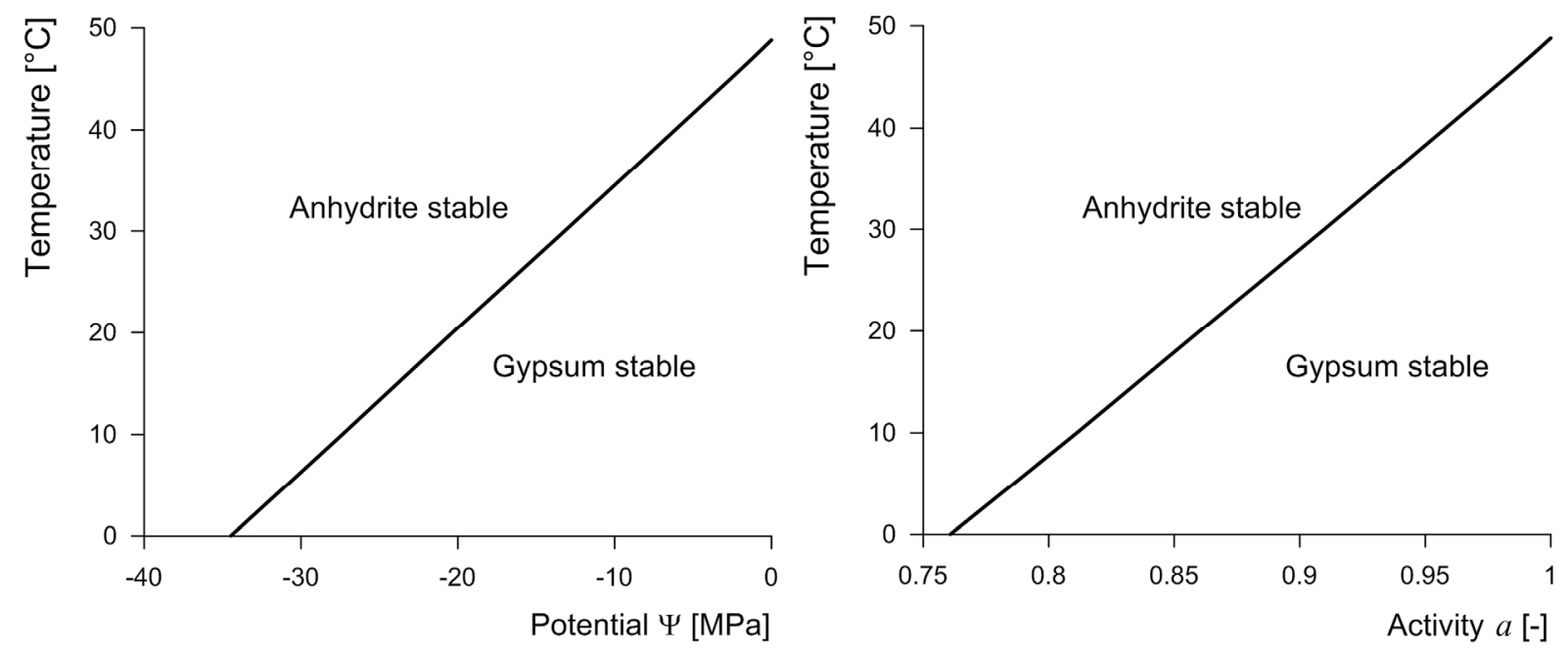

Figure 2-4: $\quad$ Influence of temperature on the potential (left) and water activity (right) of the equilibrium point (i.e., where $c_{e q, A}=c_{e q, G}$ ).

\subsubsection{Influence of stress and pore water pressure}

The stress and the pore water pressure acting on the rock influence the equilibrium concentrations as well. This too was thoroughly discussed by Anagnostou et al. (2014). In Figure 2-5 the equilibrium concentrations for anhydrite and gypsum were computed in dependence of the total stress acting on the rock, for two values of the pore water pressure (i.e., 0 and $20 \mathrm{MPa}$ ). Here, dilute water $\left(a_{W}=1\right)$ at $20^{\circ} \mathrm{C}$ was assumed. It can be seen that both equilibrium concentrations increase with increasing stress (whereas this is more pronounced in the case of gypsum), and that the considered range for the pore water pressure has nearly no influence on the equilibrium concentration of anhydrite, while the equilibrium concentration of gypsum decreases with increasing pore pressure.

The experiments described later in this work were conducted under nearly atmospheric conditions ( $p_{W}=0 \mathrm{MPa}$ can be assumed), whereas the stress did not exceed $3.5 \mathrm{MPa}$ (therefore, the concentration gradient $c_{e q, A}-c_{e q, G}$ can be assumed to remain constant in all cases).

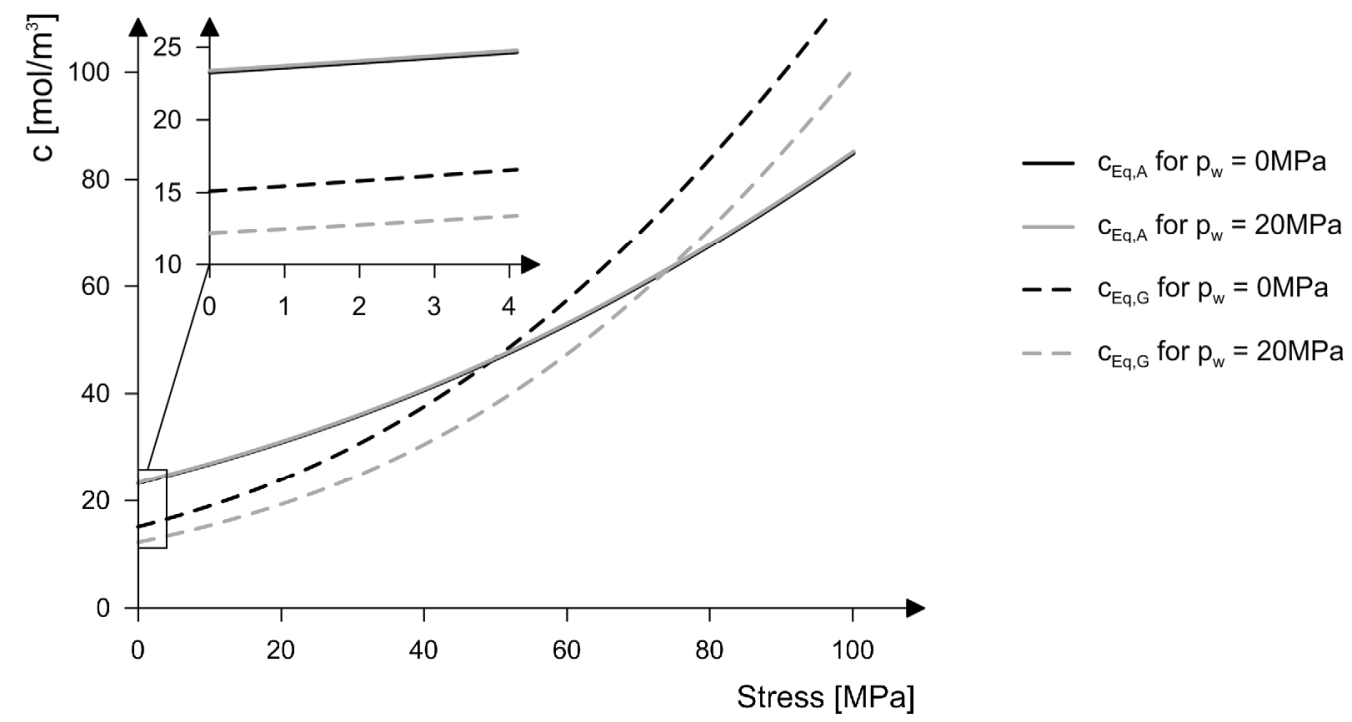

Figure 2-5: $\quad$ Equilibrium concentrations of anhydrite and gypsum as a function of the stress for two different values of the pore water pressure $p_{W}$. (Note that the two solid curves for $c_{e q, A}$ are overlapping one another). 


\subsubsection{Influence of foreign ions}

As discussed, e.g., in the works of Serafeimidis and Anagnostou (2014b) and Ramon et al. (2017), dissolved salts in the pore water influence the equilibrium concentrations as well. To illustrate the influence of "other" ions in the solution on the equilibrium concentrations, the diagram in Figure 2-6 was computed with the model of Serafeimidis and Anagnostou (2014b), see Appendix A. Here, the concentrations of calcium and sulfate in the pore water were assumed to be equal and correspond to the respective equilibrium concentrations. Thus solely an additional term for the ionic strength for the other ions in solution were considered in the equations in Appendix A, i.e.:

$$
\begin{aligned}
& I_{G}=0.5 \cdot c_{e q, G} \cdot\left(z_{C a}^{2}+z_{S O_{4}}^{2}\right)+I_{\text {otherions }} \\
& I_{A}=0.5 \cdot c_{e q, A} \cdot\left(z_{C a}^{2}+z_{S O_{4}}^{2}\right)+I_{\text {otherions }}
\end{aligned}
$$

Figure 2-6 assumes conditions from the laboratory, i.e., $20^{\circ} \mathrm{C}$, atmospheric pressure and that the water activity remains equal to one. A change in ionic strength does not influence the transition temperature (i.e., $48.8^{\circ} \mathrm{C}$, see Chapter 2.3.1) for the low concentrations considered in the present discussion. From Figure 2-6 it can clearly be seen that both equilibrium concentrations increase with additional ions in the solution.

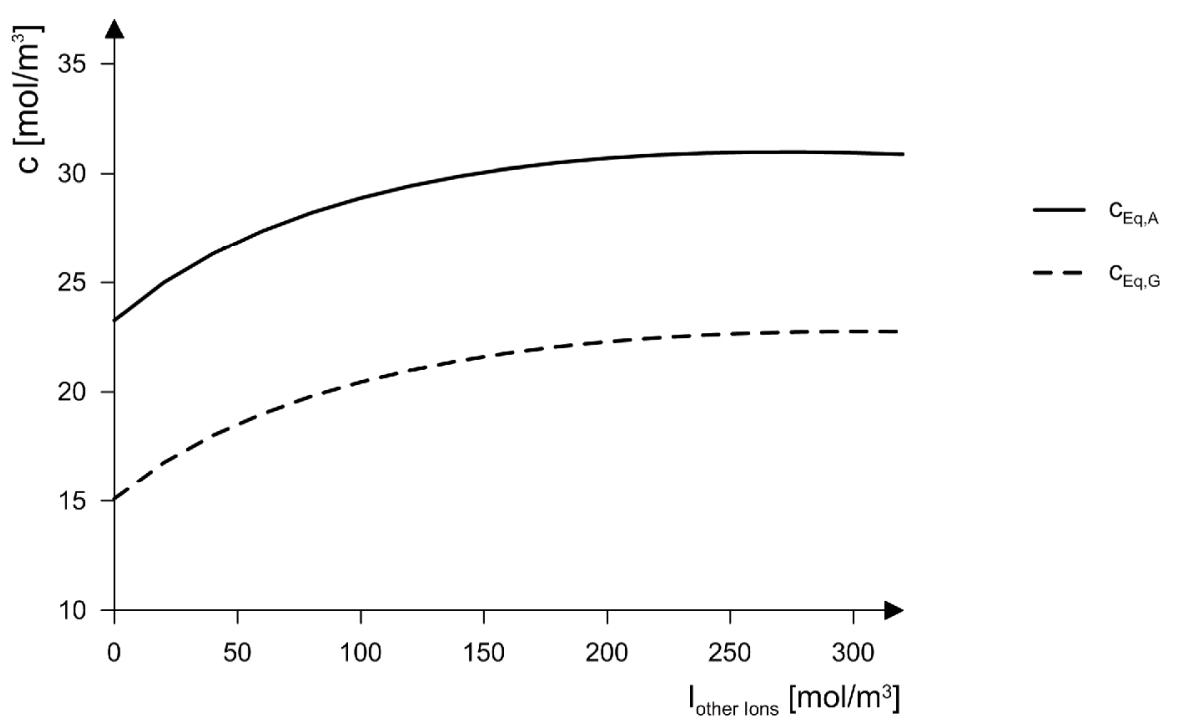

Figure 2-6: Influence of the "additional" ionic strength due to other ions (i.e., any ions except for calcium and sulfate) in the solution on the equilibrium concentrations of anhydrite (solid line) and gypsum (dashed line).

\subsection{Kinetic models}

The kinetics of the dissolution of anhydrite and precipitation of gypsum can be described through the changes (rates) of their masses, $d m_{A} / d t$ and $d m_{G} / d t$. The equations for the mass change rates are taken here after Serafeimidis and Anagnostou (2012a). They are based on a common law for the mass change rate of a mineral with a surface area $A$ in contact with water:

$$
\frac{d M}{d t}=k A f(c)
$$


whereas $f(c)$ is a function of the relative supersaturation (Mullin, 2001) which is brought into a dimensionless form and its sign indicates the direction of the reaction (positive mass change for precipitation, i.e., $c>c_{e q}$, negative mass change for dissolution, i.e., $c<c_{e q}$ ):

$$
f(c)=\operatorname{sgn}\left(c-c_{e q}\right) \cdot\left|\frac{c-c_{e q}}{c_{e q}}\right|^{\delta}
$$

The difference $\left|c-c_{e q}\right|$ indicates the "driving force" of the reaction (see Mullin, 2001) and is referred to here also as "concentration gradient" 1 .

Serafeimidis and Anagnostou (2012a) therefore formulate the mass change rate of the minerals according to the following Equations (2 - 25) and (2 - 26). As seen in Chapters 2.2.1 and 2.2.2, anhydrite dissolution only takes place if $c<c_{e q, A}$ and gypsum precipitation only takes place if $c>c_{e q, G}$.

For anhydrite dissolution $\left(c<c_{e q, A}\right)$ :

$$
\frac{d m_{A}}{d t}=\operatorname{sgn}\left(c-c_{e q, A}\right) \cdot k_{A} \phi_{A} F_{A}\left|\frac{c-c_{e q, A}}{c_{e q, A}}\right|^{\delta_{A}} \quad \text { with } \quad \delta_{A}=2
$$

and, accordingly, for gypsum precipitation $\left(c>c_{e q, G}\right)$ :

$$
\frac{d m_{G}}{d t}=\operatorname{sgn}\left(c-c_{e q, G}\right) \cdot k_{G} \phi_{G} F_{G}\left|\frac{c-c_{e q, G}}{c_{e q, G}}\right|^{\delta_{G}} \quad \text { with } \quad \delta_{G}=2
$$

${ }^{1}$ It is also possible to express the magnitude of super- or undersaturation and, therefore, the driving force for anhydrite dissolution or gypsum precipitation via the ratio between the ionic product $Q$ and the solubility product $K$ (see Chapters 2.2.1 and 2.2.2), see, e.g., Bildstein et al. (2001):

$$
\left|\frac{Q}{K}-1\right|=\left|\left(\frac{c \cdot \gamma_{ \pm, c}}{c_{e q} \cdot \gamma_{ \pm, c e q}}\right)^{2}-1\right|
$$

Equations (2 - F1) and (2 - 24) indicate different approaches for the driving force, and are plotted in the comparison shown in Figure (2-F1). While in both cases the driving forces approach zero as $c \rightarrow c_{e q}$, the formulation according to Equation (2 - 24) presents an asymptotic approach (considering the order of reaction $\delta_{A}=\delta_{G}=2$ for anhydrite dissolution and gypsum precipitation), as opposed to the formulation according to Equation (2 - F1).

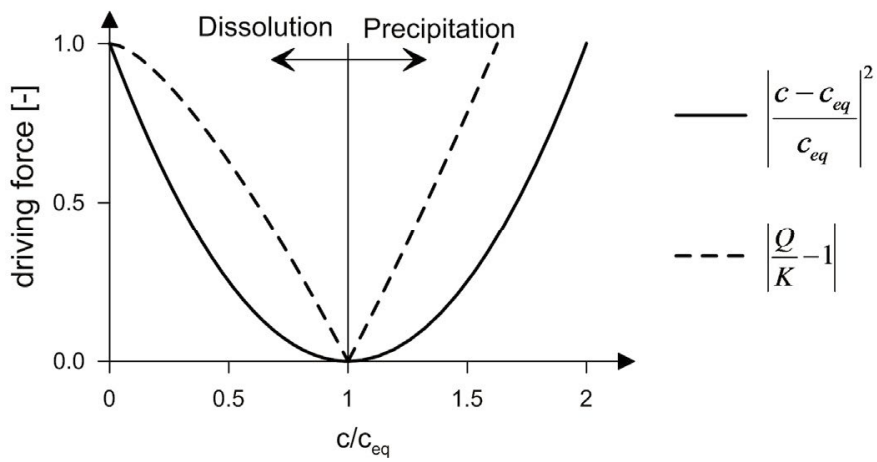

Figure 2-F1: Comparison of formulations for the driving force for dissolution and precipitation. 
The orders of reaction $\delta_{A}$ and $\delta_{G}$ for both anhydrite dissolution and gypsum precipitation are equal to two (a second order law for these processes was confirmed experimentally by the authors listed in Table 2-2; see also, e.g., Klimchouk, 2000, Serafeimidis and Anagnostou, 2012a).

Table 2-2: $\quad$ Literature references for the orders of reaction for anhydrite dissolution and gypsum precipitation.

\begin{tabular}{|c|c|c|c|}
\hline Reference & $\begin{array}{c}\delta_{A} \\
\text { (anhydrite dissolution) }\end{array}$ & $\begin{array}{c}\delta_{G} \\
\text { (gypsum growth) }\end{array}$ & Investigated temperature range \\
\hline Smith and Sweett (1971) & & $\begin{array}{c}2 \\
(1.80 \ldots 2.14)\end{array}$ & $30^{\circ}-90^{\circ} \mathrm{C}$ \\
\hline Liu and Nancollas (1970) & & 2 & $15^{\circ}-45^{\circ} \mathrm{C}$ \\
\hline James and Lupton (1978) & 2 & & $\begin{array}{l}\text { (not specified; for gypsum dissolution } \\
\text { experiments } 5^{\circ}-23^{\circ} \mathrm{C} \text { was investigated) }\end{array}$ \\
\hline Kontrec et al. (2002) & $\begin{array}{c}2 \\
(1.95 \ldots 2.10)\end{array}$ & $\begin{array}{c}2 \\
(1.97 \ldots 2.32)\end{array}$ & $10^{\circ}-40^{\circ} \mathrm{C}$ \\
\hline
\end{tabular}

Through Equations (2 - 25) and (2 - 26) it becomes apparent, which factors influence the processes concerning the mass changes of anhydrite and gypsum:

Anhydrite dissolution

Reaction rate constant

Equilibrium concentration

Volume fractions

Specific surface

Order of reaction

$$
k_{A}
$$$$
c_{e q, A}
$$

$\phi_{A}$

$F_{A}$

$\delta_{A}$
Gypsum precipitation
$k_{G}$
$c_{e q, G}$
$\phi_{G}$
$F_{G}$
$\delta_{G}$

as well as the concentration $c$ in the solution.

Note that Equation (2 - 26) considers gypsum precipitation on already existing gypsum crystals or nuclei. If gypsum is assumed to precipitate on inert minerals, the mass change of gypsum is formulated according to Serafeimidis and Anagnostou (2012b) as:

$$
\frac{d m_{G}}{d t}=\operatorname{sgn}\left(c-c_{e q, G}\right) \cdot k_{G} \phi_{S} F_{S}\left(1+\frac{\phi_{G}}{\phi_{S}}\right)^{2 / 3}\left|\frac{c-c_{e q, G}}{c_{e q, G}}\right|^{\delta_{G}}
$$

The terms $\phi_{A} F_{A}, \phi_{G} F_{G}$ and $\phi_{S} F_{S}$ in Equations $(2-25)$ to $(2-27)$ describe the surface of the anhydrite, gypsum and inert minerals, respectively, which is in contact with the pore water.

In order to visualize the interactions and dependencies between the above mentioned factors, a so-called N2-diagram (NASA, 2007) is developed in Figure 2-7. It is built up of relations between two terms, which are investigated as to how they influence each other, while all other terms are assumed to remain constant. These influences are to be read in a clockwise manner, as indicated by the arrows.

The left-hand side in Figure 2-7 represents anhydrite dissolution (cf. Equation (2 - 25)), while the right-hand side represents gypsum precipitation. 
It is assumed here that gypsum precipitates on gypsum crystals or nuclei (i.e., no foreign minerals). Hereby, the shape of the particles is assumed to remain constant, as they grow or dissolve, respectively.

The following subchapters discuss each influencing factor individually for anhydrite dissolution and gypsum precipitation. When both reactions occur simultaneously in a system, they are coupled via the concentration $c$. This is discussed in Chapter 2.4.3.

Furthermore, the kinetics of simultaneous anhydrite dissolution and gypsum precipitation was studied experimentally and the results are shown in Chapter 4.

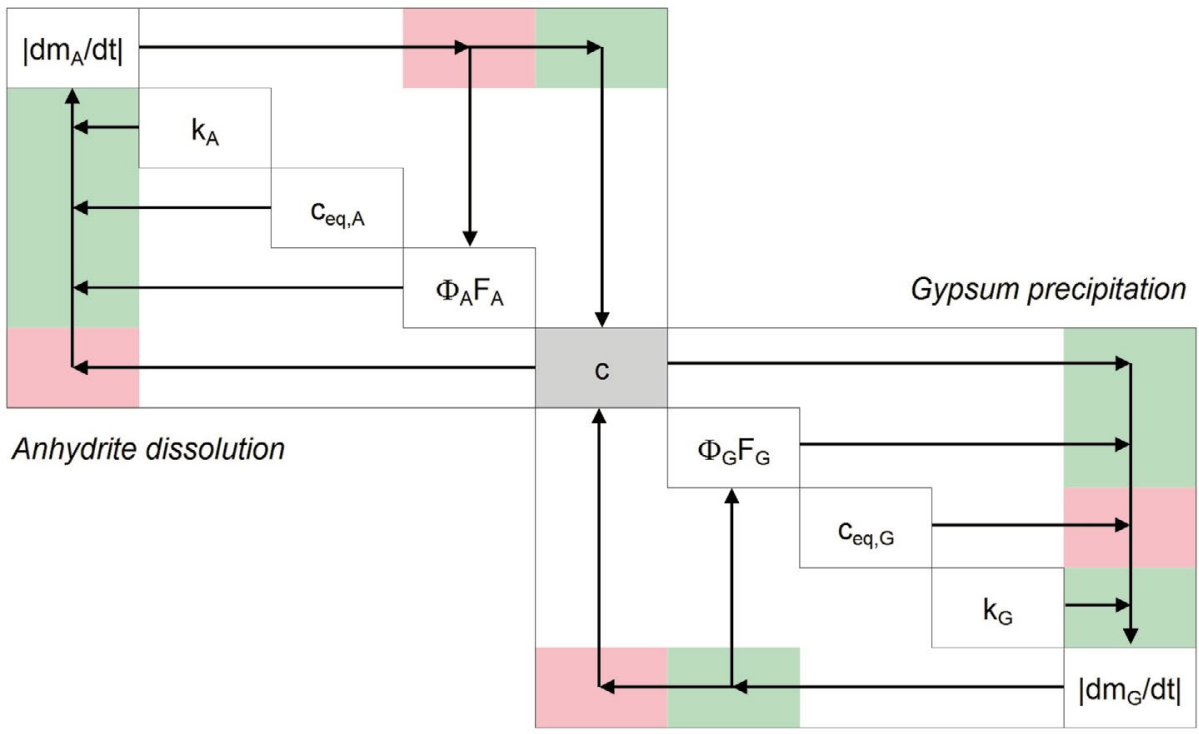

an increase of the first entity leads to an increase of the second entity

an increase of the first entity leads to a decrease of the second entity

Figure 2-7: N2-diagram considering the kinetic models for anhydrite dissolution and gypsum precipitation.

\subsubsection{Anhydrite dissolution $\left(d m_{A} / d t\right)$}

The following factors influence or are influenced by the dissolution of anhydrite (cf. left-hand side in Figure 2-7). They will be discussed with respect to the absolute value of the mass change rate.

Reaction rate constant $k_{A}$ :
The larger the reaction rate constant of anhydrite is, the larger the value of its mass change will be. However, the reaction rate constant is directly dependent on the present temperature (and can be estimated via the equation of Arrhenius, see Appendix C). Therefore, the latter will need to be considered as the actual influencing factor, since the reaction rate constant does not change if the temperature remains constant. Due to the fact that the values differ in literature (by about one order of magnitude, see Appendix C), the same value is taken as in Serafeimidis and Anagnostou (2012a) for $20^{\circ} \mathrm{C}$ :

$$
k_{A}=3 \cdot 10^{-6} \mathrm{~kg} /\left(\mathrm{m}^{2} \cdot \mathrm{s}\right)
$$


Equilibrium A higher equilibrium concentration will lead to an increase of the conconcentration $c_{e q, A}$ centration gradient, thus an increase in the mass change rate of anhydrite : $\quad$ (the reaction will occur faster), cf. Equation (2 - 25).

Similar to the previous factor, the equilibrium concentration of a mineral also depends on external factors, such as pressure, temperature and the existence of foreign ions in the solution (cf. Chapter 2.3).

Assuming $20^{\circ} \mathrm{C}$, atmospheric pressure and absence of foreign ions in the solution, the equilibrium concentration of anhydrite is equal to $c_{e q, A}=23.31 \mathrm{~mol} / \mathrm{m}^{3}=3.17 \mathrm{~kg} / \mathrm{m}^{3} \quad$ (determined with the thermodynamic fundamentals presented in Serafeimidis and Anagnostou, 2013b, and 2014b; see also Appendix A).

Surface in contact The mass change rate of anhydrite rises with an increasing surface area of with water $\phi_{A} F_{A}$ : the minerals in contact with water. This interaction proves to be interdependent, as the sizes of the particles (and ultimately their surfaces) decrease during the process of dissolution (i.e., an increase in the mass change results in a decrease of the surface area).

Concentration $c$ of The dependency between the mass change of anhydrite and the present the solution: concentration also describes an interdependency:

A small ion concentration in the solution leads to a large concentration difference $\left(\left|c-c_{e q, A}\right|\right)$ which accelerates the dissolution process and therefore the mass change of anhydrite.

On the other hand, the dissolution of anhydrite increases the ion concentration in the solution, which results in a reduction of the above mentioned concentration gradient (although, independent on whether the mass change rate (i.e., $d m_{A} / d t$ ) is faster or slower, anhydrite dissolves in any case and the concentration in the solution will rise during dissolution until the saturation concentration of anhydrite is reached).

\subsubsection{Gypsum precipitation $\left(d m_{G} / d t\right)$}

The influences of the following factors on the precipitation of gypsum (as indicated on the righthand side in Figure 2-7) are discussed here, assuming that the concentration is larger than the equilibrium concentration of gypsum ( $c>c_{e q, G}$, otherwise leaching of gypsum occurs, which is not further discussed in this work).

Reaction rate constant $k_{G}$ :
A higher reaction rate constant leads to a faster mass change of gypsum. Analogue to the reaction rate constant of anhydrite, it is directly dependent on the temperature (see Appendix $\mathrm{C}$ ). If the temperature is constant, the reaction rate constant remains unchanging. As for the reaction rate of anhydrite, the values for gypsum differ in literature (by about one order of magnitude, see Appendix $\mathrm{C}$ ), and the same value is taken as in Serafeimidis and Anagnostou (2012a) for $20^{\circ} \mathrm{C}$ :

$$
k_{G}=5 \cdot 10^{-7} \mathrm{~kg} /\left(\mathrm{m}^{2} \cdot \mathrm{s}\right)
$$


Equilibrium The concentration gradient in Equations (2 - 26) and (2 - 27) decreases, if the concentration $c_{e q, G}$ : equilibrium concentration of gypsum rises. This leads to reduction of the mass change rate of gypsum. As mentioned before, the equilibrium concentration of a mineral depends on the pressure and temperature, as well as the existence of foreign ions in the solution (cf. Chapter 2.3).

Should the external conditions be $20^{\circ} \mathrm{C}$, atmospheric pressure and zero foreign ions in the solution, the equilibrium concentration of gypsum (calculated with the thermodynamic fundamentals presented in Serafeimidis and Anagnostou, 2013b and 2014b; see also Appendix A) amounts to:

$$
c_{\text {eq, } G}=15.1 \mathrm{~mol} / \mathrm{m}^{3}=2.05 \mathrm{~kg} / \mathrm{m}^{3}
$$

Surface in contact The mass rate change of gypsum will also increase while the surface of the with water $\phi_{G} F_{G}$ : minerals (in contact with water) grows. This relationship is interdependent, as the particle sizes (and their surfaces) increase with ongoing gypsum precipitation (regardless of whether the rate accelerates or decelerates, the gypsum surface will increase; still assuming that $\left.c>c_{e q, G}\right)$.

Concentration $c$ of $\mathrm{A}$ higher concentration in the solution will result in a larger concentration the solution: difference (i.e., $\left|c-c_{e q, G}\right|$ ), and thus accelerate the precipitation of gypsum. Simultaneously, the ions in the solution get used up during gypsum precipitation, causing the concentration to be reduced. This process occurs also independent of whether the mass change rate of gypsum stagnates or accelerates (analogue to the behavior of the concentration with respect to anhydrite dissolution in the previous chapter).

\subsubsection{Simultaneous chemical reactions}

When the two processes occur simultaneously in the same solution, their rates are obviously both dependent on the present concentration in the solution. This can be visualized by overlapping the dependencies for anhydrite dissolution and gypsum precipitation as shown in Figure 2-7, thus generating a connection between the rates of anhydrite dissolution and gypsum precipitation through the concentration $c$ in the solution. Since both processes of anhydrite dissolution and gypsum precipitation are mutually dependent on the concentration in the solution, they can often not be considered isolated from one another.

As mentioned before, external influences such as temperature, pressure and existence of foreign ions must be considered additionally, but were omitted in Figure 2-7 for the sake of simplicity (in order to describe both processes independent of external factors). They are, however shown in a more elaborate N2-diagram depicted in Appendix B. Furthermore, as stated in Chapter 2.2.3, the discussions here do not consider any transport mechanisms of the ions in the solution (i.e., no pore water flow or similar; the influence of hydraulic transport on the mass changes of anhydrite and gypsum was discussed in Serafeimidis, 2014, cf. Chapter 1.3.2). The chemical reactions were thus considered as isolated processes.

The enlarged N2-diagram shown in Appendix B also qualitatively considers further influencing factors, such as hydraulical and mechanical aspects. 



\section{Description of standard analytical testing techniques used}

Within the scope of the experimental investigations performed for this thesis, a number of analytical testing techniques were used to quantitatively or qualitatively determine the compositions and structures of the investigated specimens, as well as to analyze the water used in the respective experiments. This chapter lists all standard analytical testing techniques used in the presented research.

\subsection{Thermogravimetric analysis (TGA)}

TGA is a thermal analysis method where the change of the mass of a specimen is recorded in dependency of temperature and time while it is heated (cf., e.g., Haines, 2002). This can be used to determine the amount of bound water in a crystal or in clay minerals, as well as other compounds released by thermal decomposition (e.g., carbon dioxide). In some cases, where the qualitative mineralogical composition of a specimen is known (such as artificial specimens post swelling, which are known to contain solely anhydrite, gypsum and an inert aggregate), TGA can be used to calculate the amount of gypsum in the specimen by quantifying the amount of water bound by the gypsum. For this, a small representative sample $(17-20 \mathrm{mg})$ is heated $\left(10^{\circ} \mathrm{C}\right.$ per minute) and the change in weight is measured. At about $90-140{ }^{\circ} \mathrm{C}$ a drop in the weight can be observed (see Appendix I), which is attributed to the reverse reaction of AGT (cf. Equation (2 - 9)): The gypsum dehydrates $\left(\mathrm{CaSO}_{4} \cdot 2 \mathrm{H}_{2} \mathrm{O} \rightarrow \mathrm{CaSO}_{4}+2 \mathrm{H}_{2} \mathrm{O}\right)$ and the now free water evaporates. By considering the molar masses of water and gypsum it is then possible to calculate the mass of gypsum in the specimen post test and to determine (via back-calculation) the corresponding amount of dissolved anhydrite, as well as the mass of remaining anhydrite in the specimen. TGA was performed with a Q50 Thermogravimetric Analyzer by TA Instruments (TA Instruments, 2015) of the Institute for Building Materials at ETH Zurich. The Analyzer has a weighing precision of $+/-0.01 \%$ and a temperature precision of $+/-0.1^{\circ} \mathrm{C}$.

\subsection{Microscopy}

Some selected specimens were investigated with scanning electron microscopy (SEM), where an electron beam scans the surface of a specimen. From the interaction between the electrons and the specimen, images of the topography of the specimens (secondary electrons, SE) as well as images reflecting material contrast (back scattered electrons, BSE) can be collected (cf., e.g., Goldstein et al., 2003). SEM was mainly used to observe changes in structures or to identify the shape and form of gypsum within the specimens after the experiments. Furthermore, SEM in combination with Energy-dispersive X-ray spectroscopy (EDX, with which the elements in a specimen can be identified) was used, e.g., to map out the distribution of calcium and sulfur in the specimens. The investigations were performed with a Quanta 600 SEM and with a Quanta 200 3D with EDX by FEI.

Additionally, optical microscopes were used to study the surface of some specimens (stereo microscope Leica M60) as well as to perform thin section analysis (transmitted light microscope Leica DM750 $\mathrm{P}$ in polarized light mode). All microscopic investigations were performed at the Institute for Building Materials at ETH Zurich. 


\subsection{X-ray diffraction and Rietveld analysis (XRD analysis)}

In the cases where it was necessary to determine the mineralogical composition of a specimen, $X$ ray diffraction was executed and the composition was quantified via Rietveld analysis (cf., e.g., Young, 1995). For XRD, the rock is milled to a particle size of maximally $20 \mu \mathrm{m}$ and distributed on the specimen holder (roughly $0.5 \mathrm{~g}$ ). A Theta-Theta-diffractometer (AXSD8 advance by Bruker with a climate chamber TTK 450) was used, together with the analysis program EVA, the peak fit program Topas $\mathrm{P}$ (both also from Bruker) and for the quantitative analysis the Rietveldprograms AutoQuan and BGMN were used (the maximal errors of the results were $+/-6.6 \mathrm{wt} \%$ in the case of kaolin, and $+/-1.8 w t \%$ in the case of calcium sulfates; the average error was $0.8 w t \%)$. The investigations were performed in the Clay Lab of the Institute for Geotechnical Engineering at ETH Zurich.

\subsection{Mercury-Intrusion Porosimetry (MIP)}

During MIP analysis mercury (as a non-wetting liquid) is pressed in a specimen placed in the porosimeter. The required pressure for the mercury intrusion in a pore is a function of the contact angle and surface tension of the liquid and of the diameter of the pore, according to the Washburn equation (Washburn, 1921). By recording the applied pressure and the volume of mercury intruded in the specimen, the porosity, pore volume and pore size distribution can be determined (Abell et al., 1999). However, due to the fact that some large pores may only be accessible by small throats, MIP may overestimate the amount of smaller pores (so-called "ink-bottle effect", cf., e.g., Abell et al., 1999, Giesche, 2006). This could be corrected by performing a second cycle of MIP on the same samples, which was not done in the case of the results presented here (therefore, the obtained pore size distributions may indicate a too high amount of small pores). However, this does not influence the measured value for the total porosity and pore volume. Furthermore, the samples are dried prior to the measurements and the degree of drying, as well as the vacuum applied during MIP, may influence the results, e.g., if shrinkage occurs due to transformation of gypsum to bassanite. The fine pores (structural channels) created during the production of bassanite are $0.2-$ $0.4 \mathrm{~nm}$ in diameter according to Seufert et al. (2009a) and Seufert et al. (2009b) and are thus too small to be detected with the used porosimeter. MIP was performed on some selected specimens (whereas at least two pieces of the same specimen were tested to ensure the reproducibility of the results) in the Clay Lab of the Institute for Geotechnical Engineering at ETH Zurich with a Porotec Pascal $140+440$ Porosimeter (pore range of 2-60000 nm).

\subsection{Laserdiffractometry}

The particle size distribution of the used powders was determined via laserdiffractometry (cf., e.g., Eshel et al., 2004), where the intensity of light scattered when passing through a particle in suspension is used to calculate the particle size. Depending on the type of powder, it was either in suspension in distilled water (e.g., kaolin, quartz flour) or in isopropanol (e.g., anhydrite). The investigations were performed with a Laser Particle Size Analyzer LA-950 by HORIBA (2015), with a measuring range of $0.01-3000 \mu \mathrm{m}$ and a precision of $+/-0.1 \%$ ) in the Clay Lab of the Institute for Geotechnical Engineering at ETH Zurich. 


\subsection{Surface area measurements based on the theory of Brunauer, Emmett and Teller (BET)}

Based on the theory of Brunauer, Emmett and Teller (BET, Brunauer et al., 1938), the specific surface area of a powder can be determined via the physical adsorption of gas molecules on the solid surface (cf., e.g., Fagerlund, 1973).

BET surface measurements were performed with a Quantachrome Autosorb 1MP (Quantachrome Instruments, 2007). A sample of 2-3 g of each of the investigated anhydrite powders (adsorbent; see Chapter 8.4.3) was inserted in the testing tubes and degassed at a temperature up to $150^{\circ} \mathrm{C}$. Note that the degassing temperature can influence the results when gypsum is present (see Mantellato et al., 2015), since it may cause a transformation of gypsum to bassanite. However, in the investigations performed in the present case, BET was done only on anhydrite powders without any gypsum. Nitrogen gas was used as adsorbate. At a certain temperature and vapor pressure the material adsorbs a certain amount of gas, which can be determined with the help of isotherms. The amount of adsorbed gas, on the other hand, is proportional to the surface of the investigated material (Fagerlund, 1973). The BET measurements were performed in the Clay Lab of the Institute for Geotechnical Engineering at ETH Zurich.

\subsection{Pycnometry}

In order to measure the density of grains (e.g., of the anhydrite powders used), pycnometry was undertaken. The used device was an Accupyc II 1340 Pycnometer by Micrometrics with a precision of $+/-0.02 \%$ (cf. micrometrics, 2014). The sample (ca. $5 \mathrm{~g}$ ) is sealed in the instrument compartment of known volume. By gas-displacement with an inert gas within the compartment (here with Helium) and by determining the amount of inert gas admitted and discharged, the solid volume of the specimen can be determined. The density of the grains can then be calculated from the mass of the used powder and the measured volume. Pycnometry was performed in the Clay Lab of the Institute for Geotechnical Engineering at ETH Zurich.

\subsection{Atomic absorption spectroscopy (AAS)}

The concentration of some elements within solutions were determined with AAS (specifically the cations $\mathrm{Na}, \mathrm{K}, \mathrm{Ca}, \mathrm{Mg}$, Fe; the sulfates cannot be detected with this method). Atomic spectroscopy allows the determination of the elemental composition of an analyte by its electromagnetic or mass spectrum. With atomic absorption spectroscopy, the elements under investigation absorb energy in the form of light at a specific wavelength. By measuring the amount of light absorbed and relating that to known concentrations in standards, the concentration of the element in the solution can be determined (cf. PerkinElmer, 2008).

AAS was performed with a PerkinEImer AAnalyst 400 Spectrometer in the Clay Lab of the Institute for Geotechnical Engineering at ETH Zurich. 


\subsection{Inductively coupled plasma - Optical emission spectrometry (ICP-OES)}

With the aim of determining the concentration of certain elements ( $\mathrm{Al}, \mathrm{Ca}, \mathrm{Fe}, \mathrm{K}, \mathrm{Mg}, \mathrm{Na}, \mathrm{S}$ and $\mathrm{Si}$ ) in a solvent, ICP-OES was performed. The identification and quantification of the elements requires, however, a rough knowledge of the concentration range in which they are expected to be present in the solvent.

During ICP-OES, the liquid specimen is converted to aerosol (nebulized) and plasma is then used to atomize the gas and excite the atoms. As the atoms gain energy from collisions they emit light of a characteristic wavelength, which is detected for each element (see Manning and Grow, 1997). ICP-OES was performed at the Institute for Building Materials at ETH Zurich.

\subsection{Conductivity measurements}

During a conductivity measurement, the resistance of the solution is measured between two electrodes. As will be seen later (Chapter 4), in cases where the dissolved ions are known (e.g., sulfate and calcium in distilled water), the concentration of the solution can be indirectly determined by measuring its electrical conductivity (i.e., its ability to conduct electricity).

It was possible to determine the conductivity of solutions with a SevenMulti $\mathrm{pH}$ meter from Mettler Toledo with a conductivity expansion unit (Mettler Toledo Intl. Inc., 2015) from the Institute for Building Materials at ETH Zurich. 


\title{
PART II \\ ANHYDRITE DISSOLUTION AND GYPSUM \\ PRECIPITATION IN A SOLUTION
}

\begin{abstract}
Part II presents two sets of experimental campaigns, which investigate the time-development of anhydrite dissolution and gypsum precipitation when anhydrite is dissolved in water.

In a first series of experiments, powdered anhydrite was dissolved in water and the development of the concentration was determined indirectly by measuring the conductivity of the solution. Upon inserting the anhydrite in the water, the concentration of dissolved ions increased rapidly, exceeding the equilibrium concentration of gypsum (depending on the amount of dissolved anhydrite), and reaching a peak which was lower than the theoretically determined equilibrium concentration of anhydrite. After several days, the concentration settles at the equilibrium concentration of gypsum, indicating that the AGT-process is completed. The development of the concentration was investigated for a variety of mixtures in solution. The assumed reaction rate constants derived from literature could not be verified and are too low to model the experimental observations. However, it was possible to confirm the calculated equilibrium concentration of gypsum and verify the calculated equilibrium concentration of anhydrite.

A second set of experiments investigated the precipitation of gypsum directly on the surface of a dissolving platelet of anhydrite. This creates a diffusion barrier for the dissolving ions and slows down further anhydrite dissolution (referred to as "self-sealing" of anhydrite). The development of such gypsum layers on anhydrite is observed on natural rock specimens consisting of $96 \%-99 \%$ anhydrite which were placed in water at temperatures of either $5{ }^{\circ} \mathrm{C}$ or $20^{\circ} \mathrm{C}$. The thickness of the developing gypsum layer is observed optically via photography during the tests and via microscopic analysis after drying of the specimens. The measured thicknesses corresponded well to the amount of precipitated gypsum determined post test via thermogravimetric analysis and to predicted values which were calculated using an existing kinetic model. The plausibility of this model could thus be verified.
\end{abstract}





\section{Development of the ion concentration in a solution}

\subsection{Introduction and aim}

Serafeimidis and Anagnostou (2012a, 2012b, 2013a and Serafeimidis, 2014) studied the kinetics of simultaneous anhydrite dissolution and gypsum precipitation with the aim of improving the understanding of the factors governing the time-dependency of swelling due to AGT and compared predictions based on their kinetic model (see Chapter 2.4) to literature values. In order to confirm the assumptions for the kinetic parameters (particularly the reaction rate constants $k_{A}$ and $k_{G}$ in Equations (2 - 25) to (2 - 27) in Chapter 2.4) and verify the equilibrium concentrations for the conditions prevailing in the laboratory while considering the different kinds of materials used, the change of the ion concentration in water over time needed to be quantified.

The ion concentration in a solution can be determined in different ways, such as: via an ionselective electrode (in this case calcium selective electrodes; cf., e.g., Kontrec et al., 2002), titration with EDTA (cf., e.g. Kontrec et al., 2002, Wu and Boyd, 1990), ICP-OES analysis (cf., e.g., Azimi and Papangelakis, 2011, Dai et al., 2014), gravimetry (cf., e.g., Partridge and White, 1929), or with quartz crystal microbalance (cf., e.g., Alimi and Gadri, 2004). However, many of these methods require specimens from the investigated solutions to be sacrificed and are arduous in their application. In this research, the main aim was to observe the change in ion concentration in the solution over time for various mixtures, which required a large amount of specimens and the ability to measure the concentration within the same solution at various points in time. For this reason, the concentration was determined indirectly by repeatedly measuring the conductivity of each solution (cf. Chapter 3.10). The conductivity is a colligative property of the solutions, i.e., it is dependent only on the amount of dissolved ions in the water and not on the type of ions dissolved. Therefore, the change in concentration over time could be observed for varying conditions and the expected equilibrium concentrations could be verified with these experiments. For solutions with concentrations lower than $c_{e q, G}(2.05 \mathrm{~g} / \mathrm{l}$ at room temperature), a linear relationship between the total amount of dissolved solids and the conductivity was expected. This linear relationship was verified by dissolving clearly defined amounts of anhydrite up to $2 \mathrm{~g} / \mathrm{l}$ in water and measuring the electrical conductivity of the solutions. All other experiments are calibrated considering this relationship (shown in Chapter 4.3, Figure 4-2).

\subsection{Experimental procedure}

The experiments were conducted with powders of commercial anhydrite ("SA"), kaolin ("PW"), limestone ("KM") and quartz (“QM"). The powders are described in more detail in Chapter 8.2, where also the particle size distributions are shown (Figure 8-1). They were mixed with either $100 \mathrm{ml}$ or $250 \mathrm{ml}$ of demineralized water and immediately after adding water, the conductivity of each solution was measured with the equipment described in Chapter 3.10. The bottles containing the solutions were then shaken and the conductivity was measured again after shaking. The measurements were repeated at multiple points in time (up to several months), whereas the solutions were shaken at each point of measurement to remove concentration gradients in the solutions, but otherwise remained stationary between the measurements (since the water during swelling tests performed within the scope of this work is also stationary). At each point of measurement the conductivity of the mixtures was noted before, immediately after and ca. ten 
minutes after shaking the bottles. As will be seen in the next chapter, shaking the bottles affected the conductivity of each mixture to a different extent.

On the one hand, various amounts of commercial anhydrite SA (Chapter 8.2.1) were dissolved in distilled water, i.e., $0.5 / 1 / 2 / 2.5 / 3 / 4 / 8$ and $32 \mathrm{~g} / \mathrm{l}$. On the other hand, the influence of the aggregates (Chapter 8.2.2) on the dissolution of anhydrite and precipitation of gypsum was investigated for the following mixtures: $4 \mathrm{~g} / \mathrm{SA}$ and $6 \mathrm{~g} / \mathrm{l}$ of either PW, KM or QM; $4 \mathrm{~g} / \mathrm{SA}$ and $18 \mathrm{~g} / \mathrm{l}$ of either PW, KM or QM; $32 \mathrm{~g} / \mathrm{SA}$ and $48 \mathrm{~g} / \mathrm{l}$ of either PW, KM or QM.

At the temperatures prevailing in the laboratory, i.e., $20^{\circ} \mathrm{C}$, the expected equilibrium concentration of gypsum is $2.05 \mathrm{~g} / \mathrm{l}\left(15.1 \mathrm{~mol} / \mathrm{m}^{3}\right)$ and that of anhydrite $3.15 \mathrm{~g} / \mathrm{l}\left(23.3 \mathrm{~mol} / \mathrm{m}^{3}\right)$. The latter value will not be reached during the tests, since gypsum precipitation (during which ions are consumed, $c f$. Chapter 2.4.2) occurs simultaneously to anhydrite dissolution (cf. Serafeimidis and Anagnostou, 2012b).

In order to investigate the influence of the particle size of anhydrite, it was sieved through a $20 \mu \mathrm{m}$ sieve using ethanol (the maximal grain size of SA is $40 \mu \mathrm{m}$ ). Two additional conductivity experiments were performed with the fractions larger and smaller than $20 \mu \mathrm{m}$. Additionally, a mixture was produced with $3 \mathrm{~g} / \mathrm{l}$ anhydrite and $3 \mathrm{~g} / \mathrm{l}$ gypsum which functions as seed material (and which was obtained from previous hydration of the same anhydrite).

\subsection{Results}

Figure 4-1 shows the results of the conductivity measurements made from the solutions where up to $2 \mathrm{~g} / \mathrm{l}$ of anhydrite was dissolved, i.e., with a concentration lower than $c_{e q, G}$. The maximal values of these conductivity measurements are plotted against the amount of initial anhydrite mixed in water in Figure 4-2 (together with the maximal values from all other conductivity tests where more anhydrite was dissolved, see Figure 4-3 to Figure 4-7). From the values below $2 \mathrm{~g} / \mathrm{l}$ a clear linear relationship between conductivity and concentration can be seen. The established linear relationship can be used for the quantification of the concentrations observed during the other tests (where only anhydrite was used) with an initial amount of anhydrite greater than $c_{e q, G}$. It is assumed that this relationship remains also when one of the aggregates is added to the mixture, however for a definite quantification of the concentration this needs to be verified with other measures (e.g., with a calcium selective electrode).

From the theoretical values of the equilibrium concentrations $\left(c_{e q, A}, c_{e q, G}\right)$, the corresponding values for the conductivity can be obtained. Therefore, the conductivity corresponding to the equilibrium concentration of anhydrite is estimated to be at $3.1 \mathrm{mS} / \mathrm{cm}$ (this value is indicated also by the dotted lines in Figure 4-2 to Figure 4-7).

Figure 4-3 shows the results of the conductivity experiments performed with varying amounts of anhydrite powder (no aggregates), whereas Figure 4-4 shows the conductivity over time for mixtures of anhydrite and each one of the three aggregates and Figure 4-5 shows the conductivity of the aggregates alone (no anhydrite). Note that in Figure 4-4c (anhydrite and quartz flour) the time axis is scaled to twice the duration of the other two. 


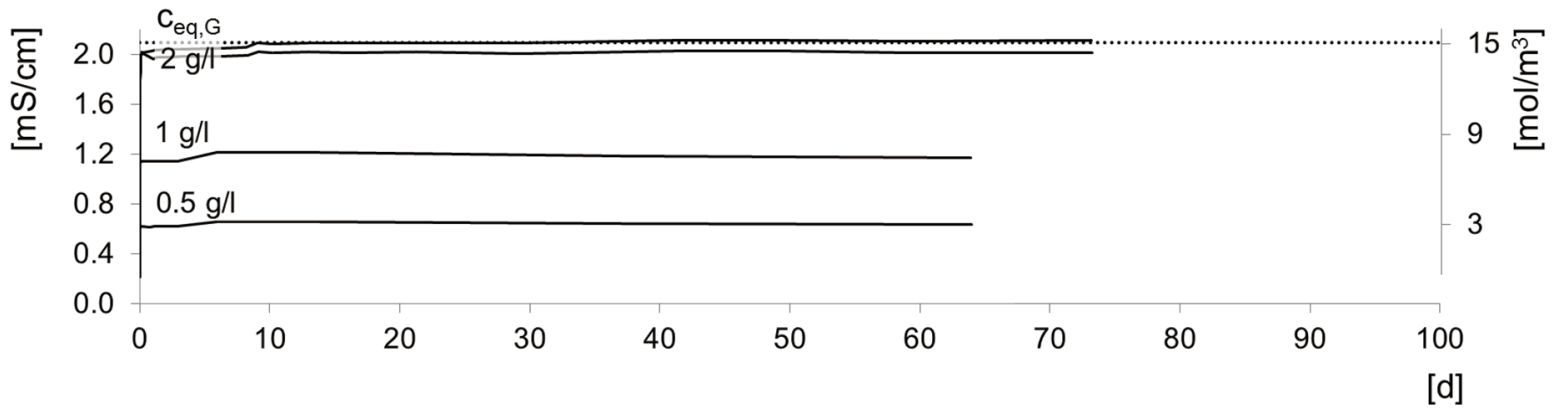

Figure 4-1: $\quad$ Results of conductivity measurements with only anhydrite up to $2 \mathrm{~g} / \mathrm{l}$. The dotted line indicates the expected equilibrium concentration of gypsum.

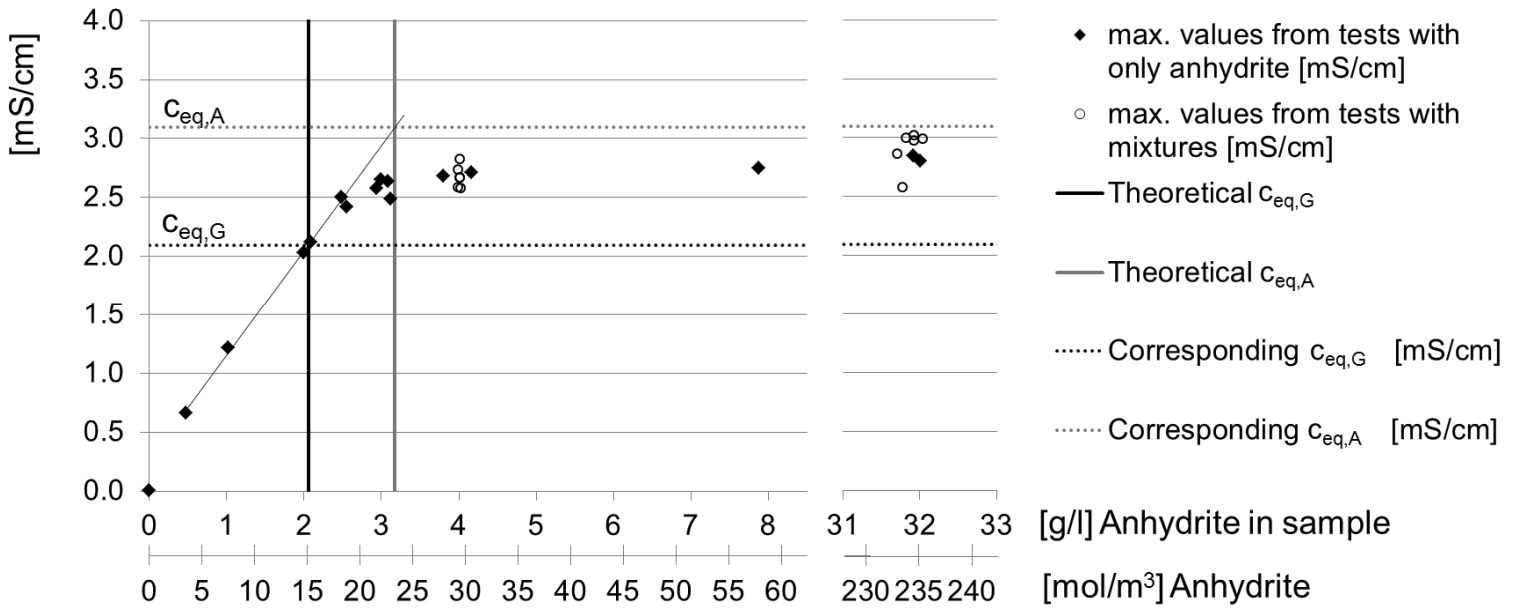

Figure 4-2: $\quad$ Maximal measured values for conductivity in [mS/cm] vs. amount of anhydrite used (in [g/l] and $\left.\left[\mathrm{mol} / \mathrm{m}^{3}\right]\right)$ for each experiment.

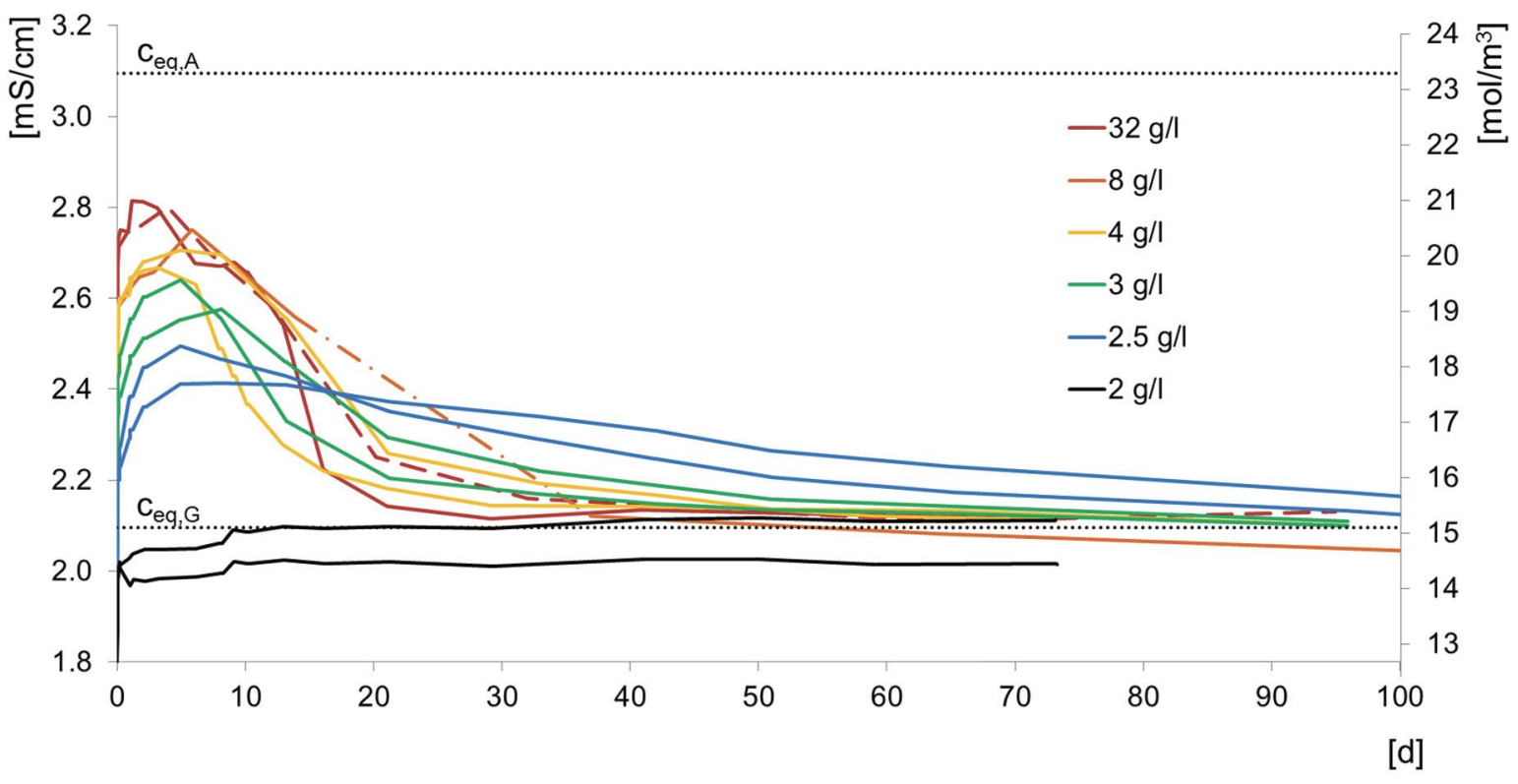

Figure 4-3: $\quad$ Results of conductivity measurements with different concentrations of only anhydrite. (The dashed curve indicates a specimen that was not shaken. The dot-dashed line indicates a longer period without measurement. The dotted lines indicate the expected equilibrium concentrations of anhydrite and gypsum.)

Apart from the dashed curves in Figure 4-3 and Figure 4-4, all bottles were shaken as described in the previous chapter. The immediate influence of shaking varied among the specimens, some not experiencing any change while others were acutely influenced. An example is given in Figure 4-6, 
where the left diagram shows a specimen (4 g/l SA and $6 \mathrm{~g} / \mathrm{l} \mathrm{PW}$ ) which did not exhibit any change due to shaking, whereas the concentration of the specimen in the diagram on the right $(32 \mathrm{~g} / \mathrm{SA}$ and $48 \mathrm{~g} / \mathrm{lPW}$ ) was affected immediately after shaking (these measurements are indicated by the circles). It can be seen that the conductivity resumes its value prior to shaking within a couple of minutes after shaking. This behavior was strongest for the specimens containing $32 \mathrm{~g} / \mathrm{SA}$ and $48 \mathrm{~g} / \mathrm{l} \mathrm{PW}$ and $32 \mathrm{~g} / \mathrm{l} \mathrm{SA}$ and $48 \mathrm{~g} / \mathrm{l} \mathrm{QM}$. However, the reason for which these specimens were acutely affected stronger than the other specimens was so far not investigated further. For the sake of clarity, the data points after shaking were removed from the diagrams in the other Figures in this chapter (i.e., for each session of measurements only the data point prior to shaking is plotted).

a)

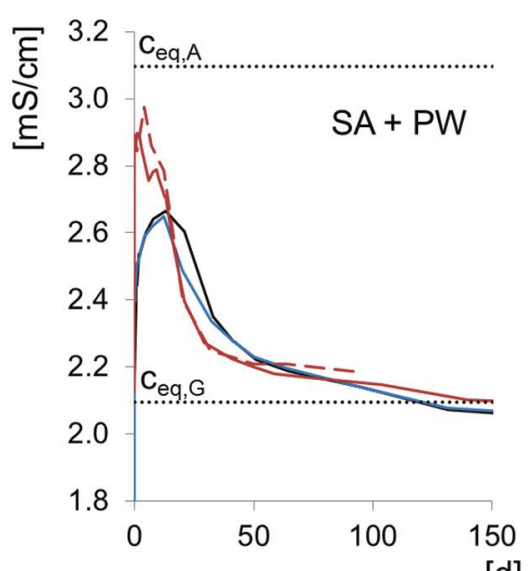

[d] b)

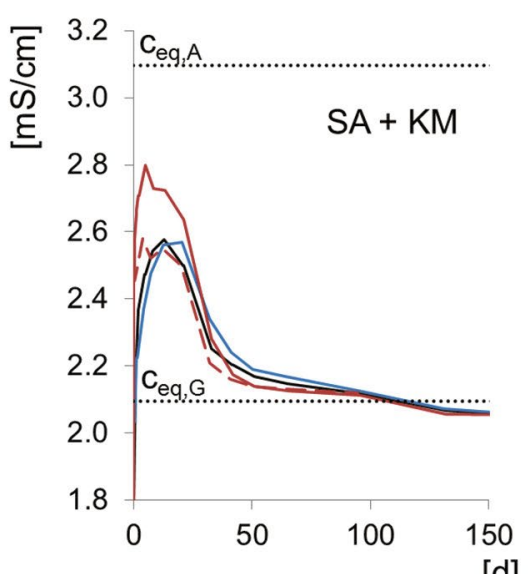

c)

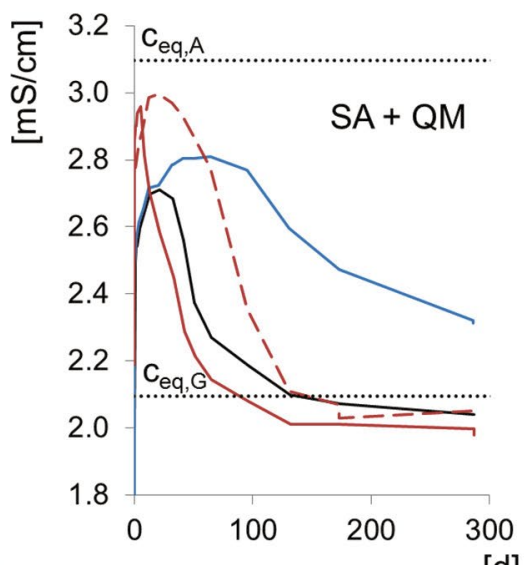

$-4 \mathrm{~g} / \mathrm{l}$ Anhydrite $+6 \mathrm{~g} / \mathrm{l}$ Aggregate

$-4 \mathrm{~g} / \mathrm{l}$ Anhydrite $+18 \mathrm{~g} / \mathrm{l}$ Aggregate
$32 \mathrm{~g} / \mathrm{l}$ Anhydrite $+48 \mathrm{~g} / \mathrm{l}$ Aggregate

$--32 \mathrm{~g} / \mathrm{l}$ Anhydrite $+48 \mathrm{~g} / \mathrm{l}$ Aggregate, not shaken

Figure 4-4: Results of conductivity measurements with mixtures of anhydrite and aggregates; a) kaolin, b) limestone, c) quartz flour.

a)

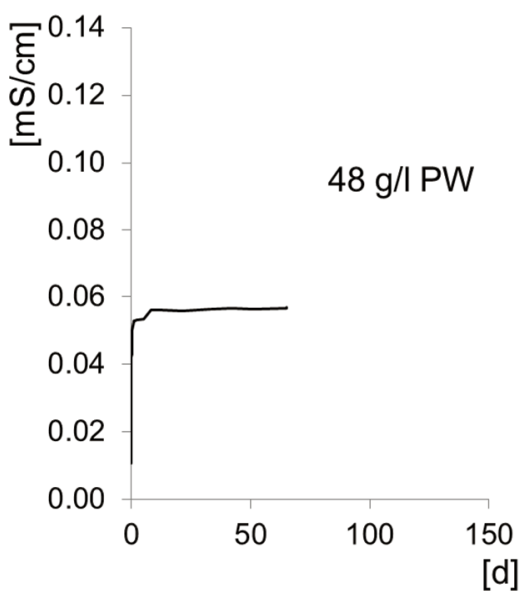

b)

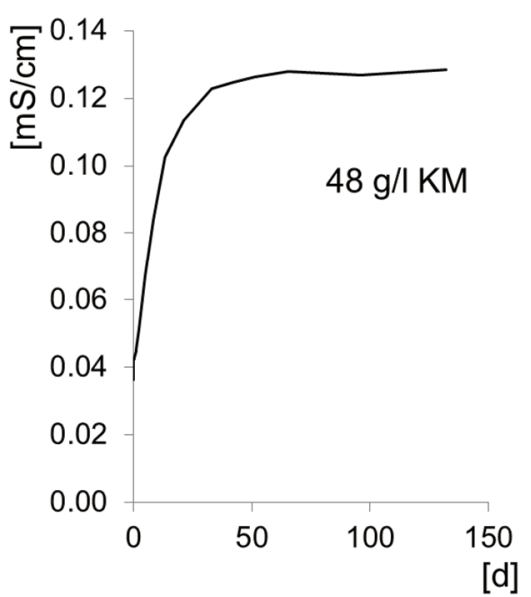

c)

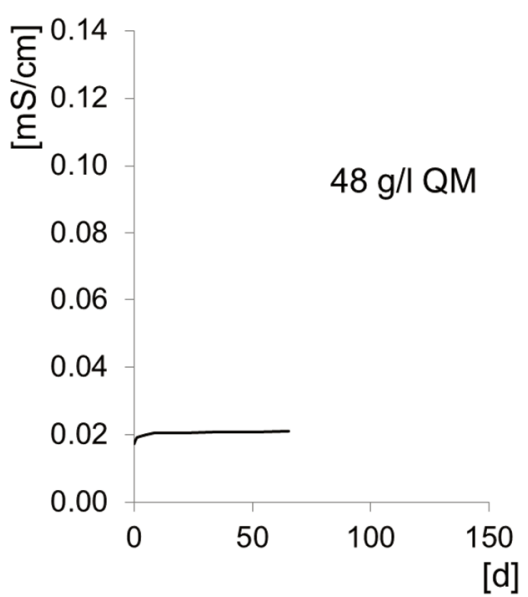

Figure 4-5: $\quad$ Results of conductivity measurements with only aggregates; a) kaolin, b) limestone, c) quartz flour. 

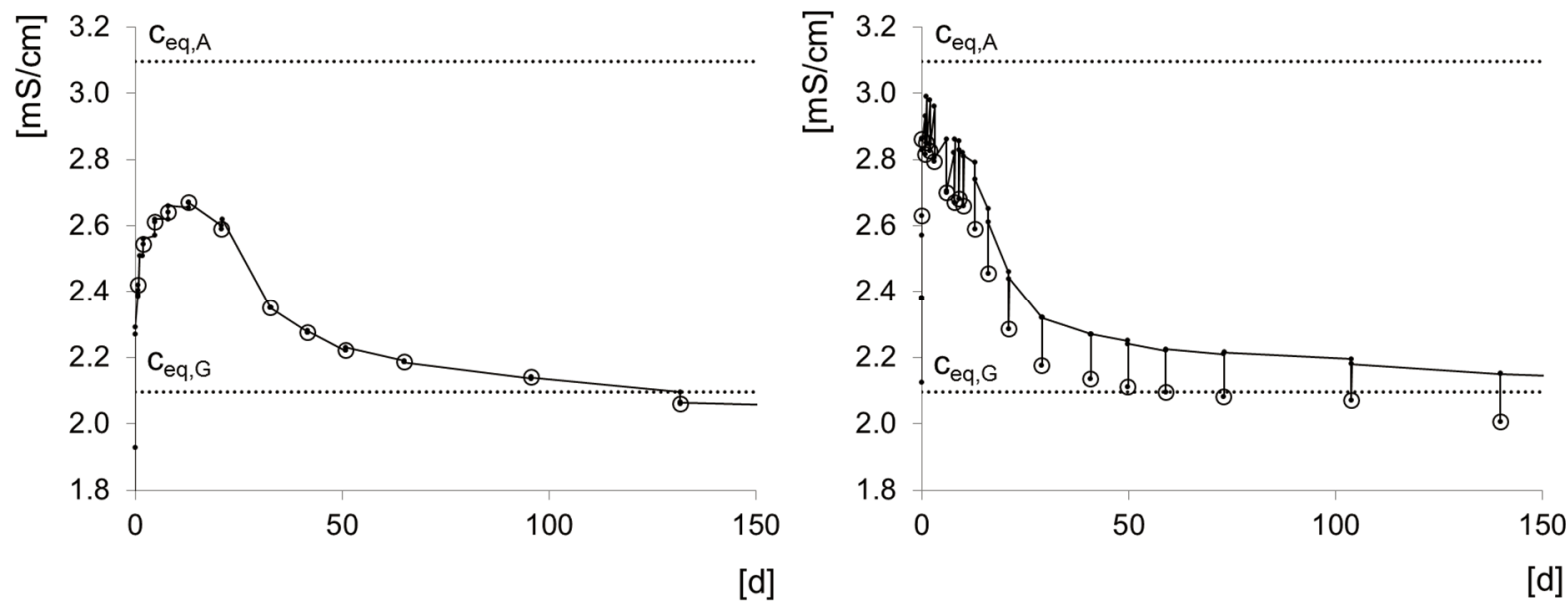

Figure 4-6: $\quad$ Acute influence of shaking: The circles correspond to the measurements taken immediately after shaking. Left: $4 \mathrm{~g} / \mathrm{l}$ anhydrite and $6 \mathrm{~g} / \mathrm{l}$ kaolin, right: $32 \mathrm{~g} / \mathrm{l}$ anhydrite and $48 \mathrm{~g} / \mathrm{l}$ kaolin.

It needs to be pointed out that the equilibrium concentrations indicated in Figure 4-4 and Figure 4-6 correspond to that obtained with the specimens containing only anhydrite. They do not consider the influence of the aggregates on the conductivity, i.e., the values may differ from those indicated in Figure 4-4 and Figure 4-6 (due to foreign ions in the solution, cf. Chapter 2.3.4).

The experiments containing $3 \mathrm{~g} / \mathrm{l}$ anhydrite alone (of different grain sizes) and anhydrite mixed with $3 \mathrm{~g} / \mathrm{l}$ gypsum are plotted in Figure 4-7. For a comparison with the results from Kontrec et al. (2002), the results from one of their experimental data was added to the plot, where anhydrite (4 to $5 \mu \mathrm{m}$ in size) and dihydrate (gypsum) with an initial mass ratio of 1:1 were added to deionized water. The kinetic model of Serafeimidis and Anagnostou (2012b) was then used to model the theoretical development of the concentration for three cases: based on the data by Kontrec (blue solid curve), $3^{\circ} \mathrm{g} / \mathrm{l}$ of anhydrite alone (green solid curve) and with $3 \mathrm{~g} / \mathrm{l}$ gypsum additionally (red solid curve).

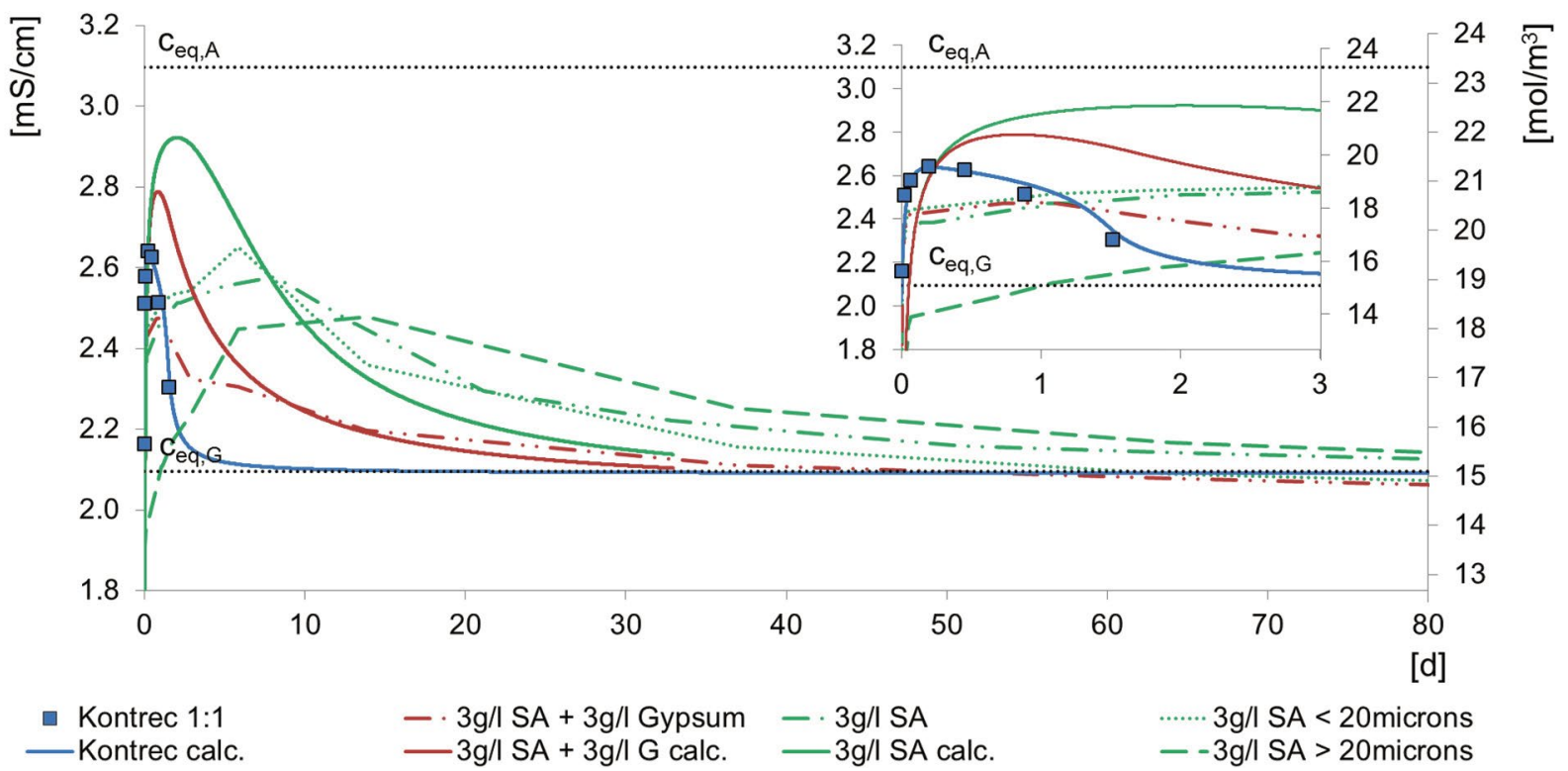

Figure 4-7: $\quad$ Results of conductivity measurements with $3 \mathrm{~g} / \mathrm{l}$ of anhydrite under various conditions (red and green dash-dotted curves) and comparison to the results from Kontrec et al. (2002, blue squares) and corresponding numerical predictions (solid curves) which were calculated based on the kinetic model of Serafeimidis and Anagnostou (2013a). The image on the top right shows the same curves in greater detail for the first 3 days. 


\subsection{Discussion}

As expected, a linear relationship between the maximally measured conductivity and the concentration of dissolved calcium and sulfate ions could be determined for solutions with low concentrations (Figure 4-2). It appears that this proportionality between conductivity and concentration even exceeds $c_{e q, G}$, i.e., up to $2.5 \mathrm{~g} / \mathrm{l}$ anhydrite. For higher initial amounts of anhydrite the maximal measured value was $2.8 \mathrm{mS} / \mathrm{cm}$ (see Figure 4-2), which corresponds to $21.3 \mathrm{~mol} / \mathrm{m}^{3}$, and in the case of mixtures with aggregates even $3.0 \mathrm{mS} / \mathrm{cm}$ was measured (i.e., $22.6 \mathrm{~mol} / \mathrm{m}^{3}$ ).

In general, the experiments with more than $2 \mathrm{~g} / \mathrm{l}$ of anhydrite (see results in Figure 4-3 to Figure 4-7) behaved as expected: At first the concentration increases rapidly, exceeds the equilibrium concentration of gypsum $\left(c_{e q, G}\right)$, from which point on gypsum precipitation occurs simultaneously to anhydrite dissolution. Due to the decreasing difference between $c_{e q, A}$ and the concentration in the solution as well as the consumption of ions due to gypsum precipitation, the rate at which the concentration increases slows down until it reaches a peak value (lower than $\left.c_{e q, A}\right)$. The concentration then begins to decrease again due to further gypsum precipitation until it reaches its end value at $c_{e q, G}$ (at which point anhydrite dissolution and gypsum precipitation are completed).

One could also observe that for specimens with higher initial amounts of anhydrite not only the maximum values were reached faster (which corresponds to the findings in Serafeimidis and Anagnostou, 2012b), but also the decrease in concentration over time occurred quicker (cf. Figure 4-3, e.g., red lines vs. blue lines).

From the experiments with mixtures (i.e., anhydrite and aggregates, Figure 4-4) it becomes evident that the type and amount of aggregate influences the anhydrite dissolution / gypsum precipitation process. The mixtures containing anhydrite and kaolin or limestone showed a fairly similar behavior during the experiments (Figure 4-4a and b), despite the fact that limestone itself dissolves more than kaolin, as can be seen in Figure 4-5. However, the maximally reached values were a bit higher in the case of anhydrite and kaolin (Figure 4-4a) as opposed to the anhydrite and limestone mixtures and the concentration decreased quicker for higher initial anhydrite and kaolin-contents. Furthermore, the long-term behavior of the concentrations of the anhydrite / kaolin mixtures seemed unaffected by shaking of the bottles (the red curves in Figure 4-4a are nearly identical), whereas the mixtures with limestone reached a much smaller peak value, when not shaken (dashed red curve in Figure 4-4b). It seems that the amount of kaolin or limestone barely changed the behavior of the concentration in the water (comparison of black curves to blue curves in Figure 4-4a and b). However, in the case of quartz flour, it is clearly noticeable that a smaller ratio of initial anhydrite to quartz flour (i.e., $4: 18 \mathrm{~g} / \mathrm{l}$, blue curve, $v s .4: 6 \mathrm{~g} / \mathrm{l}$, black curve) slowed the gypsum precipitation process down by far. Furthermore, shaking the bottles containing quartz flour seemed to have increased the speed of the process (when comparing the dashed and the solid red lines in Figure 4-4c). No explanation was found why the mixtures with quartz flour showed a different behavior. Possibly, nucleation and crystal growth occur slower when quartz flour is present. Further insight may be given if the effect of dissolution is separated from nucleation and crystal growth. Since the dissolution process was seen to occur very abruptly in the results shown above, it may, however, be difficult to measure this with conductivity experiments. While this would be beyond the scope of this thesis, it can be noted that studies on pure dissolution kinetics could prove useful. They would typically be conducted under high dilution conditions preventing the precipitation of other phases, and would use either flow-through dissolution cells or highly dilute suspensions. 
As expected, Figure 4-7 indicates that the anhydrite dissolution / gypsum precipitation process occurs faster, if (a) smaller grain sizes of anhydrite are used and (b) gypsum is used as seed material. However, it can be seen that the measurements performed by Kontrec et al. (2002) (cf. Serafeimidis and Anagnostou, 2013a) delivered a much faster change in concentration. On the one hand, this may be due to the far smaller grain size of anhydrite (4-5 $\mu \mathrm{m}$, Kontrec et al., 2002), on the other hand, some parameters used in their research are unknown to us (e.g., the amount of anhydrite / gypsum used for this specific test or the size of the seed material). Many assumptions and simplifications needed to be made to model the exemplary theoretical predictions shown in Figure 4-7 (solid curves), e.g., the grain sizes, shape and specific surface areas of anhydrite and gypsum. Also, the cases where no seed material was used in the experiment could not be modeled accurately (solid green curve), since a minimal amount of seed material needs to be considered in the model to implement Equation (2 - 26) or (2 - 27).

\subsection{Conclusions}

While the calculated equilibrium concentration of gypsum was confirmed with the measurements, the equilibrium concentration of anhydrite could not be confirmed experimentally, since the measured concentration lies below $c_{e q, A}$ in all cases. It was seen that the maximally measured conductivity varies depending on the amount of dissolving anhydrite (see Figure 4-2 and Figure 4-3). Therefore, it is wrong to assume that $c_{e q, A}$ corresponds to the maximal value measured, which was the case in the works of Bock (1961) and Kontrec et al. (2002), see also Chapter 2.3.1. However, the calculated value for $c_{e q, A}\left(23.3 \mathrm{~mol} / \mathrm{m}^{3}\right.$ according to Appendix $\left.\mathrm{A}\right)$ is deemed plausible and will be used for the further considerations in this work.

It was not possible to definitively confirm the reaction rate constants as given in Serafeimidis and Anagnostou (2013a) with the performed extensive and systematic investigation campaign, since many assumptions need to be made in order to model the change of concentration in the solutions. No set of parameters was found that could successfully model all cases measured in the experiments described herein. Nevertheless, the research performed in this work (e.g., in Chapter 5) assumes the values from the above mentioned authors (cf. Chapter 2.4). 



\section{Self-sealing of anhydrite}

\subsection{Introduction}

Anhydrite can be encountered as particles of different sizes, veins or layers within a clay matrix, but also occurs in the form of massive, bulky anhydrite beds. Gypsum often precipitates directly on the surface of the dissolving anhydrite, since seepage flow in the rock is usually negligibly slow compared to the reaction rate of gypsum precipitation. Especially in the case of big particles, very thick veins, layers or massive anhydrite (which is the main focus of this chapter), the growing layer of gypsum on the anhydrite surface slows down further anhydrite dissolution, since the dissolving ions must now diffuse through the porous layer of gypsum. This phenomenon is referred to here as "self-sealing" of the anhydrite, even though the anhydrite is never completely sealed by the gypsum but its dissolution rate is strongly retarded. Due to self-sealing, massive anhydrite is often considered as less problematic in underground construction, since it does not express as large swelling deformations (or when restricted: swelling pressures) within the lifetime of the respective underground construction, compared to cases where anhydrite is finely distributed in the rock (cf., e.g., Amstad and Kovári, 2001, Rauh et al., 2006).

\subsection{Conceptual model}

Serafeimidis and Anagnostou (2013a) and Serafeimidis (2014) formulated a model to determine the effect of sealing on anhydrite dissolution. It shows that the rate of anhydrite dissolution indeed reduces when gypsum grows directly on its surface and thus begins to seal the anhydrite. They discovered that depending on the gypsum porosity and the thickness of the anhydrite layers, the hydration time of anhydrite may increase by many orders of magnitude and exceed the usual service life of tunnels (100 years) by far. For example, Serafeimidis and Anagnostou (2013a) indicate that an anhydrite platelet of a thickness of $100 \mathrm{~mm}$ would be completely dissolved after roughly 200 years without considering the effect of sealing, and 5000 years when taking sealing into account (assuming the porosity of the gypsum layer to be 0.1 ). Serafeimidis and Anagnostou studied two possible shapes of dissolving anhydrite particles: parallelepipeds and spherical particles. For the present study anhydrite dissolution and gypsum precipitation is investigated on parallelepipeds of anhydrite (Figure 5-1, left). When fully immersed in water, the anhydrite will dissolve and the gypsum is expected to precipitate directly on the surface of the anhydrite itself, as the latter functions as seed for the growth of gypsum nuclei. At any given time, a cross-section of that same specimen is expected to have changed according to Figure 5-1, right: A certain "thickness" of anhydrite has dissolved $\left(s_{A}\right)$ and was replaced by precipitated gypsum, which has a larger thickness $\left(s_{G}\right)$. The total thickness of the platelet (anhydrite and gypsum) changed by $s_{t o t}$ and is now $S_{G, A}$, while $S_{A}$ is the thickness of the remaining anhydrite.

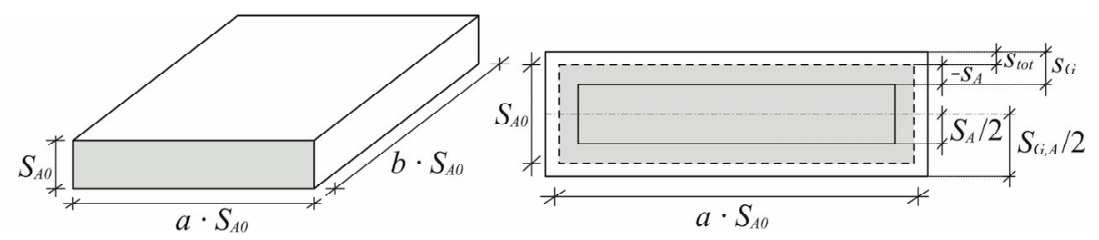

Figure 5-1: Left: Parallelepiped, right: Cross section area after anhydrite dissolution and gypsum precipitation, whereas $S_{A 0}$ is the initial thickness of the parallelepiped. 


\subsection{Experiment}

\subsubsection{Aim and procedure}

In the interest of observing sealing experimentally, simple laboratory tests were performed. The thicknesses of growing layers of gypsum on anhydrite was quantified and compared to the predictions made based on the kinetic model which Serafeimidis and Anagnostou (2013a) established for simultaneous anhydrite dissolution and gypsum precipitation, and thus the plausibility of the model is proven. For the experiments, some platelets cut from natural anhydrite were inserted in water, the growing gypsum layers and gypsum needles were observed optically and the thicknesses of the gypsum layers were quantified with scanning electron microscopy (SEM, Chapter 3.2). The amount of precipitated gypsum was determined via weight change and thermogravimetric analysis (TGA, Chapter 3.1).

The used specimens can be considered as large-scale anhydrite platelets, which were cut from natural rocks containing $96 \%$ to $99 \%$ of anhydrite (see specimen compositions in Table $5-1$ ). The rocks stem from the lower layers of the gypsum-quarries in Bex and Leissigen, Switzerland (i.e., of the Ultrahelveticum in the cantons of Vaud and Berne) and from bore-cores originating from the exploratory campaign for the new Bözberg-Tunnel in Switzerland (i.e., from the Anhydritgruppe of the Faltenjura in the canton of Aargau).

The dimensions of the platelets were roughly $9 \times 23 \times 65 \mathrm{~mm}^{3}$. So far, tests on four specimens (of the 17 platelets in total) were terminated and will thus be discussed in detail in the following chapters. The properties of these specimens (Bex 1b, Bex 1f, Bözberg "BB" 1e and BB 1f) are listed in Table 5-2.

The platelets were immersed in ca. $30 \mathrm{ml}$ of water (saturated with respect to gypsum, i.e., $15 \mathrm{~mol} / \mathrm{m}^{3}$ ) in a container as shown in Figure 5-2. Two series of experiments were performed, one at room temperature $\left(20^{\circ} \mathrm{C}\right)$ and one in a cooling box $\left(5^{\circ} \mathrm{C}\right)$, at which the concentration gradient between $c_{e q, A}$ and $c_{e q, G}$ is higher (see Figure 2-1), but the reaction rate constant will be smaller, as will be discussed later. The experimental conditions, as well as the main measurements taken before and after the experiments are listed in Table 5-2. Every 1-2 months each specimen is photographed and the change of the specimen surfaces are observed qualitatively. In order for the images to be compared to one another as accurately as possible, the frame of the test setup provided a haltering for the camera to allow the photographs to be taken from the same position during each session.

Table 5-1: $\quad$ Mineralogical composition of the rocks prior to contact with water (X-ray diffraction results, weight\%).

\begin{tabular}{llllll}
\hline Specimen name & Anh & Dol & III/ Ms & Kfs & Qtz \\
\hline Bex1 & 96.5 & 3.2 & & 0.3 \\
\hline Bözberg1 & 98.8 & & 0.3 & 0.9 \\
\hline Bözberg3 & 94.5 & 3.0 & 1.3 & 0.8 & 0.4 \\
\hline Leissigen12 & 97.9 & 1.5 & & 0.6 \\
\hline
\end{tabular}

Key: Anh = Anhydrite, Dol = Dolomite,$I I I=I I$ ite,$M s=$ Muscovite, $K f s=K-F e l d s p a r$, Qtz $=$ Quartz 
Table 5-2: $\quad$ Overview of experimental conditions, measurements prior and post test and back-calculated specimen properties.

\begin{tabular}{|c|c|c|c|c|}
\hline Specimen & Bex1b & Bex1f & BB1e & BB1f \\
\hline \multicolumn{5}{|l|}{ Experimental conditions } \\
\hline Testing temperature $\left[{ }^{\circ} \mathrm{C}\right]$ & 5 & 20 & 20 & 20 \\
\hline Test duration [d] & 889 & 800 & 800 & 422 \\
\hline \multicolumn{5}{|c|}{ Specimen measurements prior to test } \\
\hline Mass [g] & 40.6 & 41.2 & 28.3 & 33.2 \\
\hline Thickness $S_{A 0}[\mathrm{~mm}]$ & 8.6 & 8.4 & 9.1 & 9.4 \\
\hline Width $d_{0}=a \cdot S_{A 0}[\mathrm{~mm}]$ & 22.3 & 27.8 & 18.7 & 21.3 \\
\hline Height $h_{0}=b \cdot S_{A 0}[\mathrm{~mm}]$ & 72.6 & 61.3 & 57.9 & 57.8 \\
\hline \multicolumn{5}{|l|}{ Back-calculated initial values } \\
\hline Density $\left[\mathrm{g} / \mathrm{cm}^{3}\right]$ & 2.90 & 2.89 & 2.88 & 2.88 \\
\hline \multicolumn{5}{|l|}{ Specimen measurements post test } \\
\hline Mass (dry) [g] & 41.3 & 41.9 & 31.1 & 34.3 \\
\hline \multicolumn{5}{|c|}{ Back-calculated values from specimen mass $(\Delta M)$} \\
\hline Mass of bound water, post test $[\mathrm{g}]$ & 0.76 & 0.70 & 2.74 & 1.10 \\
\hline Mass of dissolved anhydrite [g] & 2.86 & 2.65 & 10.35 & 4.16 \\
\hline Mass of gypsum post test [g] & 3.62 & 3.36 & 13.09 & 5.26 \\
\hline Corresponding $s_{G}[\mathrm{~mm}]$ & 0.35 & 0.33 & 1.84 & 0.65 \\
\hline \multicolumn{5}{|c|}{ Back-calculated values from TGA results } \\
\hline Mass of bound water, post test $[\mathrm{g}]$ & 0.26 & 0.11 & 3.10 & - \\
\hline Mass of dissolved anhydrite [g] & 0.98 & 0.43 & 11.71 & - \\
\hline Mass of gypsum post test [g] & 1.24 & 0.54 & 14.81 & - \\
\hline Corresponding $s_{G}[\mathrm{~mm}]$ & 0.12 & 0.05 & 2.12 & - \\
\hline
\end{tabular}

The four specimens mentioned above were extracted from their containers after a certain period of time (see Table 5-2), weighed, dried at $40{ }^{\circ} \mathrm{C}$ (which is low enough to ensure that the formed gypsum does not transform back to anhydrite or to bassanite, see Chapter 2.1 and Appendix I) and weighed again in order to obtain the new dry mass of the specimen. A comparison of the dry mass post test to the dry mass prior to the test delivers the amount of bound water in the gypsum crystals (see Table 5-2). Then the lower sections of the specimens were embedded in epoxy (as is shown in Figure 5-3). From this, samples could be sawed off from the bottom of the specimens for the investigations with SEM (see Chapter 3.2), where images reflecting material contrast (back scattered electrons, BSE) can be collected. Due to the various densities of the minerals (i.e., gypsum $2.32 \mathrm{~g} / \mathrm{cm}^{3}$, anhydrite $2.96 \mathrm{~g} / \mathrm{cm}^{3}$ ), anhydrite appears whiter than the gypsum in the 
BSE images while the pore space remains black. Therefore, it is possible to qualitatively distinguish between anhydrite and gypsum. In the interest of comparing the state of the rocks post test to their initial state prior to contact with water, BSE images were collected from samples adjacent to the actual specimens (referred to as "specimens prior to test"). Additionally, optical microscopes were used to study the surface of some specimens (see, e.g., on the right in Figure 5-3) as well as to perform thin section analysis on the specimens Bex $1 \mathrm{~b}$, Bex $1 \mathrm{f}$ and BB 1e. From the top areas of these three specimens, samples were sawed off and ground to powder for TGA (Chapter 3.1).

View from top (A-A):

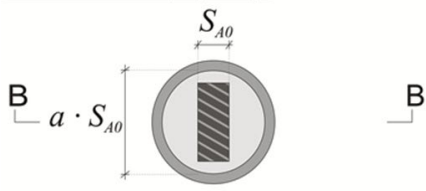

View from side (B-B):
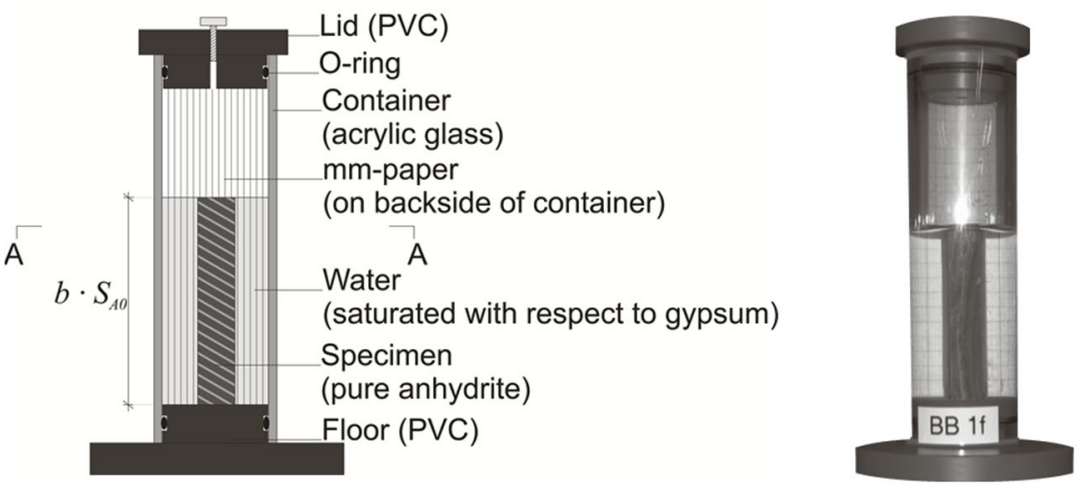

Figure 5-2: $\quad$ Left: conceptual sketch of the test setup for the sealing experiments (average dimensions of the specimens were $S_{A 0}=8.8 \mathrm{~mm}, a=2.6, b=7.4$ ), right: photograph of the specimen BB $1 f$ during the test.
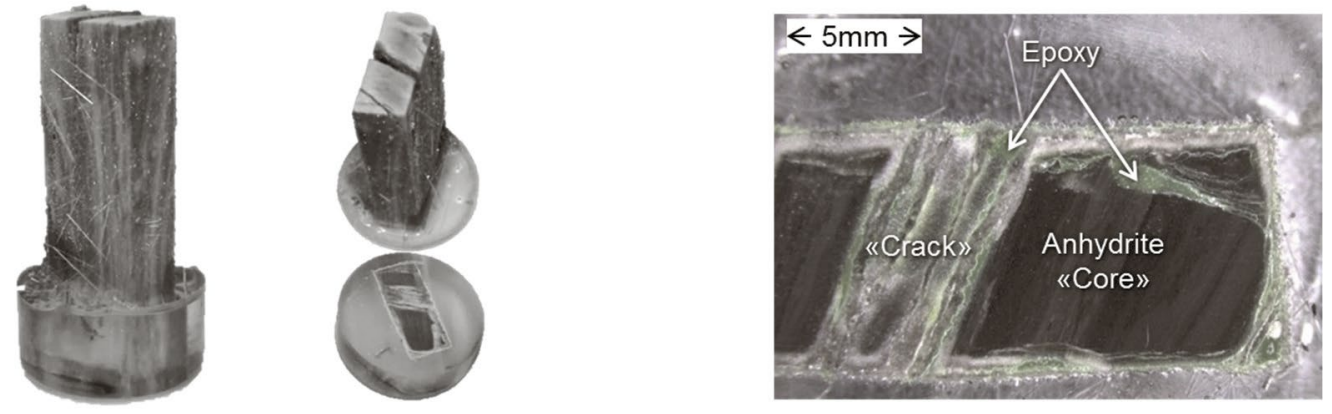

Figure 5-3: $\quad$ Left: photographs of the specimen BB $1 f$ after embedding in epoxy and after sawing. Right: image of the cross-section of BB 1 obtained with an optical microscope.

\subsubsection{Results}

\section{a. Photography}

Figure 5-4 shows the evolution of the four exemplary specimens, whereas the specimen in the top row (Bex 1b) was tested at $5{ }^{\circ} \mathrm{C}$, the others at $20^{\circ} \mathrm{C}$. Generally, all specimens at $20^{\circ} \mathrm{C}$ produced clear clusters of (long) needles, as can be seen in the bottom three rows of Figure 5-4. The specimens that were tested at $5{ }^{\circ} \mathrm{C}$ were, however, rather covered by a "fleece" of very fine and much smaller gypsum needles. At both temperatures, gypsum precipitation appeared to occur preferentially in the lower area of the specimens. 
It needs to be noted that the cooling box malfunctioned after about 100 days and the water surrounding the $5^{\circ} \mathrm{C}$-specimens (such as Bex $1 \mathrm{~b}$ ) froze completely (the temperature nearly reached $-40{ }^{\circ} \mathrm{C}$ ). They were then thawed and the experiments continued. No substantial change of the specimens could be observed optically.
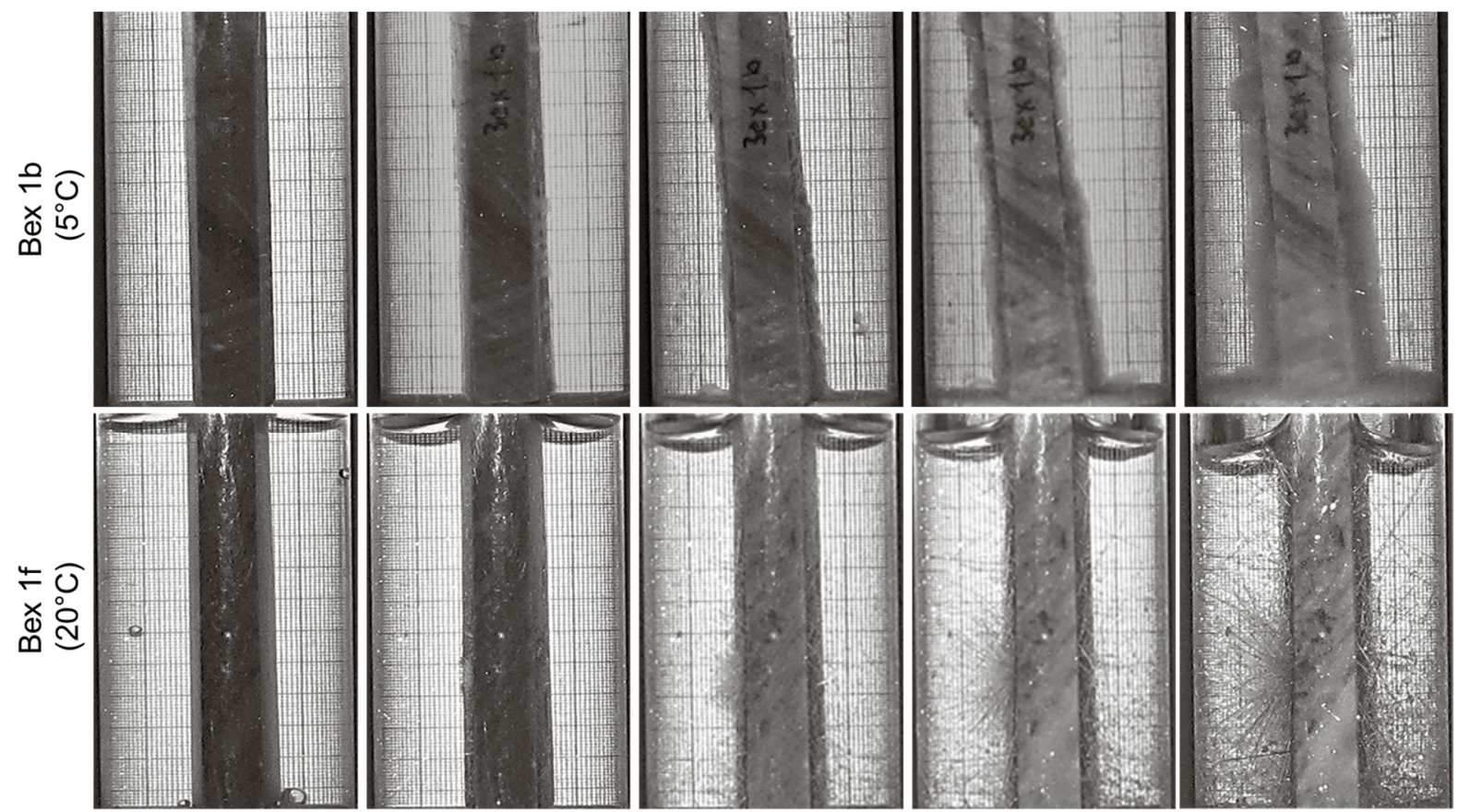

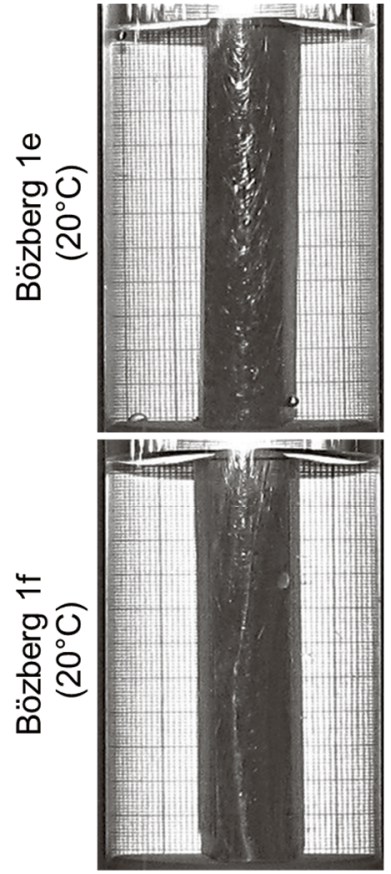

$0 \mathrm{~d}$

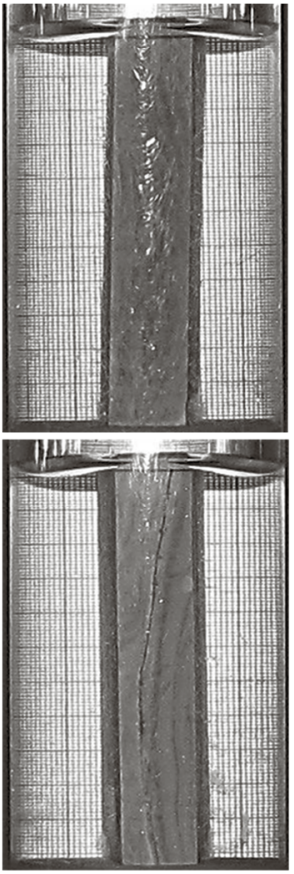

$90 \mathrm{~d}$

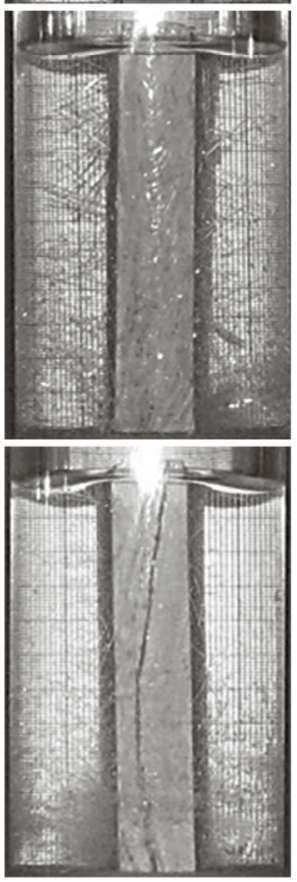

$200 d$

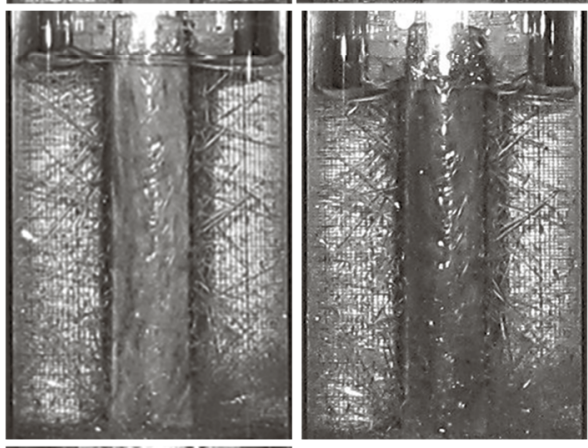

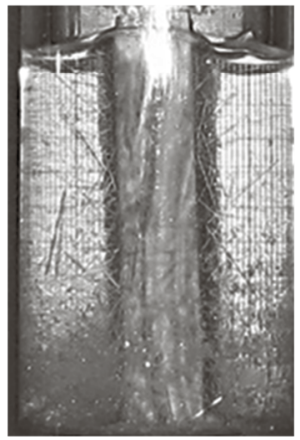

$400 d$
$800 \mathrm{~d}$

Figure 5-4: $\quad$ Photographs of four specimens after various durations. Top row: Bex $1 \mathrm{~b}$ at $5^{\circ} \mathrm{C}$, bottom three rows: Bex 1f, BB 1e (Bözberg) and BB $1 f$ at $20^{\circ} \mathrm{C}$. (The distance between two vertical lines on the scale behind the specimens is $0.5 \mathrm{~mm}$.) 


\section{b. Microscopy}

Figure 5-5 shows images of the rocks (prior to contact with water) which were obtained with BSE from SEM. As expected, the rock matrices in Figure 5-5 appear very homogeneous (i.e., light grey) since they consist of $96-99 \%$ of anhydrite (cf. Table 5-1). On a smaller scale (images $c$ and $d$ in Figure 5-5) a difference in texture of the two specimens can be observed: Bex shows rather bulky plates with easily distinguishable fissures, while the Bözberg specimen appears to have more of a granular texture with more, finer fissures. In both cases it is uncertain whether the fissures were caused by sampling or specimen preparation or whether they correspond to the initial state the rocks were in.
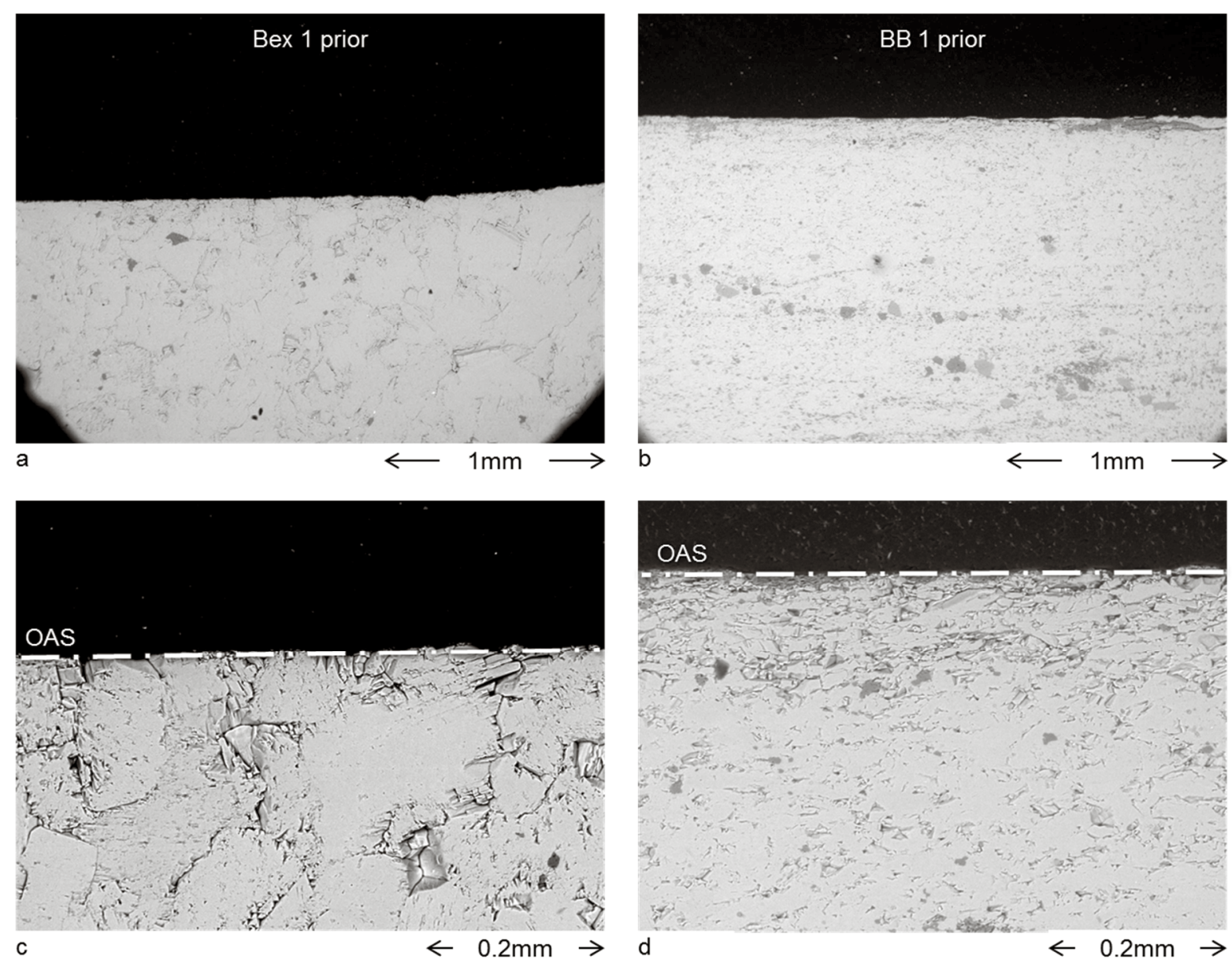

Figure 5-5: BSE images from SEM. Left column (a,c): Bex 1 prior, right column (b,d): BB 1 prior. "OAS" indicates the original anhydrite surface.

For the cases after contact with water, the transformed specimen surfaces are shown in the following images for all four specimens.

Figure 5-7, Figure 5-10, Figure 5-13 and Figure 5-16 show BSE images of the four extracted specimens on a relatively large scale (comparable to the top images in Figure 5-5). As mentioned above, one can distinguish between the rather compact inner core of anhydrite (light grey, i.e., in the bottom areas of Bex 1b, Bex $1 \mathrm{f}$ and BB 1e or in the areas of BB $1 \mathrm{f}$ denoted as "A") and the gypsum (dark grey, denoted as "G") which can be found in the shape of gypsum needles along the surface and within the pores near the edge of the specimen (the latter is mainly in the case of the Bözberg specimens). 
Based on these images an attempt was made to determine the thicknesses of the receding anhydrite front (from the original anhydrite surface "OAS" to the new anhydrite surface "NAS") as can be seen in the examples in Figure 5-8, Figure 5-11, Figure 5-14 and Figure 5-17. In some cases, gypsum was only observed in the shape of needles along the anhydrite surface, whereas the latter did not seem to recede at all and can still be seen as a clearly defined line (especially for the Bex specimens), whereas in other cases (mainly on the specimens of Bözberg) a penetration of gypsum into the specimen could be observed (see, e.g., the grey gypsum matrix with some remaining anhydrite crystals in Figure 5-17c).

As mentioned previously, thin sections were made of three specimens, images of which are shown in in Figure 5-8, Figure 5-11 and Figure 5-14 (right-hand side). Naturally, it was not possible to display the identical areas as the BSE images, however similar areas were found and are shown at a comparable scale to the BSE images on the left-hand side of the same Figures. In thin section analysis with polarized light mode, the gypsum crystals can be distinguished from the anhydrite crystals by the lower birefringence (Nesse, 1986), i.e., the gypsum crystals will appear in greyscales, as opposed to the "colorful" anhydrite crystals.

The following sub-sections show the collected microscopic images for each investigated specimen.

\section{b.i. $\operatorname{Bex} 1 b\left(5^{\circ} \mathrm{C}\right)$}

The examined cross-section of the specimen Bex $1 \mathrm{~b}$ (tested at $5^{\circ} \mathrm{C}$ ) is shown in Figure 5-6 and a large-scale overview obtained with BSE images is presented in Figure 5-7. With the possible exception of Figure 5-8c (it is not clear, whether the dark grey area in Figure $5-8 \mathrm{c}$ is gypsum), the smaller scaled images of Figure 5-8 as well as the large scale images in Figure 5-7 lead to believe that gypsum did not precipitate within the specimen.

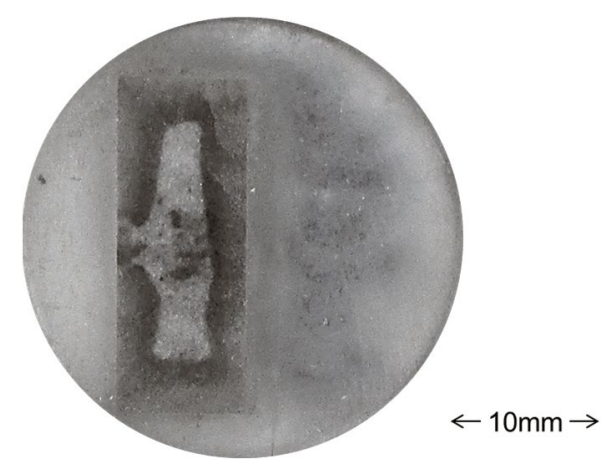

Figure 5-6: Photograph of the specimen Bex $1 \mathrm{~b}$ after embedding in epoxy and sawing. 

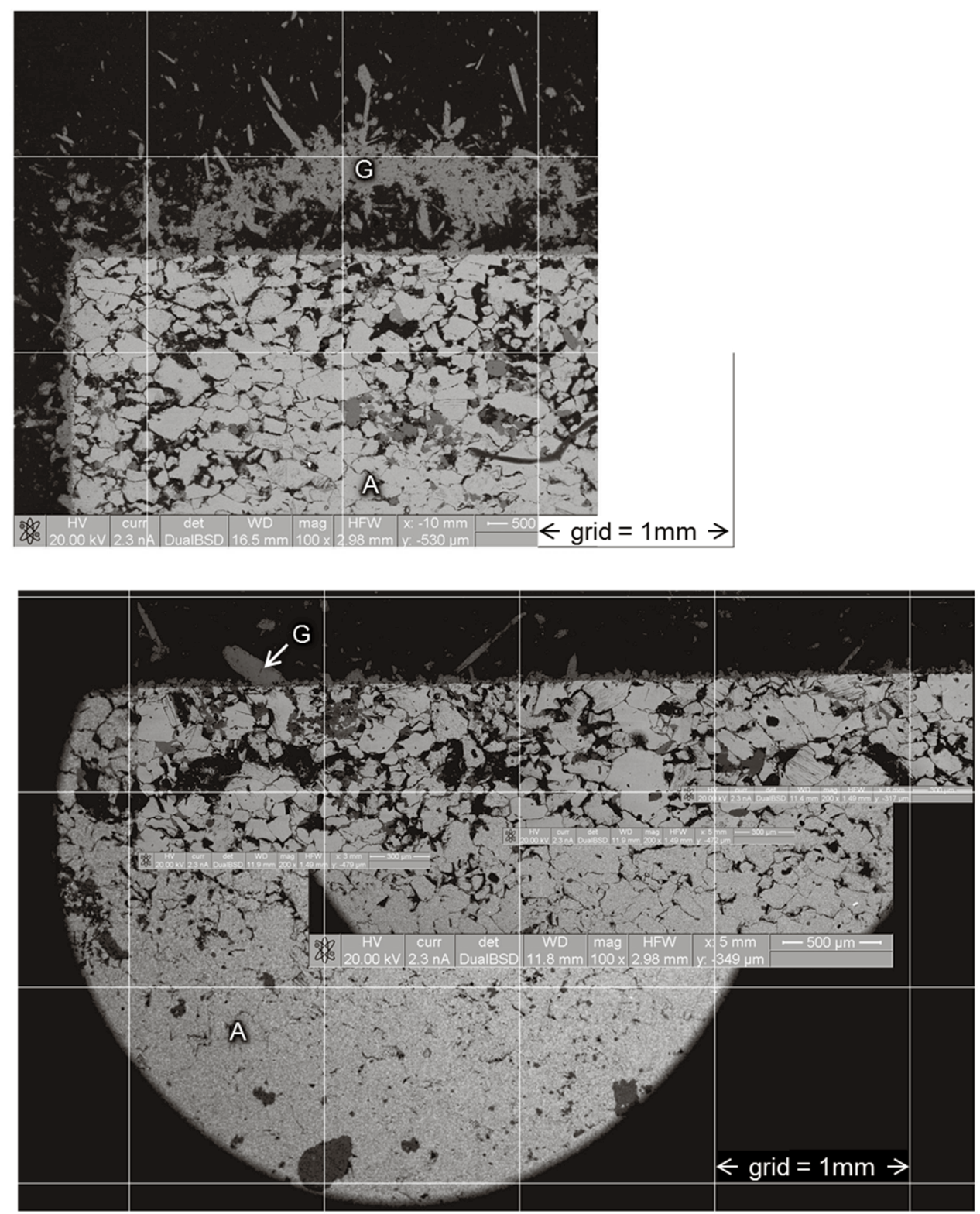

Figure 5-7: $\quad$ Large-scale SEM images (BSE) of the specimen Bex $1 \mathrm{~b}$ (multiple images pasted together). 

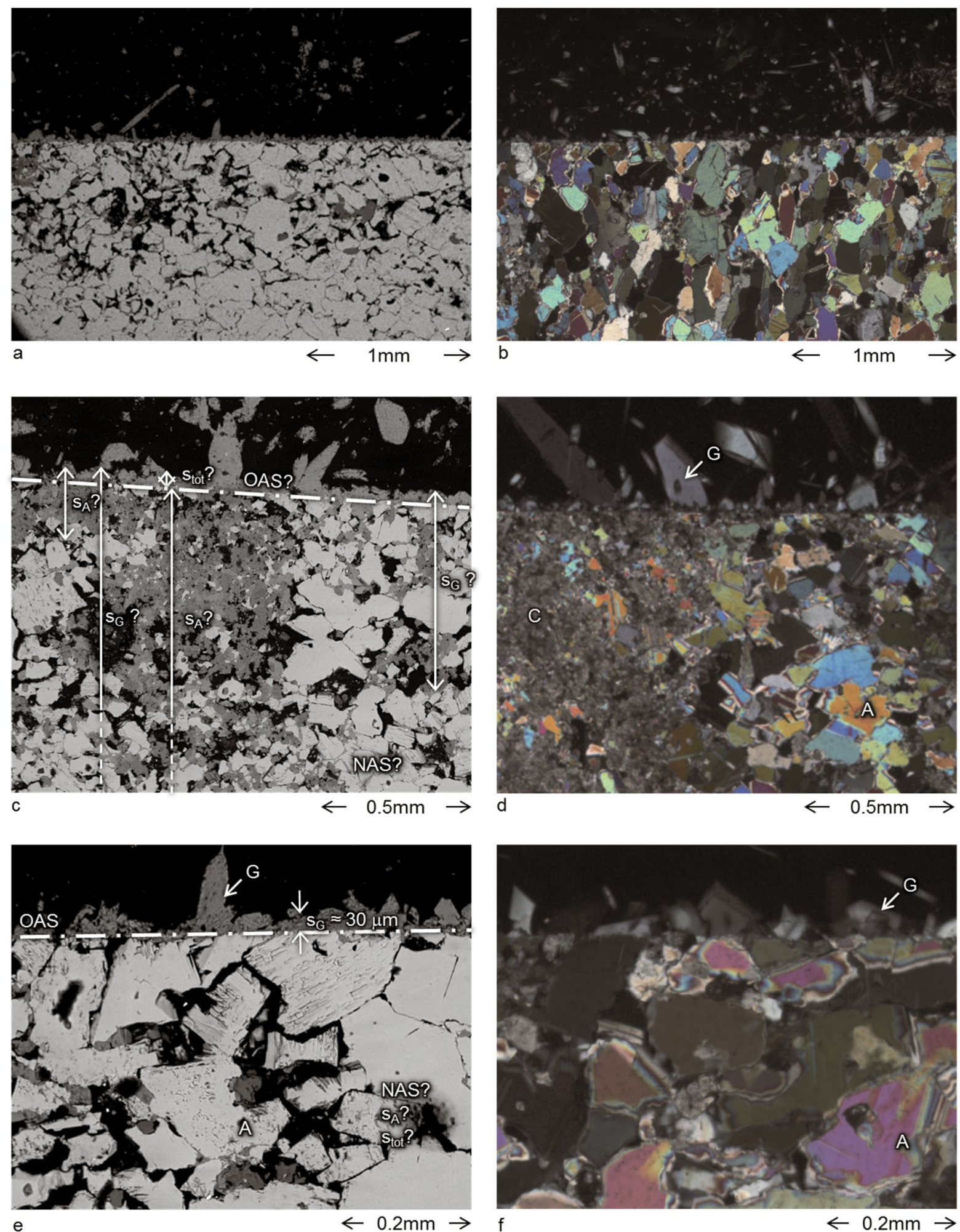

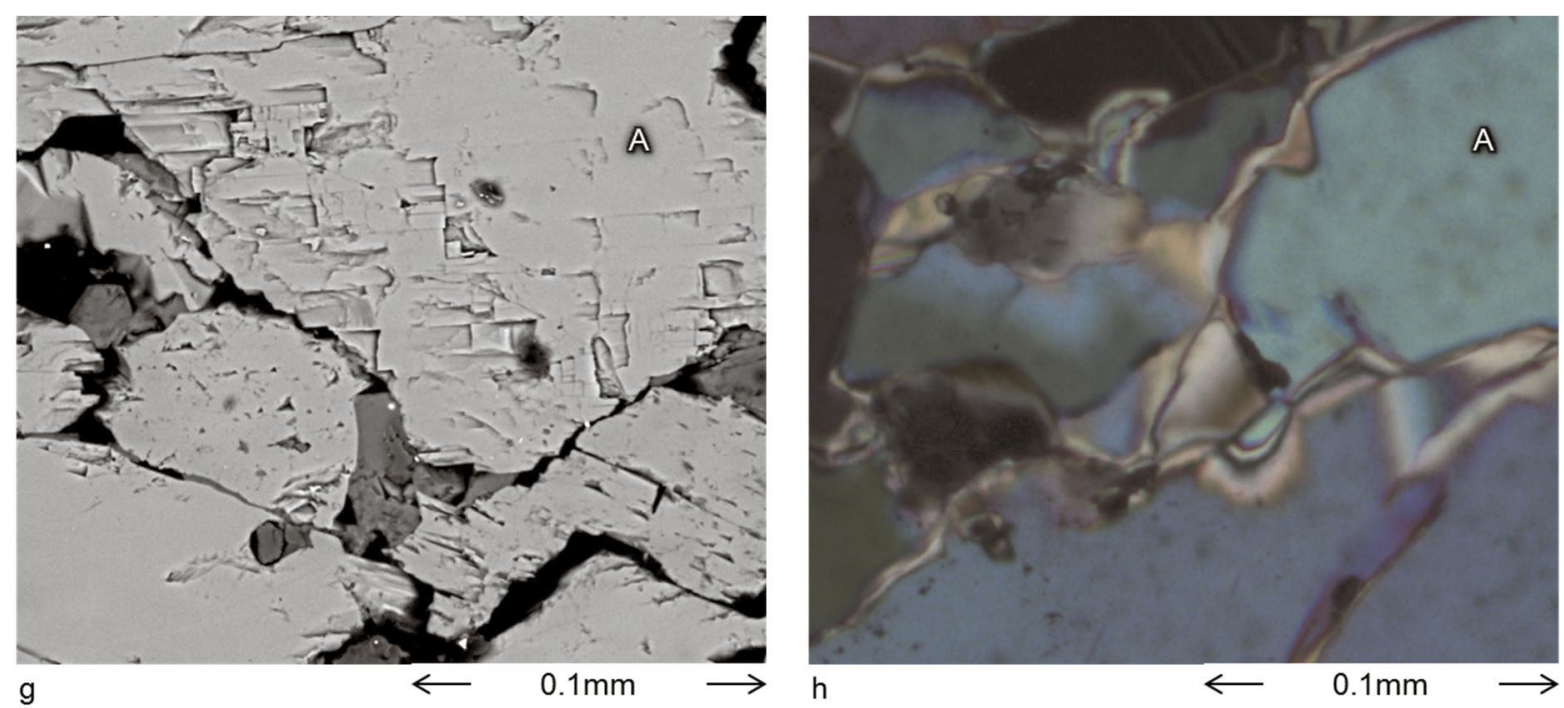

Figure 5-8: $\quad$ BSE $(a, c, e, g)$ and thin section $(b, d, f, h)$ images of the specimen Bex $1 b$. The brown area marked "C" in Figure (d) is calcite (A. M. Aguilar Sanchez, ETH Zurich, personal communication).

\section{b.ii. Bex $1 f\left(20^{\circ} \mathrm{C}\right)$}

The cross-section of Bex $1 \mathrm{f}$ in Figure 5-9 (tested at $20^{\circ} \mathrm{C}$ ) delivered the BSE and thin section images presented in Figure 5-10 and Figure 5-11. Here too, gypsum did not appear to have precipitated within the anhydrite close to the surface.

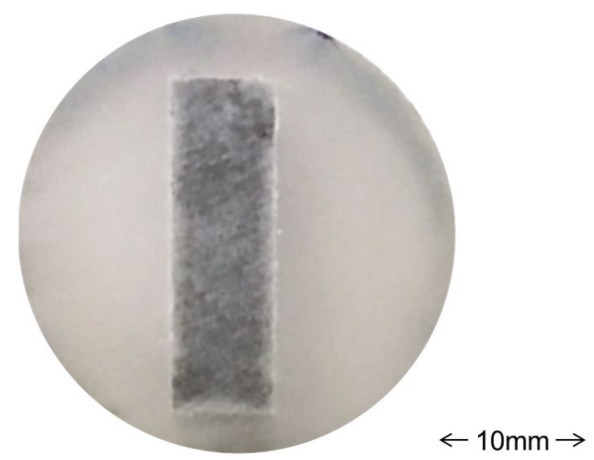

Figure 5-9: $\quad$ Photograph of the specimen Bex $1 b$ after embedding in epoxy and sawing.

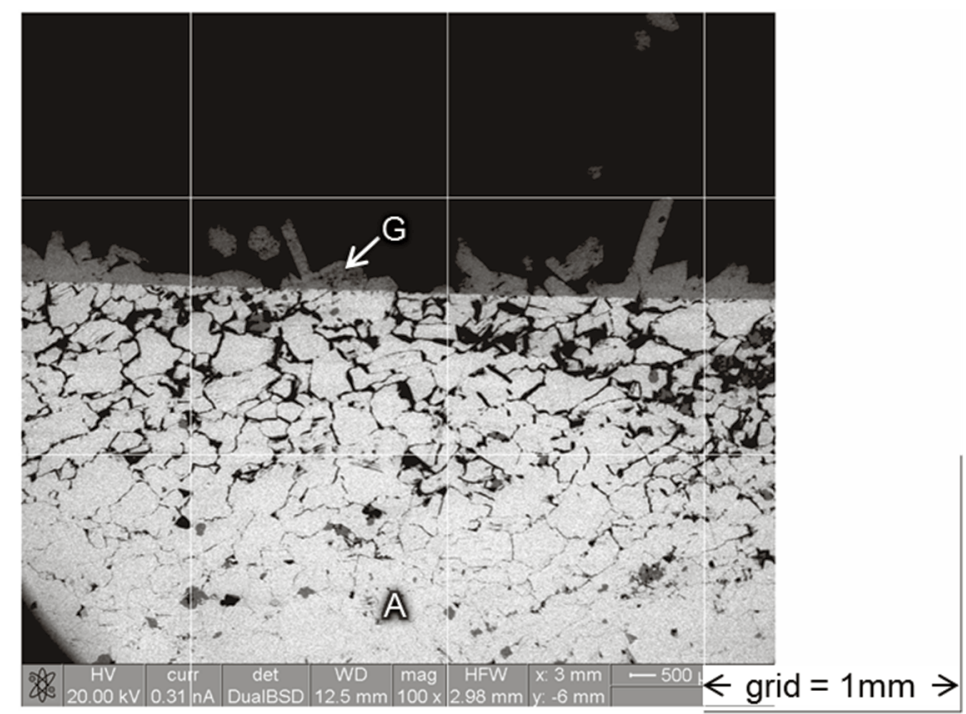

Figure 5-10: $\quad$ Large-scale SEM images (BSE) of the specimen Bex $1 f$. 

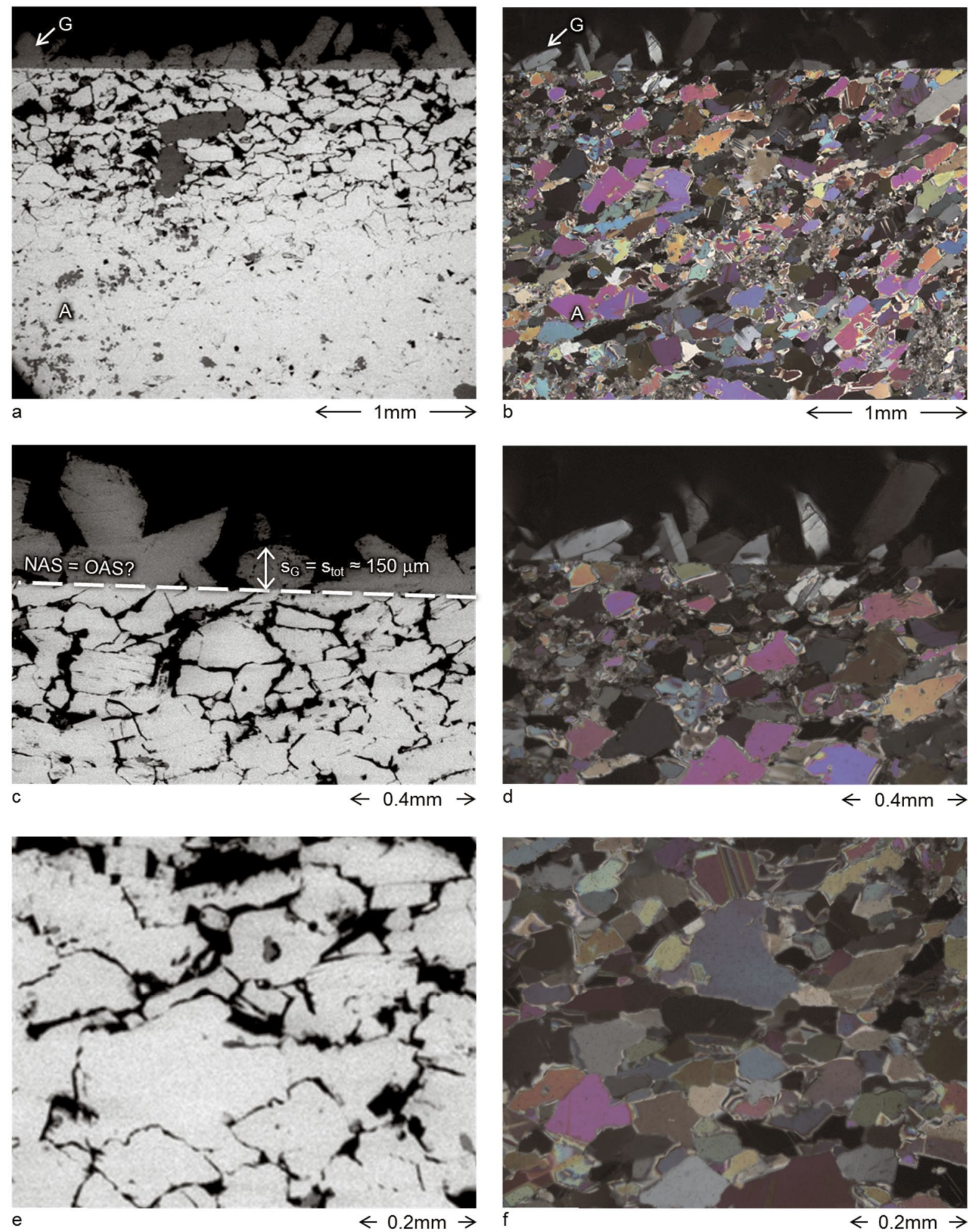

Figure 5-11: $\quad B S E(a, c, e)$ and thin section $(b, d, f)$ images of the specimen Bex $1 f$. 


\section{b.iii. $B B$ 1e $\left(20^{\circ} \mathrm{C}\right)$}

The investigated cross-section of specimen BB1e (tested at $20^{\circ} \mathrm{C}$ ) is shown in Figure 5-12. Already from the photograph it can be seen that the specimen was cracked and gypsum appeared to precipitate within the cracks. These cracks were very well visible in the BSE images of SEM (see the overview in Figure 5-13 and the images shown in Figure 5-14). In some parts the gypsum has strongly penetrated the anhydrite (as can be seen, e.g., in Figure 5-14b, c and e), whereas the "new" anhydrite surface ("NAS") is not distinguishable in all cases and it is not clear, how far the gypsum precipitated within the specimen. This can also be seen in the thin section images in Figure 5-14d and f: The gypsum (in grey scales) penetrated the (more colorful) anhydrite.

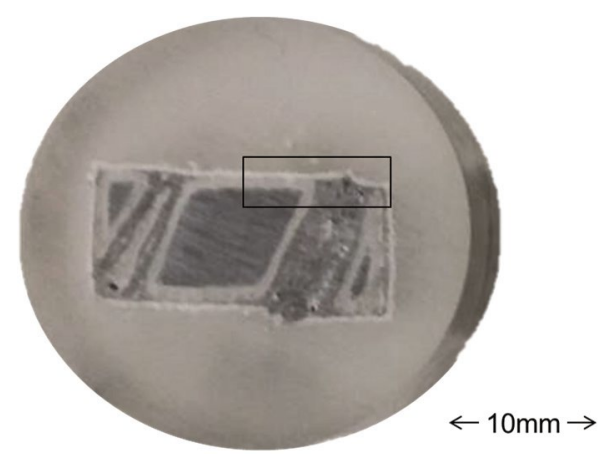

Figure 5-12: Photograph of the specimen BB 1e after embedding in epoxy and sawing. (The rectangle roughly indicates the area of Figure 5-13.)

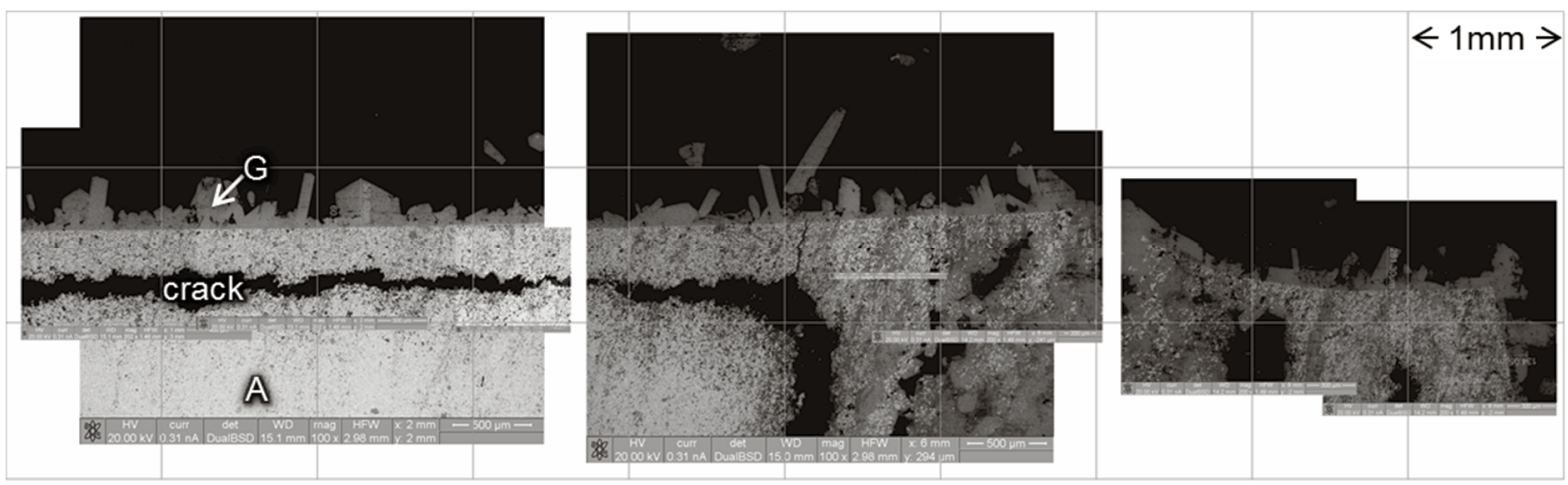

Figure 5-13: $\quad$ Large-scale SEM image (BSE) of the specimen BB 1e (multiple images pasted together). 

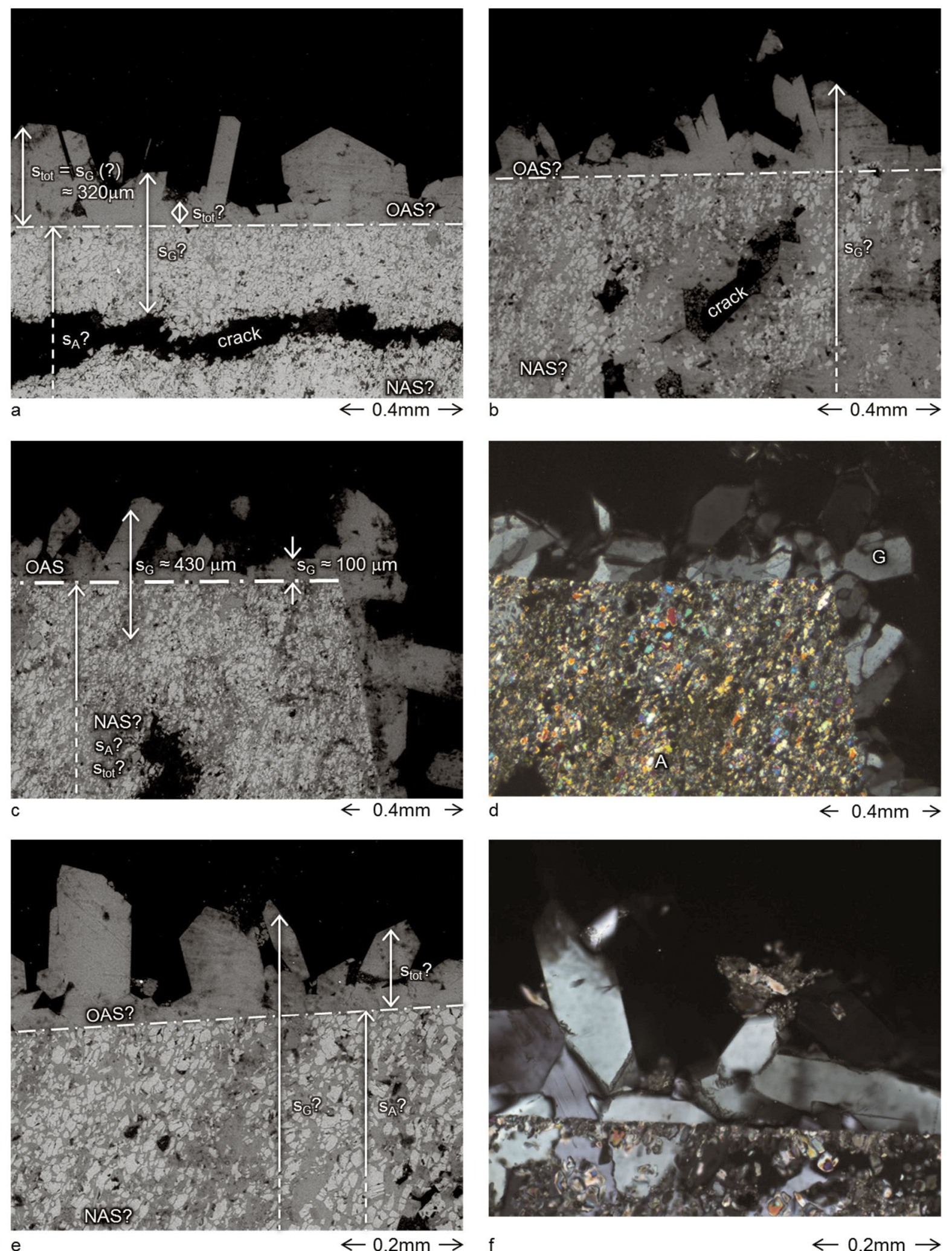

Figure 5-14: $\quad B S E(a, b, c, e)$ and thin section $(d, f)$ images of the specimen BB $1 e$. 


\section{b.iv. $B B 1 f\left(20^{\circ} \mathrm{C}\right)$}

Figure 5-15 presents the cross-section of the specimen BB1f, which contains clear cracks (which was already indicated in Figure 5-3). Large scale "overview" images of three areas of the specimen BB 1f (see Figure 5-15b) is shown in Figure 5-16 while Figure 5-17 shows some areas in more detail (Figure 5-17b corresponds to the bottom left area of image 2 in Figure 5-16). Here too, one can see a clear layer of gypsum, whereas the area between the gypsum and the anhydrite appears very porous.

Figure 5-16(1) shows an area, where the anhydrite was clearly cracked (the cracks can also be seen in the SEM-sample in Figure 5-15). The rather large cracks were originally hairline fissures, which seem to have been filled with gypsum in most cases, as indicated by the arrows in Figure 5-17a. It appears that the gypsum crystals expanded the cracks further.

(a)

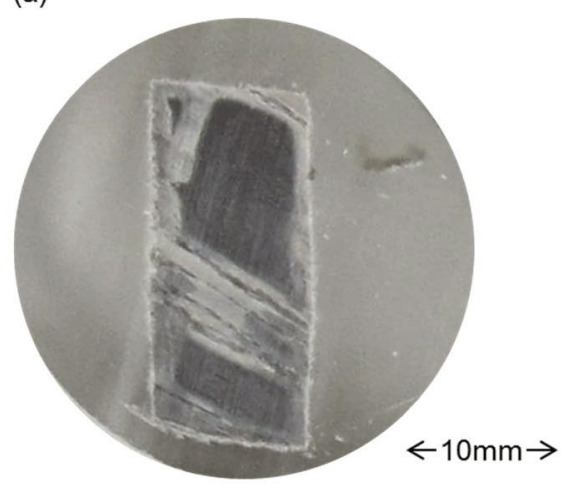

(b)

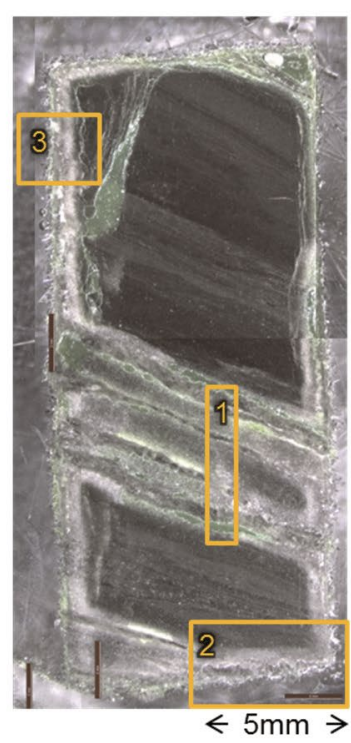

Figure 5-15: (a) Specimen BB1f, embedded in epoxy and cut; (b) Image of specimen BB1f obtained with optical microscope (multiple images pasted together); the rectangles 1-3 indicate the areas of the BSE images in Figure 5-16. 


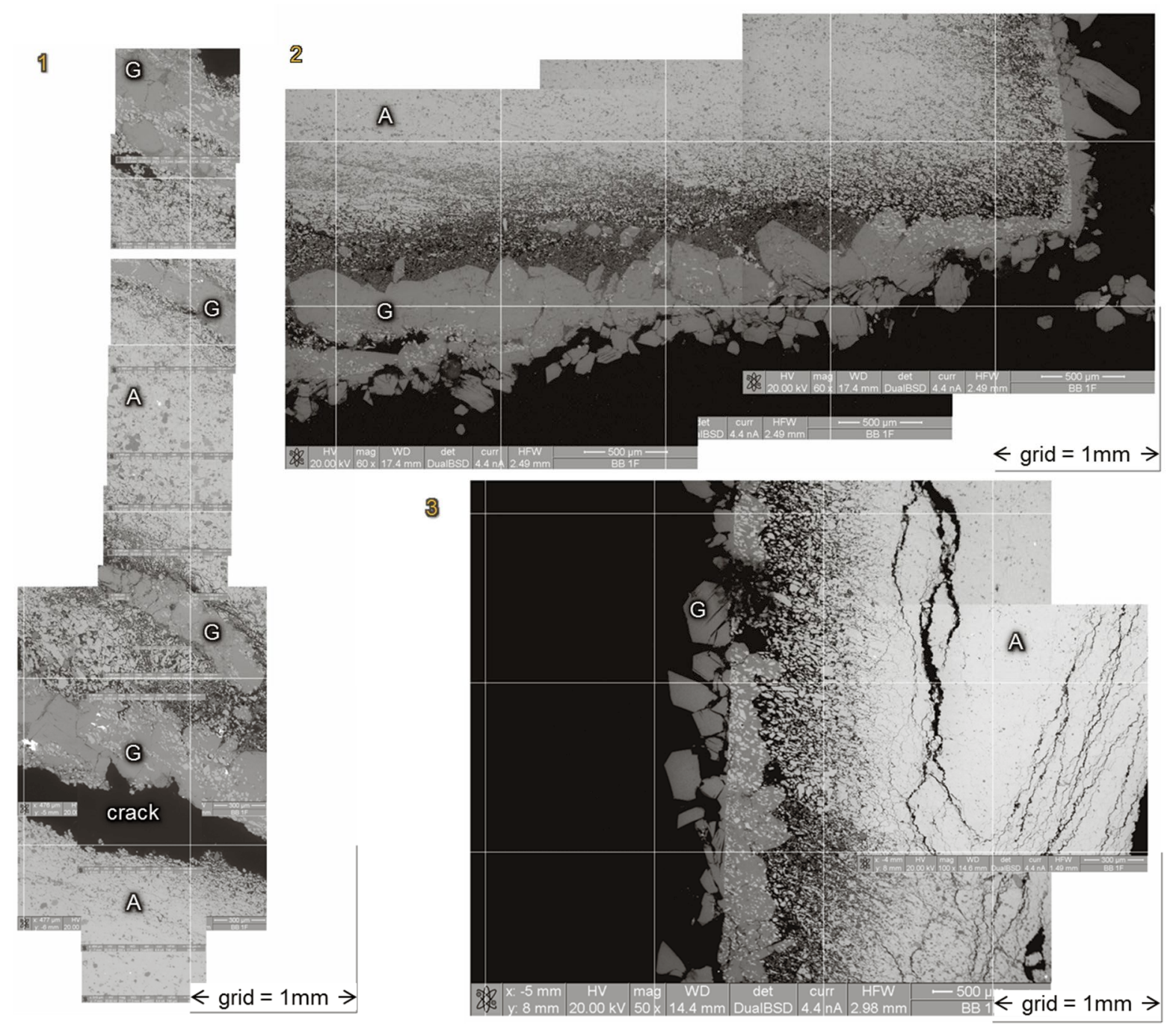

Figure 5-16: Large-scale SEM images (BSE) of three areas (see Figure 5-15) of the specimen BB $1 f$ (multiple images pasted together). 

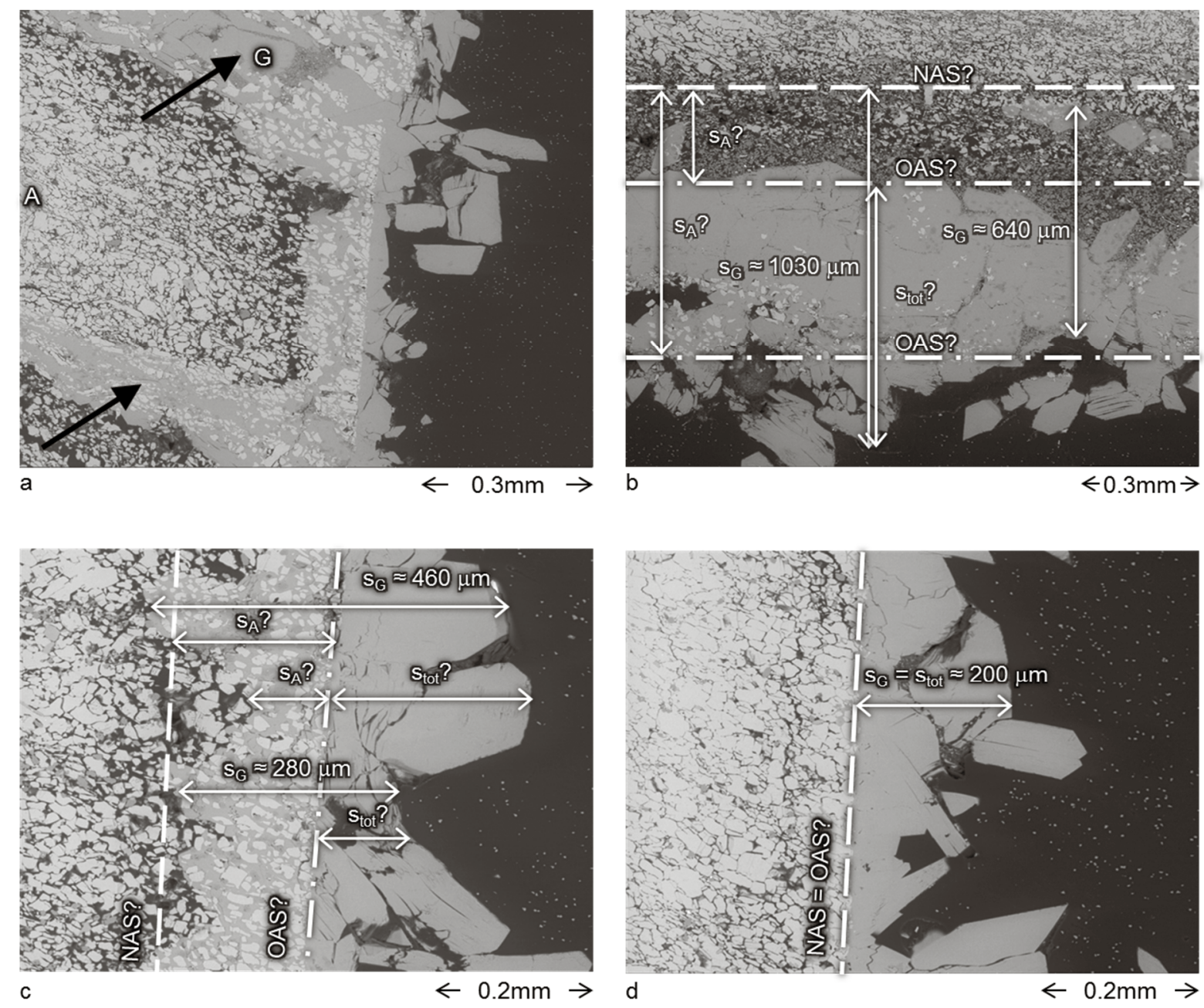

Figure 5-17: Small-scale SEM images (BSE) of the specimen BB 1f. (The scale is indicated in the bottom right corner of each SEM image.) In image (a) gypsum precipitation in cracks is indicated by arrows.

\subsubsection{Theoretical prediction}

The theoretical change of the thicknesses from the original anhydrite surface (OAS) to the new anhydrite surface (NAS) as well as the gypsum coating was calculated by using the kinetic model of Serafeimidis and Anagnostou (2013a), as mentioned in Chapter 5.2. The model assumes an even retreat of the anhydrite surface and a clearly defined gypsum layer, both with constant porosities. The change in thicknesses $s_{A}$ and $s_{G}$ were thus calculated using Equations (5-1) and $(5$ - 2) while considering the geometries from the experiments.

$$
\begin{gathered}
\frac{d s_{A}}{d t}=-\frac{k_{A}}{\rho_{A}} \cdot \min \left[\left(\frac{c_{e q, A}-c}{c_{e q, A}}\right)^{\delta_{A}} ; n_{G} \cdot T_{G} \cdot \frac{\tilde{k}}{k_{A}} \cdot \frac{c_{e q, A^{*}}}{s_{G}} \cdot\left(\frac{c_{e q, A}-c}{c_{e q, A}}\right)\right] \\
\frac{d s_{G}}{d t}=\frac{k_{G}}{\rho_{G}}\left(\frac{c-c_{e q, G}}{c_{e q, G}}\right)^{\delta_{G}} \cdot \frac{1}{1-n_{G}}
\end{gathered}
$$

These rates are coupled via the concentration in the solution $c$ which depends on the initial concentration, the densities of anhydrite and gypsum, the current amount of anhydrite and gypsum as well as the water content in the system (see also Chapter 2.4). Note, that the rates at which these thicknesses change depend on whether the rate of anhydrite dissolution (i.e., the kinetics, 
first term in the bracket of Equation (5 - 1)) or the diffusive flow of the dissolving ions through the gypsum layer (second term in the bracket of Equation $(5-1)$ ) is the limiting mechanism. When anhydrite begins to dissolve the former will be the limiting mechanism; after a while, when the ions need to diffuse through a formed gypsum layer, the latter will be the limiting mechanism.

The thicknesses of the remaining anhydrite core as well as the total thickness of the specimen amount to:

$$
\begin{gathered}
S_{A}=S_{A 0}+2 \cdot s_{A} \\
S_{G, A}=S_{A 0}+2 \cdot s_{A}+2 \cdot s_{G}
\end{gathered}
$$

The definitions and assumptions for the parameters used in Equations (5 - 1) and (5 - 2) are listed in Table 5-3 and were generally taken from Serafeimidis and Anagnostou (2013a), with the following additions:

- The values for the reaction rate constants at $5{ }^{\circ} \mathrm{C}$ were assumed based on an extrapolation via the Arrhenius equation (cf., e.g., Atkins and De Paula, 2006) from experimental data found in the literature (Kontrec et al., 2002, Bildstein et al., 2001, Barton and Wilde, 1971, James and Lupton, 1978, Liu and Nancollas, 1970, see Appendix C). It needs to be noted, that the experimental data at the temperature ranges of interest in the present case are scarce and vary strongly in the literature (Serafeimidis and Anagnostou, 2013a, and Serafeimidis, 2014). Therefore, the reaction rate constants at $5{ }^{\circ} \mathrm{C}$ are to be seen as rough estimates, since the parameters for the Arrhenius equation also need to be determined based on experimental results and no consistent set of parameters was found that fits the various experimental data.

- The orders of reaction ( $\delta_{A}$ and $\delta_{G}$ ) are assumed to be independent of the temperature and are thus taken equal to two, cf. Chapter 2.4 (e.g., Kontrec et al., 2002, investigated the reaction rates at a temperature range of $10{ }^{\circ} \mathrm{C}-40{ }^{\circ} \mathrm{C}$ experimentally and have found that the kinetics of anhydrite dissolution and gypsum precipitation correspond to a second order law).

- The equilibrium concentrations ( $c_{e q, A}$ and $c_{e q, G}$, see Figure 2-1) were calculated according to Serafeimidis and Anagnostou (2013b and 2014b) for the prevailing conditions in the laboratory (i.e., temperatures according to Table 5-2 and atmospheric pressure, see also Chapter 2.3.1 and Appendix A).

- The porosity of the sealing gypsum layer is assumed to be $n_{G}=0.1$. This value was chosen arbitrarily, since it was not possible to reliably estimate the porosity from the microscopic images, due to the fact that the gypsum and void areas vary strongly in the different images shown in Chapter 5.3.2. However, the gypsum layer is assumed to have a far higher porosity than the anhydrite (porosimetry on the Bex and Bözberg specimens revealed a porosity of about $0.005-0.007$ ). The influence of the porosity of the gypsum layer on the hydration time of anhydrite is discussed in Serafeimidis and Anagnostou (2013a) and Serafeimidis (2014).

- The diffusion coefficient at $5^{\circ} \mathrm{C}\left(\tilde{k}=6.4 \cdot 10^{-10} \mathrm{~m}^{2} / \mathrm{s}\right)$ is taken according to Jeschke (2002).

The predictions for the development of $s_{A}, s_{G}$ and $s_{t o t}$ for $5{ }^{\circ} \mathrm{C}$ and $20^{\circ} \mathrm{C}$ are shown in Figure $5-18$. The times of extraction of the four experimental specimens mentioned previously are indicated by the red lines. 
As can be seen from Equations (5 - 1) the rate at which $s_{A}$ changes will increase with a greater undersaturation and, accordingly, $s_{G}$ grows faster with a greater supersaturation based on Equation (5 - 2), which is the case at $5^{\circ} \mathrm{C}$ as can be seen in Figure 2-1. On the other hand, the rates increase with higher reaction rate constants, which is the case at $20^{\circ} \mathrm{C}$. With the set of parameters assumed in Table 5-3, these two factors appear to be nearly compensating each other, as can be seen in Figure 5-18. Thus, the influence of the temperature seems negligible in this case. Nonetheless, it was seen that concerning the condition in Equation $(5-1)$, at $20^{\circ} \mathrm{C}$ the diffusive flow will become the governing mechanisms faster than at $5^{\circ} \mathrm{C}$.

Table 5-3: $\quad$ Input parameters and assumptions for the prediction of $s_{A}, s_{G}$ and $s_{\text {tot }}$.

\begin{tabular}{|c|c|c|c|c|}
\hline Input parameter & Symbol & Unit & $5^{\circ} \mathrm{C}$ & $20^{\circ} \mathrm{C}$ \\
\hline \multicolumn{5}{|l|}{ Reaction rate constants } \\
\hline Anhydrite & $k_{A}$ & {$\left[\mathrm{~kg} / \mathrm{m}^{2} / \mathrm{s}\right]$} & $1.8 \cdot 10^{-6}$ & $3 \cdot 10^{-6}$ \\
\hline Gypsum & $k_{G}$ & {$\left[\mathrm{~kg} / \mathrm{m}^{2} / \mathrm{s}\right]$} & $9 \cdot 10^{-8}$ & $5 \cdot 10^{-7}$ \\
\hline \multicolumn{5}{|l|}{ Orders of reaction } \\
\hline Anhydrite dissolution & $\delta_{A}$ & {$[-]$} & 2 & 2 \\
\hline Gypsum precipitation & $\delta_{G}$ & {$[-]$} & 2 & 2 \\
\hline Tortuosity & $T_{G}$ & {$[-]$} & 0.66 & 0.66 \\
\hline Diffusion coefficient & $\tilde{k}$ & {$\left[\mathrm{~m}^{2} / \mathrm{s}\right]$} & $6.4 \cdot 10^{-10}$ & $8 \cdot 10^{-10}$ \\
\hline \multicolumn{5}{|l|}{ Equilibrium concentrations } \\
\hline \multirow[t]{2}{*}{ Anhydrite } & $c_{e q, A}$ & {$\left[\mathrm{~mol} / \mathrm{m}^{3}\right]$} & 29.7 & 23.3 \\
\hline & $c_{e q, A^{*}}$ & {$\left[\mathrm{~kg} / \mathrm{m}^{3}\right]$} & 4.05 & 3.16 \\
\hline Gypsum & $c_{e q, G}$ & {$\left[\mathrm{~mol} / \mathrm{m}^{3}\right]$} & 15.5 & 15.6 \\
\hline Porosity of the gypsum layer & $n_{G}$ & {$[-]$} & 0.1 & 0.1 \\
\hline
\end{tabular}

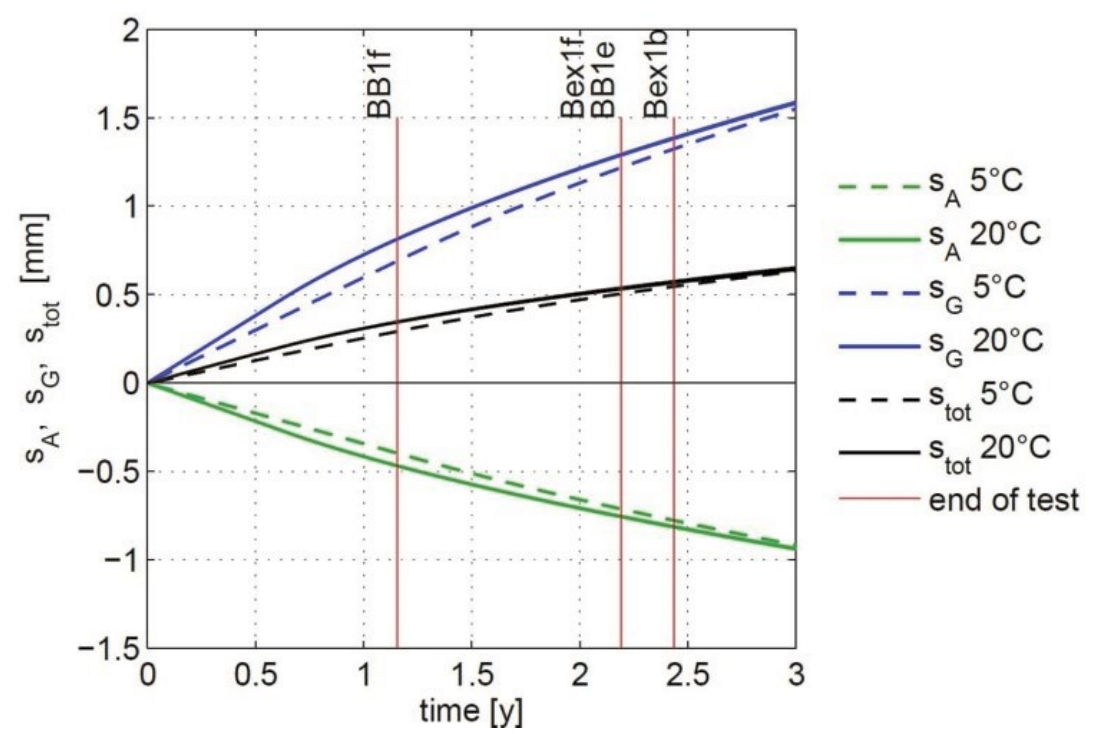

Figure 5-18: Prediction of the change in thicknesses $s_{A}, s_{G}$ and $s_{\text {tot }}$ over time. 


\subsection{Comparison and discussion}

The measurements $\left(s_{A}, s_{G}\right.$ and $\left.s_{t o t}\right)$ obtained from the mass change of the specimens, TGA and SEM are illustrated in Figure 5-19 together with the respective predicted values (solid lines). It appears that the measurements taken on specimens from Bex are generally smaller than their predicted values, compared to the Bözberg specimens. This could also be seen in the SEM images (Figure 5-8 and Figure 5-11), where the anhydrite surface did not seem to be "penetrated" by the gypsum in the case of the Bex specimens. It is conjectured that this is strongly dependent on the texture of the rock, since the Bex specimens appeared denser and with fewer fissures than the Bözberg specimens prior to the tests (Figure 5-5). The fissures allow the water to infiltrate further into the specimen and thus facilitate gypsum precipitation at a greater depth instead of only along the anhydrite surface. Considering test duration, there is a clear difference when comparing the Bözberg specimens BB 1e (2.2 years) and BB $1 \mathrm{f}$ (1.2 years). Based on the change in mass and the TGA results, clearly more gypsum has precipitated after 2.2 years. However, when comparing their BSE images (Figure 5-14c vs. Figure 5-17c), the sizes of the gypsum crystals (or "layers") were not obviously larger after the longer duration (BB 1e vs. BB 1f), as was expected. Furthermore, the porosity of the gypsum layers and the anhydrite below appeared very irregular in the microscopic images, whereas the prediction assumes a constant porosity, as described in the previous chapter.

The experiments revealed an entirely different shape of gypsum precipitation at $5{ }^{\circ} \mathrm{C}$ than at $20{ }^{\circ} \mathrm{C}$ ("fleece" in the top row of Figure 5-4 vs. needles in the bottom three rows). This may be due to the fact that, for one, the diffusion rate is smaller at lower temperatures, and, that the concentration gradient $\left(c-c_{e q, G}\right)$ is higher at lower temperatures (since $c_{e q, A}$ is higher at lower temperatures and may thus raise the value of $c$ ). The diffusion rate is dependent on the diffusion coefficient $D\left[\mathrm{~m}^{2} / \mathrm{s}\right]$, which can be described with the Stokes-Einstein equation:

$$
D=\frac{k_{B} T}{6 \pi \eta R_{0}}
$$

where $k_{B}, T, \eta, R_{0}$ are the Boltzmann constant $[\mathrm{J} / \mathrm{K}]$, the temperature $[\mathrm{K}]$, the dynamic viscosity $\left[\mathrm{N} \cdot \mathrm{s} \cdot \mathrm{m}^{-2}\right]$ of the solvent and the radius of the diffusing particle $[\mathrm{m}]$. Thus, the diffusion coefficient is 1.6 times smaller at $5{ }^{\circ} \mathrm{C}$ than at $20^{\circ} \mathrm{C}$ and, consequently, the diffusion rate is slower at lower temperatures.

When regarding the pictures in Figure 5-4, the gypsum appeared to have precipitated preferentially in the lower areas of the specimens compared to the upper areas. Hence, the dissolved ions seem to sink slightly towards the bottom of the specimens due to gravity and thus increase the ion concentration locally, leading to preferential gypsum precipitation in the lower areas.

Furthermore, the SEM images of the cross sections of the Bözberg specimens gave a first impression of the complexity of the sealing process: Due to the receding anhydrite border a new pore space develops, which gets (at least) partly filled by gypsum. However, this border is usually not as clearly defined as anticipated. It proves to be difficult to quantify the effect of sealing in terms of clearly defined thicknesses $s_{A}, s_{G}$ and $s_{t o t}$, upon which the kinetic model is founded. This becomes obvious when regarding the scatter of the measured values ( $x$ in Figure 5-19). It also needs to be noted, that the model assumes constant porosities of the anhydrite and of the gypsum, which could not be confirmed in the experiments. 

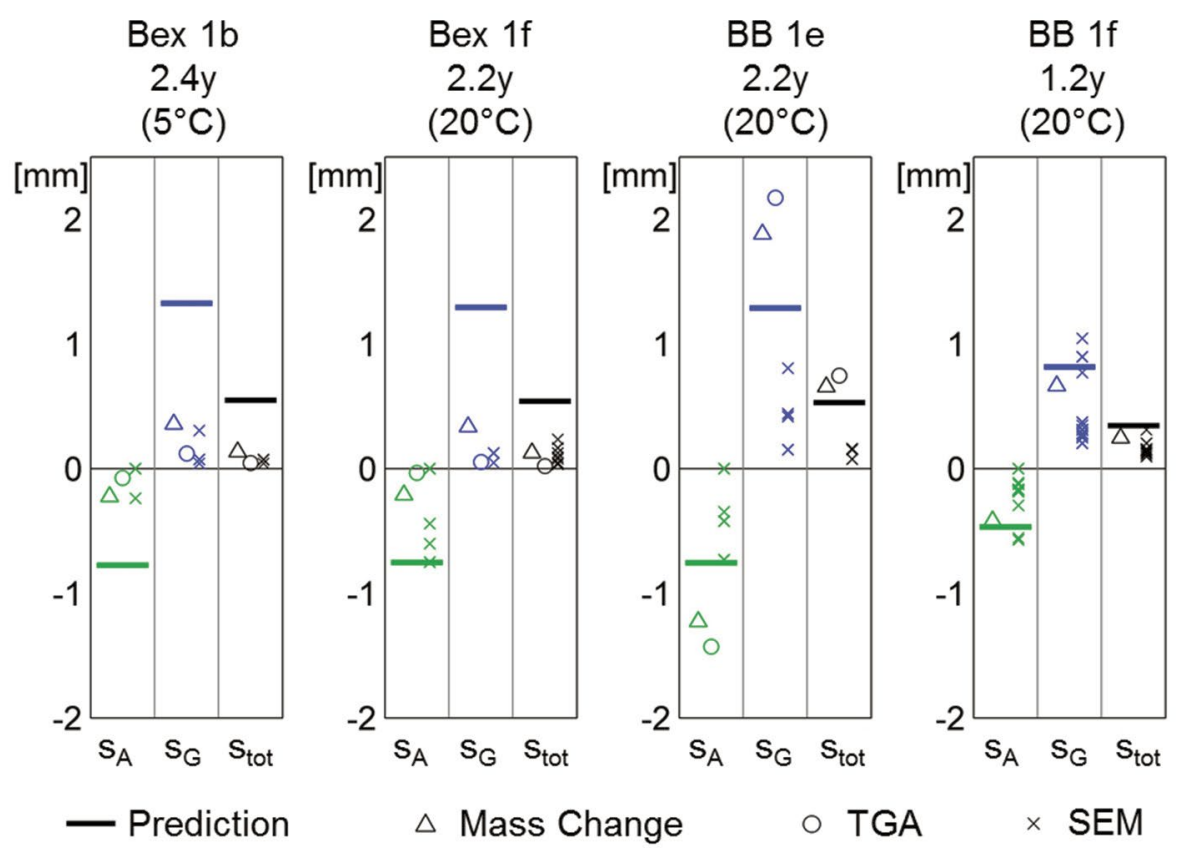

Figure 5-19: Comparison between prediction and measurements (obtained via change in dry mass, TGA, and SEM images) of $s_{A}$ (green), $s_{G}$ (blue) and $s_{\text {tot }}$ (black) for each specimen.

\subsection{Conclusions and outlook}

Although the development of the anhydrite and gypsum surfaces of the nearly pure anhydritic rock specimens in water occurred unevenly, whereas in some cases the change in anhydrite surface could not even be observed, the gathered values for the thicknesses (determined via backcalculation from the specimen masses, TGA and optically by measuring the gypsum layer in BSE images) lie reasonably well within the predicted values.

It was seen that gypsum precipitates in slightly different shapes, depending on the testing temperature (i.e., different sizes and clusters of needles), and not in the form of a clearly defined layer, as is the basis for the theoretical prediction. Furthermore, the texture of the anhydritic rock appeared to influence the spatial precipitation of gypsum, i.e., in some cases gypsum visibly precipitated within the pore space or cracks (Bözberg specimens), whereas in other cases (Bex specimens) gypsum was only found along the outside of the anhydrite surface in the shape of needles. It needs to be stated however, that the growth of gypsum needles was completely unhindered.

In order to quantify the thicknesses with less scatter, the free growth of the gypsum needles perpendicular to the anhydrite surface should be restricted, so that the gypsum grows more as a homogenous layer, which is expected to occur in nature and corresponds to the model assumptions. This could be enforced by embedding the anhydrite so that some counter pressure acts on its surface. For this reason, two further specimens were clamped between two glass platelets by a rubber band and inserted in water (ongoing tests). Furthermore, more data needs to be collected in order to compare the behavior of the specimens better with the prediction. For example, cross sections at different levels of the specimens would need to be investigated (as mentioned previously, the gypsum seemed to precipitate mainly in the lower area of the specimens) and multiple specimens would need to be examined (for instance, further specimens tested at $5{ }^{\circ} \mathrm{C}$ ). This, however, requires a time consuming, systematic SEM investigation program of multiple specimens at various points in time which could not be done within the scope of this work. 


\title{
PART III \\ COUPLED CHEMO-MECHANICAL PROCESSES (C-M)
}

\begin{abstract}
One of the main knowledge gaps concerning swelling of anhydritic rocks is the unknown swelling law, i.e., the constitutive relationship between the mass changes of anhydrite and gypsum due to AGT and the resulting swelling pressure and swelling strain.

Part III presents a constitutive model which connects these factors, as well as conceptual models which describe the individual chemical processes and their possible influence on stresses and strains for a variety of material structures. It gives an overview of how these individual influences could in principle be determined with experiments. A first ever systematic experimental campaign is featured which was conducted to obtain specific results for the constitutive relationship between the mass change of anhydrite due to AGT and the resulting stresses and strains. The experiments were performed under a variety of clearly defined boundary conditions where some processes that may occur simultaneously in nature and may influence the swelling behavior were eliminated (such as swelling of clay or transport processes of the ions in the pore water). This was controlled by using artificial specimens of highly compacted powdered anhydrite and other aggregates.
\end{abstract}

With this material it was seen that a semilogarithmic relationship exists between the maximal swelling strains and the applied stresses acting on the specimen, and a maximal swelling stress was found. Furthermore, the stresses and / or strains developed nearly linearly with decreasing mass of anhydrite in the specimens in most cases. 



\section{Introduction}

\subsection{Knowledge gap}

In anhydritic claystones, two main swelling processes can occur simultaneously upon watering: "physical swelling" due to osmotic swelling of clay and reduction of negative pore pressures, i.e., an inverse consolidation which is henceforth referred to as "mechanical swelling", and swelling due to AGT (referred to here as "chemical swelling"). While physical swelling of the clay is well understood, the relationship between stresses and strains due to chemical swelling represents a particularly important knowledge gap regarding the swelling behavior of anhydritic rock. An understanding of the coupled chemo-mechanical processes, i.e., the development of stresses and strains during AGT and the determination of a "swelling law" is highly important for the conceptual design of tunnels through anhydritic rock. Knowledge on the stress-strain relationship enables the designing engineer to decide whether the resistance principle or the yielding principle is more adequate (cf. Chapter 1.2 and, e.g., Amstad and Kovári, 2001).

The establishment of a chemo-mechanical model which can take account of chemical reactions (anhydrite dissolution, gypsum precipitation, or both reactions simultaneously, cf. Chapter 2.2) and also stresses and strains is therefore of interest. Only few approaches for a chemo-mechanical model are found in literature, the so far most elaborate model being that described in the research of Oldecop and Alonso (2012), Ramon and Alonso (2013) and Ramon (2014), where they relate the strains to the mass change of gypsum via a - so far unknown - bulking parameter (see Equation (1 - 1) in Chapter 1.4.8).

The reason for the deficiency of chemo-mechanical models is that no systematic, long-term experiments under clearly defined mechanical boundary conditions exist which would deliver a databasis for the development of such a model. This is due to the fact that too many indeterminate factors exist, which make the establishment of such a model difficult, such as heterogeneity, presence of clay and especially the very slow swelling process of anhydritic rock. Furthermore, the development of stresses and strains is so far not brought into relation with the mass changes of anhydrite and gypsum (see Chapter 1.4). This is essential to determine with experiments, since it is not possible to reliably calculate the strains solely due to the volume changes of anhydrite and gypsum on a theoretical basis (i.e., 61\%, cf. Chapter 2.2.3), but the changes in pore volume are not known and depend on the acting stress.

So far, no systematic experimental research was found which investigates the developing swelling strains and stresses occurring solely due to anhydrite dissolution and gypsum precipitation (i.e., due to chemical swelling), since in most cases swelling of clay occurred simultaneously and was not distinguished from chemical swelling.

\subsection{Aim and overview of Part III}

Part III of this thesis presents the bulk of the work undertaken. It aims at establishing a relationship between the mass changes of anhydrite to gypsum and the resulting swelling stresses and strains by means of an extensive, systematic experimental campaign.

First, a constitutive model for the description of the chemo-mechanical couplings is introduced, where equations are formulated which combine the chemical processes gypsum precipitation and anhydrite dissolution and the stresses and strains induced by the chemical reactions (Chapter 7.1). 
Next (in Chapter 7.2), the possible mechanical responses due to the chemical reactions are discussed with the help of conceptual models. As indicated by the overview in Figure 6-1, this influence of the chemical reactions on the mechanical responses $(C \rightarrow M)$ is merely one branch of the entire hydraulic-mechanical-chemical (HMC) coupled processes which the topic of swelling of anhydritic rocks contains. Factors concerning the other branches, e.g., the influence of advection on the concentration and thus on the mass changes of anhydrite and gypsum $(\mathrm{H} \rightarrow \mathrm{C})$, are qualitatively discussed in the N2 diagram in Appendix B and are not investigated further in this work.

As shown in the overview in Figure 6-1, the influences of the chemical reactions on the mechanical responses are discussed for four different types of rock- / or specimen-materials (for example: the influence of anhydrite dissolution and gypsum precipitation on stresses for a rock with fissures). In Chapter 7.3 (as well as in the Appendix E) thought experiments are described with which these couplings could be investigated.

The focus of this work lies, however, on a small aspect of the entire hydraulic-mechanical-chemical coupled processes (red path in the "HMC-tree" in Figure 6-1): the influence of both chemical reactions (i.e., simultaneous anhydrite dissolution and gypsum precipitation) on the occurring stresses and strains for a fine granular homogeneous material. Based on this, experimental investigations were performed which are presented and discussed in Chapter 8.

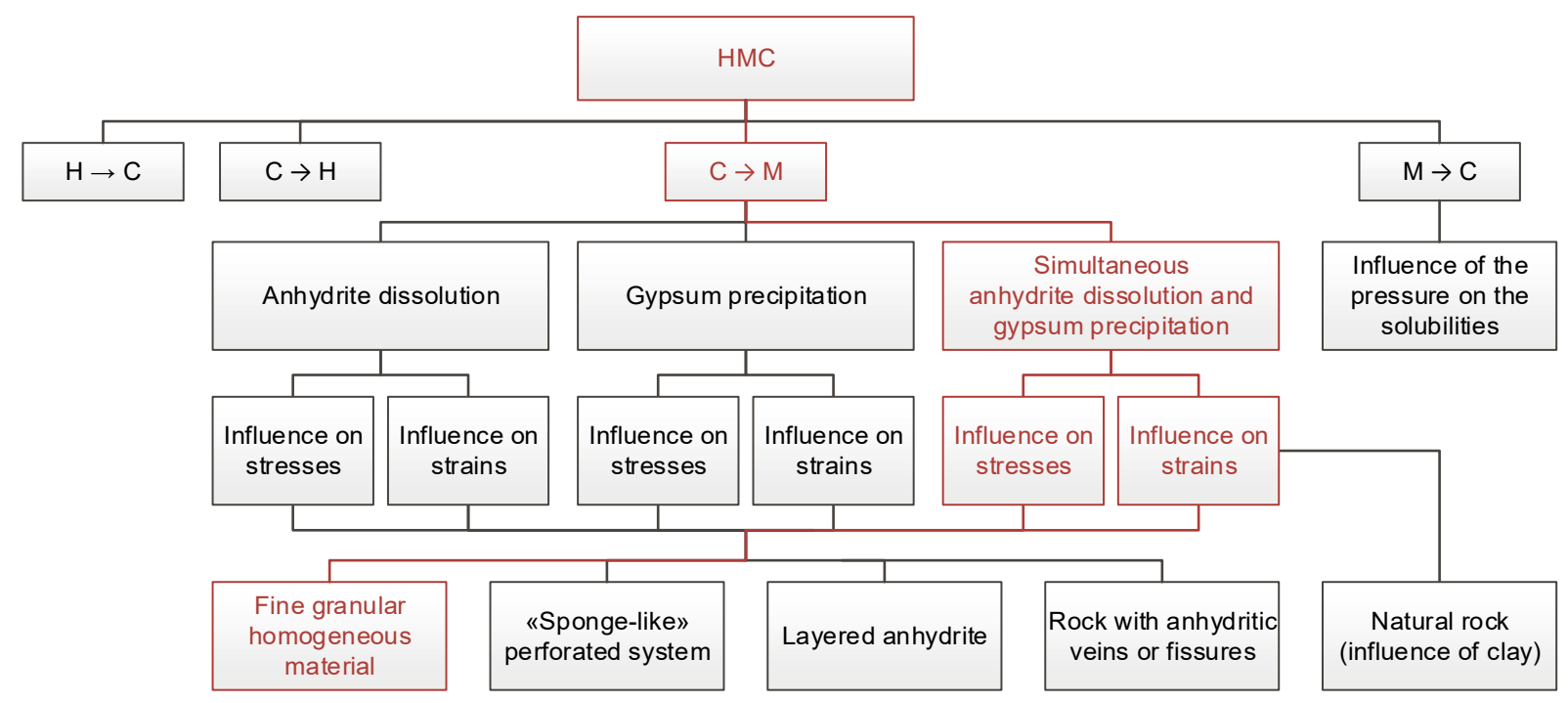

Figure 6-1: Overview HMC-tree: This work focuses on the influence of chemical on mechanical processes, specifically of the influence of simultaneous anhydrite dissolution and gypsum precipitation on the stresses and strains for granular material (red path). 


\section{Constitutive and conceptual models for the description of the C-M coupling}

\subsection{Constitutive model}

Due to AGT strains may occur without any changes of the stresses, or, vice versa, stresses can develop while strains are prohibited. Therefore, the constitutive chemo-mechanical model must consider that stresses or strains may change while the other is held constant. This is possible with the general formulation

$$
\dot{\sigma}^{\prime}{ }_{i j}=D_{i j k l} \cdot\left(\dot{\varepsilon}_{k l}-\dot{\varepsilon}_{k l}^{A G T}\right)
$$

where the effective stress increments $\dot{\sigma}^{\prime}{ }_{i j}$ are defined as usually in geotechnics (Terzaghi, 1943); $D_{i j k l}$ denotes the incremental stiffness tensor and $\dot{\varepsilon}_{k l}^{A G T}$ are the chemically induced strain increments (cf., e.g., Hueckel, 1997, Bary, 2008, Cheng, 2016).

Equation (7 - 1) allows to map the development of strains under constant stress $\left(\dot{\varepsilon}_{k l}=\dot{\varepsilon}_{k l}^{A G T}\right.$ if $\left.\dot{\sigma}_{i j}^{\prime}=0\right)$ or changes in the stress state under constant strains $\left(\dot{\sigma}_{i j}^{\prime}=-D_{i j k l} \cdot \dot{\boldsymbol{\varepsilon}}_{k l}^{A G T}\right.$ if $\left.\dot{\boldsymbol{\varepsilon}}_{k l}=0\right)$.

In literature (e.g., Coussy, 2006) alternative formulations can be found, expressing the effective stress as a function of the strains and of an internal stress term that accounts for the crystallization pressure $\dot{p}_{k l}^{C}$, i.e. (in a simplified form):

$$
\dot{\sigma}_{i j}^{\prime}=D_{i j k l} \cdot \dot{\varepsilon}_{k l}-\dot{p}_{k l}^{C}
$$

Formulations $(7-1)$ and $(7-2)$ are equivalent as $\dot{\boldsymbol{\varepsilon}}_{k l}^{A G T}$ can be set equal to $\boldsymbol{C}_{i j k l} \dot{\boldsymbol{p}}_{k l}^{C}$, where $\boldsymbol{C}_{i j k l}$ denotes the inverse of the stiffness tensor. However, as opposed to situations where the stress development especially due to crystallization pressure is of interest (e.g., in stiff matrices such as stones or cement, see for example Scherer, 2002, Flatt, 2002) a primary interest here is to determine the strains occurring due to AGT. Therefore, Equation $(7-1)$ was deemed more convenient in this respect, as it can be used directly for the evaluation of experiments, where in most cases the measurable quantities are macroscopic strains, $\dot{\varepsilon}_{k l}$. Consequently, the crystallization pressure is not explicitly determined here, but can be considered as a cause for the strains due to AGT. The chemically induced strains due to AGT are made up of the change in solid volume $\left(\dot{\varepsilon}_{k l}^{A V_{A, G}}\right)$ and the change in pore volume $\left(\dot{\varepsilon}_{k l}^{P}\right)$ :

$$
\dot{\varepsilon}_{k l}^{A G T}=\dot{\varepsilon}_{k l}^{A V_{A, G}}+\dot{\varepsilon}_{k l}^{P}
$$

These strains are, furthermore, dependent on the change in the masses of anhydrite and gypsum:

$$
\dot{\boldsymbol{\varepsilon}}_{k l}^{A G T}=\frac{\boldsymbol{a}_{\boldsymbol{k} l}}{\rho_{A}} \cdot \dot{m}_{A}+\frac{\boldsymbol{g}_{\boldsymbol{k l}}}{\rho_{G}} \cdot \dot{m}_{G}
$$

whereas $\boldsymbol{a}_{k l}$ and $\boldsymbol{g}_{k l}$ are two material-specific tensors and $\dot{m}_{A}$ and $\dot{m}_{G}$ are the rates of mass change of anhydrite and gypsum per unit volume (cf. Equation (2 - 11)).

The situation is now simplified to the axisymmetric case, where the axial and radial stresses ( $\sigma_{a x}$ and $\left.\sigma_{r a d}\right)$ and strains ( $\varepsilon_{a x}$ and $\varepsilon_{r a d}$ ) will be regarded (see Figure 7-1). This simplification is only possible if the investigated material exhibits an isotropic or a transversal isotropic behavior (e.g., a homogenous mixture of granular material or rock layered perpendicularly to the axial direction). 
Furthermore, the simplest model for the stiffness tensor $\boldsymbol{D}_{i j k l}$ is considered here, i.e., the elasticity tensor.

For axisymmetric conditions, the relationships between effective stresses and elastic strains (cf. Equation (7 - 1)) can be determined based on Hooke's linear-elastic law (see Appendix D):

$$
\left[\begin{array}{c}
\sigma_{a x}^{\prime}-\sigma_{a x, 0}^{\prime} \\
\sigma_{r a d}^{\prime}-\sigma_{r a d, 0}^{\prime}
\end{array}\right]=\frac{E}{(1+v)(1-2 v)}\left[\begin{array}{cc}
(1-v) & 2 v \\
v & 1
\end{array}\right]\left[\begin{array}{c}
\varepsilon_{a x}-\varepsilon_{a x}^{A G T} \\
\varepsilon_{r a d}-\varepsilon_{r a d}^{A G T}
\end{array}\right]
$$

Equation (7 - 6) shows the derivatives of Equation (7 - 5) with respect to time $(t)$ while substituting the chemically induced strains according to Equation (7 - 4) and under the simplifying assumption that the material parameters $E$ (Young's modulus) and $v$ (Poisson ratio) remain constant over time. In reality the stiffness parameters may, however, not remain constant during swelling, as was seen by Pimentel (1996), who observed the change in rock properties (i.e., the stiffness and the strength of the rock) during swelling of purely argillaceous claystones.

$$
\left[\begin{array}{c}
\dot{\sigma}_{a x}^{\prime} \\
\dot{\sigma}_{r a d}^{\prime}
\end{array}\right]=\frac{E}{(1+v)(1-2 v)}\left[\begin{array}{cc}
(1-v) & 2 v \\
v & 1
\end{array}\right]\left[\begin{array}{c}
\left(\begin{array}{c}
\dot{\varepsilon}_{a x}-\frac{a_{a x}}{\rho_{A}} \dot{m}_{A}-\frac{g_{a x}}{\rho_{G}} \dot{m}_{G}
\end{array}\right) \\
\left(\dot{\varepsilon}_{r a d}-\frac{a_{r a d}}{\rho_{A}} \dot{m}_{A}-\frac{g_{r a d}}{\rho_{G}} \dot{m}_{G}\right)
\end{array}\right]
$$

Evidently, Equation $(7-6)$ presents a system of two equations which contain four unknown parameters: $a_{a x}, a_{r a d}, g_{a x}$ and $g_{r a d}$. In order to simplify the system of equations, the assumption is made that all dissolved anhydrite gets used for gypsum precipitation according to Chapter 2.2.3. The chemically induced strains of Equation ( 7 - 5) are thus expressed via the change in the mass of anhydrite by using Equation $(2-10)$ and a single unknown material-specific tensor $\chi_{k l}$ :

$$
\dot{\boldsymbol{\varepsilon}}_{k l}^{A G T}=\left(\frac{\boldsymbol{a}_{k l}}{\rho_{A}}-\frac{\boldsymbol{g}_{k l}}{\rho_{G}} \cdot 1.265\right) \cdot \dot{m}_{A}=\frac{\left(\boldsymbol{a}_{k l}-\boldsymbol{g}_{k l} \cdot 1.61\right)}{\rho_{A}} \cdot \dot{m}_{A}=\frac{\chi_{k l}}{\rho_{A}} \cdot \dot{m}_{A}
$$

These strains are comparable to the strains occurring from precipitated gypsum as proposed by Oldecop and Alonso (2012) and Ramon and Alonso (2013), where they introduce a coefficient which indicates the bulking of the rock in a specific direction (see Equation (1 - 1)). Ramon et al. (2017) calculated the bulking parameter based on early results from this research project (see Huber et al., 2015) which are described in further detail in Chapter 8.5.

Therefore, Equation ( $7-6)$ can be simplified to a system of equations with solely two unknown parameters:

$$
\left[\begin{array}{c}
\dot{\sigma}_{a x}^{\prime} \\
\dot{\sigma}_{r a d}^{\prime}
\end{array}\right]=\frac{E}{(1+v)(1-2 v)}\left[\begin{array}{cc}
(1-v) & 2 v \\
v & 1
\end{array}\right]\left[\begin{array}{c}
\left(\dot{\varepsilon}_{a x}-\frac{\chi_{a x}}{\rho_{A}} \cdot \dot{m}_{A}\right) \\
\left(\dot{\varepsilon}_{r a d}-\frac{\chi_{r a d}}{\rho_{A}} \cdot \dot{m}_{A}\right)
\end{array}\right]
$$


Ultimately, we want to determine the unknown parameters $\chi_{a x}$ and $\chi_{\text {rad }}$ which are referred to hereafter as "coupling parameters". Thus, solving Equation (7 - 8) for the coupling parameters leads to:

$$
\left[\begin{array}{c}
\chi_{a x} \\
\chi_{\text {rad }}
\end{array}\right]=\frac{\rho_{A}}{\dot{m}_{A}} \cdot\left(\left[\begin{array}{c}
\dot{\varepsilon}_{a x} \\
\dot{\varepsilon}_{\text {rad }}
\end{array}\right]+\frac{1}{E}\left[\begin{array}{cc}
-1 & 2 v \\
v & (v-1)
\end{array}\right]\left[\begin{array}{c}
\dot{\sigma}_{a x}^{\prime} \\
\dot{\sigma}_{r a d}^{\prime}
\end{array}\right]\right)
$$

i.e., (by applying partial derivation):

$$
\left[\begin{array}{c}
\chi_{a x} \\
\chi_{r a d}
\end{array}\right]=\rho_{A} \cdot\left(\left[\begin{array}{c}
\frac{\partial \varepsilon_{a x}}{\partial m_{A}} \\
\frac{\partial \varepsilon_{r a d}}{\partial m_{A}}
\end{array}\right]+\frac{1}{E}\left[\begin{array}{cc}
-1 & 2 v \\
v & (v-1)
\end{array}\right]\left[\begin{array}{c}
\frac{\partial \sigma_{a x}^{\prime}}{\partial m_{A}} \\
\frac{\partial \sigma_{r a d}^{\prime}}{\partial m_{A}}
\end{array}\right]\right)
$$

In some cases (e.g., when the change in radial stresses is unknown in an oedometer test) it may not be possible to determine $\chi_{a x}$ and $\chi_{\text {rad }}$ individually, which is why a combined parameter $\chi$ is introduced:

$$
\chi=\chi_{a x}+\frac{2 v}{(1-v)} \chi_{r a d}=\left(\frac{\partial \varepsilon_{a x}}{\partial m_{A}}+\frac{2 v}{(1-v)} \frac{\partial \varepsilon_{r a d}}{\partial m_{A}}-\frac{(1+v)(1-2 v)}{E(1-v)} \frac{\partial \sigma_{a x}^{\prime}}{\partial m_{A}}\right) \cdot \rho_{A}
$$

It needs to be noted that the mass of anhydrite per unit volume $m_{A}(t)$ is in itself also dependent on the change in volume (see Equation $(2-11)$ ), and therefore also on the strains. As an alternative to $m_{A}$, the value $\vartheta$ is also used in this work, which indicates the degree of AGT in the system, i.e.,

$$
\vartheta=\frac{M_{A, 0}-M_{A}}{M_{A, 0}}
$$

The equations derived above for $m_{A}(t)$ are transformed for the $\vartheta$-value in Appendix F.

The typical sign convention from geotechnical engineering (compression / settlement positive) is used for the stresses and strains in the constitutive model presented herein (see Figure 7-1). However, for a more intuitive interpretation of the strains due to swelling (especially in the diagrams showing the experimental results in the following chapters), the terms $\varepsilon_{a x, \text { swell }}$ and $\varepsilon_{\text {rad,swell }}$ are used as positive in the opposite direction, i.e.:

and

$$
\begin{aligned}
& \operatorname{sgn}\left(\varepsilon_{a x}\right)=-\operatorname{sgn}\left(\varepsilon_{a x, \text { swell }}\right) \\
& \operatorname{sgn}\left(\varepsilon_{\text {rad }}\right)=-\operatorname{sgn}\left(\varepsilon_{\text {rad,swell }}\right)
\end{aligned}
$$




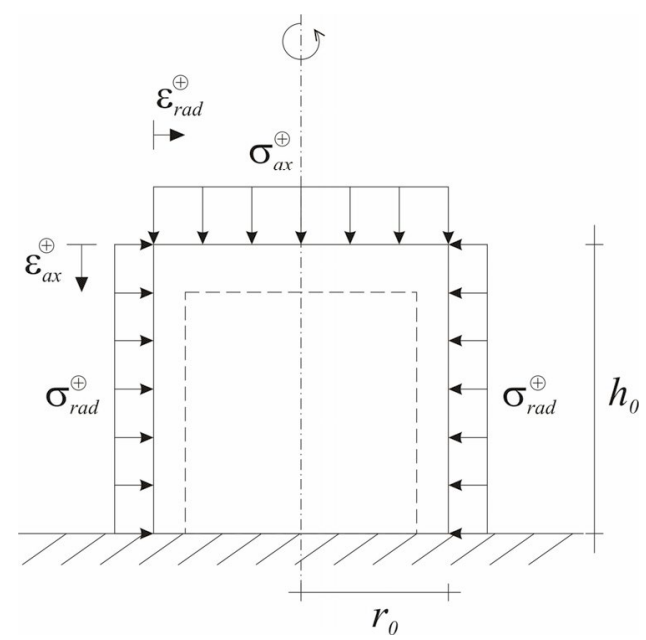

Figure 7-1: $\quad$ Sign convention and notation for the axisymmetric case.

\subsection{Conceptual models}

With the aim of determining the unknown coupling parameter $\chi$ introduced in the previous chapter, conceptual models are formulated which illustrate, why the mass changes of anhydrite and gypsum during AGT lead to strains resp. stresses for four different material structures. These conceptual models give an idea of possible future experiments and which results may be expected.

Before the coupling parameter $\chi$ for simultaneous processes is investigated (which is generally taken into account in this work, see Chapter 2.2.3), the following Chapters (7.2.2 and 7.2.3) abandon the assumption of simultaneous anhydrite dissolution and gypsum precipitation and instead focus on each of the two chemical processes individually. The influence of the mass changes of anhydrite or gypsum on stresses and strains is discussed for each case, thus rendering hypothetical developments of $a$ and $g$ (cf. Equation (7 - 6)) for the isolated processes. Chapter 7.2.4 then revisits the general supposition of this thesis that both chemical processes occur simultaneously and the development of the coupling parameter $\chi$ is discussed for various scenarios.

The illustrations and discussions of the conceptual models assume the following "general" relationships between the stresses and the mass changes for constant strains (Equation (7 - 15)), resp. the strains and the mass changes for constant stresses (Equation ( 7 - 16)), while assuming the pore water pressure $p_{W}$ to remain constant:

$$
\begin{aligned}
& \dot{\sigma}=f(E, v) \cdot\left(\frac{a}{\rho_{A}} \cdot \dot{m}_{A}+\frac{g}{\rho_{G}} \cdot \dot{m}_{G}\right) \quad \text { or } \quad \dot{\sigma}=f(E, v) \cdot \frac{\chi}{\rho_{A}} \cdot \dot{m}_{A} \quad \text { for } \quad \dot{p}_{W}, \dot{\varepsilon}=0 \\
& \dot{\varepsilon}=-\dot{\varepsilon}_{\text {swell }}=\frac{a}{\rho_{A}} \cdot \dot{m}_{A}+\frac{g}{\rho_{G}} \cdot \dot{m}_{G} \quad \text { or } \quad \dot{\varepsilon}=-\dot{\varepsilon}_{\text {swell }}=\frac{\chi}{\rho_{A}} \cdot \dot{m}_{A} \quad \text { for } \quad \dot{p}_{W}, \dot{\sigma}=0
\end{aligned}
$$

whereas $E, v, \rho_{A}$ and $\rho_{G}$ are considered to be constants.

The development of the stresses and strains, and thus the relationships $a, g$ and $\chi$ depend on the structure and material of the investigated specimen. Different structures can be encountered in nature, examples of which are shown in Figure 7-2 (see also, e.g., Riley and Byrne, 1961, who present a classification of structures in anhydrite rock). 

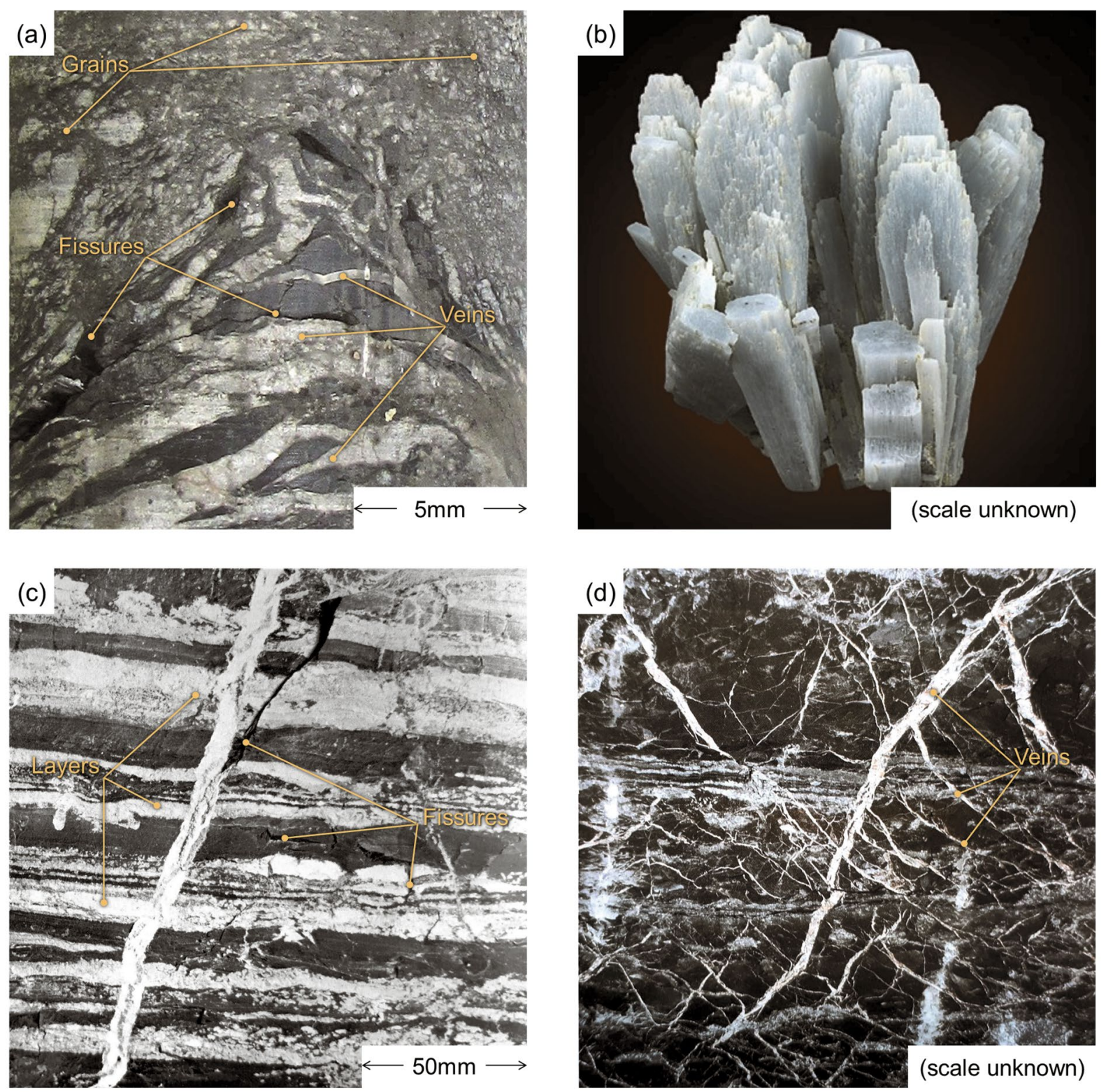

Figure 7-2: $\quad$ Examples for different structures of anhydrite found in nature. (a) Belchen specimen used in the present work with grains of anhydrite and veins of anhydrite embedded in a rock (clay) matrix with fissures; (b) anhydrite found in the Naica caves, Chihuahua, Mexico (image from mindat.org, 2019); (c) layers of anhydrite (between clay layers in rock containing fissures; modified after Berner, 1991); (d) veins of anhydrite in rock matrix (modified after Berner, 1991).

For the conceptual models presented here, the following specimen structures were considered (indicated in the sketches in Figure 7-3, from left to right): (a) a homogeneous, fine granular material consisting of anhydrite and other components; (b) a skeletal, porous block of anhydrite (referred to as a "sponge-like" perforated system); (c) anhydritic layers within a fine, inert matrix; (d.1) anhydritic veins or (d.2) fissures (in the absence of anhydrite) within a rock matrix.

The different structures are expected to influence the mechanical behavior of the specimens during anhydrite dissolution and/or gypsum precipitation and are discussed individually in the following subchapters. Note that swelling of clay is not taken into account in the conceptual models described herein (the volume of the inert material is assumed to remain constant and the void space changes solely due to anhydrite dissolution, gypsum precipitation or a combination of both) and dissolution of gypsum is not considered in this work. 

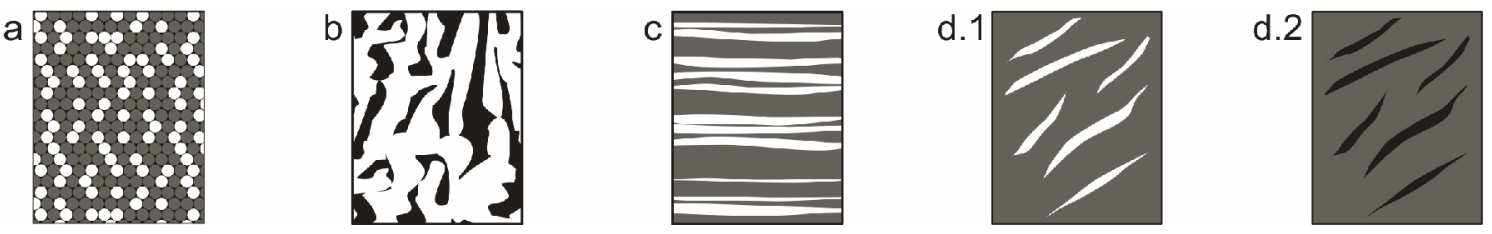

Figure 7-3: Conceptual model of a cross-section through a matrix of (a) a fine granular homogeneous material, (b) a porous block of anhydrite, (c) an inert material with anhydritic layers (d) a rock specimen with anhydrite veins (d.1) or fissures (d.2). (White: anhydrite; black: pore space; grey: inert material, e.g., non-swelling clay, quartz flour or rock).

Generally, the total volume ( $\left.V_{\text {tot }}\right)$ of each conceptual specimen is made up of inert material (rock or granular, powdered material; $\left.V_{S}\right)$, anhydrite $\left(V_{A}\right)$ and the pore volume $\left(V_{P}\right)$. Gypsum $\left(V_{G}\right)$ may be present as well after precipitation, depending on the considered situation. Exceptions are the porous block of anhydrite (Figure 7-3b; no inert material, $V_{S}=0$ ) and a rock with fissures (no anhydrite, $V_{A}=0$, image d.2 in Figure 7-3).

$$
V_{t o t}=V_{S}+V_{A}+V_{P}+V_{G}
$$

The pore volume can be expressed as a function of the void ratio $(e)$ or porosity $(n)$ :

$$
V_{P}=e \cdot\left(V_{S}+V_{A}+V_{G}\right)=\frac{n}{1-n}\left(V_{S}+V_{A}+V_{G}\right)
$$

leading to

$$
V_{t o t}=\frac{V_{S}+V_{A}+V_{G}}{1-n}
$$

The influence of anhydrite dissolution and gypsum precipitation on stresses and strains are discussed by formulating conceptual models and, later in Chapter 7.3, with thought experiments. For each case (anhydrite dissolution, gypsum precipitation and simultaneous reactions), the influence of the chemical reaction on stresses (while the strains are held constant) and strains (while the stresses are held constant) is described for each structure introduced in Figure 7-3 (see also the overview in Figure 6-1).

\subsubsection{Overview of regarded structures/materials}

\section{a. Fine, homogeneous material}

A system is considered, consisting of a matrix of fine, granular inert material, e.g., kaolin or quartz flour, and which contains anhydrite powder and/or gypsum, depending on the regarded model. Thus, the total volume of the system is made up of the volumes of the inert powder, anhydrite powder, gypsum (if present) and the pore volume (see Equation (7 - 17)).

If any one of the components change in volume (e.g., due to anhydrite dissolution or gypsum precipitation), a change in the total volume is most likely to occur and will thus lead to volumetric strains. In the general case:

$$
\varepsilon_{v o l}=\frac{V_{t o t_{0}}-V_{t o t}}{V_{t_{0}}}=1-\frac{V_{A}+V_{G}+V_{S}+V_{P}}{V_{A_{0}}+V_{G_{0}}+V_{S}+V_{P_{0}}}=1-\frac{V_{A}+V_{G}+V_{S}}{V_{A_{0}}+V_{G_{0}}+V_{S}} \cdot \frac{1-n_{0}}{1-n}
$$


whereas the individual volumes can also be expressed via the respective masses $M_{i}$ and densities $\rho_{i}$ :

$$
V_{i}=\frac{M_{i}}{\rho_{i}}=V_{t o t} \cdot \frac{m_{i}}{\rho_{i}}
$$

\section{b. "Sponge-like", perforated system}

A skeletal, "perforated" block of anhydrite is considered (see Figure 7-3b), which represents a porous system, although made out of one block of anhydrite as opposed to the previously described granular material. As an idealization for the conceptual discussions later, a cylindrical anhydritic block is assumed, which contains pipe-like pores in axial direction (see Figure 7-4).

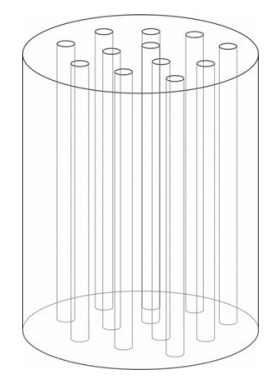

Figure 7-4: Idealization of a porous block of anhydrite.

\section{c. Layered anhydrite}

Entire layers of pure anhydrite are considered within a matrix of inert material. In order to idealize the situation sketched in Figure 7-3c, artificial layers of anhydrite are regarded within a matrix of, e.g., quartz flour (see Figure 7-5). Such an idealized system is more clearly defined compared to, e.g., layers of anhydrite in natural rock, where the layers are not easily quantifiable.

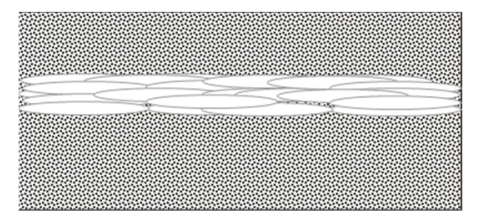

Figure 7-5: Idealization of a layer of anhydrite powder within quartz sand.

\section{d. Rock with anhydritic veins or fissures}

Similar to the previous model, veins of anhydrite are considered. As opposed to the model of layered anhydrite, where granular or powdered material is taken into account, here the anhydritic veins are incorporated in a rock matrix. If the anhydrite is absent (e.g., dissolved and leached), the rock matrix is assumed to contain fissures or cracks where the anhydrite used to be. In order to have axisymmetric conditions, the veins or fissures need to lie parallel or perpendicular to the axial direction (i.e., transversal isotropic behavior).

\subsubsection{Influence of anhydrite dissolution on the stresses and strains}

This chapter discusses the influence of mass change of anhydrite (due to dissolution) on the stresses and/or strains with the aim gaining an understanding for the coupling parameter $a$. For the determination of $a$ (isolated from $g$ ) with conceptual models, the process of gypsum precipitation needs to be (at least hypothetically) eliminated (i.e., $\dot{m}_{G}=0$ ). Situations where this 
may be enabled in practice are, for instance if the water in which the anhydrite is dissolved is transported from the system immediately (before gypsum precipitation may occur; so-called "leaching" of the system) or if anhydrite dissolves at a temperature higher than the transition temperature, where the equilibrium concentration of gypsum is higher than that of anhydrite (and therefore gypsum precipitation is prevented, see Chapter 2.3.1).

Dissolution of anhydrite leads to a reduction of the volume of anhydrite and to a change in the volume of the pores, whereas the latter depends on the structure of the specimen. The presented conceptual models (following subchapters) are based on the idealized specimens as described above, whereas the specimens are assumed not to contain any gypsum initially. In all cases, the total volume (and thus the swelling strains) will either remain constant or decrease, since anhydrite dissolution is the only chemical process.

\section{a. Fine granular homogeneous material}

\section{a.i. Influence of anhydrite dissolution on the strains}

When anhydrite dissolves, its volume $V_{A}$ reduces. As seen from Equation $(7-20)$, this may lead to volumetric strains, depending on the change in porosity (in the most extreme case, the entire matrix may not change as anhydrite dissolves and thus the porosity increases strongly). Depending on the circumstances (grain size, external stresses, degree of compaction etc.), the porosity may increase or decrease during the process of anhydrite dissolution. When immersed in water, the anhydritic grains should reduce evenly on all sides, leading to equal strains in radial and axial direction. In theory this merely applies, if the porosity of the specimen remains constant and the grains do not shift or rotate within the specimen. Practically, the pore spaces are expected to increase at first (rising porosity), whereas the continuously shrinking grains may shift and thus fill up the pore spaces again. The porosity will fluctuate during the process of anhydrite dissolution, as illustrated in Figure 7-6, where the blue areas indicate pores that increased with anhydrite dissolution, while the red pores shrunk due to shifting of the grains (in this illustration solely grains of anhydrite are sketched).

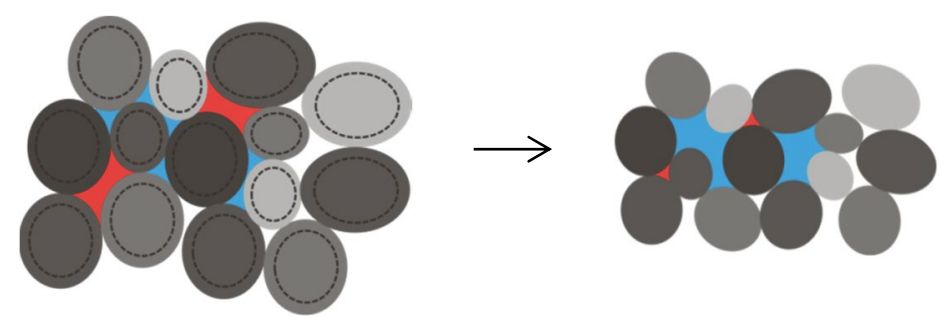

Figure 7-6: $\quad$ Change in porosity of granular anhydrite during anhydrite dissolution.

Therefore, it is possible that the strains will not evolve evenly, but rather gradually as the pores grow and get filled up alternately.

Figure 7-7 shows possible outcomes of various scenarios for the development of the pore volume (and thus of the porosity), whereas in all cases the total mass (or volume) of anhydrite is assumed to reduce equally over time, as can be seen in the top row of Figure 7-7. Based on the development of the porosity (second row), different behaviors for the swelling strains are expected (third row), and thus the relationship between strains and mass change of anhydrite, a (cf. Equation (7 - 16)), may vary (fourth and fifth rows). 
The following conceptual scenarios are considered (from left to right in Figure 7-7):

- Constant porosity: The grains remain under tight packing throughout the observed period of time and the volume of anhydrite changes, leading to a continuous reduction of the total volume and thus of the strains (first column in Figure 7-7);

- Increasing porosity: The grains dissolve, decrease in size, and the packing density decreases (see second column in Figure 7-7); in the most extreme case, the entire volume of dissolved anhydrite remains as void space, and thus the total volume and the strains would remain constant;

- Slowly varying porosity: The grains dissolve (porosity $n$ increases) and shift their position due to newly available pore space ( $n$ decreases again), see third column in Figure 7-7;

- Abruptly varying porosity: As the grains dissolve they shift suddenly as a slight collapse of the system which repeats itself over and over during further anhydrite dissolution (fourth column in Figure 7-7).

Assuming that the stresses and pore water pressures are constant, it is possible to determine the development of the relationship $a$ over time according to Equation $(7-16)$ (see bottom row in Figure 7-7).

As described in Equation (2-11), $m_{A}$ is dependent on the total volume. Therefore, abrupt changes in volume (as for example in the right column of Figure 7-7) also cause abrupt changes in the mass of anhydrite per unit volume. 
constant porosity
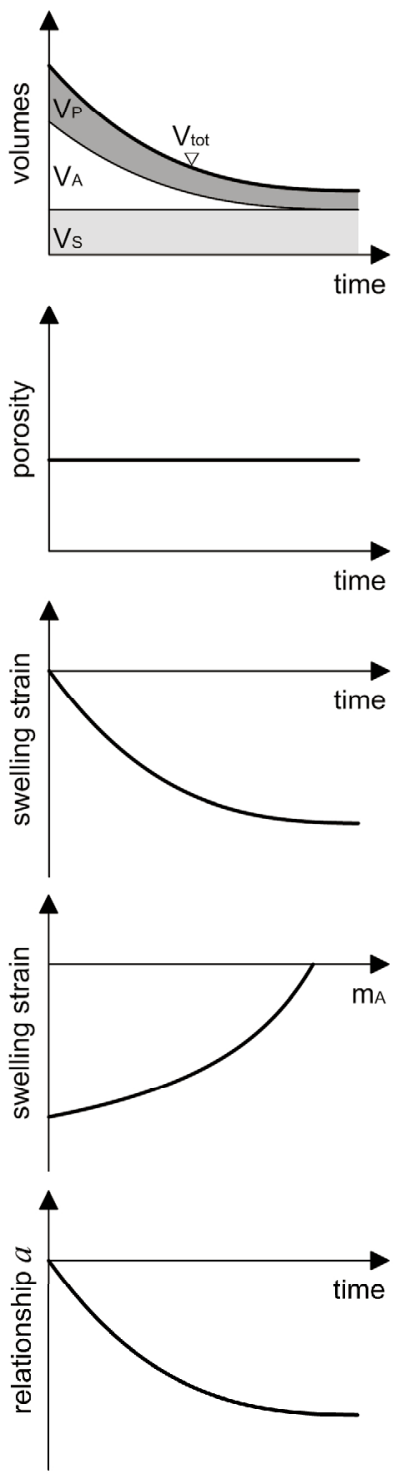

increasing porosity
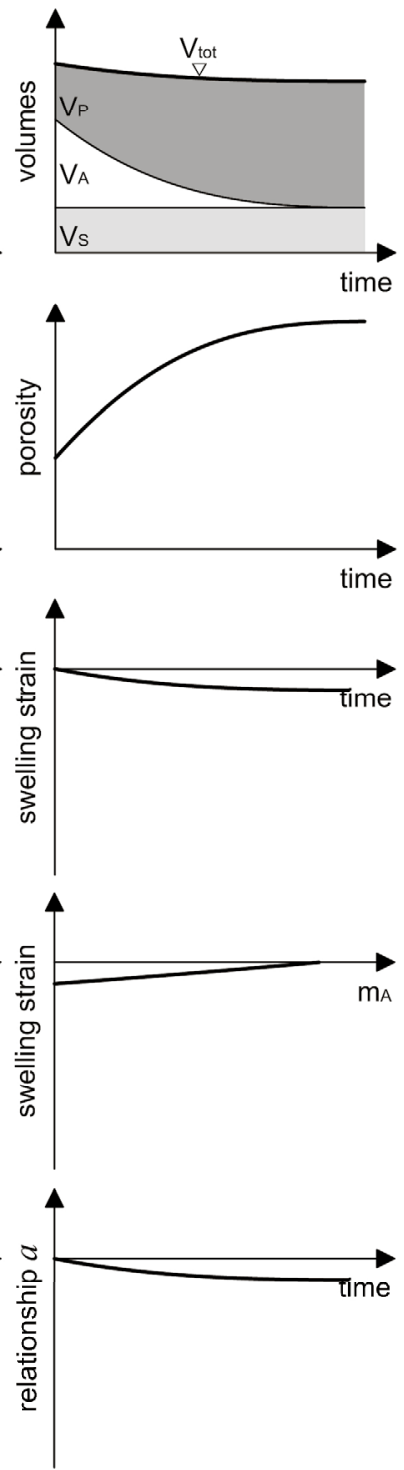

slowly varying porosity abruptly varying porosity
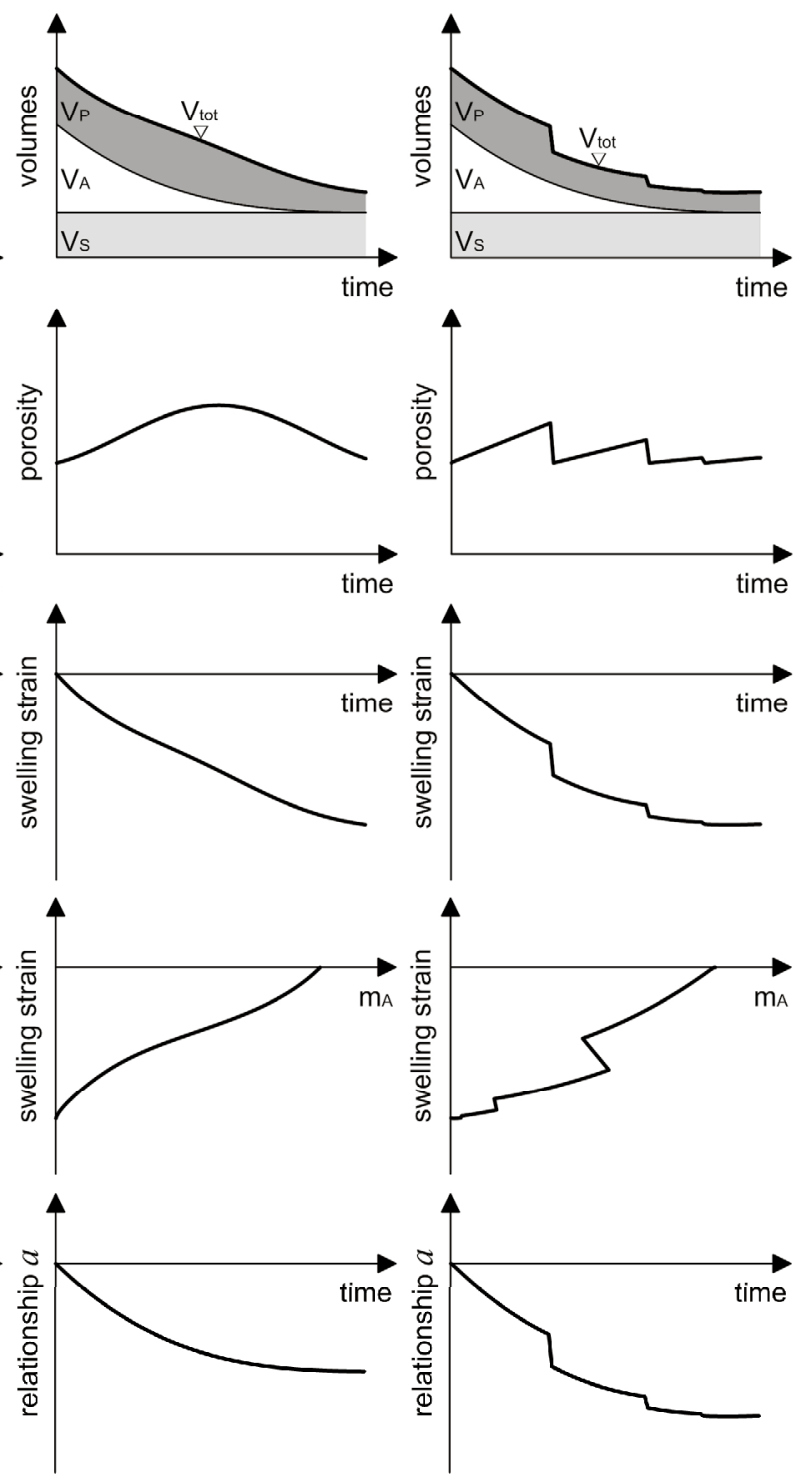

Figure 7-7: $\quad$ Various scenarios for the development of the porosity $n$ for the influence of anhydrite dissolution on strains for granular material. Top to bottom: volumes, porosity, and swelling strains vs. time; swelling strains vs. change in mass of anhydrite and resulting relationship a vs. time.

\section{a.ii. Influence of anhydrite dissolution on the stresses}

The system of granular material is now considered to be under initial compression, with the strains held constant. Dissolution of the anhydrite powder under constant strains will lead to an increase in porosity. Due to the decrease in grain size, the contact stresses between the grains will weaken, thus reducing the initial total stresses acting on the system when assuming the total volume (i.e., the initially set strains) to remain constant.

A possible (qualitative) behavior of the stress could be as shown in Figure 7-8. In this case the reduction of the contact pressure (and thus of the stress) is linearly dependent on the change in mass of anhydrite (i.e., $a=$ const., cf. Equation (7 - 15)). 

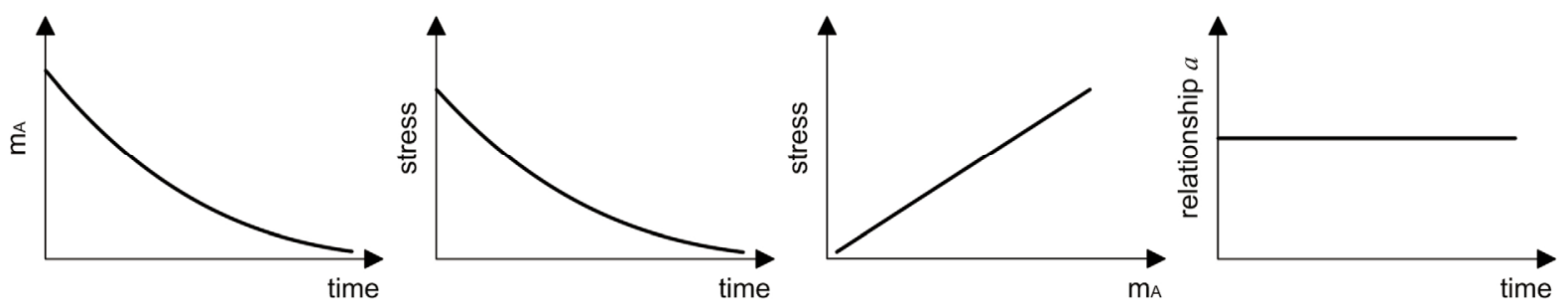

Figure 7-8: Influence of anhydrite dissolution on the stress for granular material.

\section{b. "Sponge-like", perforated system}

In a "sponge-like", perforated system, the dissolution of anhydrite leads to a reduction in the volume (or mass) of the block, i.e., the material around the pipe-like pores (see Figure 7-4) will dissolve. The surface area, which is exposed to the water, will increase linearly over time. Thus, the pore radii grow linearly over time, as they are directly proportional to the surface area of the pipes, leading to a linear reduction of the thickness of the material between the pores ("material-bridges"). The height of the block is assumed to be much larger than the total radius, so that anhydrite dissolution on the top and bottom surfaces can be neglected for the model.

\section{b.i. Influence of anhydrite dissolution on the strains}

Assuming that the block underlies no stresses $\left(\sigma_{a x}=0\right)$, and the anhydrite dissolves evenly within the pipes as described above, no external strains will occur until the material bridges are completely dissolved.

However, a change in axial strains is conceivable when assuming a constant total axial stress $\sigma_{a x}$ acting on the block (i.e., an axial stress is applied on the total top surface area of the cylindrical specimen, $A_{t o t}$, and then held constant), whereas the following stress $\sigma_{a x, A}$ is then acting axially on the anhydrite itself (i.e., on the material-bridges, denoted as the anhydrite surface area $A_{A}$ ):

$$
\sigma_{a x, A}=\sigma_{a x} \frac{A_{t o t}}{A_{A}}=\sigma_{a x}\left(\frac{A_{t o t}}{A_{t o t}-A_{P}}\right)=\sigma_{a x}\left(\frac{A_{t o t}}{A_{t o t}-n_{P} \pi r_{P}^{2}}\right)=\sigma_{a x}\left(\frac{A_{t o t}}{A_{t o t}-n A_{t o t}}\right)=\sigma_{a x}\left(\frac{1}{1-n}\right)
$$

with $n$ being the porosity, $n_{P}$ the number of pores and $r_{P}$ the pore-radius. Therefore, during anhydrite dissolution, the internal axial stresses on the material-bridges $\left(\sigma_{a x, A}\right)$ increase asymptotically with growing pore-radii resp. with increasing porosity $n$. This increase in local stress on the material-bridges is shown in the second image of Figure 7-9 (for two different external axial stresses), and thus anhydrite dissolution causes an elastic change of strains. The anhydrite fails, as soon as the stress acting on the material-bridges exceeds the strength of the material and thus the system collapses, which leads to an abrupt increase in axial strain (thus a decrease in swelling strain, see Figure 7-9). The relationship between the strains and the mass change of anhydrite then describes the coupling parameter $a$ (Figure 7-9 right). 

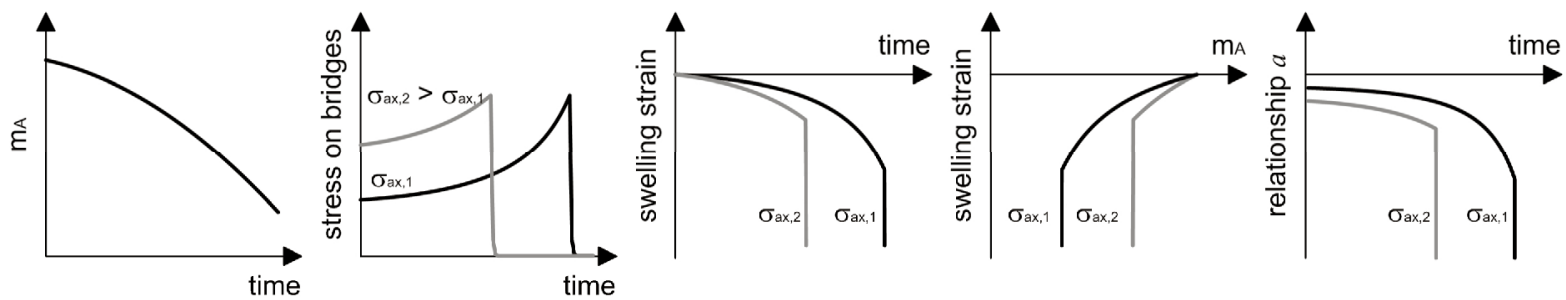

Figure 7-9: $\quad$ Influence of anhydrite dissolution on axial strains of a porous rock. From left to right: change in mass of anhydrite over time; development of axial stress in the material-bridges (after initial external loading for two axial stresses); change in swelling strain over time; swelling strain vs. mass of anhydrite; development of the parameter a over time.

\section{b.ii. Influence of anhydrite dissolution on the stresses}

Now a constant axial strain (i.e., $\varepsilon_{0}=\varepsilon_{a x}=$ const. in this case) is forced upon the specimen, which (under assumption of Hooke's linear elastic law) is combined with a change in stress acting on the anhydrite, $\sigma_{a x, A}$ (i.e., the stress on the material bridges with a surface area $A_{A}$ ). The total axial stress $\sigma_{a x, t o t}$ acting from the outside on the specimen area (i.e., on the entire top surface area of the cylindrical specimen including the pores, $A_{10 t}$ ) can thus be calculated according to Equation (7 - 23):

$$
\sigma_{a x, t o t}=\sigma_{a x, A} \frac{A_{A}}{A_{t o t}}=f(E, v) \cdot \varepsilon_{0} \cdot \frac{A_{A}}{A_{t o t}}
$$

Therefore, as anhydrite dissolves and the surface area $A_{A}$ (and thus the volume/ mass) of the anhydrite reduces, the total (external) stress $\sigma_{a x, t o t}$ will decrease while the strain remains constant. This is illustrated in the following graphs, where it was assumed that the pore radii grow linearly over time, from which the change in volume resp. mass of anhydrite over time is derived. The qualitative relationships are shown for two different initial axial strains. It can be seen that the relationship between the total stress acting on the block and the change in mass of anhydrite is linear, thus $a=$ const.
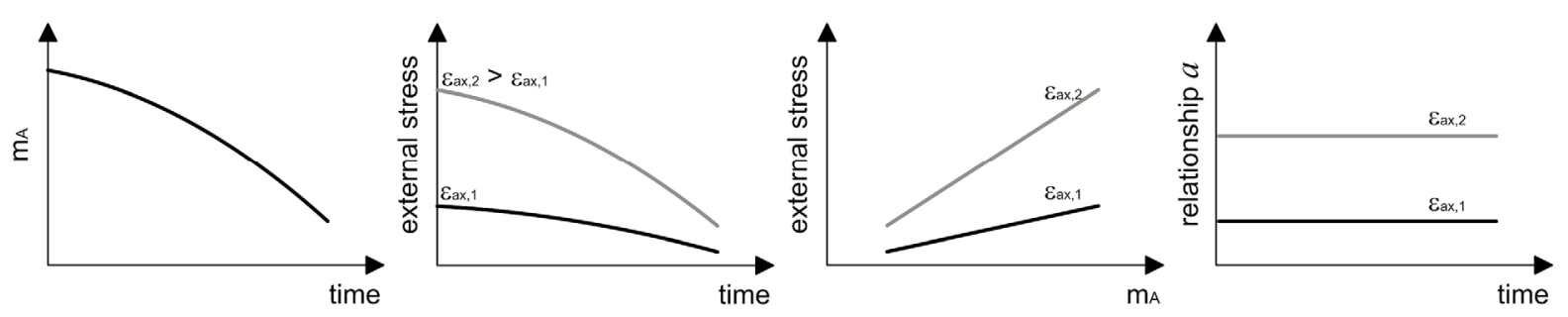

Figure 7-10: Influence of anhydrite dissolution on the stresses for a porous block.

\section{c. Layered anhydrite}

\section{c.i. Influence of anhydrite dissolution on the strains}

The dissolution of the anhydrite will lead to chemically induced strains mainly perpendicular to the layers (in the axisymmetric case assumed here, the strains will occur mainly in axial direction). This is due to the fact that all surfaces will reduce by the same amount, and therefore the strains will be the largest perpendicular to the shortest dimension. 


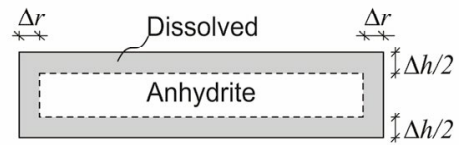

Figure 7-11: Dissolution of a thin layer of anhydrite.

For a layer (or platelet) of anhydrite with measurements $r=10 \mathrm{~h}$, assuming that the anhydrite dissolves evenly on all sides ( $\Delta h=2 \Delta r$, see Figure 7-11), the resulting strains amount to:

$$
\varepsilon_{a x}=-\varepsilon_{a x, \text { swell }}=\frac{\Delta h}{h}
$$

and

$$
\varepsilon_{\text {rad }}=-\varepsilon_{\text {rad }, \text { swell }}=\frac{\Delta r}{r}=\frac{\Delta h}{20 h}=5 \% \varepsilon_{a x}
$$

i.e., the axial strains will be $20 x$ larger than the radial strains.

Thus, for this model, the dissolution of anhydrite is expected to lead to strains mainly in the axial direction of the specimen (up to the point where all anhydrite is dissolved). Figure 7-12 shows the change in mass of anhydrite and the response in axial strains (assuming radial strains to be negligible) and the corresponding relationship $a$.
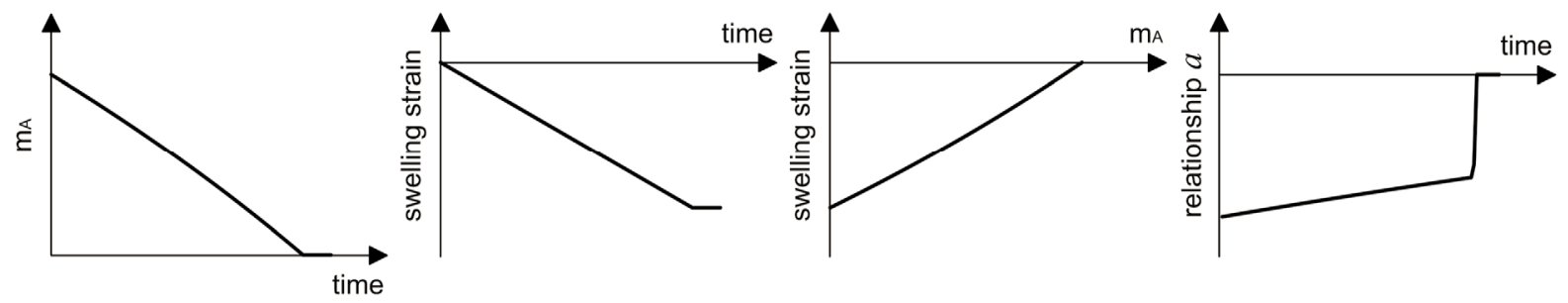

Figure 7-12: Influence of anhydrite dissolution on the strains for layered anhydrite.

\section{c.ii. Influence of anhydrite dissolution on the stresses}

A system consisting of layered anhydrite within inert material under an initially applied strain (and thus: initially applied stress) is considered to react as shown in Figure 7-13: Assuming the strain and therefore the total volume to remain constant, anhydrite dissolution will lead to an increase in pore volume and a "loosening" of the material, i.e., the contact stresses will diminish, leading to smaller total stresses. When considering the volume of anhydrite to decrease linearly over time while the total volume is assumed to remain constant, $m_{A}$ will also change linearly over time. The stresses will also reduce linearly over time, and thus the parameter $a$ will be constant.
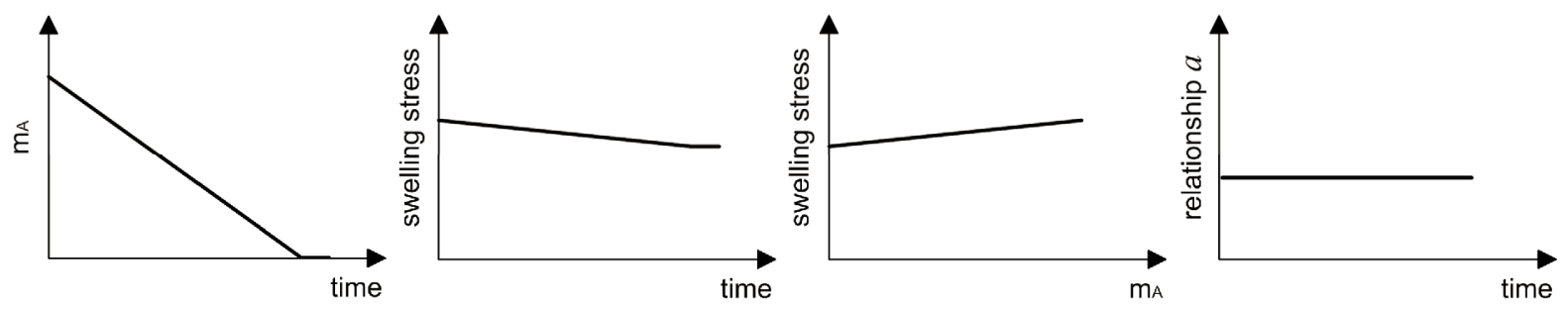

Figure 7-13: Influence of anhydrite dissolution on the stress for layered anhydrite. 


\section{d. Rock with anhydritic veins}

The influence of the dissolution of anhydritic veins within a rock on the stresses and strains at the outer boundaries of the entire rock matrix is strongly dependent on the size, amount, and distribution of the veins, the strength of the surrounding matrix, as well as on the stresses and strains acting initially on the rock.

\section{d.i. Influence of anhydrite dissolution on the strains}

The influence of anhydrite dissolution on the strains for the case of rock with anhydritic veins can be conceived similarly to that of the perforated system:

Assuming a constant external stress to be acting on the rock matrix, it is possible that the rock matrix (comparable to the "material-bridges" in the perforated system) becomes overstressed and fails after the anhydritic veins dissolve and cracks in the matrix remain. Thus anhydrite dissolution may lead to a collapse of the matrix when the stress on the material bridges overcomes the strength of the rock matrix (analogue to the behavior shown in Figure 7-9).

However, if the strength of the rock matrix is sufficiently high compared to the stress acting upon the rock matrix, or if the veins are few and/or small, no strains may occur at all or if, then merely small elastic strains (due to an increase in the local stress of the material-bridges).

\section{d.ii. Influence of anhydrite dissolution on the stresses}

Here too, the distribution of the veins within the rock matrix is a governing factor when investigating the influence of anhydrite dissolution on the stresses. Assuming the rock to be subjected to an initial strain, and the veins to be sparsely distributed within the matrix, the stress acting on the rock matrix will change only marginally with anhydrite dissolution. However, if the veins are larger and more frequent, the reduction of the stress acting on the rock matrix will be more pronounced as the anhydrite dissolves; comparable to the case of the perforated system (see Figure 7-10, bearing in mind that the stress will most likely not reduce quite as much due to the remaining rock matrix in this case).

\subsubsection{Influence of gypsum precipitation on the stresses and strains}

Now the influence of gypsum precipitation on the strains and stresses is investigated qualitatively for the different materials and conceptual models are introduced that may allow the evaluation of the coupling parameter $g$ (specifically $g_{a x}$ and $g_{r a d}$ for axisymmetric conditions, see Equation $(7-6))$.

For this, it is hypothetically assumed here that the regarded system contains no anhydrite initially and gypsum precipitation occurs due to ions in the pore water, which are supplied from an external source. Therefore, the following models consider an open system with a sufficient supply of supersaturated solution and the difference between the molar volume of gypsum and the molar volume of the constituents can be neglected. Dissolved ions in a solution can lead to gypsum precipitation, if the concentration in the solution is higher than the equilibrium concentration of gypsum $\left(c_{e q, G}\right)$, see Chapter 2.2.2. This induces a change in the volume of gypsum and possibly in the pore volume. 


\section{a. Fine granular homogeneous material}

Regarding a granular specimen, gypsum will precipitate around the grains of inert material, filling up the pore space and - depending on the stresses, the porosity and the amount of gypsum expand the specimen.

The total volume of the specimen consists of inert grains $\left(V_{S}\right)$, pores $\left(V_{P}\right)$ and gypsum $\left(V_{G}\right)$, see Equation (7 - 17).

$$
V_{t o t}=V_{S}+V_{G}+V_{P}=V_{S}+V_{G}+e \cdot\left(V_{S}+V_{G}\right)=V_{S}+V_{G}+\frac{n}{1-n}\left(V_{S}+V_{G}\right)=\frac{V_{S}+V_{G}}{1-n}
$$

\section{a.i. Influence on the strains}

Strains due to gypsum precipitation are thus dependent on the change in porosity and on the volume (and therefore the mass) of the gypsum while the inert grains themselves will not change in volume $\left(V_{S}=V_{S_{0}}\right)$. The strains can only occur, if the constant stresses acting on the system are low enough to enable crystallization and expansion of the system.

$$
\varepsilon_{\text {swell }}=\frac{V_{\text {tot }}-V_{\text {tot }_{0}}}{V_{\text {tot }_{0}}}=\frac{\left(V_{S}+V_{G}\right)\left(1-n_{0}\right)}{\left(V_{S}+V_{G_{0}}\right)(1-n)}-1
$$

Depending on how the gypsum precipitates, e.g., if it develops within the pores (creating an agglutination of the grains) and thus reducing the porosity or if it precipitates evenly around the grains and pushes them apart continuously (keeping the porosity constant), different developments of the strains are expected. The following scenarios were considered for the development of the porosity (see Figure 7-14, from left to right) whereas the change in volume of gypsum is considered the same in each case:

- Constant porosity: The gypsum precipitates evenly around each grain, while they maintain tight packing (left column in Figure 7-14);

- Increasing porosity: The gypsum crystals may slowly push the grains apart and create additional pore space (second column in Figure 7-14);

- Decreasing porosity: The gypsum may fill up the pores completely (hypothetical case), e.g., if a constant external stress is acting on the system through which the gypsum needles will preferentially grow in the pore space (third column in Figure 7-14) whereas as soon as the pores are sufficiently filled further gypsum precipitation will lead to external strains;

- Abruptly varying porosity: The gypsum may precipitate in the pores, fill them on the one hand, on the other hand the gypsum needles push the grains apart and thus create additional pore space (cracking) which can be filled again, thus simultaneously (or alternately) decreasing and increasing the porosity (right column in Figure 7-14). 
constant porosity
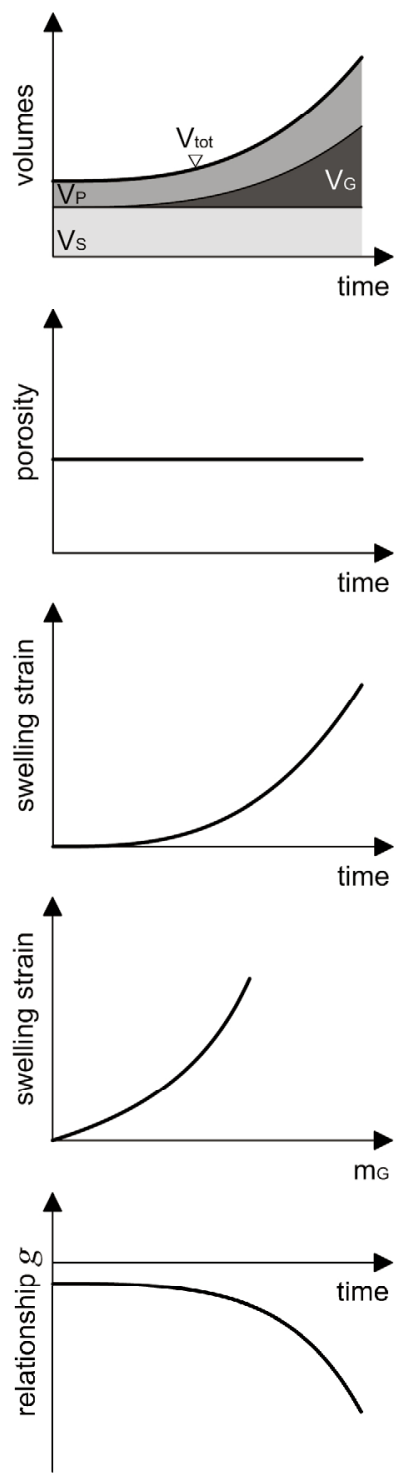

increasing porosity
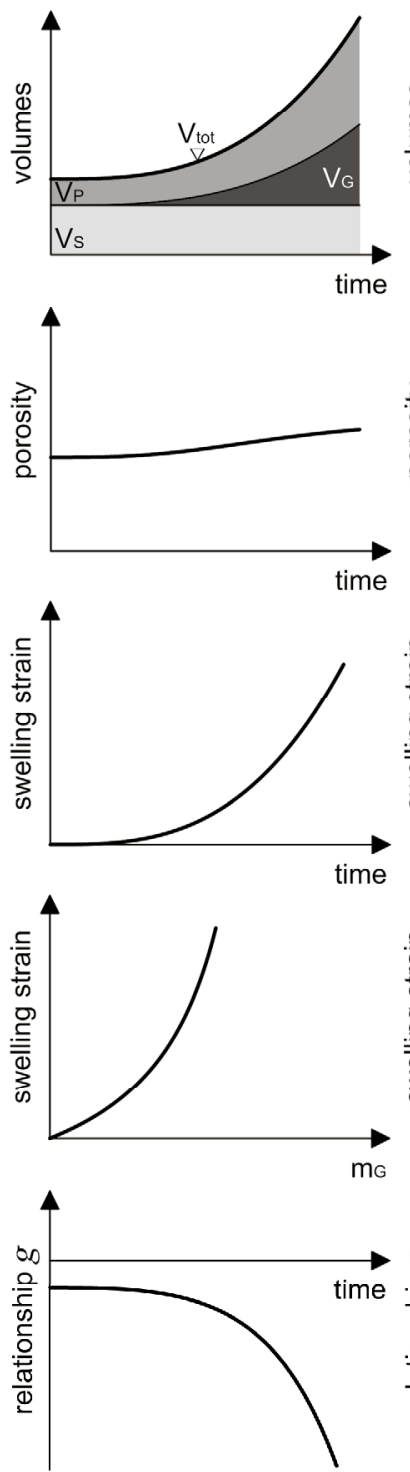

decreasing porosity

abruptly varying porosity
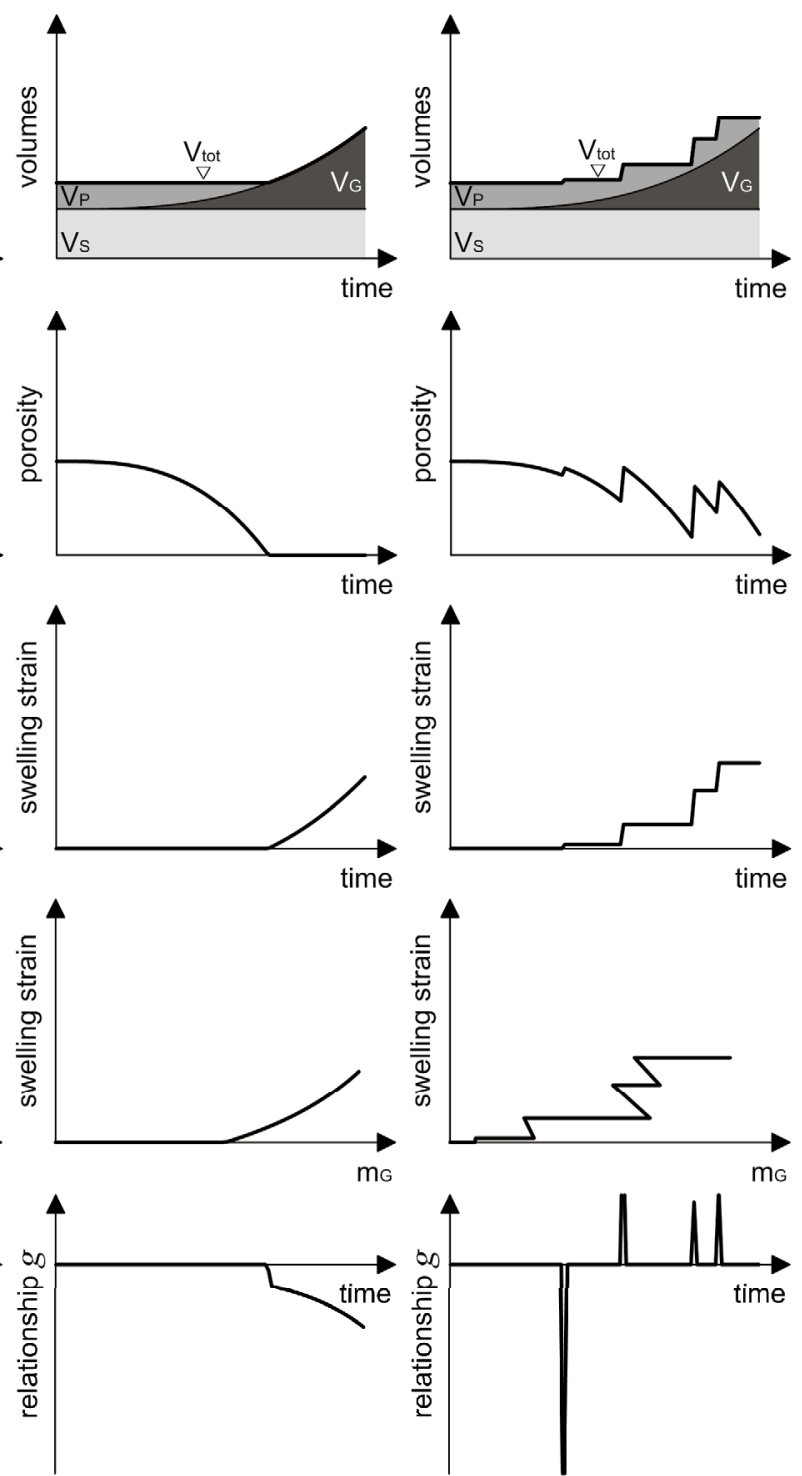

Figure 7-14: Various scenarios for the development of the porosity $n$ for the influence of gypsum precipitation on strains for granular material. Top to bottom: volumes, porosity, and swelling strains vs. time; swelling strains vs. change in mass of anhydrite and resulting relationship $g$ vs. time.

\section{a.ii. Influence on the stresses}

Assuming the system of granular material to be completely confined (i.e., all strains prohibited), gypsum precipitation within the system will lead to stresses on the confining walls. It is, however, conceivable that the gypsum needles will first begin to grow in the direction of least resistance, i.e., within the pores. It is, therefore, possible that no change in stresses are observed at first, until the pore space is sufficiently filled up and the gypsum needles begin to induce pressure on the grains and thus on the outer walls. However, depending on the concentration in the water, gypsum precipitation may cease with increasing pressure (since the equilibrium concentration of gypsum increases and may exceed the concentration in the water, cf. Chapter 2.3.3). 


\section{b. "Sponge-like", perforated system}

Considering the hypothetical case, where such a porous system as idealized in Figure 7-4 (consisting of anhydrite or - in this case - of any inert rock) is subjected to water which is highly supersaturated with respect to gypsum while the anhydrite does not dissolve (e.g., due to a temperature above the transition temperature, see Chapter 2.3.1), gypsum would fill up the pipes as it precipitates. As long as the water remains supersaturated with respect to gypsum, the growing gypsum crystals may induce cracking of the block (i.e., develop strains) or, if expansion is prohibited, exert stresses on the surrounding environment (depending on the pore space, the strength of the inert rock and the stress surrounding the rock; similar to the case of rock with fissures, as described more in depth below).

\section{c. Layered anhydrite}

In the case of solely gypsum precipitation, the system of layered anhydrite within a granular material will behave like the fine granular homogeneous material (and is therefore not discussed further here).

\section{d. Rock with fissures}

Now a rock is taken into account which contains some cracks or fissures (e.g., if it contained anhydritic veins previously which have been completely dissolved and empty cavities remain, see image d.2 in Figure 7-3). Assuming the pore water within the fissures to be supersaturated with respect to gypsum, gypsum will begin to precipitate within the cavities. The possible influences of gypsum precipitation on the stresses and strains the system undergoes are discussed in the following sub-chapters.

\section{d.i. Influence on the strains}

As the gypsum precipitates within the fissures, the pore volume of the specimen decreases while the volume of gypsum increases. Assuming that the pore water is always supersaturated with respect to gypsum (in reality the equilibrium concentration of gypsum will increase due to increasing local stress within the fissures and thus slow further gypsum precipitation down since the concentration gradient between the equilibrium concentration and the concentration in the pore water will become smaller) and that no stresses act on the rock, these changes in volume may lead to strains, should the rock begin to crack due to precipitation of gypsum crystals. The volume of the rock itself will not change, as it is assumed to be inert; i.e., $V_{S}=V_{S_{0}}$ and therefore:

$$
\varepsilon_{\text {vol }}=-\varepsilon_{\text {swell }}=\frac{\Delta V}{V_{0}}=\frac{\left(V_{P 0}+V_{G 0}\right)-\left(V_{P}+V_{G}\right)}{V_{P 0}+V_{G 0}+V_{S}}
$$

The change in the volume will happen step by step, as can be seen exemplarily in Figure 7-15, where a rock with two fissures is taken into account: While gypsum precipitates in the fissures, the total volume will not change; when the pores are sufficiently filled, further gypsum precipitation generates a pressure on the rock, which - if the pressure is higher than the tensile strength of the rock - can lead to cracking (cf. Scherer, 2002), i.e., the green crack of the material bridge between the fissures in Figure 7-15. Thus, the pore volume of the rock increases abruptly. Further gypsum precipitation will then occur within the first crack and cause the final two cracks (red). In the case of multiple fissures, this continues until the rock fails completely. Therefore, the rock exhibits no 
strain at first, then abrupt changes in strains (when the cracks occur) and eventually an increase in swelling strains with increasing mass of gypsum, at which point the relationship $g$ will change continuously as well (see Figure 7-15).
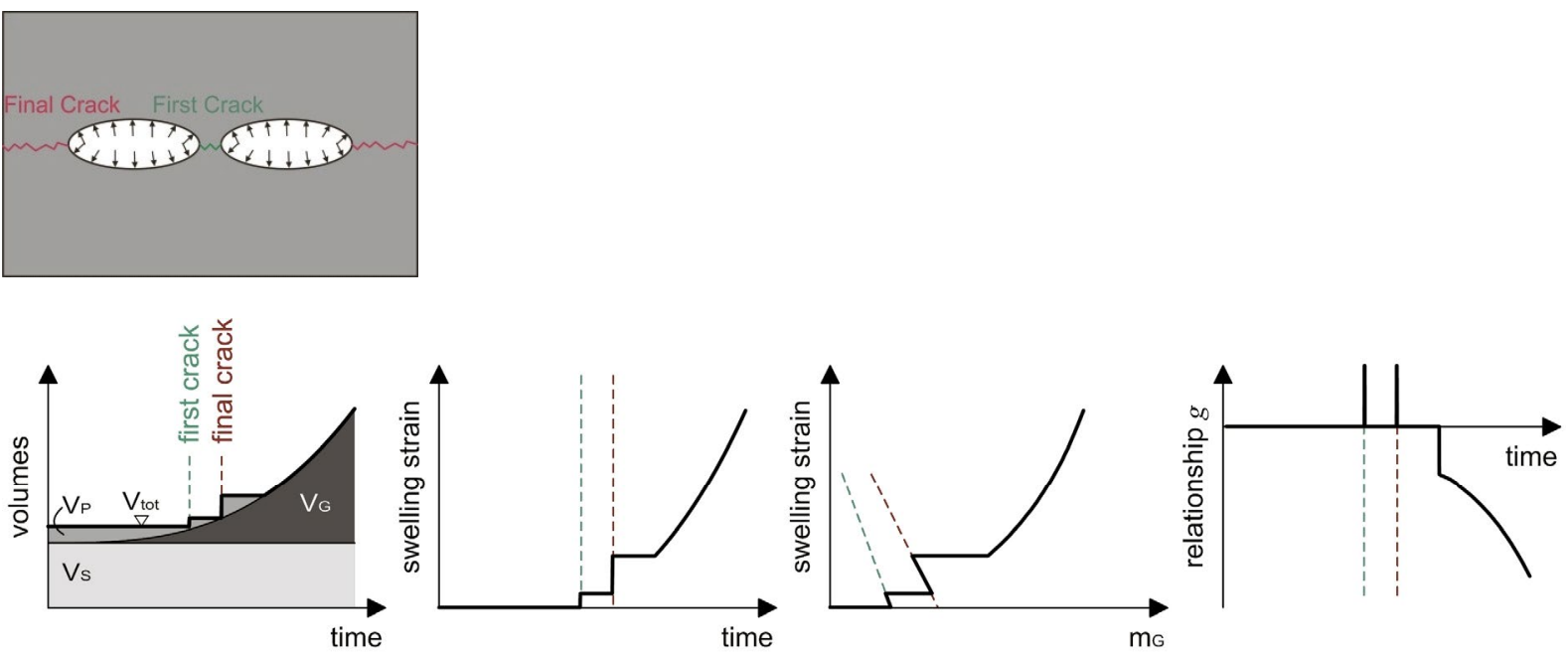

Figure 7-15: Top left: example of a rock with two fissures (pores). Bottom row: changes in volumes (gypsum, pores, and total volumes) vs. time, swelling strain vs. time, swelling strain vs. change in mass of gypsum and corresponding relationship $g$.

\section{d.ii. Influence on the stresses}

The same kind of structure is now considered under strictly confined conditions, i.e., all strains are prohibited, and the influence of gypsum precipitation on the stresses acting from the rock on the confinement is discussed.

By inducing gypsum precipitation through supersaturated pore water within the fissures, the fissures will begin to get filled up with gypsum, during which the external stress of the rock on the confining walls is most likely not to change. As soon as the fissures are sufficiently filled, however, further gypsum precipitation increases the pressure within the fissures and attempts to crack (or expand) the rock (as indicated by the red line in Figure 7-16). Since the latter is confined, the rock matrix will exhibit an increasing stress on the confinements. The pressure exerted from gypsum precipitation and from the confinements may lead to a slight elastic deformation of the rock matrix ( $V_{S}$ decreases).

As opposed to the previous case, where the influence of the local stress on the growing gypsum needles was neglected, it is here indispensable to consider said effect: In the confined system, the continuously increasing stress due to gypsum precipitation will most likely increase the equilibrium concentration of gypsum so far, that the process of gypsum precipitation will slow down and reach an asymptotical value (the equilibrium concentration will reach the concentration of the water). Therefore it is plausible that the internal and external stresses will reach a maximal value, at which no further gypsum will precipitate (the system will be in a state of thermodynamic equilibrium and the crystallization pressure of gypsum is reached). For the diagrams in Figure 7-16 it was assumed that the stress within the cracks (which the gypsum exerts on the inside walls of the fissures) is transmitted to the outer walls confining the rock matrix and is therefore equal to the total stress acting on the rock. 


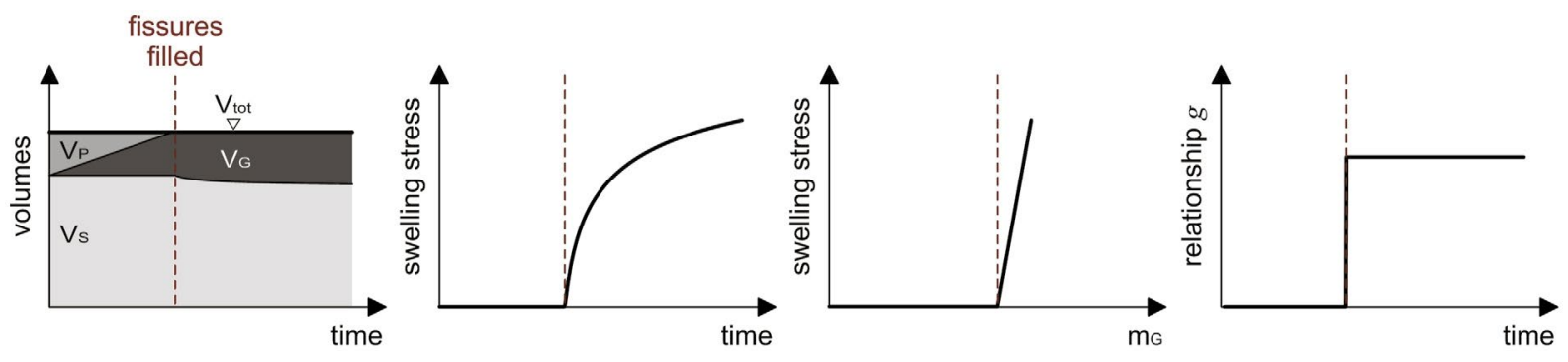

Figure 7-16: (From left to right) changes in volumes, assumed change of stress over time due to gypsum precipitation in the fissures, stress vs. mass of gypsum and corresponding relationship $g$.

\subsubsection{Influence of simultaneous anhydrite dissolution and gypsum precipitation on the stresses and strains}

As seen in the previous chapters (7.2.2 and 7.2.3), anhydrite dissolution and precipitation of gypsum both lead to changes in stresses and strains of the regarded systems. Now, the general supposition made in this thesis is resumed, that both anhydrite dissolution and gypsum precipitation occur simultaneously and without transport, whereas anhydrite dissolution is considered to be the governing process (cf. Chapter 2.2.3). Similar to the previously introduced conceptual models, the following models discuss the influence of simultaneous anhydrite dissolution and gypsum precipitation on stresses and strains, and thus deliver an indication for the coupling parameters $\chi_{a x}$ and $\chi_{\text {rad }}$ or the "combined" parameter $\chi$ (see Equations $(7-7)$ to $(7-11)$ ).

\section{a. Fine granular homogeneous material}

\section{a.i. Influence on the strains}

Based on Equation (7 - 20), the strains occurring in a granular material during both anhydrite dissolution and gypsum precipitation are dependent on the change in porosity and on the volumes of anhydrite and gypsum (the inert material will not change in volume).

It is possible for the porosity to decrease, i.e., if the gypsum fills up the pores, or for the porosity to increase due to gypsum growth (see also Chapter 7.2.3). In a closed system, where no water flows into or out of the system, not only the volume of the solids but also the change in water volume due to gypsum precipitation needs to be considered. The specimen will shrink (see Equation (2 - 17)) unless gypsum precipitation increases the pore space and creates a vacuum.

In a closed system, Equations (2 - 13) and (2 - 14) can be used to simplify Equation (7 - 20) for the calculation of volumetric strains:

$\varepsilon_{v o l}=\frac{V_{\text {tot }}-V_{\text {tot }}}{V_{\text {tot }}}=\frac{\Delta V_{A}+\Delta V_{G}+\Delta V_{W}}{\left(V_{A_{0}}+V_{G_{0}}+V_{S_{0}}+V_{W_{0}}\right)}=\frac{\Delta V_{A} \cdot 0.171}{V_{\text {tot }_{0}}}=\frac{\Delta V_{G} \cdot(-0.106)}{V_{\text {tot }}}=\frac{\Delta V_{W} \cdot 0.218}{V_{\text {tot }_{0}}}$

l.e., in this case the change in strains is linearly dependent on the changes in volumes (and therefore: of the masses) of either anhydrite, gypsum or water. Therefore, $\chi$ is a constant in the case of a closed system.

In an open system the change in volumetric strains can be established with Equation (7 - 20) via the volumes of anhydrite and gypsum as well as the porosity of the specimen for any given time. Here, $V_{G_{0}}$ is chosen to be equal to zero (no gypsum in the initial specimen). 
If the pore volume changes, independently from the water content or type of system (e.g., if the porosity increases due to cracking and air-filled pores exist), the strain needs to be calculated again via Equation (7 - 20). In Figure 7-7 and Figure 7-14, various scenarios are conceived for the development of the pore volume during anhydrite dissolution or gypsum precipitation. In the case of simultaneous anhydrite dissolution and gypsum precipitation, any combination of those scenarios is possible. The following exemplary cases are regarded in Figure 7-17, whereas the specimens are considered fully saturated at all times $\left(V_{P}=V_{W}\right)$ and the volumes of anhydrite and gypsum change simultaneously in each case (from left to right in Figure 7-17):

- a closed system, where gypsum precipitates in the pore space and no water is added or escapes (thus the porosity decreases);

- an open system where the porosity remains constant;

- an open system where the pore volume remains constant and (due to increasing total volume) the porosity decreases slightly;

- an open system where the gypsum precipitates within the pores until the pore volume equals zero, from which point on the specimen expands. (Note that this too represents a hypothetical case; in reality, especially when small pores are present, the precipitating gypsum would cause an expansion of the specimen before the pores are completely filled. Furthermore, small gypsum crystals in the proximity of larger crystals can dissolve and the solute will diffuse toward the larger crystal, leaving behind newly created small pores, see Scherer, 2002).

For each case the swelling strains, change in mass of anhydrite per unit volume and thus the unknown relationship $\chi$ were determined according to Equation $(7-16)$ and are shown in Figure 7-17. As can be seen, $\chi$ is strongly dependent on the type of system and the change in porosity (i.e., whether the gypsum precipitates within the pores or around the grains and therefore expands the specimen). 
closed system constant porosity constant pore volume, decreasing porosity

decreasing porosity, pores filled
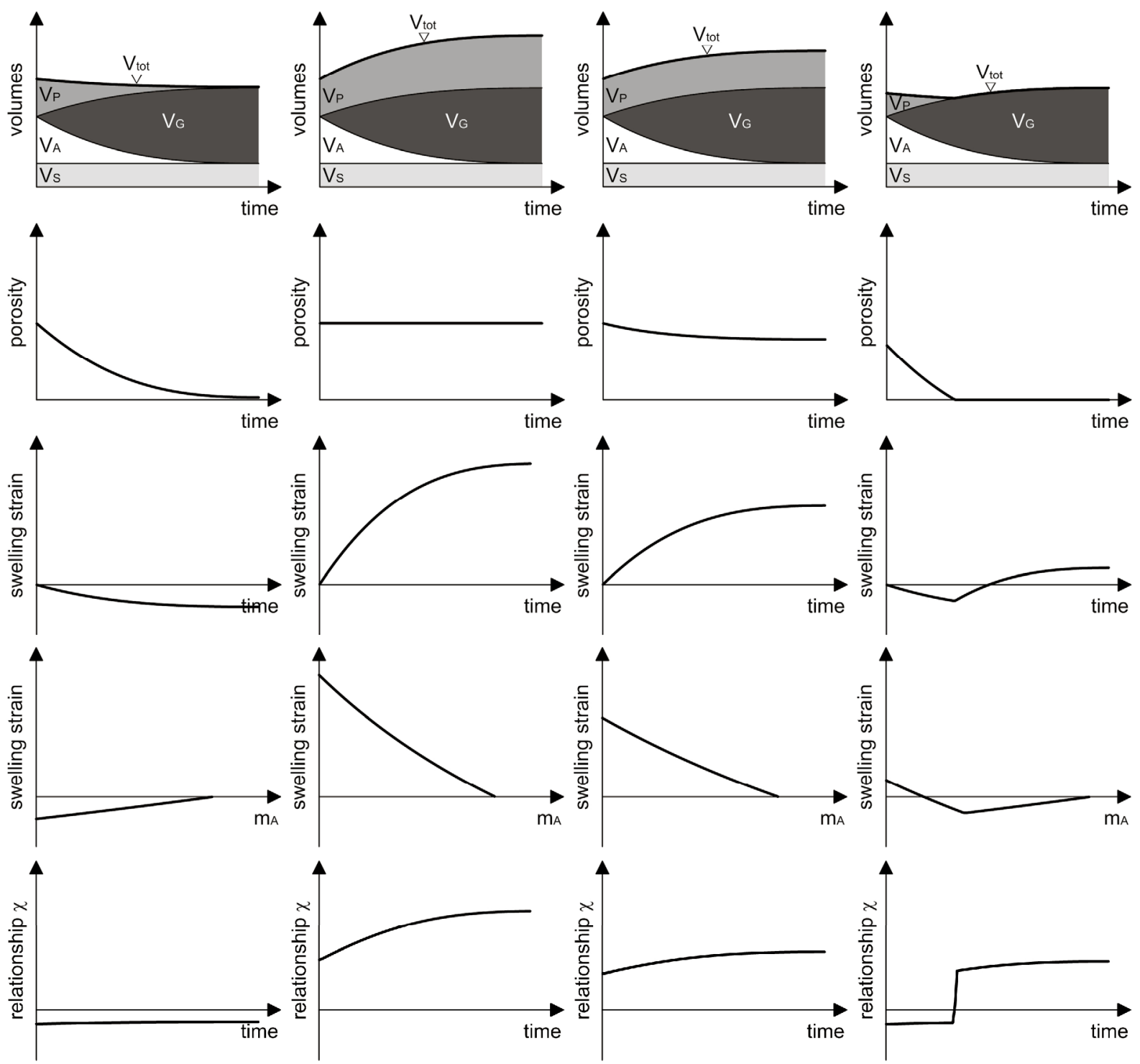

Figure 7-17: Various scenarios for the development of the porosity $n$ for the influence of anhydrite dissolution and gypsum precipitation on strains for granular material. Top to bottom: volumes, porosity, and swelling strains vs. time; swelling strains vs. change in mass of anhydrite and resulting relationship $\chi$ vs. time.

\section{a.ii. Influence on the stresses}

If a change in strains (and thus in volume) in an open system is prohibited, AGT will induce stresses. Anhydrite dissolution will reduce the contact stresses between the grains, as the grains decrease and the pore space increases. Similar to the scenarios in Figure 7-17, gypsum precipitation may occur within the pore space, which - depending on the pore space and the porosity - may either not affect the external stresses at all, or gypsum precipitation may cause the grains to be pushed apart, thus leading to an increase in stresses. However, an increase in stress will increase the equilibrium concentration of gypsum which may slow further gypsum precipitation down strongly or even lead to a state of thermodynamic equilibrium, in which case no further anhydrite dissolves and no gypsum precipitates (see Figure 2-5; note that the necessary pressure for an equilibrium, i.e., the crystallization pressure, may exceed $50 \mathrm{MPa}$ ). 


\section{b. "Sponge-like", perforated system}

The perforated block from Chapter 7.2.1.b is regarded while assuming gypsum to precipitate in the pipes when anhydrite dissolves (cf. also Chapters 7.2.2.b and 7.2.3.b.).

On the one hand, it is possible that the anhydritic material bridges will simply decrease until the system fails (depending, of course, on the layout of the boreholes). On the other hand, gypsum may precipitate evenly on the anhydritic surface, thus cause sealing (cf., Chapter 5) and slow the process of anhydrite dissolution down and even "heal" the material and therefore keep the system from collapsing. However, due to the fact that the uniaxial strength of gypsum is lower than that of anhydrite (cf., e.g., Bell, 1994), the structure may fail after a certain amount of AGT has occurred (depending, of course, on the acting stresses and thicknesses of the material bridges). This strength reduction is even more pronounced when the precipitated gypsum is porous.

The gypsum could also fill up the pipes, and if the crystallization pressure eventually overcomes the strength of the material, lead to cracking. Depending on the pressure, the equilibrium concentration of gypsum may, however, increase to a value where no further gypsum precipitation occurs.

\section{b.i. Influence on the strains}

A situation is assumed, where a perforated system is subjected to an initial axial stress. While it is in contact with water, anhydrite dissolves and gypsum precipitates. Depending on the initial stress and the effect of sealing and crystal-growth in the pipes on anhydrite dissolution, the block may maintain enough strength to withstand a collapse (as opposed to the situation described in Chapter 7.2.2.b.i, where gypsum precipitation is undermined).

However, it is also imaginable that as certain material bridges may fail, gypsum precipitates in the growing cracks and may even lead to an expansion of the entire system.

For a combination of both processes, anhydrite dissolution and gypsum precipitation, various outcomes and influences on the strains are therefore possible.

\section{b.ii. Influence on the stresses}

It can also not be predicted, what the influence of simultaneous anhydrite dissolution and gypsum precipitation will be on the stresses while the strains are held constant. Depending on many factors, the system can either weaken, leading to a decrease in applied stress, or the crystallization pressure may lead to an increase in stress. Another possibility is, that gypsum "seals" the anhydrite, thus keeping the material intact and prohibiting further dissolution.

\section{c. Layered anhydrite}

The expected behavior of a specimen as described in Chapter 7.2.1.c will be rather anisotropic, if simultaneous anhydrite dissolution and gypsum precipitation are considered. Since the anhydrite is distributed in layers, it is expected to cause strains and stresses mainly in the axial direction, perpendicular to the layers (cf. Chapter 7.2.2.c). However, if gypsum precipitates additionally in the same specimen (assuming that the specimen consists of granular material, apart from the anhydritic layers), it is expected to produce stresses resp. strains in all directions but mainly in the axial direction, perpendicular to the layers. Therefore a heterogeneous, anisotropic specimen is being dealt with, as the resulting strains and stresses will vary in the two directions. 


\section{c.i. Influence on strains}

A combination of the following two cases will occur when regarding the influence of simultaneous anhydrite dissolution and gypsum precipitation on strains: Anhydrite dissolution will cause axial strains (i.e., a reduction in specimen height, see also Chapter 7.2.2.c.i) while gypsum precipitation will cause axial and radial strains (i.e., an increase in height and diameter) if the specimen is granular; however, if the anhydritic layers were embedded in a rock matrix (i.e., anhydritic veins, cf. Chapter 7.2.4.d), gypsum precipitation will cause mainly axial strains.

\section{c.ii. Influence on stresses}

Should the strains be prohibited, the chemical processes (i.e., the changes in solid and pore volumes) will naturally induce stresses. The dissolution of anhydrite leads to a higher relaxation of the axial stress compared to the radial stress, while gypsum precipitation may occur in all directions in the case of granular material and thus cause an increase in stresses. It may be that gypsum precipitates in the same planes as anhydrite dissolved, therefore attempting an expansion mainly in axial direction and thus causing higher axial swelling stresses. On the other hand, gypsum may also grow evenly in all directions, thus increasing the radial swelling stress as well.

\section{d. Rock with anhydritic veins}

Now a situation is regarded, where anhydritic veins dissolve (as described in Chapter 7.2.2.d), and gypsum precipitates in existing and newly created fissures due to anhydrite dissolution (creating a situation comparable to the one in Chapter 7.2.3.d).

\section{d.i. Influence on strains}

Depending on the thickness and distribution of the veins, as well as the presence of further pore space (or fissures in the rock), the following scenarios are conceivable and are illustrated in Figure 7-18:

On the one hand it is possible for the anhydrite dissolution and gypsum precipitation not to influence the total volume of the specimen at first, until all previously existing and (through anhydrite dissolution) newly created fissures are filled with gypsum. In order for further gypsum to precipitate, the pressure caused by the crystallizing gypsum needles would need to crack the surrounding matrix, thus creating new pore space. This was assumed in Figure 7-18a. The new pore space gets filled up again with gypsum and eventually keeps on expanding the entire cracked specimen.

On the other hand, assuming a high initial stress acting on the specimen, dissolution of anhydrite may weaken the material bridges so far that they collapse and the entire pore space is closed (see Figure 7-18b). Further gypsum precipitation will then cause the total volume to expand. 

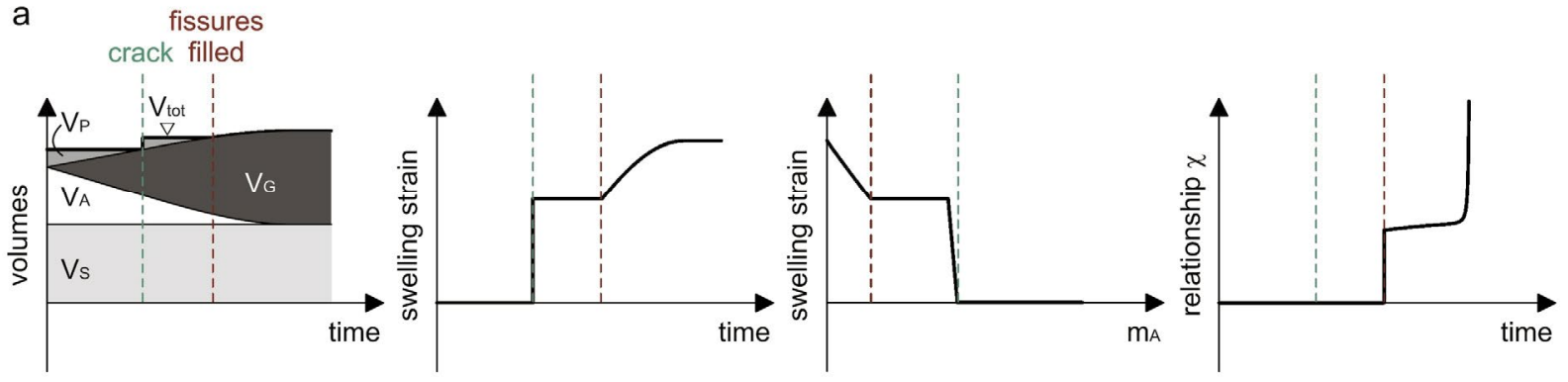

b
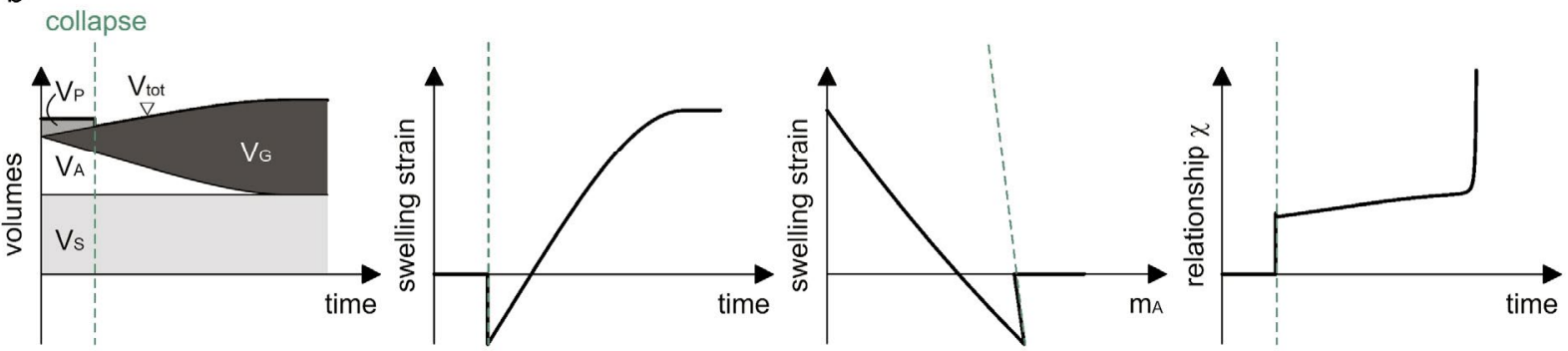

Figure 7-18: Influence of simultaneous anhydrite dissolution and gypsum precipitation on strains for a rock with anhydritic veins: Possible developments of volumes, strains, mass of anhydrite per unit volume and thus of the relationship $\chi$. (a) Gypsum precipitation causes rock to crack; (b) anhydrite dissolution causes rock to collapse.

\section{d.ii. Influence on stresses}

Analogue considerations can be made when prohibiting any strains: On the one hand (see Figure 7-19a), a specimen under initial stresses may not react at all at first while the anhydrite dissolves and gypsum precipitates, and only when the fissures are filled with gypsum, the stress begins to increase as gypsum precipitation exerts a stress on the rock. With increasing stress, however, the equilibrium concentrations both increase to a different extent (see Figure 2-5), whereas the equilibrium concentration of gypsum may even exceed that of anhydrite, thus stopping the AGT process.

On the other hand, similar as in the previous sub-chapters where the influence of AGT on the strains was discussed, the material-bridges may fail during anhydrite dissolution (depending of course on the applied stress and the strength of the rock), causing an abrupt (elastic) increase in solid volume and a drop in external stresses, while the total volume is assumed to remain constant (cf. Figure 7-19b). Further gypsum precipitation will then increase the stress again. 

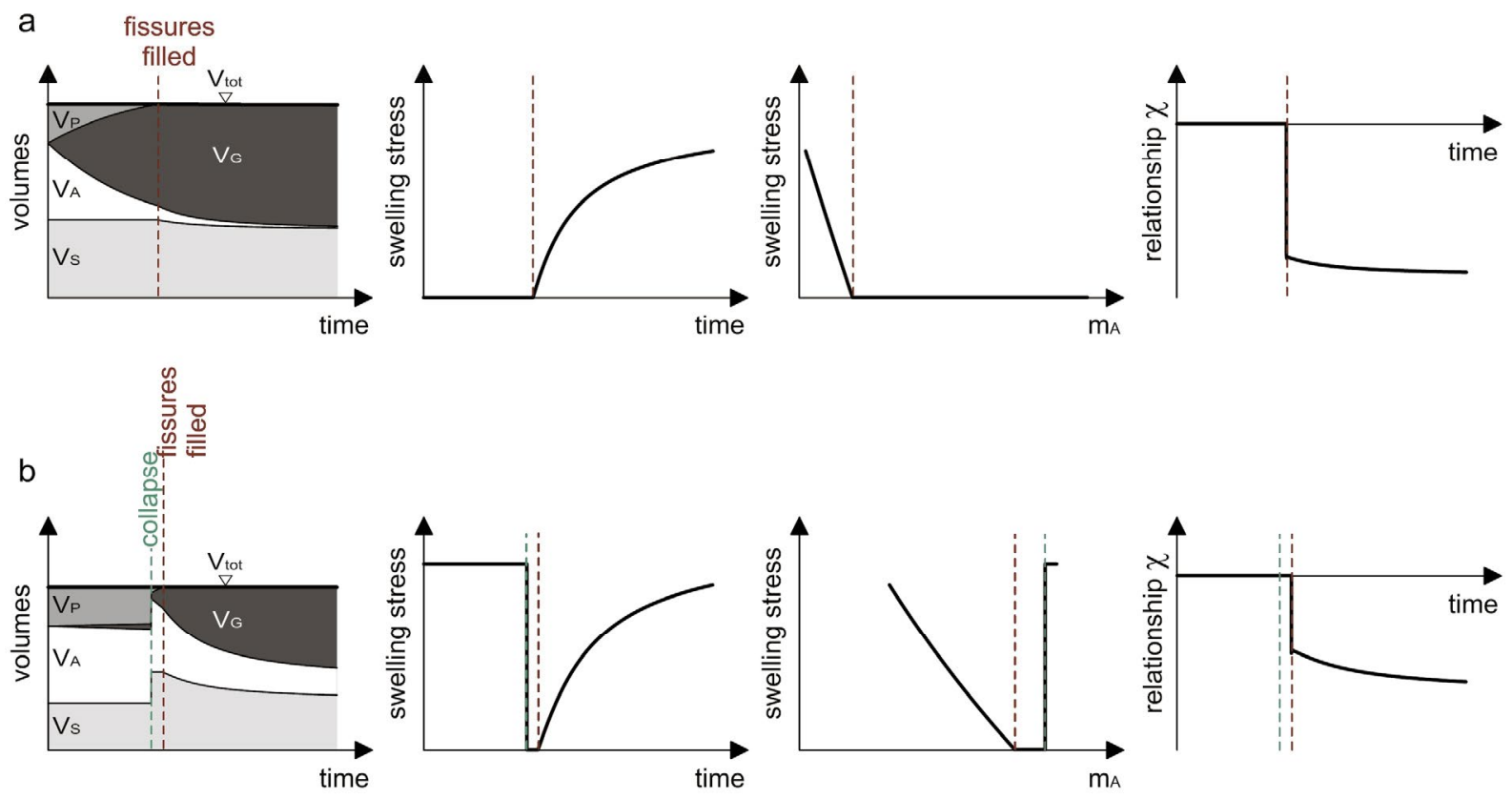

Figure 7-19: Influence of simultaneous anhydrite dissolution and gypsum precipitation on stresses for a rock with anhydritic veins: Possible development of volumes (a and b, whereas the total volume is held constant), stresses, mass of anhydrite per unit volume and thus of the relationship $\chi$.

\subsection{Thought experiments}

In order to plan an experimental campaign to determine the coupling parameters introduced in the previous Chapters $(a, g$ and $\chi$ ), thought experiments are now devised for selected cases of the conceptual models. Conditions are discussed, under which experiments would need to be executed in order to determine the coupling parameters.

These thought experiments consider an axisymmetric system, as introduced in Chapter 7.1, i.e., isotropic or transversal isotropic material behavior of cylindrical specimens is assumed (e.g., granular, homogeneous material or layers/cracks perpendicular to the axial direction).

First, a schematic testing apparatus is introduced and the general testing procedure described in Chapter 7.3.1. Depending on which chemical reactions are considered (solely anhydrite dissolution or gypsum precipitation or both reactions simultaneously), different conditions need to be met, an overview of which is given in Chapter 7.3.2. In order to differentiate between the coupling parameters in axial and radial direction, four systems of mechanical boundary conditions and measured variables are considered and described in Chapter 7.3.3.

Specific remarks on the execution and evaluation of thought experiments are then made in Chapter 7.3.4 for the case of simultaneous anhydrite dissolution and gypsum precipitation, due to the fact that anhydrite dissolution or gypsum precipitation alone are unlikely to occur (cf. Chapter 2.2.3) and will not be considered further in the planning of experiments. Thought experiments concerning the hypothetical cases of solely anhydrite dissolution or gypsum precipitation are further discussed in Appendix E.

In practice, however, it will be very difficult, unfeasible or even impossible to execute some of the experiments (see Chapter 7.3.4 and Appendix E). 


\subsubsection{Apparatus and general procedure}

If not indicated otherwise, the "general" testing apparatus shown in Figure 7-20 can be considered for the thought experiments and it corresponds to a triaxial test in soil mechanics, in which a cylindrical specimen is assembled in the cell. The dimensions of the specimen (height $h$ and diameter $2 r$ ) as well as the fractions of all compounds (inert, anhydrite and pores), their distribution (e.g., homogeneously distributed or layered) and particle sizes are known prior to the test and the specimen is initially free of gypsum. During the test, the specimen is saturated (no air) and sealed radially (e.g., by a rubber membrane) while the top and bottom ends are covered by perforated filter plates and are connected to the water supply and water outlet. As described in the following, in addition to the typical measurements it is necessary to also measure or control the ion concentration of the water as well as the temperature within and outside of the cell.

The axial $\left(\sigma_{a x}\right)$ and radial loads ( $\left.\sigma_{\text {rad }}\right)$ are applied with a piston and liquid pressure respectively. Both loads can be controlled to a prescribed value or measured if the deformation is prohibited, and, vice versa, the axial $(\Delta h)$ and radial $(\Delta r)$ displacements can be controlled or measured if the loads are constant. Therefore, any mechanical boundary conditions ranging from completely constrained to oedometric, isotropic or triaxial conditions (as will be described in Chapter 7.3.3) can be executed. The water flux (denoted by $Q_{i n}$ and $Q_{\text {out }}$ ) is measured at both ends of the specimen and depends on the applied hydraulic gradient, which can also be controlled by prescribed constant values for the water pressures before $\left(p_{\text {in }}\right)$ and after the specimen $\left(p_{\text {out }}\right)$. The ionic concentration of the inflowing water $\left(c_{i n}\right)$ is pre-defined (see Table 7-1), while the concentration of the exiting water $\left(c_{\text {out }}\right)$ needs to be measured in most cases, in order to determine the amount of consumed or dissolved ions within the specimen. If possible, the specimen should be saturated with an inert fluid (e.g., ethanol) in certain time intervals, which pauses the test, and the total mass of the saturated specimen weighed; however, this necessitates an unloading of the specimen which most likely causes the structure to change. If the inert fluid can be separated from water and quantified, the pore volume of the specimen can be established, thus allowing a backcalculation of the masses of gypsum and/or anhydrite in the specimen (see Appendix E.3).

Finally, it may be necessary to perform the experiment at a temperature within the cell ( $\left.T_{\text {int }}\right)$ different to that prevailing outside the cell $\left(T_{\text {ext }}\right)$ in order to control the chemical reactions.

Post test, the specimen is measured, weighed and dried and the specimen composition determined (e.g., with XRD or TGA). In order to investigate the change in structure of the material, the specimen can be investigated, e.g., by microscopy, porosimetry or laserdiffractometry (to investigate the change in grainsize distribution in the case of granular material). 


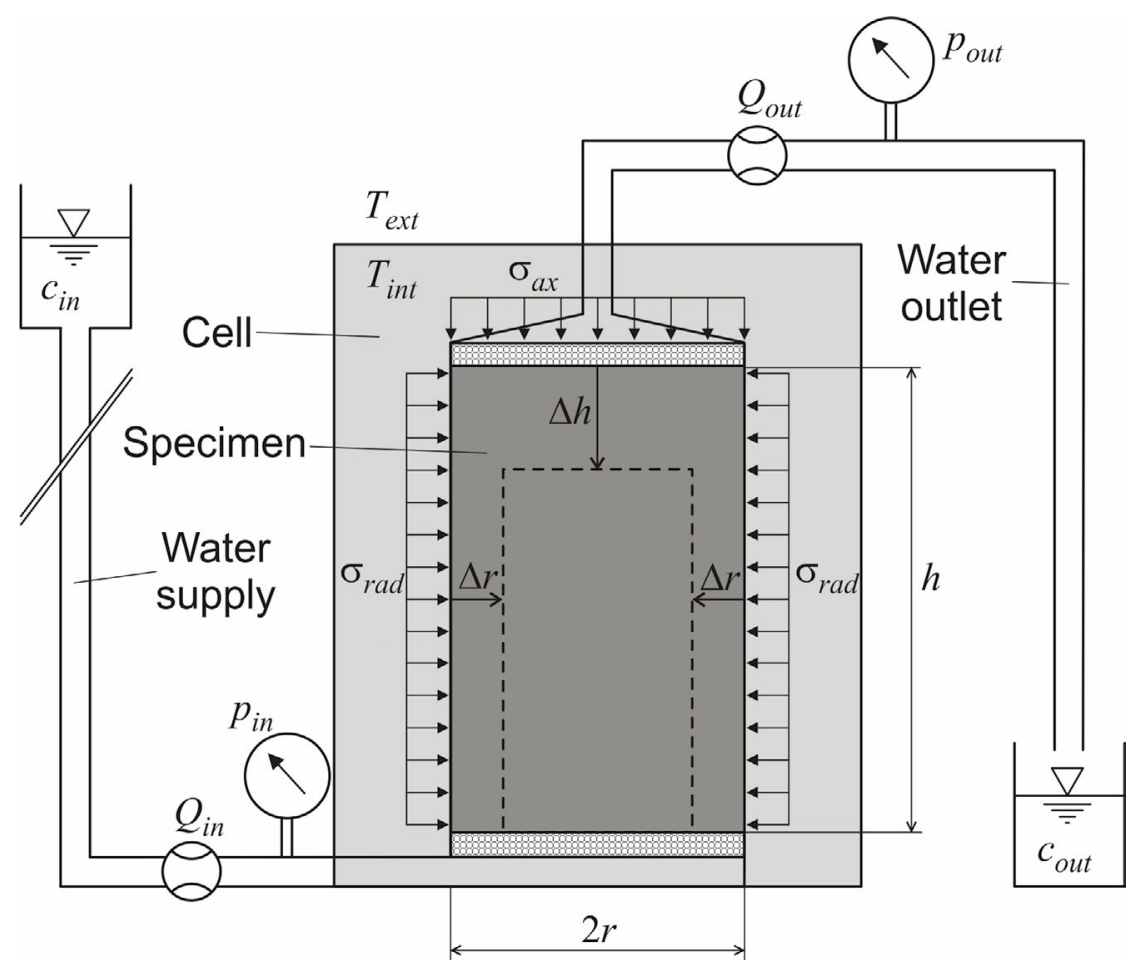

Figure 7-20: Schematic sketch of an apparatus for the C-M experiments with all controlled and measured variables.

The conditions under which the experiments are run and the measurements that need to be taken can be grouped into boundary conditions concerning the chemical reactions (Chapter 7.3.2) as well as mechanical conditions and variables (Chapter 7.3.3).

\subsubsection{Initial and boundary conditions concerning the chemical reactions}

Depending on whether solely anhydrite dissolution, gypsum precipitation or both processes (simultaneously) are considered, some initial and boundary conditions differ. Table 7-1 summarizes these parameters. Note that here an open system is assumed; in Chapter 7.3.4 and in Appendix E some selected examples for experiments in closed systems are discussed separately. 
Table 7-1: $\quad$ Initial and boundary conditions concerning the chemical reactions.

\begin{tabular}{|c|c|c|c|}
\hline & Anhydrite dissolution & Gypsum precipitation & Simultaneous reactions \\
\hline \multicolumn{4}{|l|}{ Initial conditions } \\
\hline Mass of anhydrite [g] & $M_{A, 0}>0$ & $M_{A, 0}=0$ & $M_{A, 0}>0$ \\
\hline \multicolumn{4}{|l|}{ Boundary conditions } \\
\hline Mass of gypsum $\left[\mathrm{g} / \mathrm{cm}^{3}\right]$ & $M_{G}=0$ & & \\
\hline Concentration of inflowing water $\left[\mathrm{mol} / \mathrm{m}^{3}\right]$ & $c_{i n}=0$ & $c_{i n} \leq c_{e q, \mathrm{G}}$ & $c_{i n}=c_{e q, G}$ \\
\hline $\begin{array}{l}\text { Concentration of water in specimen } \\
{\left[\mathrm{mol} / \mathrm{m}^{3}\right]}\end{array}$ & $\begin{array}{l}c \leq c_{o u t}<c_{e q, A} \\
c<c_{e q, \mathrm{G}}\end{array}$ & $c>c_{e q, \mathrm{G}} \geq c_{o u t}$ & $c_{e q, \mathrm{G}}<c<c_{e q, A}$ \\
\hline Concentration of exiting water $\left[\mathrm{mol} / \mathrm{m}^{3}\right]$ & $c_{\text {out }}<c_{e q, G}$ & $c_{o u t} \leq c_{e q, \mathrm{G}}$ & $c_{o u t} \approx c_{e q, \mathrm{G}}$ \\
\hline Temperature in cell $\left[{ }^{\circ} \mathrm{C}\right]$ & $T_{i n t} \geq T_{e q}$ & $T_{i n t}<T_{e x t} \leq T_{e q}$ & $T_{i n t}<T_{e q}\left(e . g .20^{\circ} \mathrm{C}\right)$ \\
\hline Temperature outside cell $\left[{ }^{\circ} \mathrm{C}\right]$ & $0^{\circ} \mathrm{C}<T_{\text {ext }} \leq T_{i n t}$ & $T_{\text {ext }}$ & $T_{e x t}=T_{i n t}$ \\
\hline
\end{tabular}

\subsubsection{Mechanical boundary conditions and variables}

Four different systems are taken into consideration for the experiments. The boundary conditions are sketched schematically in Figure 7-21 (black) together with the measured variables (green):

(a) Isotropic compression: Investigation of the influence of chemical reactions on the strains, while keeping the stresses constant;

(b) Complete constraint: Investigation of the influence of chemical reactions on the stresses, while keeping the strains constant;

(c) Oedometric conditions: Investigation of the influence of chemical reactions on the axial strains and (possibly) radial stresses, while keeping the radial strains and axial stresses constant;

(d) "Flexible" oedometer: Investigation of the influence of chemical reactions on the axial strains, radial strains and radial stresses, while keeping the axial stresses constant.

Regarding the apparatus sketched in Figure 7-20, the Table 7-2 summarizes the mechanical initial conditions, boundary conditions and the measured variables for each system. 

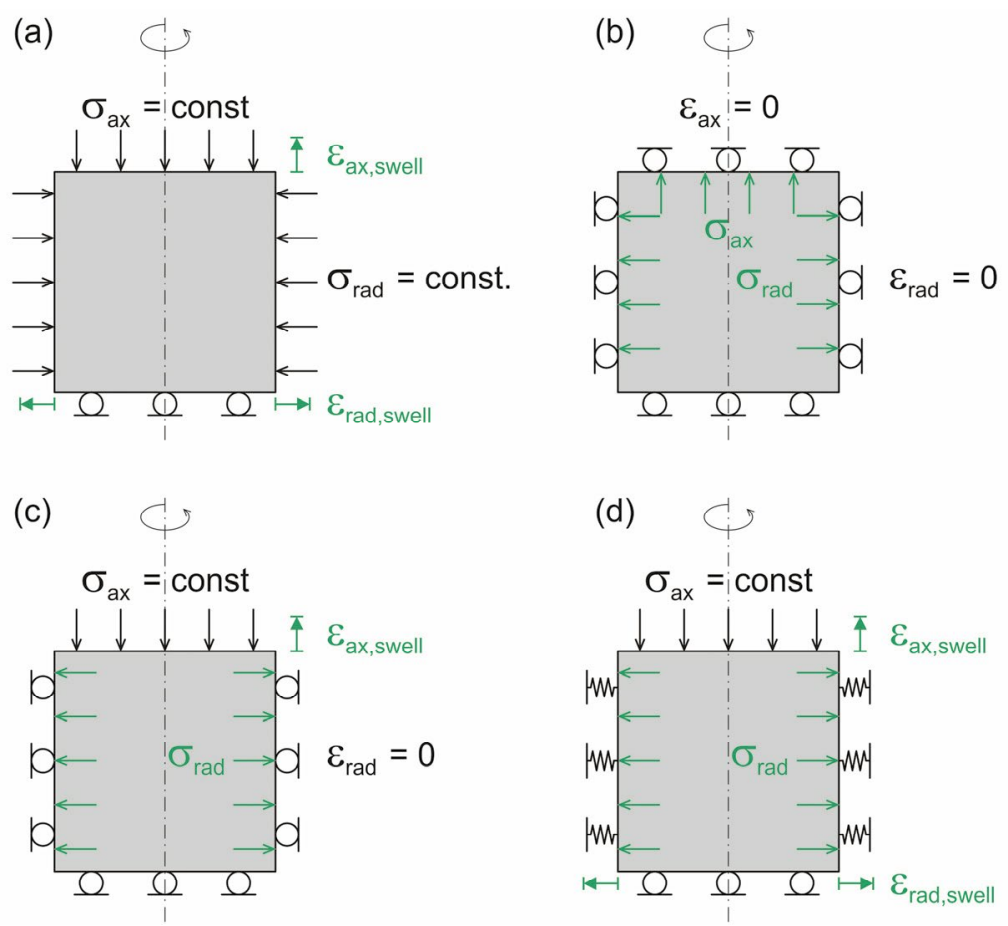

Figure 7-21: Mechanical boundary conditions (black) and measured variables (green) for the thought experiments. (a) Isotropic compression, (b) complete constraint, (c) oedometer, (d) flexible oedometer.

Table 7-2: $\quad$ Mechanical boundary conditions and measurements for the thought experiments.

\begin{tabular}{|c|c|c|c|c|}
\hline & $\begin{array}{c}\text { Isotropic } \\
\text { compression }\end{array}$ & $\begin{array}{l}\text { Complete } \\
\text { constraint }\end{array}$ & Oedometer & $\begin{array}{c}\text { Flexible } \\
\text { oedometer }\end{array}$ \\
\hline \multicolumn{5}{|l|}{ Boundary conditions } \\
\hline Axial stress [kPa] & $\sigma_{a x}=$ const & & $\sigma_{a x}=$ const. & $\sigma_{a x}=$ const \\
\hline Radial stress [kPa] & $\sigma_{r a d}=$ const & & & \\
\hline Axial deformation [mm] & & $\Delta h=0$ & & \\
\hline Radial deformation [mm] & & $\Delta r=0$ & $\Delta r=0$ & \\
\hline
\end{tabular}

\section{Measurements during test}

\begin{tabular}{llcc} 
Axial stress $[\mathrm{kPa}]$ & $\sigma_{a x}$ & & \\
\hline Radial stress $[\mathrm{kPa}]$ & $\sigma_{\text {rad }}$ & $\sigma_{\text {rad }}$ & $\sigma_{\text {rad }}$ \\
\hline Axial deformation [mm] & $\Delta h$ & $\Delta h$ & $\Delta h$ \\
\hline Radial deformation $[\mathrm{mm}]$ & $\Delta r$ & & $\Delta r$ \\
\hline
\end{tabular}


From the changes in radius and height of the specimen, the radial and axial strains can be determined, as well as the changes in total volume of the specimen:

$$
\begin{gathered}
\varepsilon_{a x}=-\varepsilon_{a x, \text { swell }}=\frac{\Delta h}{h} \\
\varepsilon_{r a d}=-\varepsilon_{\text {rad,swell }}=\frac{\Delta r}{r} \\
V_{\text {tot }}=\left(h_{0}-\Delta h\right) \cdot\left(r_{0}-\Delta r\right)^{2} \cdot \pi
\end{gathered}
$$

These thought experiments assume that the conditions listed in Table 7-2 can be met and the respective variables can be measured (i.e., with a conceptual apparatus as shown in Figure 7-20). In practice this may, however, not be possible to realize. For example, it is not possible to measure radial stresses with conventional oedometers (for this reason, so-called "flexible oedometers" are introduced in this thesis, $c f$. Chapter 8.8 , where the radial deformation is measured and the radial pressure is calculated based on the stiffness of the oedometer), with isotropic compression tests the stresses may fluctuate slightly (e.g., due to slightly changing temperatures) and with completely constrained tests it may not be possible to completely prohibit axial strains (e.g., due to the stiffness of the apparatus as well as slightly changing temperatures). This will be seen in Chapter 8 , where the executed experiments are described.

\subsubsection{Evaluation of thought experiments for simultaneous anhydrite dissolution and gypsum precipitation}

The evaluation of possible thought experiments with respect to the (unknown) coupling parameters are now discussed more in depth for the case of simultaneous anhydrite dissolution and gypsum precipitation. Analog considerations for the hypothetical cases of solely anhydrite dissolution or gypsum precipitation are featured in Appendix E.

Depending on the mechanical boundary conditions, $\chi_{a x}, \chi_{\text {rad }}$ and $\chi$ (cf. Equations $(7-7)$ to $(7-11)$ ) can thus be determined as follows (the pore water pressure is assumed to be constant in all cases):

- Isotropic compression (constant stresses, cf. Equation (7 - 9)):

$$
\begin{gathered}
\dot{\varepsilon}_{a x}=\frac{\chi_{a x}}{\rho_{A}} \dot{m}_{A} \\
\dot{\varepsilon}_{r a d}=\frac{\chi_{r a d}}{\rho_{A}} \dot{m}_{A}
\end{gathered}
$$

And $\chi_{a x}, \chi_{\text {rad }}$ and $\chi$ amount to:

$$
\begin{aligned}
& \chi_{a x}=\frac{\partial \varepsilon_{a x}}{\partial m_{A}} \cdot \rho_{A} \\
& \chi_{\text {rad }}=\frac{\partial \varepsilon_{r a d}}{\partial m_{A}} \cdot \rho_{A}
\end{aligned}
$$




$$
\chi=\chi_{a x}+\frac{2 v}{(1-v)} \chi_{r a d}=\left(\frac{\partial \varepsilon_{a x}}{\partial m_{A}}+\frac{2 v}{(1-v)} \frac{\partial \varepsilon_{r a d}}{\partial m_{A}}\right) \cdot \rho_{A}
$$

- Complete constraint (constant strains):

$$
\begin{gathered}
\dot{\sigma}_{a x}=\frac{-(1-v) E}{(1+v)(1-2 v)} \frac{1}{\rho_{A}} \dot{m}_{A}\left(\chi_{a x}+\frac{2 v}{(1-v)} \chi_{\text {rad }}\right)=\frac{-(1-v) E}{(1+v)(1-2 v)} \frac{1}{\rho_{A}} \dot{m}_{A} \chi \\
\dot{\sigma}_{r a d}=\frac{-E}{(1+v)(1-2 v)} \frac{1}{\rho_{A}} \dot{m}_{A}\left(v \chi_{a x}+\chi_{\text {rad }}\right)
\end{gathered}
$$

and Equations $(7-10)$ and $(7-11)$ are reduced to:

$$
\begin{gathered}
\chi_{a x}=\frac{\rho_{A}}{E} \cdot\left(-\frac{\partial \sigma_{a x}}{\partial m_{A}}+\frac{\partial \sigma_{r a d}}{\partial m_{A}} \cdot 2 v\right) \\
\chi_{\text {rad }}=\frac{\rho_{A}}{E} \cdot\left(\frac{\partial \sigma_{a x}}{\partial m_{A}} \cdot v-\frac{\partial \sigma_{r a d}}{\partial m_{A}} \cdot(1-v)\right) \\
\chi=\frac{\partial \sigma_{a x}}{\partial m_{A}} \cdot \frac{(1+v)(1-2 v)}{-E \cdot(1-v)} \cdot \rho_{A}
\end{gathered}
$$

- Oedometric conditions (constant axial stress, constant radial strain):

$$
\begin{gathered}
\dot{\varepsilon}_{a x}=\left(\chi_{a x}+\frac{2 v}{(1-v)} \cdot \chi_{r a d}\right) \cdot \frac{1}{\rho_{A}} \cdot \dot{m}_{A}=\frac{\chi}{\rho_{A}} \cdot \dot{m}_{A} \\
\dot{\sigma}_{r a d}=\frac{-E}{(1-v)} \cdot \frac{\chi_{r a d}}{\rho_{A}} \cdot \dot{m}_{A}
\end{gathered}
$$

If it is possible to measure the radial stresses:

$$
\begin{gathered}
\chi_{a x}=\left(\frac{\partial \varepsilon_{a x}}{\partial m_{A}}+\frac{2 v}{E} \frac{\partial \sigma_{r a d}}{\partial m_{A}}\right) \cdot \rho_{A} \\
\chi_{\text {rad }}=-\frac{(1-v)}{E} \frac{\partial \sigma_{r a d}}{\partial m_{A}} \cdot \rho_{A}
\end{gathered}
$$

However, as mentioned above, in conventional oedometer cells merely the axial strains are measured while the radial stresses cannot be measured and therefore only the combined parameter $\chi$ can be determined:

$$
\chi=\frac{\partial \varepsilon_{a x}}{\partial m_{A}} \cdot \rho_{A}
$$


- Flexible oedometer (constant axial stress):

$$
\begin{gathered}
\dot{\varepsilon}_{a x}=\frac{(1+v)(1-2 v)}{E v} \dot{\sigma}_{r a d}-\frac{1}{v} \dot{\varepsilon}_{r a d}+\frac{\dot{m}_{A}}{\rho_{A}}\left(\chi_{a x}+\frac{1}{v} \chi_{\text {rad }}\right) \\
\dot{\varepsilon}_{r a d}=\frac{(1+v)(1-2 v)}{E} \dot{\sigma}_{r a d}-v \dot{\varepsilon}_{a x}+\frac{\dot{m}_{A}}{\rho_{A}}\left(v \chi_{a x}+\chi_{\text {rad }}\right) \\
\dot{\sigma}_{r a d}=\frac{E}{(1+v)(1-2 v)} \cdot\left(v \dot{\varepsilon}_{r a d}+\dot{\varepsilon}_{r a d}-\frac{\dot{m}_{A}}{\rho_{A}}\left(v \chi_{a x}+\chi_{r a d}\right)\right)
\end{gathered}
$$

And from Equations $(7-10)$ and $(7-11), \chi_{a x}, \chi_{\text {rad }}$ and $\chi$ amount to:

$$
\begin{gathered}
\chi_{a x}=\left(\frac{\partial \varepsilon_{a x}}{\partial m_{A}}+\frac{2 v}{E} \frac{\partial \sigma_{r a d}}{\partial m_{A}}\right) \cdot \rho_{A} \\
\chi_{\text {rad }}=\left(\frac{\partial \varepsilon_{r a d}}{\partial m_{A}}-\frac{(1-v)}{E} \frac{\partial \sigma_{r a d}}{\partial m_{A}}\right) \cdot \rho_{A} \\
\chi=\left(\frac{\partial \varepsilon_{a x}}{\partial m_{A}}+\frac{2 v}{(1-v)} \frac{\partial \varepsilon_{r a d}}{\partial m_{A}}\right) \cdot \rho_{A}
\end{gathered}
$$

For the evaluation of each test, it will be of importance to determine the masses of gypsum and anhydrite, during and/or after the test. If the conditions for strictly simultaneous anhydrite dissolution and gypsum precipitation are given (the ion transport into and out of the specimen in the open system are equal) and either the pore volume, specimen mass or amount of "consumed" water is known in addition to the total volume, this can be obtained indirectly through the mass balance of the AGT process (Equation (2 - 9)). Further specifications for the (theoretical) possibilities of determining the masses of anhydrite and gypsum during an experiment are given in Appendix E.3. In practice, these possibilities are not considered realizable. For one, the hydraulic boundary conditions, such as the exact mass of water inflow and outflow, would need to be held or measured with highest precision to determine the consumed ions and the change in pore space. It is deemed that this is not attainable under practicable laboratory conditions over such a long duration as required for swelling tests (e.g., due to evaporation or other loss of water over time). Secondly, while interrupting a running experiment to weigh the specimen could give information on the amount of transformed anhydrite and gypsum (assuming that it is at all possible to replace the pore water completely with an inert fluid), an interruption may not be advisable, since the condition (such as the structure) of the specimens changes, e.g., due to unloading or drying. It is, therefore, concluded that the mass changes of anhydrite and gypsum can only be determined through destructive analyses (where a part of the specimen needs to be sacrificed, e.g., for TGA or XRD, cf. Chapter 3).

As mentioned in the conceptual models (e.g., Chapter 7.2.4), the behavior of a specimen during a swelling experiment is strongly dependent on the geometry of the pore space and its change (i.e., the change in porosity). 


\subsection{Summary and conclusions}

A constitutive model is shown which establishes the unknown relationships between the mass changes due to chemical reactions and the developing stresses and strains, i.e., the introduced coupling parameters. Possible theoretical developments of stresses and strains are then discussed with the help of conceptual models for various material structures due to solely anhydrite dissolution, gypsum precipitation or both processes combined. In order to determine the unknown coupling parameters used in the constitutive model, thought experiments are then featured with which the unknown relationships can be evaluated. In all cases it is, however, not clear, whether the porosity decreases or increases due to the chemical reactions, whereas both behaviors are possible in theory.

In order to determine the unknown coupling parameters with experimental investigations in practice, the following considerations need to be made:

For one, the elimination of one chemical process during an experimental series is most likely not possible (at least not to such an extent which would be necessary for the respective specimens to produce reliable, quantifiable stresses and strains). Therefore, it is not possible to determine the individual coupling parameters $a_{a x}, a_{r a d}$ and $g_{a x}, g_{r a d}$. It is, furthermore, more likely to encounter both anhydrite dissolution and gypsum precipitation combined in nature, since gypsum often precipitates in the spaces where anhydrite dissolves according to Serafeimidis (2014), and as already discussed in Chapter 2.2.3, leaching of the rock is not considered here. For this reason, the simultaneous processes and thus the "combined" coupling parameters $\chi_{a x}, \chi_{\text {rad }}$ and $\chi$ are of interest to determine and will be the focus of the experimental investigations in the following chapter. In order to avoid ions from dissolved anhydrite to be transported out of the specimen (and thus all dissolved ions are used for gypsum precipitation within the specimen), the experiments are planned to be performed under an approximately constant water pressure, i.e., without a hydraulic gradient and thus no flow-through. This does, however, not prohibit ions from diffusing out of the specimen but due to the fact that the concentration gradient between the water surrounding and entering the specimen $\left(c_{i n}=c_{e q, G}\right)$ and the water in the specimen is considered small, diffusion is neglected here.

Of the discussed specimen structures (see Figure 7-3), a granular homogenous material is chosen for the experimental investigations in the laboratory, in order to create clearly defined, homogeneous mixtures (while considering the specimen size) and obtain results faster than with rock. Furthermore, the specimen preparation is deemed simplest (compared to other structures), with the chances of creating reproducible specimens being the highest. However, it is necessary to use a high degree of compaction and thus obtain specimen properties as close to rock as possible.

As discussed in Chapter 7.3.4, the determination of mass changes of anhydrite and gypsum during a test is not deemed possible with the necessary accuracy and without disrupting the specimens. It was, therefore, decided to determine the development of stresses and strains as a function of the mass change of anhydrite in the specimens by performing a large number of tests and terminating them after various stages of swelling.

The experiments are executed for the mechanical boundary conditions described in Chapter 7.3.3, and are discussed in detail in the following chapter. 



\section{Executed C-M-experiments}

\subsection{Overview}

With the aim of quantifying the coupling parameters $\chi_{a x}, \chi_{\text {rad }}$ and $\chi$ for the constitutive relationship between AGT (i.e., the simultaneous processes) and the resulting stresses and strains (as introduced in the constitutive model in Chapter 7.1), a first ever systematic experimental campaign was executed (referred to here as "C-M-experiments"). The experiments were performed on specimens created from homogeneous powdered materials (based on Chapter 7.2), whereas the mechanical boundary conditions listed in Table 7-2 were applied.

This chapter begins with the characterization of the specimen materials and a description of the specimen preparation procedure, general testing procedure and an overview of how the strains are evaluated (Chapters 8.2 and 8.3). Chapter 8.4 describes the results of different preliminary tests which were necessary to perform as a basis for a proper understanding and evaluation of the results of the actual C-M-experiments.

Chapters 8.5 to 8.8 describe four different series of C-M-experiments and their results in detail, whereas they are grouped by the respective mechanical boundary conditions of Table 7-2: Oedometer tests (Chapter 8.5), completely constrained tests (Chapter 8.6), isotropic compression tests (Chapter 8.7) and so-called "flexible oedometer" tests where triaxial conditions could be investigated (Chapter 8.8).

Finally, the structures of some selected specimens before and after the swelling experiments were studied, which is described in Chapter 8.9, and the conclusions to the experiments presented in this chapter are drawn in Chapter 8.10.

\subsection{Characterization of specimen materials}

Artificially created specimens consisting of anhydrite and aggregates were used for the major part of the experiments concerning the investigation of the chemo-mechanical processes. This was decided in order to reduce uncertainties caused by the inhomogeneous compositions and structures of natural rock specimens, to guarantee reproducibility (by adhering to the same specimen preparation and testing procedures) and to isolate the swelling process due to AGT from that due to clay (which is often present in sulfatic rock as well) by using ideally inert aggregates.

Unless stated otherwise, the specimens consisted of $40 \%$ anhydrite powder and $60 \%$ of one of the aggregates. This composition was determined based on a series of preliminary tests described in Chapter 8.4.1 (so-called free swelling tests) where the influence of the types and amounts of materials was investigated.

\subsubsection{Anhydrite}

Unless indicated otherwise, the anhydrite used in the tests was purchased from Sigma-Aldrich (abbr. "SA") with a certified purity of $99 \%$ and a particle size below $44 \mu \mathrm{m}$ (-325mesh).

As will be discussed in Chapter 8.4.3, different batches of anhydrite were supplied from SA and then used in the experiments, whereas the swelling behaviors differed strongly in some cases. For this reason, additional preliminary tests with anhydrite powders from other suppliers (ProChem, abbr. "PC", and Alfa Aesar, abbr. "AA") were performed and compared to the results with SA. 
Further preliminary tests (see Chapter 8.4.2) were performed with powder milled from natural blocks of nearly pure anhydrite (95-99\%, cf. Chapter 5 ) and also compared to the results with SA. The natural anhydrite stems from the stone-quarries in Bex (canton of Vaud) and Leissigen (canton of Bern) and from bore-cores originating from the new Bözberg-Tunnel (canton of Aargau) whereas the blocks were crushed, milled and sieved to create a powder to use in artificially created specimens. The mineralogical compositions of some of the used rocks are listed in Table 5-1 (results from XRD analysis). Figure 8-1 shows the particle size distributions for the commercial anhydrite (black dotted line) and the milled natural anhydrite (green and blue dashed lines), which were measured with laserdiffractometry, where isopropanol was used as solvent (see Chapter 3.5). As can be seen, the commercial anhydrite has a steeper particle size distribution with a grain size of $d_{90}=16 \mu \mathrm{m}$, while the natural rock was milled to grain sizes of $d_{90}=46 \ldots .84 \mu \mathrm{m}$.

\subsubsection{Aggregates}

For the artificial specimens anhydrite powder was mixed with either kaolin (Polwhite ${ }^{\mathrm{TM}} \mathrm{E}$ China Clay, a high quality medium particle size kaolin produced from deposits in the south west of England, with datasheets available from Richard Baker Harrison LTD, 2011 and Imerys Performance \& Filtration Minerals, 2008; abbr. "PW"), ground limestone (Nekafill 15 from Kalkfabrik Netstal AG, 2015; abbr. "KM" for the German term "Kalkmehl") or quartz flour (Sikron® from Sibelco Benelux, 2009; abbr. "QM" for the German term "Quarzmehl"). The particle size distributions of these aggregates are shown in Figure 8-1 (solid lines): While PW has nearly the same particle size distribution as SA ( $d_{90}=18 \mu \mathrm{m}$ for PW resp. $16 \mu \mathrm{m}$ for SA), QM has far smaller particles $\left(d_{90}=4 \mu \mathrm{m}\right)$ and $\mathrm{KM}$ has larger particles and is more poorly graded $\left(d_{90}=140 \mu \mathrm{m}\right)$.

Kaolin has a very low swelling potential compared to other so-called swelling clays (e.g., montmorillonite, vermiculite etc.). On the one hand, its main component kaolinite (see Table 8-1) has no significant negative structural charge, so that little or no water is adsorbed in the lattice. The cation exchange capacity of PW was measured in the Clay Lab of ETH Zurich to be $3-5 \mathrm{meq} / 100 \mathrm{~g}$, which corresponds well to the literature values of Weiss (1958), i.e., 1-10 meq/100 g for kaolinite (as opposed to, e.g., montmorillonite, a swelling clay, which has a cation exchange capacity of 70 $120 \mathrm{meq} / 100 \mathrm{~g}$ according to Jasmund and Lagaly, 1993). On the other hand, kaolinite has a small specific surface compared to swelling clays, i.e., the adsorption of water molecules due to surface charge is negligible (the specific surface of kaolinite is $10-30 \mathrm{~m}^{2} / \mathrm{g}$ while that of montmorillonite amounts to $750-820 \mathrm{~m}^{2} / \mathrm{g}$, cf., e.g. van Olphen and Fripiat, 1979, and Meunier, 2005). It should be noted, however, that kaolin, like any fine powdered and compacted dry material, can swell upon saturation due to reduction of suction pressure (cf., e.g. Thom et al., 2007, Pimentel, 2015). However, this swelling mechanism is much faster than the swelling caused by AGT and thus the two swelling mechanisms can be distinguished from one another, as will be discussed in Chapter 8.3.3.

The average mineralogical composition of the kaolin (Table 8-1) was obtained with Rietveld analysis. The density of the kaolin is $2.6 \mathrm{~g} / \mathrm{cm}^{3}$ (Richard Baker Harrison LTD, 2011 and Imerys Performance \& Filtration Minerals, 2008). 
Table 8-1: $\quad$ XRD results of the kaolin, Polwhite E Chinaclay (weight\%).

\begin{tabular}{llllll}
\hline Specimen name & III/ Ms & Kfs & Kln & PI & Qtz \\
\hline Kaolin & 10 & 16 & 69 & 2 & 3 \\
\hline
\end{tabular}

Key: III = IIlite, Ms = Muscovite, Kfs $=K$-Feldspar, KIn $=$ Kaolinite, $P I=$ Plagioclase, $Q t z=$ Quartz

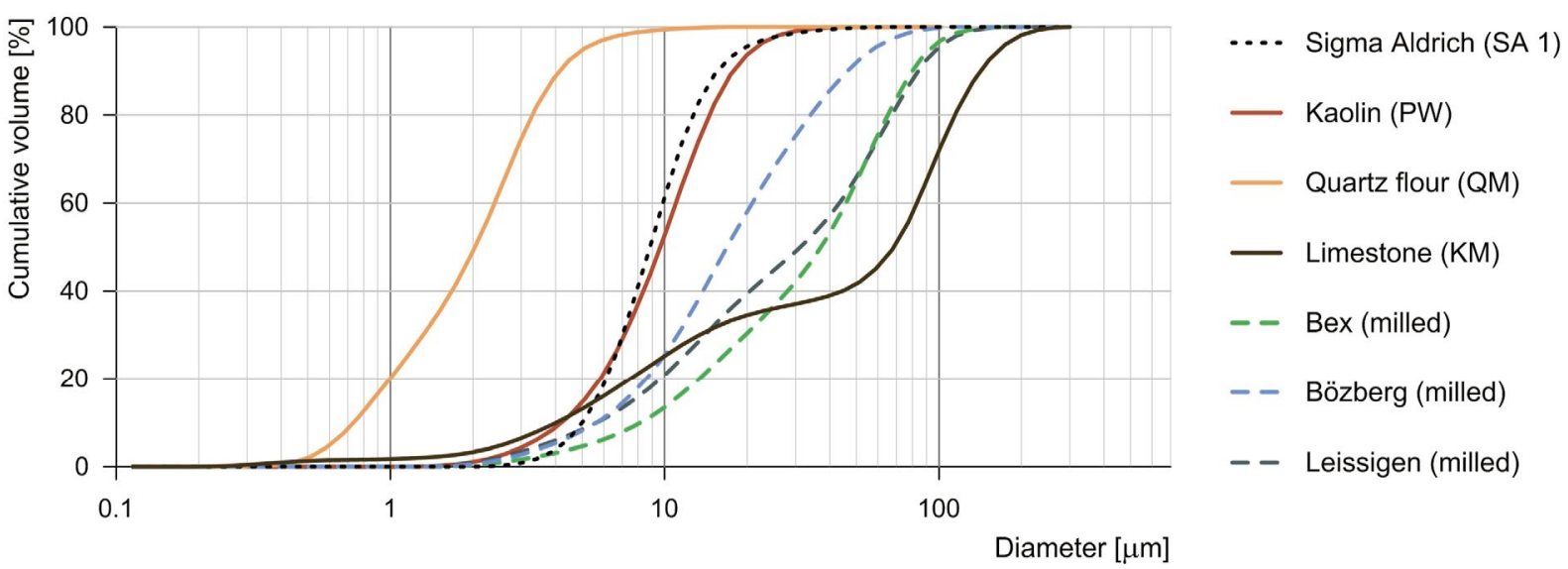

Figure 8-1: $\quad$ Particle size distribution of the used (granular) specimen materials; results obtained with laserdiffractometry.

\subsection{General procedure of the experiments}

\subsubsection{Specimen preparation}

During specimen preparation, the anhydrite and the aggregate are weighed and mixed together while adding about $10 \%-15 \%$ of inert liquid (pure ethanol) in order to improve the compaction, reduce formation of dust during compaction and to bind the powder, thus ensuring that the compacted specimens did not crumble after compaction. The mixed material was then inserted in a steel ring with a diameter of either 56 or $70 \mathrm{~mm}$ in 3-5 layers which were compacted slightly by hand in between and when all material was inserted in the ring, the specimen was compacted mechanically by cyclic loading with increasing axial pressure (0-2-0-20-2-80-0-100 MPa). It was attempted to achieve high densities, comparable to the one of swelling rocks. With the high compaction load of up to $100 \mathrm{MPa}$ used, it was possible to create cylinders or cylindrical disks with an average density of about $1.9 \mathrm{~g} / \mathrm{cm}^{3}$.

Table 8-2 summarizes the specimen dimensions depending on the test type. In the case of the preliminary free swelling tests (Chapter 8.4.1), the disks had a height of $20 \mathrm{~mm}$ and were pressed out of the steel rings after compaction. For the tests in oedometers (Chapters 8.4.2, 8.4.3 and 8.5) and complete constraint tests (Chapter 8.6) the disks (with a height of 20 or $25 \mathrm{~mm}$ ) remained in the oedometer rings they were compacted in. In the case of the isotropic compression tests (Chapter 8.7), the specimens (specimen height of $40 \mathrm{~mm}$ and diameter of $57 \mathrm{~mm}$ ) were compacted in a steel cylinder, pressed out of the cylinder and inserted in a rubber membrane. In the case of the so-called "flexible oedometer tests" (Figure 7-21d and Chapter 8.8) it was necessary to have cylindrical specimens (specimen height of $40 \mathrm{~mm}$ and diameter $57 \mathrm{~mm}$ ) fitted reasonably tight in PVC cylinders. For this reason, the first specimens were compacted directly in PVC cylinders (which were placed within steel cylinders during compaction), whereas for the later series the 
specimens were first compacted in separate steel cylinders from which they were pressed out and inserted tightly into the PVC cylinders.

Table 8-2: $\quad$ Overview of specimen dimensions according to the type of test (unless indicated otherwise in the respective chapters).

\begin{tabular}{lcccc}
\hline Test type & height $[\mathrm{mm}]$ & diameter $[\mathrm{mm}]$ & $\begin{array}{c}\text { radial confinement } \\
\text { during the experiments }\end{array}$ & chapter(s) \\
\hline Preliminary free swelling tests & 20 & 70 & rubber membrane & 8.4 .1 \\
\hline Oedometer tests & 20 & 56.3 & steel cylinder & $8.4 .2,8.4 .3$ and 8.5 \\
\hline Complete constraint tests & $20 / 25$ & $56 / 70$ & steel cylinder & 8.6 \\
\hline Isotropic compression tests & 40 & 56.7 & rubber membrane & 8.7 \\
\hline Flexible oedometer tests & 40 & 56.7 & PVC cylinder & 8.8 \\
\hline
\end{tabular}

After compaction, the specimens were air-dried for at least 24 hours in order for the ethanol to evaporate. Based on the measured masses, the specimens may still have contained up to ca. $5 \%$ of ethanol after air-drying. In order to achieve a more uniform and accelerated watering of the specimens during the following tests, a small hole with a diameter of $1.1 \mathrm{~mm}$ was bored through the center of the specimens (which corresponds to $0.04 \%$ of the total specimen area and has thus no influence on the macroscopic swelling behavior). However, this was not possible with all specimens, especially when the specimens were deemed too brittle to withstand boring (e.g., in the cases where quartz flour or where finely milled SA was used for specimens with $40 \mathrm{~mm}$ height which were pressed out of the steel rings). Figure 8-2 illustrates the described specimen preparation procedure and shows examples for two compacted specimens (one in an oedometer ring and one for a free swelling test).

The main properties of the specimens (height, porosity, dry mass, density and anhydrite content) are summarized in the tables in Appendix $\mathrm{J}$, whereas the porosity, density and the anhydrite content were calculated from the measured values, i.e., from the specimen dimensions and the dry masses of the components.

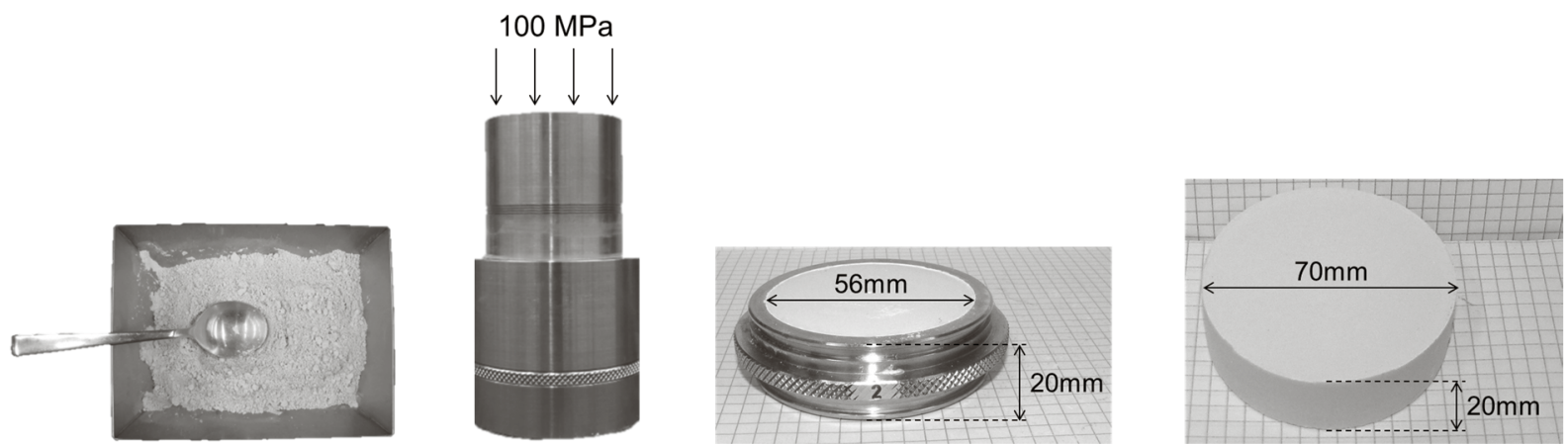

Figure 8-2: $\quad$ Specimen preparation procedure. From left to right: mixture of powders; powders in steel cylinder under axial load (compaction); intact disk in steel ring after compaction (oedometer tests); intact disk after removing from $70 \mathrm{~mm}$ steel ring (free swelling tests). 


\subsubsection{Testing procedure}

After air-drying upon compaction, all specimens were measured, weighed and installed in the respective apparatuses. The specimens were then loaded in a dry state with a constant stress, until the deformation settled. The specimens were then watered (if not indicated otherwise, water saturated with respect to gypsum i.e., $15 \mathrm{~mol} / \mathrm{m}^{3} \mathrm{Ca}$ and $\mathrm{SO}_{4}$, was used), thus beginning the actual swelling test, and the developing deformation and/or stress was measured.

The experiments were terminated by disconnecting the water supply, unloading the specimens and extracting them from the respective apparatus. The specimens were measured and weighed directly after extraction, then dried in an oven at $40^{\circ} \mathrm{C}$ for at least 24 hours (i.e., until all pore water dissipated). It was crucial to keep the temperature at maximum $40{ }^{\circ} \mathrm{C}$, in order to prevent the precipitated gypsum from dehydrating and forming bassanite (this problem is discussed in more detail in Appendix I).

Upon drying, the specimens were weighed again, in order to determine the dry mass of each specimen as well as its water content post test, and a representative part of each specimen was broken or sawed off and ground to powder with a pestle and mortar. With the exception of some preliminary tests, a powdered sample of each specimen was investigated with thermogravimetry ("TGA", Chapter 3.1) in order to indirectly determine the amount of precipitated gypsum (cf. Huber et al., 2015, and Appendix I). In selected cases, microscopy, porosimetry or X-ray diffraction analysis ("XRD", Chapter 3.3) was performed additionally. It was seen that the results obtained via TGA agree well with the XRD results (Huber et al., 2015, and Appendix I).

\subsubsection{Evaluation of the strains}

As will be seen in the following chapters, the measured deformations can be subdivided and assigned to the different occurring processes. The schematic graph in Figure 8-3 depicts the total measured deformation $\Delta h_{\text {total }}$ (here a heave is positive, a settlement is negative, see Equations $(7-13)$ and $(7-14))$ over time $t$ and gives an example for how the measured deformations were evaluated.

The total deformation $\Delta h_{\text {total }}$ is measured starting from the specimen height $h_{\text {prior }}$ after specimen preparation. Before starting the actual swelling experiment (i.e., at a time $t<0$ ), the specimens were loaded in a dry state until the settlement $\Delta h_{d r y}$ subsided. At the end of dry loading, the specimens have a height $h_{0}$ (which is the new starting height for the swelling strains). At $t=0$, the specimens are then watered, thus beginning the swelling test. All deformations measured from this point on are denoted as "swelling" deformations, $\Delta h_{\text {swell }}$.

As mentioned above, these swelling deformations can be further subdivided: In nearly all cases, a first rapid response to the wetting of the specimens was recorded due to physical swelling, indicated here as the "initial" deformation $\Delta h_{I}$ (i.e., when the specimens change their height from $h_{0}$ to $h_{I}$, see Figure 8-3).

In nearly all tests, the point indicating the height $h_{I}$ could be well distinguished due to a prominent change in the rate of the deformation. Depending on the applied axial load, some specimens experienced a rapid heave (as shown figuratively in Figure 8-3), while some exhibited an abrupt settlement. The reasons for these different responses depend on the testing conditions and are thus discussed later for the respective experiments. It was seen (cf. also Pimentel, 2015) that these initial deformations $\Delta h_{I}$ can be explained on the one hand with mechanical processes, $\Delta h_{\text {mech }}$ (such as reduction of negative pore water pressures during water uptake or overcoming friction between 
the specimen and its confining walls upon wetting, as will be described, e.g., in Chapter 8.5), on the other hand due osmotic swelling of clay $\left(\Delta h_{\text {clay }}\right)$. Therefore,

$$
\Delta h_{I}=\Delta h_{\text {mech }}+\Delta h_{\text {clay }}
$$

whereas $\Delta h_{\text {mech }}$ and $\Delta h_{\text {clay }}$ are indicated qualitatively in Figure 8-3, but their amounts cannot be distinguished from one another in the experiments. Due to the fact that this phase (i.e., before reaching the specimen height $h_{I}$ ) occurs fast in comparison to the remainder of the test (at the most within half a day), and that no gypsum was detected in specimens that swelled for a few hours, AGT is negligible during the initial deformation $\Delta h_{I}$. Since the primary aim is to investigate the swelling behavior due to AGT, the strains of interest were therefore calculated by considering the heave from this point on (i.e., $\Delta h_{A G T}$ starting from the height $h_{I}$ ). This was only possible due to the sequential nature of the different processes, as will be seen in later chapters, where the swelling processes were distinguished from one another (e.g., Chapter 8.5.2, where swelling of specimens without anhydrite was investigated and Chapter 11, where AGT was prohibited by performing the swelling tests at higher temperatures). Furthermore, this gives a more accurate sense of the deformation due to AGT, since the initial deformations, $\Delta h_{I}$, were not the same in all cases (as will be seen and discussed in further detail later). The swelling deformations due to AGT are caused on the one hand by the change in solid volume of anhydrite and gypsum $\left(\Delta h_{V_{A, G}}\right)$, which can be calculated based on the stoichiometry of the reaction and the different densities of anhydrite and gypsum (see Equation $(2-12)$ ), on the other hand by the change of the pore volume $\left(\Delta h_{P}\right)$.

Therefore,

$$
\Delta h_{A G T}=\Delta h_{V_{A, G}}+\Delta h_{P}
$$

In summary, the total deformation of the specimen amounts to:

$$
\Delta h_{\text {total }}=\Delta h_{d r y}+\Delta h_{s w e l l}=\Delta h_{d r y}+\left(\Delta h_{I}+\Delta h_{A G T}\right)=\Delta h_{d r y}+\left(\left(\Delta h_{\text {mech }}+\Delta h_{\text {clay }}\right)+\left(\Delta h_{V_{A, G}}+\Delta h_{P}\right)\right)
$$

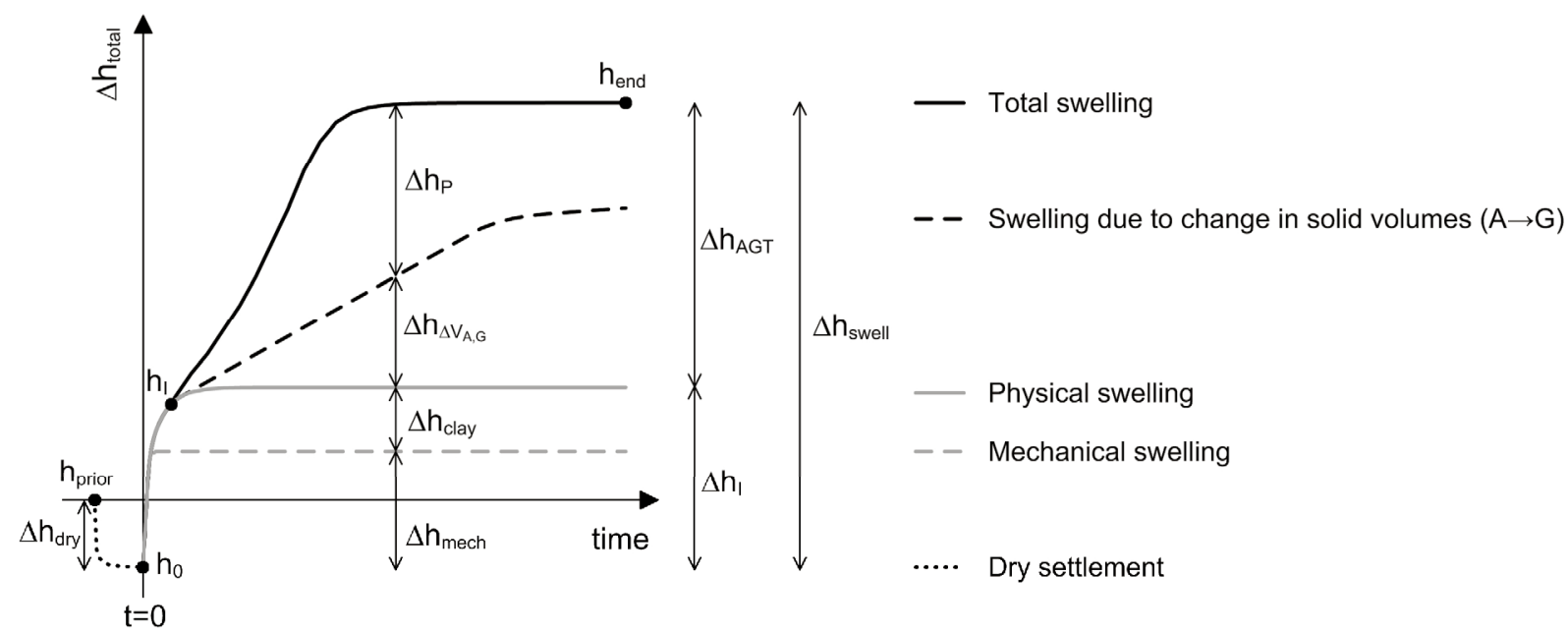

Figure 8-3: $\quad$ Subdivision of the measured deformation $\Delta h_{\text {total }}$ based on the occurring processes: dry loading $\left(\Delta h_{d r y}\right)$, mechanical swelling $\left(\Delta h_{\text {mech }}\right)$, swelling due to clay $\left(\Delta h_{\text {clay }}\right)$, due to change in solid volume $\left(\Delta h_{V_{A, G}}\right)$ and in pore volume $\left(\Delta h_{P}\right) \cdot h_{\text {prior }}, h_{0}, h_{I}$ and $h_{\text {end }}$ denote the respective specimen heights at the marked points of the deformation curve. 
The strains are then defined as follows:

Total strains

Swelling strains

Strains due to AGT

$$
\varepsilon_{\text {ax, total }}=\frac{\Delta h_{\text {total }}}{h_{\text {prior }}}
$$

Note that at very small loads (e.g., $3 \mathrm{kPa}$ ) the deformations due to dry loading of the specimens were not measured (the dial gauge is mounted after the piston is placed on the specimen as can be seen later in Figure 8-8, i.e., the dry settlement occurred before the axial measurements begin), and therefore it is not possible to distinguish between the total deformations and the swelling deformations, thus $h_{\text {prior }}=h_{0}$ resp. $\Delta h_{\text {swell }}=\Delta h_{\text {total }}, \varepsilon_{a x, \text { swell }}=\varepsilon_{a x, \text { total }}$.

The same considerations as described here for the axial deformations and strains can also made for the deformations and strains in radial direction.

\subsection{Preliminary tests}

\subsubsection{Preliminary tests I: Free axial swelling tests}

\section{a. Aim and procedure}

Multiple free swelling tests (with no axial load) were performed with the aim of gaining experience with the specimen preparation procedure, trying out various mixtures for the specimens and comparing their swelling behavior.

If not indicated otherwise, the specimens were prepared as described in Chapter 8.3 with anhydrite from Sigma Aldrich and either kaolin, limestone or quartz flour (see Table J-1 in Appendix J).

The kaolin specimens could easily be extracted from the cylinder after compaction. The same accounts for the limestone specimens, although they had the tendency to break slightly at the edges or perpendicular to the direction in which they were compacted. However, the quartz flour proved to generate problems when attempting to extract the specimens from the apparatus after compacting. It was not possible to create intact, unconfined specimens with the same procedure as described above. Therefore mixtures containing quartz flour could only be used for testing when the compacted specimens were left within the steel ring and were not tested further in the preliminary free swelling tests presented here, but were used for some of the oedometer tests described later (see Chapter 8.5).

During these preliminary tests, most specimens were radially surrounded by a Teflon band (allowing an axial deformation without friction) and slightly confined by a neoprene membrane (thickness of ca. $2 \mathrm{~mm}$ and diameter of $70 \mathrm{~mm}$ ), as indicated in Figure 8-4. The rubber membranes provided sufficient radial support in order to prevent the specimens from crumbling during the test, but did not prohibit radial expansion. Some specimens were radially completely confined by stiff steel cylinders (i.e., in oedometers with diameters of $56 \mathrm{~mm}$ or $70 \mathrm{~mm}$ ), and had a slight axial load of $3 \mathrm{kPa}$. Each specimen was inserted in a separate container (cylinders made of acrylic glass with 
a stainless steel base) and covered with demineralized or saturated water (with an ionic concentration equal to the equilibrium concentration of gypsum, i.e., $c_{e q, G}=15 \mathrm{~mol} / \mathrm{m}^{3}$ ), while the occurring axial deformation was measured with a dial gauge.

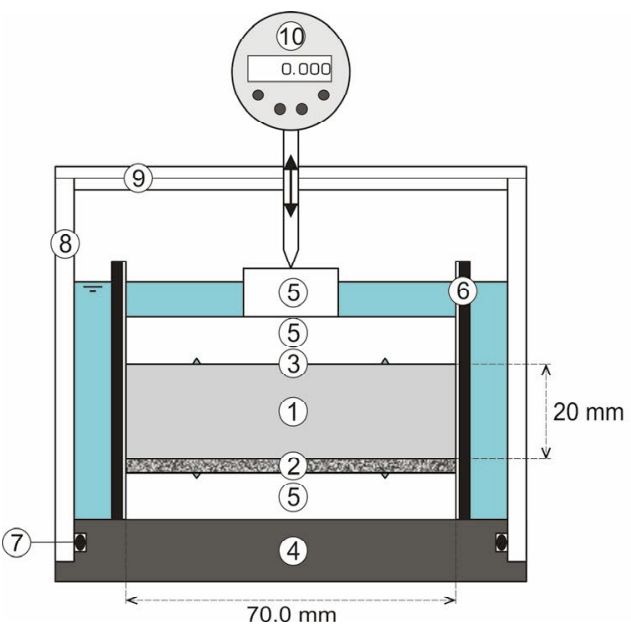

(1) Specimen

(2) Filter plate

(3) Filter paper

(4) Steel base

(5) Distance holder \& leveller (acrylic glass)

(6) Radial support (neoprene membrane and teflon band)

(7) O-rings (rubber)

(8) Cylinder (acrylic glass)

(9) Lid (acrylic glass)

(10) Dial gauge

Figure 8-4: Cross-section through an apparatus for free swelling tests.

\section{b. Results}

Eight specimens were produced with varying mixtures of kaolin and anhydrite, five specimens with only kaolin, four specimens with mixtures of limestone and anhydrite, and two specimens with only limestone.

Table 8-3 summarizes all specimens containing kaolin, their testing conditions and reached strains. The swelling strain curves over time are shown in Figure 8-5. Analogue, the information on the specimens containing limestone is given in Table 8-4 and the results from the free swelling tests are presented in Figure 8-6. Further information on the specimen properties can be found in Appendix $\mathrm{J}$ (Table $\mathrm{J}-1$ ), whereas the composition of the specimens post test was only determined for two specimens containing limestone within the scope of these preliminary tests (in order to investigate whether AGT occurred at all). 
Table 8-3: $\quad$ Overview of the preliminary tests with mixtures containing anhydrite (SA) and kaolin (PW).

\begin{tabular}{|c|c|c|c|c|c|}
\hline Specimen & Composition & Specimen preparation & Radial confinement & Fluid & $\begin{array}{c}\text { Max. swelling } \\
\text { strain } \varepsilon_{a x, \text { swell }}[\%]\end{array}$ \\
\hline РT01 & SA $60 \%$ PW $40 \%$ & \multirow{7}{*}{$\begin{array}{l}\text { mixed with ethanol, } \\
\text { air-dried }\end{array}$} & \multirow[t]{11}{*}{ rubber membrane } & saturated water & 85 \\
\hline РT02 & SA $60 \%$ PW $40 \%$ & & & $\left(\mathrm{Ca}, \mathrm{SO}_{4}\right)$ & 75 \\
\hline РT03 & SA $40 \%$ PW $60 \%$ & & & & 80 \\
\hline РT04 & SA $40 \%$ PW $60 \%$ & & & & 77 \\
\hline РT05 & SA $20 \%$ PW $80 \%$ & & & & 66 \\
\hline РT06 & SA $20 \%$ PW $80 \%$ & & & & 66 \\
\hline РT07 & PW $100 \%$ & & & & 23 \\
\hline РT08 & PW $100 \%$ & $\begin{array}{l}\text { mixed with ethanol, } \\
\text { test started immediately }\end{array}$ & & & 28 \\
\hline РT09 & PW $100 \%$ & $\begin{array}{c}\text { mixed with } 50 \% \text { ethanol } \\
\text { and } 50 \% \text { demineralized } \\
\text { water, air-dried }\end{array}$ & & & 22 \\
\hline PT10 & PW $100 \%$ & \multirow{4}{*}{$\begin{array}{l}\text { mixed with ethanol, } \\
\text { air-dried }\end{array}$} & & demineralized water & 33 \\
\hline PT11 & PW $100 \%$ & & & ethanol & 8 \\
\hline PT12 & SA $20 \%$ PW $80 \%$ & & $\begin{array}{c}\text { steel cylinder } \\
\left(D=70 \mathrm{~mm}, \sigma_{a x}=3 \mathrm{kPa}\right)\end{array}$ & $\begin{array}{l}\text { saturated water } \\
\qquad\left(\mathrm{Ca}, \mathrm{SO}_{4}\right)\end{array}$ & 73 \\
\hline PT13 & SA $20 \%$ PW $80 \%$ & & $\begin{array}{c}\text { steel cylinder } \\
\left(D=53 \mathrm{~mm}, \sigma_{a x}=3 \mathrm{kPa}\right)\end{array}$ & $\begin{array}{l}\text { saturated water } \\
\left(\mathrm{Ca}, \mathrm{SO}_{4}\right) \text {, water } \\
\text { supply via pipette }\end{array}$ & 60 \\
\hline
\end{tabular}

Table 8-4: $\quad$ Overview of the preliminary tests with mixtures containing anhydrite (SA) and limestone (KM).

\begin{tabular}{|c|c|c|c|c|c|}
\hline Specimen & Composition & Specimen preparation & Radial confinement & Fluid & $\begin{array}{c}\text { Max. swelling } \\
\text { strain Eax,swell [\%] }\end{array}$ \\
\hline PT14 & SA $60 \%$ KM $40 \%$ & \multirow{6}{*}{$\begin{array}{l}\text { mixed with ethanol, } \\
\text { air-dried }\end{array}$} & \multirow[t]{5}{*}{ rubber membrane } & \multirow{4}{*}{$\begin{array}{l}\text { saturated water } \\
\qquad\left(\mathrm{Ca}, \mathrm{SO}_{4}\right)\end{array}$} & 9 \\
\hline PT15 & SA $40 \%$ KM $60 \%$ & & & & 14 \\
\hline PT16 & SA $20 \%$ KM $80 \%$ & & & & 18 \\
\hline PT17 & KM $100 \%$ & & & & 17 \\
\hline PT18 & KM $100 \%$ & & & demineralized water & 18 \\
\hline PT19 & SA $20 \%$ KM $80 \%$ & & $\begin{array}{c}\text { steel cylinder } \\
\left(\mathrm{D=}=70 \mathrm{~mm}, \sigma_{a x}=3 \mathrm{kPa}\right)\end{array}$ & $\begin{array}{l}\text { saturated water } \\
\qquad\left(\mathrm{Ca}, \mathrm{SO}_{4}\right)\end{array}$ & 1 \\
\hline
\end{tabular}




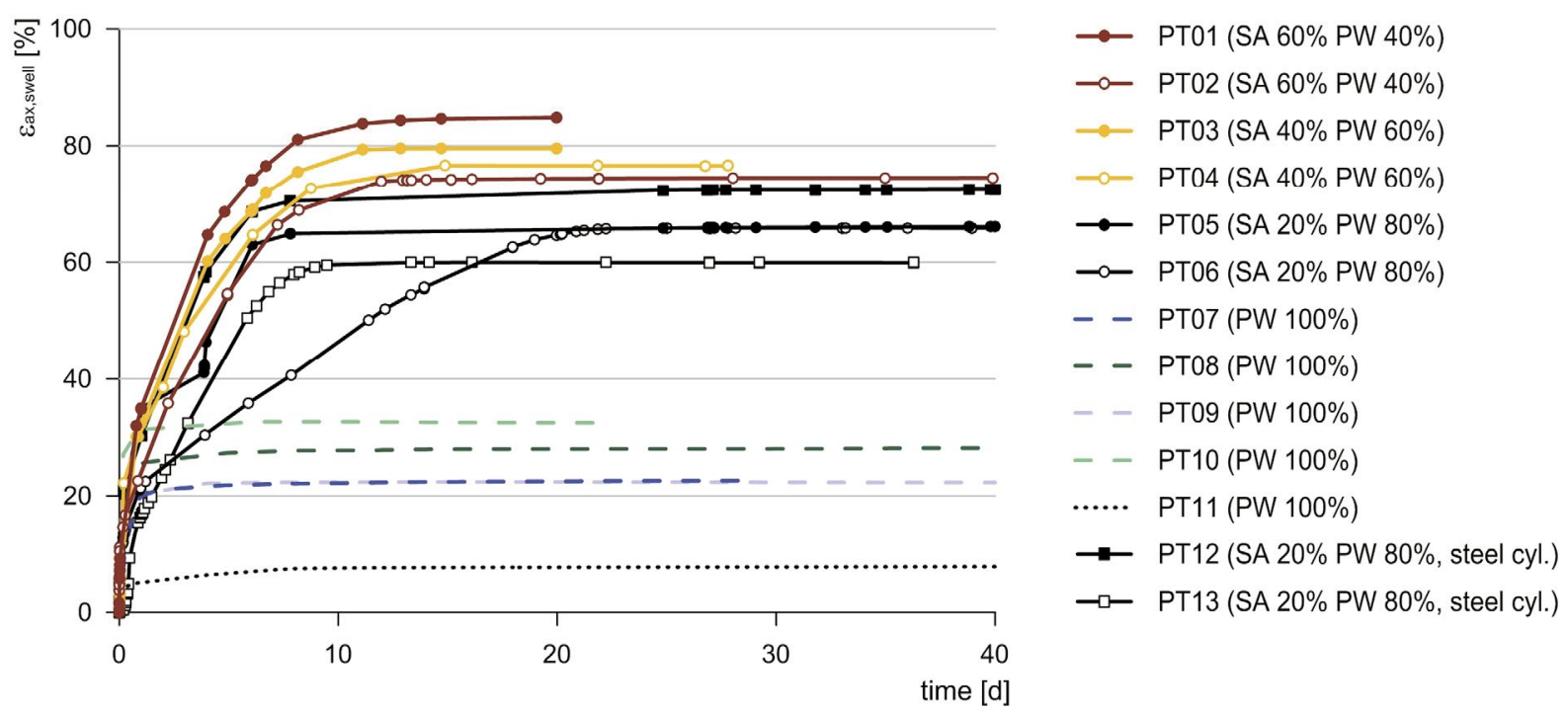

Figure 8-5: $\quad$ Swelling strain curves of preliminary tests (specimens containing kaolin); see also Table 8-3.

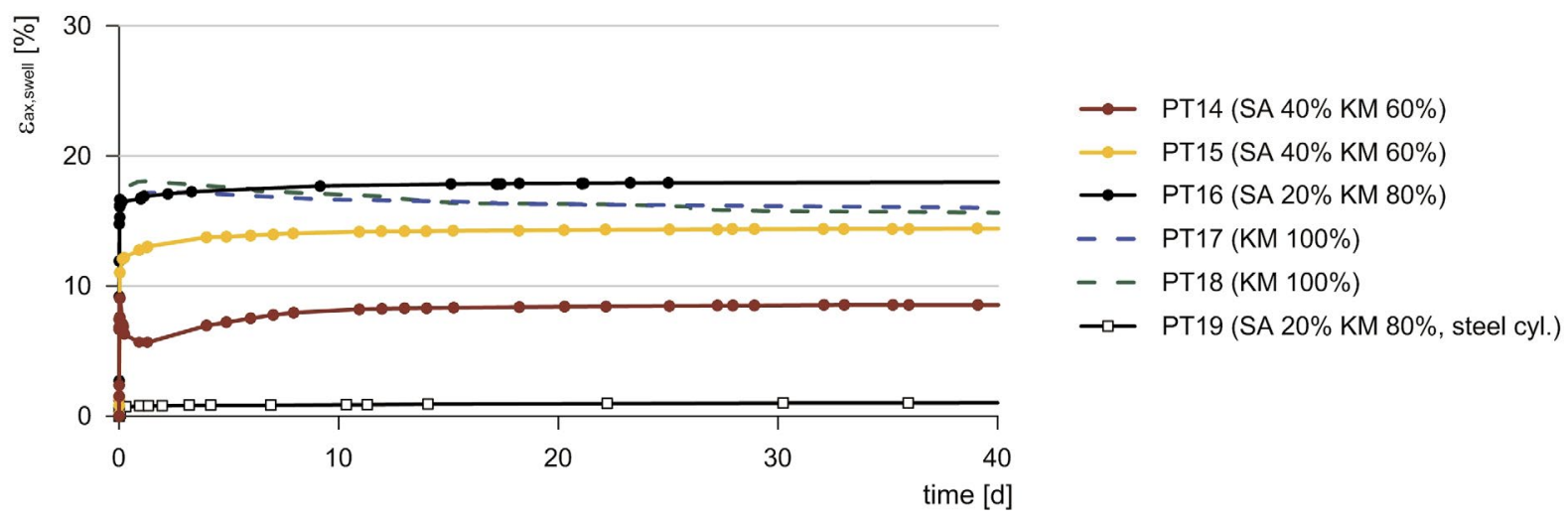

Figure 8-6: $\quad$ Swelling strain curves of preliminary tests (specimens containing limestone); see also Table 8-4.

\section{c. Discussion}

In general, a first rapid heave directly after watering the specimens can be observed. The strains then either increased almost linearly until reaching a maximal value or remained nearly constant after the initial heave (see Figure 8-5 and Figure 8-6).

The specimens containing both kaolin (PW) and anhydrite (SA) all behaved similarly (Figure 8-5): At first, they exhibited a rapid increase in strain followed by a more or less linear increase over the first ca. 7 days, then slowing down and reaching a maximal value. The linear increase in strain occurs due to AGT. This becomes evident when comparing the strains of the specimens with anhydrite (specimens PT01-PT06 and PT12, PT13 in Table 8-3 and Figure 8-5) to those without any anhydrite (PT07-PT11, which did not exhibit any further swelling strain after the initial heave).

The first rapid increase in strain also occurred in the case of the limestone specimens, with the exception of PT19. It is assumed that this first increase occurs on the one hand due to water uptake and reduction of negative pore water pressure which also leads to a reduction of the effective stress and thus to immediate strains (referred to here as "mechanical strains"), on the other hand possibly also due to some slight swelling of clay (in the case of the specimens mixed with kaolin), cf. Chapter 8.3.3. These first deformations immediately after watering (denoted as $\Delta h_{I}$ in Figure 8-3) also occurred with specimens containing no anhydrite and are therefore independent of the AGT processes. The only specimen which did not exhibit any swelling due to hydration effects 
was the specimen PT19 with $20 \%$ anhydrite and $80 \%$ pulverized limestone in a steel cylinder, where a slight axial load (ca. $3 \mathrm{kPa}$ ) may have been sufficient to restrict said strain. However, such a slight axial load did not suppress the hydration strain in the case of the kaolin specimens in a steel cylinder.

It was also investigated whether the rapid initial strain changes by varying the testing conditions with specimens containing $100 \%$ kaolin: one specimen (PT10) was tested with demineralized water instead of saturated water, another (PT08) was inserted directly after compaction (no drying), a third (PT11) was tested with ethanol instead of water, and a fourth (PT09) was mixed with some water in addition to the ethanol before compaction (so the clay platelets may already bind some water before the test starts). The last (PT09) did not show different results compared to PT07, which followed the original procedure (i.e., mixing the material with ethanol, air-drying the specimen after compaction and using saturated water for the test). However, performing the test immediately after compaction (PT08) or using demineralized water (PT10) lead to even higher initial rapid strains, while performing the test with ethanol instead of water (PT11) reduced the initial rapid strains significantly.

When comparing the results in Figure 8-5 to those in Figure 8-6 it becomes apparent that a specimen consisting of a matrix of crushed limestone does not produce the same strains due to AGT as a specimen with kaolin does. With limestone, no swelling strain occurred after the first rapid strains, even though most of the anhydrite had transformed to gypsum (as was investigated for two specimens, PT14 and PT15, AGT progressed to ca. $\vartheta=75 \%$, see Table J-1 in Appendix J). In order to find a possible explanation for this behavior, the pore space of the specimens was investigated more closely. The limestone specimens were expected to have bigger pores compared to the kaolin specimens, since the particle size of the crushed limestone is larger than that of the kaolin (cf. Figure 8-1). The larger pores could allow for gypsum to precipitate only within the pore space, thus leading to no additional swelling strain after the initial heave due to water uptake and reduction of negative pore water pressure. For this reason porosimetry and microscopic investigations (see Chapters 8.9.1 and 8.9.2) were performed on a limestone specimen prior to any wetting (i.e., initial state prior to swelling test) as well as on one of the specimens presented in the results of this chapter (PT15). As will be shown later in Chapter 8.9.1, the limestone specimens have only slightly larger pores in their initial state compared to the kaolin specimens, while the total pore volume and the porosity are smaller. After the swelling test, the smaller pores of the limestone specimens seem to disappear, while at the same time the total pore volume increases and the porosity decreases (see Figure 8-51 and Figure 8-52 in Chapter 8.9.1). This leads to the conclusion that many small pores have been filled with gypsum while larger pores were created where anhydrite dissolved. However, optical analysis of the structure of a specimen (see microscopic investigations, Chapter 8.9.2) also showed some clearly defined clusters of gypsum needles.

It is assumed that gypsum also precipitated within the pores in the case of the limestone specimen in the steel ring (PT19), which did not exhibit any initial heave. In the case of the specimens containing 100\% limestone (PT17 and PT18), the strains even begin to reduce again after the initial heave.

Figure 8-7 shows the reached swelling strain versus the initial anhydrite content of the specimen. It becomes apparent that with only $20 \%$ anhydrite in the specimen, already significant strains occur in the case of the specimens containing kaolin. Under these conditions, an increase in the amount of anhydrite in the specimen to $60 \%$ only produces an additional strain of about $10 \%$. 
Following these preliminary tests it was decided to use specimens of a mixture of $40 \%$ anhydrite (SA) and $60 \%$ kaolin (PW) for the main part of the following tests. Kaolin was chosen as aggregate because the specimen preparation had a higher success rate compared to the quartz flour specimens, which were more brittle. Limestone was discarded because of lack of swelling strains due to AGT. Since all variations of compositions (SA / PW) showed similar results, the ratio $(40 \%$ $\mathrm{SA}, 60 \% \mathrm{PW}$ ) was chosen considering that natural specimens containing anhydrite (e.g., cores from the Belchen Tunnel) showed typical values of $40 \%-60 \%$ anhydrite. Additionally, the choice of $40 \%$ anhydrite instead of $60 \%$ helps to spare resources.

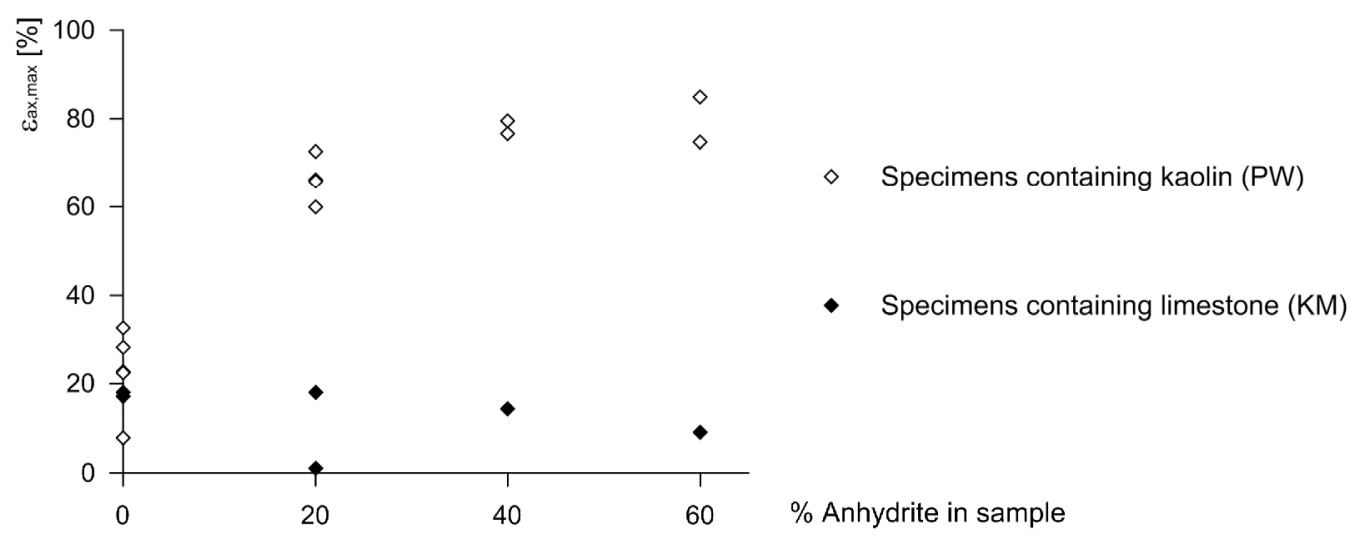

Figure 8-7: Max. swelling strain vs. anhydrite content.

\subsubsection{Preliminary tests II: Comparison milled natural anhydrite - commercial anhydrite}

\section{a. Aim and procedure}

In order to establish how well the commercial anhydrite represents natural anhydrite, a series of oedometer tests with an axial load of $3 \mathrm{kPa}$ was performed with mixtures of $40 \%$ anhydrite (either from Sigma Aldrich "SA 1", with a max. grain size of $40 \mu \mathrm{m}$, or from Bex, Bözberg or Leissigen, see Chapter 8.2.1, which were milled to powders with max. grain sizes $50 \mu \mathrm{m}$ resp. $80 \mu \mathrm{m}$ ) and $60 \%$ kaolin.

The specimen preparation occurred as described in Chapter 8.3, whereas the specimens remained in the oedometer rings after compaction, were inserted into an oedometer cell (see sketch in Figure 8-8), loaded only with a piston (ca. $0.7 \mathrm{~kg}$, i.e., $3 \mathrm{kPa}$ ) and connected to a water supply, thus initiating the swelling process. The developing heave $(\Delta h)$ of the specimens was measured with a dial gauge. 


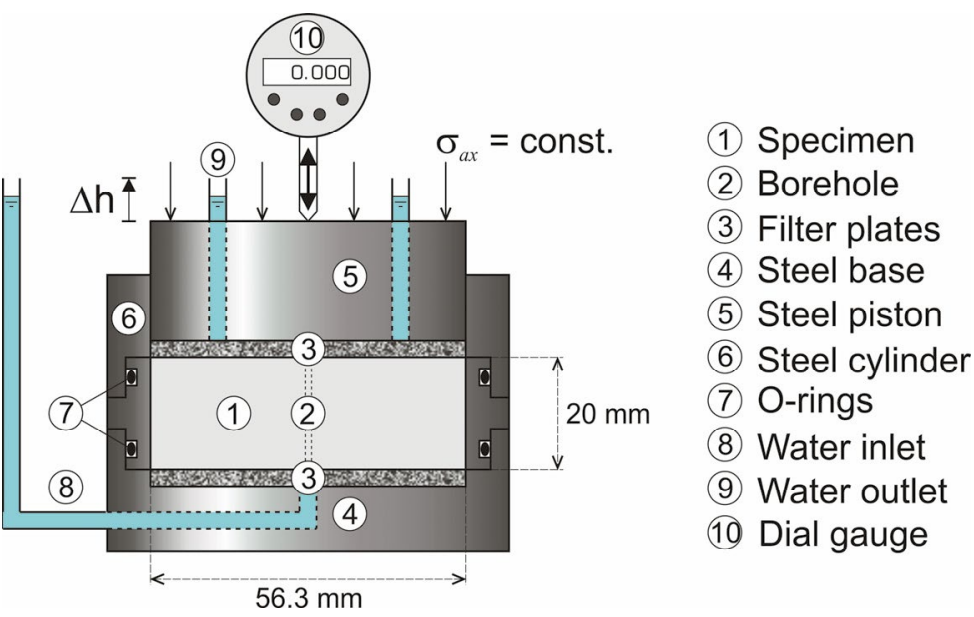

Figure 8-8: $\quad$ Basic setup of an oedometer cell (cross section).

\section{b. Results}

The results of the swelling strain tests are shown in the graph in Figure 8-9. The black curves show the results for the specimens containing commercial anhydrite (SA).

TGA post test revealed that nearly all of the commercial anhydrite was transformed to gypsum. In the case of the milled natural anhydrite, however, only about $40-60 \%$ of the anhydrite had transformed at the point of extraction (i.e., the AGT process progressed to $\vartheta=40 \%-60 \%$ according to Equation (7 - 12), see Figure 8-10), even though the specimens were subjected to water for nearly the same duration and reached similar values for the swelling strains.

The specimen properties and results from these tests can be found in Table J-2 in Appendix J.
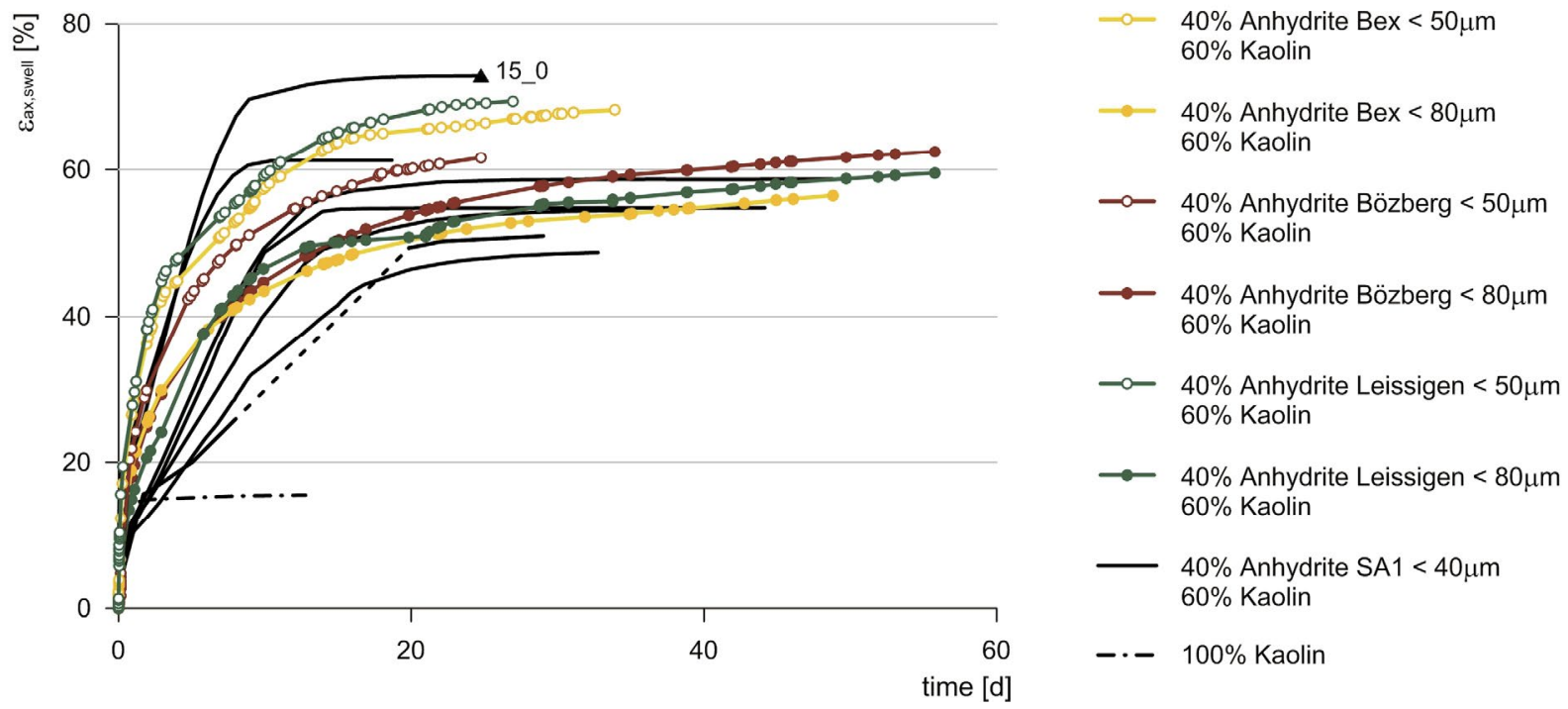

Figure 8-9: $\quad$ Time development of total swelling strains for $\sigma_{a x}=3 \mathrm{kPa}:$ comparison between mixtures containing natural and commercial anhydrite (note: the dashed segment indicates a longer period of time where the axial deformation was not measured and the curve ending with a triangle represents the SA-specimen 15_0 that had a slightly higher density than the others, i.e., $2.3 \mathrm{~g} / \mathrm{cm}^{3}$ as opposed to ca. $\left.1.9 \mathrm{~g} / \mathrm{cm}^{3}\right)$. 


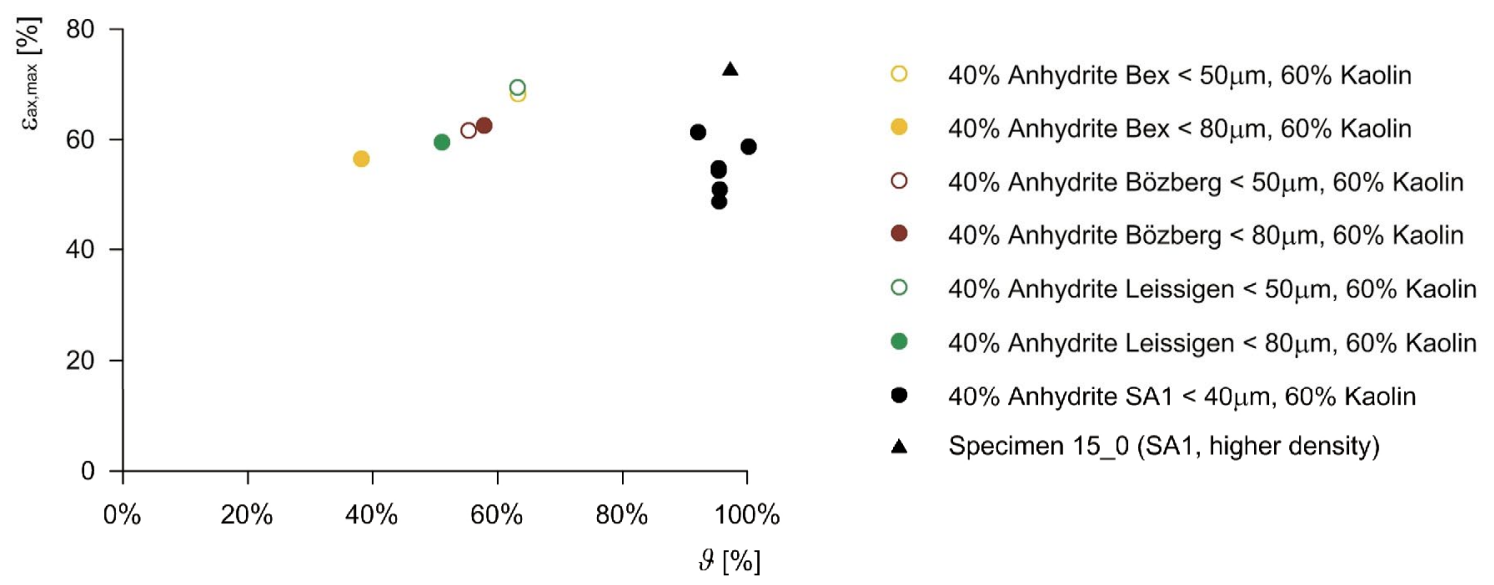

Figure 8-10: $\quad$ Total swelling strains vs. degree of completion of anhydrite to gypsum transformation (see Equation $(7-12))$ for $\sigma_{a x}=3 \mathrm{kPa}$ (preliminary tests in oedometers).

\section{c. Discussion}

The specimens containing commercial anhydrite "SA 1" (represented by the black curves in Figure 8-9) produced in general similar swelling strains as the specimens containing natural anhydrite. However, the latter seem to not have reached the maximum swelling strain at the point of extraction (i.e., after ca. 30 resp. 60 days, when the experiments were terminated), since the swelling strains still appear to be increasing and AGT was only completed to about $\vartheta=40 \%-60 \%$ (see Figure 8-10). Furthermore, the shapes of the curves are slightly different: While the specimens containing commercial anhydrite SA 1 show a rather constant rate and reach a plateau fairly abruptly, the specimens containing natural anhydrite show a more continuous decrease of the swelling rate and do not seem to have reached a steady state within the duration of the experiments. With the one exception of the specimen 15_0 (curve ending with a triangle), the end values of the commercial anhydrite-curves lie generally lower than those expected with natural anhydrite, had the tests gone on longer.

The difference between the swelling behavior of natural anhydrite and SA 1 can be explained with the different maximum grain size of the anhydrite in the specimens: A larger grain size of the anhydrite particles (and therefore a smaller specific surface) slows the AGT process down and thus causes retardation in the swelling behavior, cf. Chapter 2.4 and Serafeimidis and Anagnostou (2012b). This also becomes evident, when regarding the curves with natural anhydrite milled $<50 \mu \mathrm{m}$ as opposed to the specimens with anhydrite $<80 \mu \mathrm{m}$ : The rates of the specimens containing larger particles are smaller during the observed period of time (Figure 8-9) and even though they were tested with a longer duration (20-30 days longer), AGT had progressed less (Figure 8-10).

The influence of the grain sizes was also discussed by Rauh and Thuro (2007) (cf. Chapter 1.4.7), where they crushed natural anhydritic rock to various grain sizes as well, mixed it with quartz flour and performed powder swelling tests similar to the ones described here, whereas their specimens had a lower density than those presented here, i.e., $1.5 \mathrm{~g} / \mathrm{cm}^{3}$ and generally larger grain sizes (from $10 \mu \mathrm{m}$ to $6 \mathrm{~mm}$ ). They observed higher swelling strains after 1.5 years with specimens where finer anhydrite was used. However, they do not show the development of the swelling strain over time and it is not clear, to which extent AGT progressed. 
The scatter concerning the value of maximal swelling strain reached by the specimens was seen to be dependent on their density (see Figure 8-11). Even though the same specimen preparation procedure was strictly followed, the density of the specimens still varied to some extent. The specimens containing natural anhydrite had densities between 1.99 and $2.13 \mathrm{~g} / \mathrm{cm}^{3}$, and the specimens containing commercial anhydrite SA 1 had densities between 1.86 and $1.94 \mathrm{~g} / \mathrm{cm}^{3}$, with the one exception of specimen 15_0 with $2.29 \mathrm{~g} / \mathrm{cm}^{3}$, which showed the highest amount of swelling strain (corresponding to the black curve ending with a triangle in Figure 8-9).

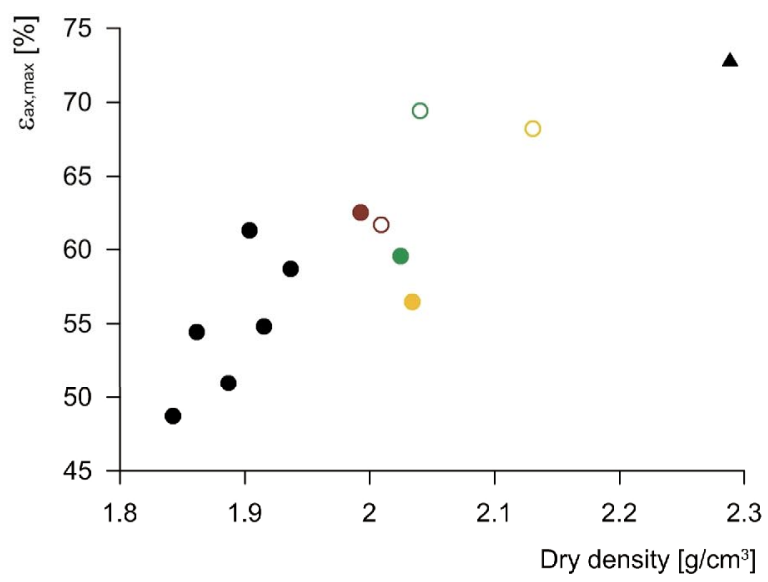

\footnotetext{
$40 \%$ Anhydrite Bex $<50 \mu \mathrm{m}, 60 \%$ Kaolin

$40 \%$ Anhydrite Bex $<80 \mu \mathrm{m}, 60 \%$ Kaolin

$40 \%$ Anhydrite Bözberg $<50 \mu \mathrm{m}, 60 \%$ Kaolin

$40 \%$ Anhydrite Bözberg $<80 \mu \mathrm{m}, 60 \%$ Kaolin

○ $40 \%$ Anhydrite Leissigen $<50 \mu \mathrm{m}, 60 \%$ Kaolin

- $40 \%$ Anhydrite Leissigen $<80 \mu \mathrm{m}, 60 \%$ Kaolin

- $40 \%$ Anhydrite SA $1<40 \mu \mathrm{m}, 60 \%$ Kaolin

- Specimen 15_0 (SA1, higher density)
}

Figure 8-11: Maximal swelling strain vs. dry density prior to the experiments.

\subsubsection{Preliminary tests III: Comparison different commercial anhydrite powders}

\section{a. Problem, aim and procedure}

Roughly two years after beginning with the swelling experiments described here (Chapter 8), anhydrite needed to be re-stocked from Sigma Aldrich. At that point, the same batch (SA 1 as also used for the first two series of preliminary tests, Chapters 8.4.1 and 8.4.2) could not be resupplied. Two (apparently equal) products were then ordered from Sigma Aldrich (referred to here as batches "SA 2" and "SA 3"), with the same purity and very similar particle size distributions (as will be seen below in Figure 8-14, left). However, the swelling behavior with oedometer tests at $3 \mathrm{kPa}$ differed from the first batch, as can be seen in Figure 8-12 (note that the black curves are the same as already shown in Figure 8-9).

Batches SA 2 and SA 3 (represented by the yellow and blue curves) showed at first a slow, then a rapid increase in strain which subsides fairly quickly ("S-shaped" curves) but reach generally slightly higher strains than SA 1. The only exceptions are the specimen 15_0 (SA 1 with a higher density, as described in the previous chapter) and one specimen with SA 3, which (for so far inexplicable reasons) did not swell at all due to AGT. However, upon repetition, SA 3 led to a similar swelling behavior as SA 2. 


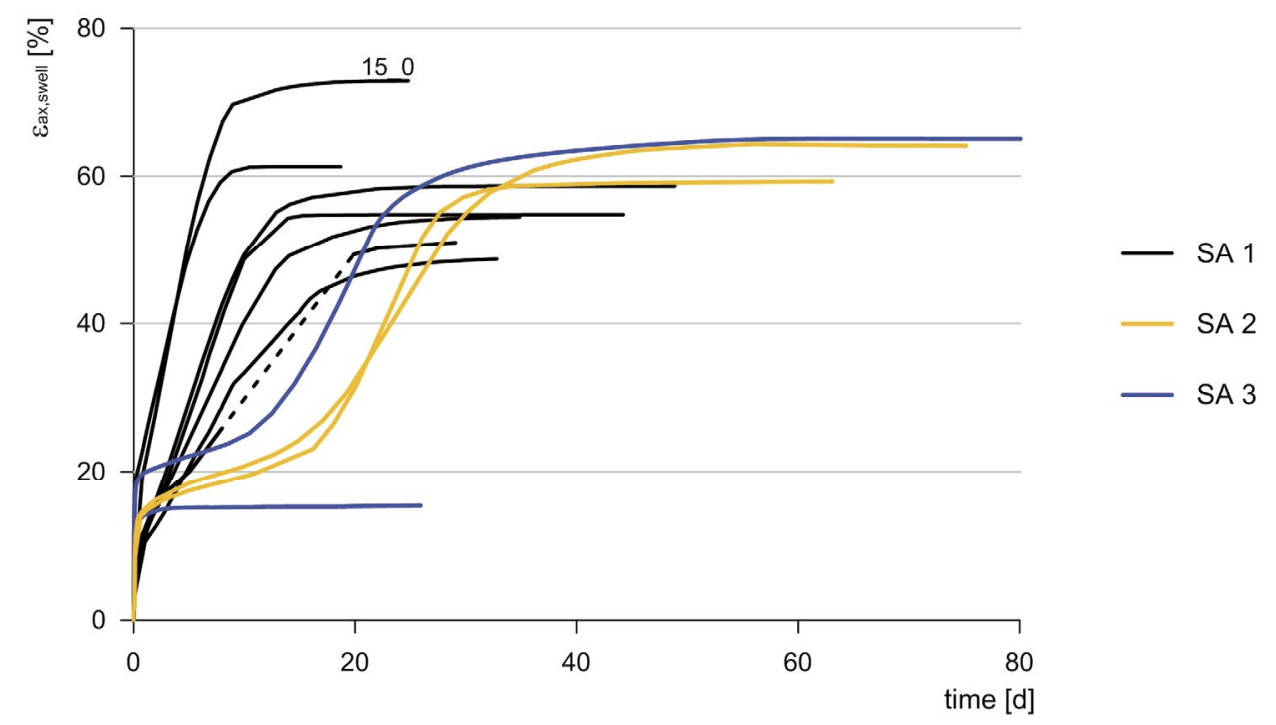

Figure 8-12: Swelling tests with anhydrite batches "SA 1", "SA 2" and "SA 3" from Sigma Aldrich.

When it was seen that the commercial anhydrites did not lead to similar swelling curves, further suppliers of anhydrite were considered: Alfa Aesar ("AA") and ProChem ("PC"). Furthermore, SA 2 and SA 3 were milled, in order to accelerate the swelling process. The swelling behaviors of these powders were then compared to one another with swelling tests in oedometers with an axial load of $3 \mathrm{kPa}$ (as in Chapter 8.4.2). With all anhydrite powders, the same specimen preparation procedure was followed as described in Chapter 8.3.

In order to determine the cause for the different swelling behaviors, the properties of these anhydrite powders were analyzed and compared more in depth (see Chapter 3 for a description of the analytical testing techniques):

- due to the known fact that smaller anhydrite particles dissolve faster, the particle size distributions were analyzed via laserdiffractometry;

- since the hydration rate is dependent also on the density and on the specific surface area of the anhydrite grains, the densities of the anhydrites were determined via pycnometry, and their specific surface area were determined via BET;

- in order to verify that the purity of the powders is as indicated by the suppliers, their purity was verified via X-ray diffraction analysis, where also the crystallite size was determined.

Furthermore the change in conductivity was observed when dissolving $4 \mathrm{~g} / \mathrm{l}$ of the powders in demineralized water (similar procedure as described in Chapter 4) and thus the kinetics of the AGT process could be qualitatively compared for the different powders in pure water.

\section{b. Results}

The usage of different anhydrite sources delivered the swelling strains depicted in Figure 8-13. The black, yellow and blue curves represent specimens with anhydrite from Sigma Aldrich and are the same as in Figure 8-12. As mentioned above, the batches SA 2 and SA 3 from Sigma Aldrich showed a slower swelling behavior compared to SA 1. However, by milling these batches in a ball mill for ca. 2 hours, the rate of the swelling strain could be increased (dashed lines). The anhydrite purchased from PC (green curves) showed an even slower swelling behavior than SA 2 and SA 3, while the AA-anhydrite did not produce any swelling strain at all during the observed period of time (red curves). Note that AA and PC were not further milled. TGA results on these specimens after 
swelling showed nearly no gypsum in the cases of the AA specimens and the first SA3 specimen (max. 2 gr of gypsum, i.e., AGT was progressed to solely $\vartheta=3 \%$ ), while all other specimens shown in Figure 8-13 exhibited AGT to at least $\vartheta=90 \%$. All specimen properties before and after swelling can be found in Table $\mathrm{J}-2$ in Appendix $\mathrm{J}$.

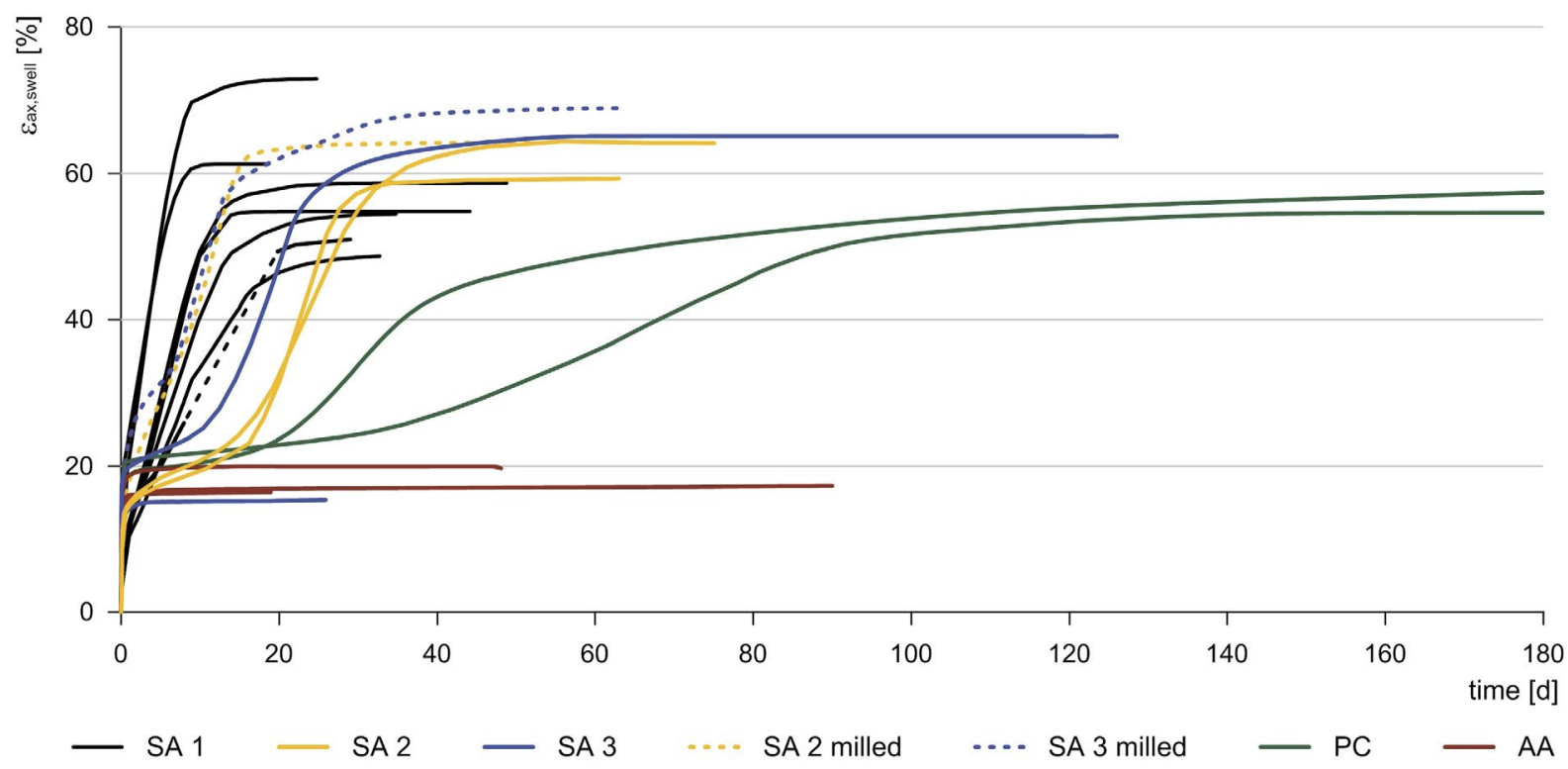

Figure 8-13: Swelling strain over time for different commercial anhydrite powders.

X-ray diffraction analysis, pycnometry and BET measurements on the anhydrite powders delivered the results in Table 8-5. It can be seen that all anhydrite powders have a purity of at least $98.9 \%$ (note that only in the case of AA, also dolomite and calcite were detected; the amounts are, however, considered negligibly small to have any influence on the chemical reactions of AGT and are thus not further discussed here). The isotropic crystallite size of the powders varies between 92 (SA 1) and $154 \mathrm{~nm}$ (PC). The densities of the grains all lie between 2.82 and $2.89 \mathrm{~g} / \mathrm{cm}^{3}$, which is slightly lower than the otherwise assumed density for anhydrite in this work (i.e., $2.96 \mathrm{~g} / \mathrm{cm}^{3}$ ). Here too, SA 1 showed the lowest value whereas PC showed the highest. The specific surface area was not measured for all powders, but the existing results lie within a relatively small range between the values of 3.66 and $5.67 \mathrm{~m}^{2} / \mathrm{g}$, whereas SA 1 showed the biggest specific surface area.

The results from laserdiffractometry (see Figure 8-14, left) have shown that the anhydrite powder from Alfa Aesar has slightly bigger particles (red curves), the powders from ProChem and Sigma Aldrich SA 2 and SA 3 show very similar particle size distributions while SA 1 (black curves) has slightly smaller particles. The additionally milled SA 2 powder shifted the particle size distribution curve to the left in the lower area, indicating a strong increase in small particles compared to the original curves (as was to be expected from the milling process).

Dissolving $4 \mathrm{~g} / \mathrm{l}$ of the anhydrite powders in demineralized water and measuring the conductivity of the solutions delivered the results in Figure 8-14, right. It can be seen that SA 1 (black curves) reaches a higher peak in shorter time compared to the other powders, which indicates faster, immediate anhydrite dissolution. Furthermore, they decrease faster than the curves representing the other powders, which suggests that AGT is completed faster. This can also be seen for the case of the dashed yellow curve representing the milled SA 2 powder, when comparing it to the original powder (solid yellow curve). 
Table 8-5: $\quad X R D$, pycnometry and BET results of the anhydrite powders ([wt\%] = weight percentage).

\begin{tabular}{|c|c|c|c|c|c|c|}
\hline Specimen name & SA 1 & SA 2 & SA 2, milled & SA 3 & PC & AA \\
\hline \multicolumn{7}{|l|}{ XRD } \\
\hline Anhydrite [wt\%] & $99.35( \pm 0.16)$ & $99.37( \pm 0.16)$ & $99.36( \pm 0.16)$ & $99.22( \pm 0.19)$ & $99.7( \pm 0.08)$ & $98.9( \pm 0.28)$ \\
\hline Celestine [wt\%] & $0.19( \pm 0.09)$ & $0.21( \pm 0.09)$ & $0.30( \pm 0.12)$ & $0.25( \pm 0.14)$ & $0.29( \pm 0.08)$ & $0.26( \pm 0.13)$ \\
\hline Quartz [wt\%] & $0.46( \pm 0.13)$ & $0.41( \pm 0.12)$ & $0.34( \pm 0.11)$ & $0.53( \pm 0.13)$ & & \\
\hline Dolomite [wt\%] & & & & & & $0.48( \pm 0.14)$ \\
\hline Calcite $[w t \%]$ & & & & & & $0.36( \pm 0.17)$ \\
\hline Crystallite size (iso.) [nm] & 92 & 99 & $93( \pm 5)$ & 129 & $154( \pm 13)$ & $128( \pm 9)$ \\
\hline \multicolumn{7}{|l|}{ Pycnometry } \\
\hline Density $\left[\mathrm{g} / \mathrm{cm}^{3}\right]$ & 2.823 & 2.879 & 2.876 & 2.880 & 2.889 & 2.884 \\
\hline \multicolumn{7}{|l|}{ BET } \\
\hline Spec. surf. area $\left[\mathrm{m}^{2} / \mathrm{g}\right]$ & 5.668 & 4.591 & & 3.666 & & 3.997 \\
\hline
\end{tabular}
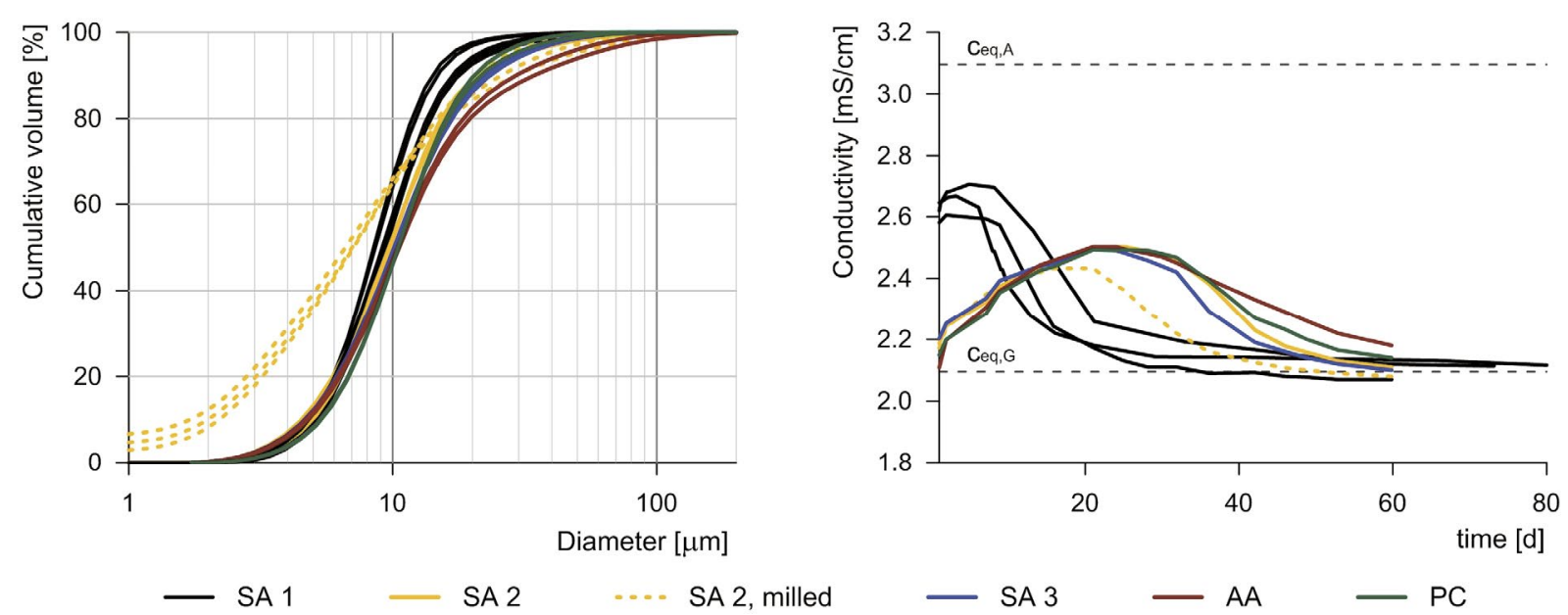

Figure 8-14: Left: laserdiffractometry results; right: conductivity measurements for the different commercial anhydrite powders.

\section{c. Discussion}

No investigated factor alone was able to explain the retardation or complete absence of swelling strain that some specimens have shown in Figure 8-13. All anhydrite powders have proven to have a purity of at least $98.9 \%$.

When comparing the swelling strains (Figure 8-13) to the conductivity measurements (Figure 8-14, right) it can be seen that in both cases the black curves (SA 1) show the most rapid AGT reactions, while the yellow (SA 2), blue(SA 3) and green (PC) curves indicate slower AGT. However, while in the conductivity results the yellow, blue, green and red curves develop very similarly (Figure 8-14, right), the swelling strains vary from slightly slower (yellow and blue curves, SA 2 and SA 3 in 
Figure 8-13), to very slow strains (green curves, PC) to no strains at all (red curves, AA). Thus the conductivity measurements could confirm faster AGT in the case of SA 1, which corresponds to the swelling strains, but do however also indicate $A G T$ to occur in the case of $A A$, which did not show any swelling strain at all (cf. Figure 8-13).

While the particle size distributions all lie within a similar range, the results from laserdiffractometry (Figure 8-14, left) indicate that of the unaltered powders SA 1 has the narrowest particle size distribution, (with d $_{95}<20 \mu \mathrm{m}$ ) while AA has the widest particle size distribution ( d $_{95}<55 \mu \mathrm{m}$ ). Naturally, the milled SA 2 powder shows more fine particles and thus an even wider distribution. Based on these results the following general statement can be made concerning the swelling behavior: the smaller the maximum grain size, the faster swelling seems to occur. However, when comparing only SA 2 and SA 3 with PC, the particle size distribution gives no indication as to why PC swells much slower.

When looking at the crystallite size, grain density and specific surface area of the grains and comparing them to the swelling strains it can be generally said that the rates of the strains tend to be higher with smaller crystallite size, smaller density and larger specific surface area. However, here too, none of the properties suffice to explain why, e.g., AA did not swell at all (for example, these values are similar for SA 3 and AA, while PC has an even bigger crystallite size and a higher density). Concerning the grain density it appears that all values lie between those of two different phases of anhydrite, as described in Chapter 2.1 (cf. Wirsching, 2000): Anhydrite III ("soluble" anhydrite, which is metastable in dry air; grain density of $2.58 \mathrm{~g} / \mathrm{cm}^{3}$ ) and Anhydrite II (which can be - depending on the formation temperature - All-s / slowly soluble anhydrite, All-u / insoluble anhydrite or All-E / "Estrichgips" with a grain density of $\left.2.93-2.97 \mathrm{~g} / \mathrm{cm}^{3}\right)$. It is therefore conceivable that the anhydrite powders consist of a mixture of these phases, whereas SA 1 contains the most amount of Anhydrite III.

In order to accelerate the swelling behavior and thus shorten the duration of the swelling tests described in the following chapters, it was decided to continue using anhydrite from Sigma Aldrich (i.e., batches SA 2 and SA 3), however milling the powders prior to specimen preparation.

\subsubsection{Preliminary tests IV: Determination of Young's modulus and Poisson ratio}

\section{a. Aim and procedure}

As seen in the constitutive model (Chapter 7.1) as well as in the thought experiments (Chapter 7.3.4), it is necessary to know the Young's modulus and the Poisson ratio of the specimens in order to evaluate most experiments (depending on the boundary conditions). For this reason a triaxial test was performed with a powdered and compressed specimen (with a diameter of $70 \mathrm{~mm}$ and a height of $140 \mathrm{~mm}$ ). Since it was not possible to compress a specimen with such a height as a whole (a minimum relationship of height:diameter equal to $2: 1$ is recommended for triaxial tests according to the ASTM standards; e.g., ASTM International, 2004 and 2007b), four specimens with a height of $35 \mathrm{~mm}$ each were compressed and stacked within the triaxial cell in order to obtain a representative specimen with a height of $140 \mathrm{~mm}$.

The triaxial test is performed under dry conditions, in order to avoid swelling during the test. Four loading steps are executed, where the specimen is first loaded isotropically up to each of the four pre-defined stress levels ( $1 \mathrm{MPa}-2 \mathrm{MPa}-4 \mathrm{MPa}-8 \mathrm{MPa})$. At each stress level, the radial stress is held constant while the axial load is increased until the measured deformation reached an axial strain of ca. $0.2 \%$, then reduced again to the last isotropic stress state. The specimen is then 
reloaded deviatorically, until the shear strength is mobilized, at which point the specimen is unloaded to the last isotropic stress. Then the specimen is reloaded again isotropically to the next stress level and the same procedure repeated.

The deformations were measured on the one hand within the cell, close to the specimen ("internal measurements" with a magnetostrictive position sensor for the axial displacements and an extensometer which measures the displacements as a digital encoder moves along a magnetic strip for the change in circumference; referred to here as "chain extensometer"), on the other hand, "external measurements" were taken, where the position of the piston (which indicates the axial deformation of the specimen), as well as the change in oil volume being pressed in and out of the cell (from which the changes in volume of the specimen can be calculated) was measured.

Additionally, a dry specimen (specimen preparation as described in Chapter 8.3) was stepwise loaded and unloaded in a conventional oedometer up to $3.2 \mathrm{MPa}$, then wetted with ethanol and unloaded to $0.8 \mathrm{MPa}$ and reloaded to $3.2 \mathrm{MPa}$, in order to observe the difference between a dry and a saturated specimen. The stress-strain relationships during loading, unloading and reloading were used for a further estimate for the Young's modulus of such specimens, in addition to the triaxial test results.

\section{b. Results}

The stress-strain path of the specimen during the triaxial test is shown in Figure 8-15, left. Each load step began by increasing the axial stress while measuring the deformations. After $0.1-0.2 \%$ axial strain, the axial stress was reduced and increased again (i.e., unloading and reloading the specimen), as indicated by the red arrows in Figure 8-15, left. As can be seen, the unloading and reloading paths occur at a steeper slope than the "first" loading (whereas it needs to be noted that during specimen preparation the specimens were already compressed with a far higher axial stress of $100 \mathrm{MPa}$ ). Therefore, the deformation of the specimens is not completely elastic.

The Young's modulus is determined from the slope of the elastic deformation, i.e., the unloading and reloading paths indicated by the red arrows in Figure 8-15. In order to model the entire deformation of the specimens, however, the Young's modulus is most likely too high. It may be conceivable to use the deformation modulus, determined by the slopes of the green secants of the first loading paths at each stress level. For both cases, the respective moduli are shown as a function of the radial stress in Figure 8-15, right.

In both diagrams, the results are shown based on the internal measurements (dotted lines) as well as the external measurements (solid lines). Since the experiments in this research generally did not undergo cyclic loading, the values obtained via the secants are taken further into account for the estimation of the Young's modulus.

The maximally reached axial stress (before shearing occurred), i.e., the peak stress, is shown in dependence of the radial stress in Figure 8-16, left. From this, the Mohr-Coulomb failure criterion can be concluded (see dashed linearization in Figure 8-16), since axial loading at each radial stress level occurred until shearing began. Therefore, an angle of friction of $25^{\circ}$ and a cohesion of $2 \mathrm{MPa}$ can be determined for the powdered compressed specimens in their dry state (i.e., prior to any swelling experiments).

In order to obtain a value for the Poisson ratio as well as the angle of dilatancy, the volumetric strain vs. the axial strain is regarded (see right diagram in Figure 8-16). Both parameters can then be determined as a function of the slope of the axial-volumetric strain curve (Vermeer and de Borst, 
1984). Here, merely one set of measurements was used (the external measurements taken during load step 4), since all other sets of measurements were either faulty (the chain extensometer was probably insufficiently pre-stressed and did not measure properly at lower stresses) or indicated a Poisson ratio near or even below 0 . Hence, the maximal determined Poisson ratio $v$ based on these measurements was ca. 0.26 while the angle of dilatancy $\psi$ is estimated to $2.3^{\circ}$.
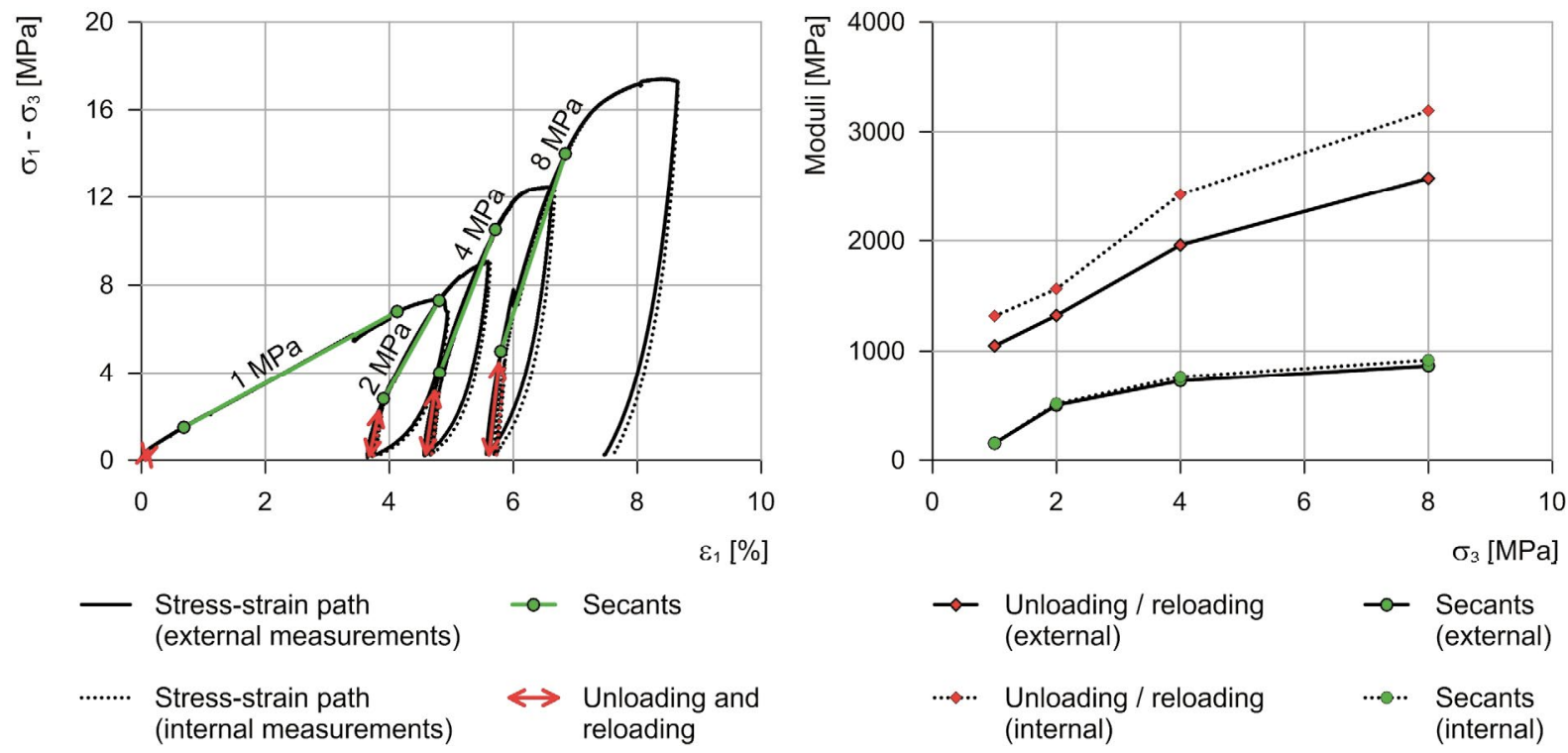

$$
\begin{array}{ll}
\rightarrow- & \begin{array}{l}
\text { Unloading / reloading } \\
\text { (external) }
\end{array} \\
\cdots \cdots & \begin{array}{l}
\text { Unloading / reloading } \\
\text { (internal) }
\end{array}
\end{array}
$$$$
\rightarrow \text { Secants }
$$$$
\text { (external) }
$$$$
\text { ..... Secants }
$$

Figure 8-15: Results from a triaxial test on a compacted powdered specimen. Left: deviatoric stress vs. axial strain for all four radial stress levels. Right: possible ranges for the E-Modulus (determined as deformation modulus from the slopes of the secants and as elastic modulus from the unloading/reloading paths in the left diagram).
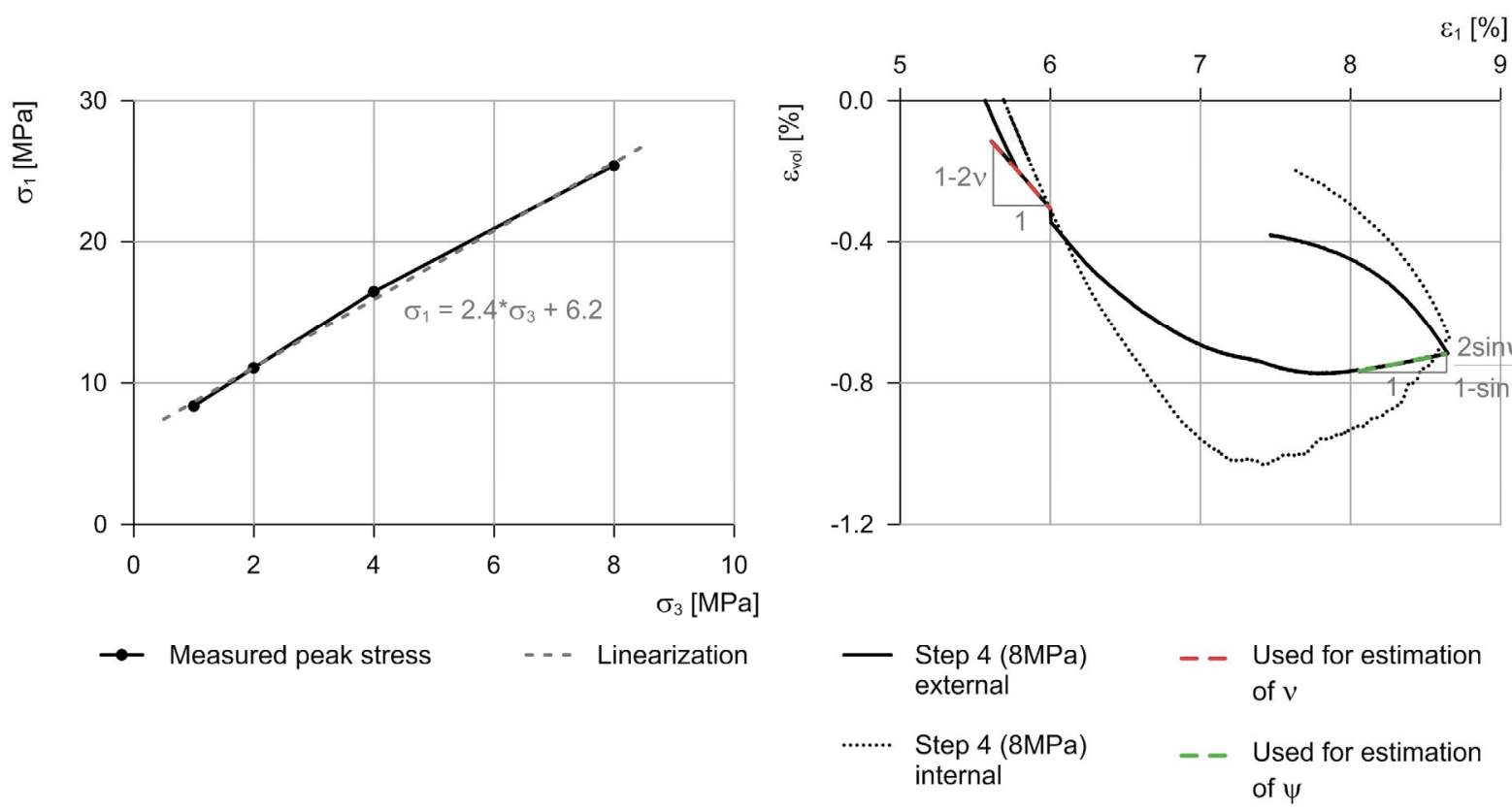

Figure 8-16: $\quad$ Results from a triaxial test on a compacted powdered specimen. Left: peak axial stress vs. applied radial stress (Mohr-Coulomb failure criterion). Right: volumetric strain vs. axial strain for stress level 4 (8 $\mathrm{MPa})$ and approximations for the determination of the Poisson ratio $v$ and angle of dilatancy $\psi$.

Additionally, a powdered specimen in an oedometer cell was stepwise loaded and unloaded, thus leading to the (axial) stress-strain relationship in Figure 8-17, left. 
Here too, the moduli are estimated based on the "first" loading path (note that this too is a reloading path, since the specimens were compacted previously with an axial load of $100 \mathrm{MPa}$ ), as well as the unloading and reloading paths, indicated by the red dashed lines in Figure 8-17, left:

$$
E=\frac{\Delta \sigma}{\Delta \varepsilon} \cdot \frac{(1+v) \cdot(1-2 v)}{(1-v)}
$$

(cf., e.g. Lang et al., 2007).

In this case it is not possible to determine the Poisson ratio from the experiments. Therefore, $v$ is varied from its extreme cases, i.e., 0 (no deformation perpendicular to the imposed deformation) to 0.5 (completely incompressible resp. constant volume) in Figure 8-17, right, and we obtain the range of $0-220 \mathrm{MPa}$ for the Young's modulus.

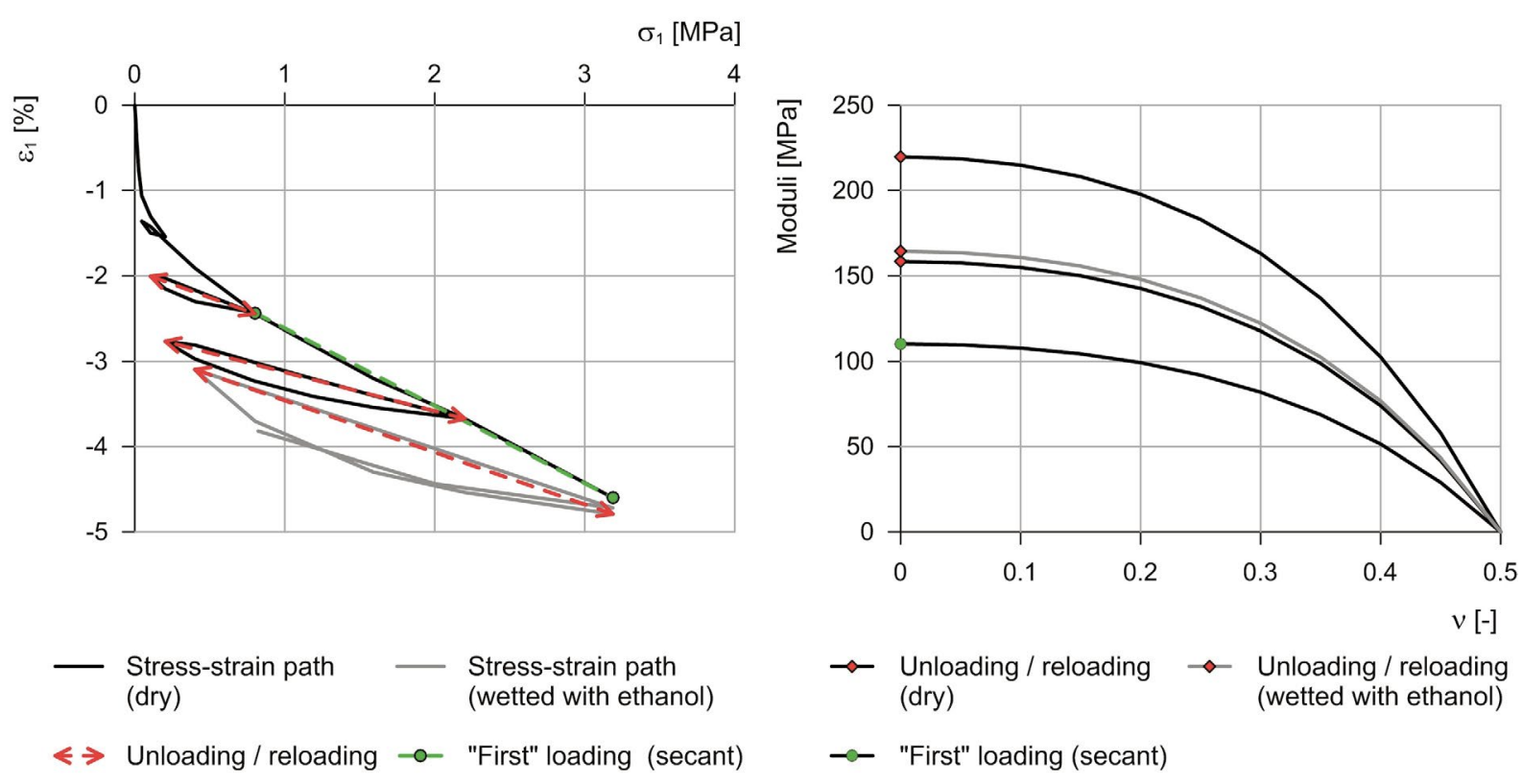

Figure 8-17: Results from an oedometer test on a compacted powdered specimen. Left: stress-strain path; right: estimation of deformation and elastic moduli (based on the results from the left diagram) for various Poisson ratios.

\section{c. Discussion}

The triaxial tests deliver a rather high estimation for the Young's modulus of a powdered, compacted and dry specimen. However, since the highest stresses used in the experiments in this work were ca. 3.5 MPa (see Chapter 8.6), the values obtained with the triaxial test are assumed to indicate an upper threshold. Furthermore, it needs to be considered that the Young's modulus can change severely (i.e., up to a factor of 10 lower) when a specimen is wetted, as Pimentel (1996) has investigated experimentally. It was seen during the experiments described here that the specimens become very soft after swelling (especially with low stresses acting on the specimens), and thus the Young's modulus is assumed to decrease (the Young's modulus of very soft clay can be below $5 \mathrm{MPa}$ ). However, in cases with high stresses acting on the specimens (and where very little or no increase in total volume was observed), the specimens remained very intact and dense, thus likely maintaining a high Young's modulus after contact with water.

Through simple unloading and reloading of a specimen in an oedometer cell, far lower values for the Young's modulus were estimated, which correspond better with literature values for clays. 
Based on these aspects, a general range of 1-200 MPa is considered for the Young's modulus of the powdered and compressed specimens in a saturated state.

From the triaxial test a maximal Poisson ratio of 0.26 was estimated. This lies within literature values of unsaturated clays (0.1 to 0.3 , cf., e.g., Bowles, 1996). For saturated clays, however, the Poisson ratio can increase to 0.4 to 0.5 . It is therefore strongly assumed that the estimated value of 0.26 indicates a lower threshold value for the Poisson ratio of these specimens.

\subsection{Oedometer tests}

\subsubsection{Aim and procedure}

A total of nearly 70 oedometer tests were performed with various axial loads and with different test durations in order to investigate the swelling stress / swelling strain behavior during AGT. The experiments can be grouped into two series, based on the aim of the experiments:

In the first series of oedometer tests (Chapter 8.5.2) the aim was to determine the influence of axial stress on the maximal strain by measuring the deformation (and thus the swelling strain) of specimens under various constant axial stresses until the strains reach a steady state. These experiments were performed with specimens consisting of anhydrite and kaolin as well as anhydrite and quartz flour.

With the second series of oedometer tests the relationship between the swelling strain and the change in mass of anhydrite in the specimens over time was to be established (i.e., to determine the coupling parameter $\chi$, c.f. Equation $(7-11)$ resp. $(7-47))$. For this purpose oedometer experiments were performed, where specimens of anhydrite and kaolin were subjected to a specific axial stress ( $3 \mathrm{kPa}$ or $800 \mathrm{kPa}$ ) and then extracted after different test durations, before the swelling strain reached a steady state (see Chapter 8.5.3).

The anhydrite used for all tests stem from Sigma Aldrich (i.e., SA 1, SA 2, SA 3 and milled versions of the latter two powders). The basic set up of the oedometer tests is the same as in Chapter 8.4.2, resp. Figure 8-8, whereas now higher loads are applied (up to $3200 \mathrm{kPa}$ ).

\subsubsection{Results of the first series (various axial loads - swelling until strain reaches steady state)}

In the first series of oedometer tests with anhydrite and kaolin axial stresses between $3 \mathrm{kPa}$ and $3200 \mathrm{kPa}$ were applied. For the series with anhydrite and quartz flour the axial stresses ranged from $3 \mathrm{kPa}$ to $800 \mathrm{kPa}$. Two additional oedometer tests were performed at $3 \mathrm{kPa}$ and $400 \mathrm{kPa}$ on specimens containing $100 \%$ kaolin, in order to compare the swelling strains with and without AGT. For each axial load at least one oedometer test was conducted until the swelling strain reached a steady state and thus the final strain was measured.

The results from the oedometer tests are presented in Figure 8-18 and Figure 8-19, which show the measured swelling strain over time for the anhydrite/kaolin specimens and the anhydrite/quartz flour specimens, respectively, until the swelling strain reached a steady state for all the axial stresses investigated. The swelling strains obtained with an axial load of $3 \mathrm{kPa}$ were taken from the experiments described in Chapters 8.4.2 and 8.4.3, i.e., the black and grey curves shown in Figure 8-18 are the same as the SA 1, SA 2 and SA 3 curves already shown in Figure 8-9 and Figure 8-13. 
At an axial stress of $3200 \mathrm{kPa}$ no swelling strain could be observed over the entire duration of the test with a specimen containing SA 1 and kaolin; for the specimens containing SA 1 and quartz flour this was the case at an axial stress of $800 \mathrm{kPa}$ (the durations of both of these tests was ca. 80 days).

At $3 \mathrm{kPa}$ and at $800 \mathrm{kPa}$ multiple tests were repeated with the anhydrite/kaolin specimens and some scatter in the results was observed (e.g., the final swelling strain of the specimens containing kaolin which were loaded with $800 \mathrm{kPa}$ varied from $6 \%$ to $10 \%$ ).

The red dot-dashed curves in Figure 8-18 indicate the swelling behavior of the specimens containing only kaolin, which also exhibited a rapid initial strain (see Chapter 8.3.3) during the first couple of hours due to wetting of the specimen and reduction of the negative pore pressure (similar to the other curves). It can be seen that this rapid initial strain is significant especially for low axial stresses.

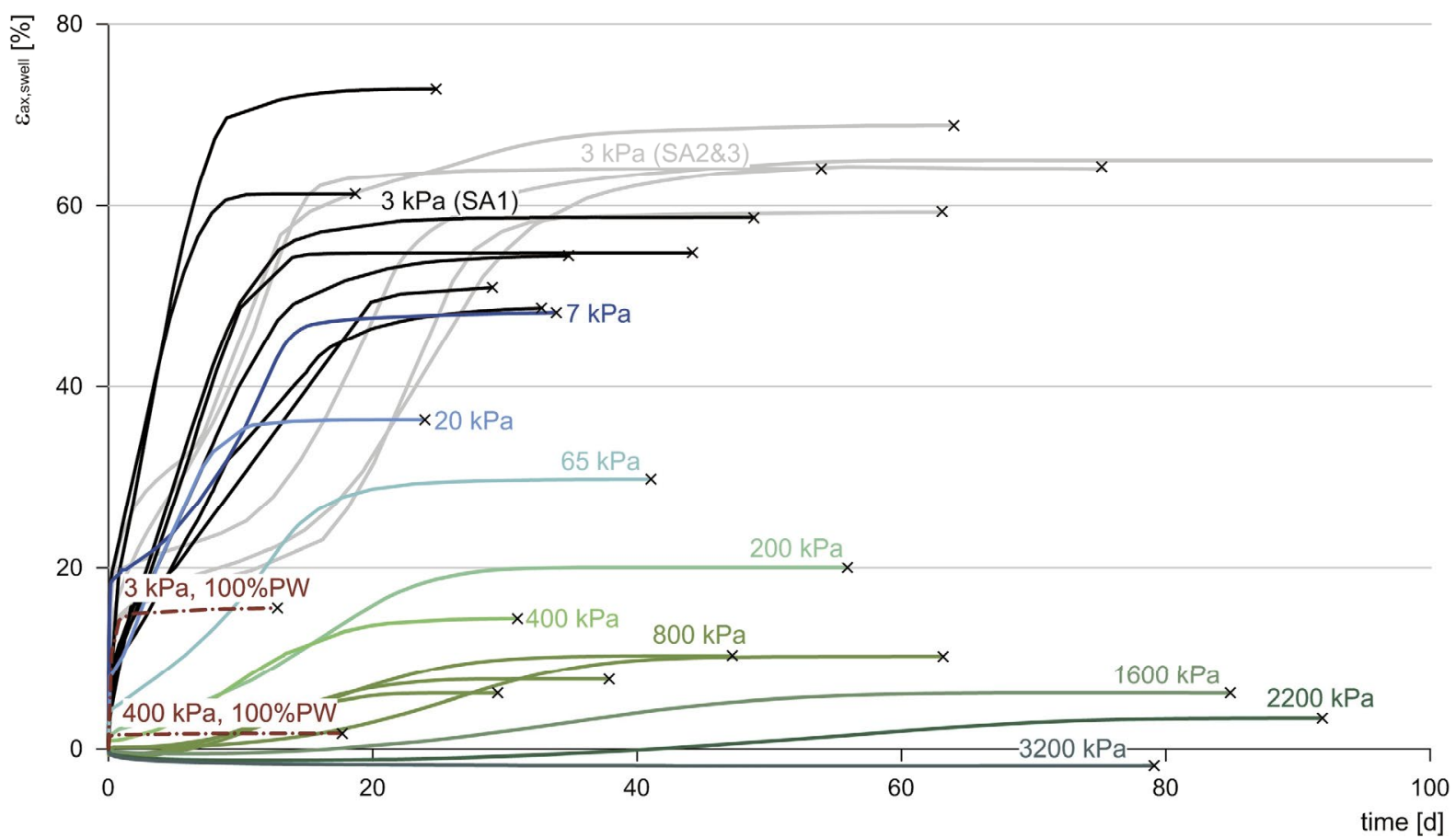

Figure 8-18: Results of oedometer tests up to a steady state for mixtures with anhydrite and kaolin. Note that all black and grey curves were loaded axially with $3 \mathrm{kPa}$.

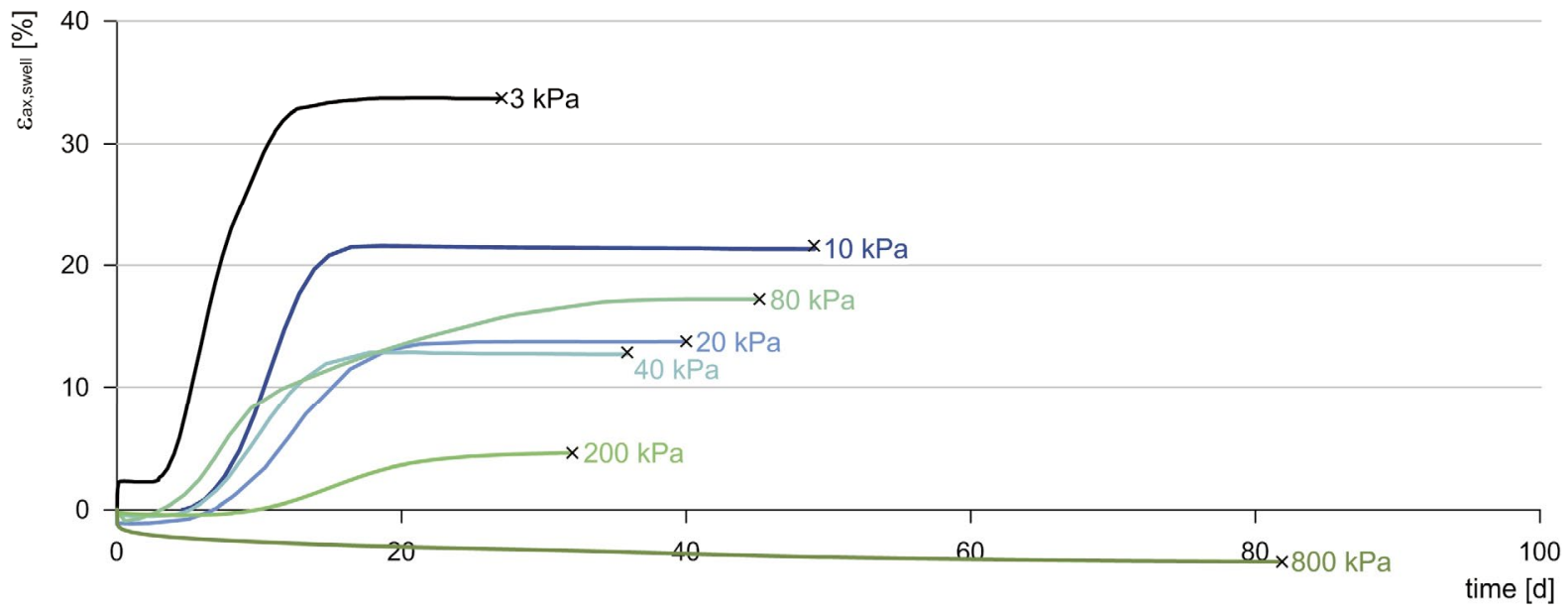

Figure 8-19: Results of oedometer tests up to a steady state for mixtures with anhydrite and quartz flour. 
Figure 8-20 shows the final strain that was reached at each test versus the corresponding axial stress in a semilogarithmic diagram. These results indicate a linear relationship between the final swelling strains and the logarithm of the axial stress for both types of specimens at axial stresses above $3 \mathrm{kPa}$.

Based on the TGA results post test, all specimens contained a high content of gypsum except in the case of the anhydrite/kaolin specimen that was loaded with $3200 \mathrm{kPa}$ and did not swell at all (but even settled slightly). This is shown in Figure 8-21, where the masses of anhydrite prior and post test as well as the mass of gypsum post test (per unit volume) are mapped against the applied axial stresses for each specimen. The values $m_{A, \text { prior }}$ are obtained directly from the initial measured geometry and mass of the specimen, while $m_{A, \text { end }}$ and $m_{G, \text { end }}$ were determined indirectly via TGA.

Note that $m_{G, \text { end }}$ is lower than $m_{A, p r i o r}$ and tends to be smaller with lower axial loads, while the amount of transformed anhydrite $(\vartheta)$ is nearly the same for all tests (see Table J-2 and Table J-3 in Appendix $\mathrm{J}$ ). This is due to the fact that $m_{i}$ is defined as the ratio between the mass of the constituent $i$ (i.e., anhydrite or gypsum) and the total volume of the specimen (Equation (2 - 11)). Prior to the tests, the specimens have nearly the same volume, and thus the values for $m_{A, \text { prior }}$ all lie between 0.7 and $0.8 \mathrm{~g} / \mathrm{cm}^{3}$ in the case of the kaolin specimens, and at about $0.6 \mathrm{~g} / \mathrm{cm}^{3}$ in the case of the quartz flour specimens. However, since the specimens loaded with a smaller axial stress exhibited higher strains, the total volume of the specimens increased far more than in the cases were the specimens were loaded with higher axial stresses. Therefore, $m_{G, \text { end }}$ is smaller at lower stresses, even though the same amount of anhydrite has transformed to gypsum.

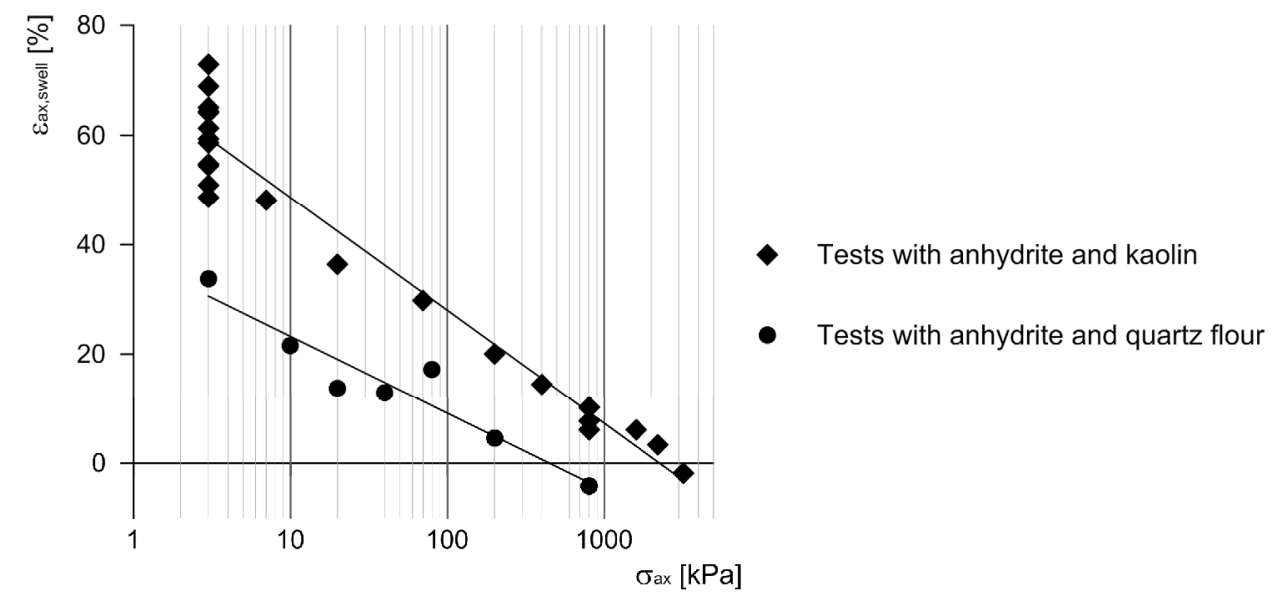

Figure 8-20: Final swelling strain vs. corresponding axially applied stress. 

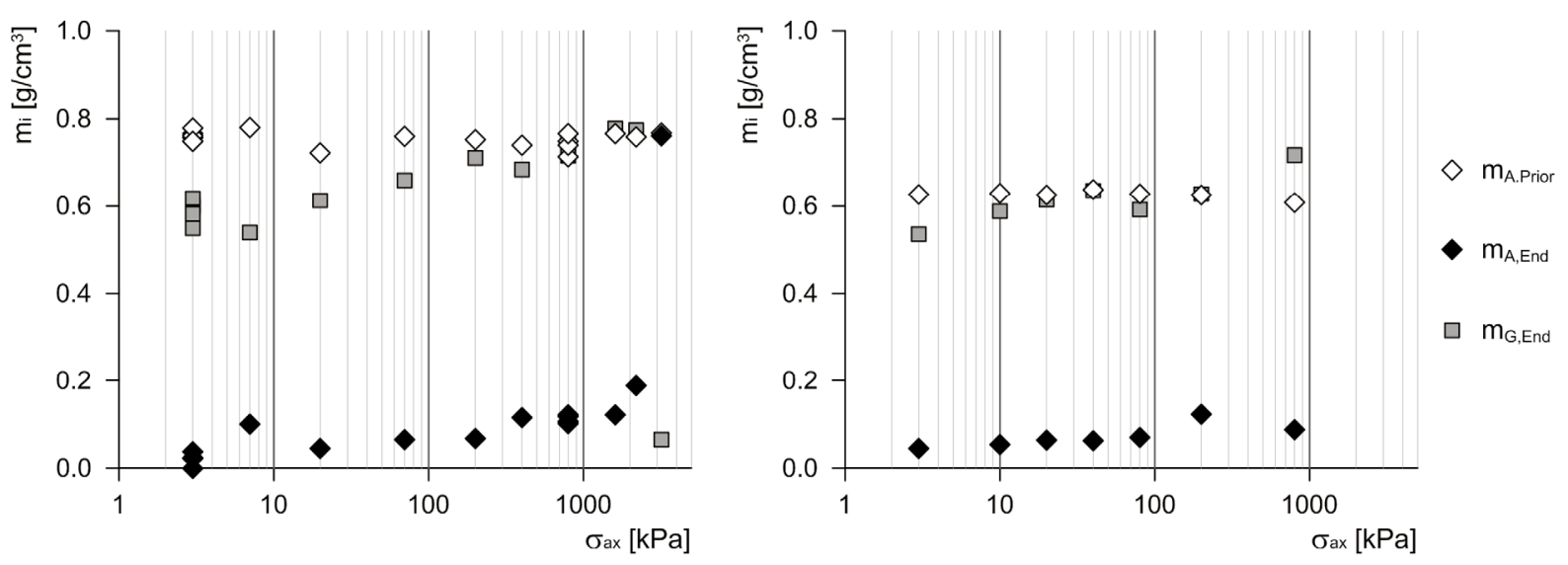

Figure 8-21: $\quad$ Masses per unit volume of anhydrite (prior and post test) as well as gypsum (post test) versus applied axial stress for the first series of oedometer tests. Left: anhydrite/kaolin specimens, right: anhydrite/ quartz flour specimens.

Based on the volumes of transformed anhydrite and gypsum (which is calculated from the respective masses) as well as the measured specimen volume prior to swelling, it is possible to determine component $\varepsilon_{V_{A, G}}$ of the strains which is caused by a change in solid volume (cf. Chapter 8.3.3):

$$
\varepsilon_{V_{A, G}}=\frac{\Delta h_{V_{A, G}}}{h_{0}}=\frac{\Delta V_{S}}{V_{0}}
$$

The change in solid volume, $\Delta V_{S}$, is calculated by considering the mass balance and the densities of anhydrite and gypsum (see Equation (2 - 17)).

The respective amounts of strains due to change in solid volume are shown in Figure 8-22 in red for the same strains previously shown in Figure 8-20. As can be seen, and as was expected due to the nearly full conversion of anhydrite to gypsum in most cases, the calculated strains due to an increase in solid volume is independent of the applied stress. Above a certain stress, they exceed the measured swelling strains (in the case of anhydrite/kaolin specimens above roughly $480 \mathrm{kPa}$; in the case of anhydrite/quartz flour specimens above roughly $80 \mathrm{kPa}$ ). This leads to conclude that the pore volume of the specimens increases at lower stresses, and decreases at higher stresses. Furthermore, more gypsum precipitates in the pores in the case of the anhydrite/quartz flour specimens, as opposed to the anhydrite/kaolin specimens, due to the fact that the change in solid volume causes similar strains, but the measured swelling strain differs in the two cases. 


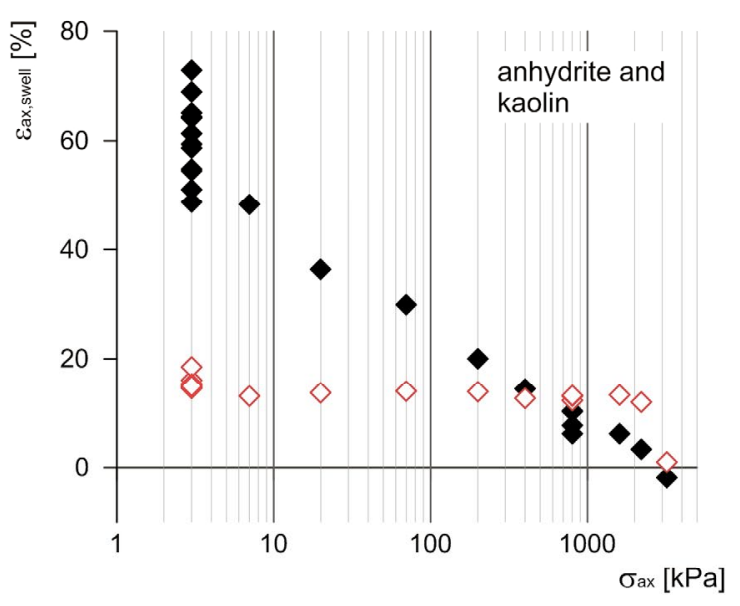

- Max. axial swelling strain

$\diamond \quad$ Calculated swelling strain due to change in solid volume $\left(\varepsilon_{\Delta V_{A, G}}\right)$

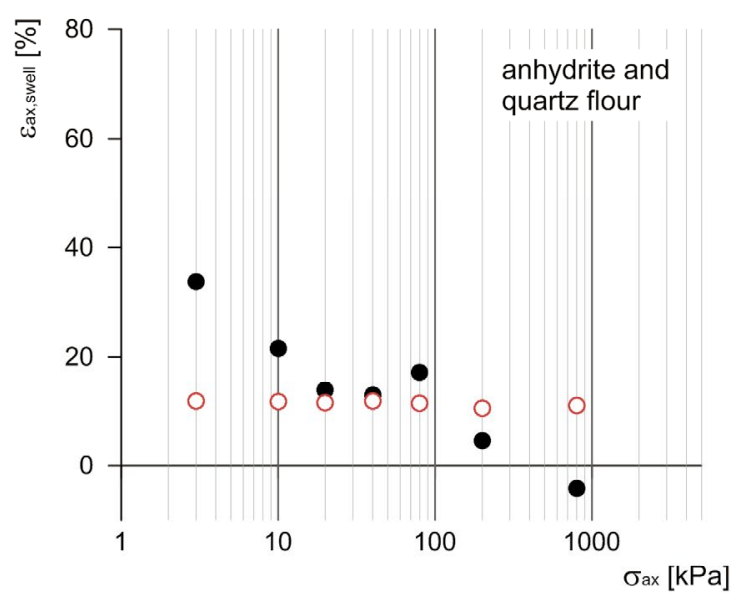

- Max. axial swelling strain

- Calculated swelling strain due to change in solid volume $\left(\varepsilon_{\triangle V_{A, G}}\right)$

Figure 8-22: Final measured swelling strains and calculated strains due to change in solid volume vs. axially applied stress. Left: anhydrite/kaolin specimens, right: anhydrite/quartz flour specimens.

\subsubsection{Results of the second series (axial loads of $3 \mathrm{kPa}$ and $800 \mathrm{kPa}-$ swelling until various degrees of AGT)}

Figure 8-23 shows the swelling strain over time for additional oedometer tests performed with anhydrite and kaolin specimens at $\sigma_{a x}=3 \mathrm{kPa}$ and $800 \mathrm{kPa}$, but where the specimens were extracted before the strains reached a steady state. The points of extraction are indicated by the crosses (" $x$ ").
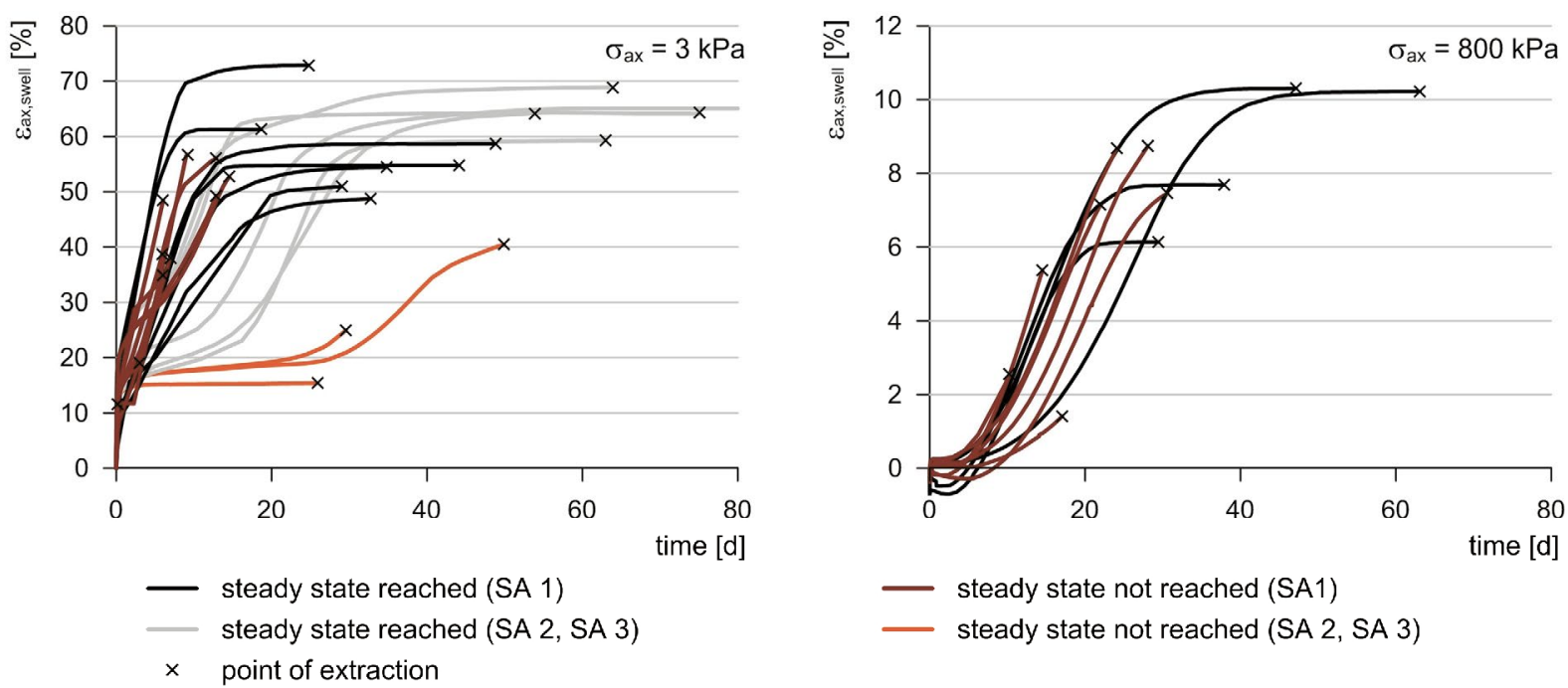

Figure 8-23: Results of oedometer tests up to various swelling strains. Left: results from tests with an axial stress of $3 \mathrm{kPa}$; right: $800 \mathrm{kPa}$.

The main goal of these tests performed up to various strains was to determine a relationship between the swelling strain and the change in mass of anhydrite. Therefore, the strains due to dry loading and mechanical resp. clay swelling that occurs in the first hours of wetting the specimens were subtracted from the total strains according to Chapter 8.3.3, and thus the strains shown Figure 8-24 consider solely strains due to AGT $\left(\varepsilon_{a x, A G T}\right)$. 
In nearly all cases, a clear change in the rate of the swelling strains can be seen in the curves about half a day after wetting and those values were therefore taken as the initial strains as described in Chapter 8.3.3 (i.e., due to physical swelling). In the case of the specimens loaded axially with $3 \mathrm{kPa}$, the initial strains were therefore estimated to be $8-18 \%$. However, in the case of $800 \mathrm{kPa}$ axial load, some specimens also exhibited small initial strains (up to $0.4 \%$ ), while other specimens settled slightly upon wetting (down to $-0.6 \%$, see Figure $8-23$, right). It is assumed that in the cases where settlements occurred, some residual stress from compaction (friction) existed between the specimens and the oedometer rings. It may be that these specimens were not completely pressed to the bottom steel plate of the oedometer due to dry loading from the beginning on and the friction between specimen and steel ring sufficed to withstand the axial dry load. Upon wetting, however, the friction between the specimens and the steel rings is overcome (at least partially) and thus the specimens settle further. This could explain, why certain specimens settle (especially at loads of $800 \mathrm{kPa}$ and higher), while other specimens exhibit a rapid heave within the first few hours after wetting. Therefore, the settlements are considered analogue to the mechanical strains indicated in Figure 8-3, since they occur independently of AGT.
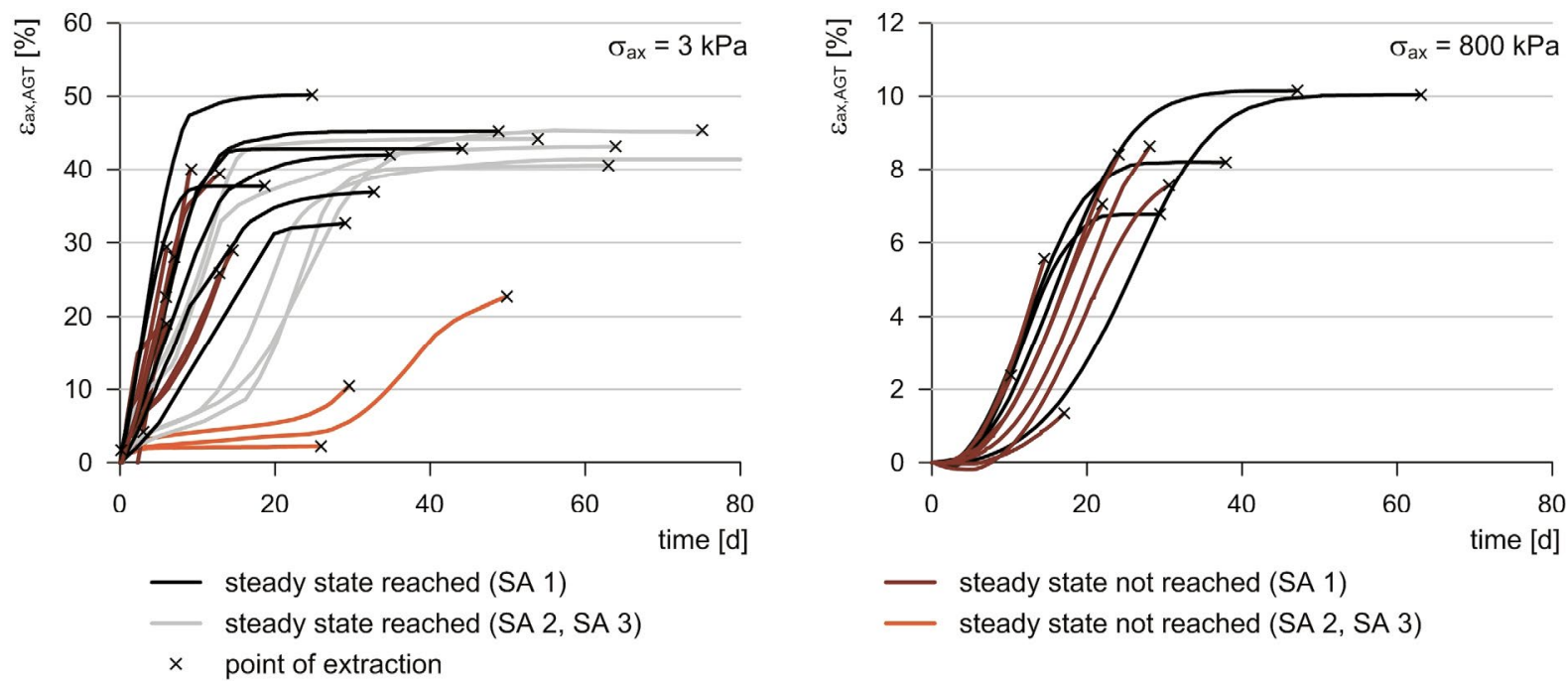

Figure 8-24: Strains due to AGT (i.e., occurring after the first ca. 10 hours of wetting). Left: results from tests with an axial stress of $3 \mathrm{kPa}$; right: $800 \mathrm{kPa}$.

The amount of anhydrite in each specimen post test $\left(m_{A, \text { end }}\right)$ versus the reached swelling strain due to AGT at the point of extraction is shown in Figure 8-25. The values for $m_{A, \text { end }}$ in Figure 8-25 are back-calculated based on the results from TGA (see Chapter 3.1 and Appendix I). 


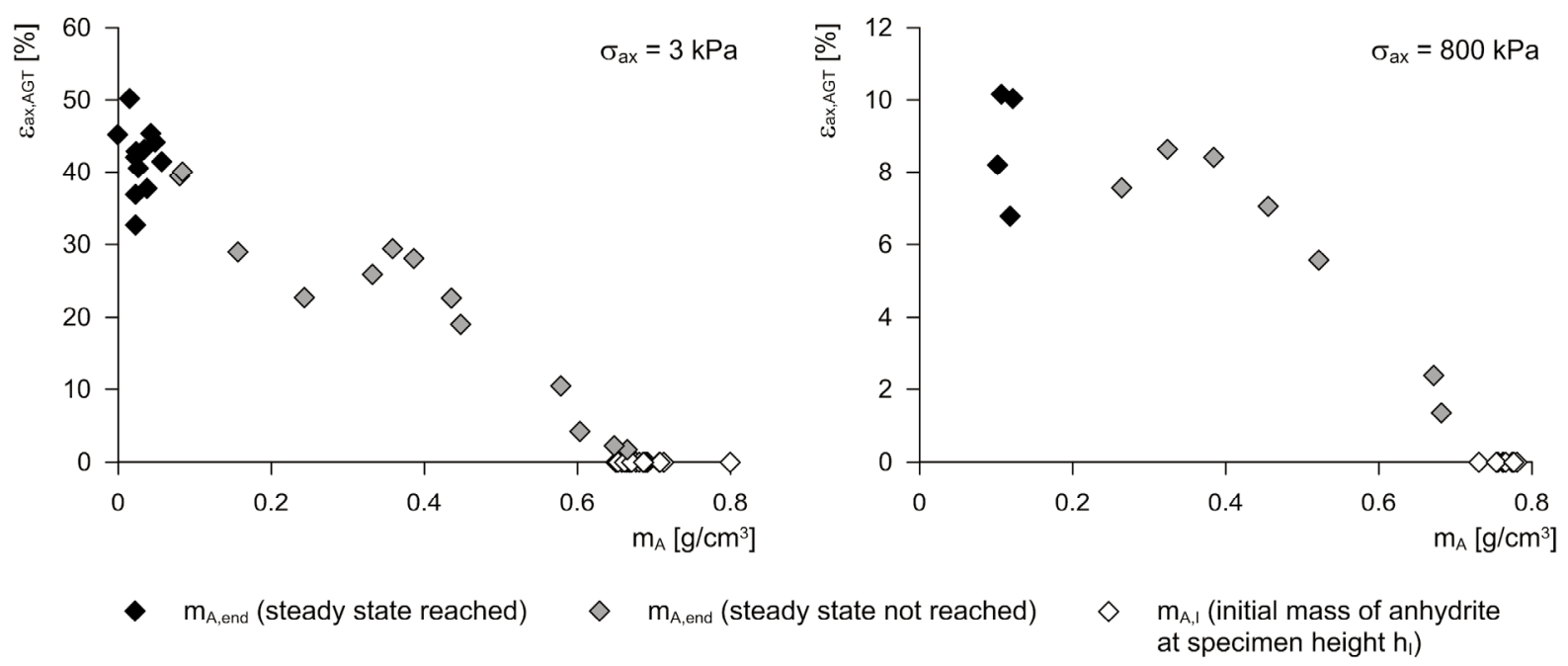

Figure 8-25: $\quad$ Swelling strains due to AGT vs. residual anhydrite mass of the kaolin specimens. Left: $3 \mathrm{kPa}$ axial stress; right: $800 \mathrm{kPa}$ axial stress.

In order to investigate whether the mass of anhydrite changes similarly with increasing swelling strain for different axial stresses, three additional oedometer tests were performed with $7 \mathrm{kPa}$, $20 \mathrm{kPa}$ and $65 \mathrm{kPa}$ axial load, until roughly $50-60 \%$ of the previously reached maximal swelling strain at steady state was measured (see red swelling strain curves in Figure 8-26a). The corresponding curves that reached steady state (black swelling strain curves in Figure 8-26a) are taken from Figure 8-18.

In Figure 8-26b and c, the results are then compared with the results already shown in Figure 8-20 and Figure 8-21. It can be seen that corresponding experiments performed with $3 \mathrm{kPa}$ and $800 \mathrm{kPa}$ which reached $50-60 \%$ of the respective steady state strains (light red symbols in Figure $8-26 \mathrm{~b}$ and $\mathrm{c}$ ), contained less anhydrite post test, compared to the three additionally performed tests (indicated by the dark red circles). Thus it is not possible to assume that the mass of anhydrite changes proportionally to the relative strain for all stresses. 

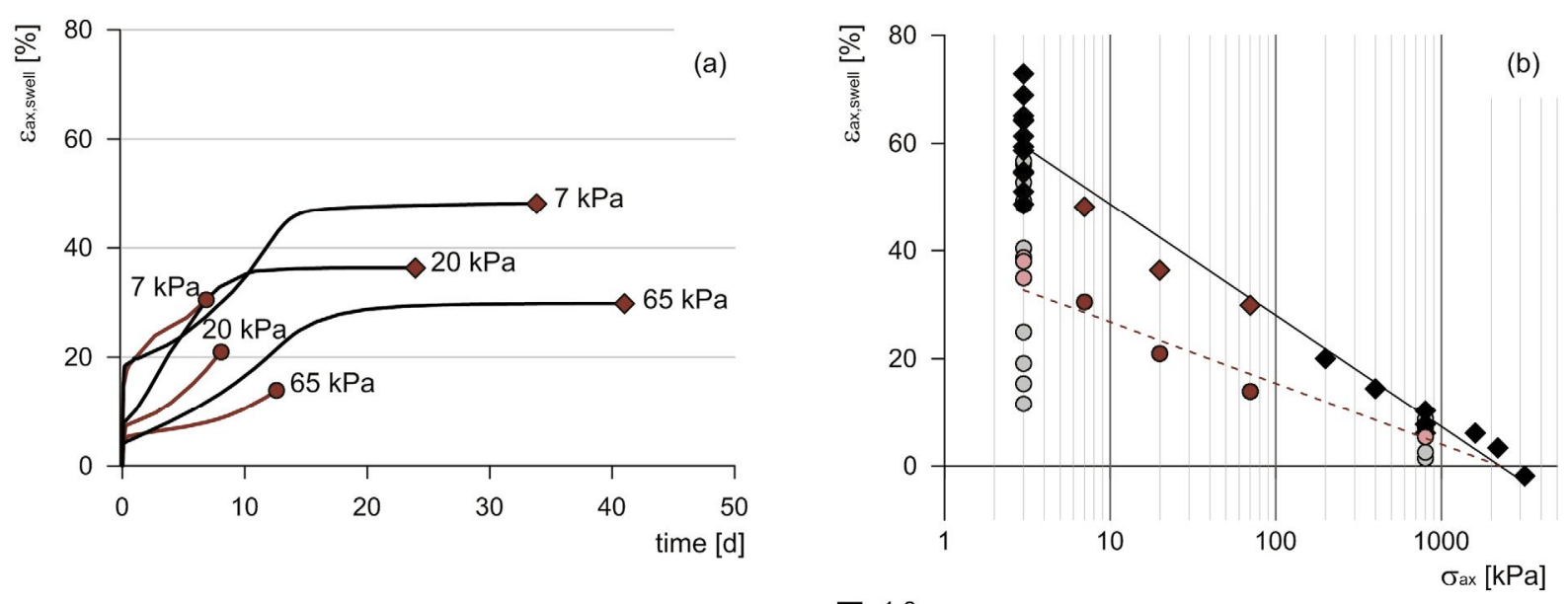

- steady state reached (all)

$\checkmark \quad$ steady state reached $(7 \mathrm{kPa} / 20 \mathrm{kPa} / 65 \mathrm{kPa})$

- - ca. $55 \%$ of strains at steady state

- $50-60 \%$ of steady state reached $(7 \mathrm{kPa} / 20 \mathrm{kPa} / 65 \mathrm{kPa})$

- $50-60 \%$ of steady state reached $(3 \mathrm{kPa} / 800 \mathrm{kPa})$

- steady state not reached $(3 \mathrm{kPa} / 800 \mathrm{kPa})$

$\diamond \mathrm{m}_{\mathrm{A}, 0}$

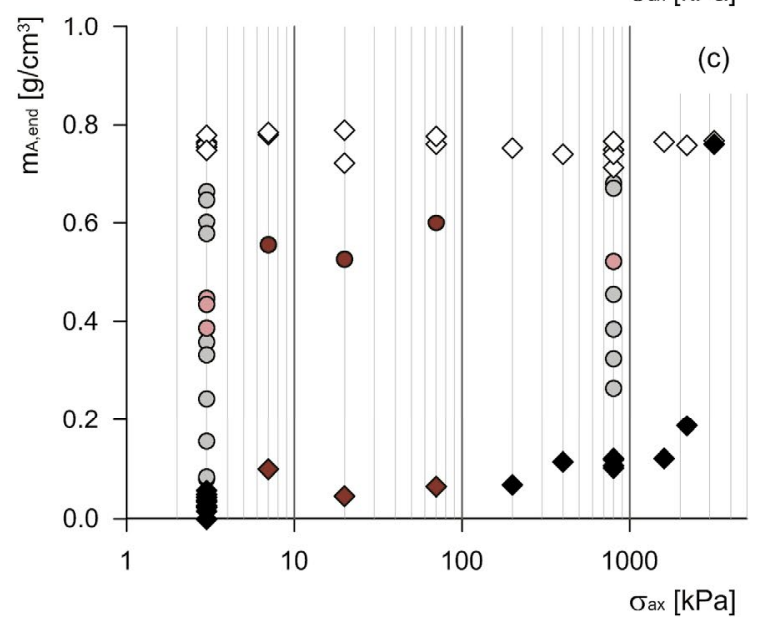

Figure 8-26: (a) Swelling strains vs. time for an axial stress of 7, 20 and $65 \mathrm{kPa}$. (b) Swelling strains at steady state (red and black diamonds) and at 50-60\% of the steady state strains (red circles) vs. stress. (c) Masses per unit volume (prior and post swelling) for all kaolin specimens, including those where steady state was not reached. The light red and dark red symbols in all diagrams indicate the same specimens.

\subsubsection{Discussion}

Concerning the influence of axial stress on the swelling strain, it becomes clear from Figure 8-18 to Figure 8-20 that a limiting stress exists, above which no swelling strain occurs. It was seen that no swelling occurred when an axial stress of $3200 \mathrm{kPa}$ was applied to the anhydrite/kaolin specimens and when $800 \mathrm{kPa}$ was applied to the anhydrite/quartz flour specimens. In both cases the specimens even settled. However, one major difference between the two specimens was that AGT was progressed to $\vartheta=87 \%$ in the quartz specimen but only to $\vartheta=6 \%$ in the kaolin specimen (cf. Table $\mathrm{J}-3$ in Appendix $\mathrm{J}$ and Figure 8-21, where the mass of anhydrite in the specimen prior and post test at $3200 \mathrm{kPa}$ was nearly identical). It is unsure, whether the specimen was in a state of equilibrium or whether AGT may have occurred further had the experiment gone longer.

The model presented by Serafeimidis et al. (2015) results in a higher confining pressure; specifically, as shown in Appendix G, the macroscopic swelling pressure after Serafeimidis et al. (2015) amounts to 5.4-13 MPa, whereas the crystallization pressure alone amounts to $16-41 \mathrm{MPa}$. Possible reasons for this discrepancy are: the soft matrix of the samples used in the experiments (thermodynamic equilibrium may not be reached before all the anhydrite is transformed to gypsum); the differences between model and experiments concerning the geometric and loading conditions (see Appendix G). 
It can be seen from the first series of tests (Chapter 8.5.2) that the rate at which the specimens swell decreases with increasing axial load, which corresponds to the observations made by Kirschke et al. (1991), cf. Chapter 1.4.4. Furthermore, a semilogarithmic relationship seems to exist between the axial strains and the axial stresses for both types of specimens, starting from a minimal axial stress of $\sigma_{0}=3 \mathrm{kPa}$ :

$$
\varepsilon=a-b \cdot \log \sigma
$$

The parameters $a$ and $b$ are dependent on the maximal swelling strain (at minimal stress, denoted as $\varepsilon_{0}$ in Figure 1-3), and the maximal stress when strains are completely prohibited (denoted as $\sigma_{\max }$ in Figure 1-3):

$$
\begin{gathered}
a=\varepsilon_{0}+b \cdot \log \sigma_{0} \\
b=\frac{\varepsilon_{0}}{\log \sigma_{\max }-\log \sigma_{0}}
\end{gathered}
$$

The semilogarithmic approximations shown in Figure 8-20 deliver the following parameters listed in Table 8-6 for the specimens containing anhydrite and kaolin resp. quartz flour:

Table 8-6: $\quad$ Parameters for the semilogarithmic relationships (see Equation (8 - 9)) for the approximations of the data shown in Figure 8-20.

\begin{tabular}{ccc}
\hline parameter & anhydrite and kaolin & anhydrite and quartz flour \\
\hline$\varepsilon_{0}[-]$ & 0.56 & 0.31 \\
\hline$\sigma_{0}[\mathrm{kPa}]$ & 3 & 3 \\
\hline$\sigma_{\max }[\mathrm{kPa}]$ & 2543 & 445 \\
\hline$a$ & 0.65 & 0.38 \\
\hline$b$ & 0.19 & 0.14 \\
\hline
\end{tabular}

The extent of the swelling strains and the maximal stress needed to suppress the strains differ from one mixture to the other. A reason for this is that the quartz specimens had higher initial porosities compared to the kaolin specimens (ca. 0.45 vs. ca. 0.30 , see Appendix J) while the anhydrite volume fractions are lower (i.e., 0.2 vs. 0.25 ) and therefore most likely a proportionally larger amount of gypsum precipitated in the pores of the quartz specimens (see also Figure 8-22). The differences in specimen properties are due to the material properties; the harder grains of the quartz flour (Mohs hardness of 7 and grain strength of several GPa) allow for less compaction during specimen preparation whereas the platelets of the kaolin (Mohs hardness of 2-3) and anhydrite (Mohs hardness of 3-4) are expected to have a far lower grain strength (specific values not found in literature) and can be crushed during compaction.

The results of the tests conducted up to various stages of completion (Figure 8-25) reveal that a correlation exists between the change in the mass of anhydrite and the swelling strain. It seems that the relationship (denoted by $\chi$ in Equation $(7-43)$ ) is linear especially during the first stages of swelling, i.e., until about half the anhydrite is dissolved (cf. Figure 8-25). In the case of $800 \mathrm{kPa}$ axial load the swelling strain then appears to stagnate while further anhydrite dissolves and gypsum precipitates. One possible explanation is that after a first swelling of the specimen the gypsum precipitates mainly in its pores, which may have expanded or been newly created. 
Two general functions are considered to represent the relationship between the swelling strains and mass change of anhydrite:

Linear approximation (a):

$$
\varepsilon=a_{1}+a_{2} \cdot m_{A}
$$

Polynomial approximation (b):

$$
\varepsilon=b_{1}+b_{2} \cdot m_{A}+b_{3} \cdot m_{A}^{2}
$$

The approximations are shown in Figure 8-27, where the parameters from Equations $(8-12)$ and (8 - 13) were chosen with the least square method and are listed in Table 8-7.

Table 8-7 also indicates the coefficients of determination $R^{2}$ between the data and the two assumed approximations. In the case of $800 \mathrm{kPa}$ axial load, a polynomial function (b) represents the data better than a linear function (a), whereas in the case of $3 \mathrm{kPa}$ both approximations fit similarly well.

Table 8-7: $\quad$ Parameters used for the approximation of the data.

\begin{tabular}{llll} 
& & $\varepsilon_{a x, A G T}$ & $\varepsilon_{a x, A G T}$ \\
& & $(3 \mathrm{kPa})$ & $(800 \mathrm{kPa})$ \\
\hline Linear & $a_{1}[-]$ & 0.43 & 0.115 \\
\cline { 2 - 4 } $\begin{array}{l}\text { approximation } \\
\text { (a) }\end{array}$ & $a_{2}\left[\mathrm{~cm}^{3} / \mathrm{g}\right]$ & -0.62 & -0.147 \\
\cline { 2 - 4 } & $R^{2}[-]$ & 0.96 & 0.91 \\
Polynomial & $b_{1}[-]$ & 0.40 & 0.093 \\
\cline { 2 - 4 } (b) & $b_{2}\left[\mathrm{~cm}^{3} / \mathrm{g}\right]$ & -0.23 & 0 \\
\cline { 2 - 4 } & $b_{3}\left[\left(\mathrm{~cm}^{3} / \mathrm{g}\right)^{2}\right]$ & -0.52 & -0.160 \\
\cline { 2 - 4 } & $R^{2}[-]$ & 0.96 & 0.95 \\
\hline
\end{tabular}

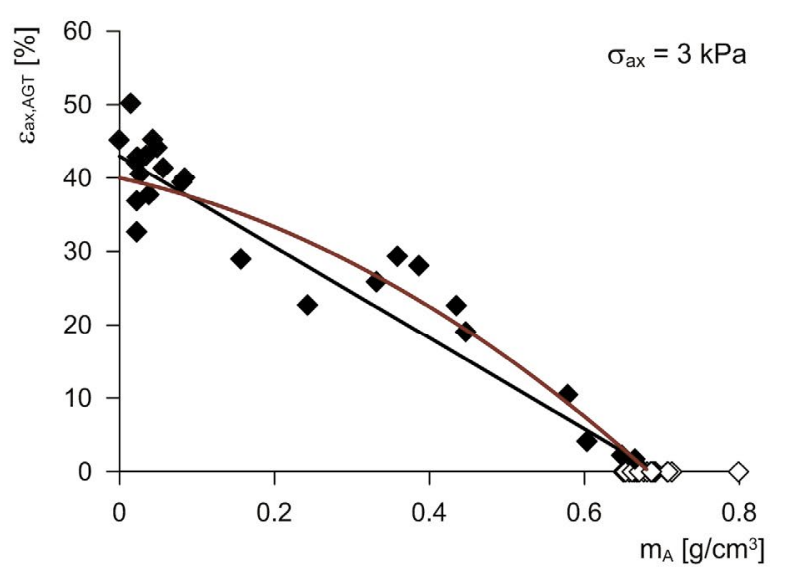

$-\mathrm{m}_{\mathrm{A}, \mathrm{end}}$ $\diamond \quad m_{A, I}$ (initial mass of anhydrite at specimen height $h_{1}$ )

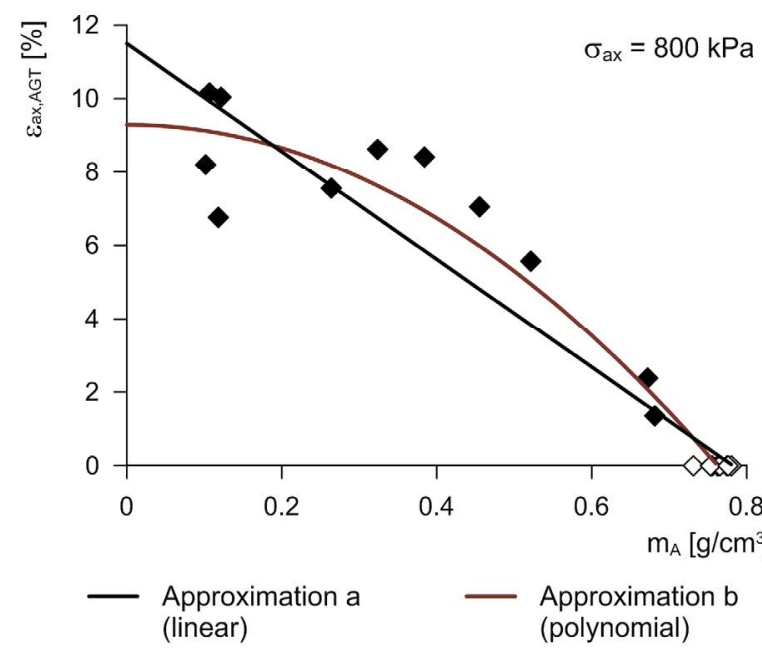

Figure 8-27: Approximations for the relationship between the axial swelling strains due to AGT and the change in mass of anhydrite. Left: $3 \mathrm{kPa}$ axial stress, right: $800 \mathrm{kPa}$ axial stress.

With these relationships, it is now possible to determine $\chi$ as a function of $m_{A}$ from Equation (7 - 43) while considering the sign conventions from Equations $(7-13)$ and $(7-14)$. Note that $\chi_{a x}$ and $\chi_{\text {rad }}$ cannot be determined since the change in radial stress is unknown. 
Approximation a: $\quad \chi=\frac{\partial \varepsilon_{a x}}{\partial m_{A}} \cdot \rho_{A}=-\frac{\partial \varepsilon_{a x, A G T}}{\partial m_{A}} \cdot \rho_{A}=-a_{2} \cdot \rho_{A}$

Approximation b: $\quad \chi=\frac{\partial \varepsilon_{a x}}{\partial m_{A}} \cdot \rho_{A}=-\frac{\partial \varepsilon_{a x, A G T}}{\partial m_{A}} \cdot \rho_{A}=-\left(b_{2}+b_{3} \cdot 2 \cdot m_{A}\right) \cdot \rho_{A}$

$\chi$ is thus shown as a function of the mass of anhydrite in Figure 8-28. For the linear approximation, $\chi$ is constant and can roughly be expressed as a function of $m_{A, I}$ and the maximally reached

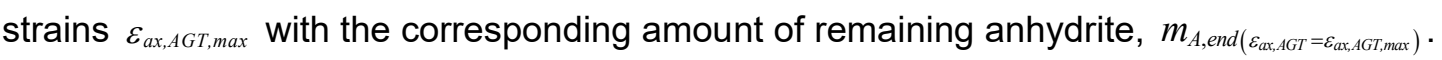

Approximation a:

$$
\chi=-a_{2} \cdot \rho_{A}=\frac{\varepsilon_{a x, A G T, \max }}{m_{A, I}-m_{A, \text { end }\left(\varepsilon_{\alpha x, A G T}=\varepsilon_{\alpha x, A G T, \max }\right)}} \cdot \rho_{A}
$$

It becomes obvious that $\chi$ is dependent on the axial stress applied, since it is dependent on the inclination of the approximations in Figure 8-27 and the value for $\chi$ at $800 \mathrm{kPa}$ axial stress is far lower than that at $3 \mathrm{kPa}$.
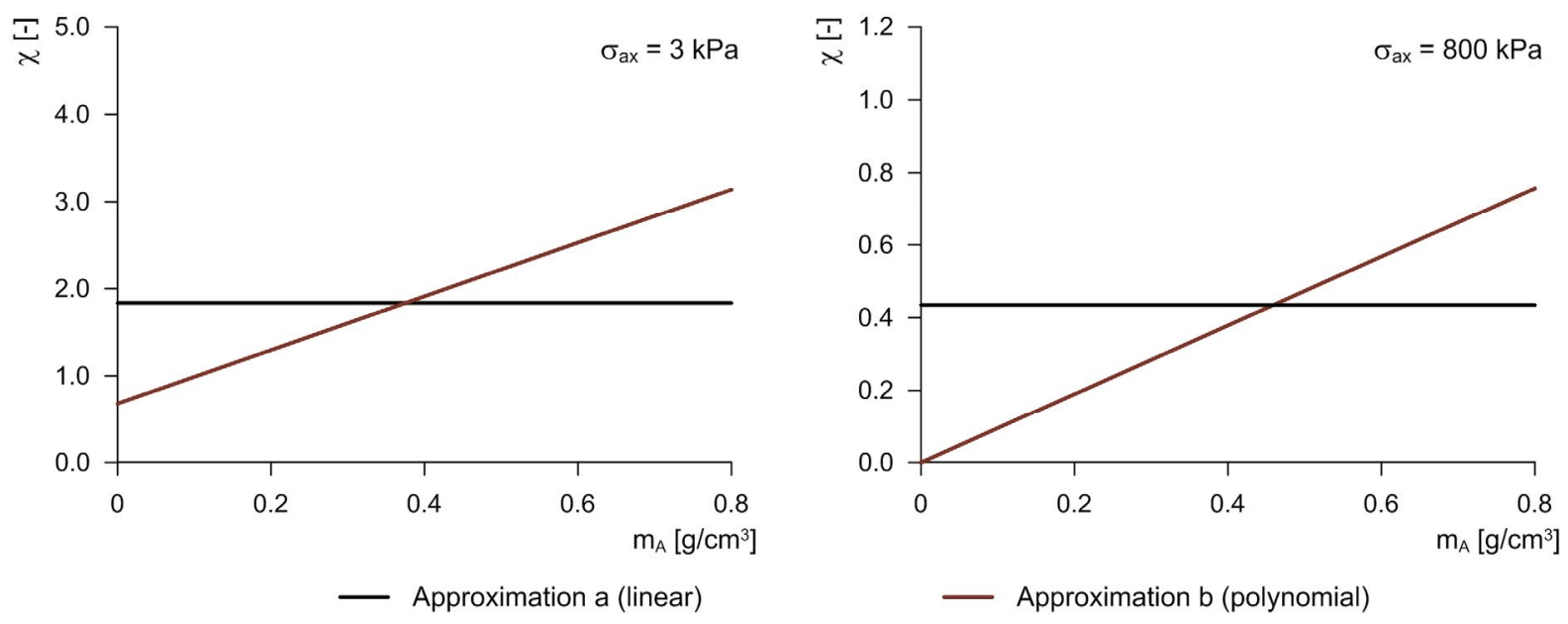

Figure 8-28: $\quad \chi$ as a function of $m_{A}$ for the two approximations shown in Figure 8-27. Left: $3 \mathrm{kPa}$ axial stress, right: $800 \mathrm{kPa}$ axial stress.

Further investigations concerning the structures of the specimens were performed on selected anhydrite/kaolin specimens. Microscopic analysis and porosimetry was done on the specimen that did not swell (at $3200 \mathrm{kPa}$ ), one that did swell until steady state (at $800 \mathrm{kPa}$ ) and one where the swelling strain did not reach a steady state (at $800 \mathrm{kPa}$ ). The results are presented and discussed in Chapter 8.9.

\subsection{Complete constraint tests}

\subsubsection{Aim and procedure}

With the aim of gaining additional information on the stress dependency of $\chi$, it is further of interest to obtain a relationship between the axial stress and change in mass of anhydrite. These investigations are performed with specimens as described in Chapter 8.3 (i.e., with a ratio of $40 \%$ anhydrite to $60 \%$ kaolin) under nearly completely constrained boundary conditions, as shown schematically in Figure 7-21b. Similar to the oedometer tests, different batches of anhydrite from 
Sigma Aldrich were used. Four specimens were prepared in oedometer rings with an inner diameter of $70 \mathrm{~mm}$ and a height of about $25.5 \mathrm{~mm}$ (specimen mass $200 \mathrm{~g}$ ), while eight specimens were prepared in the same oedometer cells described in Chapter 8.4.2., i.e., with a diameter of $56 \mathrm{~mm}$ and a height of about $20.5 \mathrm{~mm}$ (specimen mass $100 \mathrm{~g}$ ). The specimen properties can be found in Table J-4 in Appendix J.

For these experiments, four apparatuses as described in Pimentel and Anagnostou (2010) were designed and built (see Figure 8-29), in which the specimens in steel rings (e.g., oedometer cells as shown in Figure 8-8) are inserted and watered. In axial direction the deformation is restricted and the developing axial pressure is measured.

The apparatuses consist of a stiff reaction frame with four columns, as shown in Figure 8-29. In this case, the specimen ((1) in Figure 8-29, here with a diameter of $70 \mathrm{~mm}$ ) in a steel cylinder (2) is inserted in a vessel consisting of a metallic plate (3) and an acrylic cylinder (4). It is sealed hermetically with a lid containing O-rings and a small opening with a removable plug (5), which enables water to be added at the beginning of a test and withdrawn during a test for analysis of the water chemism. The specimen is embedded between two sintered metal filter plates (6), followed by perforated steel plates (7) for a more uniform watering of the specimen as well as spherical steel plates (8) in order to compensate for potentially eccentric swelling deformations. The deformation of the specimen is measured with two digital dial gauges (9), which are attached as close to the specimen as possible. In axial direction the deformation is constrained with a piston cylinder (10) and the axial stress is obtained via measuring the oil pressure in the piston cylinder with a high precision digital manometer (LEO 5 by Keller AG, Switzerland, with an accuracy of $0.05 \%$ ) which is also able to measure the temperature (11). The accuracy of the measurement obtained with a manometer in relation to the actual stress acting on a specimen was verified with an electrical load cell which was installed in the frame. All metallic components in contact with water were manufactured with corrosion-resistant steel.

In the case of the specimens with a diameter of $56 \mathrm{~mm}$, the components (2)-(7) are replaced with an oedometer as shown in Figure 8-8.

The specimen is inserted in a dry state and a small axial stress is applied ( $\sigma_{a x} \approx 0.1 \mathrm{MPa}$ ) via oil pressure. The valve (12) is then closed and the axial deformation as well as the oil pressure is measured and digitally recorded. When the stresses and strains cease to change, the vessel is filled with water (saturated with respect to gypsum), thus completely immersing the specimen and beginning the actual test.

For the evaluation of the tests, the boundary conditions are considered to be complete constraint, since the apparatus is very stiff and oil can be considered to be incompressible for the expected pressure ranges (based on the oedometer tests from Chapter 8.5 , the maximal stress was expected to be ca. 3.2 MPa). Nevertheless, a slight deformation was still unavoidable. However, this apparatus offers the possibility of increasing the oil pressure externally (and thus compensating the deformation) and of running not only deformation controlled tests but also load controlled tests by connecting an electronically controlled actuator or an external dead load to the piston cylinder, as described by Pimentel and Anagnostou (2013) (which was not done in the scope of the experiments presented here).

In order to determine the relationship between the change in mass of anhydrite and the resulting axial swelling stress, the experiments were terminated (i.e., the specimens were extracted) at 
different points in time and after reaching different values of axial swelling stress. The amount of precipitated gypsum was determined via TGA, as described in Chapter 8.3.2.
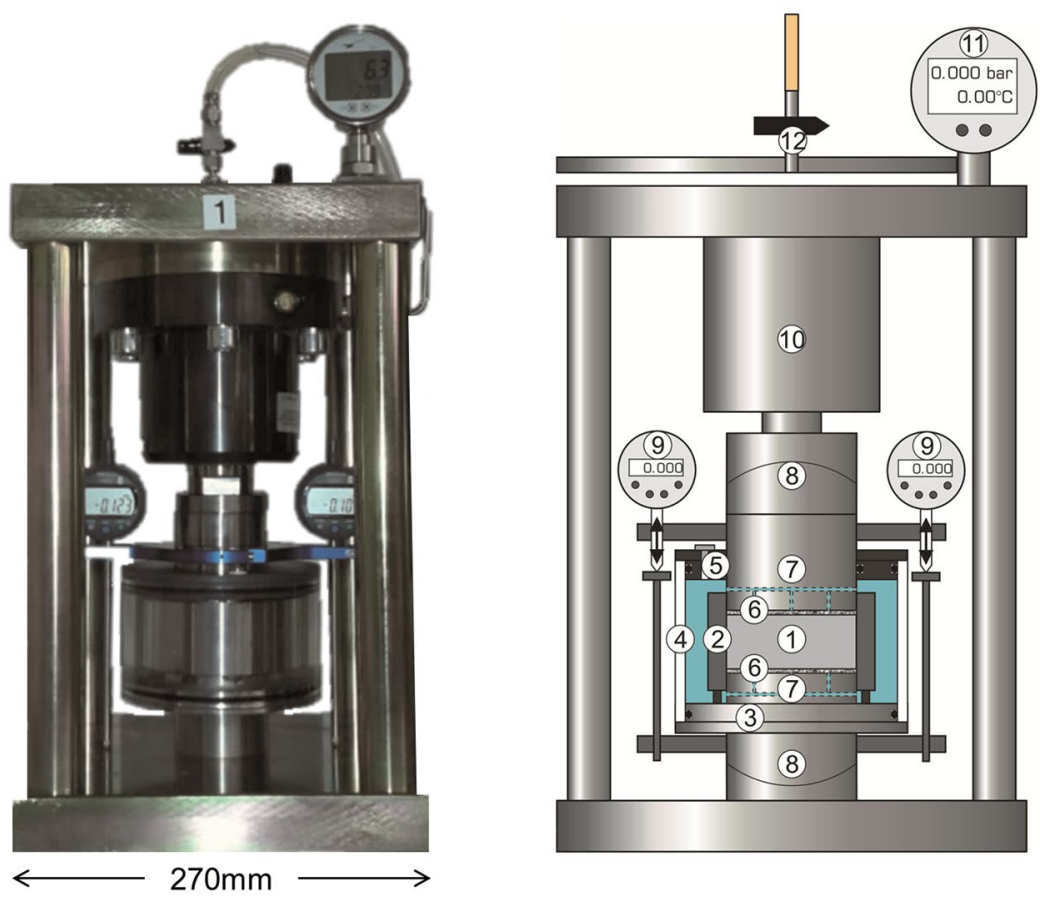

(1) Specimen

(2) Steel cylinder

(3) Steel base

(4) Acrylic cylinder

(5) PVC Lid with removable plug

(6) Filter plates

(7) Perforated steel plates

(8) Spherical steel plates

(9) Dial gauges

(10) Piston cylinder

(11) Manometer

(12) Oil inlet

Figure 8-29: Apparatus for complete constraint tests (after Pimentel and Anagnostou, 2013). Left: Photograph, right: conceptual sketch (not to scale).

\subsubsection{Results}

The obtained stresses and minor swelling strains $(<3 \%$ resp. $2 \%$ when regarding the strains solely due to AGT) of the experiments are shown on the left hand side in Figure 8-30 and Figure 8-31. With these tests, the axial deformation due to dry loading was not always possible to be measured accurately (during the first application of the load up to ca. $0.1 \mathrm{MPa}$ the spherical plates tended to shift until the pressure was high enough to firmly lock all elements), and therefore the heights of the specimens at the time of wetting are taken equal to the original specimen heights. This is not deemed problematic, since in this case (a) the strains are of secondary interest and (b) with the oedometer tests it was already seen that the dry settlement measured at such comparably small loads was often much smaller than the following deformations due to wetting.

The results show that the stress which this type of artificial samples produce under constrained axial deformation can reach $3.5 \mathrm{MPa}$ and thus exceeds the $3.2 \mathrm{MPa}$ that were assumed to be a limiting stress based on the results from the oedometer tests (Chapter 8.5). Furthermore, since some minor strains could not be prohibited in these experiments and were not compensated during the experiments, it is very likely that the actual maximal stress (at strictly zero strain) is even higher than $3.5 \mathrm{MPa}$, which was measured here.

Similar to the strains in the oedometer tests of Chapter 8.5, in the case of SA1 (black curves in Figure 8-30) the stress increases rapidly at first, then linearly for about 50 days at which point the stress rate begins to decrease. In their tests on rock samples from the Freudensteintunnel, Kirschke et al. (1991) (cf. Chapter 1.4.4) have also often seen a rapid increase in swelling stresses at first, followed by a later increase in stress due to AGT and therefore state that a distinction between the physical and chemical swelling processes is possible. 
The specimen containing SA2 showed a slower development of the stress (see yellow curve in Figure 8-30) than in the case of SA1 specimens. By milling the SA2 and SA3 powders (orange and blue curves), it was possible to accelerate the development of the stresses in most cases. It needs to be noted that it is uncertain for one of the specimens (CC_4_01, grey) whether SA2 alone was used or whether it was mixed with some anhydrite of the first batch, SA1. As can be seen from the specimens that were submitted to the experiment the longest, CC_2_01 (black) and CC_4_01 (grey), the swelling stress continues to increase even after more than one year and slowly appears to reduce again after ca. 500 days, whereas the same value of swelling stress was reached in both cases. In the case of the specimen with the slowest stress rate, CC_4_02 (blue) the stress is still increasing nearly linearly at 500 days.
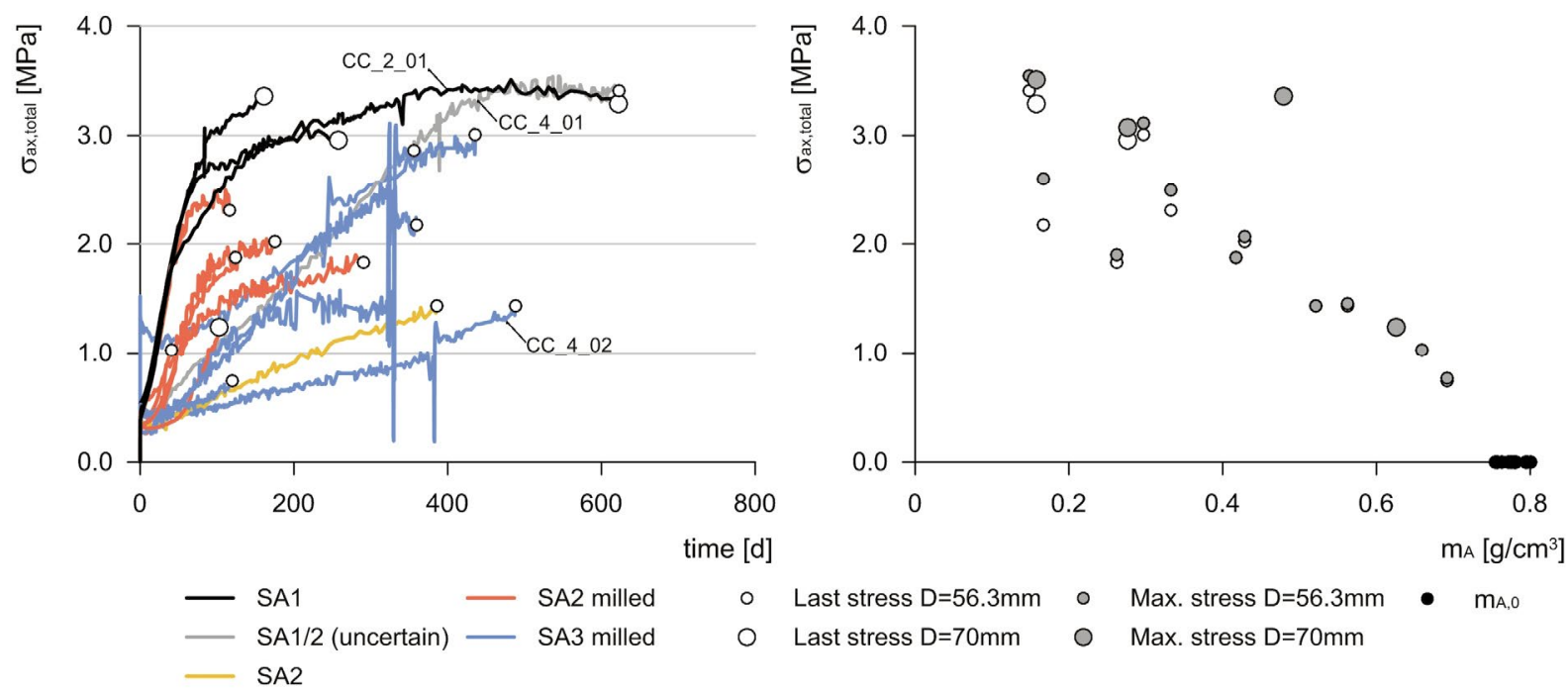

Figure 8-30: $\quad$ Results from complete constraint tests: stress vs. time (left) and mass of anhydrite per unit volume (right). The sizes of the symbols indicate the two specimen diameters used.

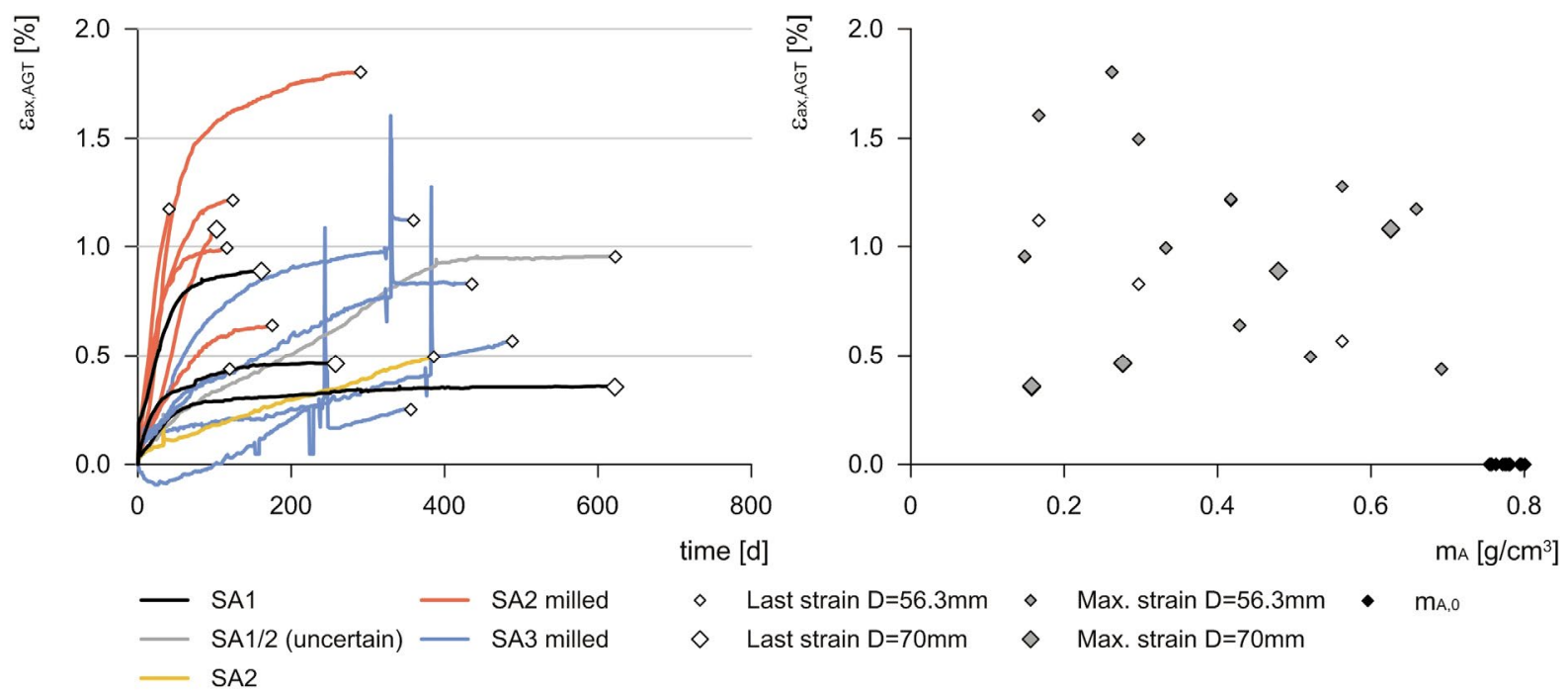

Figure 8-31: Results from complete constraint tests: strains due to AGT vs. time (left) and mass of anhydrite per unit volume (right).

The fluctuations in the measurements were seen to correlate exactly with even the slightest changes in temperature. In spite of performing the tests in a climate room where the temperature is controlled, accidental temperature changes occurred. This can be seen in Figure 8-32, where the stress developments and the average temperature measured by the manometers are shown 
contemporaneously for each apparatus: At first the apparatuses CC_1 (black) and CC_2 (yellow) were in use, and after one year two additional apparatuses CC_3 (blue) and CC_4 (grey) were built in order to increase the productivity. The correlation between the fluctuations in the measurements and the temperature is especially noticeable, when the temperature dropped by $1-1.5^{\circ} \mathrm{C}$ at roughly 350 days and 700 days, as well as at 1370 days, where the temperature even increased to $23^{\circ} \mathrm{C}$ before dropping to $13^{\circ} \mathrm{C}$ (red boxes in Figure 8-32, which occurred most likely due to a malfunction of the air conditioning system in the building). The last fluctuation was also noticeable in the deformations (blue curves in Figure 8-31). Other than those three incidents, the average measured temperature fluctuated between $20.4^{\circ} \mathrm{C}$ and $21.8^{\circ} \mathrm{C}$ for the entire duration of the tests (4.1 years).

Upon extraction of the specimens, the mass of residual anhydrite $m_{A, \text { end }}$ was determined via backcalculation from TGA. The results are presented in Figure 8-30, right, where the maximally reached swelling stresses (grey circles) as well as the last measured swelling stresses at the points of extraction (white circles) are plotted as a function of $m_{A, \text { end }}$. An overview of the specimen properties and test results is given in Table $\mathrm{J}-4$ in Appendix $\mathrm{J}$.

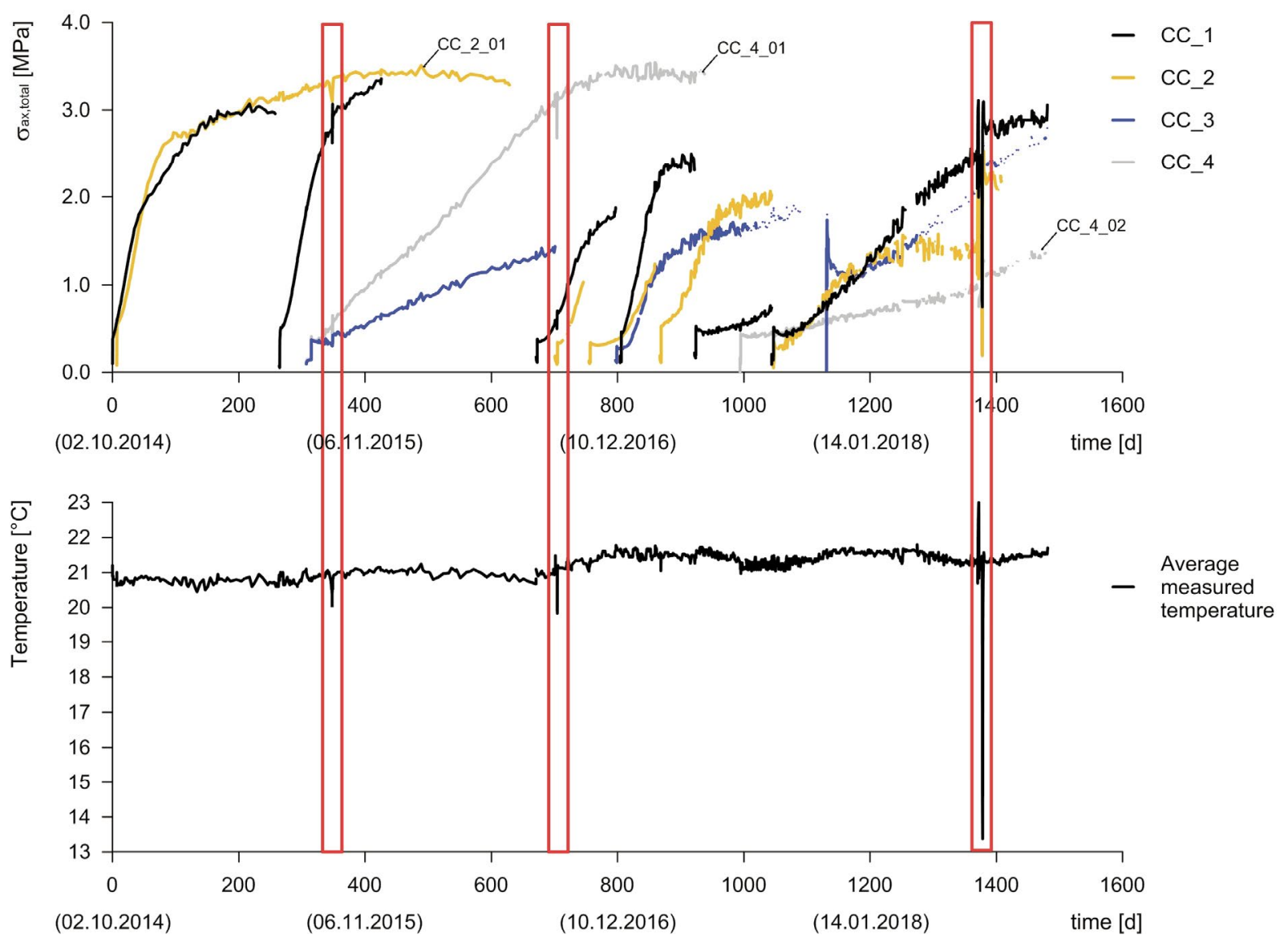

Figure 8-32: Complete constraint tests: development of stresses (top) and contemporaneous average temperature measured (bottom).

\subsubsection{Discussion}

The complete constraint tests revealed that a slightly higher swelling stress than $3.2 \mathrm{MPa}$ can be reached, as was previously assumed based on the results of Chapter 8.5. Even though the longest test duration was nearly two years and the swelling stresses ceased to increase (even began to decrease slightly again), AGT was still not completed (at most to $\vartheta=80 \%$, see Table J-4 in Appendix J). Furthermore, the swelling stress increased far slower when the batches SA2 and SA3 
were used and it is not certain, whether the same maximal stress would be reached as when SA1 was used.

It was observed that (for a so far unknown reason) the slight swelling strains that occurred and could not be avoided (see Figure 8-31) were tendentially higher in the case of milled specimens. This may be the reason for their apparent stagnation of swelling stress at smaller values.

With the exception of three specimens, it was seen that - independent of the used batch of anhydrite - the reached swelling stress correlates nearly linearly with $m_{A, \text { end }}$ (Figure 8-30 right). It needs to be noted, however, that it is uncertain how the remaining anhydrite would influence the swelling stress, considering that the stresses began to decrease slightly after a duration of 500 days in the cases of CC_2_01 and CC_4_01, even though at least $0.15 \mathrm{~g} / \mathrm{cm}^{3}$ of anhydrite remained in the specimens (see Table J-4 in Appendix J). Based on the slope of the curves in Figure 8-30, left, the residual anhydrite is not expected to cause further swelling stresses.

Nevertheless, the axial stresses in Figure 8-30 are best approximated by the general (linear) function given in Equation (8 - 17):

Linear approximation:

$$
\sigma_{a x}=a_{1}+a_{2} \cdot m_{A}
$$

However, the (minor) axial strains due to AGT appeared to develop unsystematically and seem to be independent of the amount of transformed anhydrite (no dependence on the change in mass of anhydrite can be seen, see Figure 8-33, right). Therefore, the strains are approximated by a constant in this case (i.e., $\varepsilon_{a x, A G T}=a_{1}$ ), specifically by the mean value of the last strains measured.

The approximations are shown in Figure 8-33, whereas the parameters in Table 8-8 were used. (The specimen where the most strains were measured, i.e., 1.8\%, was excluded from the determination of the approximation with linear regression.)

Table 8-8: $\quad$ Parameters used for the approximation of the experimental data.

\begin{tabular}{llcc}
\hline & & $\sigma_{a x, \text { total }}$ & $\mathcal{E}_{a x, A G T}$ \\
\hline \multirow{2}{*}{ Linear } & $a_{1}$ & $4.5[\mathrm{MPa}]$ & $0.0072[-]$ \\
\cline { 2 - 4 } approximation & $a_{2}$ & $-5.7\left[\mathrm{MPa} \cdot \mathrm{cm}^{3} / \mathrm{g}\right]$ & 0 \\
\cline { 2 - 4 } & $R^{2}$ & $0.92[-]$ & 0 \\
\hline
\end{tabular}

For the boundary conditions of the complete constraint tests, the equations for $\chi$, resp. $\chi_{a x}$ and $\chi_{\text {rad }}$, are given in Equations $(7-40)$ to $(7-42)$. However, since the radial stress could not be measured in steel rings or standard oedometer cells as used here, merely the combined parameter $\chi$ can be determined (Equation (7 - 42)), whereas the small change in axial strain measured is considered negligible (i.e., the derivative of axial strains with respect to the mass of anhydrite equals zero). Equations $(7-42)$ and $(8-17)$ lead thus to the following expression for $\chi$ (illustrated in the graph on the left in Figure 8-33):

$$
\chi=\frac{\partial \varepsilon_{a x}}{\partial m_{A}} \cdot \rho_{A}-\frac{(1+v)(1-2 v)}{E(1-v)} \frac{\partial \sigma_{a x}^{\prime}}{\partial m_{A}} \cdot \rho_{A}=-\frac{(1+v)(1-2 v)}{E(1-v)} \cdot a_{2, \sigma_{\alpha x}} \cdot \rho_{A}
$$


Similar to the linear approximation in the case of the oedometer tests (cf. Equation (8 - 16)), the parameter $a_{2, \sigma_{a x}}$ (and thus $\chi$ ) can be expressed as a function of $m_{A, \text { end }}$ and, e.g., the maximally measured swelling stress and the corresponding remaining amount of anhydrite.

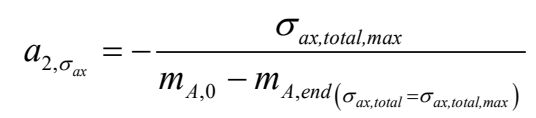

It is evident that if a linear function is assumed for $\sigma_{a x}=f\left(m_{A}\right)$ in Equation (8 - 18), $\chi$ will be a constant for any given Young's modulus and Poisson ratio.

The influence of $E$ and $v$ on $\chi$ is shown in Figure 8-34. It becomes obvious that $\chi$ decreases with increasing Poisson ratio and with increasing Young's Modulus ( $\chi$ is linearly dependent on $1 / E$ ). This may also explain, why $\chi$ was lower with the $800 \mathrm{kPa}$ oedometer tests compared to the $3 \mathrm{kPa}$ tests (cf. Figure 8-28): the more the specimen expands (especially at lower axial stresses) the softer it becomes, thus its Young's modulus reduces.

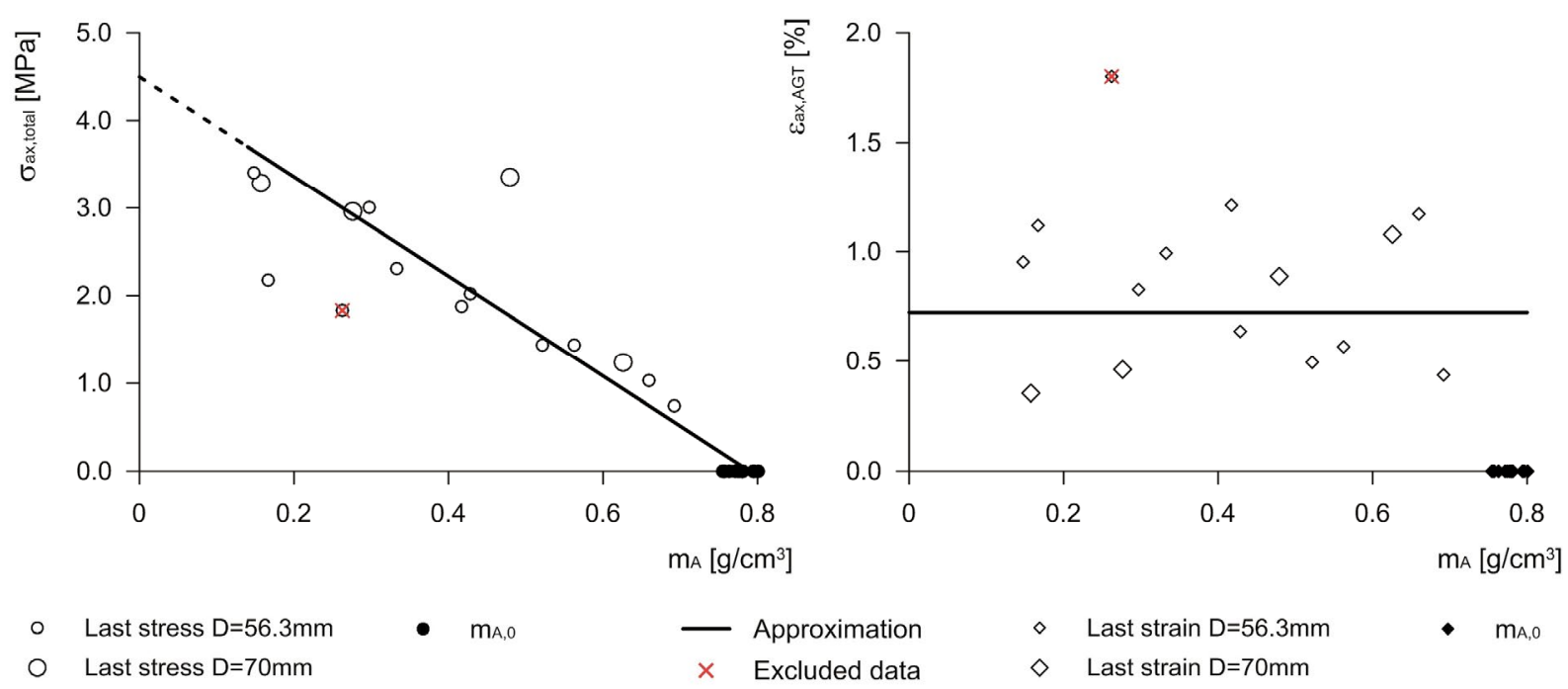

Figure 8-33: Complete constraint tests: approximation of the data.

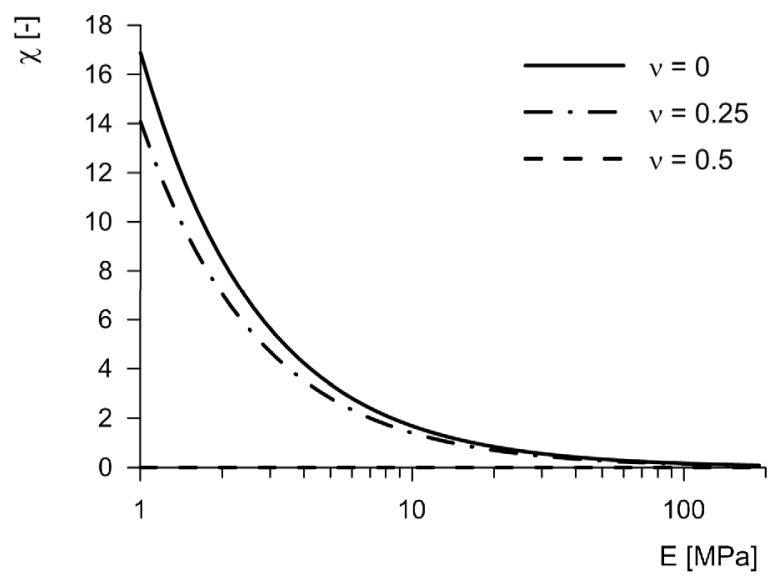

Figure 8-34: Complete constraint tests: influence of $E$ and $v$ on $\chi \quad(\chi=0$ for $v=0.5)$. 


\subsection{Isotropic compression tests}

\subsubsection{Aim and procedure}

Isotropic compression tests were performed with the boundary conditions in Figure 7-21a, in order to obtain a relationship between solely the axial/radial strains and the change in mass of anhydrite/gypsum, while keeping the surrounding stresses constant. The advantage of this test is that $\chi_{a x}$ and $\chi_{\text {rad }}$ can be determined individually (cf. Equations $(7-35)$ and $(7-36)$ ).

For this, three triaxial cells were built, in which the specimen is loaded isotropically by a surrounding oil pressure, supplied with water (saturated with respect to gypsum) and the axial and radial deformations measured. The apparatus is sketched in Figure 8-35. The specimen ((1) in Figure 8-35) is positioned between two metallic sintered filter plates (2) and centered on top of a socket with the same diameter (which is a component of the steel base (3)). In order to measure the axial deformation as close to the specimen as possible, a steel cylinder (4) is positioned on top of the upper filter plate to which extensometers ((5), which measure the displacements as a digital encoder moves along a magnetic strip in vertical direction) can be attached on two sides of the specimen. The setup consisting of the specimen, filter plates, bottom steel socket and upper steel cylinder are covered by a rubber membrane which is tightly attached with O-rings (6). In the present tests, the water infiltrated the specimen from the bottom (7) and was held at a stationary level once it reached the outlet (8) on top. In order to measure the radial deformation of the specimen, a chain extensometer ((9), cf. Chapter 8.4.4) is attached around the rubber membrane at mid-height of the specimen. The oil within the cell (10) is connected to an external piston cylinder (11) and the oil pressure is defined by the dead weights (12) placed on the piston and can be measured with a manometer (13) attached to the oil supply pipe (14). As a redundant measurement to determine the volume change of the specimen, the axial displacement of the piston is measured with a dial gauge (15), from which the change of oil volume in the cell can be calculated.

The specimens (with the standard mixture of $40 \% \mathrm{SA}$ and $60 \% \mathrm{PW}$ ) were prepared as described in Chapter 8.3.1, with a diameter of $56.7 \mathrm{~mm}$ and a height of ca. $40 \mathrm{~mm}$, i.e., a larger height than in the case of the oedometer tests. This height was chosen in order to avoid the influence of friction between the specimen and the filter plates and guarantee homogeneous deformations in the region of the chain extensometer at mid-height of the specimen and thus increase the accuracy of the measured radial deformation. The specimen properties are listed in Table J-5 in Appendix J.

The testing procedure is as described in Chapter 8.3.2, whereas each test was to be performed under constant stress (i.e., the weights were not changed during the experiments; as will be seen, however, the oil pressure and thus the stress acting on the specimens fluctuates slightly during the experiments). The experiments were terminated at different points in time and after reaching different values of swelling strains, in order to determine the development of the strains due to the mass change of anhydrite. As described in Chapter 8.3.2, the amount of precipitated gypsum was obtained via TGA from which the remaining mass of anhydrite can be determined. 


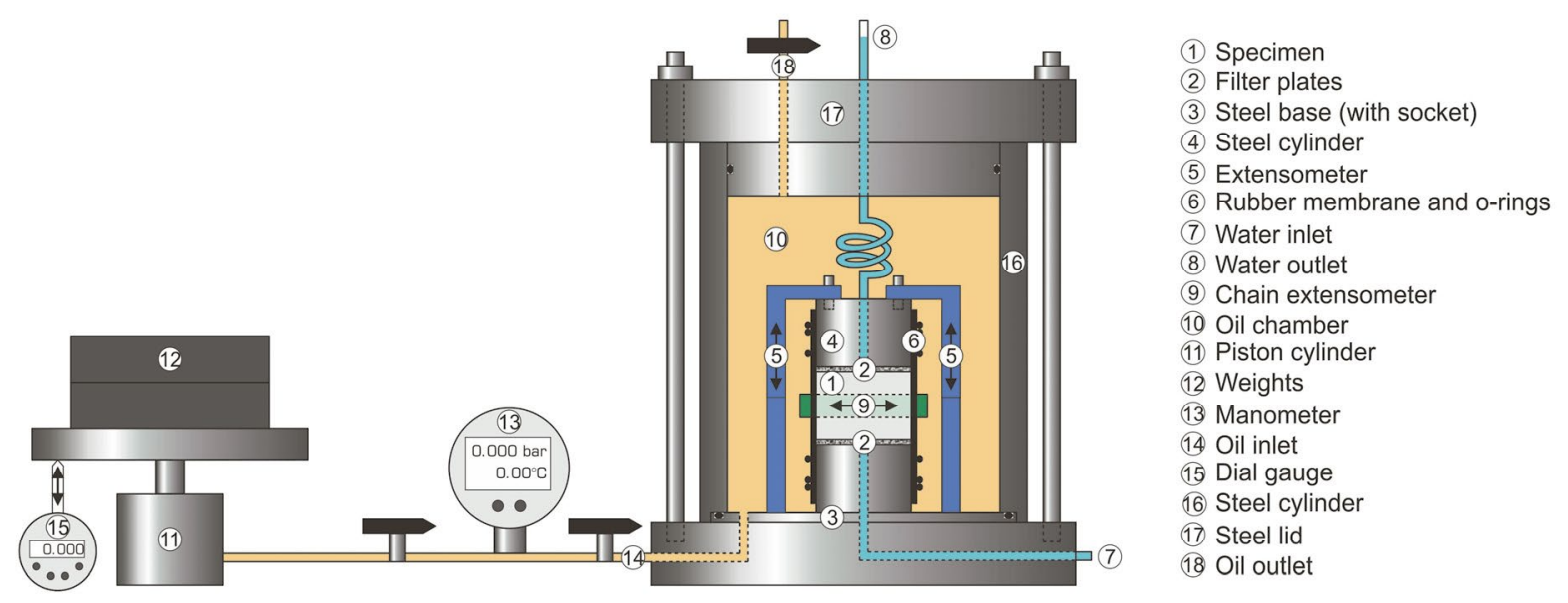

Figure 8-35: Isotropic compression tests: conceptual sketch of apparatus (sketch not to scale).

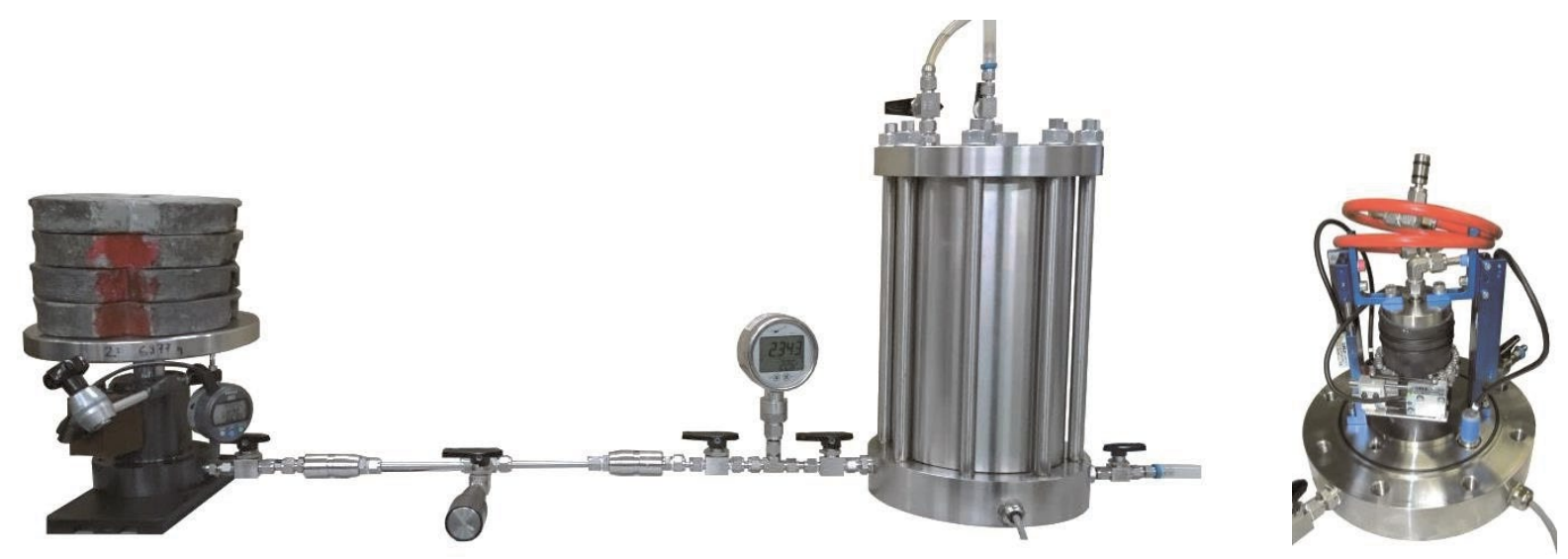

Figure 8-36: Isotropic compression tests: Photographs of the apparatus (left: isotropic compression cell from the outside, right: inside of the cell).

\subsubsection{Results}

The swelling strains in axial and radial directions as well as the volumetric swelling strain are shown in the left diagrams in Figure 8-37. On the right hand side, the reached strains are illustrated as a function of the amount of anhydrite remaining in the specimens post test (determined indirectly via TGA). Most specimens were tested with an isotropic stress of ca. $250 \mathrm{kPa}$, whereas four specimens (indicated by the green diamonds in Figure 8-37) were tested with ca. 110, 140, 360 and $450 \mathrm{kPa}$.

Since the strains developing solely due to AGT are of interest $\left(\varepsilon_{a x, A G T}, \varepsilon_{r a d, A G T}\right)$, the strains due to dry loading and within the first ca. $10 \mathrm{~h}$ after wetting were subtracted (see Chapter 8.3.3; the deformations due to dry loading and wetting can be found in Table J-5 in Appendix J).

In addition to the axial and radial strains, the volumetric strains were calculated via Equation (8 - 20) and are depicted as well in Figure 8-37 (bottom row). The volumetric strains can in principle also be determined via the piston heave (see Figure 8-39c), from which the volume of the displaced oil can be calculated; however, for reasons described below, the measurements were seen to be too inaccurate for the evaluation of the volumetric strains. 

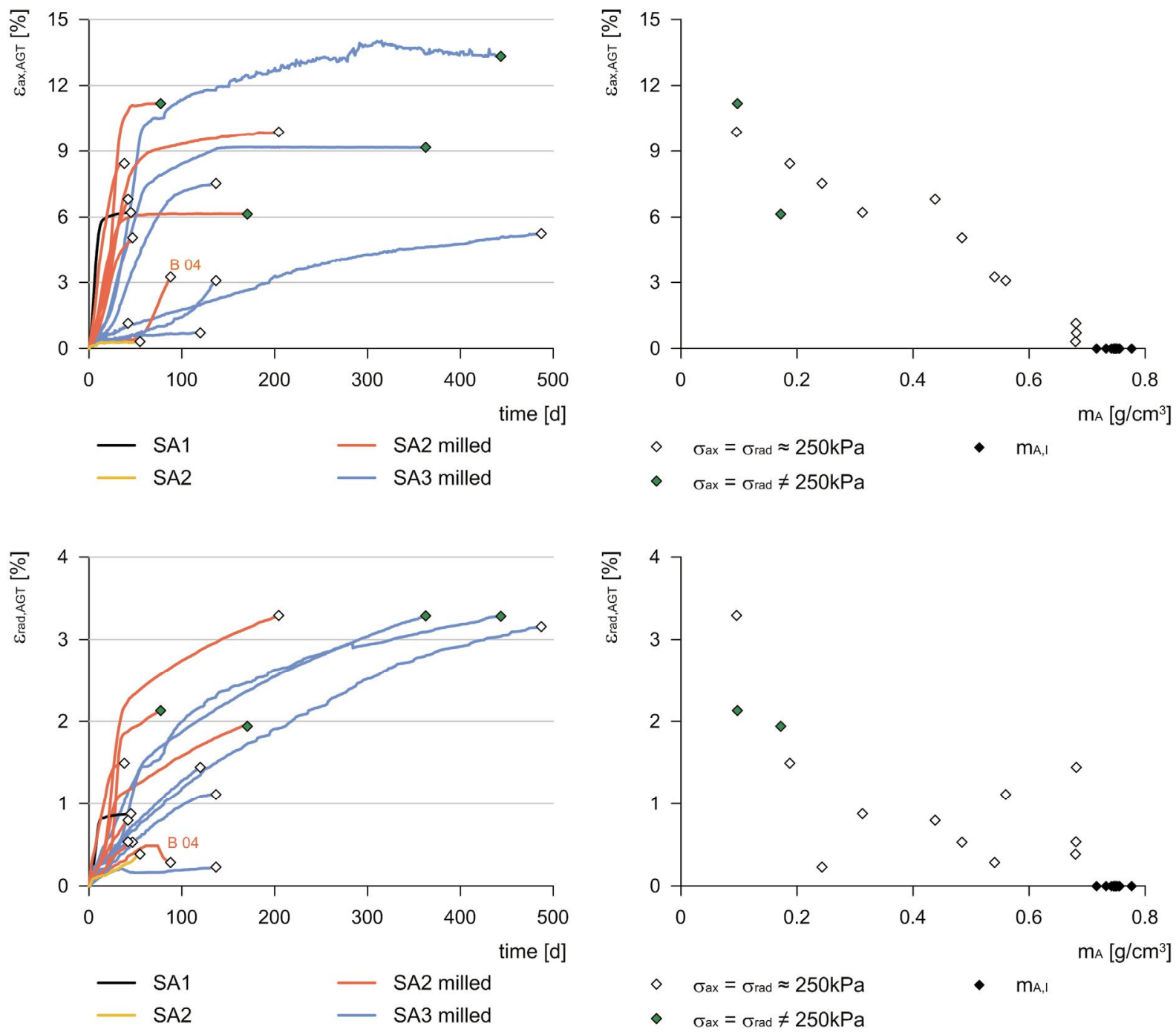

$-\mathrm{m}_{\mathrm{A}, \mathrm{I}}$

$\diamond \quad \sigma_{\mathrm{ax}}=\sigma_{\mathrm{rad}} \neq 250 \mathrm{kPa}$
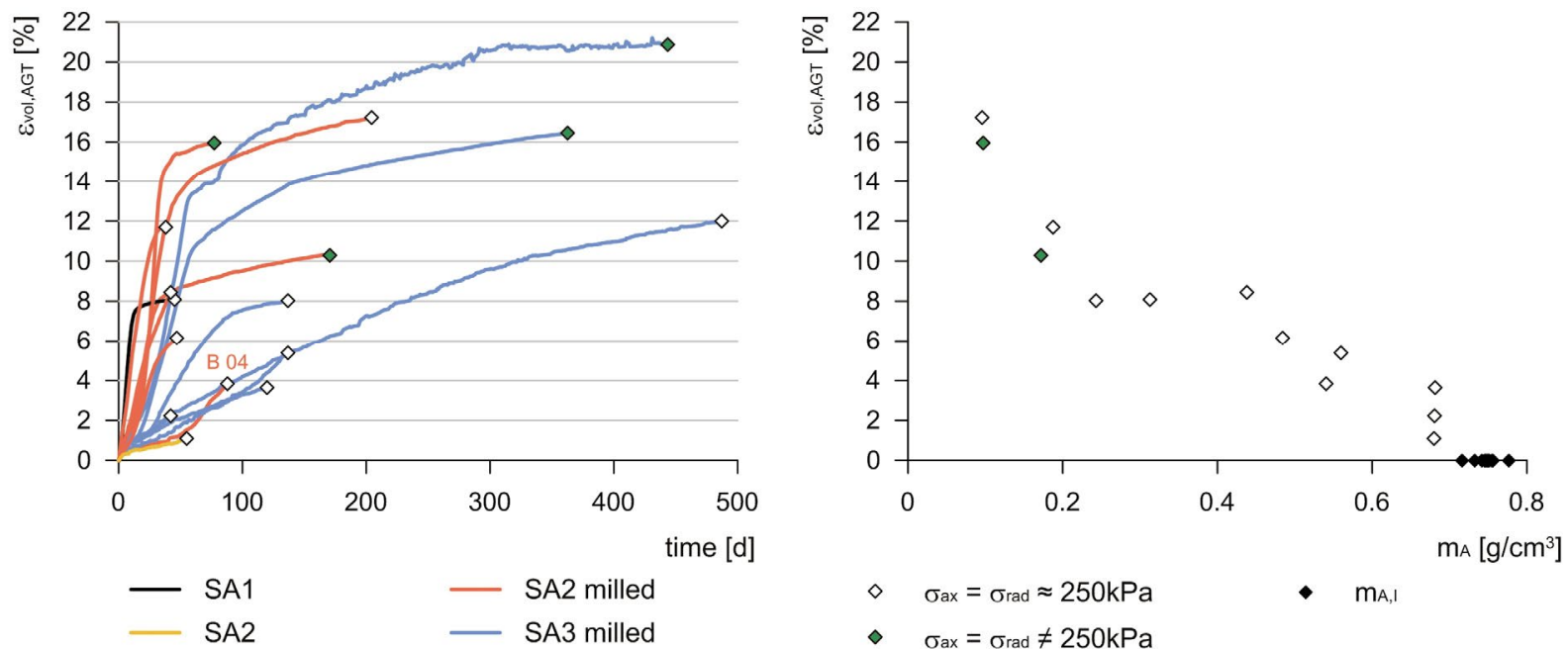

$\begin{array}{ll}\diamond & \sigma_{\mathrm{ax}}=\sigma_{\mathrm{rad}} \approx 250 \mathrm{kPa} \\ \diamond & \sigma_{\mathrm{ax}}=\sigma_{\mathrm{rad}} \neq 250 \mathrm{kPa}\end{array}$

$-\mathrm{m}_{\mathrm{A}, \mathrm{I}}$

Figure 8-37: Results from isotropic compression tests. Left: axial, radial and volumetric swelling strains vs. time; right: reached swelling strains vs. remaining mass of anhydrite per unit volume in the specimens. 


$$
\begin{aligned}
\varepsilon_{V o l} & =\frac{V_{0}-V}{V_{0}}=\frac{h_{0} \cdot r_{0}^{2}-\left(h_{0}-\Delta h\right) \cdot\left(r_{0}-\Delta r\right)^{2}}{h_{0} \cdot r_{0}^{2}}=\frac{\Delta h}{h_{0}}+2 \cdot \frac{\Delta r}{r_{0}}-\frac{\Delta r^{2}}{r_{0}^{2}}-2 \cdot \frac{\Delta h}{h_{0}} \frac{\Delta r}{r_{0}}+\frac{\Delta h}{h_{0}} \frac{\Delta r^{2}}{r_{0}^{2}} \\
& =\varepsilon_{a x}+2 \varepsilon_{r a d}-\varepsilon_{r a d}^{2}-2 \varepsilon_{a x} \varepsilon_{r a d}+\varepsilon_{a x} \varepsilon_{r a d}^{2}=1-\left(1-\varepsilon_{a x}\right) \cdot\left(1-\varepsilon_{r a d}\right)^{2}
\end{aligned}
$$

Considering that $\varepsilon_{a x, \text { swell }}=-\varepsilon_{a x}$ and $\varepsilon_{\text {rad }, \text { swell }}=-\varepsilon_{\text {rad }}$, according to Equations $(7-13)$ and $(7-14)$ :

$$
\begin{aligned}
\varepsilon_{V o l} & =-\varepsilon_{a x, \text { swell }}-2 \varepsilon_{\text {rad ,swell }}-\varepsilon_{\text {rad,swell }}^{2}-2 \varepsilon_{a x, \text { swell }} \varepsilon_{\text {rad,swell }}-\varepsilon_{\text {ax } x \text { swell }} \varepsilon_{\text {rad,swell }}^{2} \\
& =1-\left(1+\varepsilon_{a x, s w e l l}\right) \cdot\left(1+\varepsilon_{\text {rad,swell }}\right)^{2}=-\varepsilon_{\text {Vol, swell }}
\end{aligned}
$$

Note that since the strains in radial direction may not have occurred evenly but more in the shape of a barrel (at the top and bottom boundaries the specimen was more confined due to friction with the filter plates and the O-rings on the rubber membranes), the volumetric strains (depicted in the bottom diagrams in Figure 8-37) may be slightly over-estimated.

The influence of the applied stress on the maximally reached swelling strains is shown in Figure 8-38. However, as seen in Figure 8-37, most axial strains and nearly all radial strains did not reach a steady state.
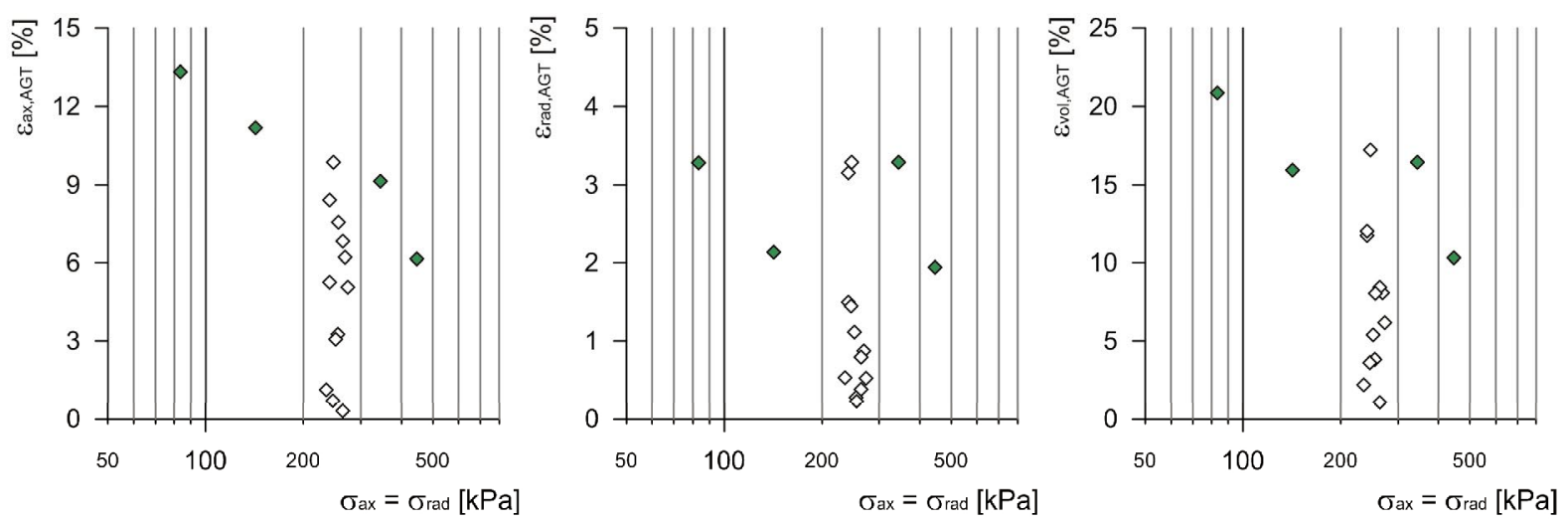

$\diamond \sigma_{\mathrm{ax}}=\sigma_{\mathrm{rad}} \approx 250 \mathrm{kPa}$

$\diamond \sigma_{\mathrm{ax}}=\sigma_{\mathrm{rad}} \neq 250 \mathrm{kPa}$

Figure 8-38: $\quad$ Reached strains vs. average oil pressure measured (i.e., axial. and radial stresses).

The main specimen properties prior and post test, as well as the testing conditions are summarized in Table $\mathrm{J}-5$ in Appendix $\mathrm{J}$.

It needs to be noted that the stresses acting on the specimens did not always remain constant. It was seen that the oil pressure varied on the one hand due to slightly changing temperatures, as well as due to the friction of the piston (stick slip). The temperatures, measured oil pressures and the piston heave during the tests are shown in Figure 8-39 for each isotropic compression cell (labelled as yellow, blue and white) over the entire duration of the experiments. It is noticeable that the different manometers registered slightly different temperatures (even though they were situated next to one another). Some manometers needed to be updated after a while and were replaced during the experimental series, which caused abrupt differences in the recorded temperatures, denoted by the red arrows in Figure 8-39a (e.g., after ca. 150 days, when the second "blue" test was completed and the third one was started, the blue manometer was replaced, which explains the increase in temperature marked " 1 " in the Figure). However, the "usual" individual fluctuations during the tests lie within $1^{\circ} \mathrm{C}$ and suffice to explain the slight fluctuations of the stresses. In two cases 
(denoted by "2" in Figure 8-39a) the blue resp. yellow manometers recorded some outliers, which were, however, not recorded by the other manometers and did not lead to any significant changes of the stresses and are therefore negligible. Only in one case (" 3 " in Figure 8-39a) all manometers recorded strong fluctuations of the temperature which were also visible in the stress and piston heave of all specimens (cf. also the temperature fluctuation during the complete constraint tests, see Chapter 8.6.2). In the case of the white apparatus, where the stress was intended to be ca. $80 \mathrm{kPa}$ during the second test, the stress increased within a month to ca. $260 \mathrm{kPa}$ (see "4" in Figure $8-39 \mathrm{~b}$ and $\mathrm{c}$ ). This occurred due to the fact that the piston heave reached its limit unnoticed after its rate had increased in the weeks before, thus allowing the oil pressure to build up. After releasing some oil and readjusting the piston, the experiment was resumed with the original stress.

Due to the fluctuations in the oil pressure, the average measured stresses (as depicted in Figure 8-38) differed slightly from the target values (which are indicated in Figure 8-39b). Both values are listed for each experiment in Table J-5 in Appendix $\mathrm{J}$.

(a)

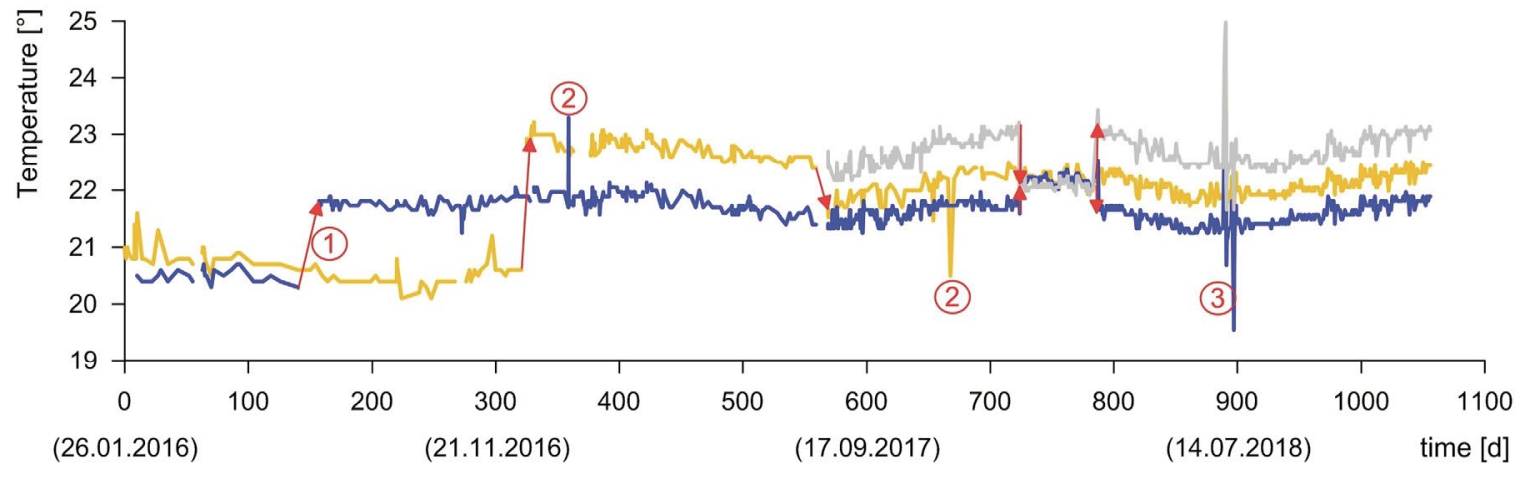

(b)

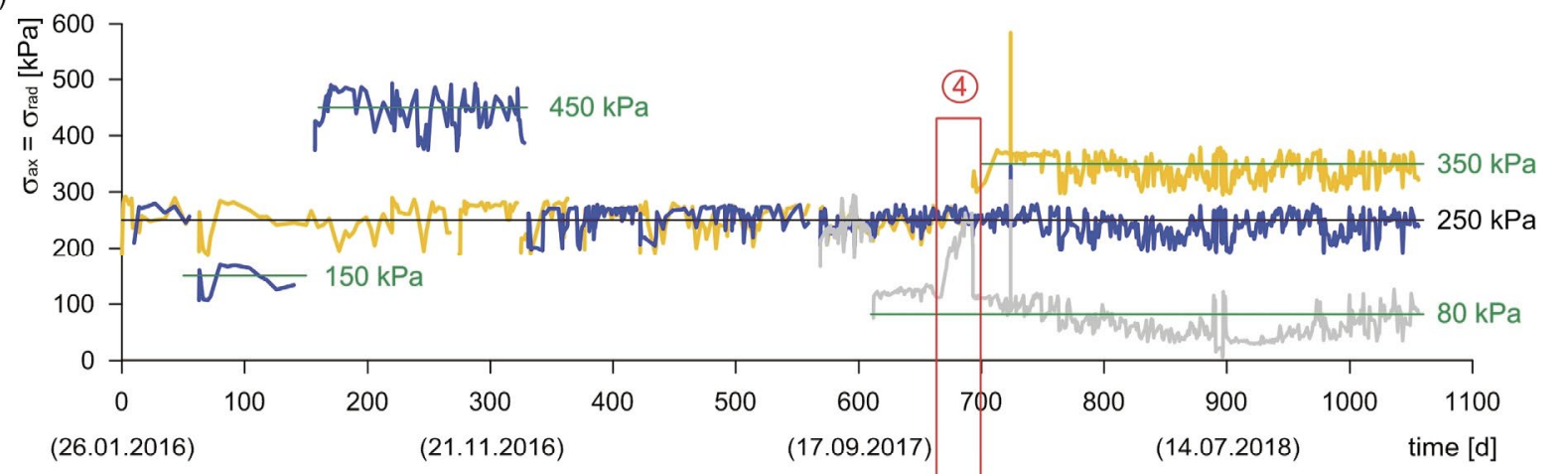

(c)

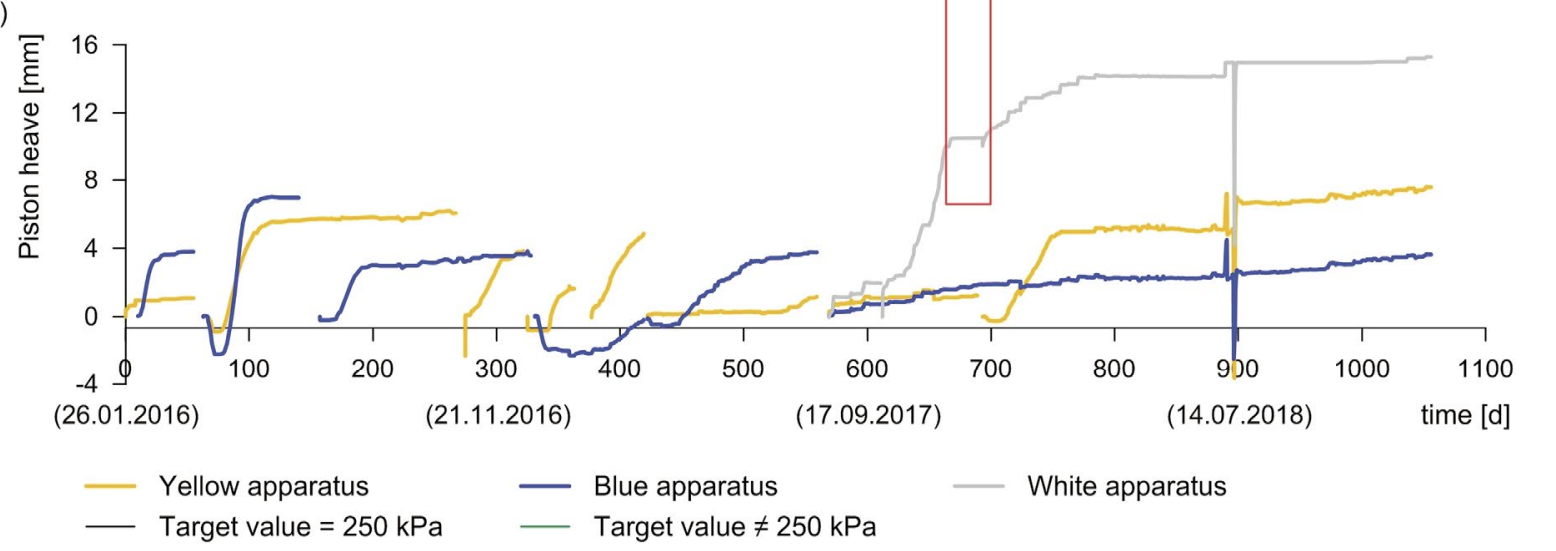

Figure 8-39: (a) Temperature, (b) oil pressure and (c) piston heave during isotropic compression tests. 


\subsubsection{Discussion}

The swelling strains differed strongly from one another in the rates at which they developed, as well as in the value of the maximal swelling strains observed, as can be seen in the left diagrams in Figure 8-37. One factor for the different behaviors is - as in the previous experiments - the type of anhydrite powder used. For example, the only specimen where SA 2 was used in its original state (i.e., not milled, see yellow curves in Figure 8-37) showed nearly no swelling strain in axial direction and very slight radial swelling strain after 61 days, at which point the specimen was extracted. However, the different batches of anhydrite do not account for most of the varying behaviors. It was seen that some specimens swelled more pronounced in axial direction and only slightly in radial direction, and vice versa. One specimen (B 04 in Figure 8-37) even began to reduce its diameter after roughly 70 days again, while the axial swelling strain increased abruptly. No explanation was found for the irregular swelling behavior of the specimens. (Note that all specimens were compact and well intact post test and showed a slight barrel-like shape, whereas small indentations were noticeable where the measuring chain was positioned.)

Nonetheless, as can be seen in Figure 8-40, left, the axial swelling strains of the specimens loaded with $250 \mathrm{kPa}$ still showed a nearly linear relationship to the mass of anhydrite per unit volume remaining in the specimens.

As was seen in Chapter 7.3.4 (Equations $(7-35)$ and $(7-36)$ ), the parameters $\chi_{a x}$ and $\chi_{\text {rad }}$ can be determined solely based on the derivative of the swelling strains over the mass of anhydrite and are independent of the Young's modulus and Poisson ratio. Although the oil pressure was seen to fluctuate slightly, the stresses are assumed to be constants for the evaluation of $\chi_{a x}$ and $\chi_{\text {rad }}$. Furthermore, the pore water pressure is taken constant and the specimen is watered after the isotropic pressure is applied, thus no elastic strains occur during swelling.

All specimens tested at $250 \mathrm{kPa}$ were used to obtain an approximation of the relationship between swelling strains and the mass of anhydrite post test in Figure 8-40. The following linear function is considered to represent the relationships between both swelling strains and the mass change of anhydrite:

Linear approximation:

$$
\varepsilon=a_{1}+a_{2} \cdot m_{A}
$$

For the approximations shown in Figure 8-40, the equation above was used in combination with the parameters listed in Table 8-9.
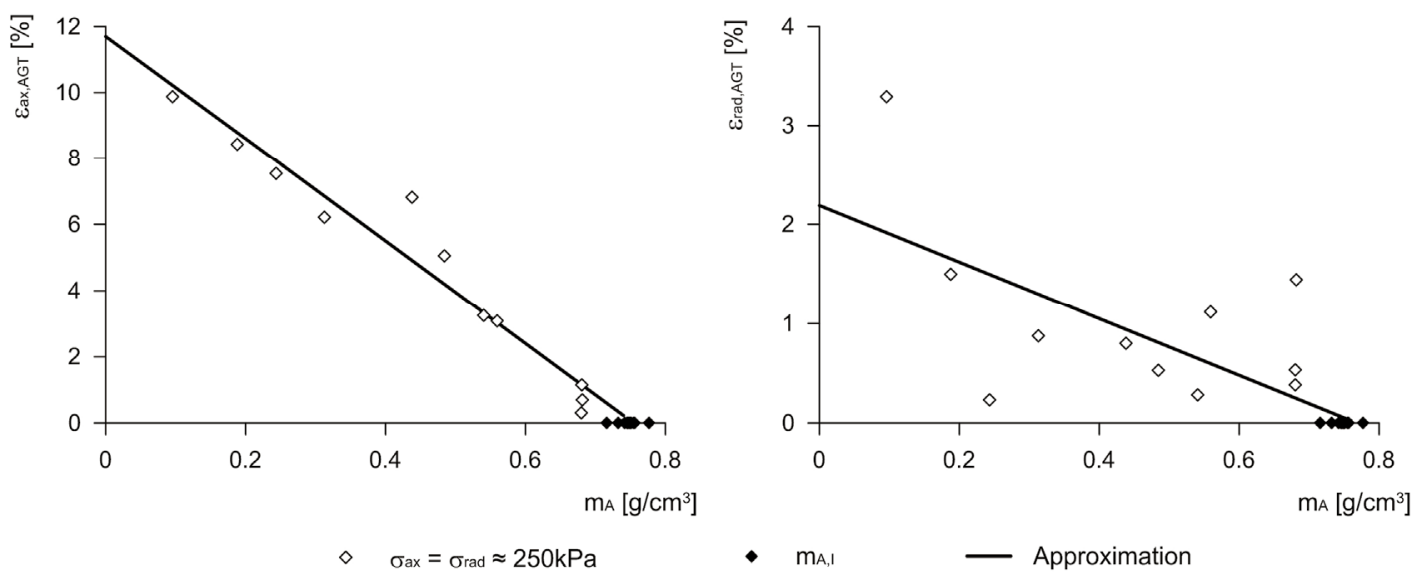

Figure 8-40: Relationship between axial (left) resp. radial (right) strain due to AGT and the final mass of anhydrite in the specimens based on the experimental results with $250 \mathrm{kPa}$ isotropic stress. 
Table 8-9: $\quad$ Parameters used for the approximation of data.

\begin{tabular}{|c|c|c|c|}
\hline & & $\varepsilon_{a x, A G T}$ & $\mathcal{E}_{\text {rad }, A G T}$ \\
\hline \multirow{3}{*}{$\begin{array}{l}\text { Linear } \\
\text { tion }\end{array}$} & approxima- $a_{1}[-]$ & 0.117 & 0.022 \\
\hline & $a_{2}\left[\mathrm{~cm}^{3} / \mathrm{g}\right]$ & -0.16 & -0.028 \\
\hline & $R^{2}[-]$ & 0.97 & 0.59 \\
\hline
\end{tabular}

From the approximations, it is now possible to determine $\chi_{a x}$ and $\chi_{\text {rad }}$ based on Equations $(7-35)$ and $(7-36)$, while bearing in mind that $\varepsilon_{a x}=-\varepsilon_{a x, A G T}$ and $\varepsilon_{r a d}=-\varepsilon_{r a d, A G T}$ (see Equations (7 - 13) and (7-14)). Since the relationships between $\varepsilon_{a x}$ and $m_{A}$ resp. $\varepsilon_{r a d}$ and $m_{A}$ are approximated to be linear, $\chi_{a x}$ and $\chi_{\text {rad }}$ are constants (see Equations $(8-23)$ and $\left.(8-24)\right)$. The combined parameter $\chi$ is, however, dependent on the Poisson ratio, as can be seen in Figure 8-41.

$$
\begin{gathered}
\chi_{a x}=\frac{\partial \varepsilon_{a x}}{\partial m_{A}} \cdot \rho_{A}=-a_{2, \varepsilon_{a x}} \cdot \rho_{A}=\underline{\underline{0.46}} \\
\chi_{r a d}=\frac{\partial \varepsilon_{r a d}}{\partial m_{A}} \cdot \rho_{A}=-a_{2, \varepsilon_{r a d}} \cdot \rho_{A}=\underline{\underline{0.08}} \\
\chi=\chi_{a x}+\frac{2 v}{(1-v)} \chi_{r a d}=-\left(\frac{\partial \varepsilon_{a x}}{\partial m_{A}}+\frac{2 v}{(1-v)} \frac{\partial \varepsilon_{r a d}}{\partial m_{A}}\right) \cdot \rho_{A}=-\left(a_{2, \varepsilon_{a x}}+\frac{2 v}{(1-v)} \cdot a_{2, \varepsilon_{r a d}}\right) \cdot \rho_{A}
\end{gathered}
$$

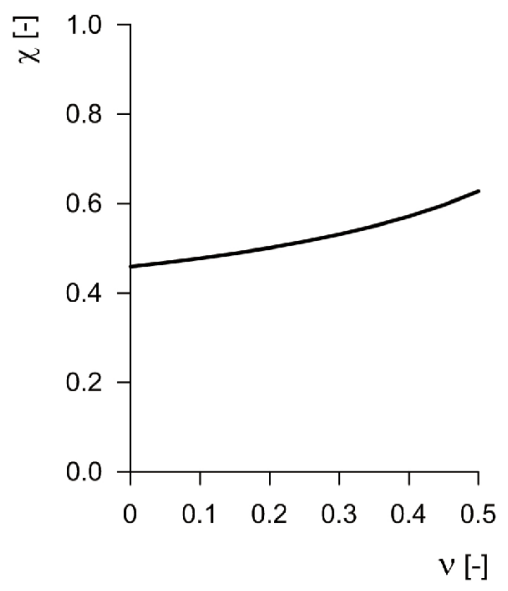

Figure 8-41: Parameter $\chi$ as a function of $v$.

A linear approximation appears to be a good fit in the case of the axial strains and therefore the value $\chi_{a x}$ is assumed to be plausible. Here too, as was the case for the oedometer tests (cf. Equation (8-16)), $a_{2, \varepsilon_{a x}}$ and thus $\chi_{a x}$ can be written as a function of $m_{A, I}$, the maximally reached strains and the corresponding amount of remaining anhydrite. The radial strains, however, show strongly varying results where the best linear fit delivers a coefficient of determination of $R^{2}=0.59$. Therefore, this also leads to a somewhat unreliable evaluation of $\chi_{\text {rad }}$ and $\chi=f(v)$. Nevertheless, all values for the coupling parameters $\chi_{a x}, \chi_{\text {rad }}$ and $\chi$ lie within the range of 0.08-0.63. It needs to be born in mind, however, that these results apply solely for a constant axial and radial stress of roughly $250 \mathrm{kPa}$. 
As can be seen in Figure 8-38, the maximal values of the axial strain seem to be linearly dependent on the logarithm of the applied stress (similar to the case of the oedometer tests, see Chapter 8.5.2). However, for the radial strain this does not seem to be the case. It can therefore be assumed that $\chi_{a x}$ and $\chi$ increase with decreasing stress.

\subsection{Flexible oedometer tests}

\subsubsection{Aim and procedure}

As stated in Chapter 7.3, additional experiments were necessary where the radial stress can be measured during swelling. Such boundary conditions could be met with an experiment in a triaxial apparatus as shown schematically in Figure 7-20. However, due to the high number of experiments required and the long duration of the tests, it was not possible to occupy a rather expensive standard triaxial apparatus over such a long period of time or to build several triaxial cells. As a comparably inexpensive solution, so-called "flexible oedometer" experiments were designed which fulfill the boundary conditions of Figure 7-21d, where the radial deformation of the cylinder surrounding the specimen is measured and the developing radial stress can be determined via the stiffness of the cylinder (i.e., the "flexible" cylinder can be modeled with springs). In order for the cylinders to be reasonably stiff, but still allowing a small measurable radial deformation, PVC was chosen as material (see Figure 8-42), with a thickness of $3.3 \mathrm{~mm}$ so that the expected deformation of the cylinder remains elastic. Prior to the actual tests the cylinders were calibrated, i.e., the characteristic curve between radial deformation and internal liquid pressure on the cylinders was determined experimentally (see Chapter 8.8.2).

For the swelling experiments, a constant axial stress is applied via a standard reaction frame used for consolidation tests (see Figure 8-42, right), while the axial strain is measured via a dial gauge during swelling (similar to the standard oedometer tests). The radial deformation of the PVC cylinder is measured during swelling with a digital high-precision chain extensometer (cf. Chapter 8.4.4), which was fastened to the cylinder either with O-rings or with springs.

The specimens were prepared as in the case of the isotropic compression tests, with the same dimensions (diameter of $56.7 \mathrm{~mm}$ and height of $40 \mathrm{~mm}$ ), again in order to guarantee homogeneous deformations of the specimens and the PVC cylinders in the region of the chain extensometers and thus increase the accuracy of the measured radial deformation. The specimens were compacted analogue to the specimen preparation described in Chapter 8.3. Hereby, eight specimens were compacted directly within the PVC cylinders (in order to ensure that the specimens are tight within the cylinders), whereas the latter were inserted into a steel cylinder for radial support to prohibit deformations of the PVC cylinders already during compaction. This however, led to a certain (unknown) initial radial stress acting on the specimens (pre-stress). For this reason, all other specimens were compacted outside the PVC cylinders, i.e., they were compacted within steel cylinders of nearly the same diameter, then pressed out and inserted tightly in the PVC cylinders after compaction.

During the experiments, the specimens were first loaded with $0.8 \mathrm{MPa}$ or $1.6 \mathrm{MPa}$ in a dry state, then watered with water saturated with respect to gypsum, thus beginning the swelling test. 

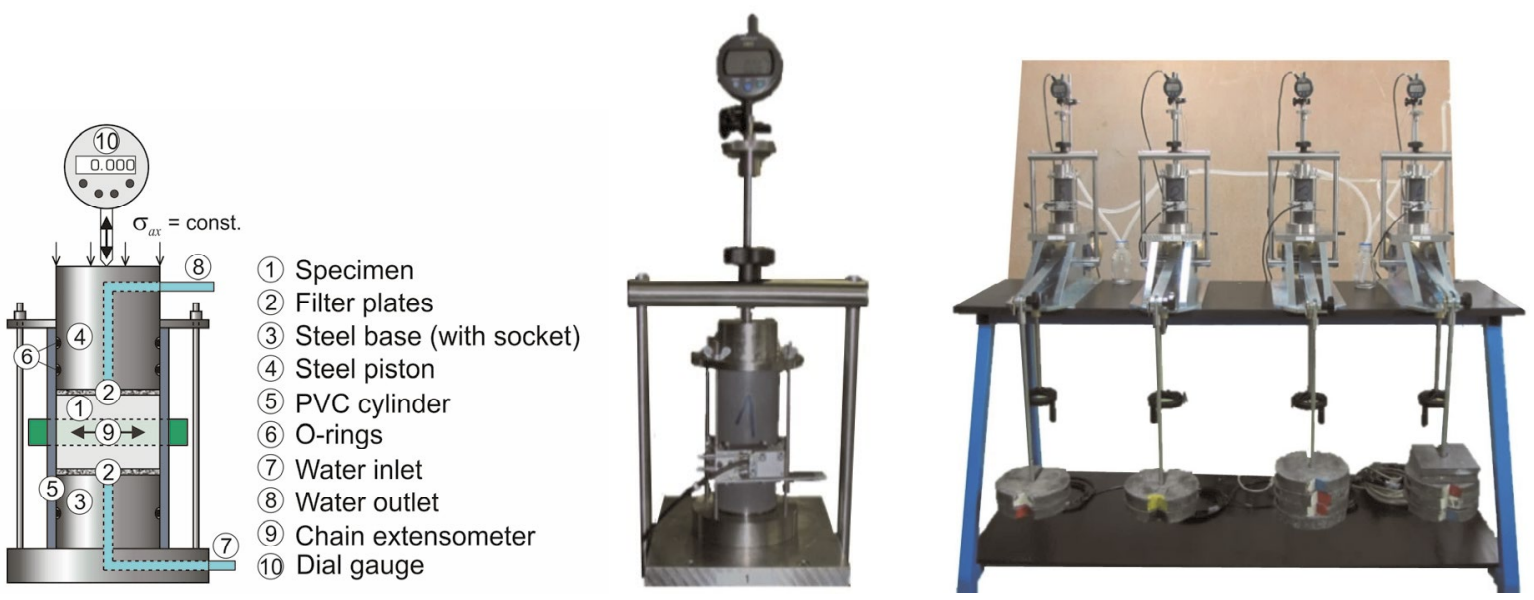

Figure 8-42: $\quad$ Apparatus for the flexible oedometer tests.

The relation between the change in mass of anhydrite and the changes in axial strain, radial strain and radial stress $\left(\chi_{a x}, \chi_{\text {rad }}\right.$ and $\left.\chi\right)$ is given in Equations $(7-51)$ to $(7-53)$. The radial stresses and strains of the specimen are connected to the measured change in circumference $\partial C_{c y l}$ (on the outside of the cylinder) via the stiffness $E_{c y l}$, Poisson ratio $v_{c y l}$ and inner and outer radii $r_{a}, r_{i}$ of the cylinder (the derivations can be found in Appendix $\mathrm{H}$ ). Therefore:

$$
\begin{gathered}
\chi_{a x}=\left(\frac{\partial \varepsilon_{a x}}{\partial m_{A}}+\frac{2 v}{E} \cdot \frac{E_{c y l} \cdot\left(r_{a}^{2}-r_{i}^{2}\right)}{4 \pi \cdot r_{i}^{2} \cdot r_{a}} \frac{\partial C_{c y l}}{\partial m_{A}}\right) \cdot \rho_{A} \\
\chi_{r a d}=\frac{\partial C_{c y l}}{\partial m_{A}} \frac{1}{4 \pi \cdot r_{a}}\left(\left(1-v_{c y l}\right)+\frac{r_{a}^{2}}{r_{i}^{2}} \cdot\left(1+v_{c y l}\right)-\frac{(1-v)}{E} E_{c y l} \cdot \frac{\left(r_{a}^{2}-r_{i}^{2}\right)}{r_{i}^{2}}\right) \cdot \rho_{A} \\
\chi=\left(\frac{\partial \varepsilon_{a x}}{\partial m_{A}}+\frac{2 v}{(1-v)} \cdot \frac{1}{4 \pi \cdot r_{a}} \cdot\left(\left(1-v_{c y l}\right)+\frac{r_{a}^{2}}{r_{i}^{2}} \cdot\left(1+v_{c y l}\right)\right) \cdot \frac{\partial C_{c y l}}{\partial m_{A}}\right) \cdot \rho_{A}
\end{gathered}
$$

As in the previous experiments, and according to Chapter 8.3.2, the coupling parameters were determined by extracting the specimens after different swelling durations and the remaining mass of anhydrite was determined via TGA.

\subsubsection{Calibration of the PVC cylinders}

The characteristic curve of the PVC cylinders was obtained by applying water pressure on the inside of the cylinders and measuring their outer radial deformation. The dimensions of the PVC cylinder (inner diameter and wall thickness) were chosen so that the oedometer behaves elastically for the expected radial pressure range and that a sufficient radial deformation occurs to enable an accurate measurement.

Since the specimens consist of uniformly distributed grains, an isotropic behavior was expected prior to the swelling experiments, i.e., the swelling strains were anticipated to occur mainly in the direction of the lowest stress. Two hypotheses for crystal growth exist which support this assumption: (i) crystal growth only in the direction of the smallest stress (Durney, 1976) or, (ii), crystal growth in all directions, the extent of which is inverse proportional to the stresses (Lecampion, 2010). Therefore, and due to the stiffness of the PVC cylinder, the radial stress was 
expected to increase until it reaches the value of the axial stress. From that point on, swelling would then be more pronounced in axial than in radial direction. For this reason, a first series of eight calibration tests were performed up to $1 \mathrm{MPa}$. It was later seen that the radial deformations and thus the radial stresses can reach higher values (as will be seen in Chapter 8.8.3), and thus a further series of three calibration tests were performed. Furthermore, different attachment methods of the chain extensometer were considered during the second series (two O-rings, four O-rings or two springs). As will be explained later (Chapter 8.8.4), the attachment method was changed during the course of the experiments from rubber O-rings to steel springs, since the O-rings experienced a loss of plasticizers after a while.

The results from the first series (calibration tests on eight cylinders) are shown in Figure 8-43, left. All cylinders deformed nearly identically under the inner radial (water-)pressure, and while they showed a slight hysteresis, no plastic deformation occurred. From these tests it was seen that a linear relationship exists between the radial stress and the deformation of the cylinders up to an inner pressure of $1 \mathrm{MPa}$ (approximated by the yellow line in Figure 8-43).

The later tests up to 2.5 resp. $3 \mathrm{MPa}$ show on the one hand that a slightly higher inner pressure was needed before any change in circumference was recorded (especially in the cases where the chain extensometer was attached with 4 O-rings or 2 springs), on the other hand that a slight softening of the cylinders occurs with increasing radial stress above ca. 1.6 MPa. These results are shown in the right diagram in Figure 8-43, whereas the original 8 calibrations from the first series and their linear approximation are the same as in the left diagram.

Note that PVC1 with 4 O-rings (after having used it previously with 2 O-rings, solid green line in Figure 8-43, right) kept on deforming when the load was increased from 2.5 to $3 \mathrm{MPa}$ (dashed green line). The point marked with a diamond does not correspond to a steady state value (as was the case for each point of the other curves), because the pressure was reduced while the cylinder was still expanding (yielding). Upon unloading, plastic deformations of $0.4 \mathrm{~mm}$ were observed.

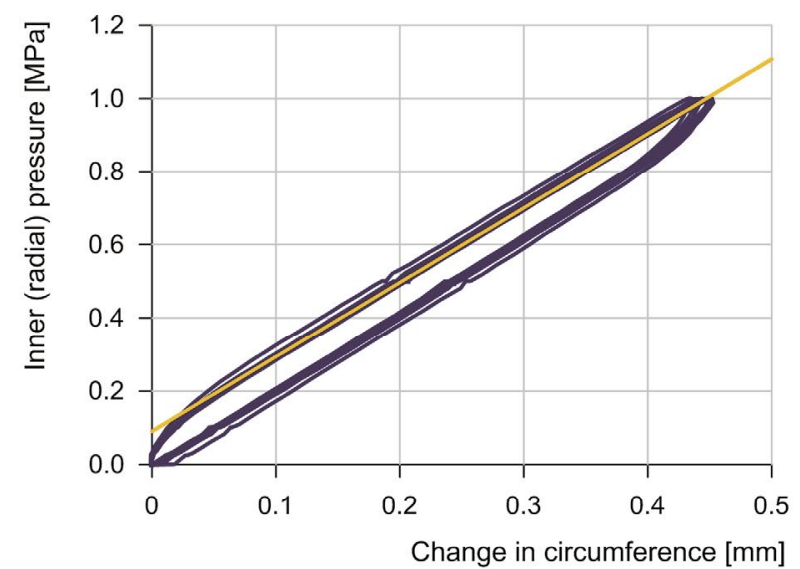
Original 8 calibrations
Linear approximation

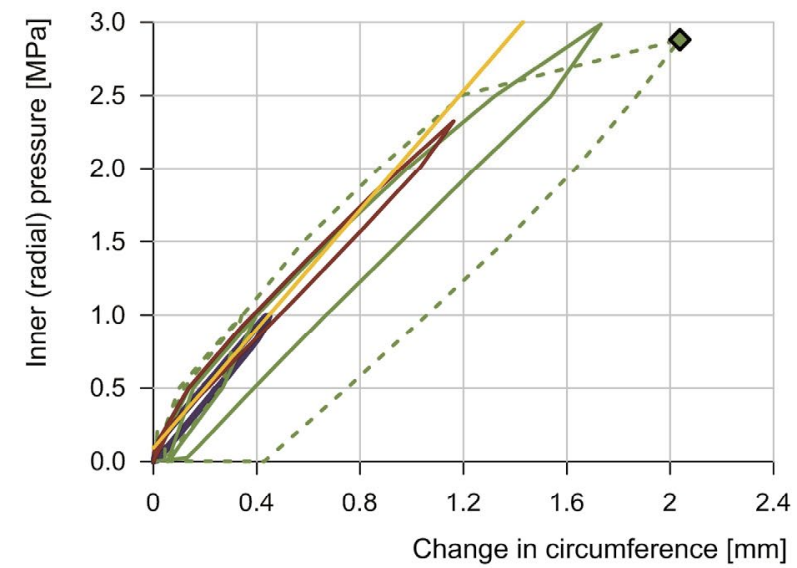

- PVC1 with 2 O-rings - - PVC1 with 4 O-rings
PVC2 with 2 springs

Steady state not reached

Figure 8-43: Calibration of PVC cylinders. Left: original calibration up to $1 \mathrm{MPa}$ with 8 PVC cylinders. Right: additional three later calibrations up to 2.5 resp. $3 \mathrm{MPa}$.

For the analysis of the "flexible oedometer" tests, a linear approximation based on the first 8 calibrations was used (yellow line in Figure 8-43), while bearing in mind that lower inner pressures (resp. when measuring changes in circumference up to about $0.8 \mathrm{~mm}$ ) may be slightly underestimated, while higher inner pressures slightly overestimated, since the inclination of the approxi- 
mation runs steeper than the later three calibration tests with PVC1 (green curves) and PVC2 (dark red curve). During the swelling tests described in Chapter 8.8.3, the average maximal change in circumference was $0.7 \mathrm{~mm}$; at most $1.4 \mathrm{~mm}$ (including the deformation during dry loading).

The radial stress can be formulated as a function of the change in circumference by considering the PVC cylinders as thick-walled cylinders and using the approximation to the calibration curves in Figure 8-43. The PVC cylinders have the following properties:

Average inner radius (measured):

$$
\begin{aligned}
& r_{i}=28.3 \mathrm{~mm} \\
& r_{a}=31.6 \mathrm{~mm} \\
& E_{c y l}=3000 \mathrm{MPa}
\end{aligned}
$$

Average outer radius (measured):

From Appendix $\mathrm{H}$, where the deformation of a thick-walled cylinder due to an inner radial pressure is derived, we have the following equation for the relationship between the change in circumference of the cylinder and the inner radial stress:

$$
\sigma_{r a d}=\frac{\Delta C_{c y l} \cdot E_{c y l} \cdot\left(r_{a}^{2}-r_{i}^{2}\right)}{4 \pi \cdot r_{i}^{2} \cdot r_{a}}
$$

Comparing this equation with the calibration curves, two adjustments need to be made in order to obtain a good fit (i.e., the yellow line in Figure 8-43):

Young's modulus (estimated from calibration tests):

$$
E_{c y l, c a l .}=3350 M P a
$$

"Fitting" pressure, after which the change in circumference increases linearly:

$$
\sigma_{0, f i t}=0.09 \mathrm{MPa}
$$

The radial stress can therefore be determined as follows:

$$
\sigma_{r a d}=\sigma_{0, f i t}+\frac{\Delta C_{c y l} \cdot E_{c y l, c a l .} \cdot\left(r_{a}^{2}-r_{i}^{2}\right)}{4 \pi \cdot r_{i}^{2} \cdot r_{a}}
$$

The radial strains of the specimen can be calculated from the radial pressure and the (outer) deformation of the cylinder (see Appendix $\mathrm{H}$ ), assuming that $r_{\text {specimen }}=r_{i}$ :

$$
\varepsilon_{\text {rad }}=\frac{\Delta r}{r_{\text {specimen }}}=\frac{\Delta r}{r_{i}}=\left[\frac{1}{E_{c y l, c a l}} \cdot \frac{\sigma_{0, f i t} \cdot r_{i}^{2}}{r_{a}^{2}-r_{i}^{2}}+\frac{\Delta C_{c y l}}{4 \pi \cdot r_{a}}\right] \cdot\left[\left(1-v_{c y l}\right)+\frac{r_{a}^{2}}{r_{i}^{2}} \cdot\left(1+v_{c y l}\right)\right]
$$

\subsubsection{Results of the swelling tests}

Figure 8-44 and Figure 8-45 show the axial and radial swelling strains due to AGT over time on the left hand side. These strains begin on average $10 \mathrm{~h}$ after wetting, and were determined according to Chapter 8.3.3, from the point $h_{I}$ on (cf. Figure 8-3), whereas $h_{I}$ was assessed for each specimen individually. The deformations up to this point are listed in Table J-6 in Appendix $\mathrm{J}$ for each specimen. The total axial strains due to dry loading and physical swelling at the point $h_{I}$ were $-1.27 \%$ on average $(-2.43$ to $-0.09 \%$, i.e., an axial settlement occurred) and the radial strains were $0.16 \%$ ( 0.03 to $0.26 \%$, i.e., the specimens expanded radially).

For the radial stresses, however, both cases are shown: Figure 8-46 depicts the radial stresses including the stresses from dry loading and from watering (physical swelling); in Figure 8-47, the initial stresses from dry loading and physical swelling are subtracted, and thus solely the stress 
increase due to AGT is shown (i.e., from point $h_{I}$ in Figure 8-3 on; analogue to the strains shown in Figure 8-44 and Figure 8-45). Note that the radial stress and radial strain are both determined via the change in circumference of the PVC cylinder and are thus linearly coupled to one another due to the elastic behavior of the cylinder. Therefore, the curves $\varepsilon_{\text {rad }, A G T}$ and $\sigma_{\text {rad,AGT }}$ show the same course.

On the right-hand side of Figure 8-44 to Figure 8-47, the reached swelling strains and stresses at the end of each test are shown in dependence of the mass of anhydrite in the respective specimens post test (which was determined via TGA).

An overview of the main specimen properties prior and post test, as well as the testing conditions and results is given in Table $\mathrm{J}-6$ in Appendix $\mathrm{J}$.
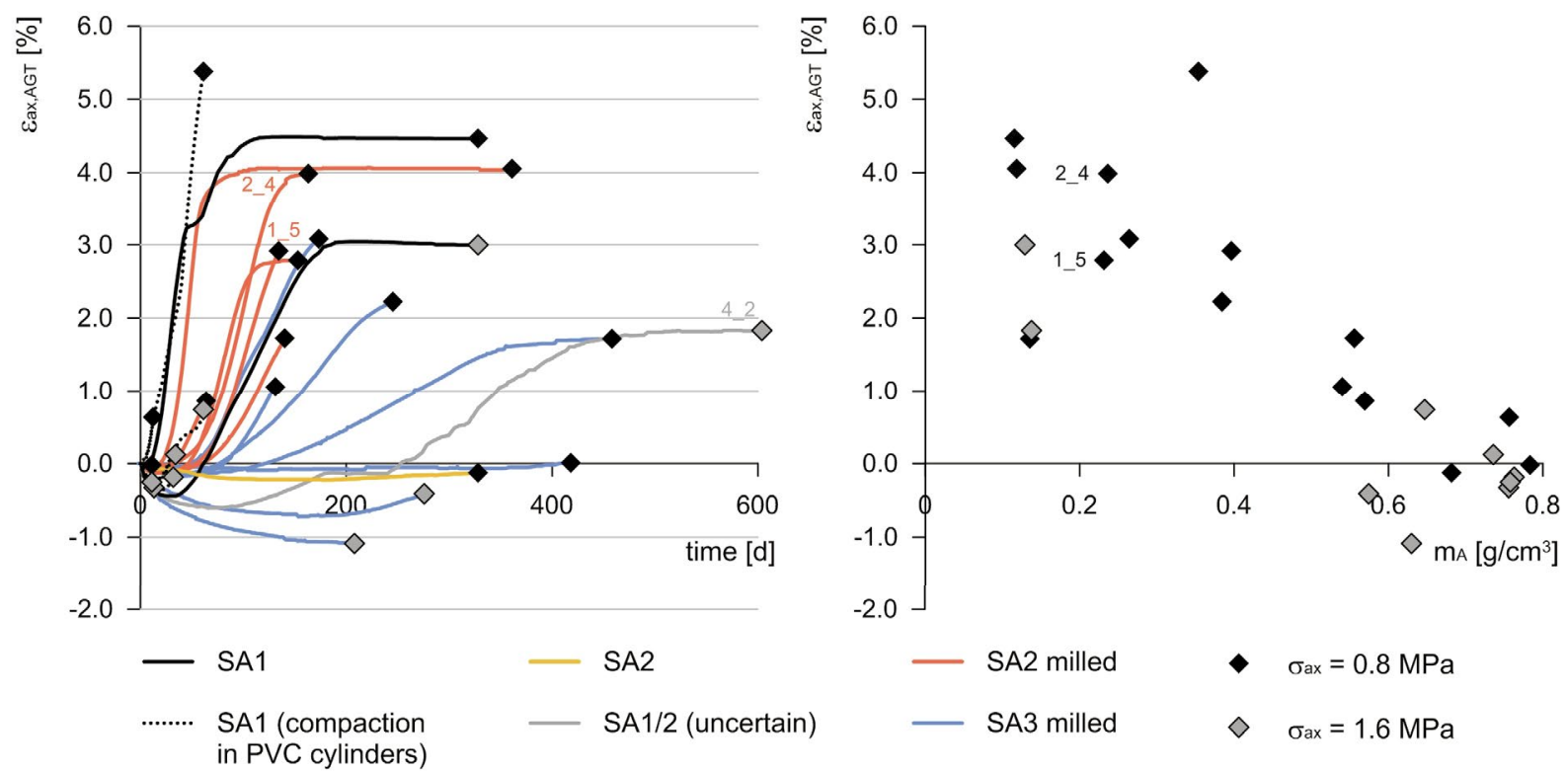

Figure 8-44: Left: axial strains due to AGT vs. time; right: axial strains due to AGT vs. mass of anhydrite per unit volume.
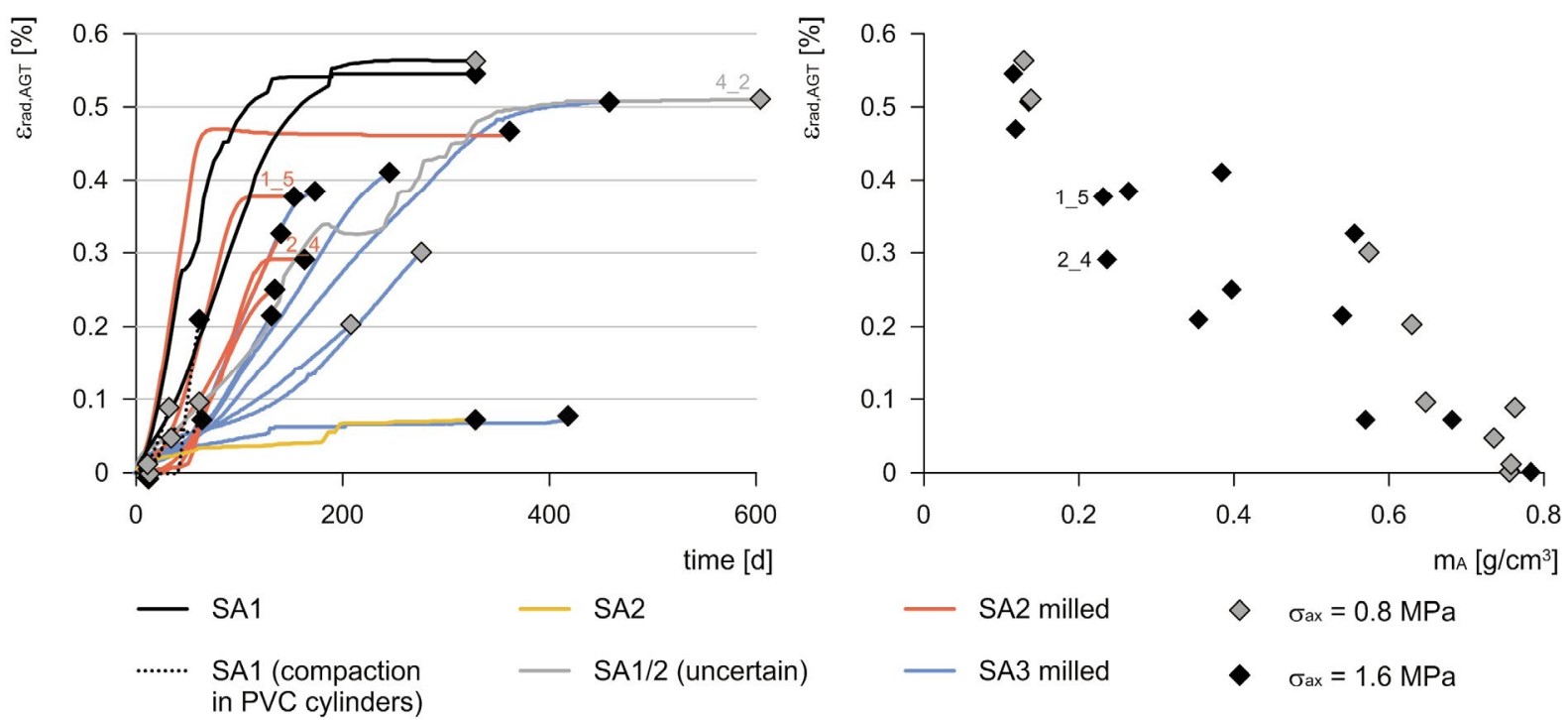

Figure 8-45: Left: radial strains due to AGT vs. time; right: radial strains due to AGT vs. mass of anhydrite per unit volume. 

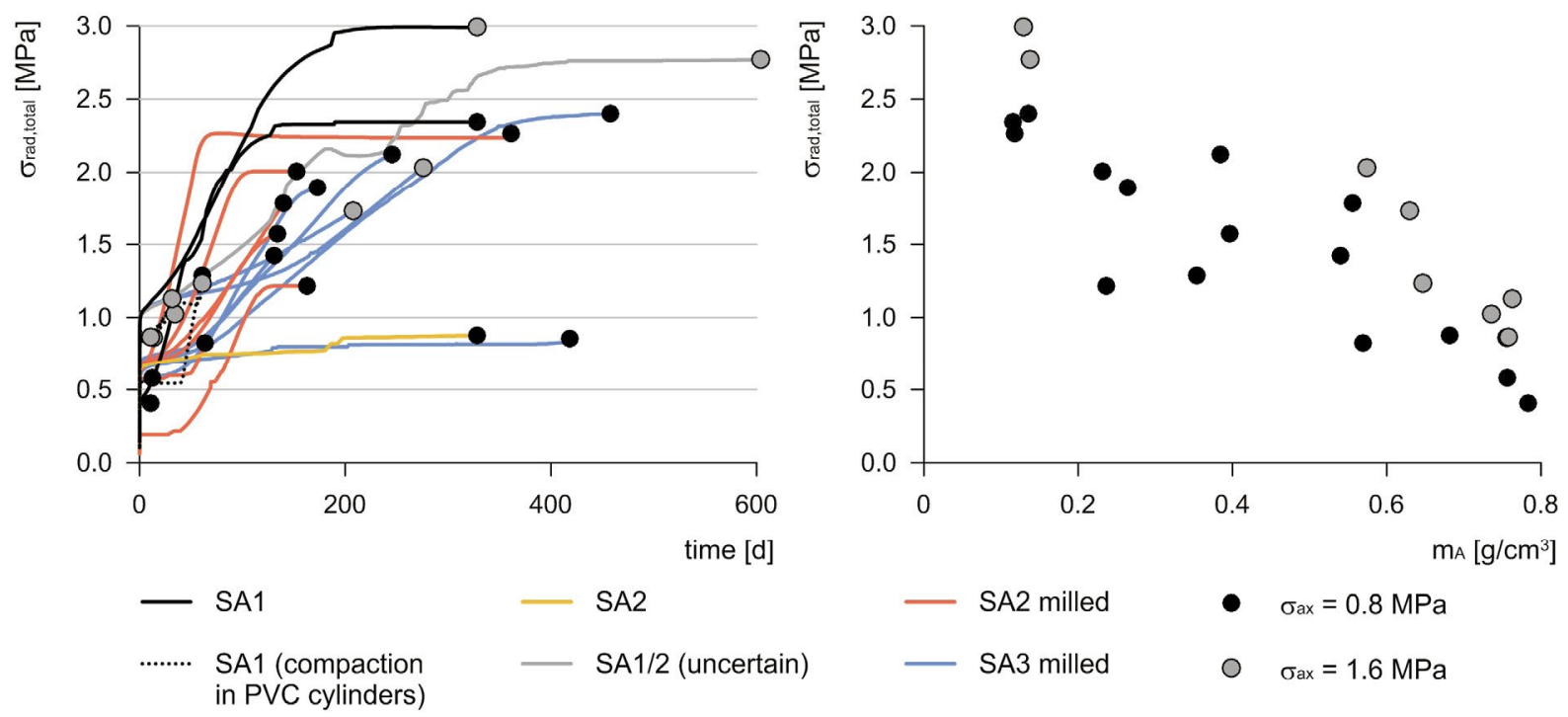

Figure 8-46: Left: radial stresses vs. time; right: radial stresses vs. mass of anhydrite per unit volume.
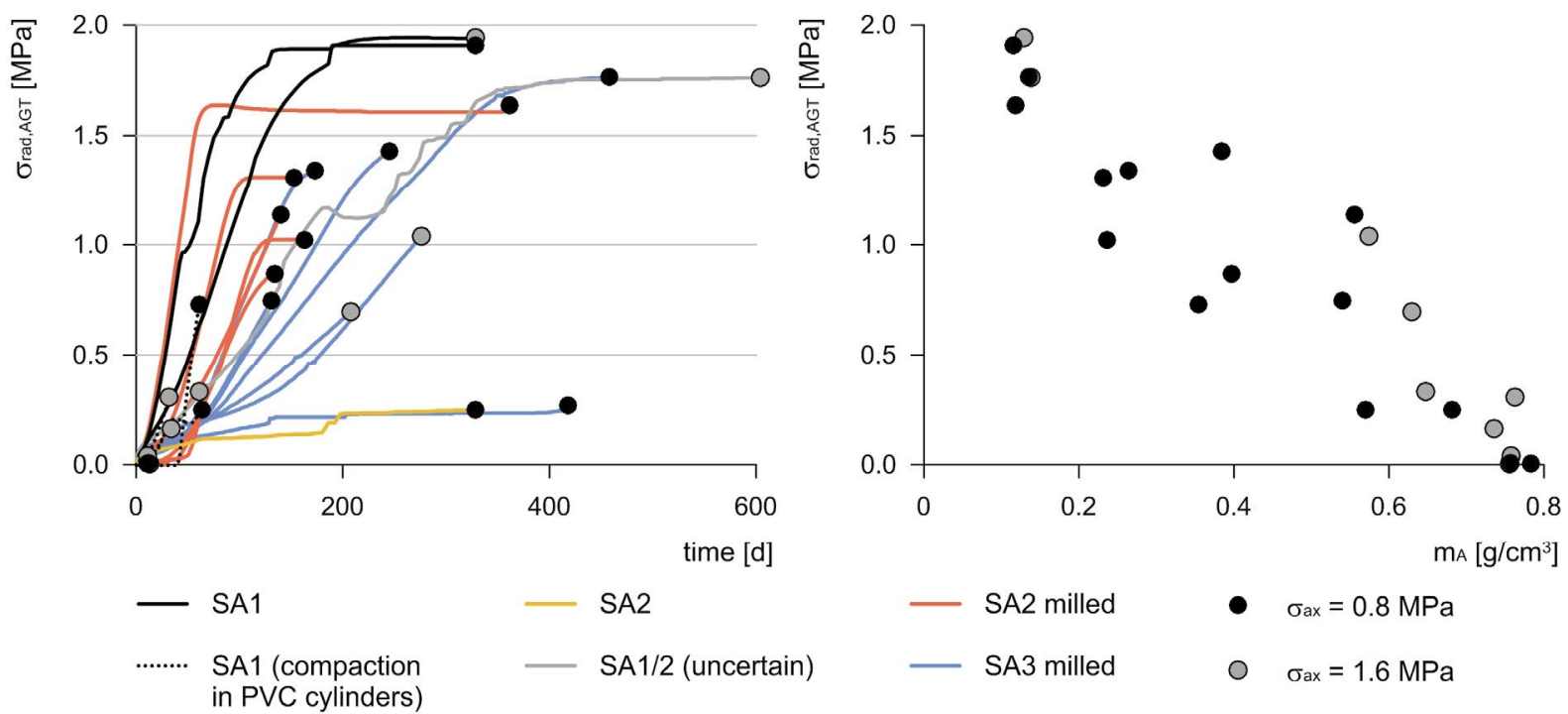

Figure 8-47: Left: radial stresses due to AGT vs. time; right: radial stresses due to AGT vs. mass of anhydrite per unit volume.

\subsubsection{Discussion}

It becomes apparent that - although the first calibrations of the PVC cylinders showed reproducible results (see Figure 8-43) - the actual "flexible oedometer"-experiments deliver varying results, both in radial and axial direction. One significant factor was the usage of different anhydrite powders, as already described in Chapter 8.4.3., which is why some specimens took longer to swell. Similar to the experiments in the previous chapters, the specimens containing SA1 swelled far faster than the specimen containing SA2 (yellow curves in Figure 8-44 to Figure 8-47). By using milled SA2 and SA3 powders, the swelling process could be accelerated, in the case of milled SA2 to nearly the swelling rate of SA1.

The applied axial stress influenced mainly the axial strains, i.e., at an applied stress of $1.6 \mathrm{MPa}$ smaller strains were measured compared to the specimens loaded with $0.8 \mathrm{MPa}$. In radial direction, however, no dependency was seen to exist between the applied axial stress and the radial response (i.e., stresses and strains). Due to the imposed boundary conditions (i.e., the stiffness of 
the PVC cylinders and constant axial load), the radial strains were lower than the axial strains, and the radial stresses even exceeded the value of the axial stresses, contrary to the expectations (see Chapter 8.8.2). This observation supports the hypothesis of Lecampion (2010) rather than the hypothesis of Durney (1976; cf. Chapter 8.8.2).

It was seen that some specimens delivered higher axial strains while others swelled more in radial direction (compare, for example, the specimens 1_5 and 2_4 in Figure 8-44 and Figure 8-45: Both were tested for a similar duration and contained the same amount of anhydrite post test, i.e., the degree of AGT was $\vartheta=68 \%$ in both cases as can be seen in Table J-6 in the appendix. However, 2_4 exhibited a higher axial swelling strain, 1_5 a higher radial swelling strain).

Furthermore, especially the specimen 4_2 (which was loaded at $1600 \mathrm{kPa}$ and was tested the longest up to $600 \mathrm{~d}$ ) shows a fairly irregular behavior when looking at the results for the radial swelling strains and stresses, while the axial strains exhibited a stronger settlement compared to most other specimens. The reason for the irregularities in radial direction lie in the attachment of the chain extensometer: The chain extensometer was held to the PVC cylinders with rubber O-rings, which developed fine fissures after a while (due to loss of plasticizers), thus causing a slight loosening of the chain extensometer. When this was discovered, the O-rings for the subsequent experiments were replaced by steel springs (cf. Chapter 8.8.2).

Nevertheless, a general tendency for the mechanical responses in axial and radial direction due to change in mass of anhydrite can be seen. This is shown by the linear approximations in Figure 8-48, where only the specimens tested with $\sigma_{a x}=0.8 \mathrm{MPa}$ are considered, as more data was gathered compared to $\sigma_{a x}=1.6 \mathrm{MPa}$. Based on the observations made with the few experiments performed with 1.6 MPa axial load (see Figure 8-44 to Figure 8-47), the radial strains (and thus the stresses) appear to develop similarly as for $0.8 \mathrm{MPa}$, whereas the axial strains reach lower values.

The following general linear function is used again to represent both the relationship between the swelling strains or the swelling stress and the mass change of anhydrite:

Linear approximation:

$$
\varepsilon \text { resp. } \sigma=a_{1}+a_{2} \cdot m_{A}
$$

The approximations are shown in Figure 8-48 and the parameters in Equation (8 - 32) were chosen as listed in Table 8-10. Note that in the diagram on the right in Figure 8-48 solely the stresses due to AGT are considered (cf. Chapter 8.3.3). These values were deemed more plausible than the total stresses for the establishment of the relationship between $m_{A, \text { end }}$ and $\sigma_{\mathrm{rad}}$, due to the fact that this way the average mass of anhydrite prior to AGT (i.e., average $m_{A, I}$ ) corresponds to the origin of the approximation (which makes sense physically). If the total stresses were used instead, the mass of anhydrite per unit volume at the origin of the approximation (i.e., at a radial stress of $0 \mathrm{MPa}$ ) would be higher than the mass of anhydrite prior to the experiment, which is not realistic.

Table 8-10: $\quad$ Parameters used for the approximation of data.

\begin{tabular}{llccc}
\hline & & $\mathcal{E}_{a x, A G T}$ & $\mathcal{E}_{\text {rad }, A G T}$ & $\sigma_{\text {rad }, A G T}$ \\
\hline Linear & $a_{1}$ & $0.053[-]$ & $0.0057[-]$ & $1.97[\mathrm{MPa}]$ \\
\cline { 2 - 4 } approximation & $a_{2}$ & $-0.069\left[\mathrm{~cm}^{3} / \mathrm{g}\right]$ & $-0.0073\left[\mathrm{~cm}^{3} / \mathrm{g}\right]$ & $-2.56\left[\mathrm{MPa} \cdot \mathrm{cm}^{3} / \mathrm{g}\right]$ \\
\cline { 2 - 4 } & 0.79 & 0.92 & 0.91 \\
\hline
\end{tabular}




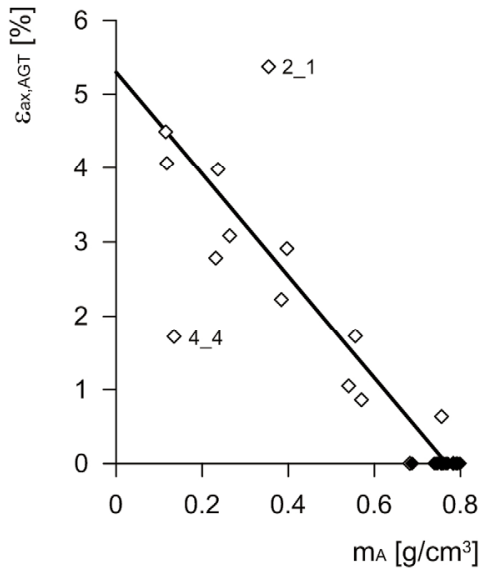

$\diamond \quad \sigma_{a x}=0.8 \mathrm{MPa}$

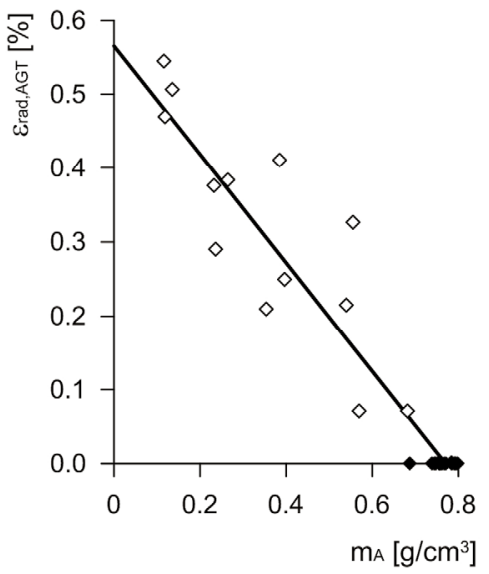

- $\mathrm{m}_{\mathrm{A}, \mathrm{l}}$

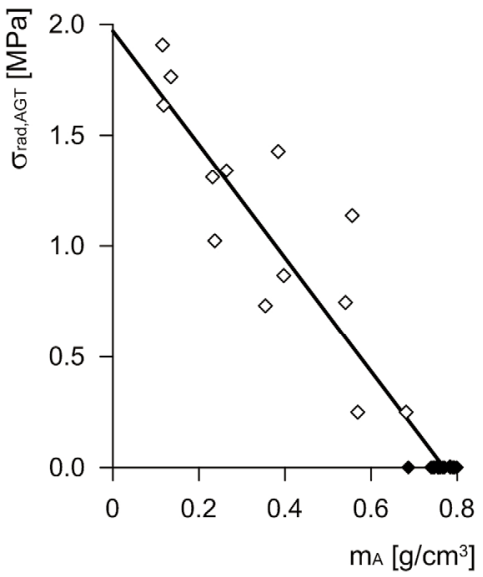

Approximation

Figure 8-48: Possible relationships between axial/radial swelling strain resp. radial swelling stress and the final mass of anhydrite per unit volume in the specimens based on the experimental results with $0.8 \mathrm{MPa}$ axial stress.

The outlier 2_1 in Figure 8-48, left $\left(\varepsilon_{a x, A G T}\right.$ vs. $\left.m_{A}\right)$ was a specimen which was compacted directly in the PVC cylinder. Possibly, a high radial stress was already produced during compaction so that the specimen then swelled more in axial direction than in radial direction. The outlier 4_4 consisted of milled SA3. As can be seen in Figure 8-44, the samples containing SA3 produced generally lower axial strains; the reason for this is so far not known.

By determining the volumetric swelling strains according to Equation (8 - 21) it can be seen that although the radial swelling strains are far smaller than the axial strains (cf. Figure 8-44 and Figure 8-45), the volumetric swelling strains lie on a slightly more distinct line (i.e., deliver a slightly better coefficient of determination) than the axial or radial strains alone, as can be seen in Figure 8-49.
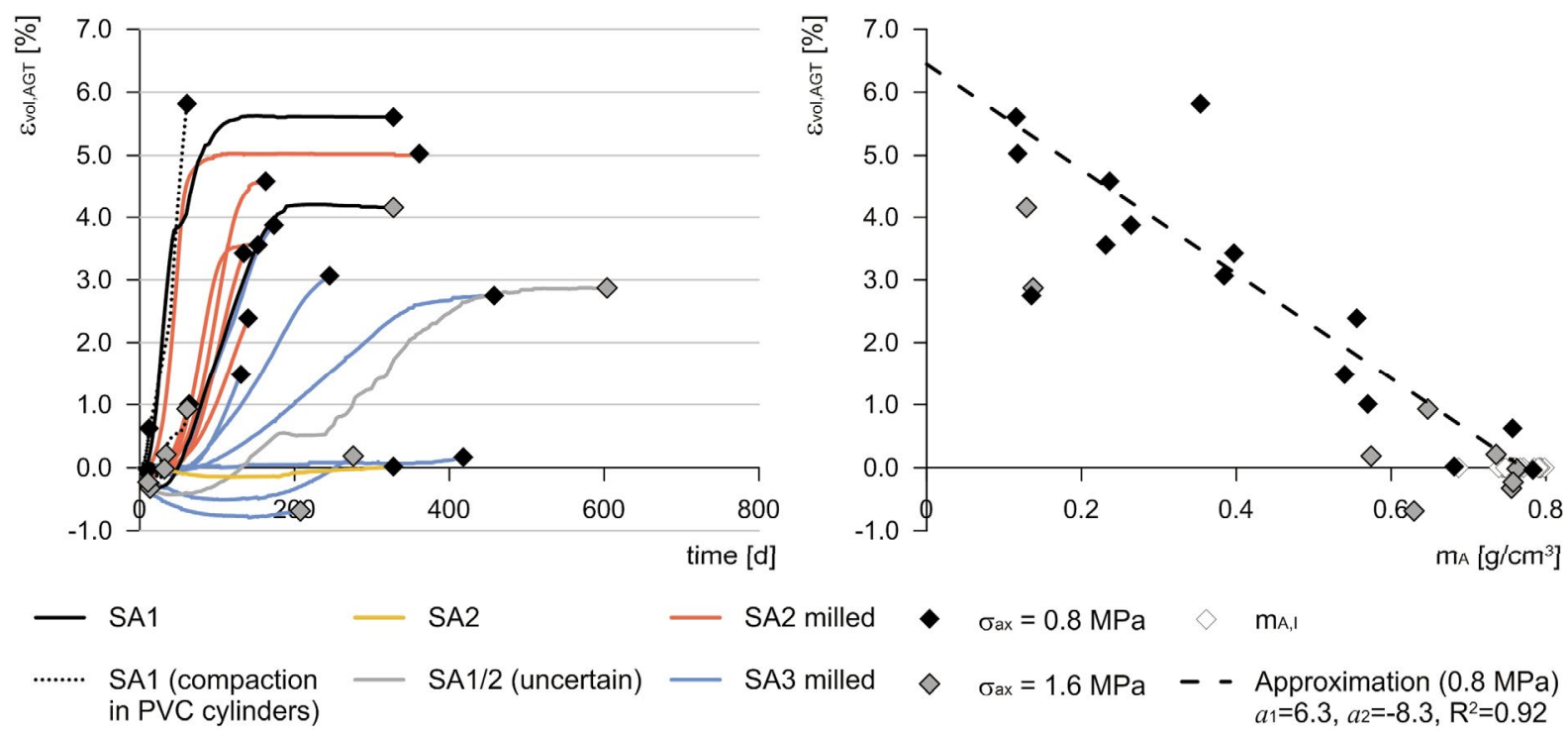

Figure 8-49: Left: volumetric strains due to AGT vs. time; right: volumetric strains due to AGT vs. mass of anhydrite per unit volume.

From the relationships between the swelling strains resp. the radial swelling stress and the change in mass of anhydrite (as shown in Figure 8-48), the parameters $\chi_{a x}, \chi_{\text {rad }}$ and $\chi$ can be estimated by using Equations $(7-51)$ to $(7-53)$ in combination with Equation ( $8-32)$ and the constants from 
Table 8-10, bearing in mind that $\varepsilon_{a x}=-\varepsilon_{a x, A G T}$ and $\varepsilon_{r a d}=-\varepsilon_{r a d, A G T}$ according to Equations $(7-13)$ and $(7-14)$ :

$$
\begin{gathered}
\chi_{a x}=\left(\frac{\partial \varepsilon_{a x}}{\partial m_{A}}+\frac{2 v}{E} \frac{\partial \sigma_{r a d}}{\partial m_{A}}\right) \cdot \rho_{A}=\left(-a_{2, \varepsilon_{a x}}+\frac{2 v}{E} \cdot a_{2, \sigma_{r a d}}\right) \cdot \rho_{A} \\
\chi_{r a d}=\left(\frac{\partial \varepsilon_{r a d}}{\partial m_{A}}-\frac{(1-v)}{E} \cdot \frac{\partial \sigma_{r a d}}{\partial m_{A}}\right) \cdot \rho_{A}=\left(-a_{2, \varepsilon_{r a d}}-\frac{(1-v)}{E} \cdot a_{2, \sigma_{r a d}}\right) \cdot \rho_{A} \\
\chi=\chi_{a x}+\frac{2 v}{(1-v)} \chi_{r a d}=\left(\frac{\partial \varepsilon_{a x}}{\partial m_{A}}+\frac{2 v}{(1-v)} \frac{\partial \varepsilon_{r a d}}{\partial m_{A}}\right) \cdot \rho_{A}=\left(-a_{2, \varepsilon_{a x}}-\frac{2 v}{(1-v)} \cdot a_{2, \varepsilon_{r a d}}\right) \cdot \rho_{A}
\end{gathered}
$$

Note that $\chi_{a x}$ and $\chi_{\text {rad }}$ are dependent on both the Young's modulus and the Poisson ratio, while $\chi$ is dependent on the Poisson ratio and independent of the Young's modulus (as already seen in Equations $(7-51)$ to $(7-53))$. This is considered in Figure $8-50$, where the results for the coupling parameters obtained with the flexible oedometer tests are shown. It can be seen that the values for $\chi_{a x}$ and $\chi_{\text {rad }}$ vary strongly depending on the Poisson ratio and Young's modulus of the specimen (which can also change during swelling, as the specimen softens slightly, cf. Chapter 8.4.4). However, $\chi$ obtained with these experiments was seen to lie in a similar range as with the oedometer tests at $0.8 \mathrm{MPa}$ (see Figure 8-28), where a value of 0.4 resp. 0 to 0.8 (depending on the approximation chosen) was obtained.
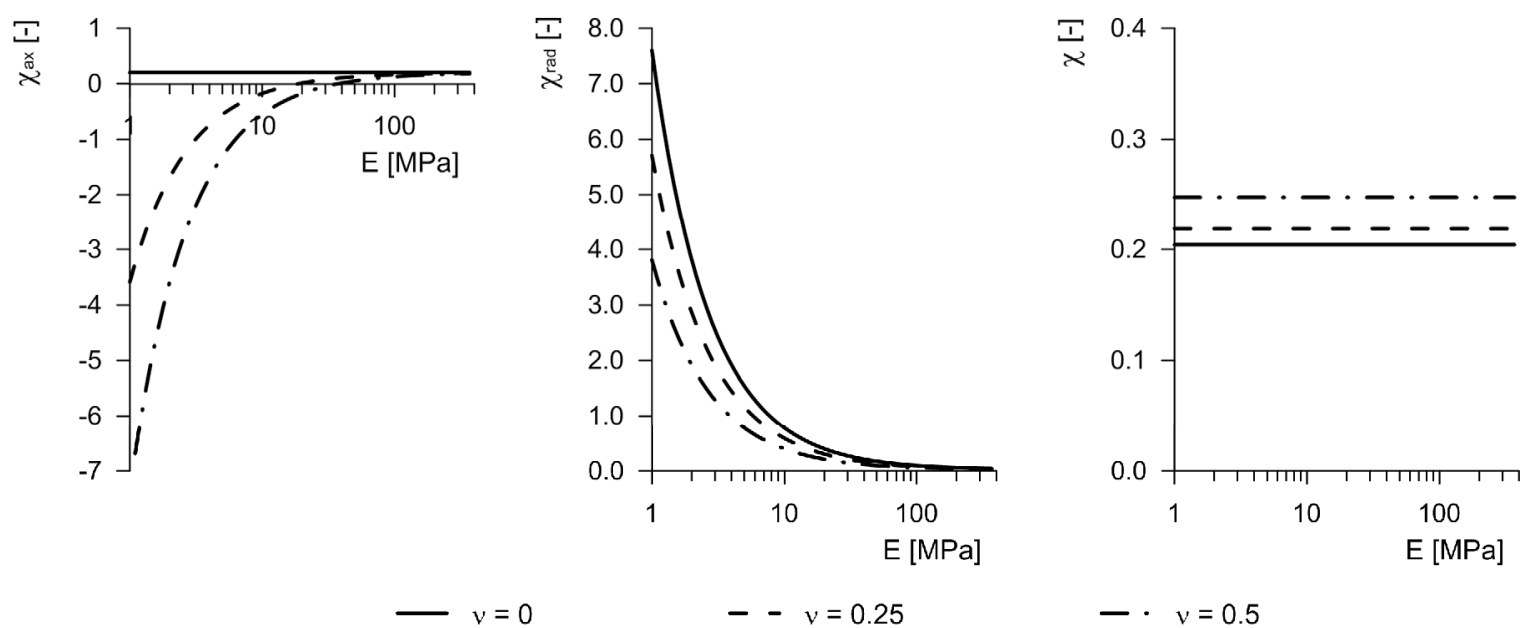

$-v=0.25$

$-\cdot v=0.5$

Figure 8-50: Parameters $\chi_{a x}$ (left), $\chi_{\text {rad }}$ (middle) and $\chi$ (right) as a function of the Young's modulus for three different values of the Poisson ratio.

It needs to be considered that these results are based on a constant axial stress of $0.8 \mathrm{MPa}$ and are likely to vary depending on the applied axial stress, as was already seen with the oedometer tests in Chapter 8.5.3. For a corresponding evaluation of the few experiments performed at 1.6 $\mathrm{MPa}$, the assumptions are made for the axial strain that, (i), the approximation of the data (grey symbols in Figure 8-44 to Figure 8-47) is linear as well and, (ii), $a_{1, \varepsilon_{\alpha x}, 1.6 M P a}=0.5 \cdot a_{1, \varepsilon_{\alpha x}, 0.8 M P a}$ and $a_{2, \varepsilon_{\alpha x}, 1.6 \mathrm{MPa}}=0.5 \cdot a_{2, \varepsilon_{a x}, 0.8 \mathrm{MPa}}$ (the higher axial stress led to smaller axial strains, and the origin of the approximation at the average $m_{A, I}$ is maintained), while the development of the radial strains and stresses remain the same as for $0.8 \mathrm{MPa}$. Therefore, we get: 


$$
\begin{gathered}
\chi_{a x, 1.6 \mathrm{MPa}}=\chi_{a x, 0.8 \mathrm{MPa}}-0.5 \cdot a_{2, \varepsilon_{a x}} \cdot \rho_{A} \approx \chi_{a x, 0.8 \mathrm{MPa}}-0.1 \\
\chi_{\text {rad }, 1.6 \mathrm{MPa}}=\chi_{\text {rad }, 0.8 \mathrm{MPa}} \\
\chi_{1.6 \mathrm{MPa}}=\chi_{0.8 \mathrm{MPa}}-0.5 \cdot a_{2, \varepsilon_{a x}} \cdot \rho_{A} \approx \chi_{0.8 \mathrm{MPa}}-0.1
\end{gathered}
$$

Consequently, while $\chi_{\text {rad }}$ may remain the same, $\chi_{a x}$ and $\chi$ become smaller with increasing stress.

\subsection{Investigations of specimen structures}

\subsubsection{Porosimetry}

The change in the structures of the specimens during swelling is accompanied by a change in porosity and pore size distribution. In order to gain information on these changes (i.e., compare the pore size distribution of a specimen post swelling test to its initial state) and verify whether the porosities determined indirectly via the grain densities, geometries and masses of the specimens are accurate, some selected specimens were analyzed with Mercury Intrusion Porosimetry (MIP, cf. Chapter 3.4).

MIP was performed on three specimens from oedometer tests after swelling (specimen Oe_6_2, loaded with $3200 \mathrm{kPa}$, where no swelling was observed; two loaded with $800 \mathrm{kPa}$ after various stages of swelling, i.e., Oe_5_3 where AGT progressed to $27 \%$ and Oe_5_2, where AGT progressed to $85 \%$, see Chapter 8.5 and Table J-3), and on the specimen PT15 of the preliminary free swelling tests performed with limestone (which showed no swelling due to AGT, cf. Chapter 8.4.1). Additionally, a specimen containing anhydrite and kaolin (40\% SA and 60\% PW) as well as a specimen containing anhydrite and limestone ( $40 \%$ SA and $60 \% \mathrm{KM})$ were prepared according to the standard specimen preparation procedure (Chapter 8.3.1), and represent therefore reference specimens for the state prior to swelling. Upon specimen preparation, the specimens were broken in order to obtain smaller samples for MIP. Of each specimen, at least two samples were taken and investigated with MIP.

Figure 8-51 shows the pore size distributions obtained with MIP, while the porosities and total pore volumes (also obtained with MIP) are presented in Figure 8-52. The respective degree of AGT of each specimen is given by the $\vartheta$-values as defined in Equation $(7-12)$ and which were obtained via TGA (see Appendix I). 

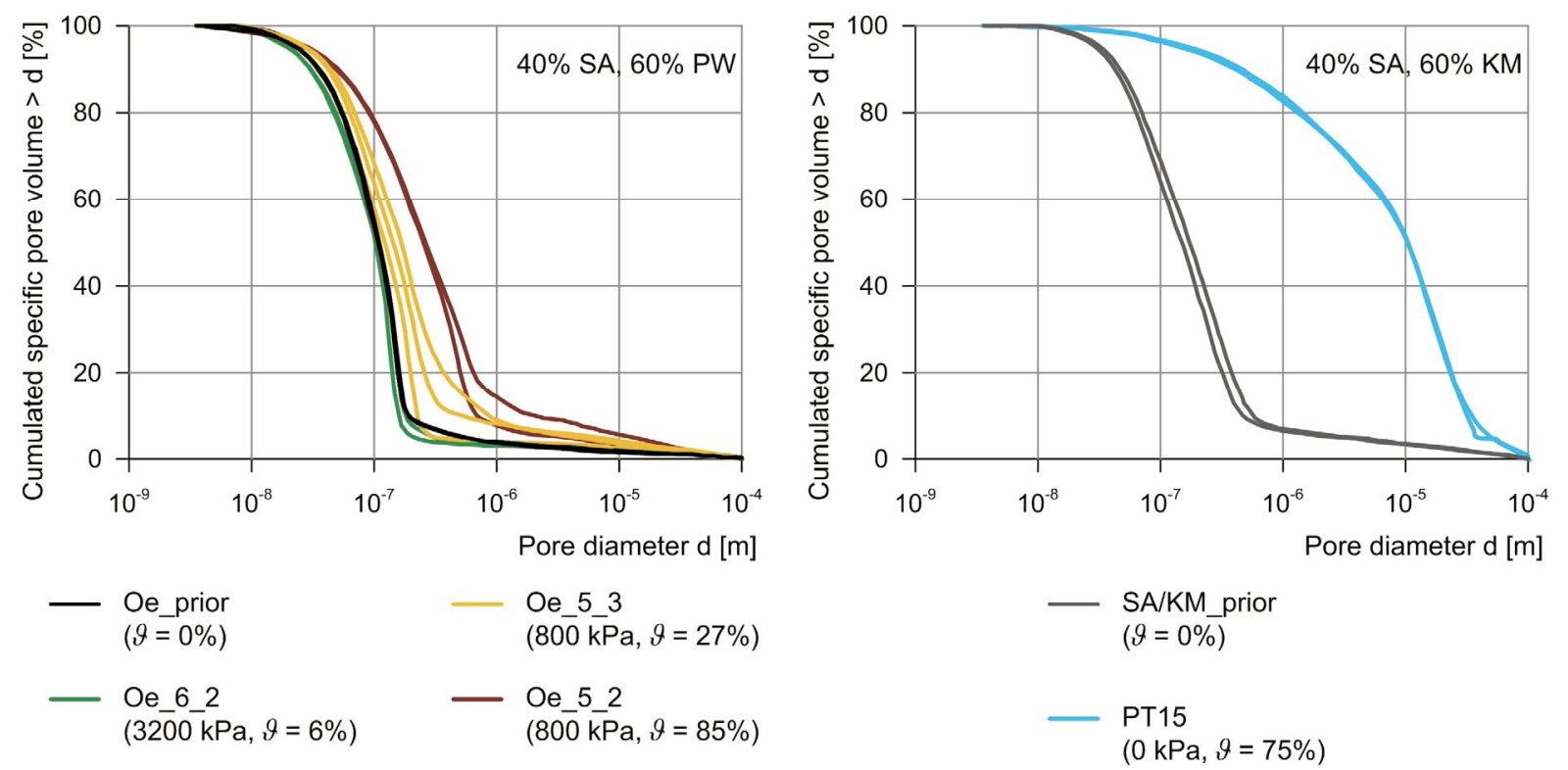

Figure 8-51: Pore size distributions for anhydrite / kaolin specimens from oedometer tests (left) and anhydrite / limestone specimens from preliminary free swelling tests (right).

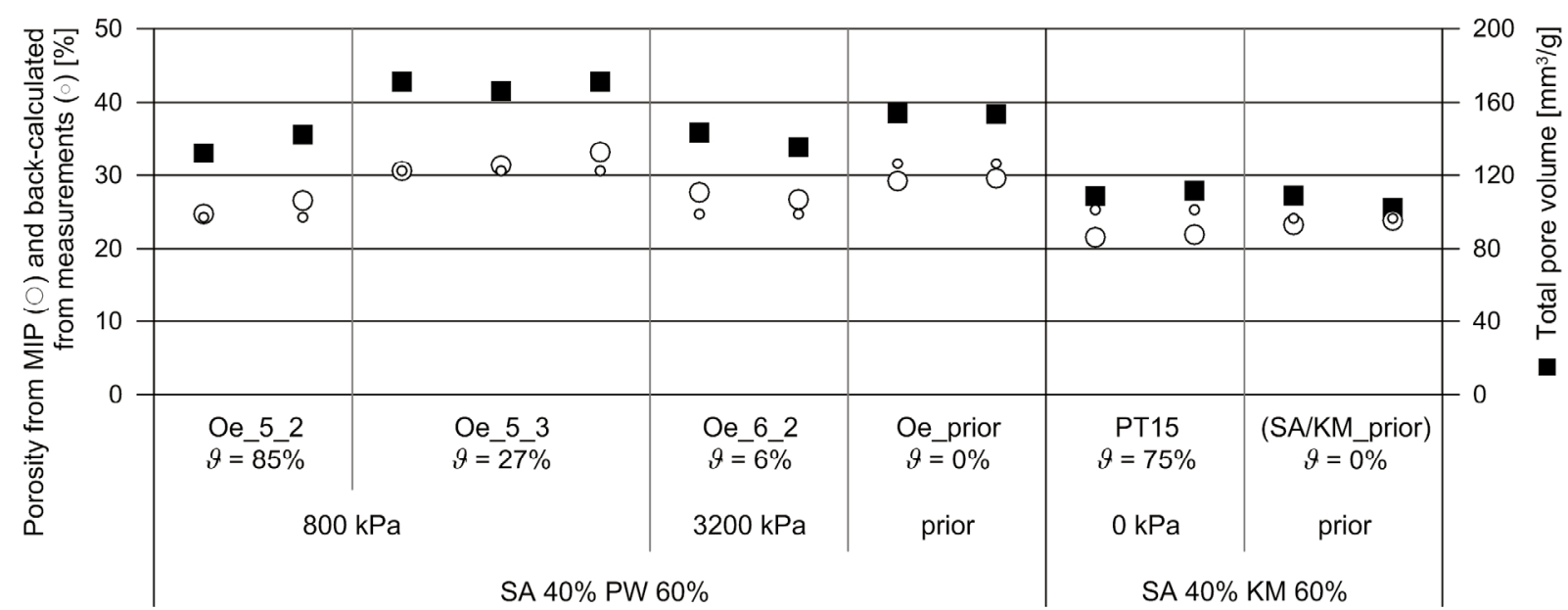

Figure 8-52: Porosity (left axis / white circles) and total pore volume (right axis / black squares) of anhydrite / kaolin specimens from oedometer tests and anhydrite / limestone specimens from preliminary free swelling tests.

From Figure 8-51, right, it becomes apparent that the pore size distribution of the limestone specimen changed significantly after the specimen was subjected to water for 46 days, while the oedometer specimens containing kaolin did not change as much (Figure 8-51, left). With the latter, the specimen loaded with $3200 \mathrm{kPa}(\vartheta=6 \%)$ appeared not to have changed at all (the green curves nearly overlap with those of a specimen prior to swelling, shown in black), while a specimen loaded with $800 \mathrm{kPa}$ tends to gain more larger pores during AGT (the pore size distribution shifts to the right with increasing values of $\vartheta$, see yellow and red curves: $d_{50}$ increases from $1.1 \cdot 10^{-7}$ to $2.5 \cdot 10^{-}$ $7 \mathrm{~m}$ ). In the case of the limestone specimen, the initial state prior to swelling (grey curves in Figure 8-51, right) is very similar to that of a kaolin specimen, however subjecting the specimen to water seems to create a large amount of bigger pores (the pore size distribution changes its shape entirely and shifts to the right; for example, $d_{50}$ changes by two orders of magnitude from $1.5 \cdot 10^{-7}$ to $\left.10^{-5} \mathrm{~m}\right)$. 
When looking at the porosities and total pore volumes (Figure 8-52), while keeping the swelling strain curves from Figure 8-18 and Figure 8-23 in mind, the following interpretations can be made concerning the anhydrite / kaolin specimens: At the beginning of swelling, gypsum precipitation appears to increase the total pore volume and porosity of the specimens. Eventually, gypsum precipitates within the pores and does not cause any further swelling strain, i.e., the swelling strain reaches a steady state and the pore volume and the porosity decrease again (see Figure 8-52, for the specimens tested at $800 \mathrm{kPa}$ : At $\vartheta=27 \%$ the values are higher than those of the specimen prior to swelling, whereas at $\vartheta=85 \%$ the values are lower). With the specimen that was loaded with $3200 \mathrm{kPa}$ a decrease in the total pore volume and porosity can be observed compared to the state prior to swelling, which can be accounted to the settlement the specimen experienced, since nearly no gypsum was found in the specimen post test.

Although the total pore volume of the limestone specimens increases from prior test to post test, the porosity decreases and - as mentioned above - the pore size distribution shifts drastically to the right. It is assumed that the initial heave created large pores, even cracks, however due to gypsum precipitation within the specimen, the ratio of total pore volume to total volume (i.e., the porosity) decreases.

The smaller circles in Figure 8-52 depict furthermore the porosities determined from the measured dimensions of the specimens and their masses (also listed in Table J-1 and Table J-3 in Appen$\operatorname{dix} \mathrm{J}$ ). It can be seen that these values lie close to the measurements performed with MIP (larger circles) in most cases and are thus considered to satisfactorily accurate. It is, therefore, assumed that the porosities of all other specimens calculated from the measurements prior and post test (see Appendix J) are reasonable.

\subsubsection{Microscopy}

Additionally, the change in structure of the specimens due to AGT (e.g., change of pore volume or aperture of cracks as well as the distribution and shape of the growing gypsum crystals) was investigated via microscopy on selected specimens. (Note that due to the arduousness of the microscopic techniques, it was not possible to investigate all tested specimens on a microscopic scale within the framework of this research project.) In the following, these investigations are grouped by the types of tests the specimens stem from. Table 8-11 gives an overview of all specimens investigated and the respective techniques used (cf. Chapter 3.2). 
Table 8-11: $\quad$ Overview of performed microscopic investigations.

\begin{tabular}{|c|c|c|c|c|}
\hline Original experiment & Specimen name & Specimen description & Sample type & $\begin{array}{l}\text { Microscopic investiga- } \\
\text { tions }\end{array}$ \\
\hline \multirow{7}{*}{$\begin{array}{l}\text { Free swelling tests } \\
\text { (Chapter 8.4.1) }\end{array}$} & PT15 (SA40 KM60) & $40 \%$ Anhydrite & Fragment & Optical microscope, \\
\hline & & $60 \%$ Limestone & & SEM \& EDX \\
\hline & & $\vartheta=75 \%$ & Embedded (Epoxy) & SEM \& EDX \\
\hline & & & and polished & \\
\hline & SA40 KM60 prior & $40 \%$ Anhydrite & Embedded (Epoxy) & SEM \& EDX \\
\hline & & $60 \%$ Limestone & and polished & \\
\hline & & Prior, $\vartheta=0 \%$ & & \\
\hline \multirow{12}{*}{$\begin{array}{l}\text { Oedometer tests } \\
\text { (Chapter 8.5) }\end{array}$} & Oe_5_2 (800kPa) & $40 \%$ Anhydrite & Fragment & SEM \\
\hline & & $60 \%$ Kaolin & Polished & Optical microscope, thin \\
\hline & & $800 \mathrm{kPa}, \vartheta=85 \%$ & & sections, SEM \& EDX \\
\hline & Oe_6_2 (3200kPa) & $40 \%$ Anhydrite & Fragment & SEM \\
\hline & & & Polished & Optical microscope, thin \\
\hline & & $3200 \mathrm{kPa}, \vartheta=6 \%$ & & sections, SEM \& EDX \\
\hline & Oe_5_4 (800kPa) & $40 \%$ Anhydrite & Polished & SEM \& EDX \\
\hline & & $60 \%$ Kaolin & & \\
\hline & & $800 \mathrm{kPa}, \vartheta=37 \%$ & & \\
\hline & Oe_7_2 (1600kPa) & $40 \%$ Anhydrite & Fragment & SEM \\
\hline & & $60 \%$ Kaolin & & \\
\hline & & $1600 \mathrm{kPa}, \vartheta=84 \%$ & & \\
\hline
\end{tabular}

\section{a. Free swelling tests}

Since the specimens containing limestone did not swell during the preliminary tests (Chapter 8.4.1), even though TGA revealed that AGT progressed to $\vartheta=75 \%$, it was of interest to see where the gypsum precipitated. In an additional step, it was investigated how the specimen structure changed compared to the state prior to the swelling test.

Figure 8-53 shows close up images of two fragments broken off of the SA40 KM60 specimen post test, one plane perpendicular to the direction the specimen was compacted, one parallel. In the plane perpendicular to compaction, clear clusters of crystals are visible (such as the one marked with an arrow in the right image), while in the plane parallel to compaction small cracks are visible (such as the one marked with an arrow in the left image). Figure 8-54 shows BSE images of the plane perpendicular to compaction. The nodular crystals visible in these images are strongly assumed to be gypsum. The gypsum appears to have precipitated in clear "clusters" of needles, however the needles are also found evenly spread over the entire specimen. A further section of this specimen (Figure 8-55) was investigated with EDX by point analyses, to identify the elements occurring in the specimen at different locations (see Table 8-12). Since the particle size of the used anhydrite is smaller than $44 \mu \mathrm{m}$ (cf. Chapter 8.2.1), it is strongly assumed that the longer monoclinic nodules (i.e., > $100 \mu \mathrm{m}$ ) which indicated a sulfur content with EDX analyses are gypsum crystals 
(point B), while there are still some remaining orthorhombic anhydrite crystals (e.g., point $A$ ) in the specimen as well. Furthermore, spots were identified that were nearly free of sulfur, which are assumed to be mainly limestone (point $\mathrm{C}$ ). These findings are in good accordance with the findings from TGA analysis that about $75 \%$ of the anhydrite had been transformed to gypsum. Based solely on the crystal size, limestone cannot be clearly identified, since the particle size distribution of limestone is well graded in its original state (particle sizes from 1 to $200 \mu \mathrm{m}$ see Figure 8-1) and it may at least partially have dissolved and precipitated again during the swelling test.
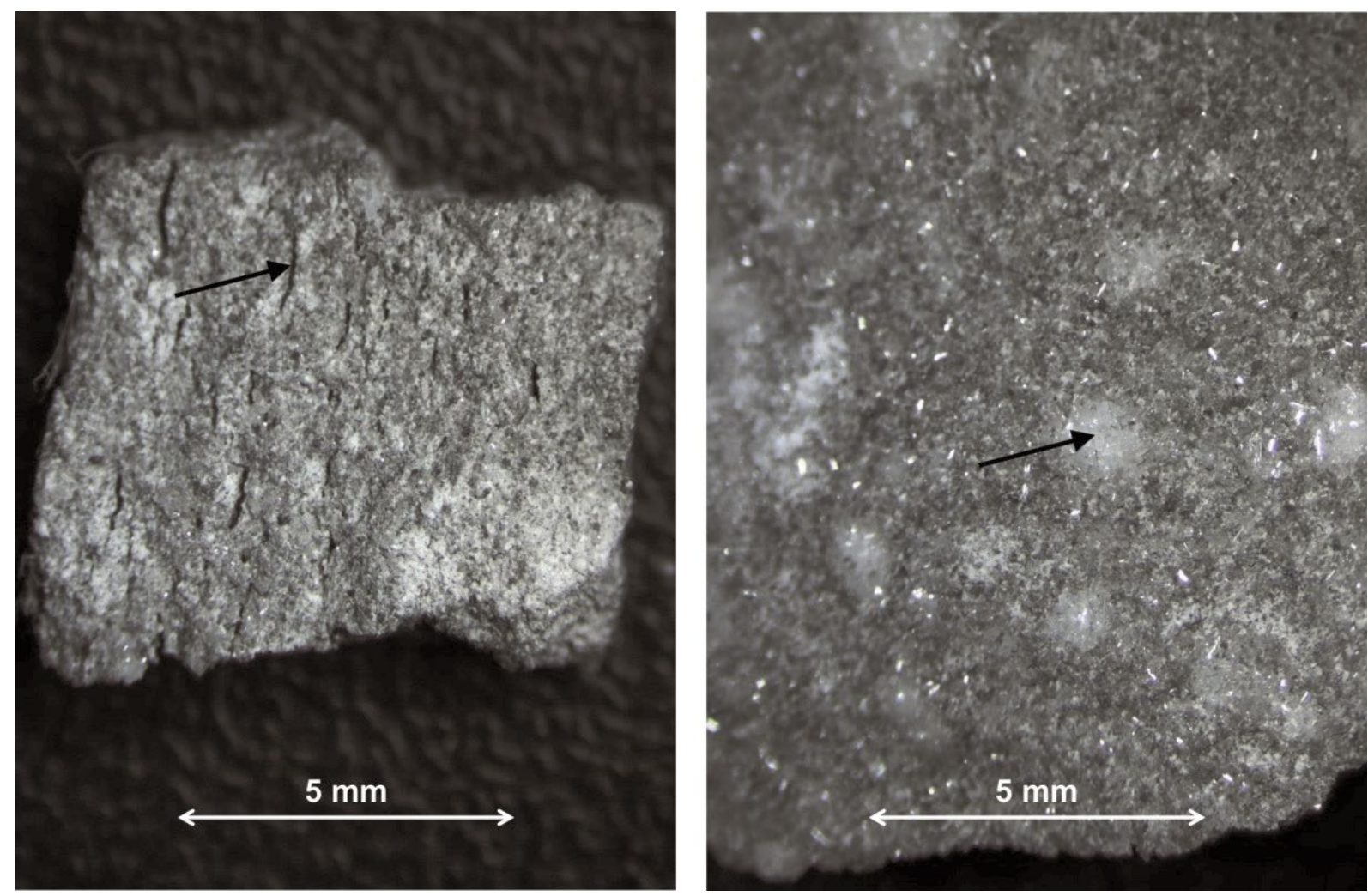

Figure 8-53: Images of the fragment sample of the specimen PT15 (SA40 KM60) post free swelling test, taken with an optical stereo microscope. Left: plane parallel to the direction of compaction, right: plane perpendicular to the direction of compaction. 

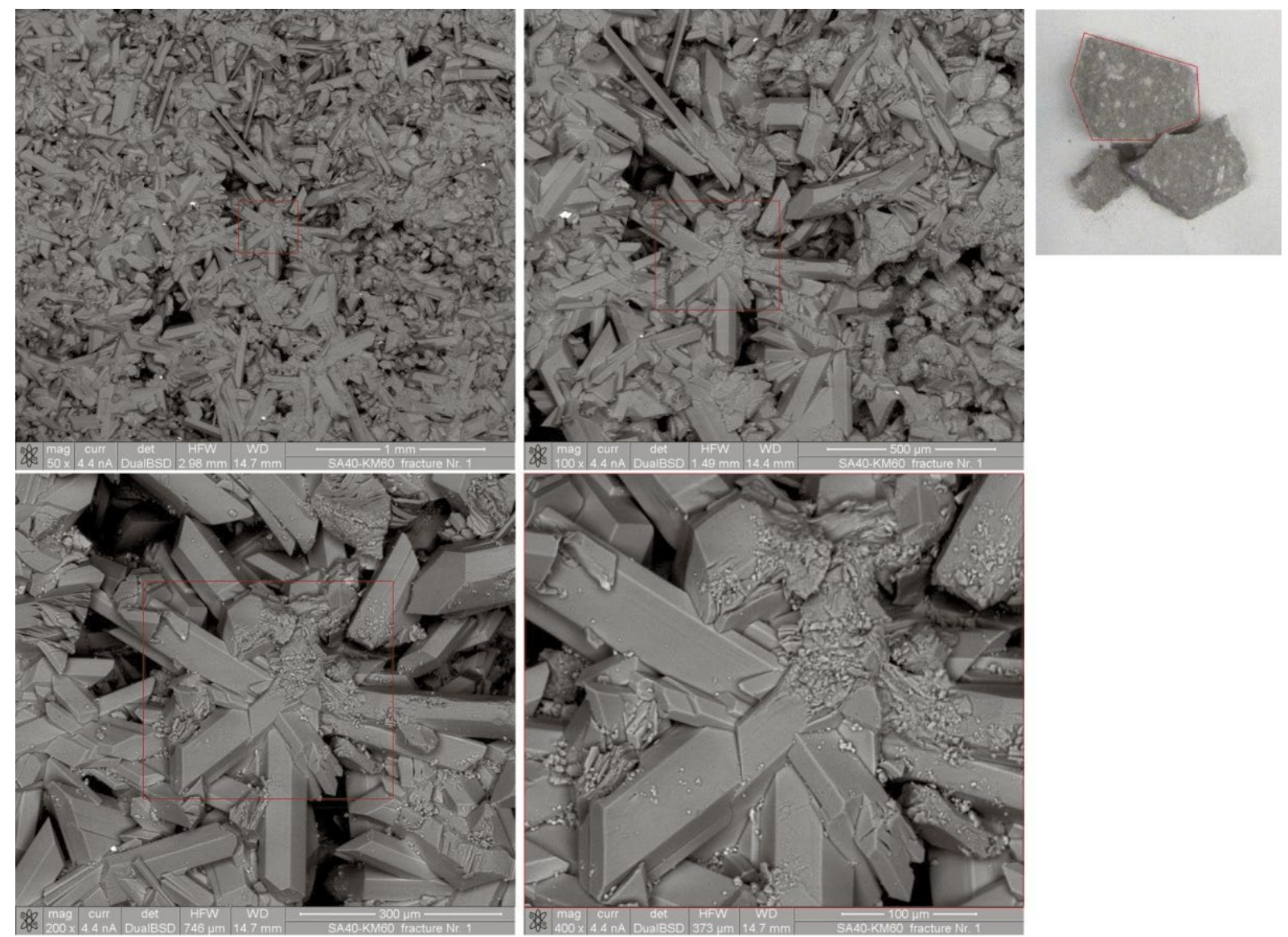

Figure 8-54: BSE images of the fragment (indicated on the top right) of the specimen PT15 (SA40 KM60) post free swelling test.

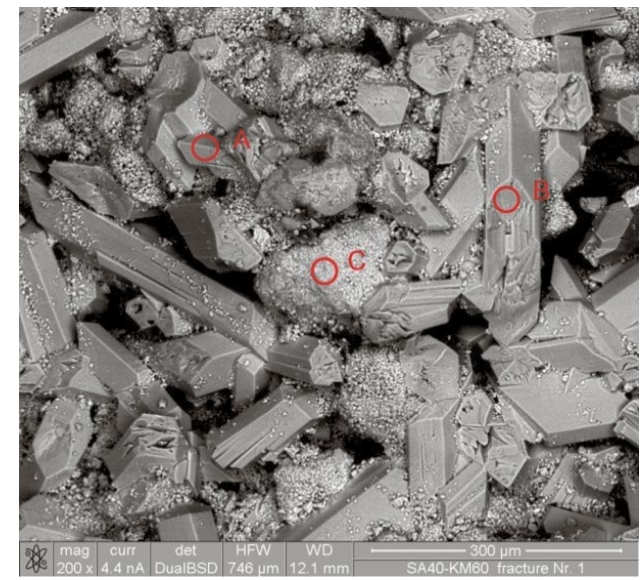

Figure 8-55: $\quad$ Point analyses of PT15 (SA40 KM60) fragment post free swelling test (cf. Table 8-12). 
Table 8-12: $\quad$ Point analyses of PT15 (SA40 KM60) fragment post free swelling (cf. Figure 8-55).

\begin{tabular}{llllllllll}
\hline Point & \multicolumn{2}{c}{$\mathbf{S}$} & \multicolumn{2}{c}{$\mathrm{Ca}$} & \multicolumn{2}{c}{$\mathbf{C}$} & \multicolumn{2}{c}{ O } & Interpretation \\
& {$[\mathbf{w t} \%]$} & {$[\mathrm{At} \%]$} & {$[\mathbf{w t} \%]$} & {$[\mathrm{At} \%]$} & {$[\mathbf{w t} \%]$} & {$[\mathrm{At} \%]$} & {$[\mathbf{w t} \%]$} & {$[\mathrm{At} \%]$} & \\
\hline A & 23.41 & 19.24 & 48.14 & 31.65 & 4.11 & 9.02 & 24.34 & 40.09 & $\mathrm{CaSO}_{4}$ \\
\hline B & 19.42 & 13.74 & 35.31 & 19.99 & 4.43 & 8.38 & 40.84 & 57.90 & $\mathrm{CaSO}_{4} \cdot 2 \mathrm{H}_{2} \mathrm{O}$ \\
\hline C & 2.75 & 2.29 & 67.64 & 45.04 & 5.94 & 13.19 & 23.67 & 39.48 & $\mathrm{CaCO}_{3}$ \\
\hline
\end{tabular}

$[w t \%]=$ weight percentage, $[\mathrm{At} \%]=$ atomic percentage

In order to investigate the distribution of calcium sulfate in the specimen more closely, a piece of the same specimen was embedded in epoxy and its surface polished (see Figure 8-56, right). The sample was investigated with SEM (BSE images in Figure 8-56) in combination with EDX, where the main occurring elements on the surface of the sample are mapped in Figure 8-57. Figure 8-58 shows another section of that same sample at a closer scale.

The same was done for a sample of the specimen SA40 KM60 prior to swelling (i.e., prior to contact with water). The SEM images are shown in Figure 8-59 and the EDX mapping is given in Figure 8-60 (same scale as Figure 8-58).
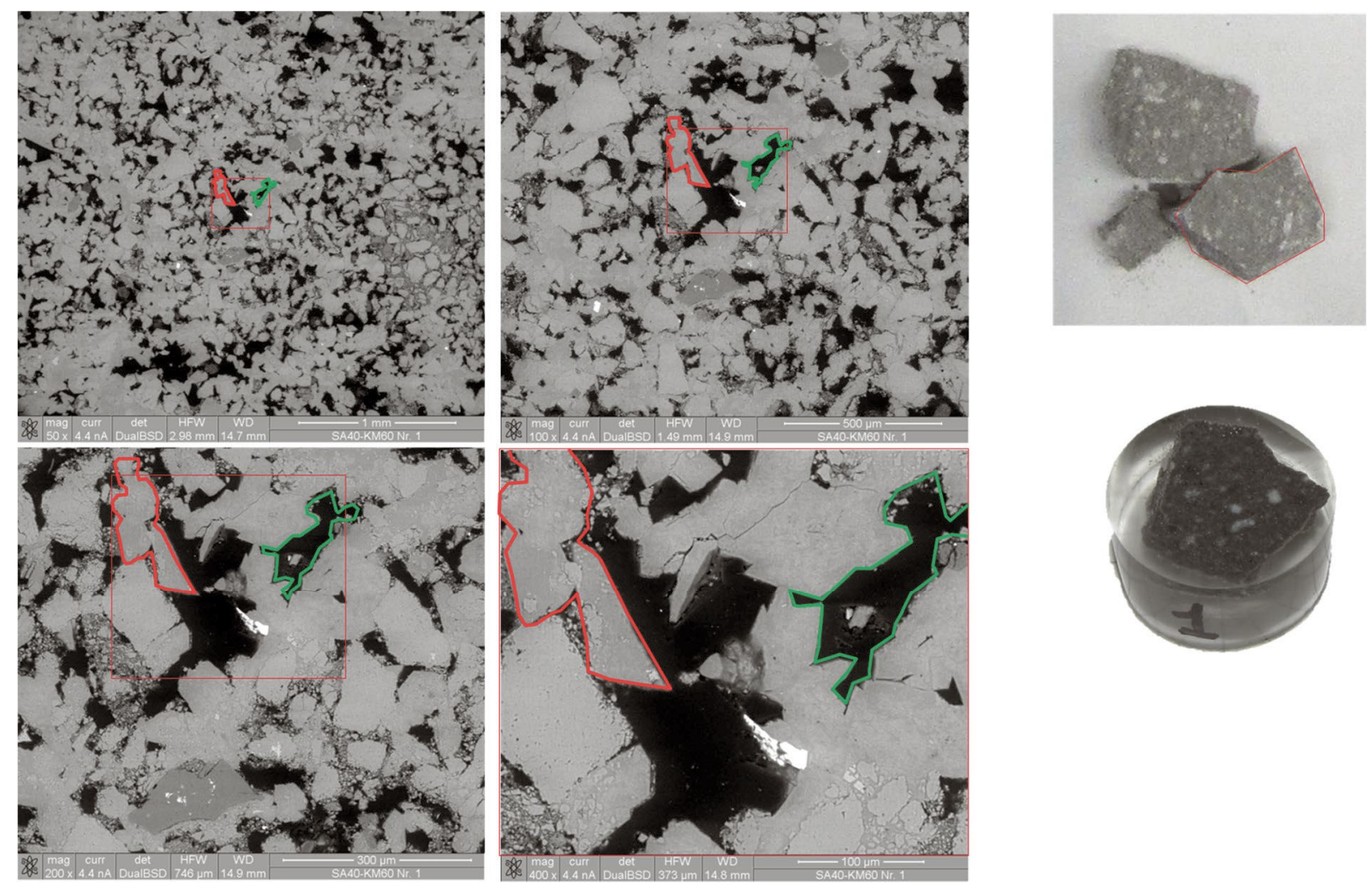

Figure 8-56: BSE images of the polished sample (shown right) of the specimen PT15 (SA40 KM60) post free swelling test. 

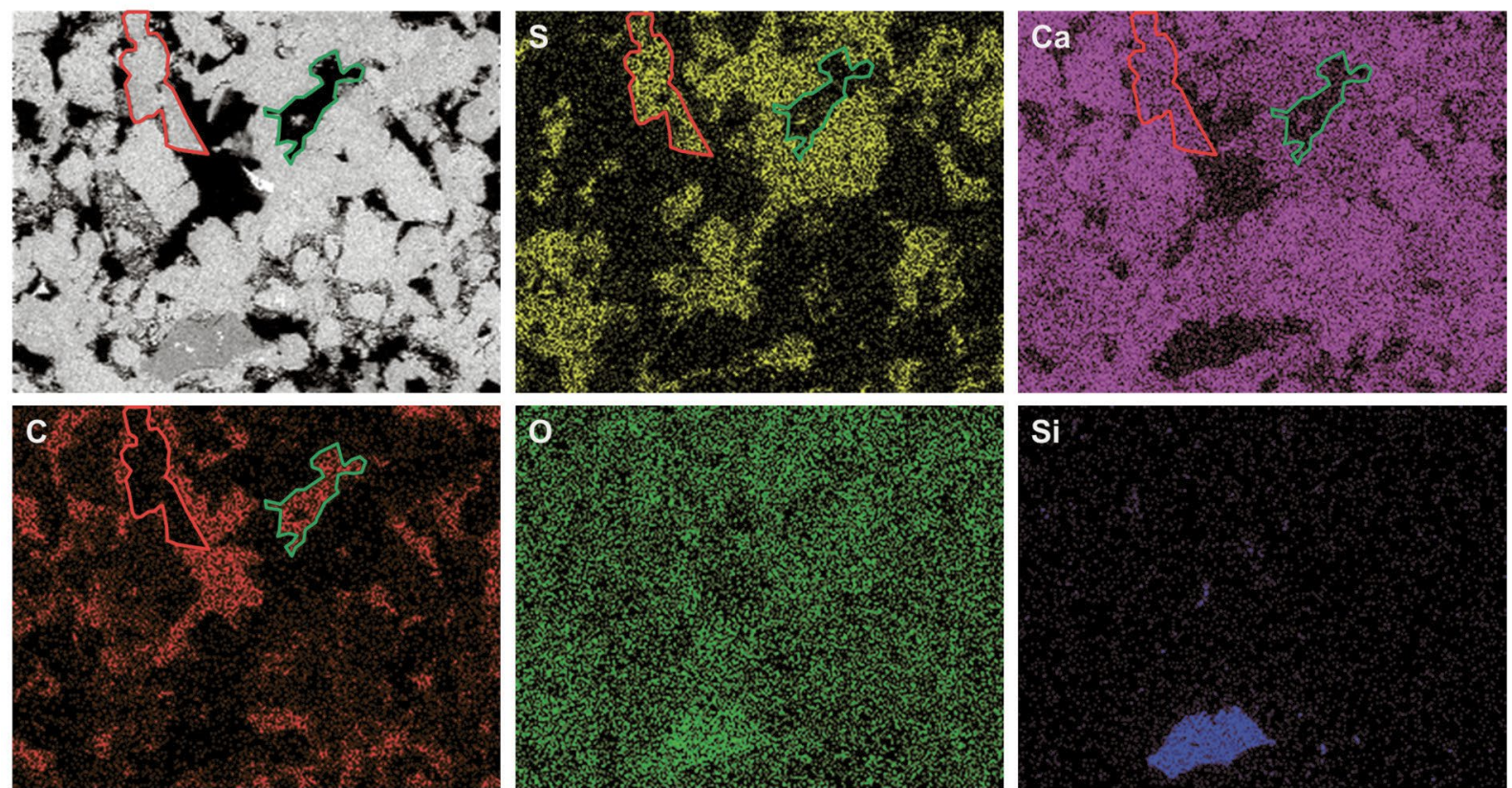

Figure 8-57: EDX mapping of the different elements of the polished sample of the specimen PT15 (SA40 KM60) post free swelling test. Note: the width of an image corresponds to ca. $800 \mu \mathrm{m} ; S=$ sulfur, Ca = calcium, $\mathrm{C}=$ carbon, $\mathrm{O}=$ oxygen, $\mathrm{Si}=$ silicon and the black areas in the mappings indicate the areas where the respective element was not detected.
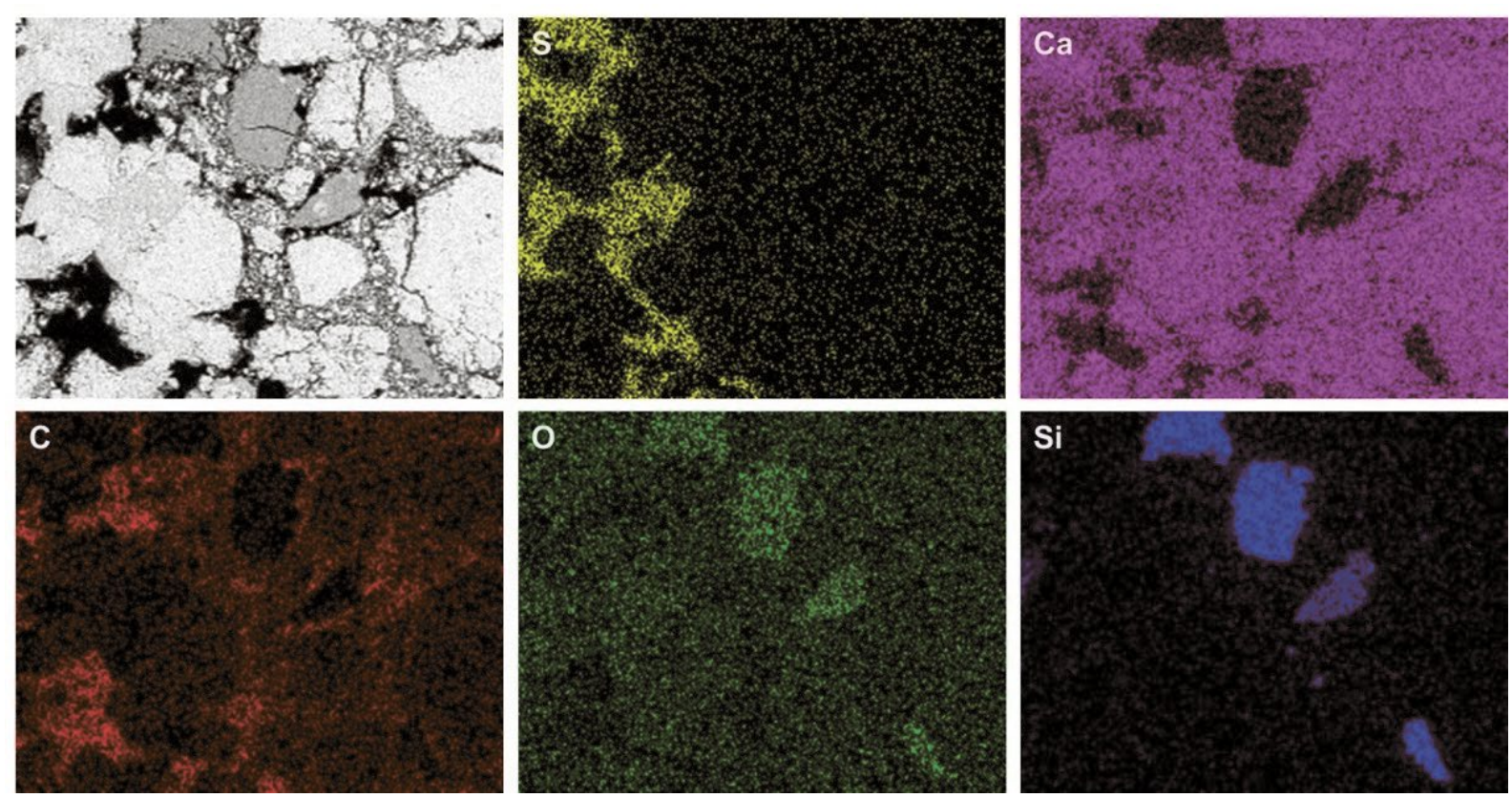

Figure 8-58: EDX mapping of the polished sample of the specimen PT15 (SA40 KM60) post free swelling test. Note: the width of an image corresponds to ca. $400 \mu \mathrm{m}$. 

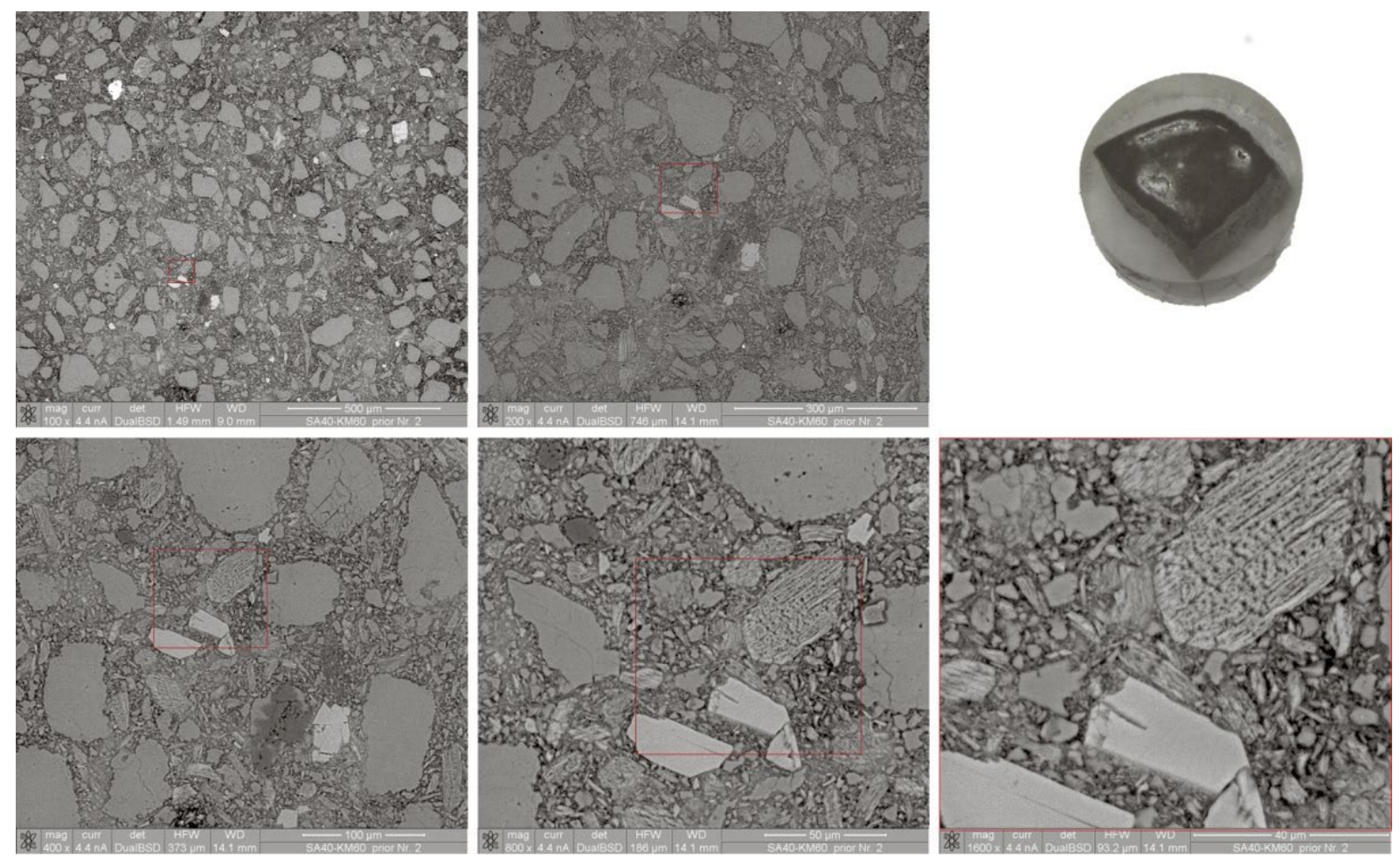

Figure 8-59: BSE images of the polished sample (shown right) of the specimen SA40 KM60 prior to swelling.
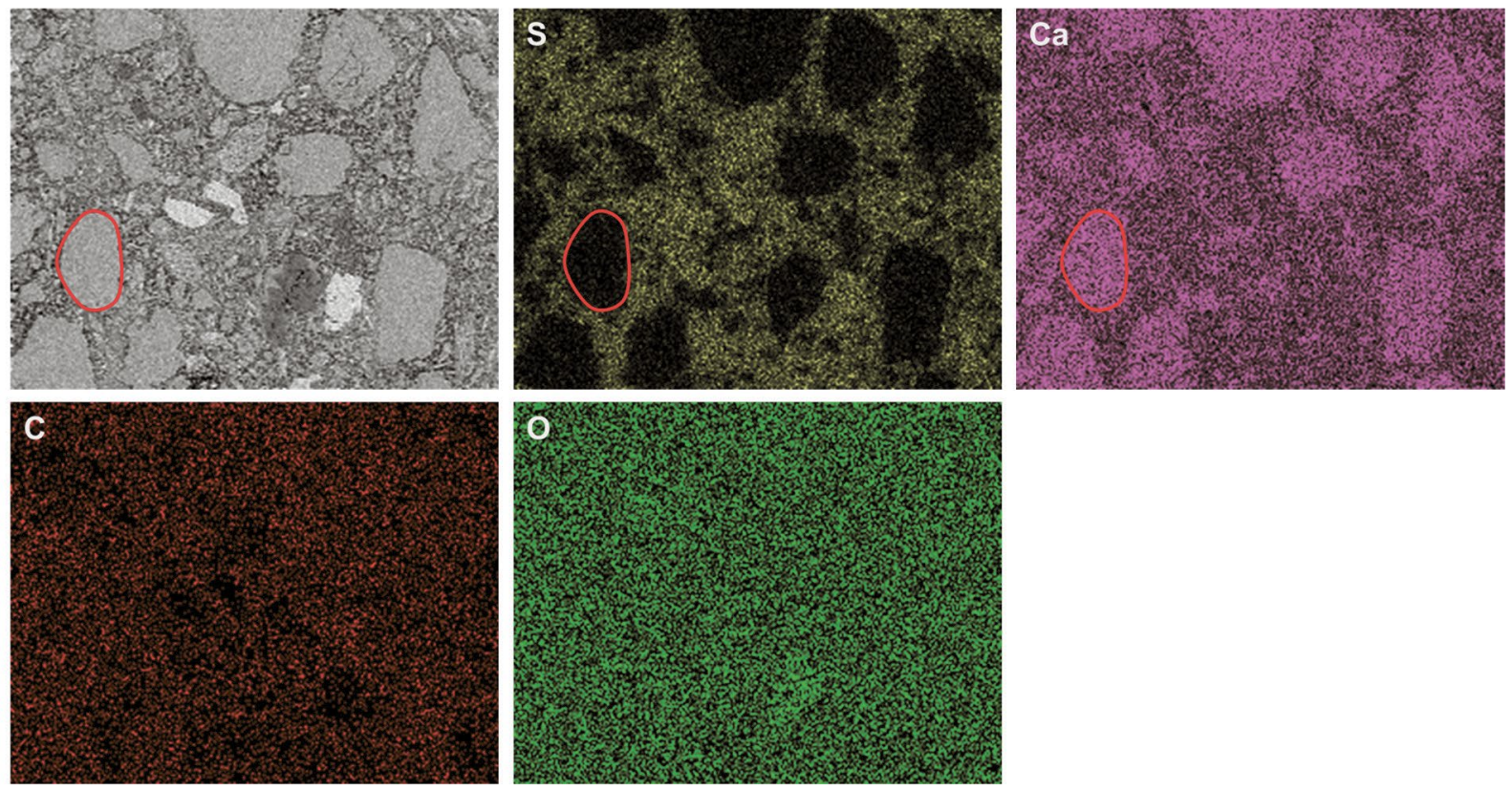

Figure 8-60: EDX mapping of the polished sample of the specimen SA40 KM60 prior to swelling. Note: the width of an image corresponds to ca. $400 \mu \mathrm{m}$.

The comparison of the specimen post swelling to that prior to swelling leads to the following observations: Prior to wetting, the sulfate seems to be finely distributed in the specimen, while larger inclusions of limestone particles exist, as exemplarily indicated by the red outline in Figure 8-60. This conclusion is drawn based on the fact that the same areas showing "holes" in the sulfur mapping, show higher calcium contents in the calcium mapping, thus most likely representing limestone particles. However, in the specimen post test the appearance is reversed: Here it seems that the sulfate (now mainly in the form of gypsum) is clustered and surrounded by the limestone (see the 
clearly defined main occurrence of sulfur in Figure 8-57 and Figure 8-58, an example of which is given by the red outline in Figure 8-57).

These observations correspond well to the expectations of an originally homogeneous specimen (with the anhydrite finely distributed within the specimen) after specimen preparation and the tendency to the formation of "clusters" of needles during gypsum precipitation due to the preferential precipitation on bigger gypsum crystals (Ostwald ripening phenomenon, cf. Brezesinski and Mögel, 1993, or Scherer, 2002, according to which small crystals dissolve and redeposit onto larger crystals). The spaces where the anhydrite dissolved remain as pore spaces post test (black patches in the top left images of Figure 8-57 and Figure 8-58 and corresponding higher amount of carbon, an example of which is given by the green outline in Figure 8-57).

\section{b. Oedometer tests}

As listed in Table 8-11, four specimens from the oedometer tests described in Chapter 8.5 were investigated microscopically post test. First, three specimens which were loaded with different axial stresses and seemed to have reached steady state were investigated and compared to one another, in order to observe the influence of the axial stress on the structure and pore space of the specimens:

- Oe_5_2 which was loaded with $800 \mathrm{kPa}$ and reached $\varepsilon_{a x, A G T}=10 \%$ and $\vartheta=85 \%$

- Oe_7_2 which was loaded with $1600 \mathrm{kPa}$ and reached $\varepsilon_{a x, A G T}=6 \%$ and $\vartheta=84 \%$

- Oe_6_2 which was loaded with $3200 \mathrm{kPa}$ and did not swell $\left(\varepsilon_{a x, A G T}=0 \%\right.$ and $\left.\vartheta=6 \%\right)$

Additionally, a specimen which swelled but did not reach steady state, and thus has a composition between those of Oe_5_2/Oe_7_2 and Oe_6_2 with respect to anhydrite and gypsum was investigated:

- Oe_5_4 which was loaded with $800 \mathrm{kPa}$ and reached $\varepsilon_{a x, A G T}=7 \%$ and $\vartheta=37 \%$

Further specimen properties and the testing conditions for these specimens can be found in Table J-3 in Appendix J.

In a first step, the surfaces of fragments of the three specimens that reached steady state under the above mentioned different loads (Oe_5_2, Oe_6_2 and Oe_7_2) were investigated with SEM (see Chapter 3.2). The images (SE and BSE) are shown in Figure 8-61, Figure 8-62 and Figure 8-63. In the latter two cases no clear image was obtained under low vacuum (which was the usual procedure), and, therefore, the samples needed to be coated with gold in order to investigate them under high vacuum. This does, however, not affect the sample structure and thus the signal from the BSE, while the signal from the SE is enhanced by the gold coating.

In Oe_5_2 (800 kPa, Figure 8-61) one can clearly see clusters of precipitated gypsum (probably in a crack of the specimen). In Oe_7_2 (1600 kPa, Figure 8-62) a single crystal was found (which is assumed to be anhydrite, based on the orthorhombic shape of the crystal and its size being smaller than $40 \mu \mathrm{m}$; the crystal is marked with an arrow in Figure 8-62). In Oe_6_2 (3200 kPa, Figure 8-63) neither anhydrite nor gypsum was distinguishable from the rest (i.e., no crystals could be identified).

When comparing the images of these three specimens, one can observe that there is a difference in the structure of the specimens: A lower axial load during the test leads to more, larger pores (caused by the crystal growth of gypsum needles), while the specimens exhibiting less or no swelling at all have a more homogeneous, compact matrix with less cracks. 

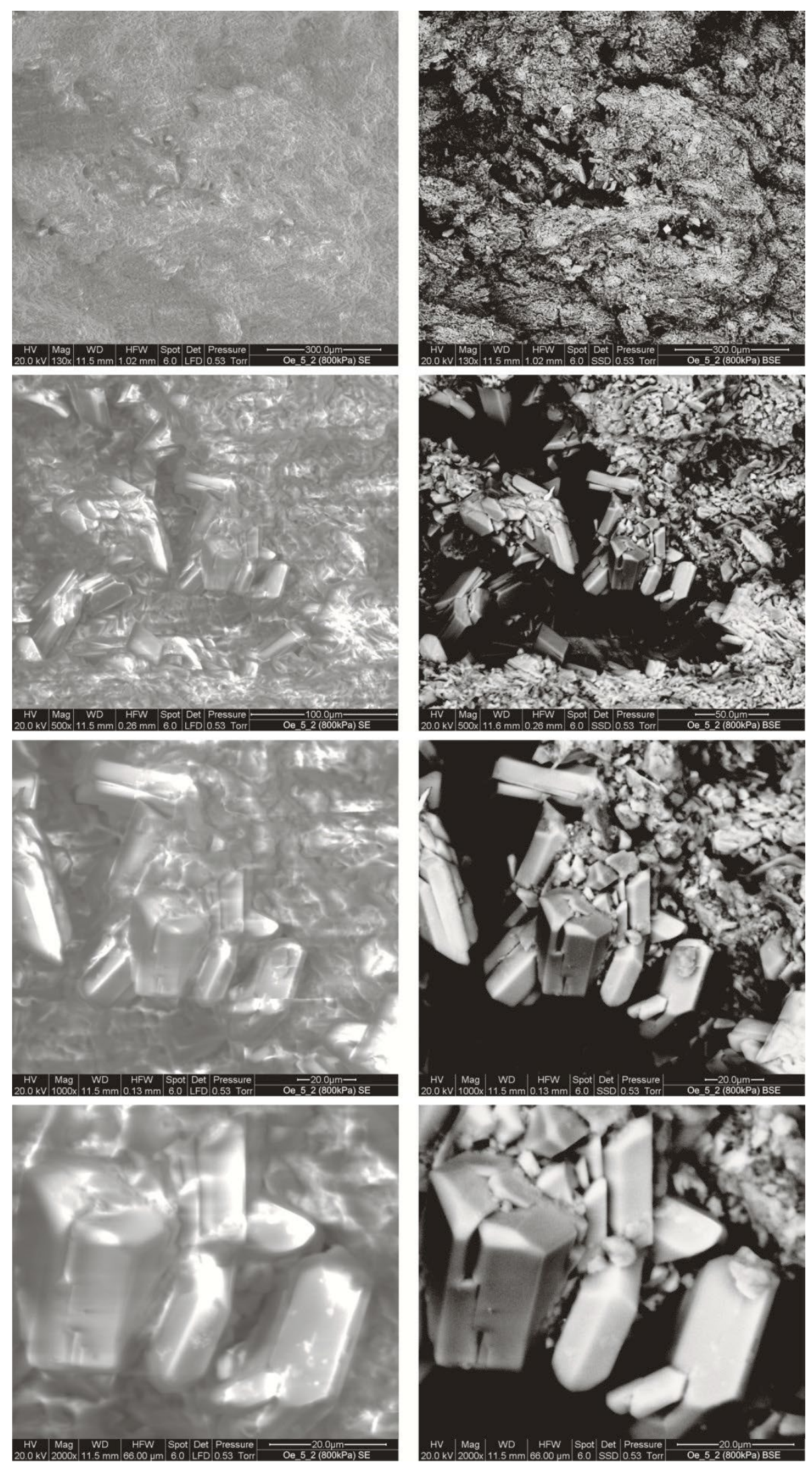

Figure 8-61: SE and BSE images of Oe_5_2 (800kPa). 

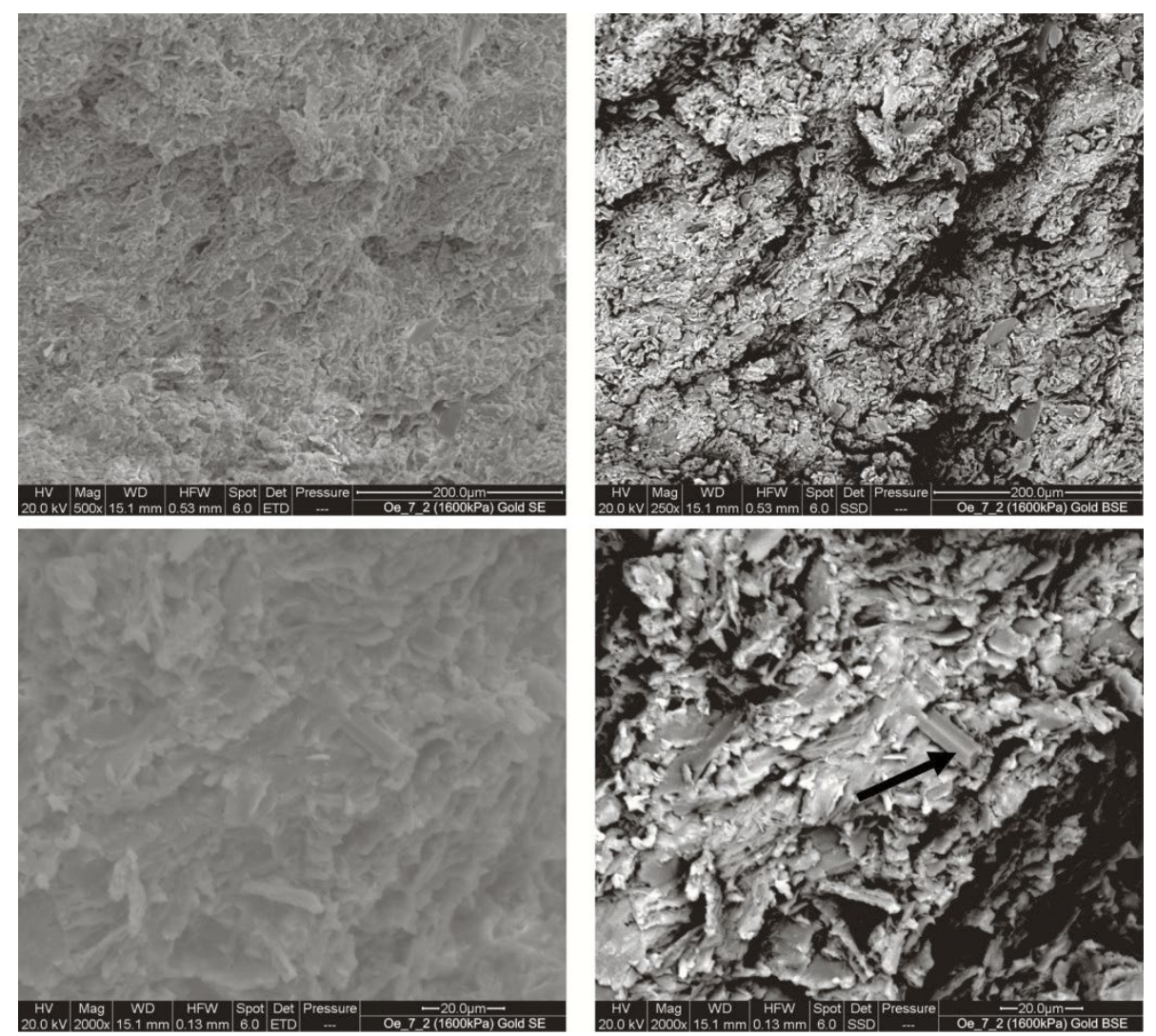

Figure 8-62: SE and BSE images of Oe_7_2 (1600kPa), coated with gold.
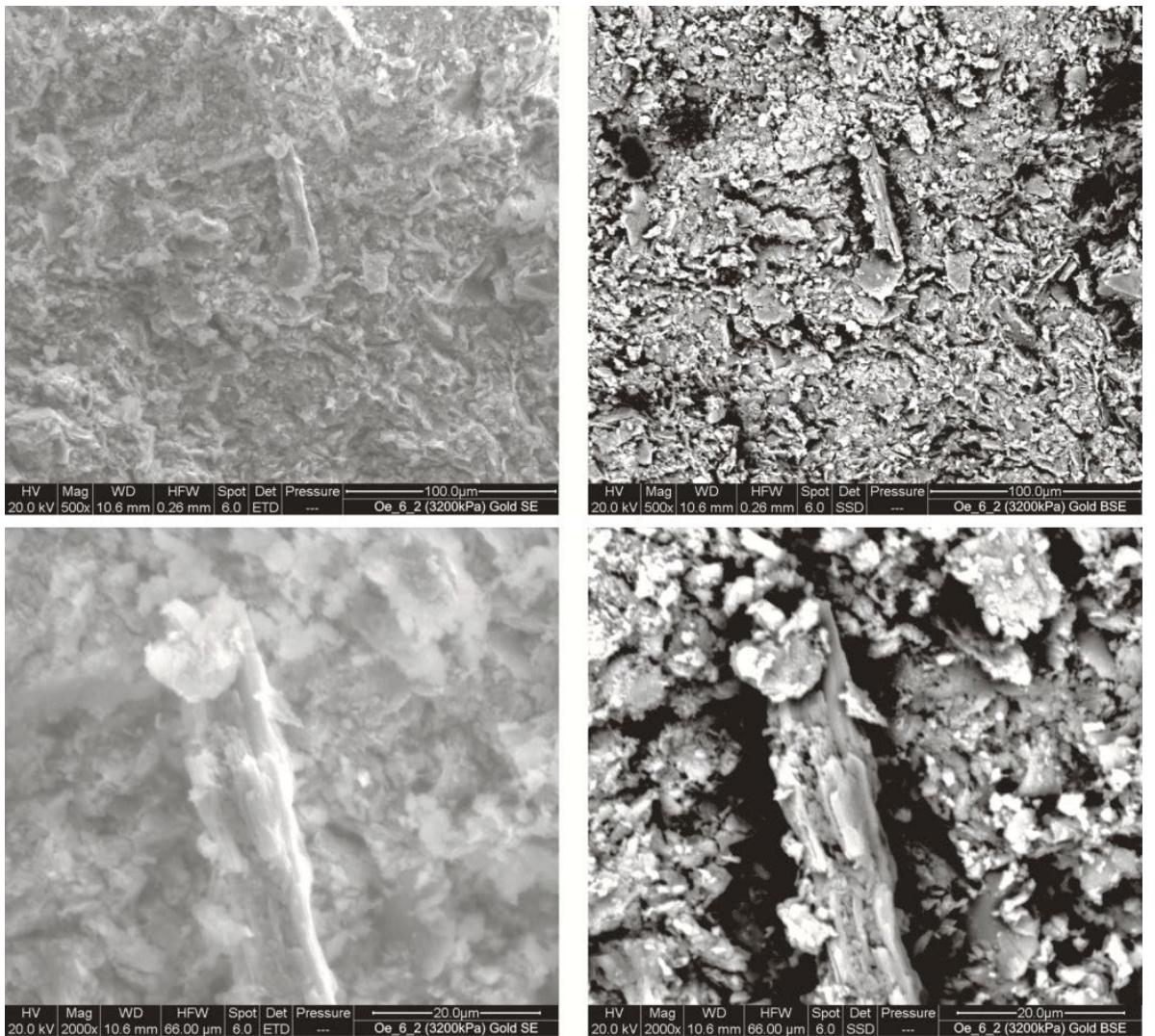

Figure 8-63: SE and BSE images of Oe_6_2 (3200kPa), coated with gold. 
In order to investigate the structural and compositional differences between the specimen Oe_5_2, containing far more gypsum than anhydrite ( $800 \mathrm{kPa}$ axial stress and $\vartheta=85 \%)$, and the specimen Oe_6_2 containing nearly no gypsum (3200 kPa axial stress and $\vartheta=6 \%$ ) optically more in depth, fragments of these specimens were embedded in epoxy and polished (see Figure 8-64). These polished surfaces were then investigated with an optical stereo microscope (Figure 8-65) and with SEM and EDX, and ultimately thin sections were made from them and investigated with a transmitted light microscope in polarized light mode.

A close up investigation of the polished surfaces with an optical microscope shows a clear difference in structure as well. As already anticipated from the previous SEM investigations, the specimen Oe_6_2 (Figure 8-65, right), which was subjected to higher pressure during the test and showed no signs of swelling, seems more homogeneous than Oe_5_2 (Figure 8-65, left), which experienced swelling and appears far more "weathered". The former also shows more rounded pores which are more easily identifiable (examples of which are indicated with "P" in Figure 8-65) as well as some very distinct white spots of (probably) clusters of anhydrite ("A"; the sizes of the clusters are up to roughly $500 \mu \mathrm{m}$, whereas the anhydrite powder had a maximal grainsize of $44 \mu \mathrm{m}$, see Figure 8-1). The latter (Oe_5_2) shows unevenly shaped pores and cracks, which in some cases are also assumed to contain gypsum crystals (“G”).

SEM and EDX investigations of the polished surfaces lead to the images in Figure 8-66. It can be seen that the specimen Oe_6_2 shows more lighter components compared to Oe_5_2 which indicate a higher content of elements of higher atomic number (anhydrite, $\mathrm{CaSO}_{4}$, is therefore a lighter shade of grey in BSE images compared to gypsum, $\mathrm{CaSO}_{4} \cdot 2 \mathrm{H}_{2} \mathrm{O}$ ), i.e., Oe_6_2 appears to have a higher content of anhydrite compared to gypsum, as was to be expected. However, anhydrite and gypsum cannot be distinguished more precisely (i.e., quantitatively) from one another with SEM and EDX, since they both contain the same elements (cf. sulfur mapping in Figure 8-66).
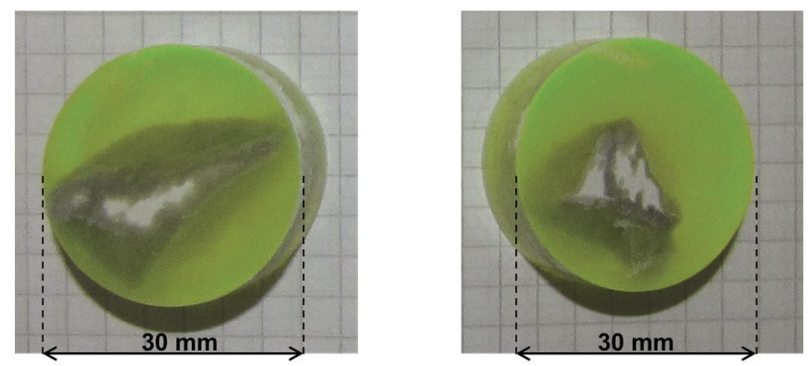

Figure 8-64: Embedded and polished specimens Oe_5_2 (800 kPa, left) and Oe_6_2 (3200 kPa, right). 

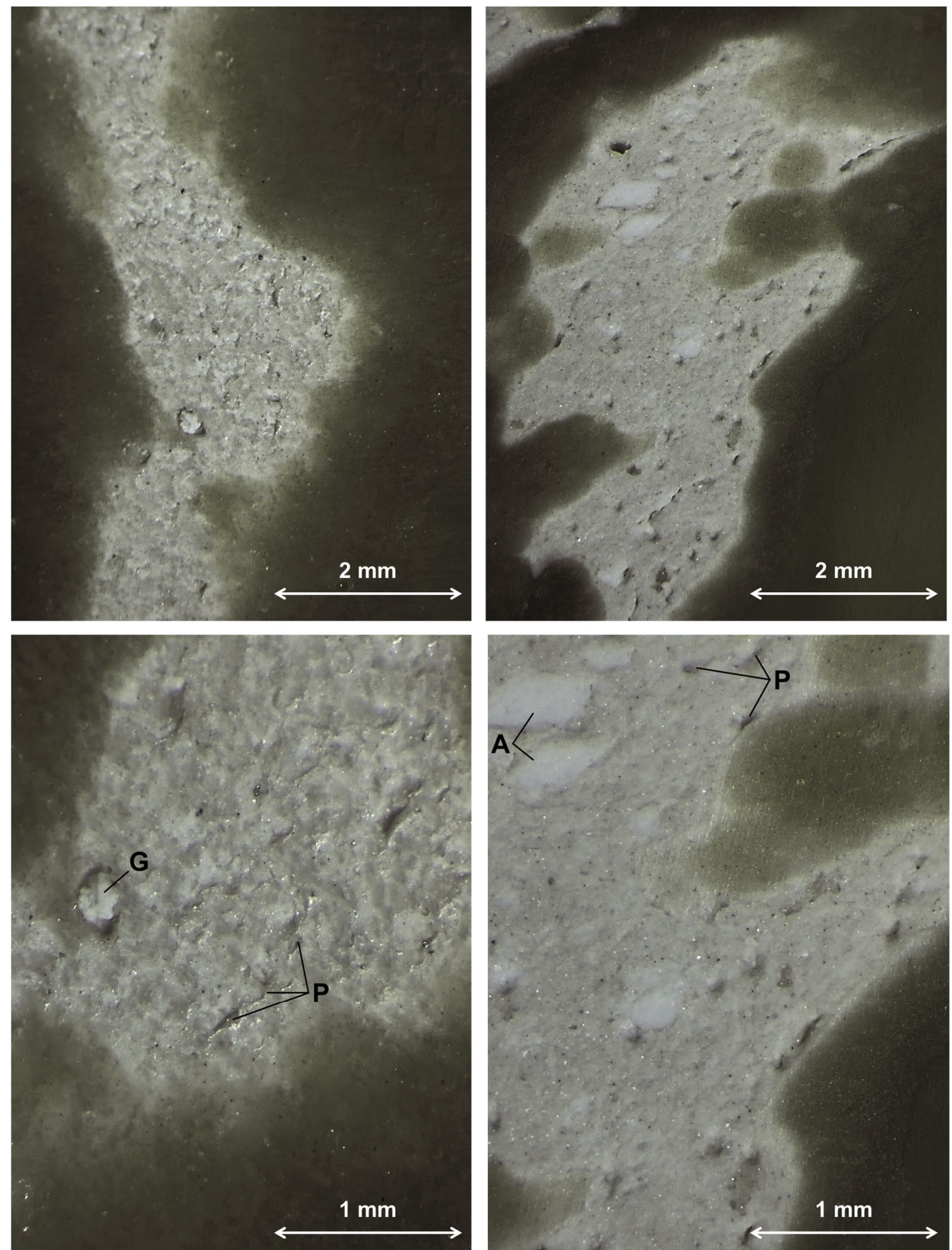

Figure 8-65: Embedded and polished samples from specimens Oe_5_2 (800 kPa, left) and Oe_6_2 (3200 kPa, right). 


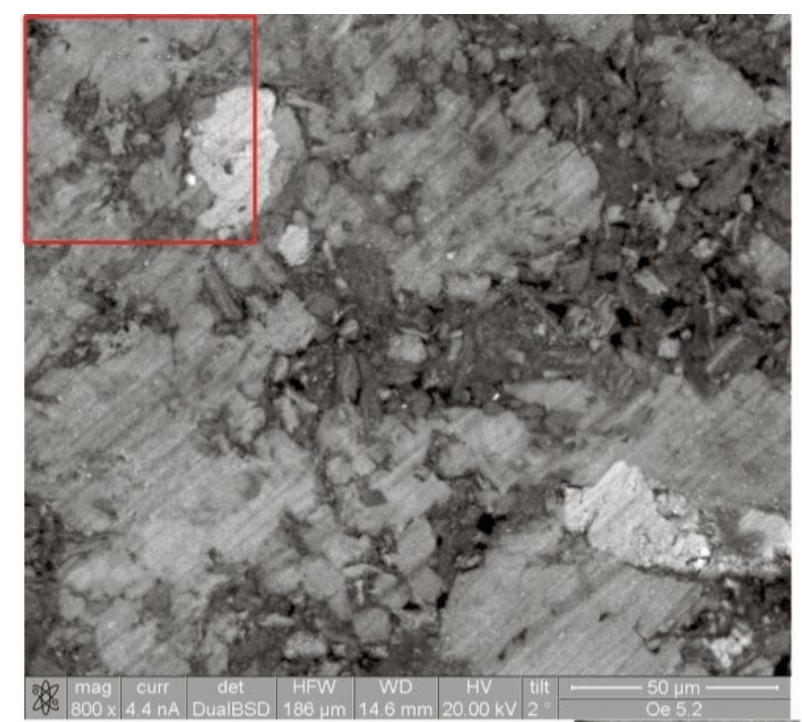

Interpretation

Medium grey: Gypsum

Light grey: Anhydrite

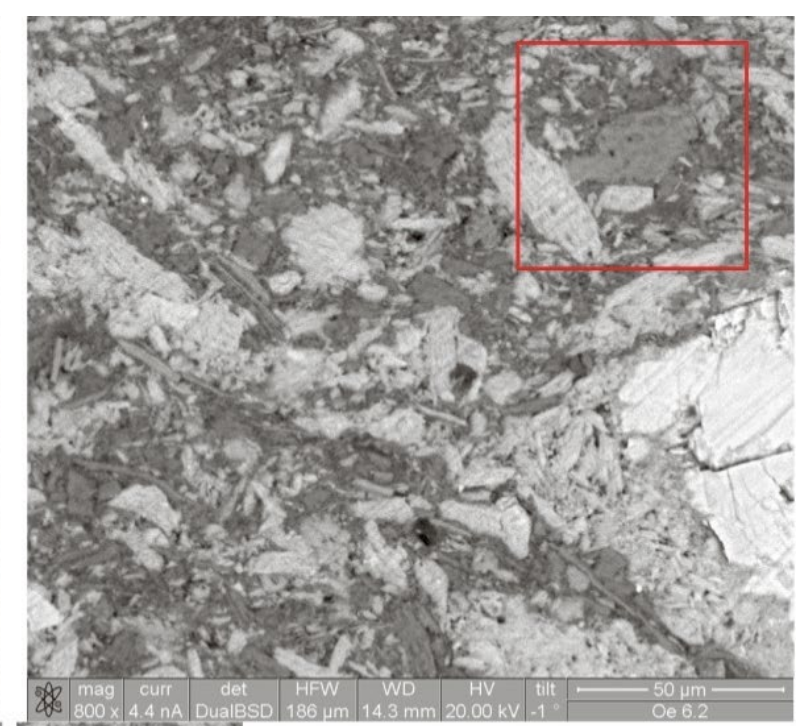

$\underline{\text { Interpretation }}$

Light grey \& white: Anhydrite
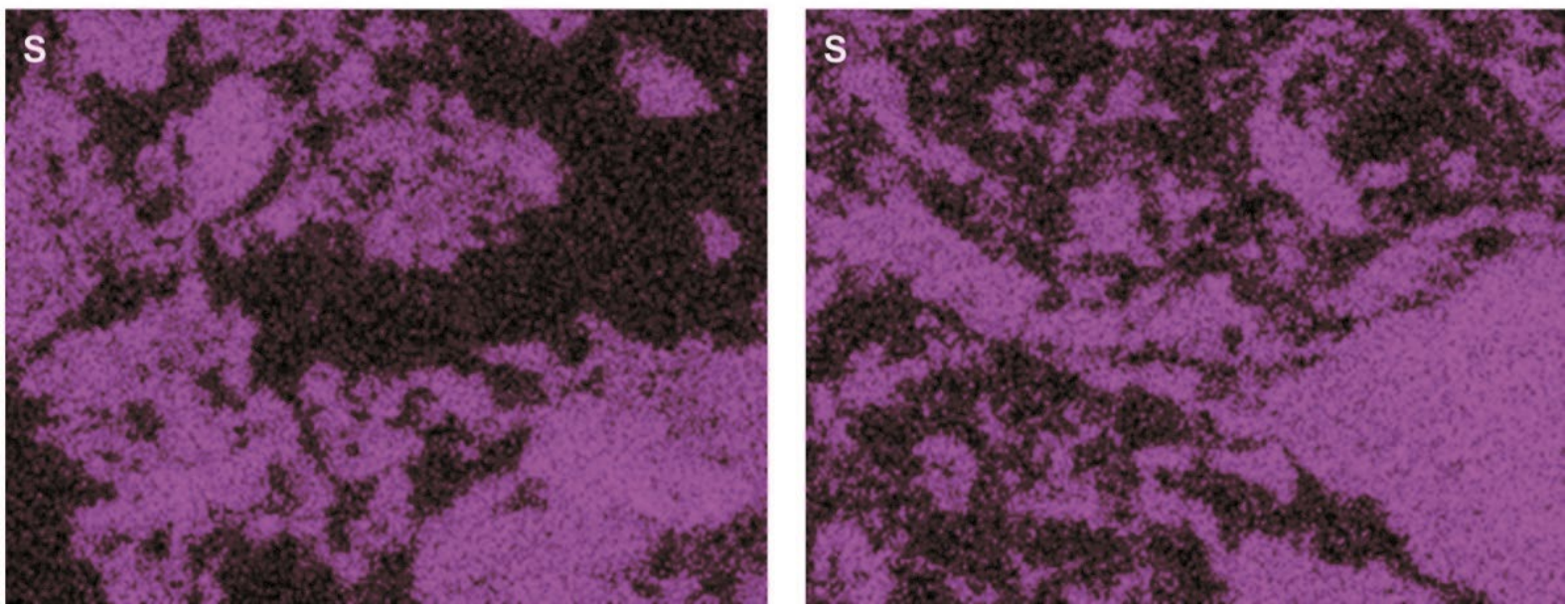

Figure 8-66: BSE images of embedded and polished samples from specimens Oe_5_2 (800 kPa, left) and Oe_6_2 (3200 kPa, right) and EDX mapping of sulfur.

In order to compare the two cases shown in Figure 8-66 with a specimen where AGT was partially progressed (as mentioned above, i.e., an "intermediary" specimen between Oe_5_2 and Oe_6_2), a fragment from the oedometer specimen Oe_5_4 (800kPa, $\vartheta=37 \%)$ was embedded and polished as well and observed with SEM and EDX (Figure 8-67). However, on a similar scale as used in Figure 8-66, the distribution of sulfur within the specimen appears very homogeneous (see Figure 8-67 bottom row), and no conclusions can be drawn regarding the distinction and distribution of anhydrite and gypsum within the specimen. 

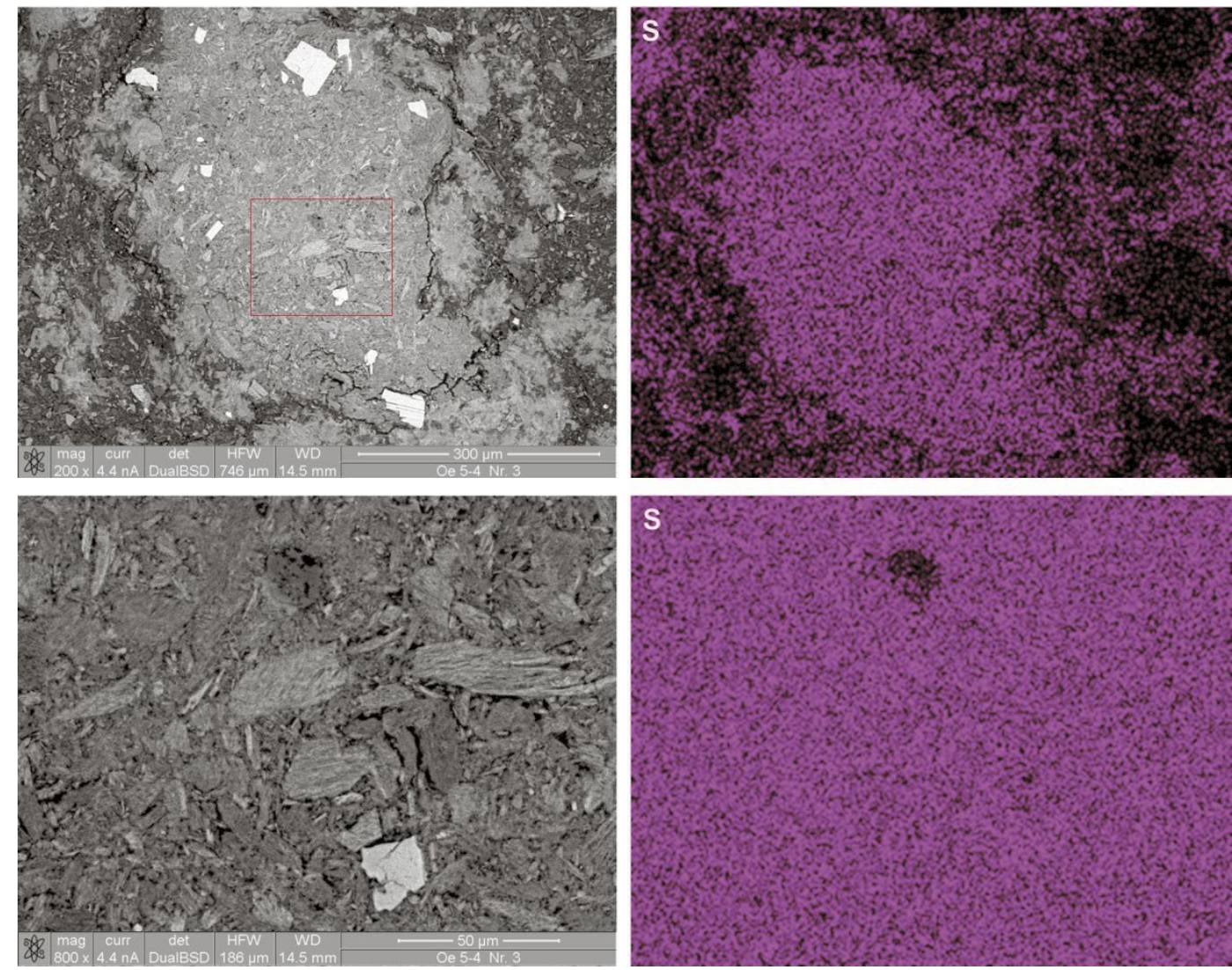

Figure 8-67: BSE images of embedded and polished sample of specimen Oe_5_4 (800 kPa, AGT 37\%) and EDX mapping of sulfur.

Furthermore, the thin sections obtained from the specimens Oe_5_2 and Oe_6_2 were analyzed with a transmitted light microscope in polarized light mode. The comparison of two images in Figure 8-68 shows that the right image (Oe_6_2) is composed of anhydrite crystals which can be distinguished by the higher birefringence. In the left image, gypsum crystals are observed as they have lower birefringence compared to anhydrite (Nesse, 1986).
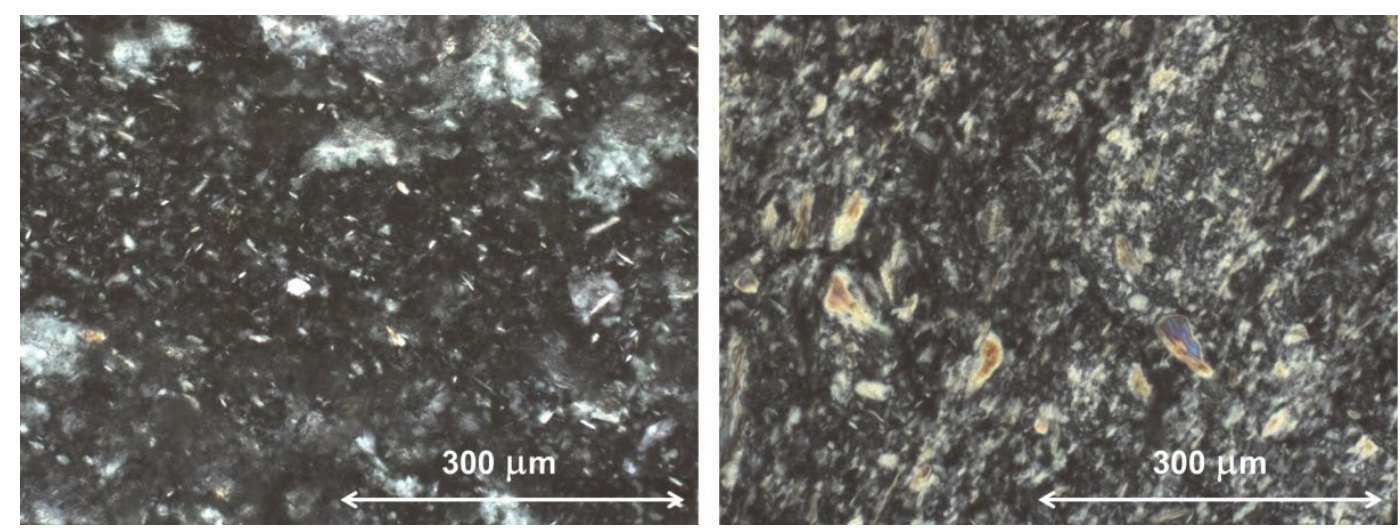

Figure 8-68: Images obtained from light microscopy in polarized light mode on thin sections of Oe_5_2 (800 kPa, left) and Oe_6_2 (3200 kPa, right). 


\section{c. Discussion}

The applied microscopic techniques allow an insight into the structures of the specimens and the distribution of anhydrite and gypsum within them.

In the case of the tests with limestone, a clear change in the structure and distribution of the elements within the specimens was observed prior and post free swelling test, even though no swelling strain occurred due to AGT. At first, larger clusters of limestone can be found within a homogenous, sulfatic (i.e., anhydritic) matrix, whereas post wetting clusters of sulfates (now gypsum) are found. Based on the results from porosimetry, the wetted specimen contains more large pores than prior to wetting. It appears that during anhydrite dissolution and gypsum precipitation a re-distribution of the components and of the pore space occurred, while the total volume of the specimen remained the same. The limestone may have created a "cementation" of the specimen when it was wetted (post test the specimen was very hard and intact in comparison to the specimens containing kaolin), which sufficed in strength for gypsum to precipitate preferentially in the pore space and first cracks which were created upon wetting (i.e., during the initial heave) rather than further expanding the specimen.

Also in the case of the tests with kaolin, it could be seen that gypsum tends to form within pore spaces and creates clusters of needles. At lower axial stress $(800 \mathrm{kPa})$ the structure of the specimen contains more, larger pores and appears more weathered compared to a specimen that was loaded with a higher stress (e.g., at $3200 \mathrm{kPa}$ ), though the change in pore size distribution prior to post test was less pronounced than in the case of the limestone specimens.

Concerning the composition of the specimens, the microscopic investigations were seen to give reliable qualitative information on the distribution of the sulfates in the specimens. With SEM the anhydrite may be qualitatively distinguished from gypsum in some cases by comparing the shades of grey. In a thin section image investigated with a transmitted light microscope, anhydrite and gypsum can be distinguished from one another by higher birefringence. With these methods it was seen that the anhydrite / kaolin specimen tested at $800 \mathrm{kPa}$ contained far more gypsum as opposed to the specimen tested at $3200 \mathrm{kPa}$ (which is consistent with the TGA results).

As mentioned above, only the described selection of specimens was investigated with microscopy. A more extensive and systematic series of microscopic investigations, where a large number of specimens are observed and compared with one another, was not performed within the scope of this thesis.

\subsection{Summary and conclusions}

The series of experiments described in this chapter are the first systematic investigations performed in a laboratory with the aim of obtaining a connection between the chemical reactions, specifically the change in mass of anhydrite, and the mechanical response due to the reactions, specifically the stresses and strains. For this, swelling tests under a variety of boundary conditions were performed.

Based on several preliminary swelling tests, it was decided to work with artificially created specimens containing $40 \%$ anhydrite and $60 \%$ kaolin. However, the results were seen to differ strongly from one another based on the source of the anhydrite: With usage of certain types, the swelling process took longer or did not even begin (see Chapter 8.4.3). By performing different analyses of the powders, it was generally seen, that the crystallite size, grain density and specific surface area 
of the grains appeared to influence the velocity of the swelling processes. However, the decisive reason for the different behaviors could so far not be determined.

Through simple oedometer tests with varying axial stresses, a clear semilogarithmic relationship could be established between the applied stresses and the developed axial strain - similar to the swelling law known to exist for clays ("Grob's law"; Grob, 1972, cf. Chapter 1.2). A dependency of the axial stresses on swelling strains was also seen for sulfatic specimens, e.g., by Sahores (1962), Kirschke (1996) or Pimentel and Anagnostou (2013).

The experiments with varying axial stresses also revealed that the duration of the swelling process is stress-dependent (i.e., at higher axial stresses the specimens took longer to reach an equilibrium), which was already seen by a number of authors (see Chapter 1.4).

The coupling parameters $\chi$, resp. $\chi_{a x}$ and $\chi_{\text {rad }}$ as defined in Chapter 7.1, were determined for four different types of mechanical boundary conditions. In all cases it was seen that the developing strains or stresses and the simultaneously reducing mass of anhydrite can be approximated by a linear relationship. Therefore, $\chi$ can be assumed to be constant for any given set of boundary conditions. However, in some cases $\chi, \chi_{a x}$ and $\chi_{\text {rad }}$ are strongly dependent on the elasticity parameters (Poisson ratio, Young's modulus). These values can change during swelling, especially in the case of high swelling strains at low stresses (cf. Pimentel, 1996). This can also be seen in the overview given in Figure 8-69, where all parameters obtained with the experiments described in this chapter are shown: Of the experiments with constant axial stresses, $\chi$ is bigger for smaller axial stresses (e.g., the oedometer tests with $3 \mathrm{kPa}$ axial stress revealed the highest value for $\chi$, while the oedometer tests and flexible oedometer tests with $800 \mathrm{kPa}$ axial stress revealed the lowest values). In the case of the complete constraint tests, where the axial stress was not constant, $\chi$ is smaller when the specimen is stiffer (which is also likely to change during the test and the increase in axial stress). It is only possible to further distinguish between $\chi, \chi_{a x}$ and $\chi_{\text {rad }}$ if the radial stresses are constant or can be measured, as was the case for the isotropic compression tests and the flexible oedometer tests.

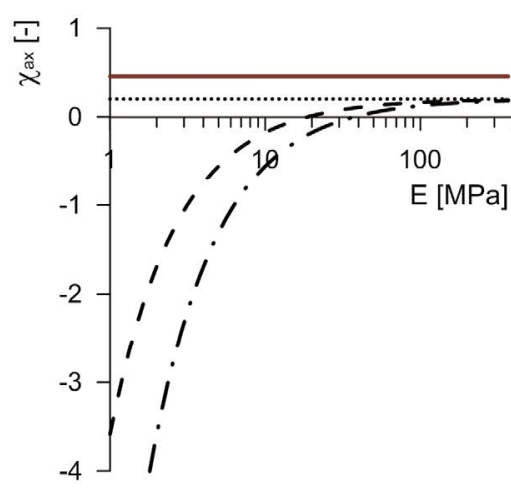

- Oedometer $\left(\sigma_{\mathrm{ax}}=3 \mathrm{kPa}\right)$

- Oedometer $\left(\sigma_{\mathrm{ax}}=800 \mathrm{kPa}\right)$

- Complete constraint

- Isotropic compression $(\sigma=250 \mathrm{kPa})$

- Flexible oedometers $\left(\sigma_{\mathrm{ax}}=800 \mathrm{kPa}\right)$
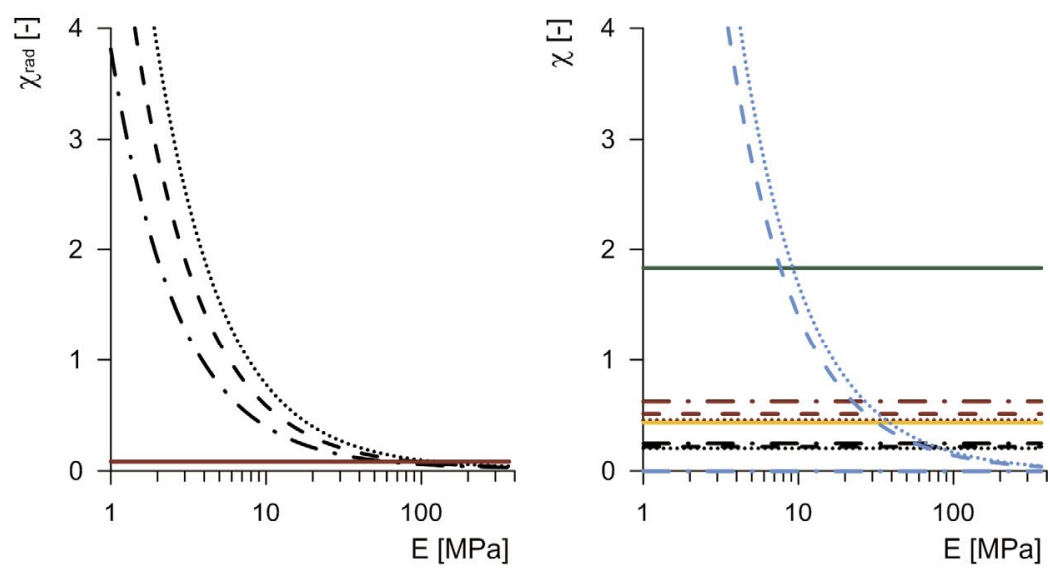

Dashes:

- Independent of $v$

….... $v=0$

- $-v=0.25$

-. $v=0.5$

Figure 8-69: $\quad$ Overview of all results for $\chi, \chi_{a x}$ and $\chi_{\text {rad }}$ as a function of the Young's modulus and Poisson ratio (when not independent of them, based on the individual mechanical boundary conditions). 
It needs to be noted that in the cases where $\chi$ appears to be independent of $E$ and / or $v$, this is only due to the fact that certain boundary conditions are constant in those individual cases (e.g., the axial stress or radial strain) and thus the respective equations to solve $\chi, \chi_{a x}$ and $\chi_{\text {rad }}$ lose the terms containing $E$ and / or $v$. As mentioned before, a lower stress acting on the specimen simultaneously decreases the stiffness of the swelling specimen (i.e., $E$ ) and - due to higher swelling strains - increases $\chi$.

In order to visualize a comparison of all experimental results from Chapters 8.5 to 8.8 , the volumetric strains and mean stresses are calculated for each experiment. Hereby it is assumed for the cases of the oedometer tests and complete constraint tests that the radial stress is equal to the axial stress (and thus also the mean stress), since the radial stress could not be determined during those experiments. The volumetric strains of the over 100 experiments in total are shown in dependence of the corresponding mean stresses in Figure 8-70. Furthermore, the shade of the symbols indicates the residual mass of anhydrite in each specimen at the point of extraction.

Two characteristics are noticeable in Figure 8-70, which would require further, longer experiments:

For one, the specimens loaded with mean stresses of 7 and $20 \mathrm{kPa}$ show lower strains than expected when looking at the maximal strains reached at other stresses. A repetition of tests at lower stresses (i.e., below $65 \mathrm{kPa}$ ) with the same mixtures is necessary in order to confirm that the semilogarithmic relationship between the maximal strains and the applied stresses is accurate (as appears to be the case when looking at the specimens loaded with $3 \mathrm{kPa}$ and $65 \mathrm{kPa}$ and above).

Furthermore, it becomes apparent that more residual anhydrite per unit volume remains within the specimens post test in the case of higher stresses (as opposed to lower stresses). On the one hand, the definition of $m_{A, \text { end }}$ itself can cause a slight difference, since it is dependent on the specimen volume (Equation (2 - 11)) which is naturally higher when larger strains occur (and thus $m_{A, \text { end }}$ is smaller, even if the same net mass of anhydrite is in the specimen). On the other hand it was seen that the AGT process was in fact slightly less progressed at higher stresses. This leads to the question, whether the specimens were extracted too soon, for example in the case of the oedometer test with 3.2 MPa axial stress (which was extracted after 80 days) AGT may still have occurred, or whether an equilibrium was reached, e.g., in the case of the complete constraint tests, whereupon AGT does not take place any further. Further tests should be considered at higher stresses and with longer durations, in order to investigate whether the AGT process can be completed in those cases.

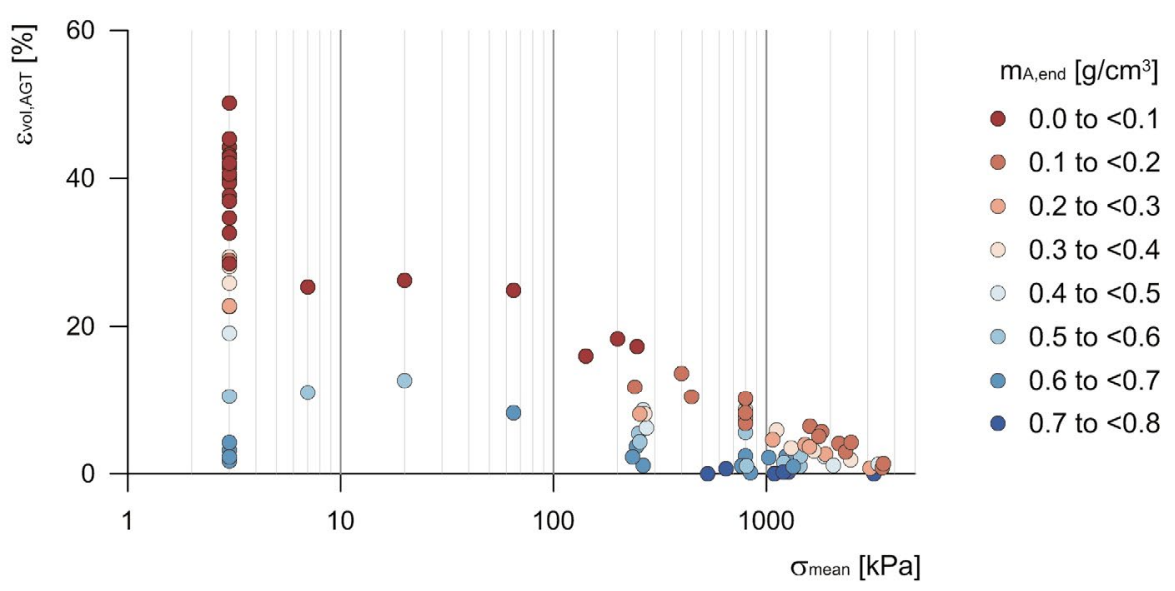

Figure 8-70: $\quad$ Volumetric swelling strains vs. mean stress and mass of anhydrite per unit volume post test for all specimens investigated in Chapters 8.5 to 8.8. 
One must keep in mind that all of these experiments were solely performed on artificially created specimens with powdered anhydrite and kaolin. As was seen, even then the swelling behavior can differ strongly depending on the anhydrite used. These experiments give a first indication of the connection between the AGT process and the developing strains and stresses for different boundary conditions. It was generally seen that a semilogarithmic relationship exists between the maximal strains and the stresses acting on the specimens, and that the stresses and / or strains develop nearly linearly with decreasing mass of anhydrite. It is, however, so far unsure, whether this behavior applies solely to artificially created specimens, or can also be applied to natural rock. Due to the far higher cohesion and tensile strength of natural rock, it is expected that cracking and creation of macropores (and thus the swelling behavior) has a different stress-dependency in the case of natural rock (cf. Pimentel, 2007a) as opposed to compacted specimens. For future experimental investigations with artificially created powdered samples it may be of interest to use dispersants known from cement grinding for the compaction of the samples. The dispersants change the interparticle forces and enable a better compaction, increase the density of the samples and possibly increase the tensile strength of the compacted samples (Flatt and Wangler, 2019, personal communication).

Nevertheless, the experiments performed within this research project help to give an understanding of the connection between the strains and stresses occurring due to anhydrite dissolution and gypsum precipitation and enable a first quantification of the introduced chemo-mechanical model for certain boundary conditions. 



\title{
PART IV \\ NATURAL ROCKS - INFLUENCE OF CLAY
}

\begin{abstract}
When natural anhydritic claystones come into contact with water, the rock swells due to physical and chemical processes: reduction of negative pore water pressure (mechanical swelling), osmotic swelling of clay (due to electric forces) and swelling due to anhydrite to gypsum transformation (AGT). So far it is unknown to which extent each of these processes contributes to the observed swelling of the rock and how they influence one another.

In an experimental campaign performed within this thesis, multiple free swelling tests with rock from the Gypsum Keuper formation were conducted to study the simultaneously occurring swelling processes. AGT can be suppressed when the rock is wetted at temperatures above $50{ }^{\circ} \mathrm{C}$. By letting the specimens swell at different temperatures, it was thus possible to observe the physical swelling (osmotic and mechanical swelling) alone, as well as the combined swelling due to both physical and chemical processes. It was seen that the clay and mechanical swelling occur nearly instantaneously upon wetting, whereas swelling due to AGT can take years to complete, even when the rock is not confined. Furthermore, AGT swelling was strongly decelerated when the rock was wetted at warmer temperatures at first (i.e., above $50^{\circ} \mathrm{C}$ ). Finally, the structure and water chemism of some selected specimens was investigated more closely.
\end{abstract}





\section{Introduction}

When investigating swelling anhydritic claystones, two swelling processes can be identified that can occur simultaneously: Physical swelling, which comprises of mechanical swelling due to water intake and reduction of negative pore water pressure as well as osmotic swelling of clay, and chemical swelling due to anhydrite to gypsum transformation (AGT). When rapid swelling occurs in tunnels (e.g., during construction of the Chienberg Tunnel, in Switzerland), it is presumed that this is mainly caused by the clay, whereas long-term swelling is more likely to be caused by the anhydrite, since AGT is a far slower process (Anagnostou et al., 2010). The conceptual diagram in Figure 9-1 shows the respective swelling strains $\varepsilon_{\text {mech }}, \varepsilon_{c l a y}$ and $\varepsilon_{A G T}$ (which were also described in Chapter 8.3.3), for the case of free swelling (no stress acting on the rock, therefore, no dry settlement occurs). Here, the clay matrix and the reduction of negative pore water pressure (which cannot be distinguished from one another) contribute to a comparably rapid swelling strain $\left(\varepsilon_{I}\right)$ while the hydration of anhydrite in the rock (which causes the strain $\varepsilon_{A G T}$ ) is a far slower process. The strains due to AGT are caused by a change in solid volume $\left(\varepsilon_{\Delta V_{A, G}}\right)$ and a change in pore volume $\left(\varepsilon_{P}\right.$, which includes new cracks that may occur, cf. Chapter 1.4.5).

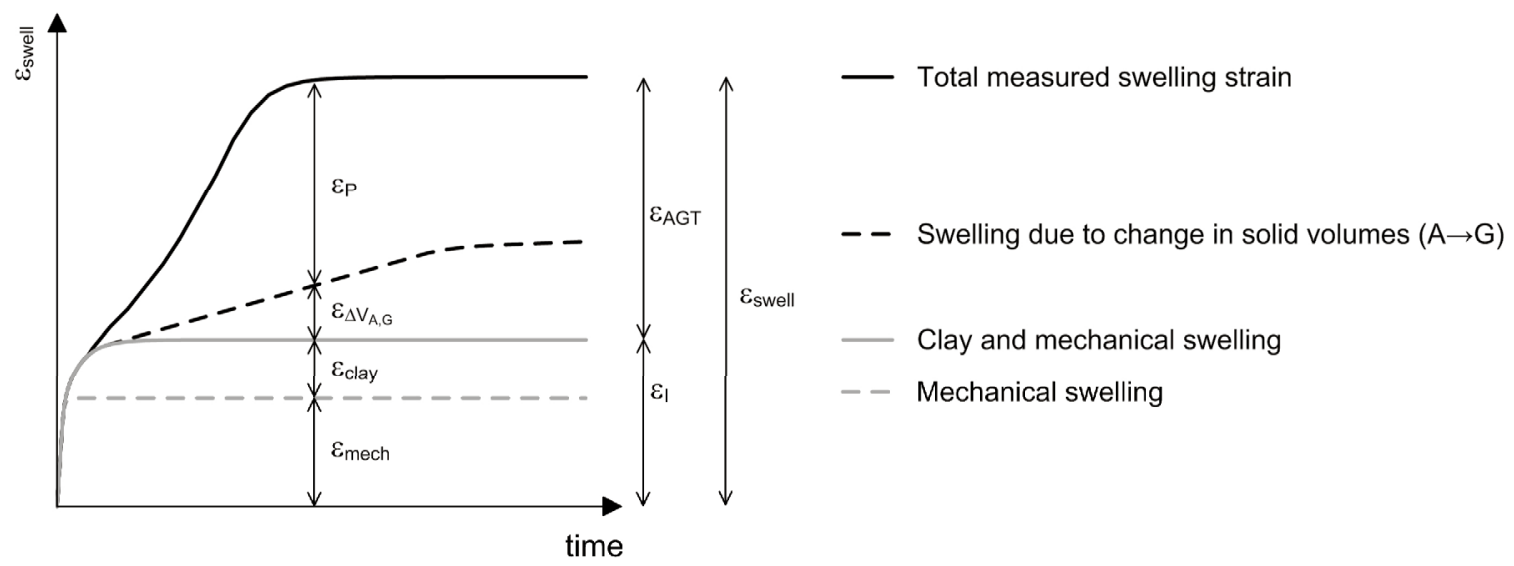

Figure 9-1: Conceptual graph of total swelling strain and possible corresponding amount of swelling strain due to physical and chemical swelling.

It is so far not known to which extent the clays and the anhydrite swell individually and how they influence one another. The quantification and distinction of the physical swelling of the clay and the chemical swelling due to the anhydrite in natural rock is of interest (indicated figuratively in Figure 9-1), in order to obtain a better understanding of the underlying processes for the modelling of anhydritic swelling claystones. The investigations described here aim at distinguishing these individual swelling processes from one another.

First (in Chapter 10), the properties of clay and the processes leading to physical swelling of the matrix surrounding anhydrite (i.e., clay and mechanical swelling) are described, followed by a discussion about two factors governing AGT in natural rock: the temperature and the pore water activity. In order to determine the soil-water potential of the rock, the suction of some rock specimens was measured with a psychrometer.

In Chapter 11 the results of swelling experiments which aim at distinguishing the swelling processes from one another are presented and discussed. Free swelling tests (i.e., without any confining stress) on natural rock specimens from the Gypsum Keuper of the Belchen Tunnel were performed, as well as oedometer tests (with an axial load of $3 \mathrm{kPa}$ ) on artificial specimens which were compacted with milled material from the same rock. The swelling tests were conducted at room 
temperature and in an oven at $50^{\circ}-52^{\circ} \mathrm{C}$. At this (higher) temperature, the equilibrium concentration of gypsum is marginally higher than that of anhydrite (see Figure 2-1) and it is thus theoretically possible to prohibit AGT. Therefore, the swelling deformation measured in the oven is attributed solely to (physical) swelling of the clay matrix and the amount of swelling due to AGT and due to clay can be distinguished from one another in the described experimental results.

Following the swelling tests, selected specimens were investigated microscopically and the chemism of the used water was analyzed. 


\section{Swelling processes}

\subsection{Physical swelling}

\subsubsection{Swelling of clay}

In mineralogy, clay minerals are phyllosilicates with a crystal structure consisting of layers of bonded tetrahedral and octahedral sheets, either 1:1, or 2:1 if an octahedral sheet is bound between two tetrahedral sheets (cf., e.g., Meunier, 2005, Jasmund and Lagaly, 1993, Mitchell, 1993, Sposito et al., 1999 etc.). The 1:1 layers (e.g., kaolinite) are electrically neutral and are held together by hydrogen bonds and van-der-Waals interaction (Jasmund and Lagaly, 1993). Of the 2:1 layers, some are electrically neutral (e.g., talc), most, however, possess a negative charge due to isomorphic substitution on the octahedral and/or tetrahedral sheets, which increases the thickness of the layer (e.g., montmorillonite). Isomorphic substitution is widely considered insignificant in the case of kaolinite, since merely the ions on the outer surface of the silicate sheets can be substituted and the specific surface area of kaolinite with ca. $10 \mathrm{~m}^{2} / \mathrm{g}$ is far lower than that of, e.g., montmorillonite which is ca. $800 \mathrm{~m}^{2} / \mathrm{g}$ (cf., e.g., van Olphen and Fripiat, 1979, Meunier, 2005 etc.). This leads to a lower cation exchange capacity (CEC) of the 1:1 layered minerals compared to the 2:1 layered minerals; e.g., the CEC of kaolin is 1-10 meq / $100 \mathrm{~g}$ (cf., e.g., Weiss, 1958, van Olphen and Fripiat, 1979, Meunier, 2005) whereas the CEC of montmorillonite is 70-120 meq / $100 \mathrm{~g}$ (Jasmund and Lagaly, 1993, van Olphen and Fripiat, 1979, Meunier, 2005).

In the case of 2:1 layers with positive charge deficiency due to isomorphic substitution, water can be adsorbed between the sheets due to hydration of the interlayer cations (creating the "Sternlayer"). Up to four layers of water molecules are adsorbed stepwise within the sheets, where (in the case of montmorillonite) the clay platelets can double their volume (the sheet distance can increase up to $20 \AA$ ). This causes "microscopic" swelling whereas the swelling pressure (under confined volume) can exceed 100MPa (Jasmund and Lagaly, 1993). This swelling process usually already occurred in natural claystones, which is why engineers are not confronted with such high swelling pressures (Jasmund and Lagaly, 1993).

When the distance between the silica sheets exceeds $20 \AA$, the cations between the sheets form a diffuse double layer. Two opposing forces are then acting on the silica sheets: electrostatic repulsion (by the diffuse double layer) and Van der Waals attraction. This interplay between the opposing forces is described by the DLVO theory (named after the researchers Derjaguin and Landau, 1941, and Verwey and Overbeek, 1948; see also, e.g., Atkins and De Paula, 2006). Due to a concentration gradient between the ionic concentration in the diffuse ionic layer and the surrounding pore water, further water molecules are attracted (in the case of hydrated 2:1 layered minerals) causing osmotic swelling which is the main swelling process of clays observed in tunneling (cf., e.g., Madsen, 1976 and Madsen and Nüesch, 1991). This attraction of water molecules, an osmotic process, leads to an increase in the distances between the silica sheets, or to a repulsive force between them, i.e., the swelling pressure.

The temperature at which clay is wetted has a slight influence on the occurring swelling strains. This was investigated, e.g., by Villar and Lloret (2004) and Villar et al. (2010), who varied the temperature of water with which compacted bentonite (density of $1.6 \mathrm{~g} / \mathrm{cm}^{3}$ ) was wetted. Especially at low vertical loads (i.e., $0.5 \mathrm{MPa}$ ) they observed drop in vertical swelling strain from ca. $23 \%$ to $6 \%$ when increasing the temperature from $30^{\circ} \mathrm{C}$ to $80^{\circ} \mathrm{C}$. At $50{ }^{\circ} \mathrm{C}$ (which is the temperature used 
in the experiments described later in this chapter), the corresponding swelling strain measured was $18 \%$. These and further results of tests performed on compacted Boom clay (main components: illite, kaolinite, smectite and quartz) are also shown in Romero et al. (2005), where the swelling strains occurring at $22{ }^{\circ} \mathrm{C}$ were seen to be lower than at $80^{\circ} \mathrm{C}$. However, Pusch et al. (1990) investigated the swelling pressure of compacted $\mathrm{Na}$-montmorillonite at different densities and saw that the influence of temperature mainly affects specimens with a density below $1.8 \mathrm{~g} / \mathrm{cm}^{3}$. It is therefore assumed here that the difference in applied temperature (i.e., $20^{\circ}$ or $50^{\circ} \mathrm{C}$, see Chapter 11) does not influence the swelling behaviour of natural rock (density of $2.3-2.6 \mathrm{~g} / \mathrm{cm}^{3}$ ) significantly.

Furthermore, most existing research on the influence of temperature on the clay (at a temperature range below $100{ }^{\circ} \mathrm{C}$ ) focus on thermally induced strains (usually below $1 \%$ ), the development of the pore pressures and variation of fluid viscosity which also affect the mechanical behavior (e.g., Hueckel and Baldi, 1990, Tang et al., 2008, Delage et al., 2010, Delage, 2015, Bossart et al., 2017). The thermally induced strains are negligible in comparison to the swelling strains presented within the scope of the investigations herein.

\subsubsection{Mechanical swelling}

Rocks in an undisturbed state, such as prior to excavation or - in the case of bore cores - after storage for a long period of time at constant temperature and relative humidity are in a state of thermodynamic equilibrium. When wetted, the degree of saturation of the rock increases, which leads to a reduction of negative pore water pressure and thus (due to a decrease in effective stresses) to a decompression of the rock specimen, causing a rapid swelling strain which is referred to here as "mechanical swelling" (cf. Pimentel, 2015).

\subsection{Chemical swelling due to AGT}

In order for AGT to occur, the equilibrium concentration of anhydrite needs to be higher than that of gypsum. As discussed in Chapter 2.2.3, multiple factors influence the equilibrium concentrations, such as the water activity, pore water pressure and in situ stress, the amount and type of salts in the pore water, the pore sizes, the temperature etc. (cf. also Serafeimidis and Anagnostou, 2014a and 2014b, Anagnostou et al., 2014). In this chapter, two factors are further discussed: the influence of the temperature (with which the AGT process can be prohibited or triggered, see Chapters 10.2.1 and 11.2.3) and influence of the water activity (which in the case of partially saturated rocks can be the reason for anhydrite to be the stable phase, see Chapter 10.2.2).

\subsubsection{Influence of the temperature}

The equilibrium concentrations (especially that of anhydrite) are strongly dependent on the temperature. This was previously discussed in Chapter 2.3.1, where the relationship between the temperature and the equilibrium concentrations was computed for the case of laboratory conditions. It can be seen that - at atmospheric pore pressure and water activity equal to $1-$ the equilibrium concentration of gypsum exceeds that of anhydrite above ca. $49^{\circ} \mathrm{C}$. This point is referred to as transition temperature, and at temperatures above that point AGT does not occur (see Chapter 2.3.1). However, mechanical and clay swelling are hardly affected at such temperatures (as indicated above), and are therefore the only swelling processes which will occur when a specimen containing anhydrite and clay is wetted. Therefore, higher temperatures can be used to decouple the swelling processes, which was also applied in the research of Flatt et al. (2017) 
(see Chapter 1.4.9), where they used the change in temperature to investigate whether applied swelling inhibitors worked. The influence of higher temperatures on the swelling processes is examined with swelling tests in the laboratory in the next Chapter (11).

\subsubsection{Influence of the water activity}

The thermodynamic equilibrium of rocks in their undisturbed state can hold AGT at bay, since the activity of the pore water in the rock (which is defined as the ratio between the acting partial vapor pressure and the standard state partial vapor pressure, see Chapter 2.3.2) is considerably smaller than 1 due to the low water potential of the partially saturated or nearly completely dry state of the rocks in situ, as was described in Chapter 2.3.2 (see Figure 2-3). In order for AGT to occur, the activity of the pore water needs to increase towards 1 , i.e., the clay matrix needs to absorb water (by mechanical swelling due to reduction of negative pore water pressure and by osmotic swelling) thus enabling so called free water (water with an activity $a_{W}$ closer to 1) to come into contact with the anhydrite particles and dissolve these.

As a verification of the relationship between the water activity (i.e., relative humidity the rock was subjected to) and the pore water potential according to the Kelvin equation (cf. Equation (2 - 20)) for rocks from anhydritic claystones, suction measurements were performed on rock specimens from Gypsum Keuper (from the Belchen, Chienberg and Bözberg tunnels in Switzerland). The specimens were stored at various pre-defined relative humidities ( $\mathrm{RH}=40 \%, 65 \%, 80 \%$ and $95 \%)$.

The suction measurements have been made with a chilled-mirror psychrometer (WP4 Dewpoint PotentiaMeter by Decagon Devices Inc., 2003). The psychrometer measures the sum of the osmotic and matric potentials of a specimen (hereafter referred to as water potential) by means of the dew point technique, i.e., by equilibrating the liquid phase of the pore water with the vapor pressure of the water in the air space above the specimen. The mirror in the air space is cooled and thus the temperature at which dew is formed on the mirror is detected. Both the dew point and soil specimen temperature are then used to determine the relative humidity above the soil specimen within the closed chamber (see, e.g., Decagon Devices Inc., 2003, Blight, 2013, Tarantino et al., 2009, Fredlund and Rahardjo, 1993, Bulut and Leong, 2009, Woodburn et al., 1993).

The specimens were cut into small pieces (max. dimensions of $35 \mathrm{~mm}$ in diameter and $5 \mathrm{~mm}$ in height), in order to fit into the specimen holder of the psychrometer. Prior to specimen preparation the specimens were stored in plastic bags (most under vacuumed conditions). Specimen preparation and the first measurements occurred at non-controlled conditions prevailing in the laboratory, i.e., at temperatures ranging from $18-25^{\circ} \mathrm{C}$ and the relative humidity was assumed to be $40 \%$ ( $\mathrm{RH} 30-50 \%$ ). Each specimen was weighed, tested in the psychrometer twice, and weighed again. Then seven specimens were stored in a conditioned room at $20{ }^{\circ} \mathrm{C}$ and $65 \% \mathrm{RH}$ for $\mathrm{ca}$. six months and then at $80 \% \mathrm{RH}$ for one month, while eight specimens were stored at $20{ }^{\circ} \mathrm{C}$ and $95 \% \mathrm{RH}$ for ca. eight months. After storage, they were weighed and measured again with the psychrometer.

Figure 10-1 shows the relationship between the activity of the pore water (resp. the relative humidity) and the water potential, calculated according to the Kelvin Equation (2 - 20), as well as the experimental results from the psychrometry measurements (average value for each specimen). 


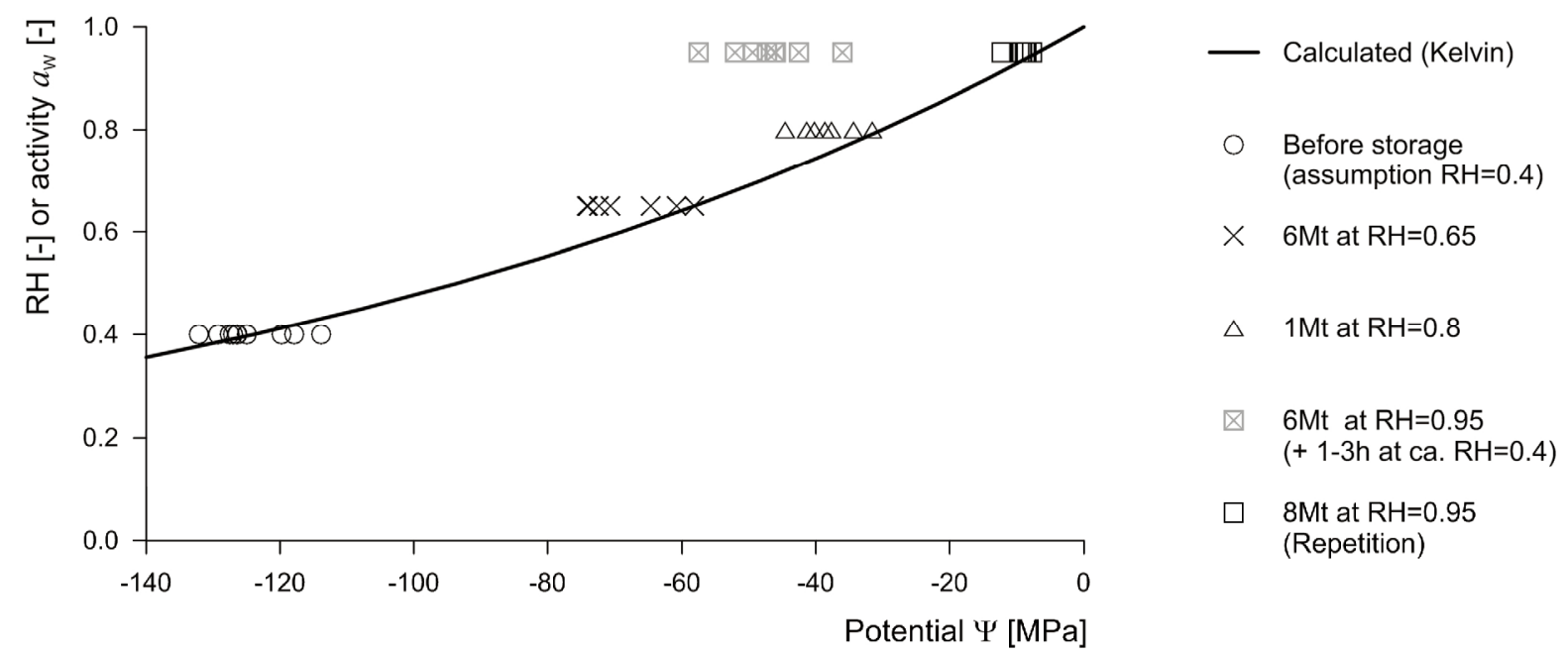

Figure 10-1: $\quad$ RH resp. pore water activity vs. water potential: calculated relationship according to Kelvin and measured values.

It becomes apparent that the measured values after storage of the specimens at $40 \%, 65 \%$ and $80 \% \mathrm{RH}$ correspond to the calculated curve. The first measurements taken on specimens stored at $95 \% \mathrm{RH}$ (during ca. 6 months, see light grey squares with crosses in Figure 10-1) showed slightly higher suction pressures than expected. It was seen that this was due to the fact that the time between removing the specimens from the $95 \% \mathrm{RH}$ storage room and performing the actual psychrometry measurement (which was performed under normal room conditions), i.e., 50200 minutes, sufficed for the specimens to dry out again and thus to increase the suction (even though they were kept in a closed plastic bag to minimize this effect). In order to prevent this, a special small environmental chamber was constructed in which the specimens could be stored at a constant relative humidity and from which the specimens could be extracted one after the other and tested immediately in the psychrometer. With usage of this chamber at $95 \% \mathrm{RH}$, the tests were repeated roughly two months later and the results from these measurements delivered the expected values (see black squares in Figure 10-1).

The data from the first attempt of measuring the suction of the $95 \% \mathrm{RH}$ specimens was investigated closer: Figure 10-2 shows the measured potential and roughly the time of each measurement since extraction from the RH 95\% room as well as an indication of the specimen masses. Each symbol indicates a different specimen, whereas the suction of each specimen was measured twice; the weight of each specimen, which is roughly shown by the color scale, was measured before and after the suction measurements and was seen to remain constant. A clear trend is visible: the later the measurement occurred, the lower the water potential was. Also, smaller specimens (less mass) appeared to have the tendency to dry out faster, and thus had lower values for the water potential (which can explain, e.g., why the dark blue specimen in Figure 10-2 has a higher value than the light blue specimens, even though they were tested at similar times). 


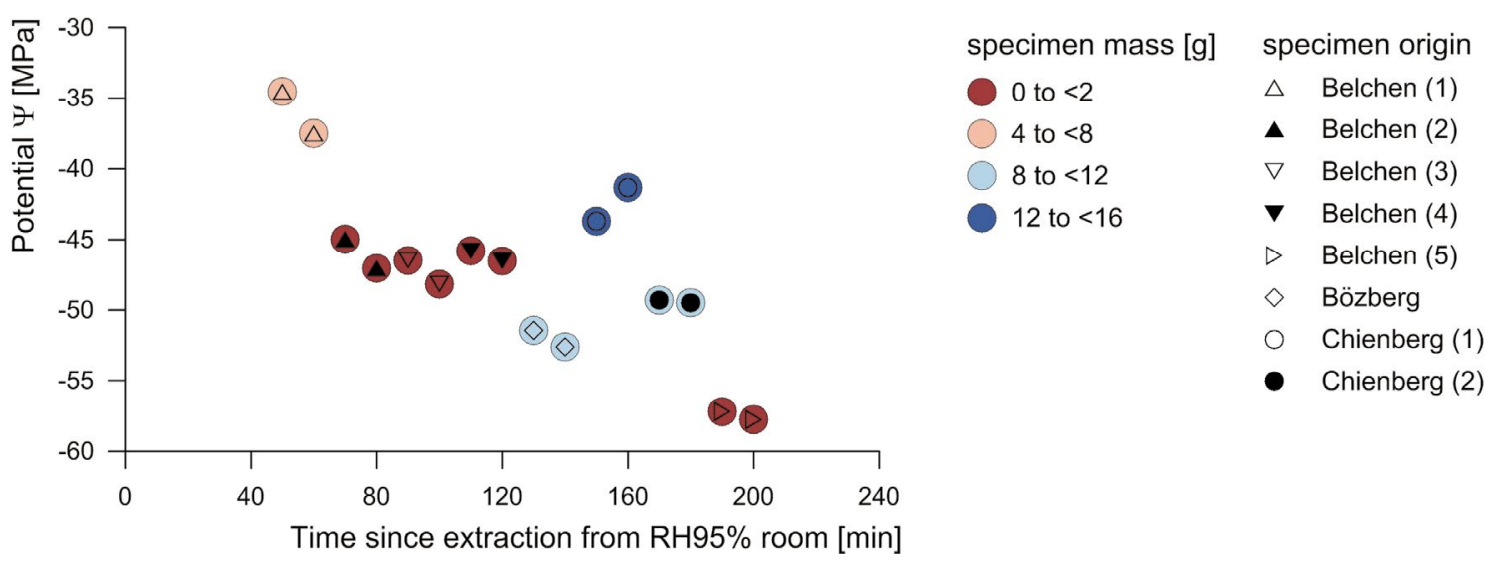

Figure 10-2: Tendency of decreasing potential after extraction from RH95\%-room, especially for specimens with lower mass. 



\section{Swelling experiments}

\subsection{Material and specimen preparation}

All specimens used for these experiments stem from borings in the Gypsum Keuper of the Belchen Tunnel. The first specimen material consisted of bore cores remaining from the ASTRA research project 2011.006 (Amann et al., 2013), which was the only specimen material from Gypsum Keuper available at the beginning of these experiments (bore core $\mathrm{BH} 3$ ). Later, further specimens were collected which were stored after an exploratory boring campaign in 2009 for the construction of the $3^{\text {rd }}$ Belchen tunnel (SB6) (Geotechnisches Institut AG and Pfirter Nyfeler + Partner AG, 2010) as well as newer bore cores from borings for sliding micrometers installed in the $3^{\text {rd }}$ Belchen Tunnel in 2016 (Tm762). All natural rock specimens were obtained by cutting the above mentioned cores air-flushed with an electronically controlled diamond band saw, which allows a precise and smooth cut without inducing AGT. Their mineralogical compositions (prior to testing) were determined via X-ray diffraction (cf. Chapter 3.3) on XRD-specimens adjacent to the actual specimens in order to ensure that the bore cores contained anhydrite (the compositions are shown in Figure 11-5 to Figure 11-8 and are also listed in Table J-7 in Appendix J).

The bore cores $\mathrm{BH} 3$ with a diameter of $84 \mathrm{~mm}$ were perforated in radial direction within the scope of the research performed by Amann et al. (2013) in order to gain oriented bore cores (with a diameter of $34 \mathrm{~mm}$ ). Figure 11-1 shows one of the bore cores, where the smaller radial boreholes with ca. $40 \mathrm{~mm}$ in diameter can be seen. In order to obtain specimens for the free swelling tests in the present project from the remaining material, the cores were first cut every $20 \mathrm{~mm}$ in radial direction, followed by individual cuts in axial direction - tangentially to the smaller boreholes. This leads to segmental specimens, as shown in Figure 11-1 (hereafter referred to as "segments").
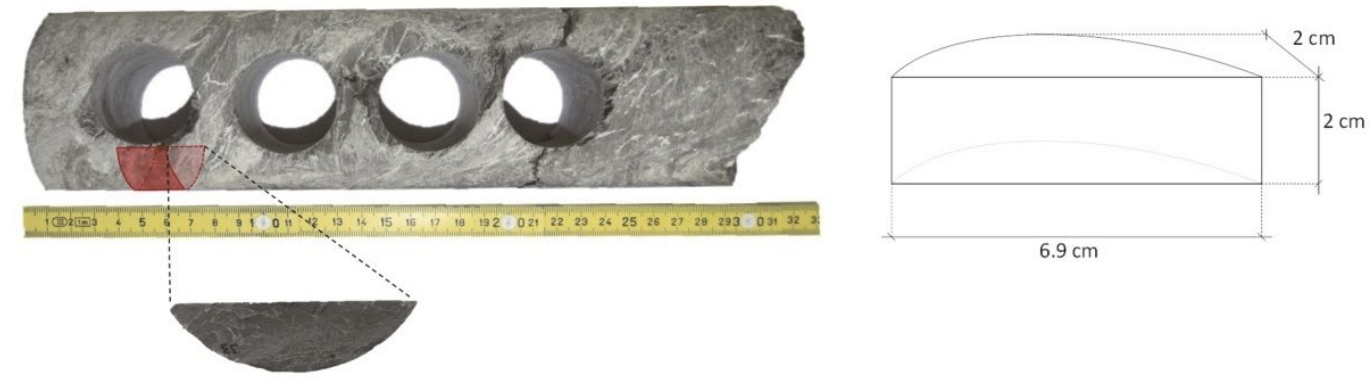

Figure 11-1: Left: bore core Belchen BH3 3.1-3.4m and example for a segmental specimen. Right: typical dimensions of segmental specimens.

A total of 32 segments were sawed for the free swelling tests from two such bore cores, indicated by the white shaded boxes in Figure 11-2. The mineralogical composition prior to the tests (of the specimens $\mathrm{X} 01-\mathrm{X} 10$ for the core $\mathrm{BH} 34.4-4.5$ and $\mathrm{X} 11-\mathrm{X} 20$ for the core $\mathrm{BH} 33.1-3.4$ in Figure 11-2), revealed that the used bore cores contained $40-80 \%$ of anhydrite and were free of gypsum. The results are shown in Figure 11-5 (hatched pillars) along with an indication of the adjacent specimen numbers. 


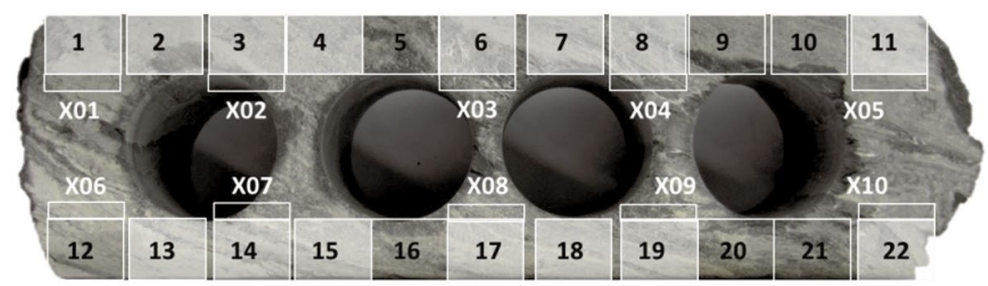

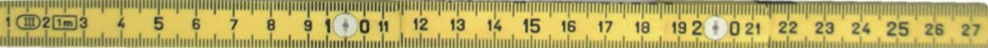

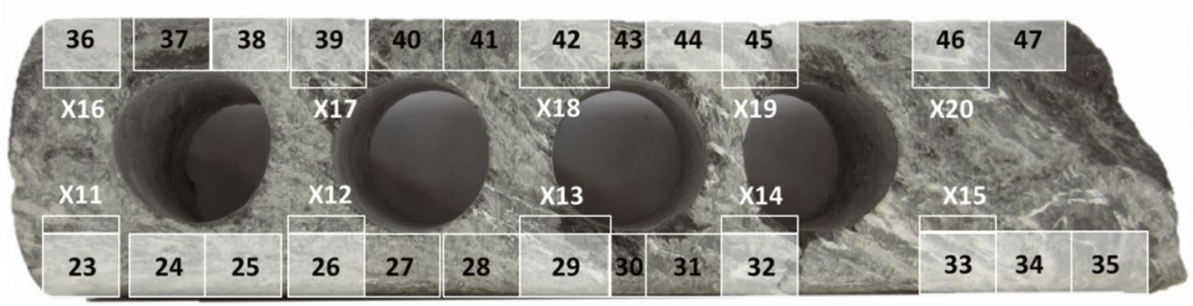

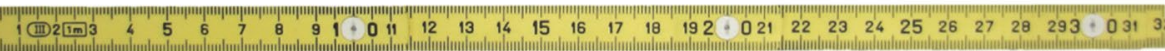

Figure 11-2: $\quad$ Bore cores BH3, 4.4-4.5m (top) and 3.1-3.4m (bottom): selection of specimens for free swelling tests (indicated by white shaded boxes).

The bore cores from SB6 $(1.25-1.56 \mathrm{~m})$ had a diameter of $72 \mathrm{~mm}$ and could be cut into "disks", as opposed to the segments from the previous series. The compositions of the cores were established via XRD on specimens adjacent to the disks (specimens X21/ X22 and X25-X28, see Figure 11-7, hatched pillars, and Table J-7). The disks were seen to contain $30-70 \%$ of anhydrite and $10-40 \%$ of gypsum. However, in the case of SB6 1.4-1.56m, these mineralogical compositions are not the exact results from the X-ray analysis but are corrected due to appearance of bassanite in the results. It is strongly assumed that the bassanite (a hemihydrate, see Chapter 2.1 ), was produced during XRD-specimen preparation: The specimens were dried in an oven at temperatures above $60{ }^{\circ} \mathrm{C}$, which lead to de-hydration of gypsum (see Appendix I).
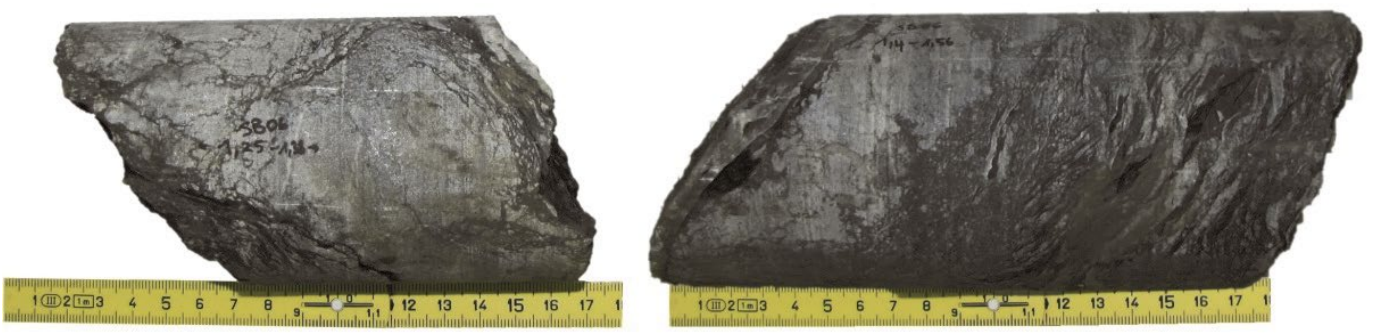

Figure 11-3: Belchen SB6, 1.25-1.38m and 1.4-1.56m.

The bore cores from borings for sliding micrometers (depicted in Figure 11-4 and henceforth denoted as "Tm762") had an original diameter of $110 \mathrm{~mm}$ and were lathed (air-flushed) to a diameter of $70 \mathrm{~mm}$, then also cut to disks with a height of about $20 \mathrm{~mm}$. Their mineralogical compositions prior to testing are shown in Figure 11-8 (hatched pillars) and revealed an anhydrite content of $50-63 \%$, and were devoid of gypsum. 


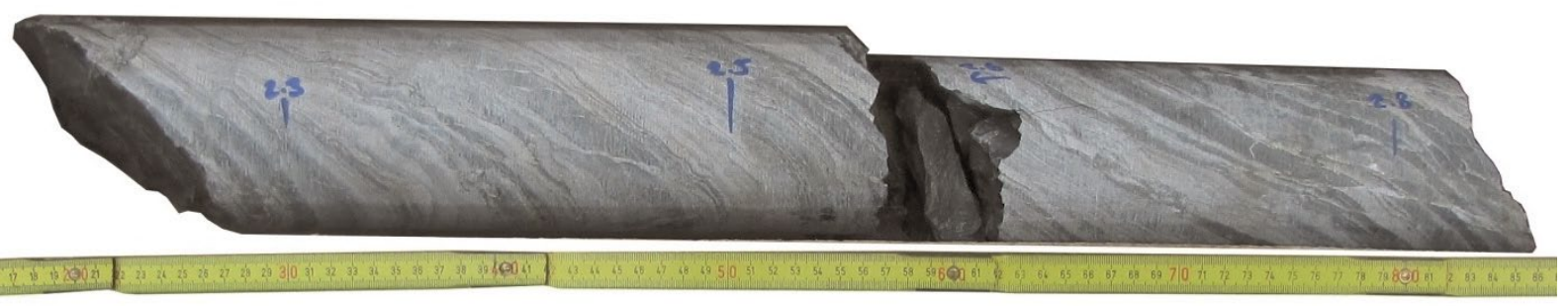

Figure 11-4: Belchen sliding micrometer boring at Tm762, 2.3-2.8m.

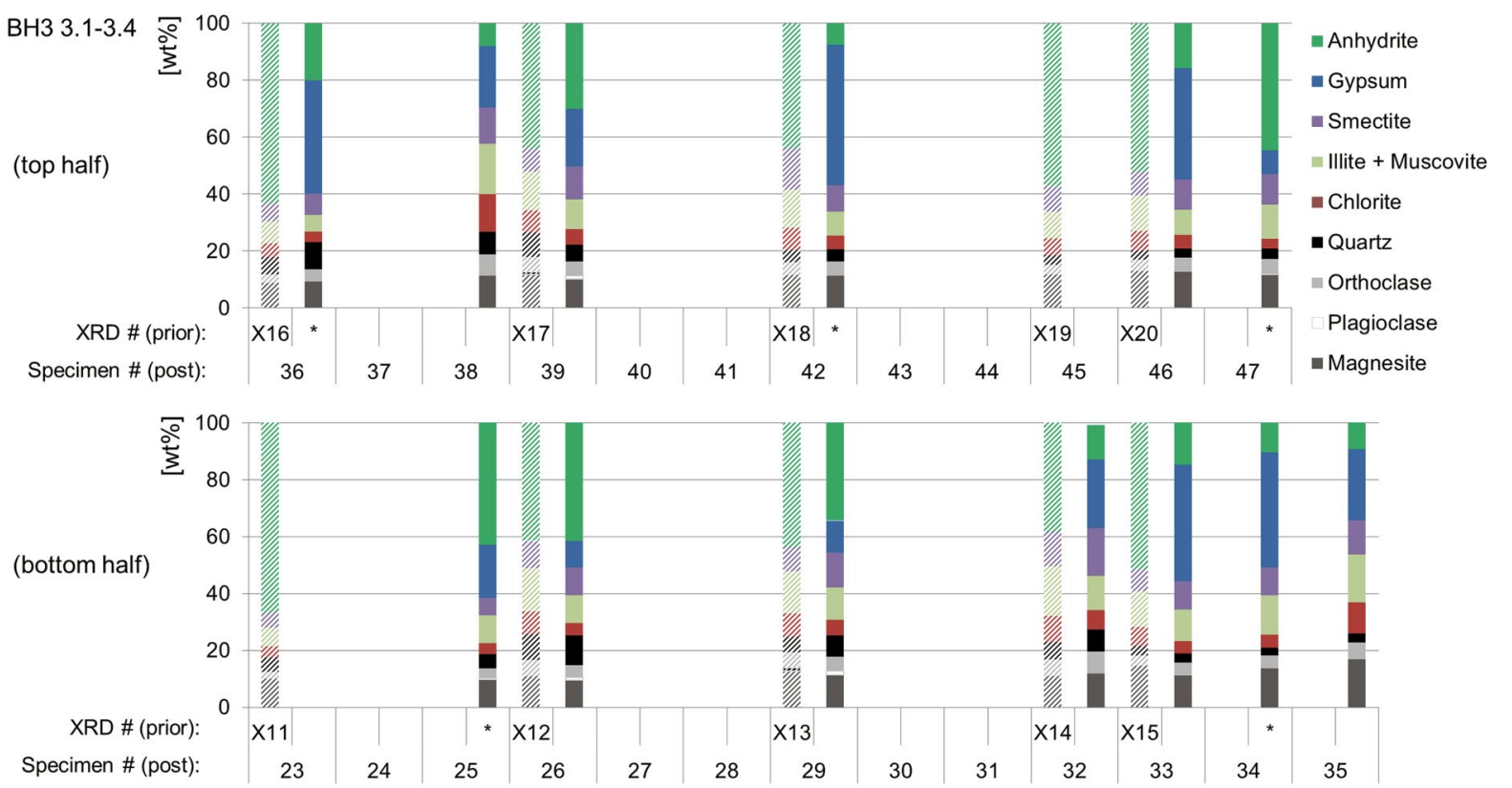

Figure 11-5: $\quad$ XRD results from Belchen BH3 3.1-3.4. Hatched pillars X11-X20 indicate XRD-specimens prior to testing (i.e., adjacent to the actual specimens, cf. Figure 11-2), while solid pillars show the mineralogical compositions of the specimens post test (the specimens marked * were corrected according to Appendix I). [wt\%] = weight percentage
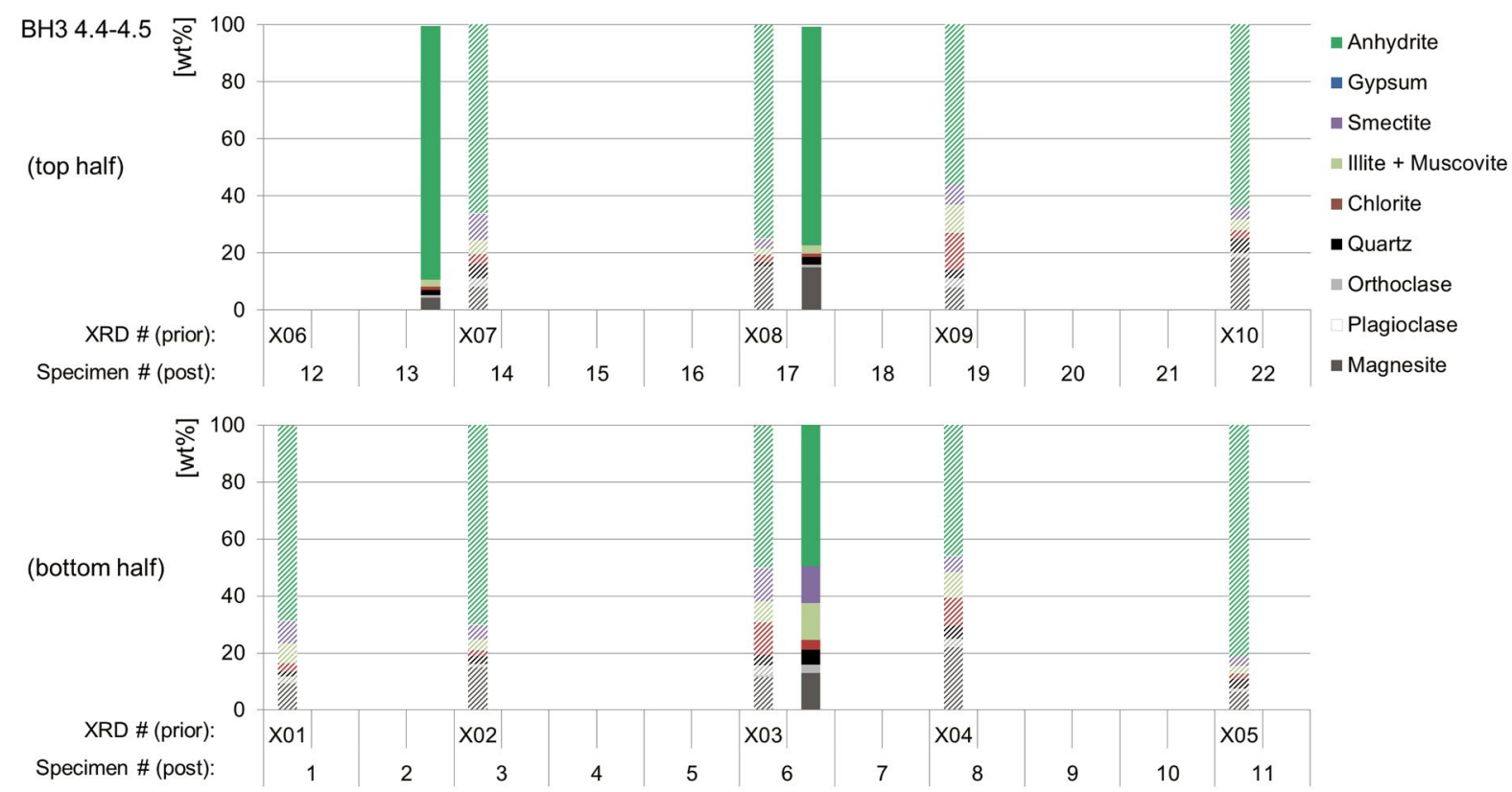

Figure 11-6: $\quad$ XRD results from Belchen BH3 4.4-4.5. Hatched pillars X01-X10 indicate XRD-specimens prior to testing (i.e. adjacent to the actual specimens), while solid pillars show the mineralogical compositions of the specimens post test. [wt\%] = weight percentage 
SB 6

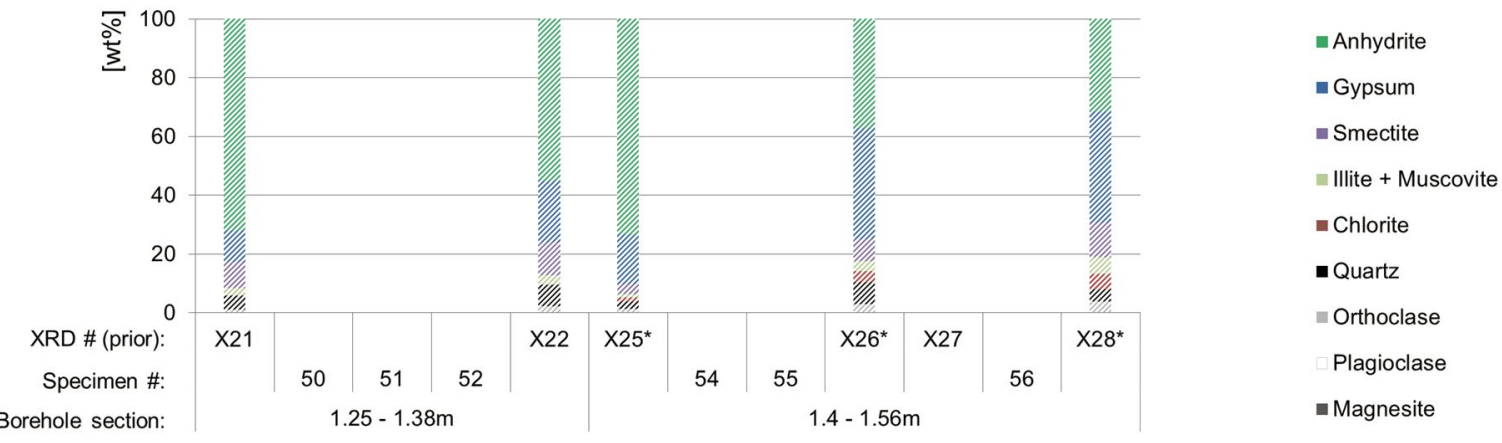

Figure 11-7: $\quad$ XRD results from Belchen SB6 1.25-1.56m prior to testing (X21-X28; the specimens marked * were corrected according to Appendix I.) [wt\%] = weight percentage

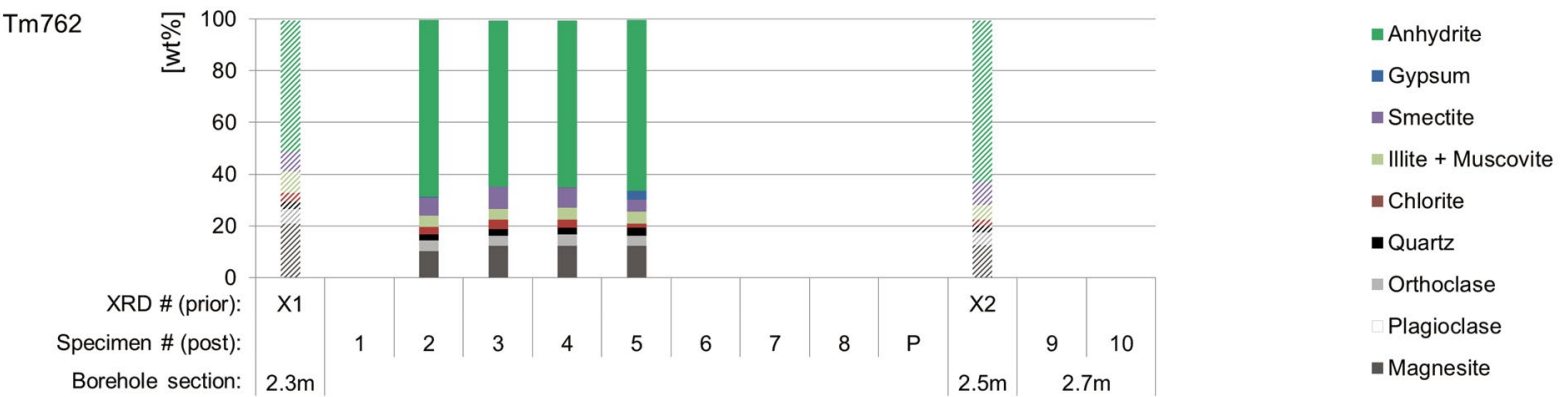

Figure 11-8: $\quad X R D$ results from Belchen Tm762. Hatched pillars $X 1$ and $X 2$ indicate $X R D$ specimens prior to testing, while solid pillars show the mineralogical compositions of the specimens post test. $[w t \%]=$ weight percentage

Additionally, the left over material of Belchen $\mathrm{BH} 34.4-4.5$ and $\mathrm{BH} 33.1-3.4$ as well as $\mathrm{Tm762}$ at about $2.5 \mathrm{~m}$ was milled in order to create compacted specimens for oedometer tests. Figure 11-9 shows the particle size distributions of the milled rock from Borehole BH3. The specimen preparation then occurred the same as described in Chapter 8.3 (without any addition of aggregates, i.e., solely the milled material was used). For the experiments, the compacted disks remained in the steel rings they were compacted in, with a diameter of $56.3 \mathrm{~mm}$.
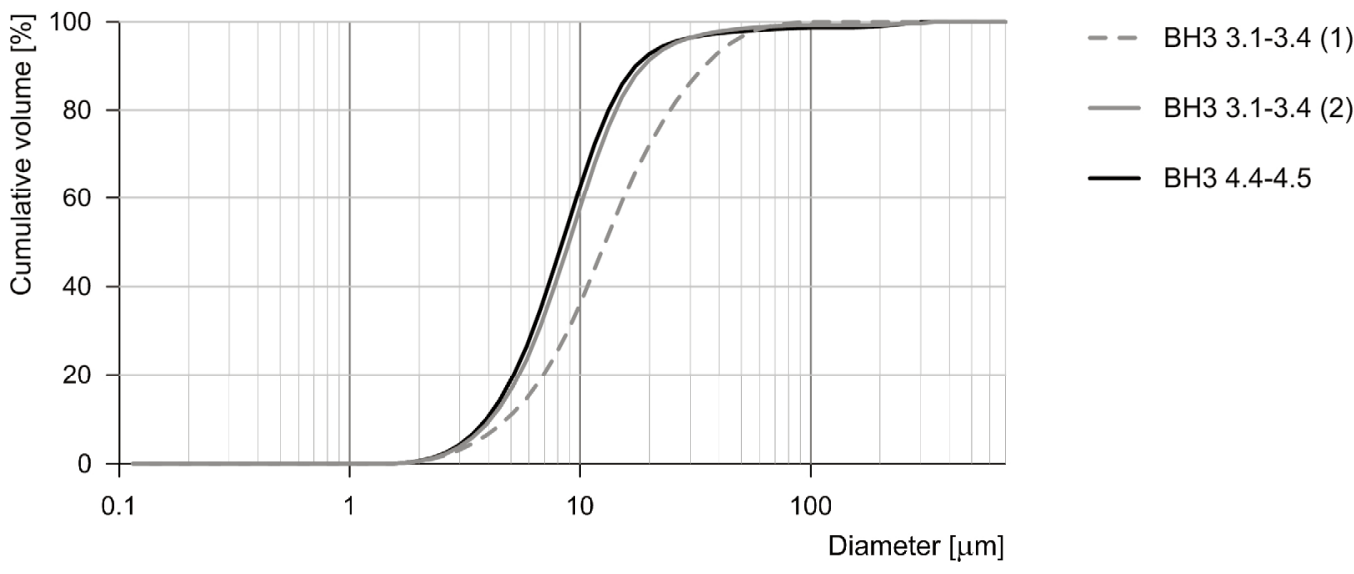

Figure 11-9: $\quad$ Particle size distributions of milled rock from Belchen $\mathrm{BH}$. 


\subsection{Testing procedure}

\subsubsection{Compacted disks}

As mentioned above, some of the rock was milled and compressed into an oedometer ring, inserted in an oedometer apparatus (the basic setup of an oedometer cell is illustrated in Figure 8-8), then loaded axially with a piston (ca. $0.7 \mathrm{~kg}$, i.e., $3 \mathrm{kPa}$ ) and connected to a water supply at a temperature of either $20^{\circ} \mathrm{C}$ or $50^{\circ} \mathrm{C}$, thus initiating the swelling process. The developing heave of the specimen was measured with a dial gauge. Upon termination of a test, the specimen was extracted from the oedometer ring, weighed before and after drying and its gypsum content measured via TGA (cf. Chapter 3.1), from which the change in mass of anhydrite could be calculated.

\subsubsection{Segments and disks (natural rock)}

First (preliminary) tests have shown that segmental rock specimens lying unsupported in water begin to decay radially (see Figure 11-11b), which thus renders the measurements of the axial heave unusable. For this reason the free swelling tests were performed with a slight radial support of the specimens by a rigid foam (in the case of segments, cf. Figure 11-10 and Figure 11-11) or PTFE bands and rubber membranes (in the case of disks, Figure 11-12). This does not, however, prohibit radial strain completely. It needs to be noted that in some cases the rigid foam was cracked by the specimens, which leads to assume that the foams which remained intact and the rubber membranes (in the case of disks) probably caused a small radial stress on the specimens.

The segments are embedded between a perforated steel filter plate below the specimen and an acrylic glass plate above (see Figure 11-10) while the disks are embedded between two acrylic glass plates and a perforated steel filter plate below the specimen (see Figure 11-12a and b), which ensure a uniform watering of the specimen. The swelling tests are then started by immersing the specimens in water at $20^{\circ} \mathrm{C}$ or $50{ }^{\circ} \mathrm{C}$ (see Chapter 11.2.3) and the axial deformation is measured with a dial gauge (digitally at room temperature, cf. Figure 11-11d and Figure 11-12d, and analogously in the oven).

Most rock specimens were extracted after various test-durations, dried (the first specimens erroneously at $65^{\circ} \mathrm{C}$, later always at $40^{\circ} \mathrm{C}$, cf. remarks in Appendix I), and the mineralogical composition was determined via $\mathrm{XRD}$, whereas some specimens still remain in ongoing tests.

In order to examine the differences in the specimen structures prior to swelling and post swelling in the oven and at room temperature, three specimens were investigated microscopically. First, the surface of each specimen was captured with an optical microscope, then the specimens were embedded in epoxy, sawed with the diamond band saw mentioned in Chapter 11.1, which delivered cross-sections of the specimens. These cross-sections were then covered with epoxy again (thus filling all visible pores with epoxy), then polished in order to obtain a smooth, uniform specimen surface for further microscopic investigations with SEM (cf. Chapter 3.2).

Additionally, the chemism of the surrounding water was investigated with atomic absorption spectroscopy (AAS, Chapter 3.8) and inductively coupled plasma - optical emission spectrometry (ICPOES, Chapter 3.9) for a selection of specimens. 


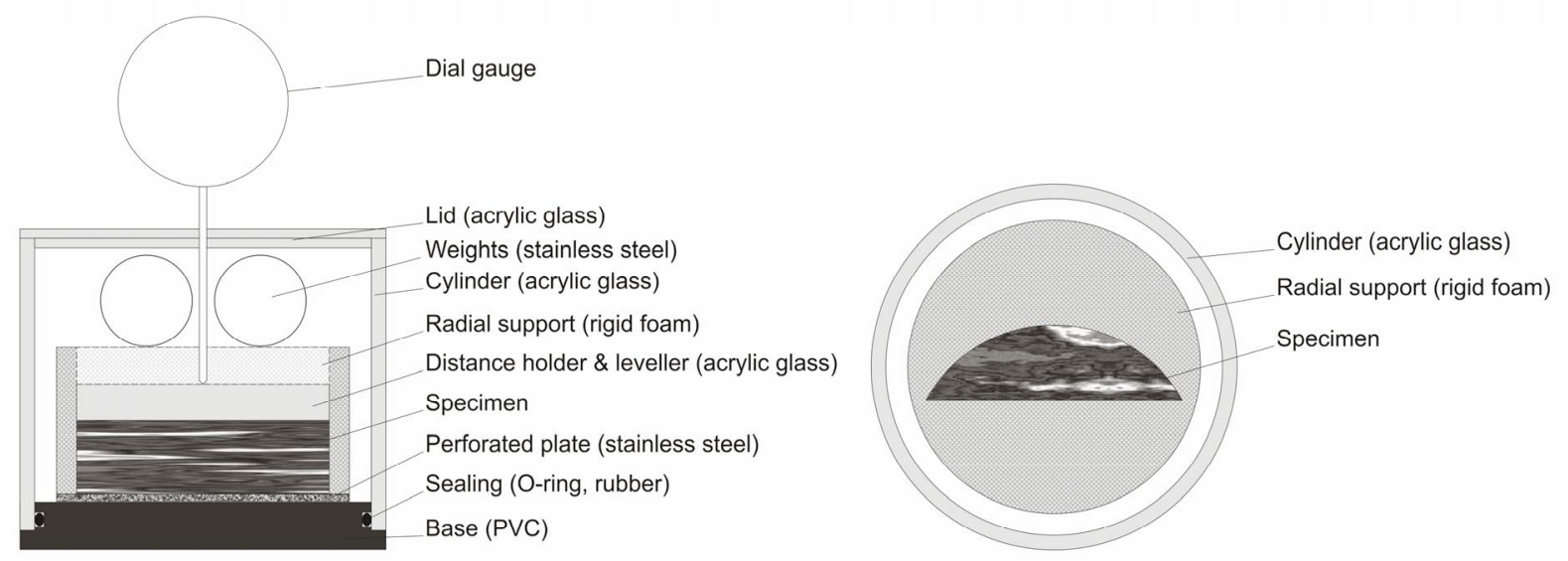

Figure 11-10: Testing apparatus. Left: Cross section. Right: View from top (without lid and distance holder).
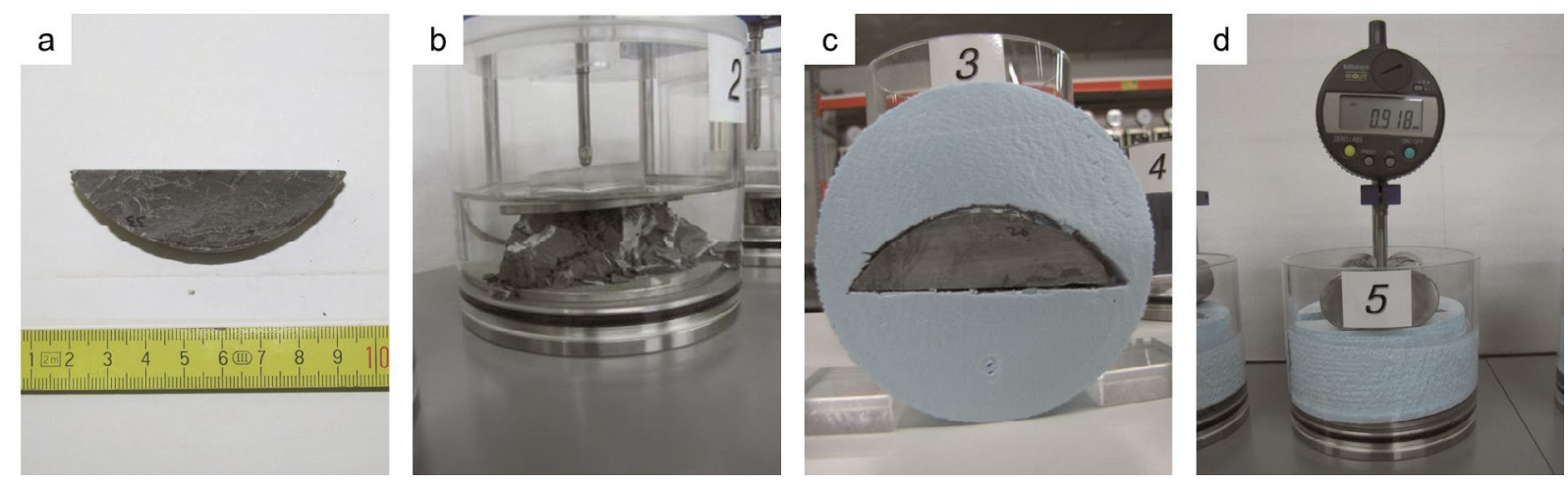

Figure 11-11: (a) Segmental specimen, (b) decay of a trial specimen, (c) use of rigid foam as radial support, (d) apparatus from the front.
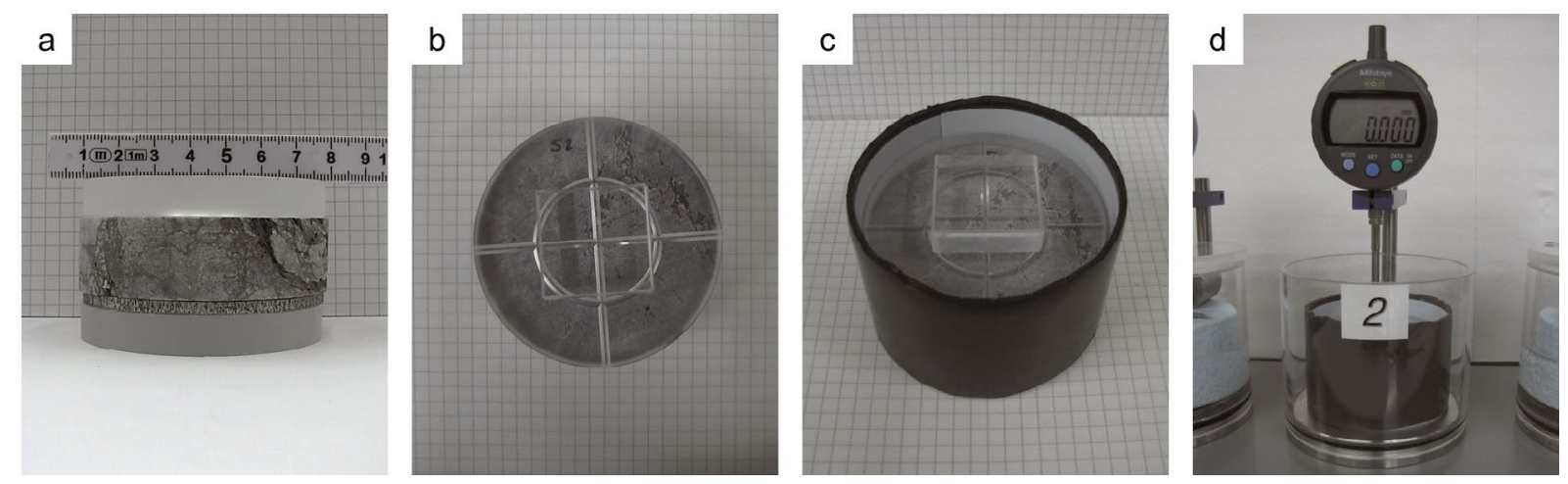

Figure 11-12: (a) Disk specimen between acrylic glass plates and filter plate from the side and (b) view from top, (c) then wrapped in a Teflon band and a rubber membrane and (d) inserted in the apparatus.

\subsubsection{Watering at different temperatures}

The specimens were immersed in water saturated with respect to gypsum (i.e., $15 \mathrm{~mol} / \mathrm{m}^{3} \mathrm{CaSO}_{4}$, see point $D$ in Figure 11-13), either at room temperature, in an oven at $50{ }^{\circ} \mathrm{C}$, or on a heating plate with varying temperature, and the axial swelling heave of each specimen was measured regularly with a dial gauge. Depending on the state the specimens are in (dry, wetted; at $20^{\circ} \mathrm{C}$ or $50^{\circ} \mathrm{C}$ ) the prevailing equilibrium concentrations of anhydrite and gypsum change and thus the concentration in the pore water may change. 
The development of the concentration of the pore water during wetting at $20^{\circ}$ resp. $50^{\circ} \mathrm{C}$ with respect to the prevailing equilibrium concentrations is visualized with Figure 11-13, where the equilibrium concentrations are shown in dependence of the potential (left) and the temperature (right):

- In their initial state, the concentration can be represented by points $A$ in Figure 11-13. The rock specimens were stored at room temperature, and were nearly dried out. The pore water potential was measured with the psychrometer, see Chapter 10.2.2; here an average value of $-125 \mathrm{MPa}$ is assumed. The concentration corresponds to the equilibrium concentration of anhydrite, since that of gypsum is far higher at such a low potential (thus, anhydrite is the stable phase).

- When the rock is wetted at room temperature (with water of a concentration equal to the equilibrium concetration of gypsum at room temperature, i.e., at point $D$ in Figure 11-13), the potential increases rapidly to 0 . The equilibrium concentration of anhydrite is slightly higher than before (from point $A$ to point $E$ in Figure 11-13), while the equilibrium concentration of gypsum decreases to a value lower than that of anhydrite (point $D$ ). This change in equilibrium concentrations thus triggers AGT, and the concentration during anhydrite dissolution and gypsum precipitation will lie between points $D$ and $E$ in Figure 11-13 (red arrow).

- Prior to wetting the rock in the oven at $50^{\circ} \mathrm{C}$, the rock and entire aparatus is placed in the oven, thus the concentration moves from point $A$ to point $B$ (Figure 11-13), during which it is theoretically possible for anhydrite to precipitate (however, since the rocks are still in a very dry state, the possibility of precipitation from the small amount of bound water is negligible). Upon wetting at $50^{\circ} \mathrm{C}$, the concentration remains between the equilibrium concentration of anhydrite and that of gypsum, i.e., at (or slightly above) point $\mathrm{C}$.

- When moving the specimen from the oven to the climate room, the conditions change from point $C$ to point $D$ (Figure 11-13). Since now the equilibrium concentration of anhydrite (point E) exceeds that of gypsum (point D), AGT can occur and the concentration will lie between points $A$ and $D$ until all anhydrite is dissolved and gypsum precipitation is completed, thus ending at point $D$. 

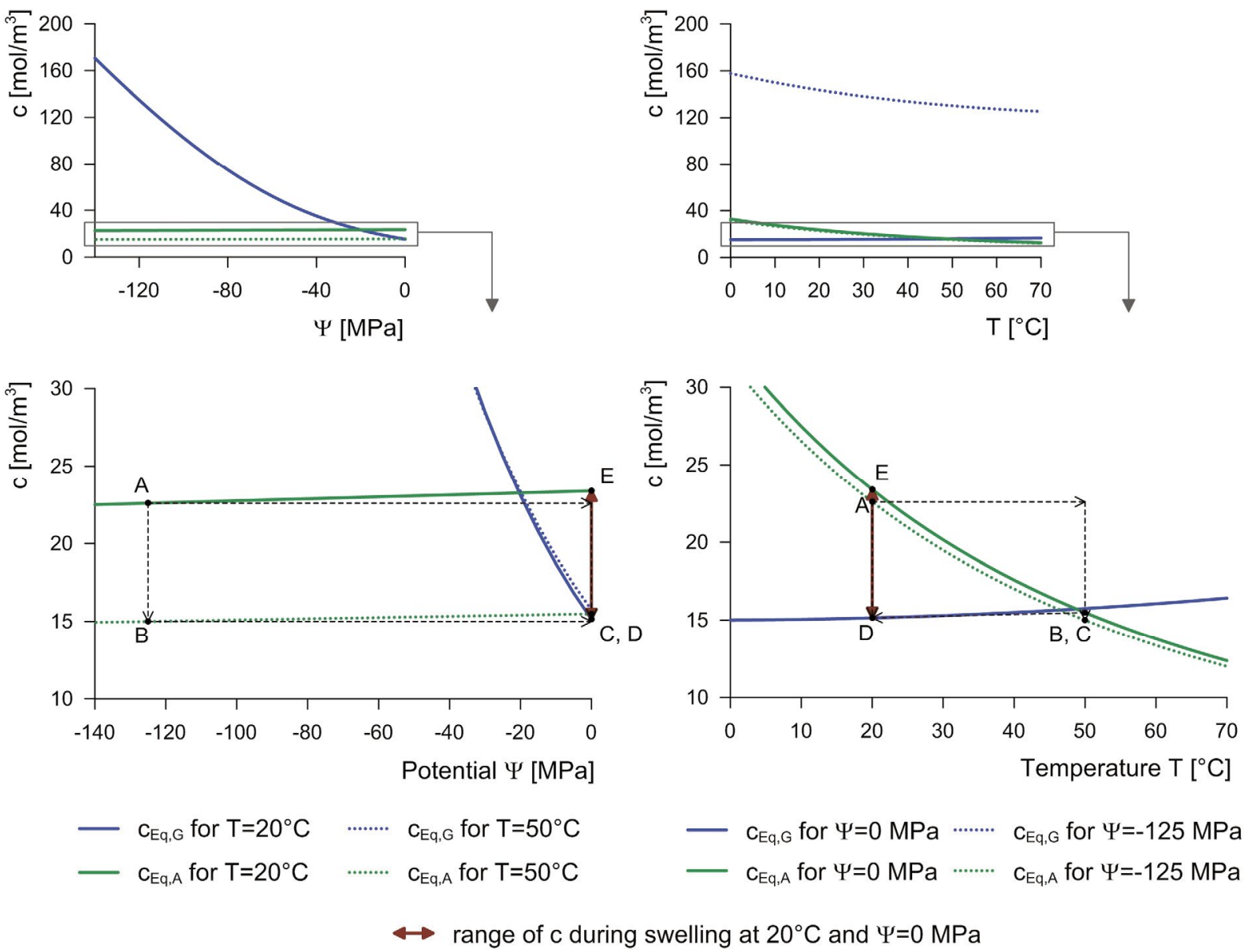

Figure 11-13: Left: Equilibrium concentrations vs. potential, right: Equilibrium concentrations vs. temperature. Top row: large scale, bottom row: detail for $c=10-30 \mathrm{~mol} / \mathrm{m}^{3}$. The points $A-E$ and arrows indicate the development of the concentration in the pore water.

\subsection{Results: Compacted disks $\left(\mathrm{T}=20^{\circ} \mathrm{C}\right.$ and $\left.50^{\circ} \mathrm{C}\right)$}

The compacted disks were submerged in water either at room temperature (i.e., $20^{\circ} \mathrm{C}$ ) or in the oven at $50^{\circ} \mathrm{C}$, and their resulting swelling strains are shown in Figure $11-14$, left. While most specimens were tested directly at room temperature, four specimens were first watered in the oven (indicated by the red lines in Figure 11-14, left), whereas three were then moved to room temperature. The following observations can be made:

The specimens that were tested solely at room temperature (continuously black, grey and green curves in Figure 11-14, left) all swelled similarly, i.e., they exhibited a very rapid heave which began to slow down after a few days. In the case of $\mathrm{BH} 34.4-4.5 \mathrm{~m}$ (black curves) the strains ceased to increase after about a month and appeared to have reached a steady state, while the strains of the specimens BH3 3.1-3.4m and Tm762 2.5m were still increasing at the point of extraction. The specimens that were first watered in the oven (red curves) also exhibited a rapid strain (presumably due to clay swelling); however, they stopped swelling abruptly after the first 1-2 days at about $20 \%$ swelling strain (as opposed to the specimens tested directly at room temperature, which reached far higher values of swelling strain). Upon moving the specimens to room temperature, further swelling was immediately triggered and the development of the swelling strains appeared the same as with the previous specimens, and also reached similar values. One specimen of material from $\mathrm{BH} 34.4-4.5 \mathrm{~m}$ which was first tested in the oven, after $c a$. one month moved to room temperature 
(where it swelled rapidly), was switched back into the oven roughly one week later when the strain reached ca. 50\%. The temperature change completely halted further swelling, and upon resuming the test in the climate room four days later the swelling continued. Based on these results the first conclusion is drawn that it is possible to distinguish between swelling of clay and swelling due to AGT: The swelling which occurs in the oven is caused by osmotic and mechanical processes, while the swelling which occurs after switching the specimens to room temperature is caused by AGT.

After termination of the tests, TGA was performed on each specimen in order to determine the amount of precipitated gypsum and therefore the amount of remaining anhydrite and thus estimate to which extent AGT progressed (see Appendix I). Figure 11-14, right, shows the remaining mass of anhydrite per unit volume according to Equation $(2-11)$ for the reached swelling strains of each specimen. The main specimen properties prior and post test are shown in Table J-8 in Appendix J.
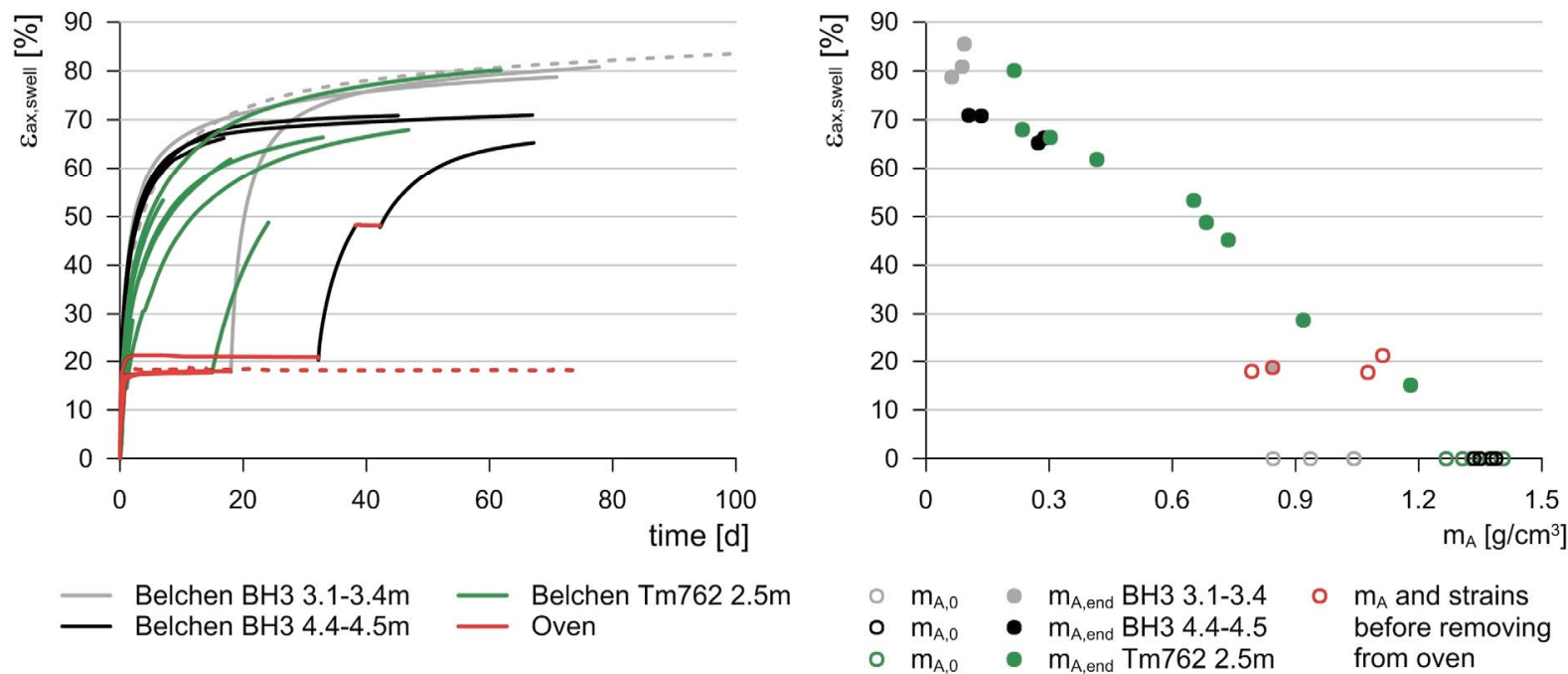

Figure 11-14: Left Swelling strain of compacted disks (BH3, 3.1-3.4m, 4.4-4.5m and at Tm762, 2.5m) over time, incl. the tests in oven (red lines). The dashed lines indicate specimens of BH3, 3.1-3.4, which had a larger particle size, cf. Figure 11-9. Right: end values of swelling strains vs. mass of anhydrite per unit volume.

\subsection{Results: Natural rock specimens $\left(T=20^{\circ} \mathrm{C}\right)$}

An overview of the strains of all rock specimens tested at solely $20^{\circ} \mathrm{C}$ is depicted in Figure $11-15$. The individual series (segments BH3 3.1-3.4m and BH3 4.4-4.5m, disks SB6 and Tm762) are discussed in the following sub-chapters. 


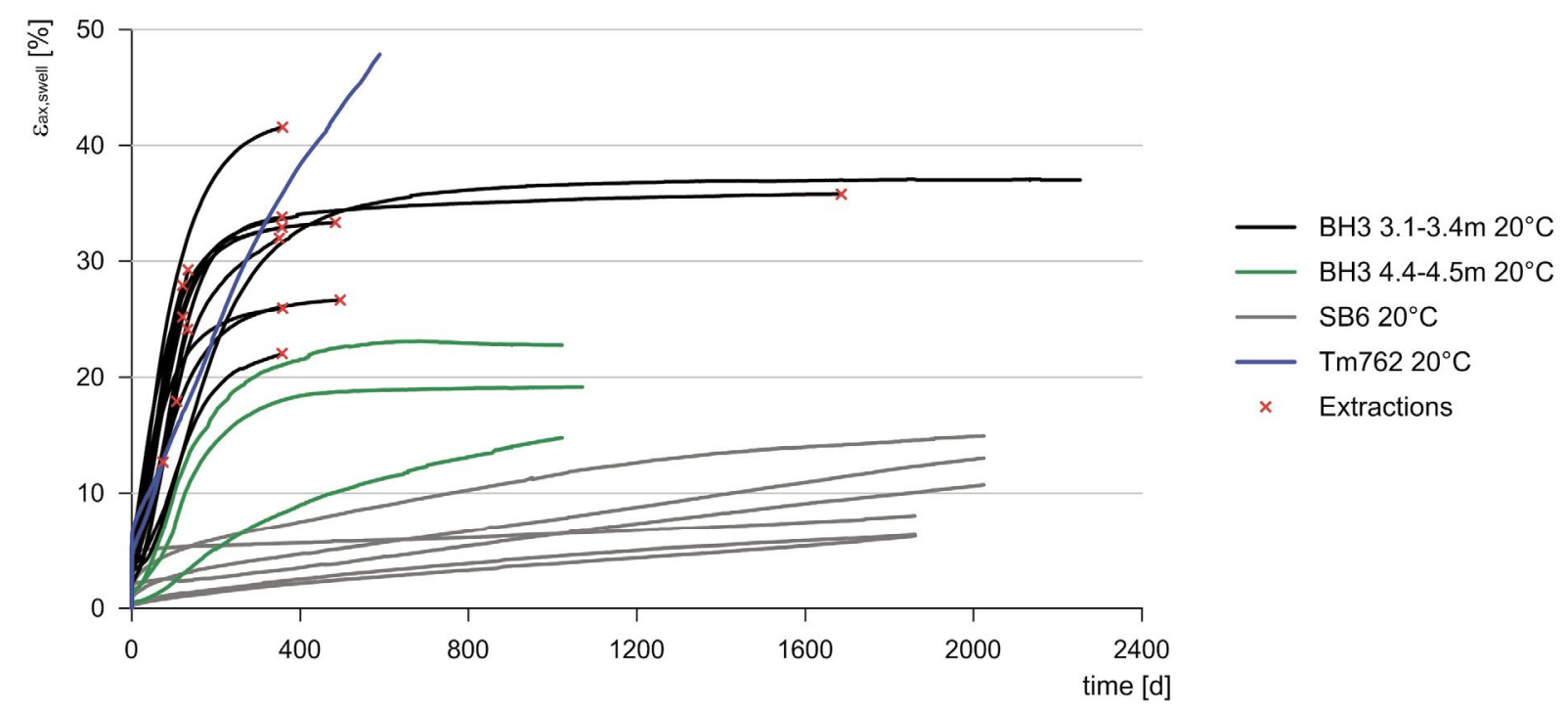

Figure 11-15: Swelling strain of all free swelling tests with natural rock specimens at $20^{\circ} \mathrm{C}$.

\subsubsection{Segments $\mathrm{BH} 33.1-3.4 \mathrm{~m}\left(\mathrm{~T}=20^{\circ} \mathrm{C}\right)$}

The diagram in Figure 11-16 shows the swelling strain over time for all segmental specimens of the bore core $\mathrm{BH} 33.1-3.4 \mathrm{~m}$ tested at $20^{\circ} \mathrm{C}$ only. Five specimens were extracted after 100 140 days, six specimens after ca. one year and two specimens after nearly 500 days. The points of extraction are indicated by the red crosses in the diagram.

Figure 11-16 shows that the specimens swelled similarly, whereas all experienced a first rapid heave (corresponds to $\varepsilon_{I}$ in Figure 9-1). These first swelling strains are mainly caused due to water uptake (i.e., mechanical swelling) and it was seen later that most of the clay swelling also occurs right at the beginning as well. After the first heave, the actual swelling due to the anhydrite in the specimens (and possibly some slight residual clay swelling) begun along a slightly S-shaped curve, some beginning with a slower rate, then accelerating and swelling nearly linearly for a while until the swelling rate begins slowing down again and even after five years (cf. the specimens 23 and 45 with the longest duration in Figure 11-16) still shows a very slight increase. However, the extent of swelling (i.e., the maximal measured value of swelling strain) scatters between ca. $22 \%$ and $42 \%$ for the section $3.1 \mathrm{~m}-3.4 \mathrm{~m}$ of the bore core $\mathrm{BH} 3$. 


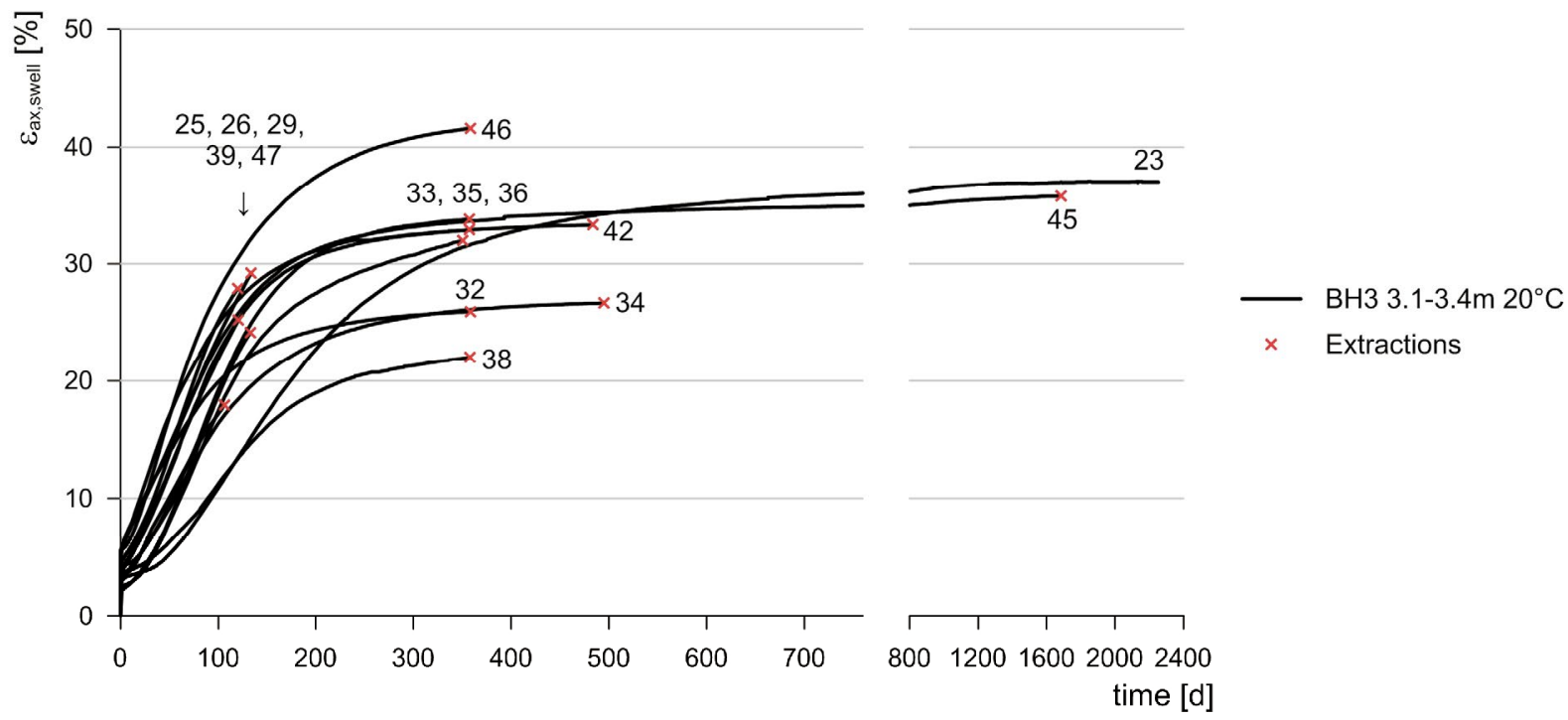

Figure 11-16: Swelling strain of segments from bore core BH3 3.1-3.4m over time.

The compositions of the extracted specimens post test were established via X-ray analysis and are shown in Figure 11-5 (solid pillars). As was already the case with some specimens from SB6 prior to the test (see Chapter 11.1), bassanite appeared in some of the XRD-results here as well, and the data shown in Figure 11-5 was corrected according to Appendix I.

In Figure 11-17 the measured strains of each extracted segment are decomposed into three components (cf. Figure 9-1):

- The green pillars in Figure 11-17 represent the rapid initial strains $\varepsilon_{I}$ due to physical processes (mechanical and osmotic swelling). Note that the last two specimens on the right were included from the tests performed at a higher temperature, where solely $\varepsilon_{I}$ occurred (specimens 24 and 44, see Chapter 11.5.1).

- The black pillars represent the amount of swelling strains solely due to the change in solid volume $\left(\varepsilon_{\Delta V_{A, G}}\right)$. These values were estimated from the mineralogical composition post test: Based on the knowledge that $\Delta V_{G}=1.61 \cdot \Delta V_{A}$ (cf. Equation (2 - 12)), the change in solid volume due to AGT was back calculated from the amount of gypsum in each specimen, since these specimens did not contain any gypsum prior to the tests.

- The grey pillars indicate the amount of swelling which is supposedly caused due to change of the pore space (e.g., due to cracking) during AGT $\left(\varepsilon_{P}\right)$.

The columns in Figure 11-17 are sorted by duration of the tests. In general, the amount of strains due to AGT (black portions of the columns) increases over time, however they vary strongly. This scatter can most likely be attributed to the heterogeneous compositions of the specimens, since the XRD results showed initial values of anhydrite in the specimens between $40 \%$ and $80 \%$. 


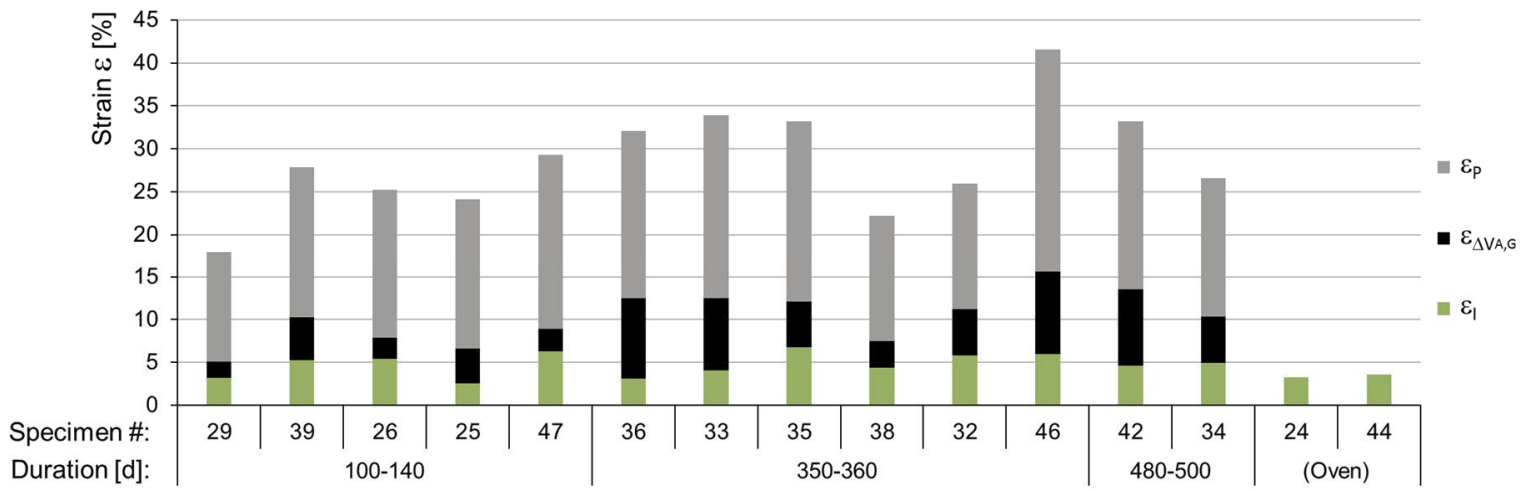

Figure 11-17: Swelling strains of segments divided into first (rapid) strains due to clay and mechanical swelling $\left(\varepsilon_{I}\right)$, chemically induced volume change $\left(\varepsilon_{\Delta V_{A, G}}\right)$ and chemically induced change of the pore space $\left(\varepsilon_{P}\right)$.

Figure 11-18 shows the amount of transformed anhydrite ( $\vartheta$ according to Equation $(7-12)$ ) for each extracted specimen over time. Within the first 140 days maximally $35 \%$ of the anhydrite in the specimens appears to have transformed to gypsum. After a year, $60-70 \%$ and after roughly 500 days $70-85 \%$ of the anhydrite has reacted. The rate with which the anhydrite transforms appears nearly constant for the entire duration of the observation period (100-500 days). Furthermore, the process was not completed with any of the terminated experiments, even after 500 days (as described previously, the swelling strain of the specimens tested still increased slightly after 500 days, cf. Figure 11-16).

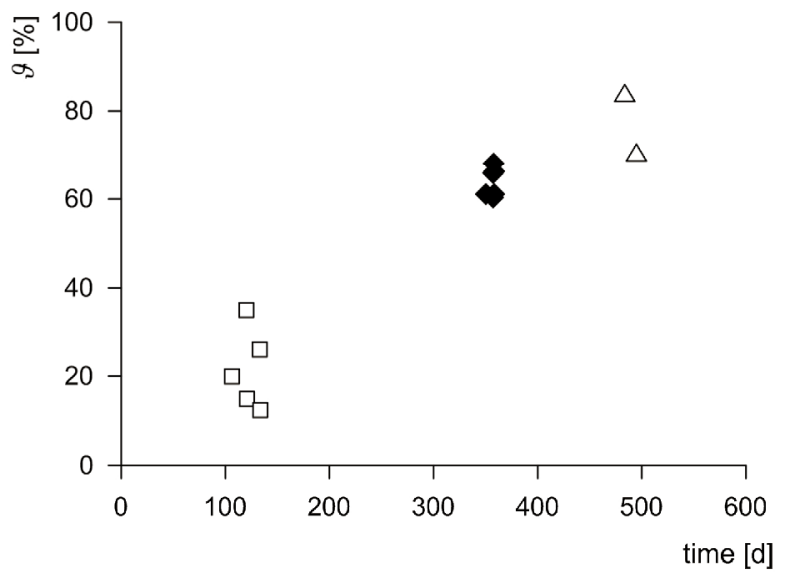

100-140 days

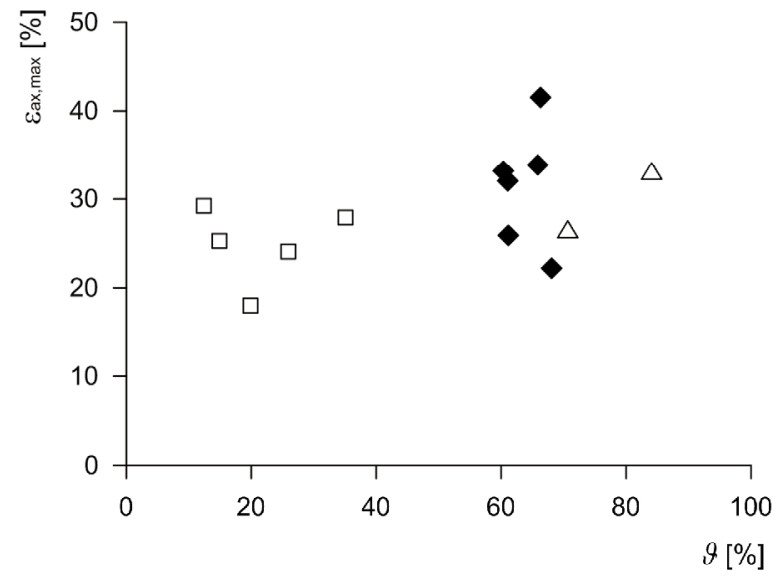

350-360 days

$\triangle 480-500$ days

Figure 11-18: Results from free swelling tests on segments from borehole BH3 3.1-3.4m. Left: degree of AGT at the points of extraction vs. duration of each test. Right: maximally reached swelling strain at extraction vs. degree of $A G T$.

\subsubsection{Segments $\mathrm{BH} 3$ 4.4-4.5m $\left(\mathrm{T}=20^{\circ} \mathrm{C}\right)$}

Three specimens of the bore core $\mathrm{BH} 34.4-4.5 \mathrm{~m}$ were tested solely at room temperature and their strains are shown in Figure 11-19. While the rate of the swelling strains of specimens 7 and 19 were similar to those of the bore core $\mathrm{BH} 33.1-3.4 \mathrm{~m}$ (see Chapter 11.4.1), the strains reached far lower values (max. 22\%). This can also be seen in the comparison of all measured strains in Figure 11-15. The specimen 2, however, was seen to swell far slower and the strain is still increasing up to date. The three tests shown in Figure 11-19 are still on-going. 


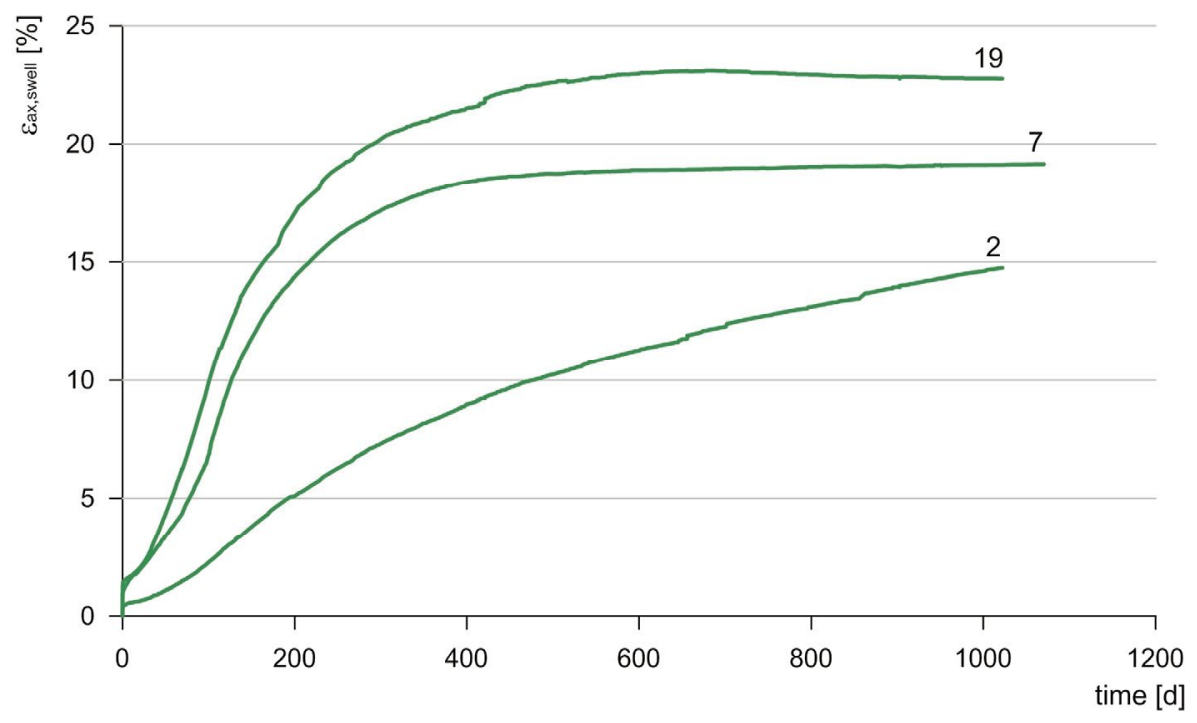

$\mathrm{BH} 34.4-4.5 \mathrm{~m} 20^{\circ} \mathrm{C}$

Figure 11-19: Swelling strain of segments from bore core BH3 4.4-4.5m over time.

\subsubsection{Disks SB6 $\left(T=20^{\circ} \mathrm{C}\right)$}

Immersing the disks from the core SB6 in water and measuring the swelling heave delivered the swelling strain curves shown in Figure 11-20. These experiments are currently still running and were so far not yet extracted.

The behavior of this series is different from that of most segments (with exception of segment number 2, cf. Figure 11-15 and Figure 11-19): In general, a much smaller initial rapid swelling strain occurs, after which the specimens swell slightly quicker at first, then steady to a linear increase in swelling strain, which is still on-going up to date. The constant rate of the swelling strain is much slower compared to the segments, the amount of swelling is much lower and the swelling strain rate did not begin to reduce considerably after about one year, which was the case with most segments.

As can be seen in Figure 11-7, this bore core contained some gypsum prior to the swelling experiment, which was not the case for the other bore cores used here.

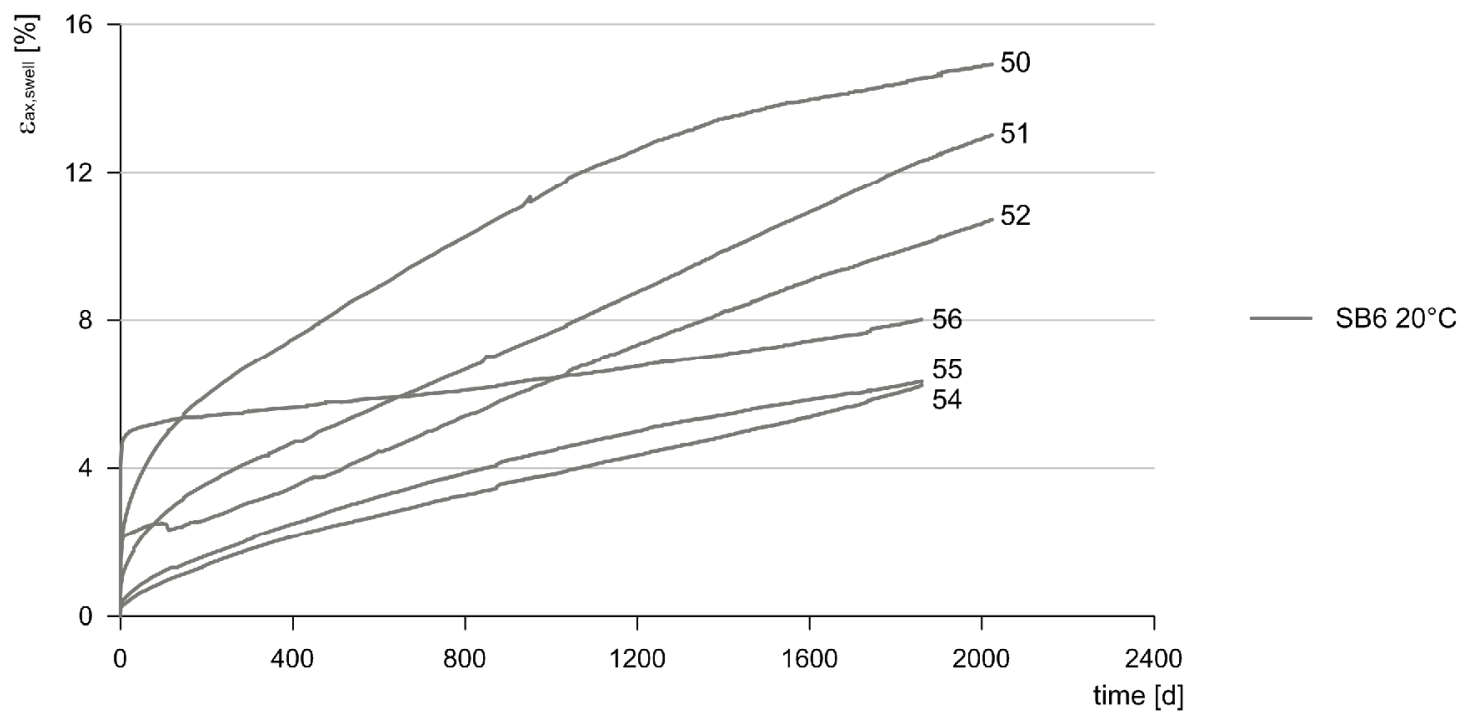

Figure 11-20: Swelling strain of disks SB6 over time. 


\subsubsection{Disks $\operatorname{Tm} 762\left(\mathrm{~T}=20^{\circ} \mathrm{C}\right)$}

Of the bore core Tm762 two disks were tested solely at room temperature (Figure 11-21). Specimen BA5 was extracted after a duration of 74 days at which point it contained $3.5 \%$ gypsum (see Figure 11-8 and Table J-7 in Appendix J). Specimen BA8 is still swelling and the swelling strain exceeded the swelling strains reached by all other natural rocks tested during this research project (cf. Figure 11-15).

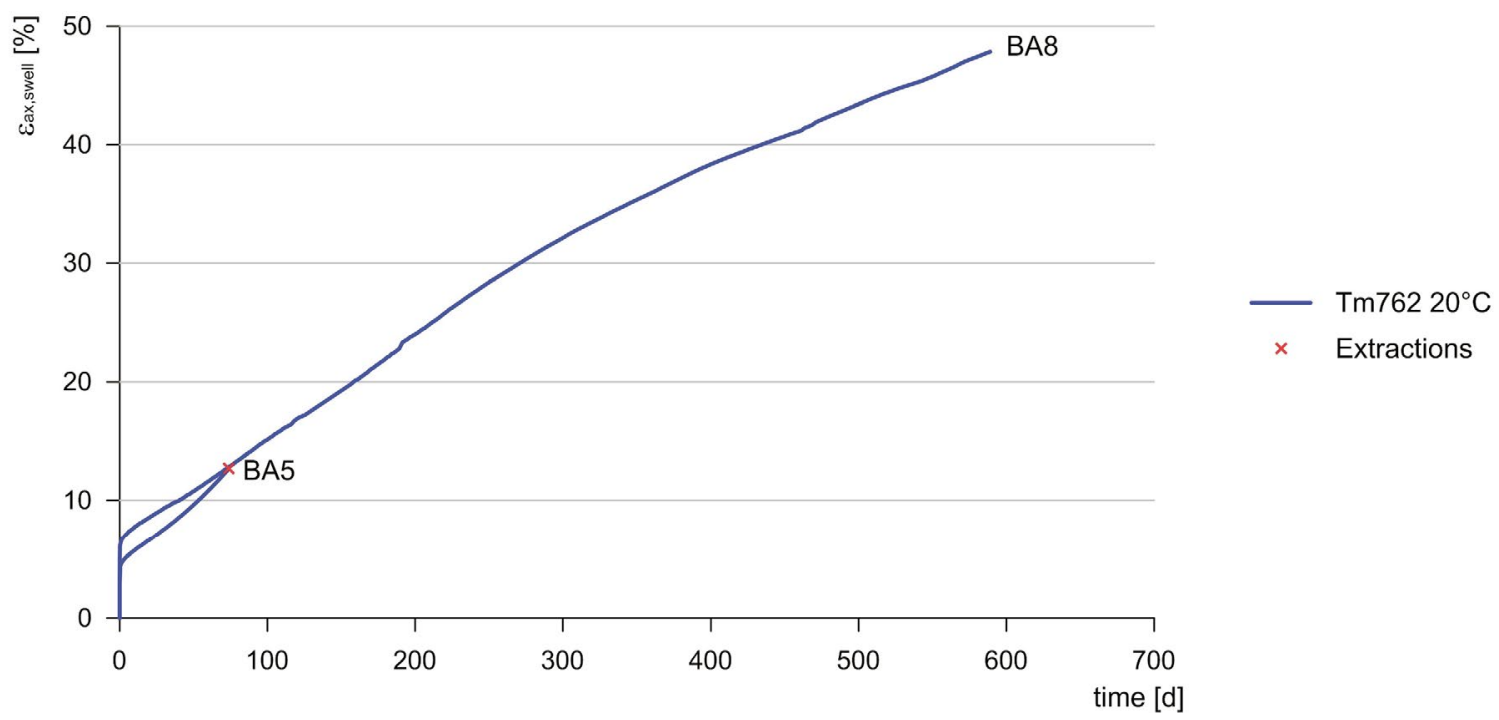

Figure 11-21: Swelling strain of disks $\operatorname{Tm} 762$ (tested solely at $20^{\circ} \mathrm{C}$ ) over time.

\subsection{Results: Natural rock specimens $\left(\mathrm{T}=20^{\circ} \mathrm{C}\right.$ and $\left.50^{\circ} \mathrm{C}\right)$}

Analogue to the tests with compacted disks (Chapter 11.3) the amount of physical swelling (cf. Figure 9-1) was to be determined with swelling tests at $50^{\circ} \mathrm{C}$, and - after reaching a steady state in the oven - by moving the specimens to room temperature, swelling due to AGT was expected to begin. However, as will be seen in the following sub-chapters, this was not the case for the natural rock specimens.

\subsubsection{Segments $\mathrm{BH} 33.1-3.4 \mathrm{~m}\left(\mathrm{~T}=20^{\circ} \mathrm{C}\right.$ and $\left.50^{\circ} \mathrm{C}\right)$}

Of the bore core $\mathrm{BH} 33.1-3.4 \mathrm{~m}$ two additional segments were tested in an oven (specimens 24 and 44; orange curves in Figure 11-22 and Figure 11-25). Here too, an initial rapid swelling strain occurred, which amounted to a similar value as the specimens tested directly in the climate room. However, following the initial heave, the strains of the specimens tested at $50{ }^{\circ} \mathrm{C}$ remained nearly constant. After 180 days specimen 24 was moved to room temperature (see Figure 11-22) whereas no swelling was observed for ca. 1 year after moving the specimen, and only then the specimen began to swell. 


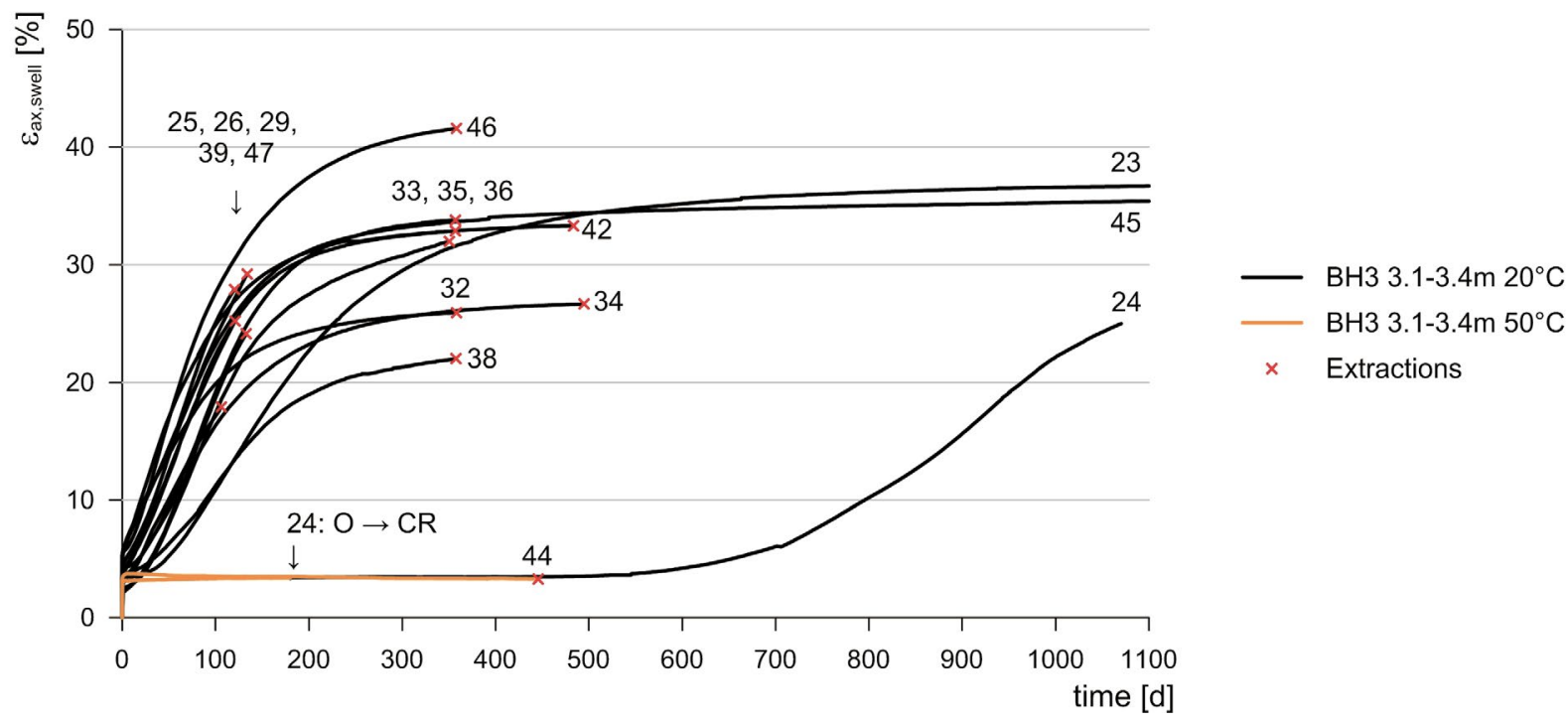

Figure 11-22: Swelling strain of segments (BH3, 3.1-3.4m) over time (cf. Figure 11-16), incl. 2 tests in oven, whereas specimen 24 was moved to room temperature after 180 days. $O=$ Oven $\left(50^{\circ} \mathrm{C}\right), C R=$ Climate Room $\left(20^{\circ} \mathrm{C}\right)$.

\subsubsection{Segments $B H 34.4-4.5 \mathrm{~m}\left(\mathrm{~T}=20^{\circ} \mathrm{C}\right.$ and $\left.50^{\circ} \mathrm{C}\right)$}

More specimens of the bore core $\mathrm{BH} 34.4-4.5 \mathrm{~m}$ were tested in the oven (see red curves in Figure 11-23 and Figure 11-25): Specimens 3, 6, 14 and 17 were tested solely at $50{ }^{\circ} \mathrm{C}$, while specimen 1 was moved to $20^{\circ} \mathrm{C}$ after 80 days, and specimens 8,13 and 18 were moved to $20^{\circ} \mathrm{C}$ after roughly 40 days.

The following observations were made:

- The initial rapid swelling strain was generally higher in the oven $\left(50^{\circ} \mathrm{C}\right)$ than that of the specimens which were watered in the climate room $\left(20^{\circ} \mathrm{C}\right)$.

- Moving the specimens from the oven to the climate room did not lead to additional swelling strains for at least an additional 100 days; after that only in two cases (specimens 8 and 18) a visible increase in strain can be observed (which begins after a total duration of ca. 200 days, i.e., ca. 150 days after moving the specimens from the oven to the climate room, see Figure 11-25).

- The swelling process could be successfully interrupted in the case of specimen 8 by moving it to the oven for nearly one month, then back to the climate room, where it continued swelling as before.

- Specimen 13 did not show any signs of swelling for 130 days after the temperature change, was then extracted and it was seen that no gypsum had precipitated.

- Specimen 1 did not show any signs of swelling up to date (1000 days after moving it from the oven to the climate room). 


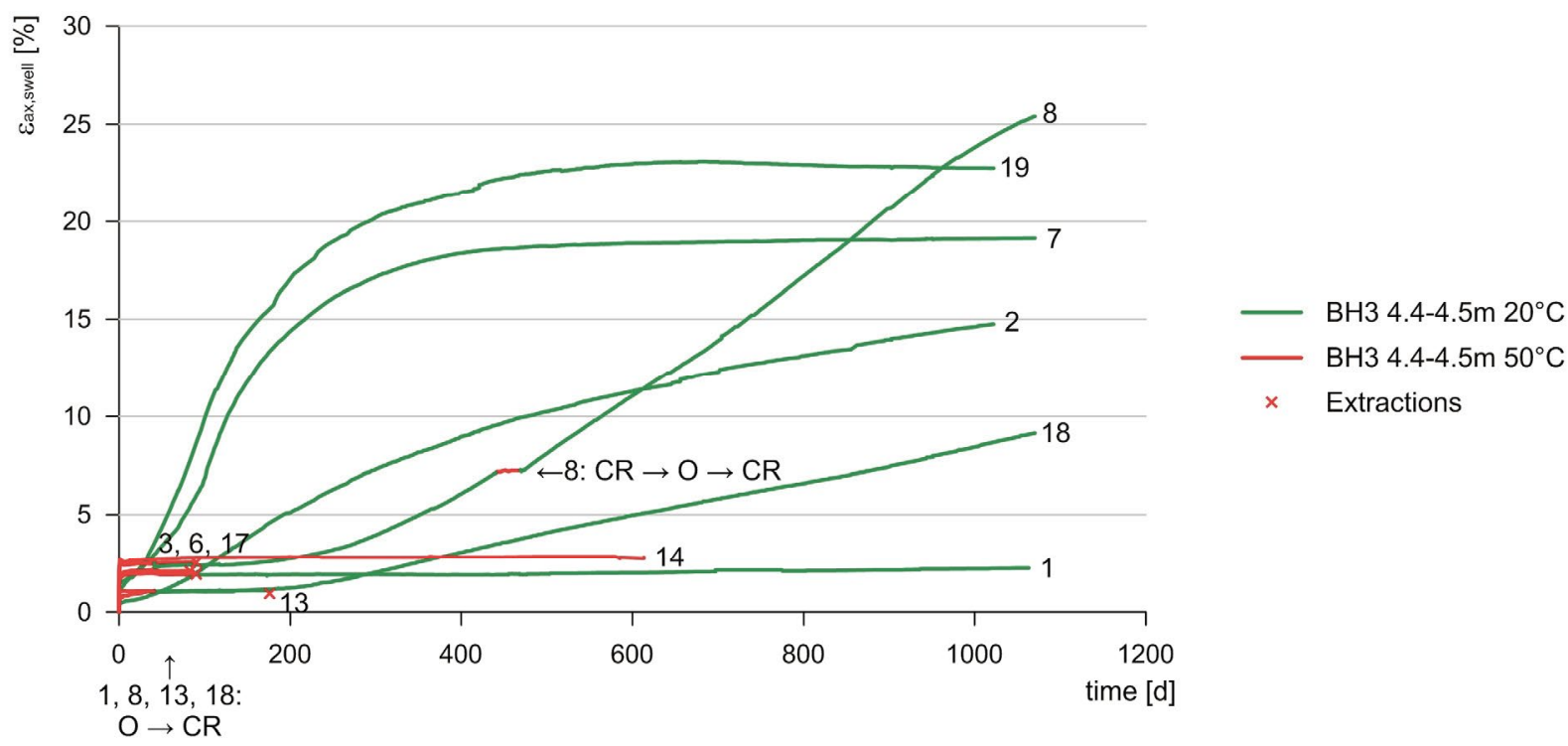

Figure 11-23: Swelling strain of segments $(B H 3,4.4-4.5 m)$ over time (cf. Figure 11-19), incl. 8 tests in oven, whereas specimens $1,8,13$ and 18 were moved to room temperature after 40 days resp. 80 days. $\mathrm{O}=$ Oven $\left(50^{\circ} \mathrm{C}\right), \mathrm{CR}=$ Climate Room $\left(20^{\circ} \mathrm{C}\right)$.

With four more specimens $(4,11,15$ and 22$)$ it was investigated whether temporary drying (i.e., extraction of water, drying at either $40^{\circ}$ or $50^{\circ} \mathrm{C}$, and re-watering them in the climate room) initiates swelling, since merely moving them to the climate room did not trigger swelling immediately. The strains of these four additional specimens are added to the diagram from Figure 11-23 in the following Figure 11-24. Furthermore, the points of temporary drying can be seen in greater detail in Figure 11-25 (yellow lines).

The specimens were tested as follows (the testing conditions for each specimen are also listed in Table J-7 in Appendix J):

Specimen 4: 40 days after watering the specimen in the oven, it was moved to the climate room, where no swelling was observed for roughly 130 days (comparable to specimen 13). The water surrounding the specimen was then extracted and the apparatus remained in the climate room for 2 days, moved to the oven for another day in order for the greater part of the water to evaporate, then moved to the climate room and re-watered with the same water. The specimen began to swell very slowly at first, then the rate increased drastically (this can be seen in Figure 11-25). So far, specimen 4 has reached the highest swelling strain of all specimens from bore core $\mathrm{BH} 3$ 4.4-4.5m (35\%).

Specimen 11: 80 days after watering the specimen in the oven, it was moved to the climate room, where no swelling was observed for 90 days (comparable to specimen 1). Analogue to specimen 4, the water was extracted in the climate room and two days later the apparatus was placed in an oven at $40^{\circ} \mathrm{C}$ for a day. The specimen was then rewatered with distilled water in the climate room. As can be seen in Figure 11-25, swelling began at a small rate. The specimen was extracted after an additional 200 days.

Specimen 15: 100 days after watering the specimen in the oven, the water was extracted and the specimen was completely dried in the oven for 6 days, upon which it was moved to the climate room and re-watered with distilled water. A very abrupt and steep increase in strains was observed (see Figure 11-25). After swelling for 120 days, 
the specimen was then moved back to the oven for 12 days, where no swelling occurred. Upon moving the specimen back to the climate room, swelling resumed (see Figure 11-24).

Specimen 22: 90 days after watering the specimen in the oven, the water was extracted and the specimen was completely dried in the oven for 3 days, upon which it was moved to the climate room and re-watered with the same water. As was the case with specimen 15, a very abrupt and steep increase in strains was observed (see Figure 11-25).

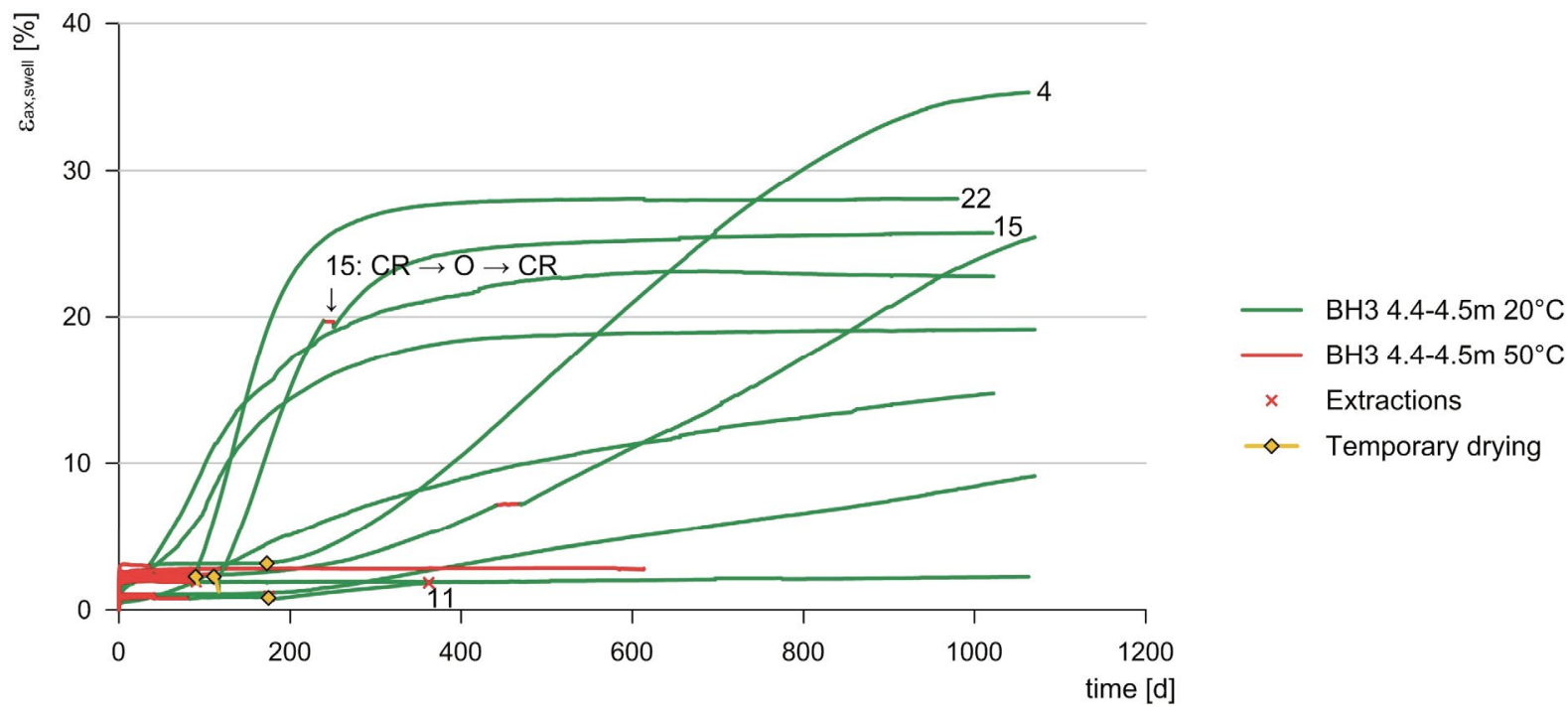

Figure 11-24: Swelling strain of segments $(B H 3,4.4-4.5 m)$ over time (cf. Figure 11-19), incl. 4 tests where the specimens $(4,11,15$ and 22$)$ were temporarily dried. $\mathrm{O}=$ Oven $\left(50^{\circ} \mathrm{C}\right), \mathrm{CR}=$ Climate Room $\left(20^{\circ} \mathrm{C}\right)$.

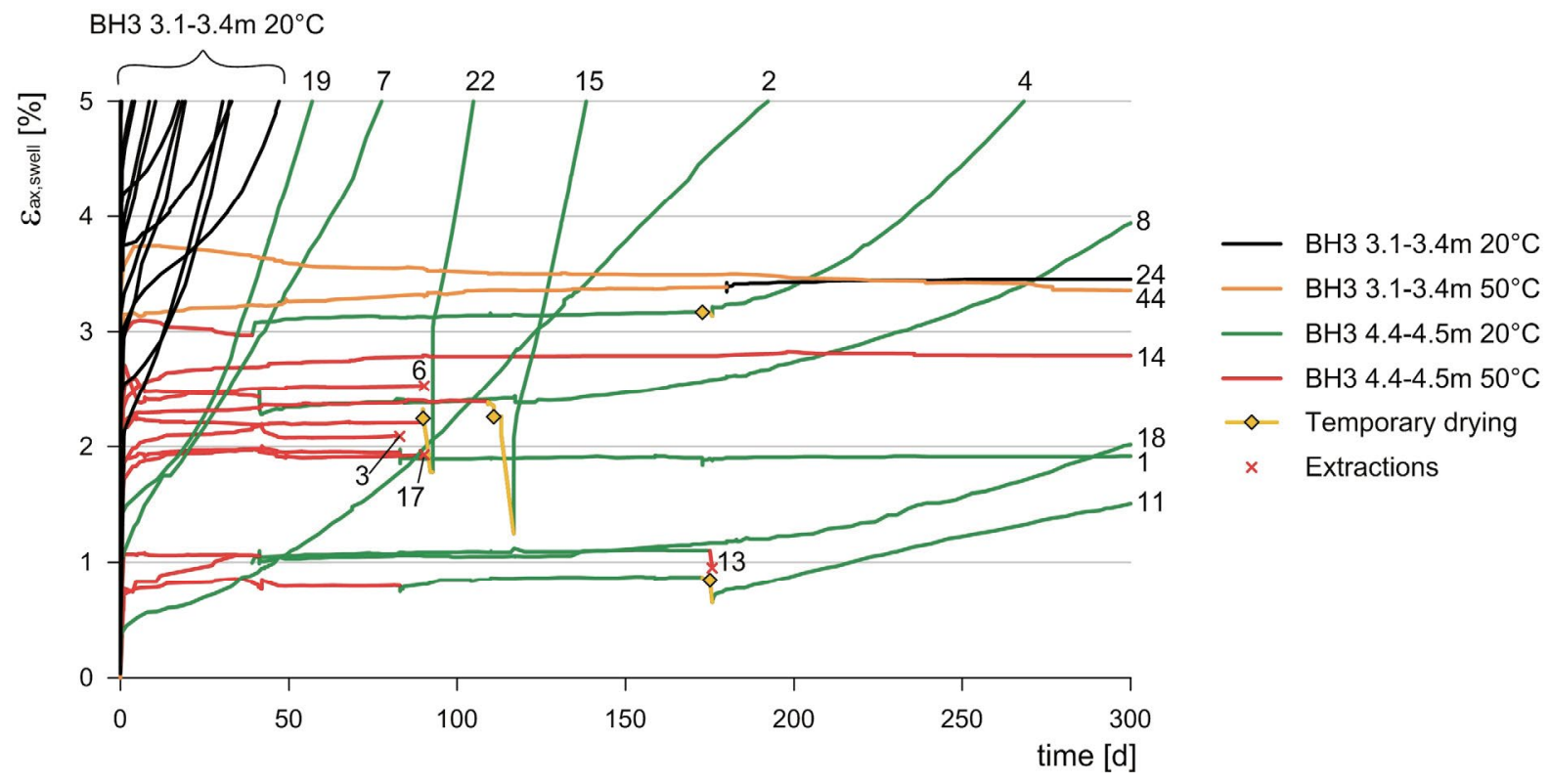

Figure 11-25: Swelling strain of all segments (BH3, 3.1-3.4m and 4.4-4.5m) over time (detailed): scaled for comparison of initial strains and change due to temperature switch and temporary drying of specimens).

The first conclusions that can be drawn from the tests with segments $(\mathrm{BH} 3,3.1-3.4 \mathrm{~m}$ and $4.4-4.5 \mathrm{~m}$ ) undergoing the temperature switch are: 
- Moving the specimens from the oven to the climate room does not trigger swelling due to AGT immediately, which is contrary to the expectations and the observations made with the powdered specimens (Chapter 11.3). At the earliest about 150 days after the temperature change a slow increase in strains was registered (specimens 8 and 18). In one case (specimen 1) no swelling has been registered up to date.

- Removing the water from specimens after they were switched to the climate room and temporarily drying the specimens (first at room temperature, then shortly in an oven), then re-watering them in the climate room leads to slowly increasing strains.

- Temporary drying at $50{ }^{\circ} \mathrm{C}$ before moving the specimens to the climate room, then rewatering them in the climate room leads to a rapid increase in swelling strain.

- Temporarily dried and re-watered specimens reach higher swelling strains compared to the specimens tested solely at room temperature.

- Moving specimens (during swelling) from the climate room to the oven interrupts the increase in swelling strains; moving them back to the climate room causes the swelling process to continue.

\subsubsection{Disks $\operatorname{Tm} 762\left(\mathrm{~T}=20^{\circ} \mathrm{C}\right.$ and $\left.50^{\circ} \mathrm{C}\right)$}

The latest bore cores obtained from Belchen (Tm762 from the borings for sliding micrometers in the $3^{\text {rd }}$ Belchen tunnel) were used to investigate the effect of the temperature on the swelling behavior further:

- For one, it was of interest to see whether (also in the case of specimens from this bore core) the temperature change from $50{ }^{\circ} \mathrm{C}$ to $20^{\circ} \mathrm{C}$ does not trigger AGT immediately, as was the case with the segments presented above. As can be seen in Figure 11-26, the same observation was made here: The specimens BA1, BA3 and BA7 did not swell after they were moved from the oven to the climate room. XRD on specimen BA3 confirmed the suspicion, that AGT had not occurred, i.e., no gypsum had precipitated (see Figure 11-8 and Table J-7 in Appendix J).

- Since also here swelling was not triggered after moving the specimens from the oven to room temperature, the duration at which the specimens are wetted at $50{ }^{\circ} \mathrm{C}$ is varied in a next step, in order to investigate whether this has an influence on the subsequent swelling behavior at $20^{\circ} \mathrm{C}$. This was done with the specimens BA9 $\left(6\right.$ hours at $\left.50^{\circ} \mathrm{C}\right), \mathrm{BA} 10(1$ day at $50^{\circ} \mathrm{C}$ ) and BA6 $\left(2\right.$ days at $\left.50^{\circ} \mathrm{C}\right)$. However, the specimens were not wetted in the oven, but placed on a heating plate in the climate room. This allowed the temperature within the apparatus to be recorded simultaneously to the vertical displacement. A further advantage of the usage of the heating plate was that the apparatus did not need to be moved (i.e., from the oven to the climate room) and the strains could be measured during cooling without interruption. The results are shown in Figure 11-27: The temperature drop (see black dashed lines in Figure 11-27, corresponding to the axes on the right) can be seen in detail for each specimen individually, i.e., after 6 hours, 1 day and 2 days. The corresponding swelling strain curves (left axes in Figure 11-27) are shown in red up to those points in time, when the heating plate was turned off, and continue then in blue. As can be seen from Figure 11-27, right, specimen BA9, which was watered at $50^{\circ}$ for 6 hours resumed swelling after about 2 days, while specimen BA10, which was watered at $50{ }^{\circ} \mathrm{C}$ for 1 day resumed swelling after 6 days, and in the case of specimen BA6 (watered at $50^{\circ} \mathrm{C}$ for 2 days) a slow 
increase in swelling strain can only be observed after about 100 days (visible in Figure 11-28). However, as can be seen in Figure 11-28, the rate of the swelling strains of BA9 and BA10 is far slower on the long run, compared to BA6 and the specimens BA2, BA5 and BA8, which were swelling in the climate room from the beginning on.

- Specimen BA2, which was watered at $20^{\circ} \mathrm{C}$, was moved to the oven after 35 days and back to the climate room two weeks later, in order to confirm that swelling due to AGT stops at $50{ }^{\circ} \mathrm{C}$ and continues again at $20^{\circ} \mathrm{C}$ (see Figure 11-26). It can clearly be seen that the switch to the oven paused further swelling, whereas the change back to $20{ }^{\circ} \mathrm{C}$ caused swelling to resume with a slightly slower rate.

- As a possible cause for the delayed (or even completely absent) swelling due to AGT after moving the specimens from $50^{\circ} \mathrm{C}$ to $20^{\circ} \mathrm{C}$, it was hypothesized that the water in and around the respective specimens contained a sufficient amount of dissolved minerals, so that the equilibrium concentrations of anhydrite and gypsum were so strongly affected that AGT was massively slowed down. For this reason, the water surrounding such a specimen (BA7, which was moved from the oven after 10 days) was extracted 30 days after having been moved to the climate room and replaced with distilled water; this did, however, not trigger swelling.

Furthermore, the water chemism of multiple specimens was investigated (this is presented in Chapter 11.7).

Note that the specimens BA5 and BA8 originating from this bore core were watered at solely $20^{\circ} \mathrm{C}$ and were already shown in Figure 11-15 (blue curves) and Figure 11-21.
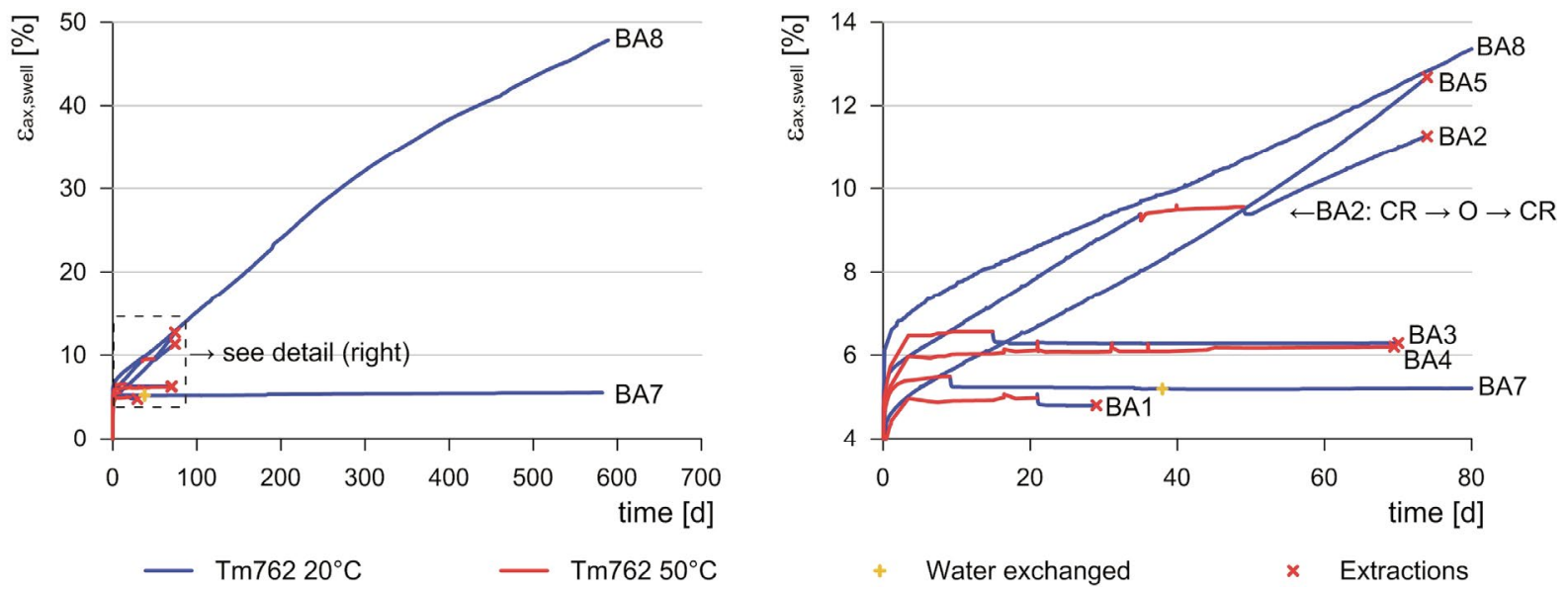

Figure 11-26: Swelling strain of disks (Tm762) over time; detail of first 80 days on the right. 

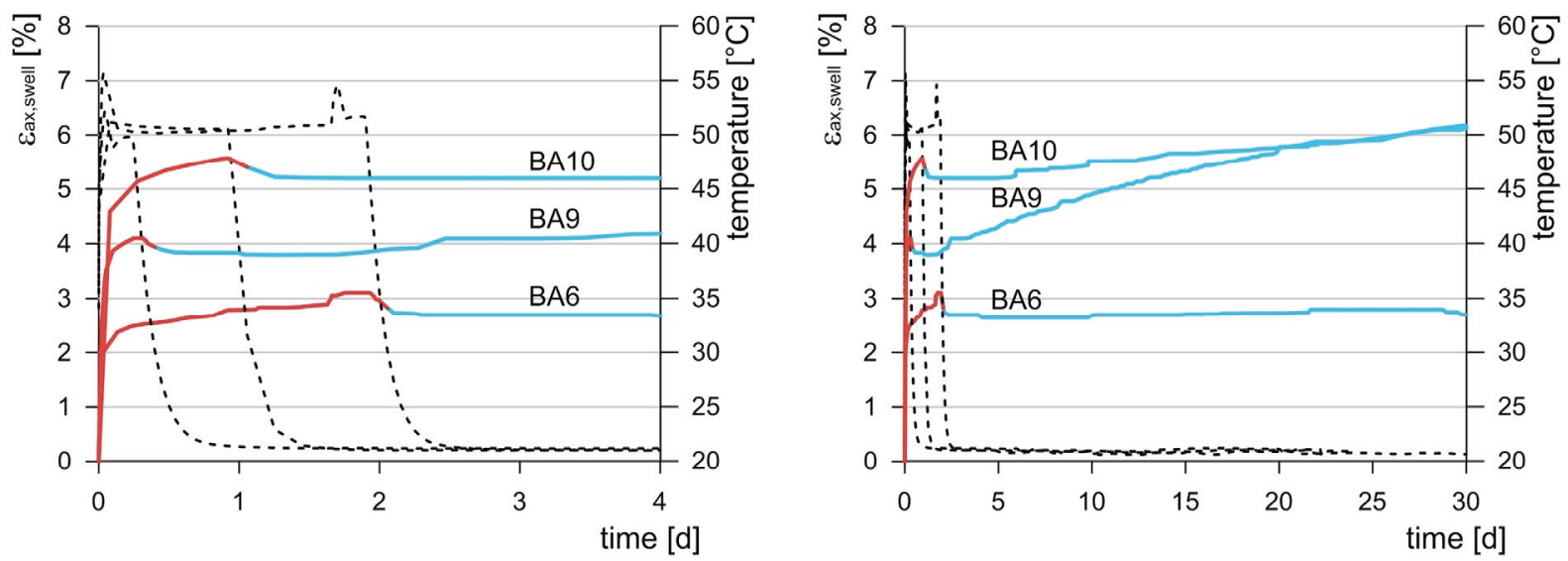

-... water temperatures

- $\operatorname{Tm} 76250^{\circ} \mathrm{C}$

Figure 11-27: Investigation of the duration at which the specimens were watered at a higher temperature. Left: detailed scale up to 4 days, right: first 30 days.

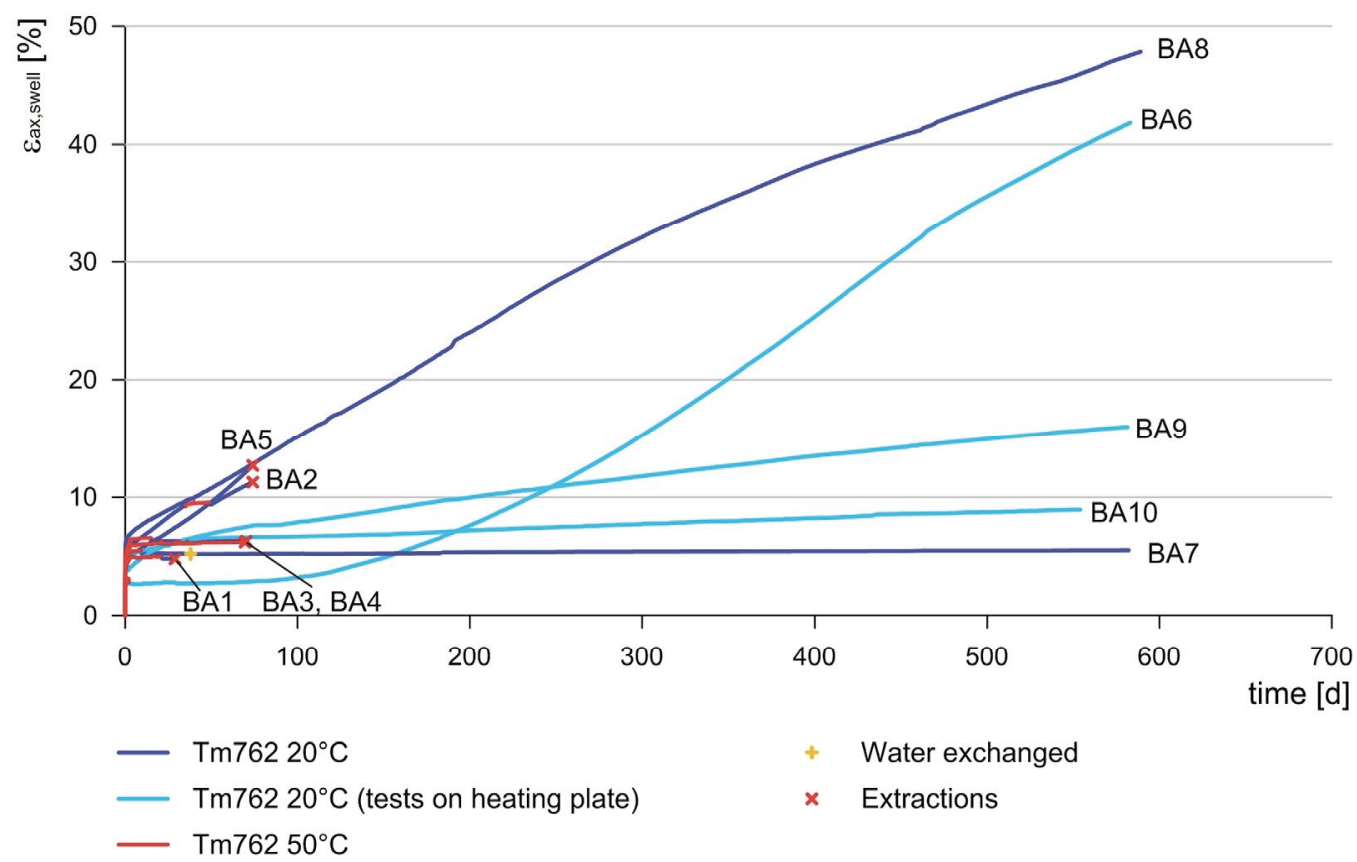

Figure 11-28: Swelling strains of all specimens from bore core Tm762.

\subsection{Microscopic investigations}

As mentioned previously, three segmental specimens were investigated microscopically (see Figure 11-2): specimen 41, which was not wetted at all (represents the rock in its state prior to swelling); specimen 44, which was tested in the oven for ca. 450 days and where no AGT occurred; and specimen 45 , which was tested in the climate room for ca. 1700 days. These three specimens were chosen, in order to distinguish between the change in specimen structure after solely clay swelling, and after both anhydrite and clay swelling. 
The top row of Figure 11-29 shows photographs of the original specimens, prior to any testing. The second and third rows depict images taken with an optical microscope at two different scales of the untreated surface of each specimen, in the case of specimen 41 in its original state, in the case of specimens 44 and 45 after swelling (i.e., after extraction from the swelling tests and drying of the specimens). Following the photographic documentation of the untreated surfaces, the specimens were prepared for investigations with scanning electron microscopy (SEM): In the cases of specimens 44 and 45 , an entire side of each specimen was first embedded in epoxy in order to maintain the stability of the structures for further handling. Pieces of the specimens were then sawed off and coated again with epoxy. Specimen 41 could be sawed directly and embedded in epoxy. After the epoxy hardened, the specimens were polished, thus uncovering a clear crosssection of each specimen for SEM. After this preparation procedure, the cross-sections of the specimens were once again investigated with an optical microscope (see bottom two rows of Figure 11-29, again at different scales).

The orange marked sections in the bottom row of Figure 11-29 could be found again during the investigation of the specimens with SEM (specifically the images from the backscattered electrons BSE), see top row in Figure 11-30. The compositions of the green marked sections of the BSE images were then quantified with energy-dispersive X-ray spectroscopy (EDX), as shown in the bottom half of Figure 11-30. Note that carbon (C) indicates areas where the epoxy remained after polishing the surfaces and represents therefore the pore spaces of the specimens. 


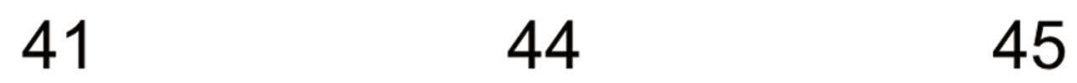

Original specimen

(prior test)

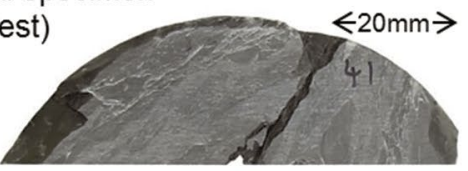

Test type

No wetting

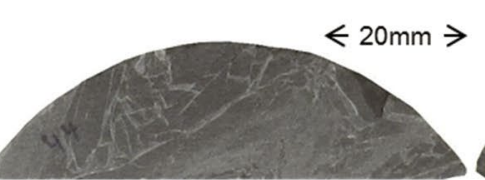

Swelling in oven
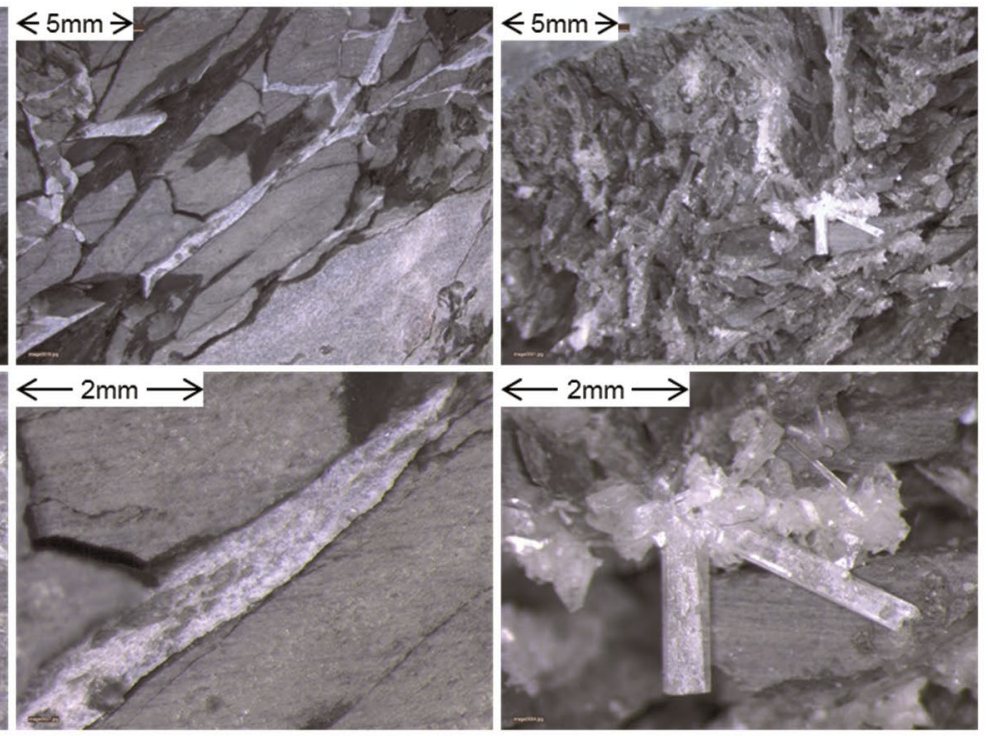

Cross section after SEM sample preparation
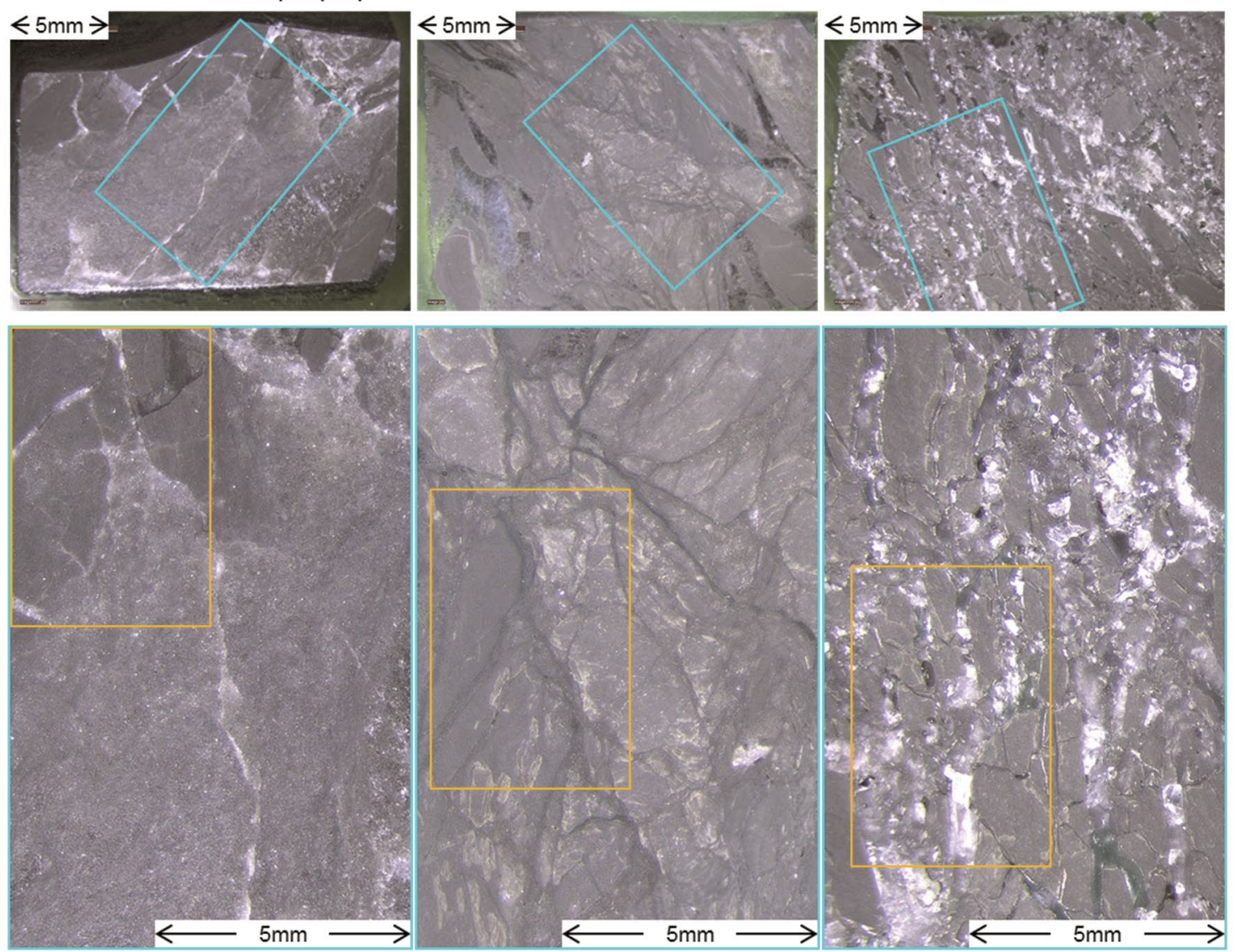

Figure 11-29: Images of the specimens 41, 44 and 45 from Bore core BH3, 3.1-3.4 obtained with optical microscopy. (Note: The length of the segments prior to the tests was roughly $70 \mathrm{~mm}$ ). 


\section{BSE images (from SEM)}
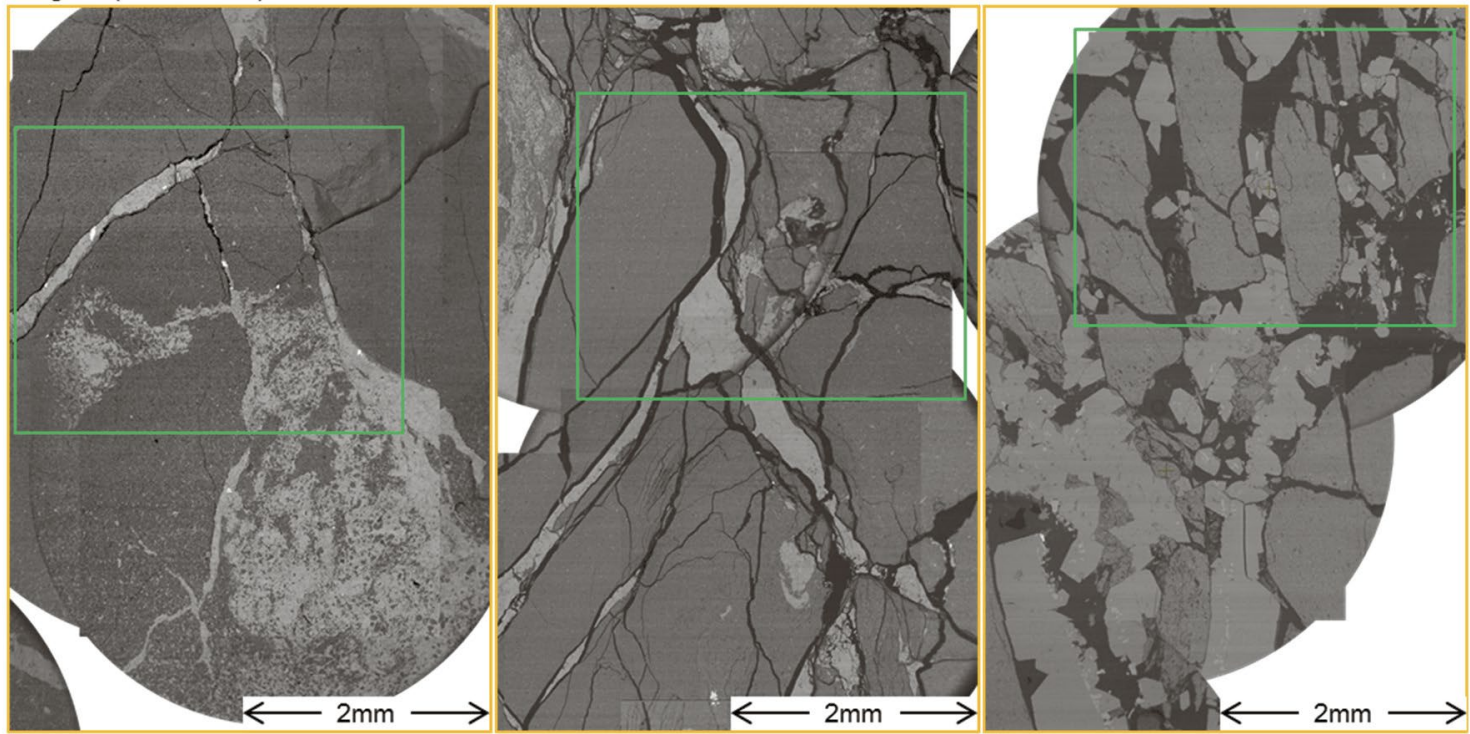

EDX
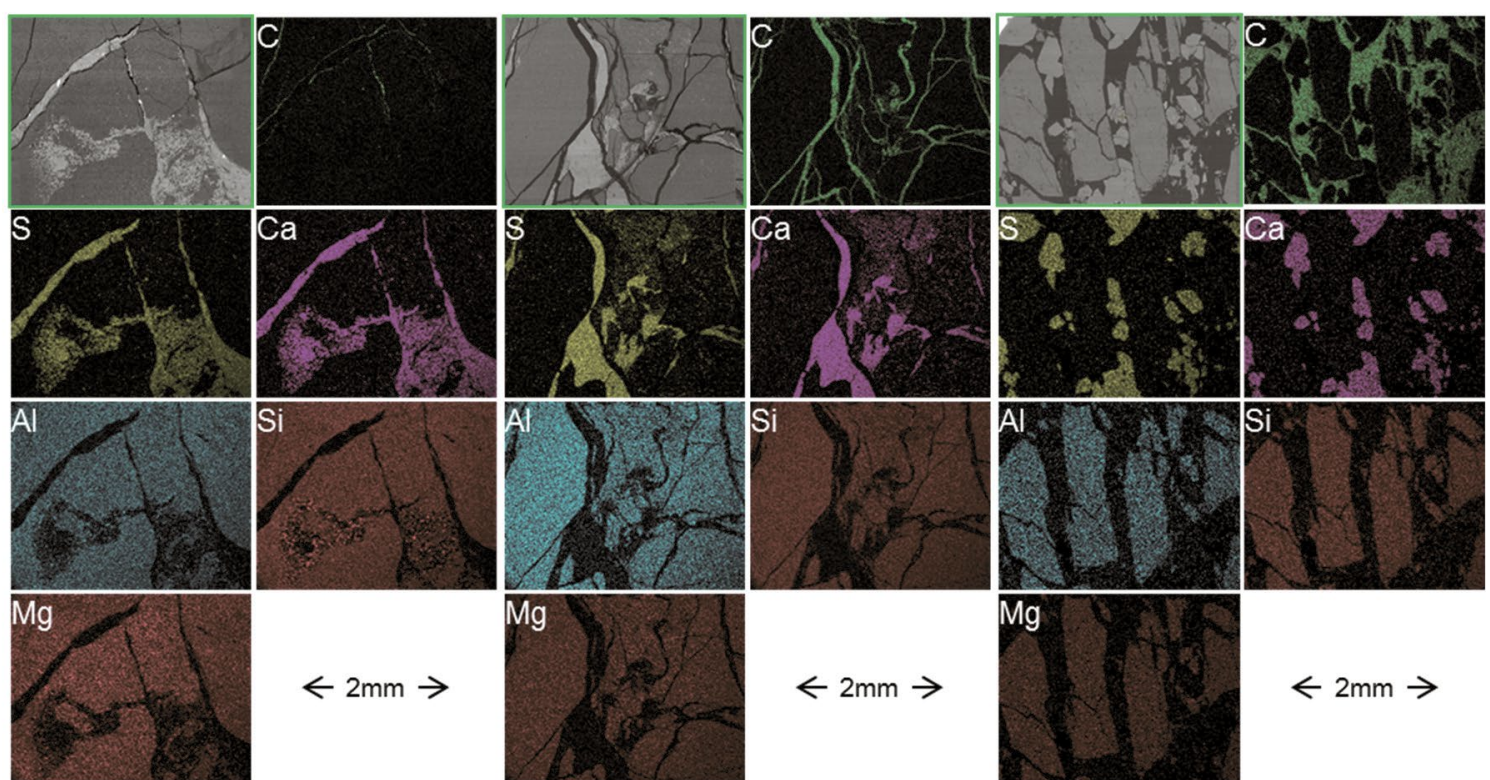

$\leftarrow 2 \mathrm{~mm} \rightarrow$
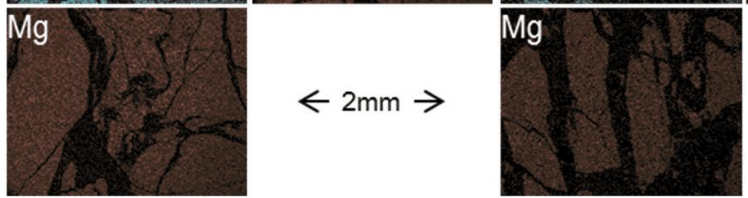

$\leftarrow 2 \mathrm{~mm} \rightarrow$

Figure 11-30: Results from SEM and EDX investigations. Columns from left to right: specimens 41, 44 and 45 from Bore core BH3, 3.1-3.4. Rows from top to bottom: BSE images of the same cross-sections and mapping of various elements with EDX analysis?

It can be seen that the distribution of calcium and sulfate is fairly similar in the cases of specimens 41 and 44: They are present in the form of anhydrite, mainly distributed in the rock as veins, but also finely distributed (see top left image of Figure 11-30). Performing a swelling test at $50^{\circ} \mathrm{C}$ therefore does not seem to change the appearance and distribution of the anhydrite. However, the difference in the carbon mapping clearly shows that some fairly distinct cracks occur due to clay swelling and the subsequent drying of the specimen after the swelling test. Specimen 45 shows a different picture: Here the pore space increased strongly, while now "specks" of calcium and sulfate can be seen within the pore space. It can be devised that the gypsum precipitated in the pore space and within the created cracks.

\footnotetext{
${ }^{2}$ Additionally, Potassium, Iron, Chloride and Oxygen were detected but did not provide as clear and specific patterns
} as those shown in Figure 11-30 and were therefore omitted here. 


\subsection{Investigations of the water chemism}

As a possible explanation why the specimens did not swell after reducing the testing temperature (i.e., after moving them from the oven to the climate room), it was deemed that the chemism of the water may have changed in the oven (due to other dissolving minerals from the matrix), enough, to influence the equilibrium concentrations and slow down the AGT process.

For this reason the chemism of the testing water was investigated for certain specimens by means of ICP-OES and AAS (cf. Chapters 3.8 and 3.9). Figure 11-31 shows all swelling tests from which water was used for the investigations of the water chemism, and the respective points where the water (10-50 ml) was extracted (blue crosses).
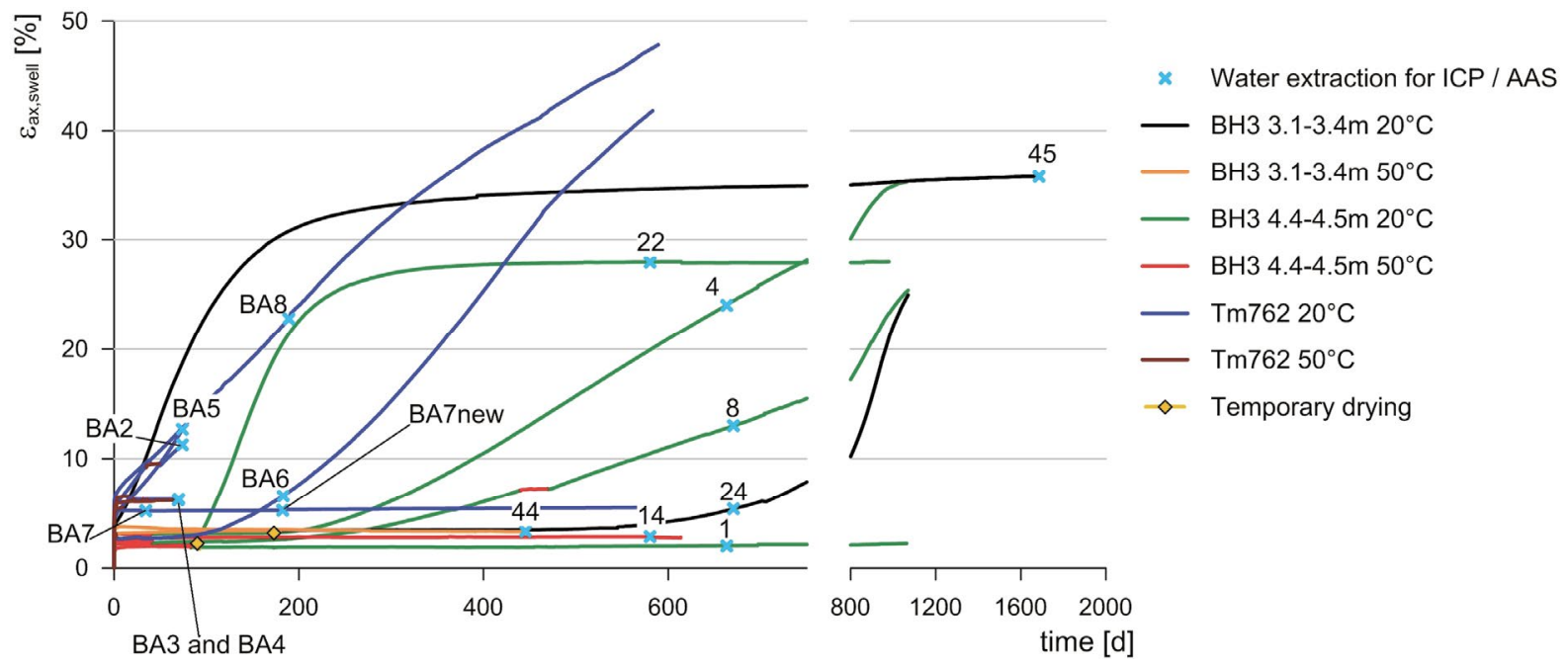

Figure 11-31: Points of water extraction for investigation of water chemism (AAS and ICP).

Since it was attempted to find a correlation between the swelling behavior and the chemism of the water, a variety of specimens that were in the oven, switched to the climate room and that were only in the climate room were investigated. Specimens from the borings $\mathrm{BH} 3$ and $\mathrm{Tm} 762$ were considered. A description of the testing procedure for each specimen is given in Table J-9 in Appendix J.

The ICP results for the most significantly present elements in the water (i.e., the elements which revealed the highest concentrations: $\mathrm{Ca}, \mathrm{S}, \mathrm{Na}, \mathrm{Mg}$ and $\mathrm{K}$ ) are shown in Figure 11-32 for each specimen. Further elements ( $\mathrm{Al}, \mathrm{Fe}$ and $\mathrm{Si}$ ) were also detected but are considered negligible in comparison (see also Table J-9 in Appendix J, where an overview of the investigated specimens, the testing conditions during the freeswell-tests and all measured concentrations are given). Note that not all elements are analyzed with ICP-OES, such as $\mathrm{C}, \mathrm{N}, \mathrm{O}$ and $\mathrm{H}$ (Manning and Grow, 1997).

Figure 11-33 depicts the strains the specimens reached at the points where water was extracted versus the concentrations of the respective element determined with the ICP-measurements for each element (the origin of the respective rock specimens and their swelling behavior are denoted in a variety of colors and symbols) as well as AAS-measurements (denoted as the grey dots, whereas the grey dashed lines indicate the corresponding ICP-measurements). Analogously, the diagrams in Figure 11-34 indicate the duration of each test versus the measured concentration of the above mentioned elements in the water. 


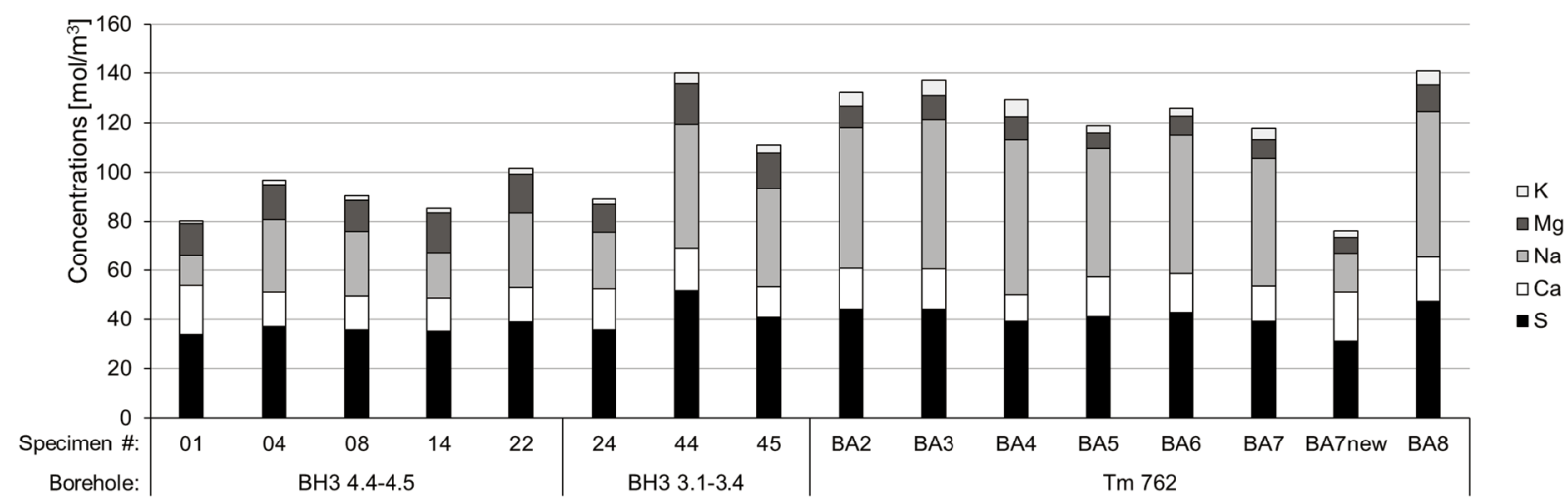

Figure 11-32: Results from ICP for the most significant elements.
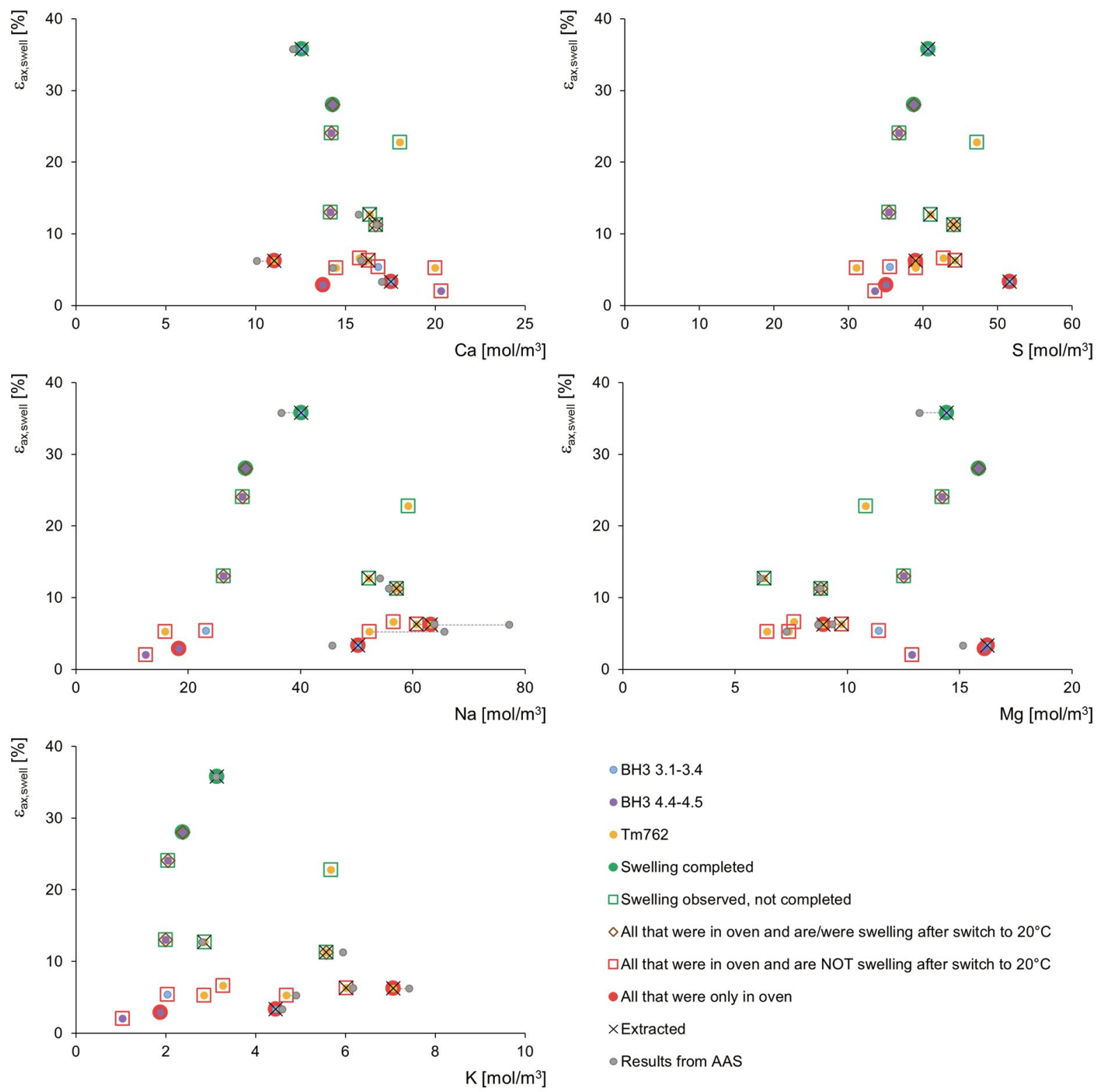

Figure 11-33: Results from ICP (as well as AAS measurements, denoted as grey dots): strain at point of water extraction vs. concentration of respective element ( $\mathrm{Ca}, \mathrm{S}, \mathrm{Na}, \mathrm{Mg}$, and K). 

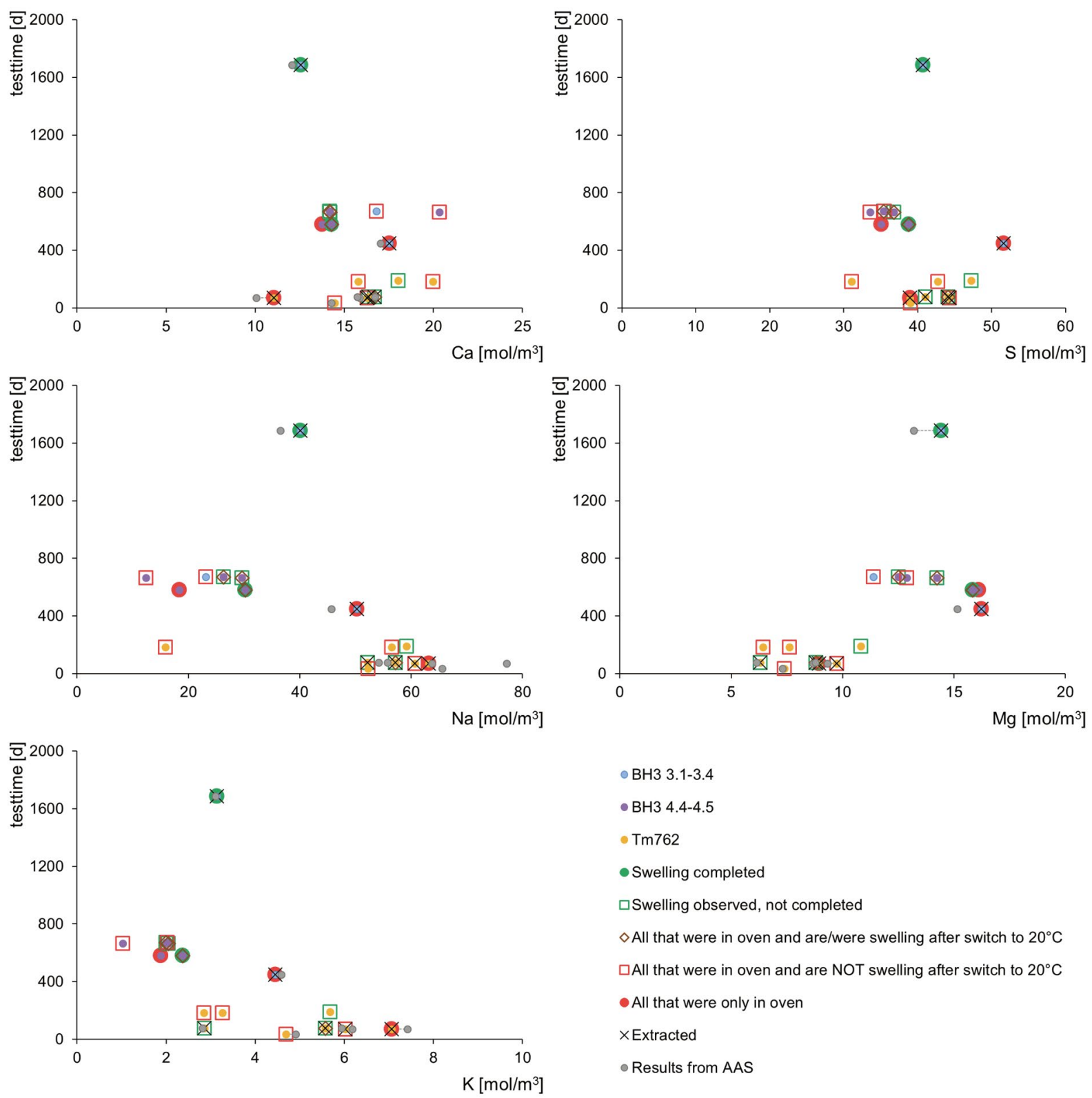

Figure 11-34: Results from ICP (as well as AAS measurements, denoted as grey dots): test time at point of water extraction vs. concentration of respective element ( $\mathrm{Ca}, \mathrm{S}, \mathrm{Na}, \mathrm{Mg}$, and K).

When comparing the results from AAS to those from ICP, it can be seen that most are the same or at least lie within a similar range. The only results that differ markedly are those of $\mathrm{Fe}$ (see Table J-9), where ICP shows higher contents than AAS. However, these very low concentrations (in the range of $\mathrm{mmol} / \mathrm{m}^{3}$ ) are near the bottom boundary of the range that can be measured with AAS (or even below it) and are therefore most likely not correct.

Assuming anhydrite dissolution and gypsum precipitation to be the only sources and sinks of sulfur and calcium, one would expect the concentrations of sulfur and calcium in the solutions to be similar. However, from Figure 11-32 and the top two diagrams in Figure 11-33 and Figure 11-34, it is clearly noticeable that the calcium and sulfur concentrations in the water do not match, whereas the concentration of sulfur is up to 3.5 times higher than that of calcium in some cases. A possible explanation for this is that other reactions or processes (apart from gypsum precipitation) consume the calcium in the solution. Two calcium-sinks are deemed plausible in this case, based on the water chemism: 
- The calcium is used for precipitation of calcite, $\mathrm{CaCO}_{3}$ :

Magnesite $\left(\mathrm{MgCO}_{3}\right)$, which has been detected in the rock specimens via XRD (see Table J-7), is assumed to have dissolved based on the amount of Mg measured in the water specimens (see Figure 11-32 to Figure 11-34). The corresponding amount of carbon trioxide $\left(\mathrm{CO}_{3}\right)$ may have precipitated to $\mathrm{CaCO}_{3}$ with the calcium in the solution. Based on this hypothesis, the concentration of $\mathrm{Mg}$ in the water corresponds to the amount of $\mathrm{Ca}$ consumed for the precipitation of $\mathrm{CaCO}_{3}$.

- Exchange of $\mathrm{Na}^{+}$with $\mathrm{Ca}^{2+}$ in the clay interlayers:

The high concentrations of $\mathrm{Na}^{+}$in the water stems most likely from the clay. It is possible that the $\mathrm{Na}^{+}$in the clay interlayers was exchanged with $\mathrm{Ca}^{2+}$ (i.e., $1 \mathrm{Ca}^{2+}$ for $2 \mathrm{Na}^{+}$; note that diffusion of water into the rock and cation exchange occur faster than the durations of the swelling tests, i.e., cation exchange can occur within minutes to hours according to correspondance with $\mathrm{M}$. Plötze, ETH Zurich). Therefore, the clay is simultaneously a $\mathrm{Na}^{+}-$ source and a $\mathrm{Ca}^{2+}$-sink. In most cases it was also seen that the amount of $\mathrm{Na}^{+}$in the solution was generally higher when the smectite content of the specimen was higher. Therefore, it is assumed that the smectite contained $\mathrm{Na}^{+}$, although a major part of the interlayer cations was most likely $\mathrm{Ca}^{2+}$ to begin with, since the rock stems from a $\mathrm{Ca}^{2+}$-rich formation. It may, however, be that some of the $\mathrm{Na}^{+}$in the solution also stems from dissolution of $\mathrm{NaCl}$ and, therefore, the $\mathrm{Na}^{+}$concentration gives an over-estimation of the corresponding amount of $\mathrm{Ca}^{2+}$ according to this hypothesis. (This cannot be confirmed due to the fact that $\mathrm{Cl}^{-}$could not be detected with the ICP measurements. However, rough striptests indicated $\mathrm{Cl}^{-}$to be present in most solutions.)

These two hypotheses can be discussed by comparing the concentration of $S$ to the sum of the concentrations of $\mathrm{Ca}, \mathrm{Mg}$ and $0.5 \cdot \mathrm{Na}$. This is shown in Figure 11-35 for each specimen. It can be seen that the sum of $\mathrm{Ca}, \mathrm{Mg}$ and $0.5 \cdot \mathrm{Na}$ amounts to a slightly higher value than the $\mathrm{S}$ concentration (which may be due to dissolving $\mathrm{NaCl}$, as described above), but lies generally within a similar range, especially in the case of $\mathrm{BH} 3$ 4.4.-4.5.

As a reference, water saturated in the laboratory with respect to gypsum (i.e., ca. $2 \mathrm{~g} / \mathrm{l} \mathrm{CaSO}$, as was used for most swelling experiments in this work) was investigated as well. As can be seen on the right in Figure 11-35, the concentrations of $\mathrm{S}$ and $\mathrm{Ca}$ in solution are nearly the same and correspond to the equilibrium concentration of gypsum.

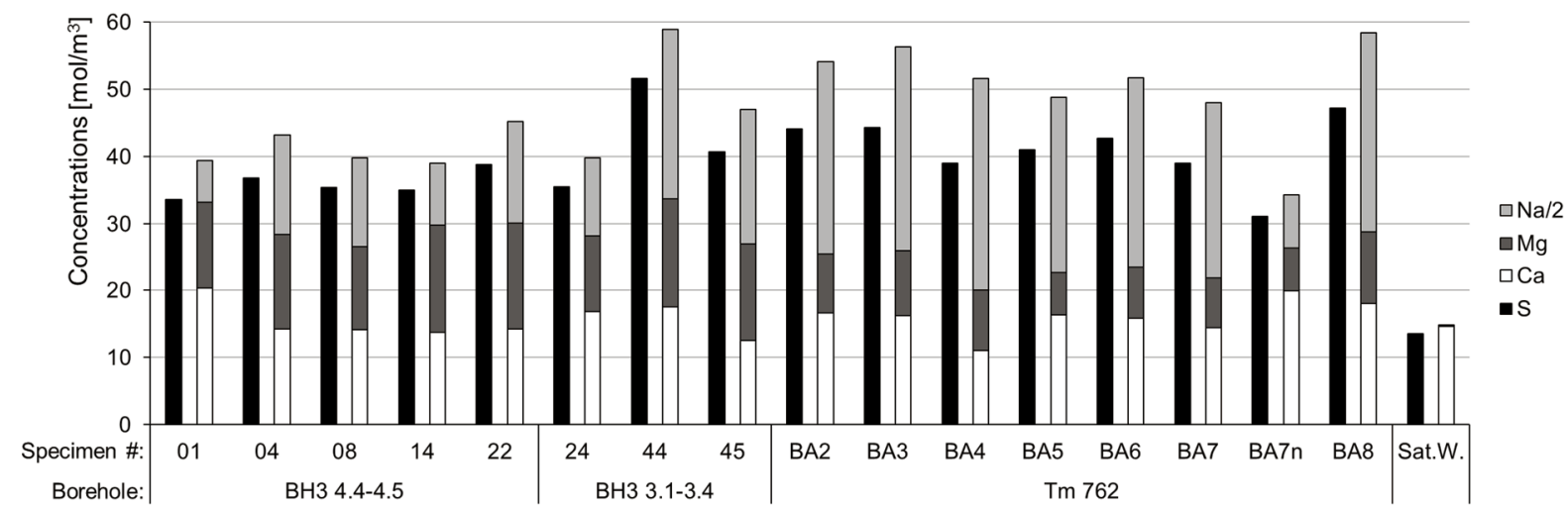

Figure 11-35: Comparison of the concentrations of sulfur to the sum of calcium, magnesium and $50 \%$ of the sodium in solution for each specimen. 
From Figure 11-33 no clear correlation can be obtained as to which elements in solution may have influenced the swelling behavior. Neither was it possible to observe a correlation between the test duration and the dissolved elements in the water (Figure 11-34). Also, no explanations could be found so far regarding the occurrence of $\mathrm{K}$ in the solutions. Though orthoclase and muscovite contain $\mathrm{K}$, dissolution of these minerals is not considered the cause here, since the amounts of $\mathrm{Si}$ and $\mathrm{Al}$ (which are also elements of orthoclase resp. muscovite) in the solutions were comparatively too low (see Appendix J, Table J-9).

Since the equilibrium concentrations influence the kinetics of AGT (cf. Chapter 2.4), in a next step the measured concentrations were used to calculate the ionic strength $I$ and ultimately the equilibrium concentrations of anhydrite and gypsum for each solution by using the Equations given in Appendix A (see Figure 11-36 and Figure 11-37). Here too, however, no correlation was seen to explain why the specimens did not swell after being watered at a higher temperature. Neither did the concentration gradients (i.e., $c_{e q, A}-c_{e q, G}$, which was calculated to $4.9-5.6 \mathrm{~mol} / \mathrm{m}^{3}$, i.e., $0.67-0.76 \mathrm{~g} / \mathrm{l}$, in all cases), where a smaller value could have indicated a slower AGT process, cf. Chapter 2.4.
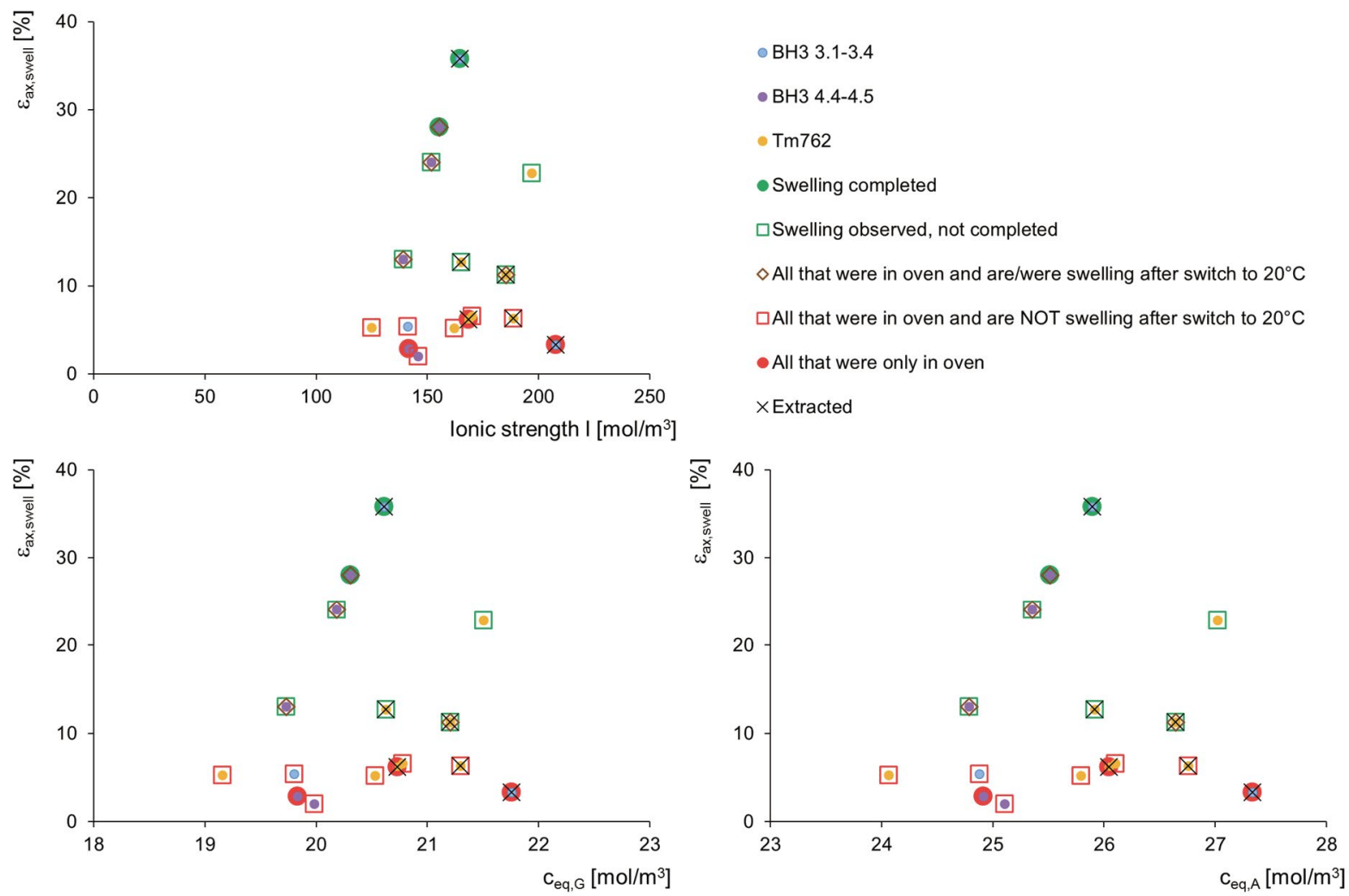

Figure 11-36: Strain at point of water extraction vs. ionic strength and equilibrium concentrations which were calculated based on the measured concentrations. 

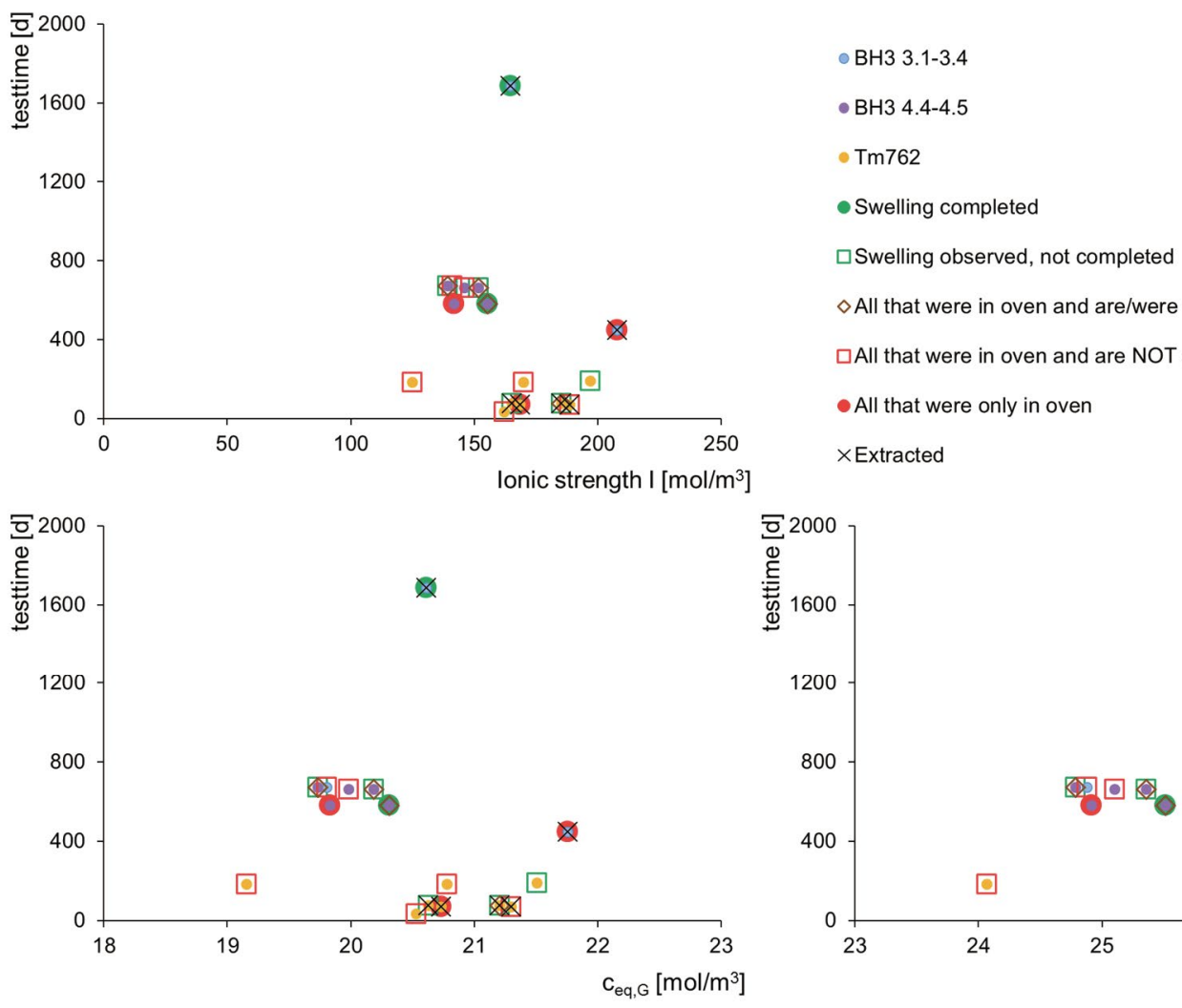

$\diamond$ All that were in oven and are/were swelling after switch to $20^{\circ} \mathrm{C}$

$\square$ All that were in oven and are NOT swelling after switch to $20^{\circ} \mathrm{C}$

- All that were only in oven

$\times$ Extracted

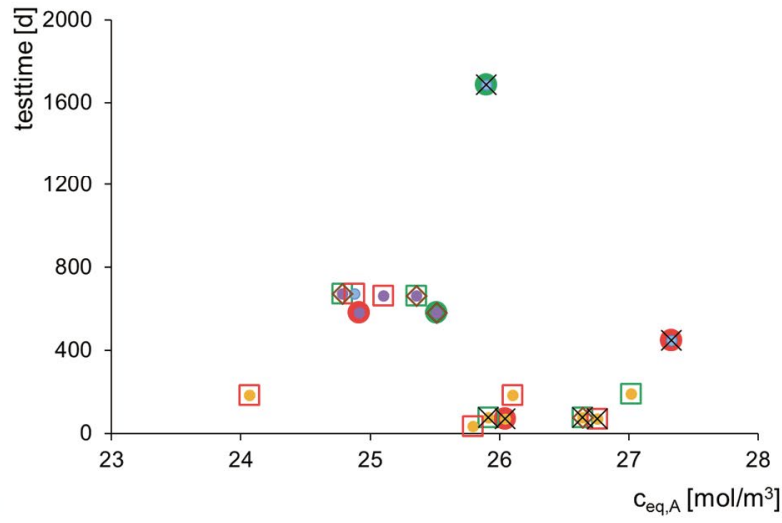

Figure 11-37: Test time at point of water extraction vs. ionic strength and equilibrium concentrations which were calculated based on the measured concentrations.

The influence of "other" ions in the solution on the equilibrium concentrations was described in Chapter 2.3.4. Note that in Figure 11-36 and Figure 11-37 the ionic strengths and thus the equilibrium concentrations were calculated with the concentrations of all ions measured (i.e., also calcium and sulfate, as opposed to Chapter 2.3.4); when subtracting the influence of the measured calcium and sulfate ions, the ionic strengths solely due to the "other" ions, $I_{\text {otherions }}$, lie between 20 and $70 \mathrm{~mol} / \mathrm{m}^{3}$ (cf. Figure 2-6).

Based on the measured ionic concentrations one obtains the charge balance of the water shown in Figure 11-38, where the negative charge mainly stems from the sulfate in the water (black columns), while the positive charge is made up by $\mathrm{K}^{+}, \mathrm{Mg}^{2+}, \mathrm{Na}^{+}$and $\mathrm{Ca}^{2+}$. A slight imbalance becomes apparent, i.e., from the known concentrations one obtains total charges of the solutions equal to $+19 \mathrm{eq} / \mathrm{m}^{3}$ on average (specifically +9 to $+33 \mathrm{eq} / \mathrm{m}^{3}$ ). This imbalance is most likely compensated with carbonate and chloride in the solution, which was not measured with ICP. 


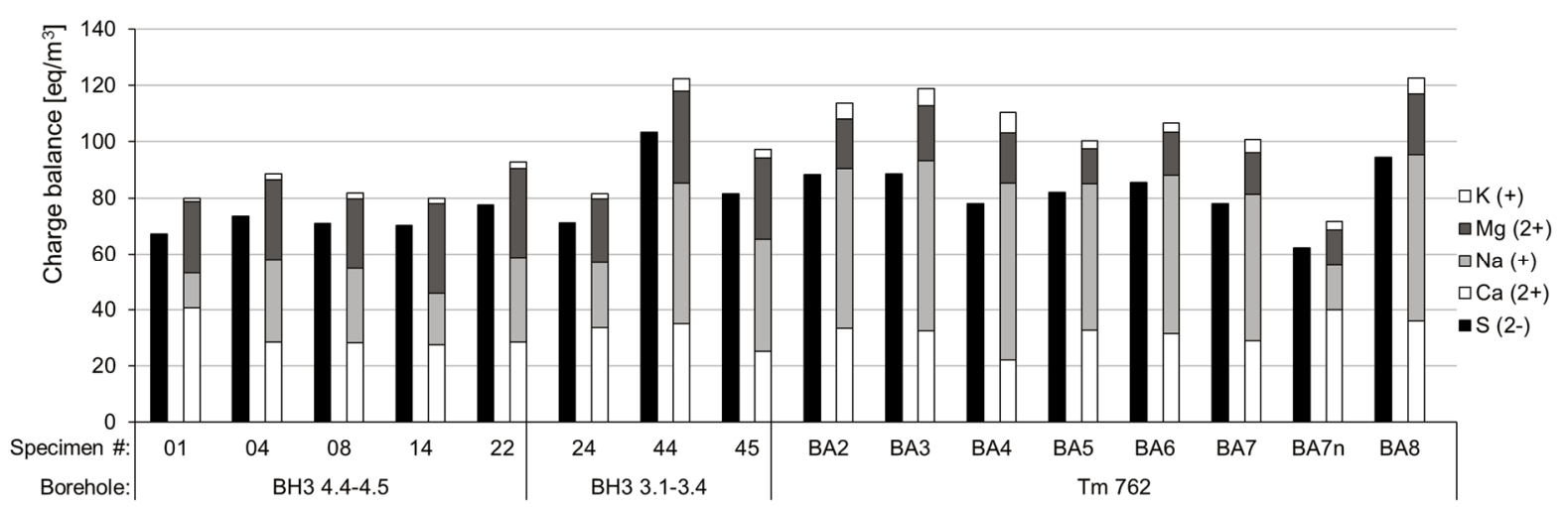

Figure 11-38: Comparison of negative (black) and positive (white and greyscale) charges of the main ions in the water.

\subsection{Discussion}

The rapid ascent occurring in the first hours of the tests (see Figure 11-14 to Figure 11-28) is a result of the physical swelling of the rock matrix surrounding the anhydrite: the osmotic swelling of clay, as well as rapid mechanical swelling due to the initially low degree of saturation of the specimens which leads to immediate water absorption. The value for these strains (i.e., $\varepsilon_{I}=\varepsilon_{\text {mech }}+\varepsilon_{\text {clay }}$ ) can easily be estimated from the measurements, since each curve exhibited a distinct change in the rate of swelling within the first 24 hours, most even within one hour of watering the specimens. This corresponds well to the total swelling strains reached in the oven. The initial heave of the SB6-disks was smaller than that of the segments and Tm762-disks, which is most likely due to the fact that the initial degree of saturation of the SB6-disks was higher than that of the other specimens (the other bore cores were not immediately preserved after sampling and thus dried out more). It appears that the physical swelling is completed within a few days, i.e., much faster than the swelling due to AGT, since no additional swelling occurs in the oven after the initial strain.

During this first stage of swelling, the structure of the specimens changes, which was also seen in the microscopic investigations. During the subsequent swelling due to AGT, the gypsum expands the cracks and precipitates within them or even creates new cracks or macropores locally (see Pimentel, 2007a). This explains why the total swelling strain remains nearly constant after a certain time, even though gypsum precipitation continues, as was seen in the case of the segments: Anhydrite dissolution (and thus gypsum precipitation) appeared to occur relatively linearly over time, whereas the total swelling strains (which developed in a curved "S" shape) slowly approach an asymptotic value, even though AGT is not yet completed.

With the disks (SB6 and Tm762), the swelling strain develops far slower and is still increasing linearly even after about five years (especially in the case of SB6). A possible cause for this is the gypsum present in the specimens of SB6 prior to the tests (i.e., due to the effect of sealing of anhydrite, $c f$. Chapter 5).

Due to the fact that the swelling strains of the segmental specimens scatter strongly and the analysis is based on some uncertain assumptions, mainly because of the segmental shape and the appearance of bassanite in the specimens after drying them at too high temperatures post test, a concluding interpretation of the results is so far not possible. The scatter in the results can furthermore be attributed to the heterogeneous composition of the specimens. It is noticeable that the strains reached by the specimens of the section 3.1-3.4m of the bore core $\mathrm{BH} 3$ are higher than 
those reached by the specimens from 4.4-4.5m. One explanation for this difference may be in the amount of swelling clays within the specimen: The X-ray analysis on $\mathrm{BH} 33.1-3.4 \mathrm{~m}$ showed an average content of about $9 \%(5-15 \%)$ of smectite whereas the section $4.4-4.5 \mathrm{~m}$ revealed an average of about $6.5 \%(3-12 \%)$. If also illite, muscovite and chlorite are considered, which are generally not known to be strongly swelling clay minerals but could form mixed-layer clays with smectite (as described, e.g., in Meunier, 2005 or Amstad and Kovári, 2001), BH3 3.1-3.4m contained on average $28 \%(15-39 \%)$ and $4.4-4.5 \mathrm{~m} 18 \%(8-31 \%)$. This may explain, why the initial strains were slightly higher in the case of $\mathrm{BH} 33.1-3.4 \mathrm{~m}$, but does not explain why the measured total strains differ so strongly. The varying swelling strains can also not be conclusively explained by the amount of anhydrite in the specimens prior to testing. It can generally be said that the specimens of the section $3.1-3.4 \mathrm{~m}$, which exhibited higher swelling strains, contained less anhydrite ( $50 \%$ on average) based on the XRD results than the specimens of the section $4.4-4.5 \mathrm{~m}$ (64\% of anhydrite on average).

Upon watering of the specimens at $50^{\circ} \mathrm{C}$ and observing an immediate heave, the swelling strain did not increase any further in both rocks and powdered compressed specimens. Moving the specimens from the oven to room temperature had a varying effect on the specimens: The powdered material began to swell immediately, whereas the rock specimens (segments and disks) did not swell any further for a significant amount of time. The latter only swelled more rapidly, when the specimens were dried temporarily; otherwise the swelling strain only began to increase slowly more than 100 days after moving the specimens from the oven to the climate room.

It was possible to "pause" the swelling processes of two segments and one disk, as well as of a powdered specimen by moving them from the climate room back to the oven. Upon returning them to the climate room, the swelling resumed.

The results of the swelling tests with the powdered specimens (oedometer tests) are similar to the ones obtained with the artificial mixtures presented in Part III (Chapter 8.5): Here too, a linear relationship between the swelling strains and the (remaining) mass of anhydrite in the specimen was identified (see Figure 11-14, right), therefore here too, $\chi$ is constant (cf. Equations $(7-43)$ and $(8-16))$ and amounts to approximately 2.

For the case of the natural rock specimens $\chi$ cannot be quantified, due to the varying amount of anhydrite in the specimens prior to the tests (e.g., solely in the case of $\mathrm{BH} 33.1-3.4 \mathrm{~m}$, the initial mass of anhydrite per unit volume, $m_{A, \text { prior }}$, varies from 0.6 to $\left.1.6 \mathrm{~g} / \mathrm{cm}^{3}\right)$. However, since it was seen that a major part of the swelling strains already occurred when only about $20 \%-40 \%$ of the anhydrite within the specimens was transformed (cf. Figure 11-18) and additional AGT caused comparably small additional swelling strains, it is strongly assumed that $\chi$ would not be a constant for natural rocks (i.e., the change in mass of anhydrite would not be proportional to the measured strains). With increasing time, $\chi$ would approach zero, since the rate of the strains decreases while AGT still continues.

When comparing the microscopic images of the specimens prior to wetting (41), after watering solely in the oven (44) and after watering and swelling in the climate room (45) it becomes apparent that watering the specimens changed the specimen structure evidently. Upon watering in the oven, all specimens already showed quite a loosening of the matrix, though some of the cracks seen in specimen 44 in Figure 11-30 may have occurred due to drying of the specimen. However, as can be seen clearly in Figure 11-30, somewhat bulky "blocks" of clay remain, with some lighter (presumably) anhydritic veins in between. On the other hand, specimen 45, which swelled at room temperature, showed a more damaged clay matrix. Gypsum needles could be observed in various 
pore spaces. Also, when looking at the polished cross-sections of the specimens, specimen 45 shows a far more granular matrix compared to specimen 44. The images from backscattered electrons, in combination with EDX, indicate that the pore space increases for one due to clay swelling (elongated fissures), while anhydrite swelling further increases the pore space, mainly by creating larger cracks between the clay particles. 


\section{Conclusions}

AGT does not occur at highly negative pore water pressures within the rock, because the equilibrium concentration of anhydrite is lower than that of gypsum. Depending on the humidity (and thus the degree of saturation), it is possible that the rock reaches low potentials, even below $-100 \mathrm{MPa}$, as was seen with psychrometer measurements performed on small dry rock samples. Similarly, Alonso and Olivella (2008) have also measured suction in the range of -40 to $-20 \mathrm{MPa}$ on specimens from bore cores recovered from the anhydritic claystone in the floor of the Lilla Tunnel. This can explain why in situ anhydrite is present rather than gypsum (see Anagnostou et al., 2014), although it needs to be considered that the measurements can be strongly influenced by the drying during sampling and testing (see Chapter 10.2.2).

As discussed in Chapter 10.2.1, temperature influences AGT: At temperatures above $49{ }^{\circ} \mathrm{C}$, the equilibrium concentration of anhydrite is below that of gypsum, at lower temperatures the opposite is the case. Thus it is possible to suppress AGT at higher temperatures and the active swelling processes can be attributed to the clay exclusively. This was seen in the experimental investigations: The free swelling tests performed in the oven at $50^{\circ} \mathrm{C}$ showed merely an initial swelling strain, which remained constant after the first couple of days. Analogous specimens tested at room temperature showed far higher swelling strains, which developed over a long period of time (at least over one year). It was also possible to stop the swelling process momentarily by changing the temperature from $20^{\circ} \mathrm{C}$ to $50^{\circ} \mathrm{C}$ and to resume the swelling process by returning back to $20^{\circ} \mathrm{C}$. It is, therefore, safe to conclude that the swelling process occurring after the initial heave can be attributed to AGT (including, of course, cracking of the specimen due to the precipitation of gypsum).

It was observed that moving the segments from the oven to the climate room did not lead to additional swelling for a long time, often more than 100 days. The duration was seen to be dependent on the length of the watering at $50^{\circ} \mathrm{C}$. However, drying the specimens temporarily and resubmerging them in water at $20^{\circ} \mathrm{C}$ rapidly triggered swelling due to AGT. So far no explanation could be found as to why this procedure led to rapid swelling (analogue to when the specimens were watered directly at $20^{\circ} \mathrm{C}$ from the beginning on).

An investigation of the chemism of the pore water did not give any indication as to why the rocks did not swell after switching them from the oven to the climate room. However, a further interesting observation was made: It was seen that the calcium and the sulfate contents did not match, which was expected based on the AGT process. This was also seen when studying the data on ion concentrations from chemical water analyses which Serafeimidis and Anagnostou (2014a) listed from various sources: Especially in the case of water specimens from Belchen, the sulfate content was higher than that of calcium. It is strongly assumed that the calcium is consumed by other means, specifically for precipitation of calcite and in the clay interlayers in exchange with sodium, which would explain the higher $\mathrm{Na}$ content in the water.

Thanks to the microscopic images of the cross-sections of the specimens it could be seen that the gypsum does not appear to grow solely where previously anhydritic veins have been, but also within the more bulky clay clusters. It appears that some ion transport occurred within the specimens due to diffusion and that crystal growth of gypsum created new cracks and macropores, as already discussed above. The specimen 45 was very clearly and strongly cracked due to AGT, while specimen 44 , where solely clay swelling occurred, experienced fewer, but larger and more clearly defined cracks. 



\title{
PART IV \\ NATURAL ROCKS - INFLUENCE OF CLAY
}

\begin{abstract}
When natural anhydritic claystones come into contact with water, the rock swells due to physical and chemical processes: reduction of negative pore water pressure (mechanical swelling), osmotic swelling of clay (due to electric forces) and swelling due to anhydrite to gypsum transformation (AGT). So far it is unknown to which extent each of these processes contributes to the observed swelling of the rock and how they influence one another.

In an experimental campaign performed within this thesis, multiple free swelling tests with rock from the Gypsum Keuper formation were conducted to study the simultaneously occurring swelling processes. AGT can be suppressed when the rock is wetted at temperatures above $50{ }^{\circ} \mathrm{C}$. By letting the specimens swell at different temperatures, it was thus possible to observe the physical swelling (osmotic and mechanical swelling) alone, as well as the combined swelling due to both physical and chemical processes. It was seen that the clay and mechanical swelling occur nearly instantaneously upon wetting, whereas swelling due to AGT can take years to complete, even when the rock is not confined. Furthermore, AGT swelling was strongly decelerated when the rock was wetted at warmer temperatures at first (i.e., above $50^{\circ} \mathrm{C}$ ). Finally, the structure and water chemism of some selected specimens was investigated more closely.
\end{abstract}





\section{Conclusions and outlook}

This thesis is part of a larger research project under the title "Modelling of Anhydritic Swelling Claystones" which aims at resolving knowledge gaps concerning swelling due to anhydrite to gypsum transformation (AGT). To this end, a large number of systematic experiments on multiple topics relating to AGT were designed and, due to the required long observation time horizon, carefully planned and executed. All results, including the experimental setup, are described, analyzed and discussed in this thesis.

The results can be grouped into three parts: (1) investigations of anhydrite dissolution and gypsum precipitation in water over time, (2) measurement of mechanical responses caused by AGT in artificial specimens containing anhydrite and kaolin, and (3) separation of different swelling processes that can occur simultaneously in anhydritic claystones.

The concentration of calcium and sulfate ions in water, while anhydrite is being dissolved and gypsum precipitates, was quantified by measuring the conductivity of the water during the process. This showed a direct correlation between the amount of dissolving anhydrite and the conductivity. Based on this, the equilibrium concentration of gypsum, as calculated on the basis of thermodynamic fundamentals (Serafeimidis and Anagnostou, 2013b and 2014b), could be confirmed experimentally.

Given that the equilibrium concentration of anhydrite presents an upper limit for the concentration in the solution during AGT, the theoretical value could not be confirmed exactly, but its plausibility could be verified. Because the measured concentrations are always lower than the equilibrium concentration of anhydrite due to simultaneously precipitating gypsum, it is incorrect to assume that the maximal measured concentration in the solution equals the equilibrium concentration of anhydrite, as is the case in some of the literature.

The development of the concentration over time was found to depend on the amount of dissolving anhydrite: A higher amount leads to higher immediate concentrations and AGT is completed faster, i.e., the concentration in the solution reaches the equilibrium concentration of gypsum faster, which corresponds to the conclusions drawn by Serafeimidis and Anagnostou. The rate of the AGT process was, however, seen to take longer than expected based on the kinetic model. Therefore, the assumed reaction rate constants could not be verified experimentally. The rate of the process was also found to vary depending on the amount and type of "foreign" aggregates that were added to the solution (i.e., kaolin, limestone, or quartz flour). However, based on the experiments with the different aggregates performed within the scope of this thesis, no correlation could be seen between the rates of the concentrations in the solutions to the rates of the swelling strains (e.g., conductivity tests with quartz flour took longer than those with kaolin, whereas oedometer tests with quartz flour reached a steady state faster than those with kaolin).

The effect of self-sealing of anhydrite was investigated by immersing specimens of massive anhydrite in water and observing the precipitation of gypsum on the anhydrite surface. Although the shape and spatial distribution of the precipitating gypsum varied depending on the testing temperature and texture of the initial rock, the thicknesses of the gypsum layers were within the predicted values according to the model by Serafeimidis and Anagnostou (2013a). Therefore, the model of Serafeimidis and Anagnostou can be used for determining, e.g., whether massive anhydrite will dissolve completely within the life-time of a tunnel (depending on the thickness of the anhydrite layers in the formation), or how fast thin particles will dissolve completely if the boundary conditions are adequate (i.e., at a small stress level and with sufficient water available). However, 
in many cases the gypsum also precipitated within fissures and cracked the rock, which is not considered in the mathematical model, where a uniform gypsum layer is assumed on the anhydrite surface. Future experimental investigations should consider an axial stress acting on the anhydrite surface or an embedding of the anhydritic rock, thus generating a more defined and denser layer of precipitating gypsum to relate more closely to the model situation.

The bulk of this thesis is about developing a chemo-mechanical relationship, which is necessary for the formulation of a swelling law. A constitutive model is defined, which connects anhydrite dissolution and gypsum precipitation to the developing stresses and strains they cause. A quantitative understanding of this relationship is of high significance for the modelling of the swelling processes of anhydritic claystones and has great practical relevance for the design of underground constructions.

The model relates the occurring swelling strains and/or swelling stresses to the mass changes of anhydrite by introducing a coupling parameter $\chi$ which is a material-specific tensor. To determine this parameter, an extensive systematic experimental study was conducted. These fundamental experiments consider four different mechanical boundary conditions and allow not only the determination of the coupling parameter $\chi$, but also a distinction between the cases for radial and axial direction (regarding the axisymmetric case), as well as an investigation of the stressdependency of $\chi$.

The experiments were performed with artificially created specimens containing anhydrite and kaolin (which is a so-called non-swelling clay mineral) with a high average density of $1.9 \mathrm{~g} / \mathrm{cm}^{3}$. It is presumed that the artificially created specimens differ from natural rocks not only in the absence of swelling clay minerals (e.g., montmorillonite) but also in the cohesion and tensile strength. They revealed that the maximal strains occurring due to AGT are linearly dependent on the logarithm of the axial stress in the case of oedometric boundary conditions. With this finding, a first step towards closing one of the fundamental knowledge gaps concerning swelling of anhydritic rocks is achieved. Furthermore, the development of strains with decreasing mass of anhydrite can be approximated in most cases by a linear function and thus $\chi$ (and it's axial and radial components) can be considered constant for a specific stress, value of the Young's modulus, and Poisson ratio, whereas a higher constant stress acting on the specimen leads to lower values for $\chi$.

Future research should address some of the remaining limitations of these investigations: For one, watering and subsequent swelling of a specimen (whether artificially created or of natural rock) causes the mechanical and hydraulical properties of the rock (i.e., structure, stiffness, strength and permeability) to change. The coupling parameter between the mass changes and the mechanical responses (the stresses and strains), therefore, needs to consider this change which was not the case here, since the Young's modulus and Poisson ratio were held constant in the development of the constitutive model. Furthermore, since $\chi$ was determined for the case of artificially created specimens, the extension of the results to natural rock needs to be investigated, especially when considering swelling clays to be present as well. In the case of natural rock, the tensile strength of the rock matrix (due to cementation) may withstand the pressure from the growing gypsum crystals in the pores at first, before the rock cracks and begins to expand. Therefore, $\chi$ may not be a constant anymore and thus further experimental investigations need to be carried out with anhydritic rock, similar to the tests described here with artificial specimens. This would enable a more realistic modelling of the swelling of anhydritic claystones.

While keeping these limitations in mind, these experiments nevertheless give a first indication of the developing stress-strain relationship during anhydrite to gypsum transformation. This con- 
stitutive relationship can be implemented and used as a basis for the modelling of swelling due to AGT in future research and, for rock, needs to be expanded by considering cementation. With the knowledge of the constitutive relationship, a swelling law for anhydritic rock can be formulated and a fundamental knowledge gap impacting the design of underground constructions in anhydritic swelling claystones can be closed.

The last set of experiments focuses on the simultaneous swelling processes that can occur in anhydritic claystones: physical swelling due to osmotic swelling of clay and mechanical processes, and chemical swelling due to AGT. The investigations were performed by conducting free swelling tests with natural rock specimens from Belchen, Switzerland, as well as oedometer tests with compacted powder obtained from the same rock.

In order to properly evaluate the contribution of each swelling process to the measured deformations, the processes needed to be de-coupled. This was done by performing some of the tests at different temperatures: At temperatures above $50{ }^{\circ} \mathrm{C}$, the AGT process could succesfully be suppressed and the swelling strains could be attributed to physical swelling, while at $20^{\circ} \mathrm{C}$ both processes occur. With these experiments it was seen that the swelling strains happen in a sequential manner: Nearly all swelling strains due to clay and mechanical swelling occur within a few hours after watering. Thereafter, a slower increase in strains which is caused by AGT can be observed.

In some cases the major part of the strains due to AGT was reached after roughly 200 days, where strains of about $30 \%$ were reached. Even though only $20-40 \%$ of the anhydrite within the rock had transformed to gypsum up to then, the subsequent rate of the swelling strains due to AGT was markedly reduced and the strains did not increase significantly anymore. It is postulated that the rock is cracked during clay and mechanical swelling, the cracks are then further expanded by growing gypsum crystals, and eventually the gypsum precipitates mainly within the cracks and pores and does not expand the specimen further. The changes of the specimen structure, more specifically the cracks due to the initial clay and mechanical swelling as well as gypsum within cracks were investigated microscopically.

The swelling strains were, however, seen to develop differently depending on rock composition and state of the rocks prior to the swelling tests. Rocks which were less dried out and contained some gypsum already prior to the tests swelled less and far slower than the other specimens. This leads to the conclusions that the initial water content of the specimens influences the physical swelling processes, and that the gypsum within the specimen may be sealing the anhydrite, thus slowing AGT down.

One important, so far inexplicable, observation was made, which should be investigated in future research: AGT could be suppressed by performing the tests at a temperature of $50{ }^{\circ} \mathrm{C}$, where anhydrite is the thermodynamically stable phase, rather than $20^{\circ} \mathrm{C}$, where gypsum is stable. The expectation was that swelling due to AGT should start when the temperature is lowered from $50{ }^{\circ} \mathrm{C}$ to $20^{\circ} \mathrm{C}$, based on the change in equilibrium concentrations. However, this only occurred with specimens of artificial, compacted powder made of milled anhydritic claystones and with natural rock specimens which had previously already exhibited some swelling at $20^{\circ} \mathrm{C}$. With natural rock specimens that were watered directly at $50{ }^{\circ} \mathrm{C}$, swelling was not triggered immediately after cooling; in some cases it did not resume for several hundred days after cooling (in one case even after three years no swelling was observed). The underlying reasons for this could not be identified. However, this could be very interesting for future research concerning the prevention of swelling due to AGT and the damage it can cause to structures. Furthermore, the known fact that 
crystallization pressure decreases with increasing temperature (cf., e.g., Flatt et al., 2014, Serafeimidis and Anagnostou, 2014a), may enable a reduction of damage in stone if it is possible to control the temperature.

Results from these experiments, in particular the findings concerning the coupling parameter $\chi$, are now being used in an ongoing thesis at ETH Zurich with the aim of developing a hydraulicchemical-mechanical coupled numerical model while also considering the thermodynamic fundamentals originally developed by Serafeimidis and Anagnostou. 
APPENDICES 



\section{A. Calculation of equilibrium concentrations}

For the computation of the equilibrium concentrations, the following equations were used (from Serafeimidis and Anagnostou, 2013b and 2014b):

$\ln \left(\frac{c_{e q, G} \cdot a_{W} \cdot \gamma_{A C, G}}{c_{0}}\right)=\frac{-\Delta_{r, G} G^{0}-p_{W} \cdot V_{G}^{0}-p_{W} \cdot \Delta_{r, G} V^{0}+p_{G} \cdot V_{G}^{0}+\frac{2 \gamma_{S E, G}}{r_{G}} \cdot V_{G}^{0}+\left(T-T_{0}\right) \cdot \Delta_{r, G} S^{0}}{2 \cdot R \cdot T}$

$\ln \left(\frac{c_{e q, A} \cdot \gamma_{A C, A}}{c_{0}}\right)=\frac{-\Delta_{r, A} G^{0}-p_{W} \cdot V_{A}^{0}-p_{W} \cdot \Delta_{r, A} V^{0}+p_{A} \cdot V_{A}^{0}+\frac{2 \gamma_{S E, A}}{r_{A}} \cdot V_{A}^{0}+\left(T-T_{0}\right) \cdot \Delta_{r, A} S^{0}}{R \cdot T}$

Whereas the activity coefficients $\gamma_{A C, G}$ and $\gamma_{A C, A}$ can be calculated according to the Davies equations, if the ionic strengths $I_{G}$ and $I_{A}$ are low (i.e., below $0.5 \mathrm{~mol} / \mathrm{l}$, which is the case in the sulfatic claystones of the Gypsum Keuper, as discussed by Serafeimidis and Anagnostou, 2013b, 2014a, 2014b):

$$
\begin{aligned}
& \log _{10} \gamma_{A C, G}=-A \cdot z_{i}^{2} \cdot\left(\frac{\sqrt{I_{G} / c_{0}}}{1+\sqrt{I_{G} / c_{0}}}-0.3 \cdot I_{G} / c_{0}\right) \\
& \log _{10} \gamma_{A C, A}=-A \cdot z_{i}^{2} \cdot\left(\frac{\sqrt{I_{A} / c_{0}}}{1+\sqrt{I_{A} / c_{0}}}-0.3 \cdot I_{A} / c_{0}\right)
\end{aligned}
$$

The ionic strengths can be calculated by considering the concentration and the valence of all ions in the water.

$$
I=0.5 \cdot \sum c_{i} z_{i}^{2}
$$

When assuming that solely calcium and sulfate ions are in the solute, the ionic strengths of gypsum and anhydrite can thus be calculated as:

$$
\begin{aligned}
& I_{G}=0.5 \cdot c_{e q, G} \cdot\left(z_{C a}^{2}+z_{S O_{4}}^{2}\right) \\
& I_{A}=0.5 \cdot c_{e q, A} \cdot\left(z_{C a}^{2}+z_{S O_{4}}^{2}\right)
\end{aligned}
$$

Equations ( $A-1),(A-3)$ and $(A-6)$ can then be used to calculate the equilibrium concentration of gypsum, while Equations $(A-2),(A-4)$ and $(A-7)$ can be used to calculate the equilibrium concentrations of anhydrite for the following (variable) parameters:

$a_{W}$

$T$

$p_{G}, p_{A}$

$p_{W}$
Water activity ( 1 for pure water at standard state), see also Chapter 2.3.2: $a_{W}=\mathrm{e}^{\frac{\psi}{R \cdot V_{W}}}$.

Temperature $[\mathrm{K}]$

Stress acting on the grains $\left[\mathrm{kJ} / \mathrm{cm}^{3}\right]$; see further remarks below.

Pore water pressure $\left[\mathrm{kJ} / \mathrm{cm}^{3}\right]$ 


$$
\begin{array}{ll}
r_{G} & \text { Radius of the gypsum crystals } \\
r_{A} & \text { Radius of the anhydrite crystals }
\end{array}
$$

and the following constant parameters (see Serafeimidis, 2014):

$$
\begin{array}{ll}
c_{0}=1 \mathrm{~mol} / \mathrm{l} & \text { Concentration at standard state } \\
T_{0}=298 \mathrm{~K} & \text { Temperature at standard state } \\
R=8.314 \cdot 10^{-3} \mathrm{~kJ} /(\mathrm{K} \cdot \mathrm{mol}) & \text { Universal gas constant (also: } \left.\mathrm{R}=8.314\left(\mathrm{MPa} \cdot \mathrm{cm}^{3}\right) /(\mathrm{K} \cdot \mathrm{mol})\right) \\
\Delta_{r, G} G^{0}=24.93 \mathrm{~kJ} / \mathrm{mol} & \text { Standard Gibbs energy of gypsum dissolution } \\
\Delta_{r, A} G^{0}=23.68 \mathrm{~kJ} / \mathrm{mol} & \text { Standard Gibbs energy of anhydrite dissolution } \\
V_{G}^{0}=74.30 \mathrm{~cm}^{3} / \mathrm{mol} & \text { Molar volume of gypsum at standard state } \\
V_{A}^{0}=45.94 \mathrm{~cm}^{3} / \mathrm{mol} & \text { Molar volume of anhydrite at standard state } \\
V_{W}=M_{W}^{0} / \rho_{W} \mathrm{~cm} / \mathrm{mol} & \text { Molar volume of water } \\
M_{W}=18.015 \mathrm{~g} / \mathrm{mol}^{3} & \text { Molar mass of water } \\
V_{W}^{0}=18.00 \mathrm{~cm}^{3} / \mathrm{mol}^{2} & \text { Molar volume of water at standard state } \\
\Delta_{r, G} V^{0}=-42.72 \mathrm{~cm} / \mathrm{mol} & \text { Standard volume of gypsum dissolution } \\
\Delta_{r, A} V^{0}=-50.36 \mathrm{~cm} / \mathrm{mol} & \text { Standard volume of anhydrite dissolution } \\
\Delta_{r, G} S^{0}=-0.08728 \mathrm{~kJ} /(\mathrm{K} \cdot \mathrm{mol}) & \text { Standard entropy of gypsum dissolution } \\
\Delta_{r, A} S^{0}=-0.1397 \mathrm{~kJ} /(\mathrm{K} \cdot \mathrm{mol}) & \text { Standard entropy of anhydrite dissolution } \\
\gamma_{S E, G}=8 \cdot 10^{-9} \mathrm{~kJ} / \mathrm{cm}^{2} & \text { Surface free energy of gypsum-water interface } \\
z_{i}=z_{\mathrm{Ca}}=z_{S O_{4}}=2 & \text { Valence of the ions }
\end{array}
$$

The coefficient $A$ depends on the temperature $T[\mathrm{~K}]$ :

$$
A=\frac{1.82483 \cdot 10^{6} \cdot \sqrt{\rho_{W}}}{(\varepsilon \cdot T)^{3 / 2}}
$$

with the dielectric constant

$$
\varepsilon=2727.586+0.6224107 \cdot T-466.9151 \cdot \ln T-\frac{52000.87}{T}
$$

and the density of water $\left[\mathrm{g} / \mathrm{cm}^{3}\right]$

$$
\rho_{W}=1-\frac{(T-277.14)^{2} \cdot(T+15.79)}{508929.2 \cdot(T-205.02)}+0.011445 \cdot \mathrm{e}^{-374.3 /(T-273.15)}
$$

As stated by Serafeimidis and Anagnostou, the solid-liquid interfacial effects are practically negligible for anhydrite, therefore $2 \gamma_{S E, A} / r_{A} \rightarrow 0$ in Equation (A - 2).

In order to determine the equilibrium concentration for the conditions in the laboratory, certain assumptions had to be made for the stresses and pore water pressures acting in the system. Furthermore, the stresses acting on the anhydrite and gypsum grains themselves are needed. It is assumed that all grains experience the same pressure $p_{S}$ (i.e., $p_{G}=p_{A}=p_{S}$ ) which is the average pressure experienced by a typical grain and can be calculated as a function of the stress acting on 
the rock matrix $\sigma$, the pore water pressure $p_{W}$ and the porosity $n$ (after Dewers and Ortoleva, 1989 and Serafeimidis and Anagnostou, 2013b:

$$
\begin{gathered}
p_{S}=\frac{\sigma-p_{W} \cdot n}{1-n} \\
p_{S}^{\prime}=p_{S}-p_{W}=\frac{\sigma-p_{W}}{1-n}=\frac{\sigma^{\prime}}{1-n}
\end{gathered}
$$

For the equilibrium diagram in Figure 2-1, the pore water pressure was taken as zero, i.e. atmospheric pressure is assumed, and no stresses are assumed to act on the system. Therefore the stresses acting on the grains equal zero $\left(p_{G}=p_{A}=p_{S}=0\right)$.

In Figure 2-3, however, the negative pore water potential $\psi$ of the rock is taken into account and is equal to the pore water pressure $p_{W}$. It was assumed that here too, the total stress acting on the rock equals zero, i.e.

$$
\begin{gathered}
p_{W}=\psi \\
p_{S}=-\psi \cdot \frac{n}{1-n}
\end{gathered}
$$





\section{B. N2 Diagram: an overview over aspects / influence factors relating to chemical swelling}

In Chapter 2.4 the so-called N2-diagram (NASA, 2007) was introduced to show interactions between simultaneous anhydrite dissolution and gypsum precipitation (thus representing the kinetic model). Going one step further and considering all factors influencing anhydrite dissolution and gypsum precipitation, an enlarged N2-diagram can be devised and is shown on the next pages. This N2-diagram considers additionally the temperature, as well as rock properties, hydraulic aspects (such as pore water pressure or seepage flow velocity and thus transport processes) as well as mechanical aspects (particularly stresses and strains).

Each influence shown in the diagram is explained in the subsequent list. The unknown relationships between anhydrite dissolution resp. gypsum precipitation and the stresses and strains (and which are the topic of PART III) are indicated by question marks within the diagram. 


\begin{tabular}{|c|c|c|c|c|c|c|c|c|c|c|c|c|c|c|c|c|c|c|c|c|c|c|c|}
\hline & \multicolumn{2}{|c|}{\begin{tabular}{l|l}
$m_{A}$ & $\left|d m_{A} / d t\right|$
\end{tabular}} & $k_{\mathrm{A}}$ & \multirow[t]{2}{*}{$\mathrm{c}_{\mathrm{eq} \mathrm{A}}$} & \multirow{2}{*}{$\begin{array}{c}\Phi_{A} F_{A} \\
1\end{array}$} & \multirow[t]{2}{*}{$m_{6}$} & $\mid \mathrm{dm}_{\mathrm{G}} / \mathrm{dt|}$ & $\mathrm{dm}_{\mathrm{GL}} / \mathrm{dt}$ & $k_{G}$ & $c_{\mathrm{eq}, 6}$ & $\Phi_{G} F_{G}$ & c & $T$ & $\Delta c_{\text {Maro }}$ & $v_{s}$ & $v_{w}$ & $v_{p}$ & $\mathrm{~V}_{\text {Tot }}$ & $\mathrm{e}$ & 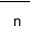 \\
\hline \multirow{14}{*}{ 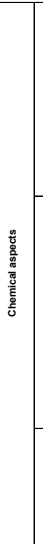 } & \multirow{5}{*}{ 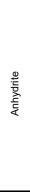 } & Mass per unit volume & $\mathrm{m}_{\mathrm{A}}$ & $m_{A}$ & & & & & & & & & & & 2 & & & 3 & & & & & \\
\hline & & Mass change rate (A-Dissolution) & $\left|\mathrm{dm}_{\mathrm{A}} / \mathrm{dt}\right|$ & 5 & $\left|\mathrm{dm}_{\mathrm{A}} / \mathrm{dt}\right|$ & & & & & & & & & & 6 & & & & & & & & \\
\hline & & Reaction rate constant & $\mathrm{k}_{\mathrm{A}}$ & & 8 & $\mathrm{k}_{\mathrm{A}}$ & & & & & & & & & & & & & & & & & \\
\hline & & Saturation concentration & $c_{\mathrm{eq} A \mathrm{~A}}$ & & 9 & & $c_{e q, A}$ & & & & & & & & & & & & & & & & \\
\hline & & Surface in contact with water & $\Phi_{A} F_{A}$ & & 10 & & & $\Phi_{A} F_{A}$ & & & & & & & & & & & & & & & \\
\hline & \multirow{9}{*}{$\frac{5}{5}$} & Mass per unit volume & $m_{G}$ & & & & & & $m_{G}$ & & & & & 11 & 12 & & & 13 & 14 & & & & \\
\hline & & Mass change rate (G-precipitation) & $\left|d m_{G} / d t\right|$ & & & & & & 16 & $\left|\mathrm{dm}_{\mathrm{G}} / \mathrm{dt}\right|$ & & & & & 18 & & & & & & & & \\
\hline & & Mass change rate (G-dissolution) & $\mathrm{dm}_{\mathrm{GL}} / \mathrm{dt}$ & & & & & & 20 & & $\left|\mathrm{dm}_{\mathrm{G}} \mathrm{L} \mathrm{dt}\right| \mid$ & & & & 21 & & & & & & & & \\
\hline & & Reaction rate constant & $k_{G}$ & & & & & & & 23 & & $k_{G}$ & & & & & & & & & & & \\
\hline & & Saturation concentration & $c_{e q, 6}$ & & & & & & & 24 & & & $c_{e q, 6}$ & & & & & & & & & & \\
\hline & & Surface in contact with water & $\Phi_{G} F_{G}$ & & & & & & & 25 & & & & $\Phi_{G} F_{G}$ & & & & & & & & & \\
\hline & & Concentration & c & & 26 & & & & & 27 & & & & & c & & 28 & & & & & & \\
\hline & & Temperature & $T$ & & & 30 & 31 & & & & & 32 & 33 & & & $T$ & & & & & & & \\
\hline & & Macroscopic concentration gradient & $\Delta c_{\text {Macro }}$ & & & & & & & & & & & & & & $\Delta C_{\text {Maro }}$ & & & & & & \\
\hline \multirow{17}{*}{ 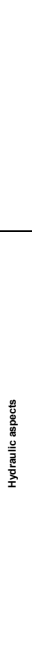 } & \multirow{10}{*}{ 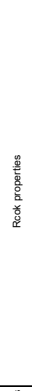 } & Volume of solids & $v_{s}$ & & & & & & & & & & & & 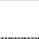 & & & $v_{s}$ & & 36 & 37 & 38 & \\
\hline & & Volume of water & $v_{w}$ & & & & & & & & & & & & 40 & & & & $v_{w}$ & & & & \\
\hline & & Pore volume & $v_{p}$ & & & & & & & & & & & & & & & & & $v_{p}$ & 44 & 45 & 46 \\
\hline & & Total volume & $\mathrm{V}_{\text {Tot }}$ & 50 & & & & & 51 & & & & & & & & & & & & $\mathrm{~V}_{\text {Tot }}$ & & 52 \\
\hline & & Void ratio & e & & & & & & & & & & & & & & & & & & & e & \\
\hline & & Porosity & $n$ & & & & & & & & & & & & & & & & & & & & $\mathrm{n}$ \\
\hline & & Permeability & $\mathrm{k}$ & & & & & & & & & & & & & & & & & & & & \\
\hline & & Degree of saturation (water) & $\mathrm{S}_{\mathrm{r}}$ & & & & & & & & & & & & 59 & & & & & & & & \\
\hline & & Water content & w & & & & & & & & & & & & & & & & & & & & \\
\hline & & Negative pore pressures & $\psi$ & & & & & & & & & & & & & & & & & & & & \\
\hline & 誉 & Water pressure & $p_{w}$ & & & & 63 & & & & & & 64 & & & & & & & & & & \\
\hline & 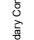 & Hydraulic gradient & $i$ & & & & & & & & & & & & & & & & & & & & \\
\hline & 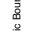 & Seepage flow (velocity) & $\mathrm{v}$ & & & & & & & & & & & & & & & & & & & & \\
\hline & 毫 & "Closedness" of the system & c & & & & & & & & & & & & & & & & & & & & \\
\hline & & Diffusion & Dif. & & 75 & & & & & 76 & & & & & 77 & & 78 & & & & & & \\
\hline & 总 & Advection & Adv. & & & & & & & & & & & & 79 & & & & & & & & \\
\hline & & Evaporation & Ev. & & & & & & & & & & & & 80 & & & & 81 & & & & \\
\hline \multirow{12}{*}{ 耪 } & & Total & $\varepsilon$ & & & & & & & & & & & & & & & & & & & & \\
\hline & 鮚 & Due to AGT & $\varepsilon^{A G T}$ & & & & & & & & & & & & & & & & & & & & \\
\hline & & Elastic & $\varepsilon^{E L}$ & & & & & & & & & & & & & & & & & & & & \\
\hline & 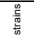 & Total & $\left|\mathrm{d}_{\varepsilon} / \mathrm{dt}\right|$ & & & & & & & & & & & & & & & & & & & & \\
\hline & 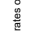 & Due to AGT & $\mathrm{d} \varepsilon^{\mathrm{AGT}} / \mathrm{dt} \mid$ & & & & & & & & & & & & & & & & & & & & \\
\hline & 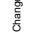 & Elastic & $\left|\mathrm{d} \varepsilon^{\mathrm{EL}} / \mathrm{dt}\right|$ & & & & & & & & & & & & & & & & & & & & \\
\hline & & Youngs modulus & E & & & & & & & & & & & & & & & & & & & & \\
\hline & & Total & $\sigma$ & & & & & & & & & & & & & & & & & & & & \\
\hline & & Effective & $\sigma^{\prime}$ & & & & & & & & & & & & & & & & & & & & \\
\hline & $\begin{array}{l}\text { 总 } \\
\text { 密 }\end{array}$ & Change in total stress & $|\mathrm{d} \sigma / \mathrm{dt}|$ & & & & & & & & & & & & & & & & & & & & \\
\hline & & Change in effective stress & $\left|d \sigma^{\prime} / d t\right|$ & & & & & & & & & & & & & & & & & & & & \\
\hline & & Intergranular stress & $p_{s}$ & & & & 106 & & & & & & 107 & & & & & & & & & & \\
\hline
\end{tabular}

$+\rightarrow+($ or $-\rightarrow-):$ an increase of the first entity leads to an increase of the second entity

$+\rightarrow-($ or $-\rightarrow+)$ : an increase of the first entity leads to a decrease of the second entity or vice-versa

$+\rightarrow+$ or $-:$ an increase of the first entity can lead to an increase or a decrease of the second entity

+ and $-\rightarrow+$ : both an increase or a decrease of the first entity lead to an increase of the second entity

+ and - $\rightarrow-$ : both an increase or a decrease of the first entity lead to a decrease of the second entity 


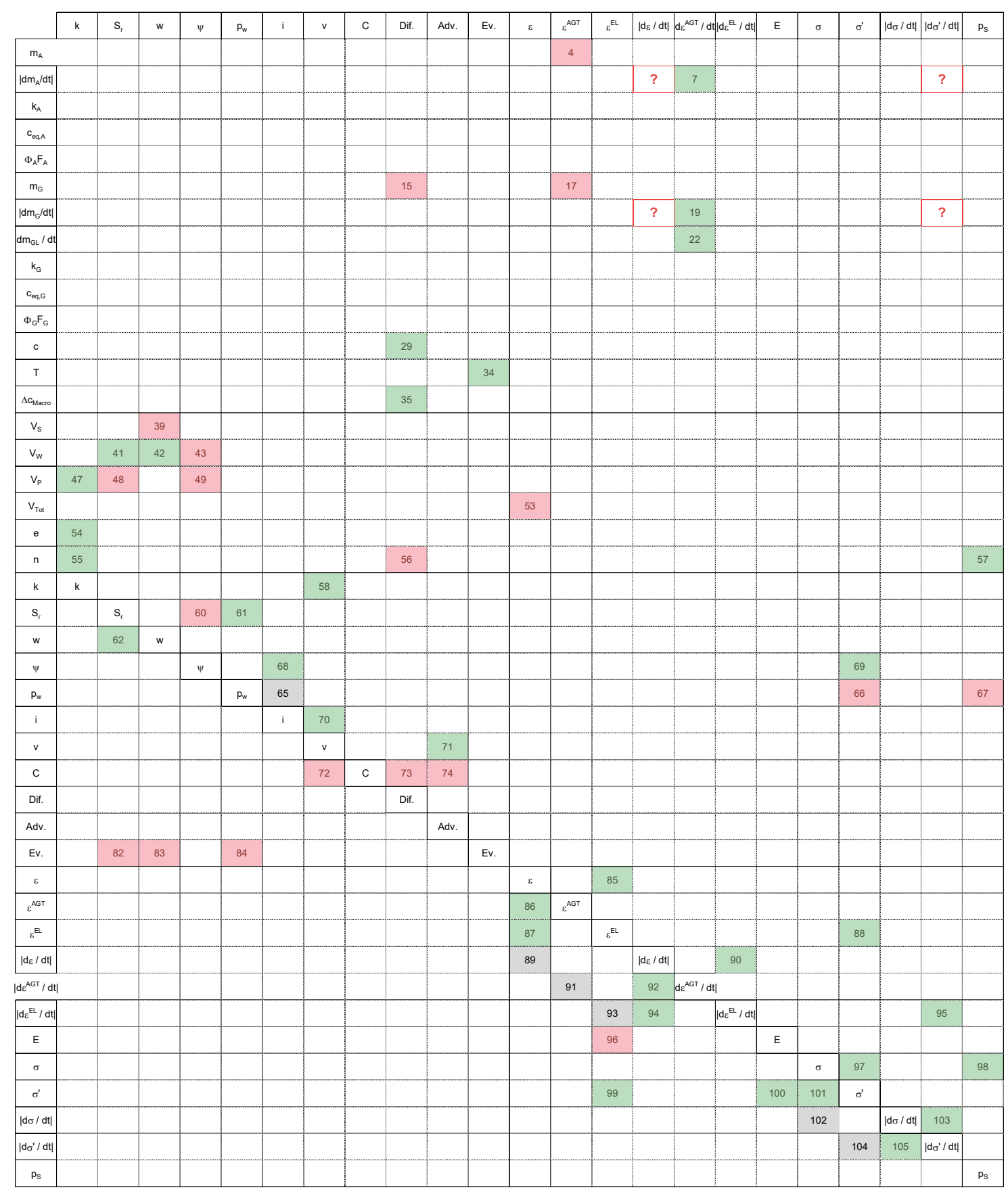


1 Depending on the structure of the material, a reduction in the mass / volume of anhydrite can lead either to an increase or decrease of the surface area in contact with water (i.e.: granular anhydrite, anhydritic layers/veins --> decrease; anhydritic block with channels/ preferential seepage ways --> increase).

A decrease in mass of anhydrite (i.e., anhydrite dissolution) leads to an increase in dissolved ions. Therefore the in-situ concentration will increase.

As the mass (and thus the volume) of anhydrite decreases, the total volume of the solids decreases.

A decrease in mass (and volume) of anhydrite leads to chemically induced strains (shrinkage).

It does not matter whether the rate of anhydrite dissolution increases or decreases; the mass of anhydrite will decrease due to dissolution.

It does not matter whether the rate of anhydrite dissolution increases or decreases; the concentration will increase in any case, as long as anhydrite is being dissolved.

The faster anhydrite dissolves, the faster the rate of chemical strains will be.

The rate of anhydrite dissolution increases with higher kinetic reaction constant.

A higher saturation concentration of anhydrite will lead to an increase in the rate of anhydrite dissolution (the concentration gradient increases)

A larger surface area in contact with water benefits the rate of anhydrite dissolution.

Depending on the structure of the material, an increase in the mass / volume of gypsum can lead either to an increase or decrease of the surface area in contact with water (i.e.: gypsum precipitates in fissures --> decrease; Gypsum precipitates around granular material --> increase).

An increase in mass of gypsum (i.e., gypsum precipitation) implies that dissolved ions are "used". Therefore the in-situ concentration will decrease.

As the mass (and thus the volume) of gypsum increases, the volume of total solids increases.

During gypsum precipitation water is bound in the crystals (thus water consumption).

If the mass of gypsum on anhydrite increases (sealing) diffusion of the dissolved minerals (from anhydrite) will be slowed down.

Both an increase and a decrease in the rate of gypsum precipitation lead to an increase in the mass of gypsum.

An increase in mass (i.e., volume) of gypsum leads to swelling, i.e. negative chemically induced strains.

18 It doesn't matter whether the rate of gypsum precipitation increases or decreases; the concentration will be reduced in any case, as long as gypsum precipitates.

The faster gypsum precipitates, the faster the increase in (negative) chemical strains will be.

20 It does not matter whether the rate of gypsum dissolution increases or decreases; the mass of gypsum will decrease due to dissolution.

21 It does not matter whether the rate of gypsum leaching increases or decreases; the concentration will increase in any case, as long as gypsum dissolves.

The faster gypsum leaches, the faster the increase in chemical strains will be.

The rate of gypsum precipitation increases with higher kinetic reaction constant. 
24 A higher saturation concentration of gypsum will lead to a decrease in the rate of gypsum precipitation (the concentration gradient decreases)

25 A larger surface area in contact with water benefits the rate of gypsum precipitation.

26 A smaller concentration will lead to an increase in the rate of anhydrite dissolution (the concentration gradient increases)

27 A larger concentration will lead to an increase in the rate of gypsum precipitation (the concentration gradient increases)

28 An increase in the concentration leads to a higher gradient between the inside and outside of the system, assuming that the concentration outside remains constant.

29 An increasing local concentration most likely causes a larger concentration gradient toward the outside of the system, thus and therefore stronger diffusion of ions occurs.

30 The reaction rate constant is dependent on the present temperature (equation of Arrhenius).

31 With increasing temperature the equilibrium concentration of anhydrite decreases.

32 The reaction rate constant is dependent on the present temperature (equation of Arrhenius).

33 The solubility of gypsum increases slightly with a higher temperature (within the relevant temperature range for this work, i.e., below $100^{\circ} \mathrm{C}$ )

34 A higher temperature increases evaporation of pore water.

35 A large concentration gradient between inside and outside a system benefits diffusion of particles from the area with higher concentration to an area of lower concentration

36 An increase in solid volume will lead to a decrease in pore volume, if the total volume remains constant. However, if cracking occurs, the pore volume will increase (as well as the total volume).

37 An increase in the volume of solids will lead to an increase in total volume, if the pore volume remains constant.

38 An increase in volume of solids will lead to a decrease of the void ratio (assuming the pore volume remains constant).

39 An increase in Mass (and thus in volume) of solids causes a decrease in water content, assuming the volume of water to remain constant $\left(w=M_{S} / M_{W}\right)$.

40 By adding pure water to water containing ions, the ion concentration will decrease.

41 The degree of saturation increases when more water is in the system.

42 The water content increases when more water is in the system.

43 As the volume of water within a matrix increases, its negative pore water pressures decrease.

44 An increase in pore volume will lead to an increase in total volume.

45 An increase in pore volume leads to a larger void ratio (assuming the volume of solids to remain constant).

46 Bigger pore volume --> larger porosity (per definition).

47 When the pore volume gets smaller (e.g., due to gypsum precipitation in the pores), the permeability is reduced. 
Assuming the volume of water in the system to remain the same, an increase in pore volume will lead to a more partially-saturated system, i.e. the degree of saturation will be reduced.

Suction (neg. pore pressure) is stronger when the pore volume is smaller.

An increase in total volume will decrease $m_{A}$ per definition $\left(m_{A}=M_{A} / V_{t o t}\right)$.

An increase in total volume will decrease $m_{G}$ per definition $\left(m_{G}=M_{G} / V_{t o t}\right)$.

If the total volume increases, but the pore volume remains constant, the porosity decreases.

An increase in total volume causes strains of the system. (Expansion is negative, $\left.\varepsilon_{\text {swell }}=-\varepsilon\right)$.

$$
\text { The permeability is higher with larger pore volume/void ratio/ porosity. }
$$

The permeability is higher with larger pore volume/void ratio/ porosity.

Regarding "sealing": the smaller the porosity of the gypsum layer (on anhydrite) is, the slower diffusion will be.

The stresses acting on the grains increase with decreasing porosity.

Darcy, assuming $i$ is constant: $v=k \cdot i$.

Assuming the amount of ions in the water to remain the same, the concentration will increase as the water content (i.e. the degree of saturation) decreases.

A lower degree of saturation benefits suction/ negative pore water pressures --> partially saturated.

A lower degree of saturation leads to smaller water pressures.

The degree of saturation is by definition dependent on the water content.

A higher pore water pressure increases the equilibrium concentration.

A higher pore water pressure increases the equilibrium concentration.

Depending on the direction of the hydraulic gradient, it may either increase or reduce with increasing water pressure.

Increasing water pressure leads to decreasing effective stresses.

An increase in pore water pressure leads to a decrease in the stresses acting on the grains.

A higher value of suction within a matrix increases the hydraulic gradient between the matrix and the surrounding water.

Increasing negative pore water pressures result in increasing effective stresses.

Darcy, assuming $\mathrm{k}$ is constant: $v=k \cdot i$.

Higher seepage flow velocity benefits advection.

In a closed system, seepage flow is prohibited; seepage flow can occur in more open systems. 
74 A closed system (with no water flowing in and out) disables advection.

75 An increase in diffusion leads to faster dissolution of anhydrite.

76 Diffusion in a small scale (sealing): if diffusion is slowed down (through an increasing gypsum-layer), the rate of gypsum precipitation is slowed down.

77 Diffusion/ ion transport (away from a point in the system) reduces the concentration.

78 Diffusion of ions leads to an equalization of the concentration and thus reduces the macroscopic concentration gradient.

79 Advection/ ion transport (away from a point in the system) reduces the concentration.

80 Since the amount of ions remain the same as evaporation occurs, but the water content reduces, the concentration will increase

81 Evaporation decreases the amount of water in the system.

82 Evaporation leads to partially saturated zones, i.e. a decrease in the degree of saturation.

83 Evaporation leads to partially saturated zones, i.e. a decrease in the water content.

84 Evaporation leads to a reduction of the water pressure.

85 An enforced deformation causes a change of elastic strains.

$86 \varepsilon=\varepsilon^{A G T}+\varepsilon^{e l}$

$87 \varepsilon=\varepsilon^{A G T}+\varepsilon^{e l}$

88 Enforced elastic strains will cause an increase in effective stress.

89 A change in the rate of total strains implies an increase or a decrease of the total strains.

90 Enforcing an increase of the rate of total strains causes an increase of the rate of elastic strains.

91 A change in the rate of chemically induced strains implies an increase or a decrease of the chemically induced strains.

$92 \varepsilon=\varepsilon^{A G T}+\varepsilon^{e l}$

93 A change in the rate of elastic strains implies an increase or a decrease of the elastic strains.

$94 \varepsilon=\varepsilon^{A G T}+\varepsilon^{e l}$

95 Enforced increase in elastic strains will cause an increase in the rate of effective stress.

96 If the rock is stiffer (higher Young's modulus), the elastic strains will be smaller.

$97 \sigma^{\prime}=\sigma-p_{W}$ (definition of effective stresses, Terzaghi).

98 A higher total stress acting on the rock matrix leads to higher stresses between the grains.

99 An increase in effective stresses causes an increase in elastic strains.

100 The Young's modulus increases with increasing in-situ stress. 
101 An increase in effective stress causes an increase in total stress (Terzaghi, $p_{W}=$ const.)

102 A change in the rate of total stress implies an increase or a decrease of the total stress.

103 A change in the rate of total stress causes the same change in the rate of effective stress, if the pore water pressure remains constant (Terzaghi).

104 A change in the rate of total stress implies an increase or a decrease of the total stress.

105 A change in the rate of effective stress causes the same change in the rate of total stress, if the pore water pressure remains constant (Terzaghi).

106 A higher stress acting on the anhydrite grains increases the equilibrium concentration of anhydrite.

107 A higher stress acting on the gypsum crystals increases the equilibrium concentration of gypsum. 


\section{Estimation of reaction rate constants}

The reaction rate constants, which are necessary to determine the reaction rates of anhydrite and gypsum (see Equations (2 - 25) to (2 - 27)), are dependent on the temperature. The assumed values for this work (for $5{ }^{\circ} \mathrm{C}$ and $20^{\circ} \mathrm{C}$ ) are denoted as red crosses in Figure 13-1. Generally, the reaction rate constants for $20^{\circ} \mathrm{C}$ were taken from Serafeimidis and Anagnostou (2013a), see black dots in Figure 13-1. The values for the reaction rate constants at $5{ }^{\circ} \mathrm{C}$ were assumed based on an extrapolation via the Arrhenius equation (see indicated equation and black curves in Figure 13-1; cf., e.g., Atkins and De Paula, 2006) and on a comparison with experimental data found in the literature, as is indicated in Figure 13-1 (Kontrec et al., 2002, Bildstein et al., 2001, Barton and Wilde, 1971, James and Lupton, 1978, Liu and Nancollas, 1970). For their numerical model, Oldecop and Alonso (2012) have also considered the work by Kontrec et al. (2002), however they assume the values for the reaction rate constants to be half as high, in order to compensate for the fact that the water was stirred in the case of the experiments by Kontrec et al. (2002).

It needs to be noted that the experimental data at these temperature ranges is scarce and vary strongly in the literature, as Serafeimidis has also seen in his work. Therefore, the reaction rate constants at $5{ }^{\circ} \mathrm{C}$ are to be seen as rough estimates, since also the parameters for the Arrhenius equation need to be determined based on experimental results and no consistent set of parameters was detected that fits the various experimental data (cf. Figure 13-1). Nevertheless, it can be seen that the assumed values lie well within the ranges found in literature.

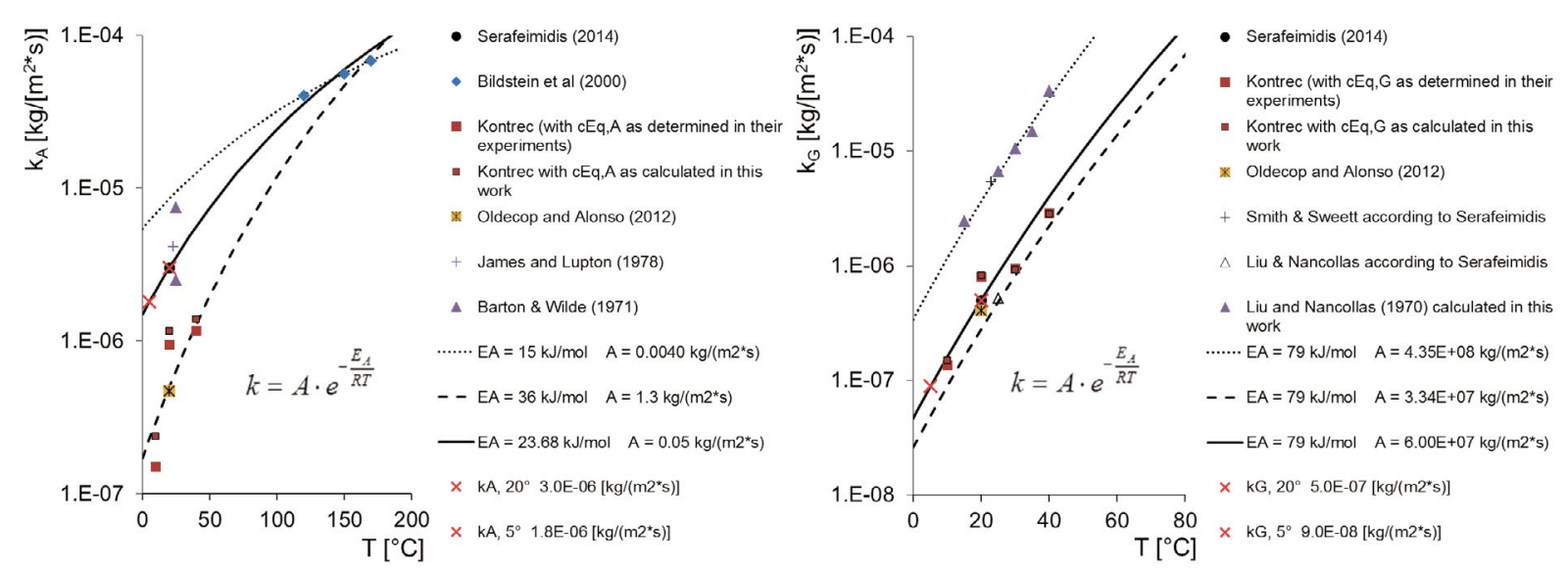

Figure 13-1: Determination of the reaction rate constants $k_{A}$ and $k_{G}$. 



\section{Derivation of equations for axisymmetric conditions}

Relationships between stresses and elastic strains for the axisymmetric situation, i.e., $\sigma_{a x}^{\prime}, \varepsilon_{a x}^{e l}$, $\sigma_{r a d}^{\prime}$ and $\varepsilon_{r a d}^{e l}$ are of interest, in order to find the elasticity tensor $\boldsymbol{D}_{i j k l}$. This can be obtained by taking the general stress-strain relationship given by Hooke's linear elastic law:

$$
\left(\sigma_{i j}^{\prime}-\sigma_{i j, 0}^{\prime}\right)=\lambda \varepsilon_{k k}^{e l} \delta_{i j}+2 \mu \varepsilon_{i j}^{e l}
$$

with Lamé's elastic constants

$$
\begin{gathered}
\lambda=\frac{E v}{(1+v)(1-2 v)} \\
\mu=\frac{E}{2(1+v)}
\end{gathered}
$$

and the general descriptions of the stress and strain tensors:

$$
\sigma_{i j}^{\prime}=\left[\begin{array}{lll}
\sigma_{11}^{\prime} & \sigma_{12}^{\prime} & \sigma_{13}^{\prime} \\
\sigma_{21}^{\prime} & \sigma_{22}^{\prime} & \sigma_{23}^{\prime} \\
\sigma_{31}^{\prime} & \sigma_{32}^{\prime} & \sigma_{33}^{\prime}
\end{array}\right], \varepsilon_{i j}^{e l}=\left[\begin{array}{lll}
\varepsilon_{11}^{e l} & \varepsilon_{12}^{e l} & \varepsilon_{13}^{e l} \\
\varepsilon_{21}^{e l} & \varepsilon_{22}^{e l} & \varepsilon_{23}^{e l} \\
\varepsilon_{31}^{e l} & \varepsilon_{32}^{e l} & \varepsilon_{33}^{e l}
\end{array}\right],
$$

and then substituting the stresses and strains for axisymmetric conditions:

$$
\sigma_{11}^{\prime}=\sigma_{a x}^{\prime}, \quad \sigma_{22}^{\prime}=\sigma_{33}^{\prime}=\sigma_{r a d}^{\prime}, \quad \sigma_{12}^{\prime}=\sigma_{13}^{\prime}=\sigma_{21}^{\prime}=\sigma_{23}^{\prime}=\sigma_{31}^{\prime}=\sigma_{32}^{\prime}=0
$$

and

$$
\varepsilon_{11}^{e l}=\varepsilon_{a x}^{e l}, \quad \varepsilon_{22}^{e l}=\varepsilon_{33}^{e l}=\varepsilon_{r a d}^{e l} \quad, \quad \varepsilon_{12}^{e l}=\varepsilon_{13}^{e l}=\varepsilon_{21}^{e l}=\varepsilon_{23}^{e l}=\varepsilon_{31}^{e l}=\varepsilon_{32}^{e l}=0
$$

$\delta_{i j}$ is the Kronecker delta and $\varepsilon_{k k}^{e l}$ describes the first invariant of the strain tensor and corresponds to the volumetric strain, i.e., for axisymmetric conditions:

$$
\varepsilon_{k k}^{e l}=\varepsilon_{a x}^{e l}+2 \varepsilon_{r a d}^{e l}
$$

Thus we can rewrite Hooke's linear elastic law for axisymmetric conditions:

$$
\left[\begin{array}{c}
\sigma_{a x}^{\prime}-\sigma_{a x, 0}^{\prime} \\
\sigma_{r a d}^{\prime}-\sigma_{r a d, 0}^{\prime}
\end{array}\right]=\left[\begin{array}{cc}
(\lambda+2 \mu) & 2 \lambda \\
\lambda & 2(\lambda+\mu)
\end{array}\right]\left[\begin{array}{c}
\varepsilon_{a x}^{e l} \\
\varepsilon_{r a d}^{e l}
\end{array}\right]
$$

whereas the 2x2-matrix on the right-hand side represents $\boldsymbol{D}_{i j k l}$ for this particular case and can be expressed by using the definitions for Lamé's constant (Equations ( $D-2)$ and $(D-3)$ ):

$$
\boldsymbol{D}_{\text {Triax }}=\left[\begin{array}{cc}
(\lambda+2 \mu) & 2 \lambda \\
\lambda & 2(\lambda+\mu)
\end{array}\right]=\frac{E}{(1+v)(1-2 v)}\left[\begin{array}{cc}
(1-v) & 2 v \\
v & 1
\end{array}\right]
$$

Therefore:

$$
\left[\begin{array}{c}
\sigma_{a x}^{\prime}-\sigma_{a x, 0}^{\prime} \\
\sigma_{r a d}^{\prime}-\sigma_{r a d, 0}^{\prime}
\end{array}\right]=\frac{E}{(1+v)(1-2 v)}\left[\begin{array}{cc}
(1-v) & 2 v \\
v & 1
\end{array}\right]\left[\begin{array}{c}
\varepsilon_{a x}^{e l} \\
\varepsilon_{r a d}^{e l}
\end{array}\right]
$$





\section{E. Thought experiments}

\section{E.1. Anhydrite dissolution}

The first thought experiments described here concern the influence of anhydrite dissolution on stresses and strains, based on the conceptual models introduced in Chapter 7.2.2. The aim of these experiments is to quantify the coupling parameters $a_{a x}$ and $a_{r a d}$. In order to achieve this, the process of gypsum precipitation needs to be eliminated. This can be done e.g. by performing the experiments at temperatures above $50{ }^{\circ} \mathrm{C}$, at which the equilibrium concentration of anhydrite is lower than that of gypsum, or if the flow-through rate of the water is fast enough to transport the dissolved ions out of the system before gypsum precipitates. If the permeability of the system decreases during a test, and/or if the exiting concentration $c_{\text {out }}$ is close to or higher than the equilibrium concentration of gypsum $\left(c_{e q, G}\right)$, gypsum precipitation may have occurred, in which case the both reactions (anhydrite dissolution and gypsum precipitation) need to be considered for the evaluation of the experiment (cf. Chapter 7.3.4).

Eliminating gypsum precipitation in the formulations in Chapter 7.1 leads to the following expressions for $a_{a x}$ and $a_{r a d}$ :

$$
\begin{gathered}
a_{a x}=\left(\frac{\partial \varepsilon_{a x}}{\partial m_{A}}-\frac{1}{E} \frac{\partial \sigma_{a x}^{\prime}}{\partial m_{A}}+\frac{2 v}{E} \frac{\partial \sigma_{r a d}^{\prime}}{\partial m_{A}}\right) \cdot \rho_{A} \\
a_{r a d}=\left(\frac{\partial \varepsilon_{r a d}}{\partial m_{A}}+\frac{v}{E} \frac{\partial \sigma_{a x}^{\prime}}{\partial m_{A}}-\frac{(1-v)}{E} \frac{\partial \sigma_{r a d}^{\prime}}{\partial m_{A}}\right) \cdot \rho_{A}
\end{gathered}
$$

Unless stated otherwise, the pore water pressure is assumed to be constant in the thought experiments, i.e. $\dot{p}=0$ and $\dot{\sigma}_{a x}^{\prime}=\dot{\sigma}_{a x}$ resp. $\dot{\sigma}_{r a d}^{\prime}=\dot{\sigma}_{r a d}$.

Depending on the mechanical boundary conditions, the changes in stresses and/or strains are measured, and $a_{a x}$ and $a_{r a d}$ can thus be determined as follows:

- Isotropic compression (constant stresses):

$$
\begin{gathered}
\dot{\varepsilon}_{a x}=\frac{a_{a x}}{\rho_{A}} \dot{m}_{A} \\
\dot{\varepsilon}_{r a d}=\frac{a_{r a d}}{\rho_{A}} \dot{m}_{A}
\end{gathered}
$$

therefore,

$$
\begin{gathered}
a_{a x}=\frac{\partial \varepsilon_{a x}}{\partial m_{A}} \cdot \rho_{A} \\
a_{r a d}=\frac{\partial \varepsilon_{r a d}}{\partial m_{A}} \cdot \rho_{A}
\end{gathered}
$$

- Complete constraint (constant strains):

$$
\dot{\sigma}_{a x}=\frac{-(1-v) \cdot E}{(1+v)(1-2 v)} \cdot\left(a_{a x}+\frac{2 v}{(1-v)} \cdot a_{r a d}\right) \cdot \frac{\dot{m}_{A}}{\rho_{A}}
$$




$$
\dot{\sigma}_{r a d}=\frac{-E}{(1+v)(1-2 v)} \cdot\left(v a_{a x}+a_{r a d}\right) \cdot \frac{\dot{m}_{A}}{\rho_{A}}
$$

therefore,

$$
\begin{gathered}
a_{a x}=\frac{1}{E}\left(-\frac{\partial \sigma_{a x}}{\partial m_{A}}+2 v \frac{\partial \sigma_{r a d}}{\partial m_{A}}\right) \cdot \rho_{A} \\
a_{r a d}=\frac{1}{E} \cdot\left(v \frac{\partial \sigma_{a x}}{\partial m_{A}}-(1-v) \frac{\partial \sigma_{r a d}}{\partial m_{A}}\right) \cdot \rho_{A}
\end{gathered}
$$

If the stress conditions prove to be isotropic $\left(\sigma_{a x}=\sigma_{r a d}=\sigma\right)$ throughout the test, the equations can be simplified further to:

$$
a_{a x}=a_{r a d}=\frac{(-1+2 v)}{E} \cdot \rho_{A} \cdot \frac{\partial \sigma}{\partial m_{A}}
$$

Therefore $a_{a x}$ and $a_{r a d}$ are proportional to $\partial \sigma / \partial m_{A}$, assuming that the parameters $E, v$ and $\rho_{A}$ are constants.

- Oedometric conditions (constant axial stress, constant radial strain):

$$
\begin{gathered}
\dot{\varepsilon}_{a x}=\left(a_{a x}+\frac{2 v}{(1-v)} \cdot a_{r a d}\right) \cdot \frac{\dot{m}_{A}}{\rho_{A}} \\
\dot{\sigma}_{r a d}=-\frac{E}{(1-v)} \cdot \frac{\dot{m}_{A}}{\rho_{A}} \cdot a_{r a d} \\
a_{a x}=\left(\frac{\partial \varepsilon_{a x}}{\partial m_{A}}+\frac{2 v}{E} \frac{\partial \sigma_{r a d}}{\partial m_{A}}\right) \cdot \rho_{A} \\
a_{r a d}=-\frac{(1-v)}{E} \cdot \frac{\partial \sigma_{r a d}}{\partial m_{A}} \cdot \rho_{A}
\end{gathered}
$$

- Flexible oedometer (constant axial stress):

$$
\begin{gathered}
\dot{\varepsilon}_{a x}=\frac{(1+v)(1-2 v)}{E v} \dot{\sigma}_{r a d}-\frac{1}{v} \dot{\varepsilon}_{r a d}+\frac{\dot{m}_{A}}{\rho_{A}}\left(a_{a x}+\frac{1}{v} a_{r a d}\right) \\
\dot{\varepsilon}_{r a d}=\frac{(1+v)(1-2 v)}{E} \dot{\sigma}_{r a d}-v \dot{\varepsilon}_{a x}+\frac{\dot{m}_{A}}{\rho_{A}}\left(v a_{a x}+a_{r a d}\right) \\
\dot{\sigma}_{r a d}=\frac{E}{(1+v)(1-2 v)} \cdot\left(v \dot{\varepsilon}_{r a d}+\dot{\varepsilon}_{r a d}-\frac{\dot{m}_{A}}{\rho_{A}}\left(v a_{a x}+a_{r a d}\right)\right) \\
a_{a x}=\left(\frac{\partial \varepsilon_{a x}}{\partial m_{A}}+\frac{2 v}{E} \frac{\partial \sigma_{r a d}}{\partial m_{A}}\right) \cdot \rho_{A} \\
a_{r a d}=\left(\frac{\partial \varepsilon_{r a d}}{\partial m_{A}}-\frac{(1-v)}{E} \frac{\partial \sigma_{r a d}}{\partial m_{A}}\right) \cdot \rho_{A}
\end{gathered}
$$

Note that for the evaluation of most experiments, the Young's modulus $E$ as well as the Poisson ratio $v$ need to be determined (e.g. in a separate triaxial test) or assumed. 
Independent of the type of boundary conditions, it is necessary to determine the amount of dissolved anhydrite during each experiment (i.e., to solve the Equations above). The following possibilities exist to obtain the change in mass of anhydrite:

1. Via measuring the concentration and flow-rate of the exiting water (during certain time intervals) and back-calculating how much anhydrite dissolved:

$$
\Delta M_{A, \Delta t}=\Delta M_{I, \Delta t}=\left(c_{i n, \Delta t}-c_{o u t, \Delta t}\right) \cdot V_{W, \Delta t}
$$

2. By measuring the pore volume in time intervals (e.g. by switching from water to ethanol or another inert fluid (or possibly gas), i.e. pressing ethanol in the specimen to fill all pores, then switching back to water and collecting all exiting fluid, separate the fluids and thus measure the volume of ethanol). However, $V_{P, 0}$ needs to be known.

$$
\Delta M_{A}=\Delta V_{A} \cdot \rho_{A}=\left(\Delta V_{t o t}-\Delta V_{P}\right) \cdot \rho_{A}
$$

3. Dry specimen in between and measure mass:

$$
\Delta M_{A}=M_{t o t}-M_{t o t, 0}
$$

4. By calculating the change in permeability and thus of the void ratio via measuring the flow velocity (assuming Darcy for the calculation of the coefficient of permeability)

$$
k=\frac{v}{i}=\frac{Q}{A i}=\frac{Q}{\pi(r-\Delta r)^{2} \frac{\Delta h_{P}}{h}}=\frac{Q h}{\pi(r-\Delta r)^{2}\left(p_{\text {in }}-p_{\text {out }}-h\right)}
$$

While for a perforated block of pure anhydrite (as described in Chapters 7.2.1.b and 7.2.2.b) the change in the cross-section area can be directly linked to the amount of dissolved anhydrite and the permeability of the specimen, in the case of granular material a relationship between $k$ and the pore volume (resp. $e$ ) needs to be assumed. One possibility is to use an empirical equation after Carrier and Beckman (1984):

$$
k_{f}=\mu \cdot \frac{(e-\delta)^{v}}{1+e}=\left(\frac{0.389}{P I}\right)^{4.29} \cdot \frac{(e-0.027 \cdot(P L-0.242 \cdot P I))^{4.29}}{1+e}
$$

PL being the plastic limit and PI the plasticity index.

Another possibility (depending on the grain size) is to use the Kozeny Carman equation:

$$
k=\frac{\gamma_{w}}{\mu_{w}} \frac{1}{C_{K-C}} \frac{e^{3}}{1+e} \frac{1}{S_{0}^{2}}=\frac{\gamma_{w}}{\mu_{w}} \frac{1}{C_{K-C}} \frac{e^{3}}{1+e}\left(\frac{r_{\text {Grain }} \rho_{A}}{3 m_{A}}\right)^{2}
$$

For the latter, using the following relationships (assuming uniform grains of anhydrite only):

$$
\begin{gathered}
S_{0}=\frac{A_{A}}{V_{\text {tot }}}=\frac{n_{\text {Grains }} 4 \pi r_{\text {Grain }}^{2}}{V_{\text {tot }}}=\frac{3 m_{A}}{r_{\text {Grain }} \rho_{A}} \\
m_{A}=\frac{M_{A}}{V_{\text {tot }}}=\frac{n_{\text {Grains }} \frac{4}{3} \pi r_{\text {Grain }}^{3} \rho_{A}}{V_{\text {tot }}}
\end{gathered}
$$


In order to determine the mass of anhydrite, the equations above need to be solved for the void ratio $e$. This, in turn, can be used to determine the amount of anhydrite currently in the specimen, whereas the volume of the inert solids $\left(V_{S}\right)$ and the total volume of the specimen $\left(V_{\text {tot }}\right)$ needs to be known:

i.e.

$$
\begin{gathered}
e=\frac{V_{P}}{V_{S}+V_{A}}=\frac{V_{t o t}-V_{S}-\frac{M_{A}}{\rho_{A}}}{V_{S}+\frac{M_{A}}{\rho_{A}}} \\
M_{A}=\rho_{A}\left(\frac{V_{t o t}}{1+e}-V_{S}\right)
\end{gathered}
$$

By measuring the changes in height and radius of the specimen (i.e. the total change in volume) and the change in volume of anhydrite, it is possible to determine the change in porosity (e.g. via Equation (7 - 19)). Possible outcomes for the porosity are shown, e.g. for granular material, in the conceptual model in Chapter 7.2.2.a.i.

Depending on the type of material used, the experimental circumstances and outcomes of the experiments may vary (as already indicated with the various conceptual models described in the previous chapter), for example:

With fine granular homogenous material in an isotropic compression test, the grains are likely to be "pushed" together while they dissolve (because of the applied radial and axial stresses) and it is expected that the total volume will change evenly or gradually over time. Depending on the circumstances (grain size, external stresses, degree of compaction etc.), the porosity may increase or decrease during the process of anhydrite dissolution (see Chapter 7.2.2.a.i). This can be monitored by calculating the resulting coefficient of permeability during the test, as described above.

With a perforated block of anhydrite in an isotropic compression test, the anhydrite will also dissolve by "rinsing" the block with water, leading to locally higher stresses in the material-bridges between the pores (while the total "external" stress remains constant), since the latter diminish while the pores become bigger (i.e. the area of anhydrite decreases). The consequence will be very slowly increasing strains at first and eventually, the locally growing stress may reach the strength of the material and lead to a total collapse in the system. (Ideally, a block made of pure anhydrite is used, in which boreholes are made in axial direction. This is way the initial conditions are clearly defined.)

Concerning layered anhydrite (where granular material is compacted to a cylindrical specimen in alternating layers of inert material and anhydrite), the dissolution of the anhydrite layers will result in a higher axial strain compared to the radial strain (cf. Chapter 7.2.2.c). In the extreme case, the radial strains may not be affected at all (i.e. remain constant), which is why the relationship between the axial strain and the change in mass of anhydrite can just as well be determined with an oedometer cell, where the radial stress is assumed to remain constant. Under this assumption, $a_{a x}=\left(\partial \varepsilon_{a x} / \partial m_{A}\right) \cdot \rho_{A}$ and $a_{r a d}=0$. The same can be argued for the case where the influence of anhydrite dissolution on the stresses is investigated: If no change in radial direction is measured (i.e., the radial stresses in a completely constrained test), the parameters can be determined as $a_{a x}=-\rho_{A} / E \cdot \partial \sigma_{a x} / \partial m_{A}$ and $a_{r a d}=-v \cdot a_{a x}$.

It may be difficult to keep all strains constant, when investigating the influence of anhydrite dissolution on the stresses. Ideally, this is done in a steel cell, where the change in radial stress 
can be determined along with the change in axial stress. However, especially in the case of a specimen made entirely of anhydritic grains (or a specimen of granular inert material with evenly distributed anhydritic grains), anhydrite dissolution leads to larger pores, reducing contact forces between the grains, thus reducing the external stresses, and it is possible, that the grains shift due to gravity during anhydrite dissolution (as the pores grow), and eventually lose contact with the lid. This leads automatically to zero axial stress. The same may occur with layered anhydrite, where the contact between the specimen and the cell may eventually be lost in axial direction.

\section{E.2. Gypsum precipitation}

Based on the previously described conceptual models, experiments are discussed which may allow a quantification of the relationships between the strains, stresses and gypsum precipitation alone, i.e., $g_{a x}$ and $g_{\text {rad }}$, while no anhydrite dissolution takes place. The only possibility to induce gypsum precipitation without any anhydrite dissolution (or precipitation), is to introduce water with an ion concentration close to the equilibrium concentration of anhydrite (at temperatures below the transition temperature of $50^{\circ} \mathrm{C}$ at atmospheric pressure) to a system which is devoid of anhydrite. Due to the concentration gradient between the concentration in the solution and the equilibrium concentration of gypsum, gypsum can precipitate. The following example shows the amount of gypsum that can precipitate from $1 \mathrm{I}$ water for $5^{\circ} \mathrm{C}$ and $20^{\circ} \mathrm{C}$ at atmospheric conditions:

Table E-1: $\quad$ Gypsum precipitation from supersaturated solution (with respect to gypsum).

\begin{tabular}{lll}
\hline & $\mathbf{5}{ }^{\circ} \mathbf{C}$ & $\mathbf{2 0}{ }^{\circ} \mathbf{C}$ \\
\hline Concentration in the solution $\approx$ equilibrium concentration of anhydrite $[\mathrm{mmol} / \mathrm{l}]$ & 29.8 & 23.3 \\
\hline Equilibrium concentration gypsum [mmol/l] & 15.0 & 15.1 \\
\hline Amount of ions for gypsum precipitation $[\mathrm{mmol} /]$ & 14.8 & 8.2 \\
\hline Mass of precipitated gypsum [g/l] & 2.5 & 1.4 \\
\hline Volume of precipitated gypsum $\left[\mathrm{cm}^{3} / \mathrm{l}\right]$ & 1.1 & 0.6 \\
\hline
\end{tabular}

The practical implementation of experiments where only gypsum precipitation occurs, offers the following difficulties:

In order for a significant amount of gypsum to precipitate in a system (e.g. enough to initiate a reasonable amount of swelling strain), a fair amount of saturated water needs to be introduced into the specimen. In the case of an open system, subjected to flow through, it will most likely not be possible to ensure that gypsum only precipitates within the specimen, and not at the borders, or in the pipes or filter plates surrounding the specimen (which is why the boundary conditions in Table 7-1 stipulate that the inflowing and outflowing water should not exceed the equilibrium concentration of gypsum).

On the other hand, in a closed system (assuming it consists only of a specimen and its pore water, i.e. to ensure that gypsum only precipitates within the specimen), the amount of pore water will not be sufficient to produce measurable swelling strains or stresses which are representable for the scale of the test (as seen in Table E-1, in 1 I of saturated water merely $1.1 \mathrm{~cm}^{3}$ of gypsum can precipitate at $5{ }^{\circ} \mathrm{C}$; assuming now a standard oedometer specimen of $50 \mathrm{~cm}^{3}$ size in total, of which $30 \%$ is pore space, merely $0.04 \mathrm{~g}$ resp. $0.02 \mathrm{~cm}^{3}$ of gypsum would precipitate from the pore water). 
As already indicated, it will be challenging to introduce a supersaturated solution to a specimen while ensuring that gypsum only precipitates within the specimen itself. It will most likely not be possible to generate a supersaturated solution without having the process of gypsum precipitation beginning in the water before it enters the specimen i.e. before the test begins. Theoretically, it is possible to create a supersaturated solution by changing the conditions of a saturated solution (e.g. reducing the pore water pressure or reducing the initial stresses) in order to reduce the equilibrium concentration of gypsum can be reduced. However, this would imply that the installation of the specimen occurs at high pressures compared to the conditions during the test itself.

Nevertheless, equations for the evaluation of the thought experiments are still discussed here which allow determining $g_{a x}$ and $g_{r a d}$, should the above mentioned practical difficulties be overcome.

Eliminating anhydrite dissolution from Equation $(7-6)$ and solving it for $g_{a x}$ and $g_{\text {rad }}$, leads to:

$$
\begin{gathered}
g_{a x}=\left(\frac{\partial \varepsilon_{a x}}{\partial m_{G}}-\frac{1}{E} \frac{\partial \sigma_{a x}^{\prime}}{\partial m_{G}}+\frac{2 v}{E} \frac{\partial \sigma_{r a d}^{\prime}}{\partial m_{G}}\right) \cdot \rho_{G} \\
g_{r a d}=\left(\frac{\partial \varepsilon_{r a d}}{\partial m_{G}}+\frac{v}{E} \frac{\partial \sigma_{a x}^{\prime}}{\partial m_{G}}-\frac{(1-v)}{E} \frac{\partial \sigma_{r a d}^{\prime}}{\partial m_{G}}\right) \cdot \rho_{G}
\end{gathered}
$$

Depending on the mechanical boundary conditions, $g_{a x}$ and $g_{\text {rad }}$ can thus be determined as follows:

- Isotropic compression (constant stresses):

$$
\begin{gathered}
\dot{\varepsilon}_{a x}=\frac{g_{a x}}{\rho_{G}} \dot{m}_{G} \\
\dot{\varepsilon}_{r a d}=\frac{g_{r a d}}{\rho_{G}} \dot{m}_{G}
\end{gathered}
$$

therefore,

$$
\begin{gathered}
g_{a x}=\frac{\partial \varepsilon_{a x}}{\partial m_{G}} \cdot \rho_{G} \\
g_{r a d}=\frac{\partial \varepsilon_{r a d}}{\partial m_{G}} \cdot \rho_{G}
\end{gathered}
$$

- Complete constraint (constant strains):

$$
\begin{gathered}
\dot{\sigma}_{a x}=\frac{-E(1-v)}{(1+v)(1-2 v)} \cdot\left(g_{a x}+\frac{2 v}{(1-v)} g_{r a d}\right) \cdot \frac{\dot{m}_{G}}{\rho_{G}} \\
\dot{\sigma}_{r a d}=\frac{-E}{(1+v)(1-2 v)} \cdot\left(v g_{a x}+g_{r a d}\right) \cdot \frac{\dot{m}_{G}}{\rho_{G}}
\end{gathered}
$$

thus

$$
\begin{gathered}
g_{a x}=\frac{1}{E}\left(-\frac{\partial \sigma_{a x}}{\partial m_{G}}+2 v \frac{\partial \sigma_{r a d}}{\partial m_{G}}\right) \cdot \rho_{G} \\
g_{r a d}=\frac{1}{E} \cdot\left(v \frac{\partial \sigma_{a x}}{\partial m_{G}}-(1-v) \frac{\partial \sigma_{r a d}}{\partial m_{G}}\right) \cdot \rho_{G}
\end{gathered}
$$


If the stress conditions prove to be isotropic $\left(\sigma_{a x}=\sigma_{r a d}=\sigma\right)$ throughout the test, the equations can be simplified further to:

$$
g_{a x}=g_{r a d}=\frac{(-1+2 v)}{E} \cdot \rho_{G} \cdot \frac{\partial \sigma}{\partial m_{G}}
$$

- Oedometric conditions (constant axial stress, constant radial strain):

$$
\begin{gathered}
\dot{\varepsilon}_{a x}=\left(g_{a x}+\frac{2 v}{(1-v)} \cdot g_{r a d}\right) \cdot \frac{\dot{m}_{G}}{\rho_{G}} \\
\dot{\sigma}_{r a d}=-\frac{E}{(1-v)} \cdot \frac{\dot{m}_{G}}{\rho_{G}} \cdot g_{r a d} \\
g_{a x}=\left(\frac{\partial \varepsilon_{a x}}{\partial m_{G}}+\frac{2 v}{E} \frac{\partial \sigma_{r a d}}{\partial m_{G}}\right) \cdot \rho_{G} \\
g_{r a d}=-\frac{(1-v)}{E} \cdot \frac{\partial \sigma_{r a d}}{\partial m_{G}} \cdot \rho_{G}
\end{gathered}
$$

- Flexible oedometer (constant axial stress):

$$
\begin{gathered}
\dot{\varepsilon}_{a x}=\frac{(1+v)(1-2 v)}{E v} \dot{\sigma}_{r a d}-\frac{1}{v} \dot{\varepsilon}_{r a d}+\frac{\dot{m}_{G}}{\rho_{G}}\left(g_{a x}+\frac{1}{v} g_{r a d}\right) \\
\dot{\varepsilon}_{r a d}=\frac{(1+v)(1-2 v)}{E} \dot{\sigma}_{r a d}-v \dot{\varepsilon}_{a x}+\frac{\dot{m}_{G}}{\rho_{G}}\left(v g_{a x}+g_{r a d}\right) \\
\dot{\sigma}_{r a d}=\frac{E}{(1+v)(1-2 v)} \cdot\left(v \dot{\varepsilon}_{r a d}+\dot{\varepsilon}_{r a d}-\frac{\dot{m}_{G}}{\rho_{G}}\left(v g_{a x}+g_{r a d}\right)\right) \\
g_{a x}=\left(\frac{\partial \varepsilon_{a x}}{\partial m_{G}}+\frac{2 v}{E} \frac{\partial \sigma_{r a d}}{\partial m_{G}}\right) \cdot \rho_{G} \\
g_{r a d}=\left(\frac{\partial \varepsilon_{r a d}}{\partial m_{G}}-\frac{(1-v)}{E} \frac{\partial \sigma_{r a d}}{\partial m_{G}}\right) \cdot \rho_{G}
\end{gathered}
$$

It will be necessary to determine the amount of precipitated gypsum during the experiments. Similar to Chapter E.1 (for the case of anhydrite dissolution), the following possibilities exist:

1. Via measuring the concentration and flow-rate of the exiting water (during certain time intervals) and back-calculating how much gypsum precipitated:

$$
\Delta M_{G, \Delta t}=\Delta M_{I, \Delta t} \cdot \frac{172}{136}=\left(c_{0}-c_{\text {out }, \Delta t}\right) \cdot V_{W, \Delta t} \cdot \frac{172}{136}
$$

2. By measuring the pore volume in time intervals (e.g. by switching from water to ethanol or another inert fluid (or possibly gas), i.e. pressing ethanol in the specimen to fill all pores, then switching back to water and collecting all exiting fluid, separate the fluids and thus measure the volume of ethanol). However, $V_{P, 0}$ needs to be known.

$$
\Delta M_{G}=\Delta V_{G} \cdot \rho_{G}=\left(\Delta V_{t o t}-\Delta V_{P}\right) \cdot \rho_{G}
$$


3. Dry specimen in between and measure mass:

$$
\Delta M_{G}=M_{t o t}-M_{t o t, 0}
$$

4. By calculating the change in permeability and thus of the void ratio via measuring the flow velocity. The mass of gypsum can be calculated as follows, as a function of the void ratio:

$$
\begin{gathered}
e=\frac{V_{P}}{V_{S}+V_{G}}=\frac{V_{t o t}-V_{S}-\frac{M_{G}}{\rho_{G}}}{V_{S}+\frac{M_{G}}{\rho_{G}}} \\
M_{G}=\rho_{G}\left(\frac{V_{t o t}}{1+e}-V_{S}\right)
\end{gathered}
$$

5. By measuring the total volume and mass $M_{\text {sat }}$ of the fully saturated specimen $\left(S_{r}=1\right.$, i.e. $V_{P}=V_{W}$ ) in-between (e.g. at $T_{\text {int }} \approx 50^{\circ}$ in order to interrupt AGT):

$$
\begin{gathered}
M_{s a t}=M_{G}+M_{S}+M_{W} \\
V_{t o t}=V_{G}+V_{S}+V_{W}=\frac{M_{G}}{\rho_{G}}+\frac{M_{S}}{\rho_{S}}+\frac{M_{W}}{\rho_{W}}
\end{gathered}
$$

From Equations $(E-71)$ and $(E-72)$ the mass of gypsum can then be calculated:

$$
M_{G}=\frac{V_{t o t} \rho_{G} \rho_{S} \rho_{W}+M_{S}\left(\rho_{G} \rho_{S}-\rho_{G} \rho_{W}\right)-M_{s a t} \rho_{G} \rho_{S}}{\left(\rho_{S} \rho_{W}-\rho_{G} \rho_{S}\right)}
$$

By determining the amount of precipitated gypsum and by measuring the change in height and radius, the strains and the change in porosity can be obtained (e.g. via Equations (7 - 19), and (7 - 30) - (7 - 32)). Possible outcomes for the porosity are shown, e.g. for granular material, in the conceptual model in Chapter 7.2.3.a. It is also possible that the strains will develop in a step-like manner, as seen in the conceptual model in Chapter 7.2.3.d.ii.

As discussed e.g. with the conceptual model in Chapter 7.2.3.a.i, the behavior of the specimen will be strongly dependent on the change in porosity (i.e. filling of the pores with gypsum as opposed to creation of new pores due to gypsum precipitation). Furthermore it is not certain whether gypsum would precipitate evenly throughout the specimen. Should gypsum grow unevenly, the permeability, pore pressures and void ratio would vary within the specimen, thus possibly falsifying the results. With changing pore pressures, Equations $(E-33)$ to $(E-50)$ need to be reformulated from Equations ( $E-31)$ and $(E-32)$, by considering changing pore pressures. For example, Equations $(E-35)$ and $(E-36)$ need to be replaced with the following equations:

$$
\begin{gathered}
g_{a x}=\left(\frac{\partial \varepsilon_{a x}}{\partial m_{G}}+\frac{(1-2 v)}{E} \frac{\partial p}{\partial m_{G}}\right) \cdot \rho_{G} \\
g_{r a d}=\left(\frac{\partial \varepsilon_{r a d}}{\partial m_{G}}+\frac{(1-2 v)}{E} \frac{\partial p}{\partial m_{G}}\right) \cdot \rho_{G}
\end{gathered}
$$

The apparatus in Figure 7-20 and the conditions listed in Table 7-1 account for the general case of an open system, where the water can flow in and out of the specimen. Another theoretical possibility (as already mentioned above) to determine e.g. the stresses caused by gypsum precipitation in a 
completely constrained test, is using a closed system where the specimen is installed in a closed steel cylinder (where the axial and radial deformations are prohibited, and without any flow through). The specimen is saturated with water at a high temperature and at a low water pressure, with a concentration of $c_{0} \approx c_{e q, G}$. By simultaneously lowering the temperature and increasing the water pressure, the equilibrium concentration of gypsum decreases below the initial concentration $c_{0}$. Now, gypsum precipitation begins, filling up the pores or fissures and possibly inducing stresses in axial and/or radial direction (depending on the type of material and structure of the specimen). However, such a concentration gradient (similar to the examples in Table E-1) would not suffice to produce a significant amount of gypsum within such a specimen.

Practically, the amount of precipitating gypsum will not suffice to create a high enough swelling pressure to crack a rock specimen or to and lead to a measurable change in confining stress also with granular material. This can be shown with the following example:

Assuming the used water to be saturated with respect to gypsum at $50{ }^{\circ} \mathrm{C}$ and atmospheric water pressure $\left(c_{0} \approx c_{e q, G, I}=15.7 \mathrm{~mol} / \mathrm{m}^{3}\right)$, then cooling the pore water to $5^{\circ} \mathrm{C}$ and increasing the pore water pressure to $20 \mathrm{MPa}\left(c_{e q, G, I I}=11.8 \mathrm{~mol} / \mathrm{m}^{3}\right)$ without changing any other factors. Therefore, the concentration gradient is roughly $3.9 \mathrm{~mol} / \mathrm{m}^{3}$. Assuming a porosity of 0.1 , a specimen $70 \mathrm{~mm}$ diameter and $20 \mathrm{~mm}$ height (total volume $25 \mathrm{~cm}^{3}$ ) would contain $2.5 \mathrm{~cm}^{3}$ of pore space (which, in this case, is equal to the volume of the pore water). From the concentration gradient and the volume of the pore water, $7 \cdot 10^{-3} \mathrm{~cm}^{3}$ of gypsum can precipitate (which, on a side note, would take a long time since the concentration gradient is very small and at $5{ }^{\circ} \mathrm{C}$ the reaction rate constant for gypsum precipitation is lower). The volume of used water for gypsum precipitation corresponds to roughly half of the gypsum volume $\left(3.5 \cdot 10^{-3} \mathrm{~cm}^{3}\right)$, i.e. the net volume increase of the closed system would be $3.5 \cdot 10^{-3} \mathrm{~cm}^{3}$ (which corresponds to a total strain on roughly $0.014 \%$ ), which a rock matrix can absorb elastically without exerting any pressure on the confinement. Note that this rough example does not consider any other effects due to temperature changes or pressure changes (e.g. shrinkage of the rock due to cooling) and it is assumed that gypsum only precipitates within the fissures and/or pores and not along the outer surface of the specimen.

As can be deducted from this chapter, experiments with only gypsum precipitation are difficult to realize and even if it is possible to avoid the mentioned problems, it is most likely not feasible to perform such tests since only a small amount of gypsum can precipitate from a slightly supersaturated solution.

\section{E.3. Simultaneous anhydrite dissolution and gypsum precipitation: possibilities to obtain the masses of anhydrite and gypsum}

The following (theoretical) possibilities exist to obtain the change in masses of anhydrite and gypsum during an experiment (whereas the technical applicability may not always be given):

1. By measuring the pore volume in time intervals (for a specimen undergoing flow-through): e.g. by switching from water to ethanol or another inert fluid (or possibly gas), i.e. pressing ethanol in the specimen to fill all pores, then switching back to water and collecting all exiting fluid, separate the fluids and thus measure the volume of ethanol). However, the initial pore volume $V_{P, 0}$ needs to be known exactly in order to determine the change in pore volume $\Delta V_{P}$ and the total change in volume of the specimen $\Delta V_{\text {tot }}$ needs to be measured. By considering Equation (2 - 16), the change in total volume is calculated as follows, assuming that all dissolved anhydrite turns into gypsum (i.e. $c_{i n}=c_{o u t}=c_{e q, G}$ when a flow-through system is considered): 


$$
\begin{aligned}
\Delta V_{\text {tot }} & =\Delta V_{A}+\Delta V_{G}+\Delta V_{S}+\Delta V_{P} \\
& =\Delta V_{A}-\Delta V_{A} \cdot \frac{545.1}{337.8}+0+\Delta V_{P} \\
& =-\Delta V_{G} \cdot \frac{337.8}{545.1}+\Delta V_{G}+0+\Delta V_{P}
\end{aligned}
$$

Therefore, the masses of anhydrite and gypsum in the system can be determined:

$$
\begin{gathered}
m_{A}=\frac{M_{A}}{V_{t o t}}=\frac{V_{A} \cdot \rho_{A}}{V_{t o t}}=\frac{M_{A, 0}}{V_{t o t}}-\frac{\left(V_{t o t, 0}-V_{t o t}\right)-\left(V_{P, 0}-V_{P}\right)}{\left(1-\frac{545.1}{337.8}\right)} \cdot \frac{\rho_{A}}{V_{t o t}} \\
m_{G}=\frac{M_{G}}{V_{t o t}}=\frac{V_{G} \cdot \rho_{G}}{V_{t o t}}=\frac{\left(V_{t o t, 0}-V_{t o t}\right)-\left(V_{P, 0}-V_{P}\right)}{\left(\frac{337.8}{545.1}-1\right)} \cdot \frac{\rho_{G}}{V_{t o t}}
\end{gathered}
$$

This procedure may, however, be quite time-consuming due to the fairly low permeability of the specimens and the accuracy of this method is questionable, since it may not be guaranteed that all water really is pressed out of the specimen.

2. Dry the specimen in between and measure the total dry mass. The change in total mass of the specimen occurs solely due to change in mass of anhydrite and gypsum (assuming that all dissolved anhydrite transforms to gypsum):

$$
\Delta M_{\text {tot }}=\Delta M_{A}+\Delta M_{G}
$$

Considering the molar masses of anhydrite and gypsum and the chemical reaction for the transformation (cf. Equation (2 - 10)), the mass changes are connected as follows:

$$
\Delta M_{G}=-\Delta M_{A} \cdot \frac{0.172[\mathrm{~kg} / \mathrm{mol}]}{0.136[\mathrm{~kg} / \mathrm{mol}]}=-\Delta M_{A} \cdot 1.265
$$

Using Equation ( $E-65)$ in Equation ( $E$ - 64), the changes in masses of anhydrite and gypsum amount to:

$$
\begin{gathered}
\Delta M_{A}=-\Delta M_{t o t} \cdot 3.778 \\
\Delta M_{G}=\Delta M_{t o t} \cdot 4.778
\end{gathered}
$$

Therefore, the masses of anhydrite and gypsum per unit volume can be determined:

$$
\begin{aligned}
& m_{A}=\frac{M_{A}}{V_{\text {tot }}}=\frac{M_{A, 0}-\Delta M_{A}}{V_{\text {tot }}}=\frac{M_{A, 0}+\Delta M_{\text {tot }} \cdot 3.778}{V_{\text {tot }}}=\frac{M_{A, 0}+\left(M_{\text {tot }, 0}-M_{t o t}\right) \cdot 3.778}{V_{\text {tot }}} \\
& m_{G}=\frac{M_{G}}{V_{\text {tot }}}=\frac{M_{G, 0}-\Delta M_{G}}{V_{\text {tot }}}=\frac{0-\Delta M_{\text {tot }} \cdot 4.778}{V_{\text {tot }}}=-\frac{\left(M_{t o t, 0}-M_{t o t}\right) \cdot 4.778}{V_{\text {tot }}}
\end{aligned}
$$


3. By measuring the flow velocity and calculating the change in permeability and thus of the void ratio (see Chapter E.1). From the void ratio, the pore volume can then be calculated:

$$
V_{P}=\frac{e}{1+e} \cdot V_{t o t}
$$

and $m_{A}$ and $m_{G}$ can be determined with Equations (E - 62) and (E - 63).

4. By measuring the total volume and mass $M_{\text {sat }}$ of the fully saturated specimen $\left(S_{r}=1\right.$, i.e. $V_{P}=V_{W}$ ) in-between (e.g. at $T_{\text {int }} \approx 50^{\circ}$ in order to interrupt AGT):

$$
\begin{aligned}
M_{\text {sat }} & =M_{A}+M_{G}+M_{S}+M_{W} \\
& =M_{A}+\Delta M_{A} \cdot \frac{0.172[\mathrm{~kg} / \mathrm{mol}]}{0.136[\mathrm{~kg} / \mathrm{mol}]}+M_{S}+M_{W}=-M_{A} \cdot 0.265+M_{A, 0} \cdot 1.265+M_{S}+M_{W} \\
V_{\text {tot }} & =V_{A}+V_{G}+V_{S}+V_{W}=\frac{M_{A}}{\rho_{A}}+\frac{M_{G}}{\rho_{G}}+\frac{M_{S}}{\rho_{S}}+\frac{M_{W}}{\rho_{W}} \\
& =\frac{M_{A}}{\rho_{A}}+\frac{\Delta M_{A}}{\rho_{G}} \cdot \frac{0.172[\mathrm{~kg} / \mathrm{mol}]}{0.136[\mathrm{~kg} / \mathrm{mol}]}+\frac{M_{S}}{\rho_{S}}+\frac{M_{W}}{\rho_{W}}=\frac{M_{A}}{\rho_{A}}+\frac{M_{A, 0}-M_{A}}{\rho_{G}} \cdot 1.265+\frac{M_{S}}{\rho_{S}}+\frac{M_{W}}{\rho_{W}}
\end{aligned}
$$

From Equations ( $E-71)$ and $(E-72)$ the mass of anhydrite can then be calculated:

$$
M_{A}=\frac{V_{\text {tot }} \rho_{G} \rho_{S} \rho_{W}-M_{\text {sat }} \rho_{G} \rho_{S}-M_{A, 0} \cdot 1.265 \cdot\left(\rho_{S} \rho_{W}-\rho_{G} \rho_{S}\right)-M_{S}\left(\rho_{G} \rho_{W}-\rho_{G} \rho_{S}\right)}{\rho_{G} \rho_{S} \rho_{W}-1.265 \rho_{A} \rho_{S} \rho_{W}+0.265 \rho_{A} \rho_{G} \rho_{S}} \cdot \rho_{A}
$$

And due to the assumption that all dissolved anhydrite was used for gypsum precipitation, the mass of gypsum can be calculated (using Equation (E - 73) for $M_{A}$ ):

$$
M_{G}=\Delta M_{A} \cdot \frac{0.172[\mathrm{~kg} / \mathrm{mol}]}{0.136[\mathrm{~kg} / \mathrm{mol}]}=\left(M_{A, 0}-M_{A}\right) \cdot 1.265
$$

5. In the case where the total volume of a specimen remains constant while water flows through (completely constrained tests with $c_{i n}=c_{o u t}=c_{e q, G}$ ), if the mass of water entering and exiting the specimen is measured with high accuracy during a certain time interval $\Delta t$, the amount of "consumed" water can be used to calculate the amount of dissolved anhydrite and precipitated gypsum with help from Equation (2 - 9).

$$
\begin{gathered}
\Delta M_{W, \Delta t}=M_{W, i n, \Delta t}-M_{W, \text { out } t \Delta t} \\
\Delta M_{A, \Delta t}=\Delta M_{W, \Delta t} \cdot \frac{0.136[\mathrm{~kg} / \mathrm{mol}]}{0.036[\mathrm{~kg} / \mathrm{mol}]} \\
\Delta M_{G, \Delta t}=-\Delta M_{W, \Delta t} \cdot \frac{0.172[\mathrm{~kg} / \mathrm{mol}]}{0.036[\mathrm{~kg} / \mathrm{mol}]}
\end{gathered}
$$

Ideally, the mass of water entering and exiting the specimen is measured continuously from the beginning on (not only during a time span $\Delta t$ ), in order to obtain an accurate value of the mass of anhydrite and gypsum in the specimen, and no loss of water occurs at any point of 
time (e.g. due to evaporation). This procedure is, however, most likely impossible to perform accurately enough in practice.

It needs to be noted that - in the case of flow-through experiments - the methods described above assume all dissolved anhydrite to be used for gypsum precipitation within the specimen. Should this not be the case (i.e., if the exiting concentration proves to be higher than the concentration of the inflowing water), the mass change of gypsum needs to be corrected by taking into account the mass of the ions from the dissolving anhydrite which were rinsed out of the specimen and were thus not used for gypsum precipitation (here during a time span $\Delta t$ ):

$$
\begin{gathered}
\Delta M_{I, \Delta t}=\left(c_{i n, \Delta t}-c_{o u t, \Delta t}\right) \cdot V_{W, \Delta t} \\
\Delta M_{G, \Delta t}=\left(\Delta M_{A, \Delta t}+\Delta M_{I, \Delta t}\right) \cdot \frac{0.172[\mathrm{~kg} / \mathrm{mol}]}{0.136[\mathrm{~kg} / \mathrm{mol}]}
\end{gathered}
$$

$V_{W, \Delta t}$ being the volume of water used to measure the concentration during the time period of $\Delta t$.

\section{E.4. Simultaneous anhydrite dissolution and gypsum precipitation: complete constraint, closed system}

As mentioned in Chapter 7.3.4, a complete constraint test cannot be performed for a closed system, since shrinkage will occur. It may be possible to maintain completely constrained conditions if the shrinkage is compensated by preloading the specimen. However, since the compressibility is very low (e.g. for water $\kappa=5 \cdot 10^{-10} \mathrm{~Pa}^{-1}$, for rock between $\kappa=2 \cdot 10^{-6} \mathrm{~Pa}^{-1}$ (plastic clay "best case") to $\kappa=3 \cdot 10^{-10} \mathrm{~Pa}^{-1}$ (sound rock "worst case")), enormous pressures may be necessary to build up, in order to generate enough change in volume. Assuming, for example, that volumetric strains of $\varepsilon_{V o l}=1 \%$ need to be compensated, the necessary preloading pressure of the grains alone amounts to

$$
\Delta p=\frac{\varepsilon_{\text {Vol }}}{\kappa} \approx \frac{0.01}{10^{-6} \ldots 10^{-10}}=10 \mathrm{kPa} \ldots 100 \mathrm{MPa}
$$

However, these values do not yet consider the water in the system, only the compressibility of the solids. Considering, furthermore, that the equilibrium concentrations of anhydrite and gypsum increase with increasing stress, whereas anhydrite becomes the stable phase rather than gypsum, such an experiment in a closed system is most likely not feasible. 


\section{F. Coupling parameters as a function of $\vartheta$}

The mass of anhydrite per unit volume $m_{A}(\mathrm{t})$ is in itself dependent on the change in volume, i.e. on the strains (see Equation ( $F-1)$ ). It may be necessary to express the relationships between stresses, strains and change in anhydrite by a volume-independent parameter. Here the formulations from Chapter 7.1 are therefore alternatively expressed as a function of the degree of anhydrite to gypsum transformation in the system (“ $\checkmark$ "-value):

$$
\begin{gathered}
m_{A}(\mathrm{t})=\frac{M_{A}(t)}{V_{t o t}(t)}=\frac{M_{A, 0} \cdot(1-\vartheta(t))}{V_{t o t, 0} \cdot\left(1-\varepsilon_{V o l}(t)\right)}=m_{A, 0} \cdot \frac{1-\vartheta(t)}{1-\varepsilon_{V o l}(t)} \\
\dot{m}_{A}=m_{A, 0} \cdot \frac{(1-\vartheta) \cdot \dot{\varepsilon}_{V o l}-\left(1-\varepsilon_{V o l}\right) \cdot \dot{\vartheta}}{\left(1-\varepsilon_{V o l}\right)^{2}} \\
\vartheta=\frac{M_{A, 0}-M_{A}}{M_{A, 0}}
\end{gathered}
$$

with the volumetric strains for cylindrical specimens according to Equation $(8-20)$, we obtain thus:

$$
\dot{m}_{A}=m_{A, 0} \cdot \frac{(1-\vartheta) \cdot\left(\dot{\varepsilon}_{a x}+\dot{\varepsilon}_{r a d} \cdot 2 \frac{\left(1-\varepsilon_{a x}\right)}{\left(1-\varepsilon_{r a d}\right)}\right)-\left(1-\varepsilon_{a x}\right) \cdot \dot{\vartheta}}{\left(1-\varepsilon_{a x}\right)^{2} \cdot\left(1-\varepsilon_{r a d}\right)^{2}}
$$

Equation $(7-8)$ can thus be re-formulated in dependence of $\vartheta$ for $\dot{\sigma}_{a x}, \dot{\sigma}_{r a d}, \quad \dot{\varepsilon}_{a x}$ and/or $\dot{\varepsilon}_{r a d}$, respectively, by using Equation ( $F-4)$.

Therefore, the parameters $\chi, \chi_{a x}$ and $\chi_{\text {rad }}$ amount to:

$$
\begin{gathered}
\chi_{a x}=\frac{\rho_{A}}{m_{A, 0}} \cdot \frac{\left(1-\varepsilon_{a x}\right)^{2} \cdot\left(1-\varepsilon_{r a d}\right)^{2} \cdot\left(\frac{\partial \varepsilon_{a x}}{\partial \vartheta}-\frac{1}{E} \frac{\partial \sigma_{a x}^{\prime}}{\partial \vartheta}+\frac{2 v}{E} \frac{\partial \sigma_{r a d}^{\prime}}{\partial \vartheta}\right)}{(1-\vartheta) \cdot\left(\frac{\partial \varepsilon_{a x}}{\partial \vartheta}+\frac{\partial \varepsilon_{r a d}}{\partial \vartheta} \cdot 2 \frac{\left(1-\varepsilon_{a x}\right)}{\left(1-\varepsilon_{r a d}\right)}\right)-\left(1-\varepsilon_{a x}\right)} \\
\chi_{r a d}=\frac{\rho_{A}}{m_{A, 0}} \cdot \frac{\left(1-\varepsilon_{a x}\right)^{2} \cdot\left(1-\varepsilon_{r a d}\right)^{2} \cdot\left(\frac{\partial \varepsilon_{r a d}}{\partial \vartheta}+\frac{v}{E} \frac{\partial \sigma_{a x}^{\prime}}{\partial \vartheta}-\frac{(1-v)}{E} \frac{\partial \sigma_{r a d}^{\prime}}{\partial \vartheta}\right)}{(1-\vartheta) \cdot\left(\frac{\partial \varepsilon_{a x}}{\partial \vartheta}+\frac{\partial \varepsilon_{r a d}}{\partial \vartheta} \cdot 2 \frac{\left(1-\varepsilon_{a x}\right)}{\left(1-\varepsilon_{r a d}\right)}\right)-\left(1-\varepsilon_{a x}\right)} \\
\chi=\frac{\rho_{A}}{m_{A, 0}} \cdot \frac{\left(1-\varepsilon_{a x}\right)^{2} \cdot\left(1-\varepsilon_{r a d}\right)^{2} \cdot\left(\frac{\partial \varepsilon_{a x}}{\partial \vartheta}+\frac{2 v}{(1-v)} \frac{\partial \varepsilon_{r a d}}{\partial \vartheta}-\frac{(1+v)(1-2 v)}{E(1-v)} \frac{\partial \sigma_{a x}^{\prime}}{\partial \vartheta}\right)}{(1-\vartheta) \cdot\left(\frac{\partial \varepsilon_{a x}}{\partial \vartheta}+\frac{\partial \varepsilon_{r a d}}{\partial \vartheta} \cdot 2 \frac{\left(1-\varepsilon_{a x}\right)}{\left(1-\varepsilon_{r a d}\right)}\right)-\left(1-\varepsilon_{a x}\right)} \\
\frac{\chi_{a x}}{\chi_{r a d}}=\frac{\partial \varepsilon_{a x}}{\frac{\partial \varepsilon_{r a d}}{\partial \vartheta}+\frac{1}{E} \frac{\partial \sigma_{a x}^{\prime}}{\partial \vartheta}+\frac{\partial \sigma_{a x}^{\prime}}{\partial \vartheta}-\frac{\partial \sigma_{r a d}^{\prime}}{\partial \vartheta}} \frac{(1-v)}{E} \frac{\partial \sigma_{r a d}^{\prime}}{\partial \vartheta}
\end{gathered}
$$


Depending on the mechanical boundary conditions, $\chi_{a x}, \chi_{\text {rad }}$ and $\chi$ can thus be determined as follows:

- Isotropic compression (constant stresses):

$$
\begin{gathered}
\chi_{a x}=\frac{\rho_{A}}{m_{A, 0}} \cdot \frac{\left(1-\varepsilon_{a x}\right)^{2} \cdot\left(1-\varepsilon_{r a d}\right)^{2} \cdot \frac{\partial \varepsilon_{a x}}{\partial \vartheta}}{(1-\vartheta) \cdot\left(\frac{\partial \varepsilon_{a x}}{\partial \vartheta}+\frac{\partial \varepsilon_{r a d}}{\partial \vartheta} \cdot 2 \frac{\left(1-\varepsilon_{a x}\right)}{\left(1-\varepsilon_{r a d}\right)}\right)-\left(1-\varepsilon_{a x}\right)} \\
\chi_{r a d}=\frac{\rho_{A}}{m_{A, 0}} \cdot \frac{\left(1-\varepsilon_{a x}\right)^{2} \cdot\left(1-\varepsilon_{r a d}\right)^{2} \cdot \frac{\partial \varepsilon_{r a d}}{\partial \vartheta}}{(1-\vartheta) \cdot\left(\frac{\partial \varepsilon_{a x}}{\partial \vartheta}+\frac{\partial \varepsilon_{r a d}}{\partial \vartheta} \cdot 2 \frac{\left(1-\varepsilon_{a x}\right)}{\left(1-\varepsilon_{r a d}\right)}\right)-\left(1-\varepsilon_{a x}\right)} \\
\chi=\frac{\rho_{A}}{m_{A, 0}} \cdot \frac{\left(1-\varepsilon_{a x}\right)^{2} \cdot\left(1-\varepsilon_{r a d}\right)^{2} \cdot\left(\frac{\partial \varepsilon_{a x}}{\partial \vartheta}+\frac{2 v}{(1-v)} \frac{\partial \varepsilon_{r a d}}{\partial \vartheta}\right)}{(1-\vartheta) \cdot\left(\frac{\partial \varepsilon_{a x}}{\partial \vartheta}+\frac{\partial \varepsilon_{r a d}}{\partial \vartheta} \cdot 2 \frac{\left(1-\varepsilon_{a x}\right)}{\left(1-\varepsilon_{r a d}\right)}\right)-\left(1-\varepsilon_{a x}\right)} \\
\frac{\chi_{a x}}{\chi_{r a d}}=\frac{\frac{\partial \varepsilon_{a x}}{\partial \vartheta}}{\frac{\partial \varepsilon_{r a d}}{\partial \vartheta}}
\end{gathered}
$$

- Complete constraint (constant strains):

$$
\begin{gathered}
\chi_{a x}=\frac{\rho_{A}}{m_{A, 0}} \cdot \frac{1}{E} \cdot\left(\frac{\partial \sigma_{a x}^{\prime}}{\partial \vartheta}-2 v \frac{\partial \sigma_{r a d}^{\prime}}{\partial \vartheta}\right) \\
\chi_{r a d}=\frac{\rho_{A}}{m_{A, 0}} \cdot \frac{1}{E} \cdot\left(-v \frac{\partial \sigma_{a x}^{\prime}}{\partial \vartheta}+(1-v) \frac{\partial \sigma_{r a d}^{\prime}}{\partial \vartheta}\right) \\
\chi=\frac{\rho_{A}}{m_{A, 0}} \cdot \frac{(1+v)(1-2 v)}{E(1-v)} \cdot \frac{\partial \sigma_{a x}^{\prime}}{\partial \vartheta} \\
\frac{\chi_{a x}}{\chi_{r a d}}=\frac{\frac{\partial \sigma_{a x}^{\prime}}{\partial \vartheta}-2 v \frac{\partial \sigma_{r a d}^{\prime}}{\partial \vartheta}}{-v \frac{\partial \sigma_{a x}^{\prime}}{\partial \vartheta}+(1-v) \frac{\partial \sigma_{r a d}^{\prime}}{\partial \vartheta}}
\end{gathered}
$$

- Oedometric conditions (constant axial stress, constant radial strain):

$$
\begin{gathered}
\chi_{a x}=\frac{\rho_{A}\left(1-\varepsilon_{a x}\right)^{2} \cdot\left(\frac{\partial \varepsilon_{a x}}{\partial \vartheta}+\frac{2 v}{E} \frac{\partial \sigma_{r a d}}{\partial \vartheta}\right)}{m_{A, 0} \cdot\left[-\left(1-\varepsilon_{a x}\right)+(1-\vartheta) \cdot \frac{d \varepsilon_{a x}}{\partial \vartheta}\right]} \\
\chi_{r a d}=\frac{\rho_{A}\left(1-\varepsilon_{a x}\right)^{2} \cdot\left[-\frac{(1-v)}{E} \frac{\partial \sigma_{r a d}}{\partial \vartheta}\right]}{m_{A, 0} \cdot\left[-\left(1-\varepsilon_{a x}\right)+(1-\vartheta) \cdot \frac{d \varepsilon_{a x}}{\partial \vartheta}\right]}
\end{gathered}
$$




$$
\begin{aligned}
\chi=\chi_{a x}+\frac{2 v}{(1-v)} \chi_{r a d}= & \frac{\rho_{A}\left(1-\varepsilon_{a x}\right)^{2} \cdot \frac{\partial \varepsilon_{a x}}{\partial \vartheta}}{m_{A, 0} \cdot\left[-\left(1-\varepsilon_{a x}\right)+(1-\vartheta) \cdot \frac{d \varepsilon_{a x}}{\partial \vartheta}\right]} \\
\frac{\chi_{a x}}{\chi_{r a d}}= & \frac{\frac{\partial \varepsilon_{a x}}{\partial \vartheta}+\frac{2 v}{E} \frac{\partial \sigma_{r a d}}{\partial \vartheta}}{-\frac{(1-v)}{E} \frac{\partial \sigma_{r a d}}{\partial \vartheta}}
\end{aligned}
$$

- Flexible oedometer (constant axial stress):

$$
\begin{gathered}
\chi_{a x}=\frac{\rho_{A}}{m_{A, 0}} \cdot \frac{\left(1-\varepsilon_{a x}\right)^{2} \cdot\left(1-\varepsilon_{r a d}\right)^{2} \cdot\left(\frac{\partial \varepsilon_{a x}}{\partial \vartheta}+\frac{2 v}{E} \frac{\partial \sigma_{r a d}}{\partial \vartheta}\right)}{(1-\vartheta) \cdot\left(\frac{\partial \varepsilon_{a x}}{\partial \vartheta}+\frac{\partial \varepsilon_{r a d}}{\partial \vartheta} \cdot 2 \frac{\left(1-\varepsilon_{a x}\right)}{\left(1-\varepsilon_{r a d}\right)}\right)-\left(1-\varepsilon_{a x}\right)} \\
\chi_{r a d}=\frac{\rho_{A}}{m_{A, 0}} \cdot \frac{\left(1-\varepsilon_{a x}\right)^{2} \cdot\left(1-\varepsilon_{r a d}\right)^{2} \cdot\left(\frac{\partial \varepsilon_{r a d}}{\partial \vartheta}-\frac{(1-v)}{E} \frac{\partial \sigma_{r a d}}{\partial \vartheta}\right)}{(1-\vartheta) \cdot\left(\frac{\partial \varepsilon_{a x}}{\partial \vartheta}+\frac{\partial \varepsilon_{r a d}}{\partial \vartheta} \cdot 2 \frac{\left(1-\varepsilon_{a x}\right)}{\left(1-\varepsilon_{r a d}\right)}\right)-\left(1-\varepsilon_{a x}\right)} \\
\chi=\frac{\rho_{A}}{m_{A, 0}} \cdot \frac{\left(1-\varepsilon_{a x}\right)^{2} \cdot\left(1-\varepsilon_{r a d}\right)^{2} \cdot\left(\frac{\partial \varepsilon_{a x}}{\partial \vartheta}+\frac{2 v}{(1-v)} \frac{\partial \varepsilon_{r a d}}{\partial \vartheta}\right)}{(1-\vartheta) \cdot\left(\frac{\partial \varepsilon_{a x}}{\partial \vartheta}+\frac{\partial \varepsilon_{r a d}}{\partial \vartheta} \cdot 2 \frac{\left(1-\varepsilon_{a x}\right)}{\left(1-\varepsilon_{r a d}\right)}\right)-\left(1-\varepsilon_{a x}\right)} \\
\frac{\chi_{a x}}{\chi_{r a d}}=\frac{\frac{\partial \varepsilon_{a x}}{\partial \vartheta}+\frac{2 v}{E} \frac{\partial \sigma_{r a d}}{\partial \vartheta}}{\frac{\partial \varepsilon_{r a d}}{\partial \vartheta}-\frac{(1-v)}{E} \frac{\partial \sigma_{r a d}}{\partial \vartheta}}
\end{gathered}
$$





\section{G. Crystallization pressure and macroscopic swelling pressure}

Serafeimidis et al. (2015) proposed a cavity expansion model (Figure 13-2) to estimate the macroscopic pressure $\sigma_{S}$ which develops at the outer border of a confined matrix containing cavities of radius $a$ within which crystals grow. This model will be used here to estimate the maximum possible swelling pressure of a rock matrix.

The crystallization pressure of gypsum $p_{G}$ (see, e.g., Scherer, 2002, Serafeimidis and Anagnostou, 2014a) is calculated as

$$
p_{G}=\frac{\left(T-T_{0}\right) \cdot \Delta_{r, G A} S^{0}-\Delta_{r, G A} G^{0}}{V_{G}^{0}}+\frac{2 R T \ln \left(a_{W}\right)}{V_{G}^{0}}+p_{A} \cdot \frac{V_{A}^{0}}{V_{G}^{0}}-p_{W} \cdot \frac{\left(V_{A}^{0}-V_{G}^{0}+\Delta_{r, G A} V^{0}\right)}{V_{G}^{0}}-\frac{2 \gamma_{S E, G}}{r_{G}}
$$

where $T_{0}$ denotes the temperature at standard state $(298 \mathrm{~K}) ; \Delta_{r, G A} S^{0}$ the standard entropy of anhydrite hydration $(-52.42 \mathrm{~J} / \mathrm{K} / \mathrm{mol}) ; \Delta_{r, G A} G^{0}$ the standard Gibbs energy of the transformation of anhydrite to gypsum $(-1250 \mathrm{~J} / \mathrm{mol}) ; V_{G}^{0}$ and $V_{A}^{0}$ the molar volumes of gypsum and anhydrite at standard state $\left(74.30 \mathrm{~cm}^{3} / \mathrm{mol}\right.$ and $\left.45.94 \mathrm{~cm}^{3} / \mathrm{mol}\right) ; \Delta_{r, G A} V^{0}$ the standard volume of the transformation of anhydrite to gypsum $\left(-7.64 \mathrm{~cm}^{3} / \mathrm{mol}\right) ; \gamma_{S E, G}$ the surface free energy of the gypsum-water interface $\left(8 \cdot 10^{-9} \mathrm{~kJ} / \mathrm{cm}^{2}\right)$ (see, e.g., Serafeimidis and Anagnostou, 2014a; for the other symbols see Notation at the end of the thesis). Equation ( $G-1)$ assumes that the ion concentration in the solute corresponds to the equilibrium concentration of anhydrite (i.e., $c=c_{e q, A}$ ) in a closed system (no ion transport in or out of the sample).

The crystallization pressure can only be exerted if a thin film develops between the two approaching solid surfaces (i.e., the crystal and the pore wall) which causes a repulsive force between the crystal and the wall (a disjoining pressure, see, e.g., Scherer, 2000, Flatt, 2002, Espinosa-Marzal and Scherer, 2010).

The following assumptions are made for the calculation of the crystallization pressure: laboratory room temperature $\left(T=20^{\circ} \mathrm{C}\right)$, atmospheric pressure $\left(p_{W}=0\right)$, water activity $a_{W}=1$, the radius of the gypsum crystals equals the weighted average of the pore radii of the samples presented in the experiments here (which were obtained with porosimetry, see Chapter 8.9.1), i.e., $r_{G}=r_{P}=34 \mathrm{~nm}$. Considering these fairly small pores, solid-liquid interfacial effects between the growing gypsum crystals, denoted by the last term in Equation ( $G-1)$, cannot be neglected (cf. Serafeimidis and Anagnostou, 2014b).

For the equilibrium concentration of anhydrite two borderline cases are discussed in Serafeimidis and Anagnostou (2014a), see Figure 13-2b:

In the first borderline case, diffusion is considered to occur very slowly relative to dissolution and, therefore, gypsum will grow only in the pores next to dissolving anhydrite. The pressure acting on the anhydrite is then assumed equal to the crystallization pressure of gypsum ( $p_{A}=p_{G}$ in Equation $(G-1))$. An increasing pressure on the anhydrite, $p_{A}$, increases the equilibrium concentration of anhydrite, which in turn will increase the crystallization pressure $p_{G}$ and so on until an equilibrium is reached. Therefore, the crystallization pressure is calculated as

$$
p_{G}=\frac{\left(T-T_{0}\right) \cdot \Delta_{r, G A} S^{0}-\Delta_{r, G A} G^{0}}{V_{G}^{0}-V_{A}^{0}}-\frac{2 \gamma_{S E, G}}{r_{G}} \cdot \frac{V_{G}^{0}}{V_{G}^{0}-V_{A}^{0}}
$$

and amounts to $41 \mathrm{MPa}$ in the first borderline case. 
In the second borderline case, gypsum grows in all pores (rapid diffusion) and the pressure acting on the anhydrite is not influenced by the crystallization of gypsum $\left(p_{A}=0\right.$ in Equation $(\mathrm{G}-1)$ ). Therefore, the equilibrium concentration of anhydrite remains constant and the crystallization pressure can be calculated with the following equation:

$$
p_{G}=\frac{\left(T-T_{0}\right) \cdot \Delta_{r, G A} S^{0}-\Delta_{r, G A} G^{0}}{V_{G}^{0}}-\frac{2 \gamma_{S E, G}}{r_{G}}
$$

and amounts to $16 \mathrm{MPa}$ for the second borderline case.

The simplified model for the calculation of the macroscopic swelling pressure according to Serafeimidis et al. (2015) assumes the rock matrix to be a linear elastic material with zero tensile strength and considers a static equilibrium between the gypsum and the matrix. Under these conditions, the stress $\sigma_{s}$ at a radius $b$ can be expressed by the stress $\sigma_{a}$ at radius $a$ (at the cavity wall) and a function of $a$ and $b$ :

$$
\sigma_{S}=\sigma_{a} \cdot\left(\frac{a}{b}\right)^{\zeta}
$$

while $\sigma_{a}$ is a function of the crystallization pressure for the underlying assumption of thermodynamic equilibrium.

The term $\zeta$ depends on the shape of the cavities. For the case of spherical cavities, $\zeta=2$, while for the case of cylindrical cavities, $\zeta=1$. The ratio $a / b$ depends on the packing density of the cavities and can be taken from Table G-1 (cf., e.g., Serafeimidis, 2014):

Table G-1: $\quad$ Ratio $a / b$ for different packing arrangements.

\begin{tabular}{lccc}
\hline $\begin{array}{l}\text { Hexagonal grid } \\
\text { densest packing) }\end{array}$ & $\frac{a}{b}=\left(\frac{6 \cdot \zeta \cdot \sqrt{4-\zeta} \cdot \delta}{(\zeta+2) \cdot \pi}\right)^{\frac{1}{\zeta+1}}$ & $\frac{a}{b}=\left(\frac{3 \cdot \sqrt{2} \cdot \delta}{\pi}\right)^{1 / 3}$ & $\frac{a}{b}=\left(\frac{2 \cdot \sqrt{3} \cdot \delta}{\pi}\right)^{1 / 2}$ \\
\hline Quadratic grid & $\frac{a}{b}=\left(\frac{3 \cdot 2^{\zeta+1} \cdot \delta}{(\zeta+2) \cdot \pi}\right)^{\frac{1}{\zeta+1}}$ & $\frac{a}{b}=\left(\frac{6 \cdot \delta}{\pi}\right)^{1 / 3}$ & $\frac{a}{b}=\left(\frac{4 \cdot \delta}{\pi}\right)^{1 / 2}$ \\
\hline
\end{tabular}

$\delta$ is the volume fraction of expanding cavities.

We consider again the two borderline cases described above for the case of a closed system (no ion transport in or out of the sample). However, in the first case (slow diffusion) it is now assumed that the gypsum-filled pores are smeared over the anhydrite (see Serafeimidis et al., 2015). The volume fraction of the expanding cavities is then equal to the volume fraction of anhydrite $\left(\delta=\phi_{A}\right)$ and the average pressure acting on the anhydrite is $p_{A}=\sigma_{a}$, which is smaller than the crystallization pressure $p_{G}$. The ratio $\sigma_{a} / p_{G}$ is taken according to Serafeimidis (2014) as the percentage of the anhydrite surface area that is in contact with water, i.e., for densest packing of spheres:

$$
\frac{\sigma_{a}}{p_{G}}=\frac{\pi}{2 \sqrt{3}} \cdot\left(\frac{r_{P}}{b_{P}}\right)^{\zeta}=\left(\frac{\sqrt{3} \cdot \phi^{2} \cdot \pi}{4}\right)^{1 / 3}
$$

where $\phi$ denotes the porosity. 
Considering additionally the same assumptions as above (i.e., $p=0$ and $a_{W}=1$ ), Equation (G - 1) yields for the first borderline case:

$$
\sigma_{a}=\left(V_{G}^{0}\left(\sqrt{3} \cdot \phi^{2} \cdot \pi / 4\right)^{-1 / 3}-V_{A}^{0}\right)^{-1}\left(\left(T-T_{0}\right) \cdot \Delta_{r, G A} S^{0}-\Delta_{r, G A} G^{0}-\frac{2 \gamma_{S E, G}}{r_{G}} \cdot V_{G}^{0}\right)
$$

from which the macroscopic stress can be calculated with Equation ( $G$ - 4):

$$
\sigma_{S}=\frac{(a / b)^{\zeta}}{V_{G}^{0} \cdot\left(\sqrt{3} \cdot \phi^{2} \cdot \pi / 4\right)^{-1 / 3}-V_{A}^{0}} \cdot\left(\left(T-T_{0}\right) \cdot \Delta_{r, G A} S^{0}-\Delta_{r, G A} G^{0}-\frac{2 \gamma_{S E, G}}{r_{G}} \cdot V_{G}^{0}\right)
$$

With $T=20^{\circ} \mathrm{C}, r_{G}=r_{P}=34 \mathrm{~nm}$, a volume fraction of anhydrite $\phi_{A} \approx 0.25$, a porosity of $\phi \approx 0.3$ and assuming densest packing of spheres $\left((a / b)^{\zeta}=\left(3 \cdot \sqrt{2} \cdot \phi_{A}\right)^{2 / 3} \cdot \pi^{-2 / 3}\right)$, the stress $\sigma_{S}$ amounts to 5.4 MPa for the first borderline case.

In the second borderline case, gypsum is assumed to grow in all pores (rapid diffusion), so that the pressure acting on the anhydrite corresponds to the macroscopic swelling pressure, i.e., $p_{A}=\sigma_{S}$, whereas now the volume fraction of the expanding cavities equals the porosity $(\delta=\phi)$ and the stress at the cavity walls corresponds to the crystallization pressure $\left(p_{G}=\sigma_{a}\right)$. Setting again $p=0$ and $a_{W}=1$ we obtain from Equation (G - 1):

$$
\sigma_{a}=\sigma_{S} \cdot \frac{V_{A}^{0}}{V_{G}^{0}}+\frac{\left(T-T_{0}\right) \cdot \Delta_{r, G A} S^{0}-\Delta_{r, G A} G^{0}}{V_{G}^{0}}-\frac{2 \gamma_{S E, G}}{r_{G}}
$$

in combination with Equation ( $G$ - 4):

$$
\sigma_{S}=\frac{(a / b)^{\zeta}}{V_{G}^{0}-V_{A}^{0} \cdot(a / b)^{\zeta}} \cdot\left(\left(T-T_{0}\right) \cdot \Delta_{r, G A} S^{0}-\Delta_{r, G A} G^{0}-\frac{2 \gamma_{S E, G}}{r_{G}} \cdot V_{G}^{0}\right)
$$

With $T=20^{\circ} \mathrm{C}, r_{G}=r_{P}=34 \mathrm{~nm}$, a porosity of $\phi \approx 0.3$ and assuming densest packing of spheres $\left((a / b)^{\zeta}=(3 \cdot \sqrt{2} \cdot \phi)^{2 / 3} \cdot \pi^{-2 / 3}\right)$, the stress $\sigma_{S}$ amounts to $13 \mathrm{MPa}$ for the second borderline case.

a)

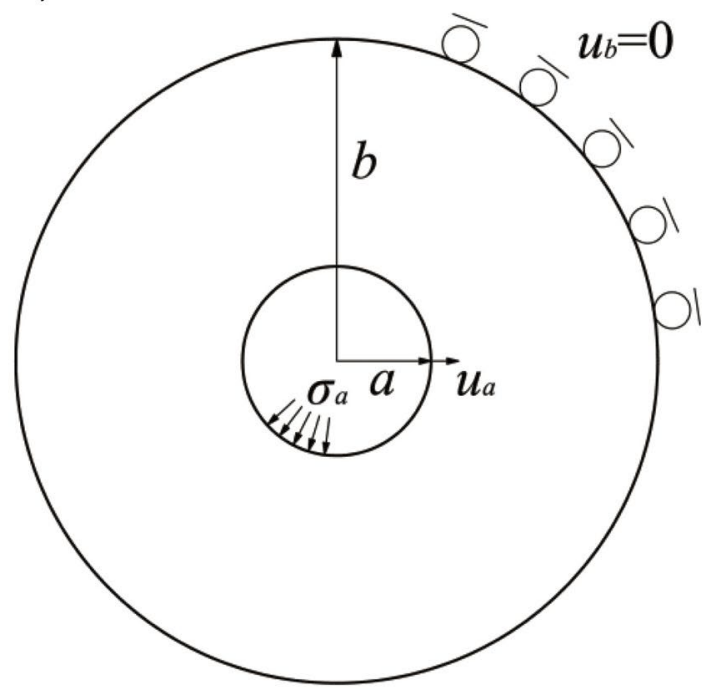

b)

First borderline case: Gypsum precipitation next to the dissolving anhydrite

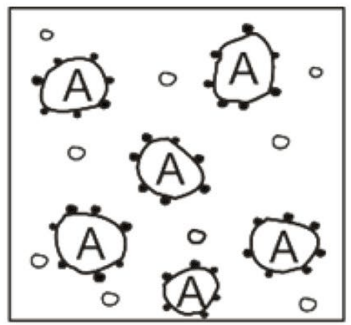

Second borderline case Gypsum precipitation in the pores

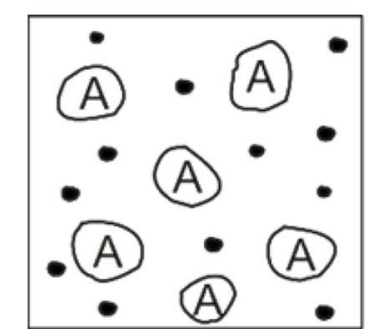
A Anhydrite
- Gypsum
Pores

Figure 13-2: a) Spherical cavity expansion model (Serafeimidis et al., 2015); b) two cases for gypsum growth (borderline cases for the calculation of the macroscopic swelling pressure, Serafeimidis, 2014). 
Serafeimidis (2014) determined the cavity expansion that must occur for the stresses to reach a level above which anhydrite and gypsum are in thermodynamic equilibrium. For densest packing of spheres:

$$
\frac{u_{a}}{a}=\frac{\sigma_{S}}{E} \cdot\left(\frac{\pi}{3 \cdot \sqrt{2} \cdot \delta}\right)^{1 / 3} \cdot\left(\left(\frac{\pi}{3 \cdot \sqrt{2} \cdot \delta}\right)^{1 / 3}-1\right)
$$

which amounts to $1.7 \%$ resp. $3.1 \%$ for the first and second borderline cases. Serafeimidis (2014) furthermore indicates an upper limit of the amount of anhydrite $\Delta \phi_{A}$ that must be transformed to gypsum, in order to reach thermodynamic equilibrium:

First borderline case $\quad \Delta \phi_{A}=\frac{\phi_{A}}{V_{G}^{0} / V_{A}^{0}-1} \cdot\left[\left(1+\frac{u_{a}}{a}\right)^{3}-1\right]=2 \%$

Second borderline case $\quad \Delta \phi_{A}=\frac{\phi}{V_{G}^{0} / V_{A}^{0}-1} \cdot\left(1+\frac{u_{a}}{a}\right)^{3}=53 \%$

Considering the second borderline case, the process may well stop before reaching equilibrium, since the amount of anhydrite is $25 \%$ (which is far less than $53 \%$ ).

An overview of the assumptions and the calculated results for both borderline cases is given in Table G-2.

Table G-2: $\quad$ Overview of first and second borderline cases.

First borderline case:

slow diffusion

gypsum precipitation next to anhydrite
Second borderline case:

rapid diffusion

gypsum precipitation in pores

Crystallization pressure
Assumption for $p_{A}$
$=p_{G}$
$=0$
Result for $p_{G}$
$41 \mathrm{MPa}$
$16 \mathrm{MPa}$

Macroscopic swelling pressure

$$
\begin{aligned}
& \text { Assumption for } p_{A} \\
& \text { Assumption for } \delta
\end{aligned}
$$

Assumptions for $\sigma_{a} / p_{G}$

Result for $\sigma_{S}$

Corresponding value of $\sigma_{a}$

Cavity expansion $u_{a} / a$

$$
\begin{gathered}
=\sigma_{a}=\sigma_{S} \cdot(a / b)^{-\zeta} \\
=\phi_{A}=0.25
\end{gathered}
$$$$
=\left(\sqrt{3} \cdot \phi^{2} \cdot \pi / 4\right)^{1 / 3}
$$

$5.4 \mathrm{MPa}$

$11 \mathrm{MPa}$

$1.7 \%$

$3.1 \%$

Amount of anhydrite that must be transformed (upper limit) $\Delta \phi_{A}$ 
According to these results, the confining pressure should therefore be at least $70 \%$ higher than the pressure of 3.2 MPa used in the oedometer tests (see Chapter 8.5) and also higher than the axial stress measured in the complete constraint tests of Chapter 8.6, i.e., 3.5 MPa.

The causes for this discrepancy are most likely due to the fact that the above mentioned (idealized) assumptions made for the development of the cavity expansion model do not correspond to the real specimen properties and experimental conditions. For example:

- A closed system is assumed, which may not have been the case in the experiments (some ions may have diffused out of the sample).

- The pores are not uniform, spherical and completely surrounded by the matrix, but of irregular shape and sizes and may also be connected (creating a network of channels).

- The geometric boundary conditions of the experimental samples and their loading history are different than in the model: While the model obeys spherical symmetry and assumes no initial stresses to act at the boundaries (the stress develops only as crystallization occurs), the oedometers are initially loaded in axial direction prior to the swelling experiments while the radial stresses are not known. Due to the initial loading, the samples are stiffer than in the case without any initial stresses (and thus the macroscopic stress may be lower).

- The model assumes that the growth of gypsum and the development of the swelling pressure occurs until thermodynamic equilibrium is reached, which is not the case if the matrix around the growing crystals is very soft (cf. Serafeimidis, 2014). When the matrix surrounding the cavities is very soft, AGT can take place without ever reaching the crystallization pressure, i.e., the development of the swelling pressure of the powdered samples is terminated prior to reaching the thermodynamic equilibrium and the above calculated macroscopic swelling pressures will not occur.

- Since the porosity is quite large (even greater than the volume fraction of anhydrite), it is very well possible that the gypsum precipitates in the pores and the space where anhydrite dissolved, without reaching thermodynamic equilibrium.

This can be shown with the following calculation: For cavity expansion to occur, the fraction of gypsum would need to be larger than the sum of the fractions of anhydrite and pores in the system (assuming for sake of simplicity that the total volume remains constant and gypsum fills the pores entirely, which is most likely not the case). In the case of the oedometers we have $\phi=0.3, \phi_{A}=0.25$ and $\phi_{G}=\phi_{A} \cdot 1.61=0.4$, which is smaller than the sum of the former two fractions. Therefore, it is theoretically possible for the entire gypsum to fill the pores without causing cavity expansion and thus the calculated macroscopic swelling stress may not be reached.

Nevertheless, the simple model presented by Serafeimidis and Anagnostou provides an upper limit of the maximal macroscopic swelling stress. 



\section{H. Stresses and strains in "flexible oedometers"}

As mentioned in Chapter 8.8.1, the radial strains and stresses of the specimen are connected to each other via the surrounding cylinder in the case of the flexible oedometers. The radial stresses acting on the inside of the cylinder (due to swelling of the specimen) cause a radial expansion of the cylinder, thus also allowing the specimen to expand radially to a certain degree. The PVC cylinders used for the experiments described in Chapter 8.8 are considered as "thick walled" cylinders in the following (see Figure 13-3) for the determination of the stresses and strains of the specimen and are calculated after Obert and Duvall (1967).
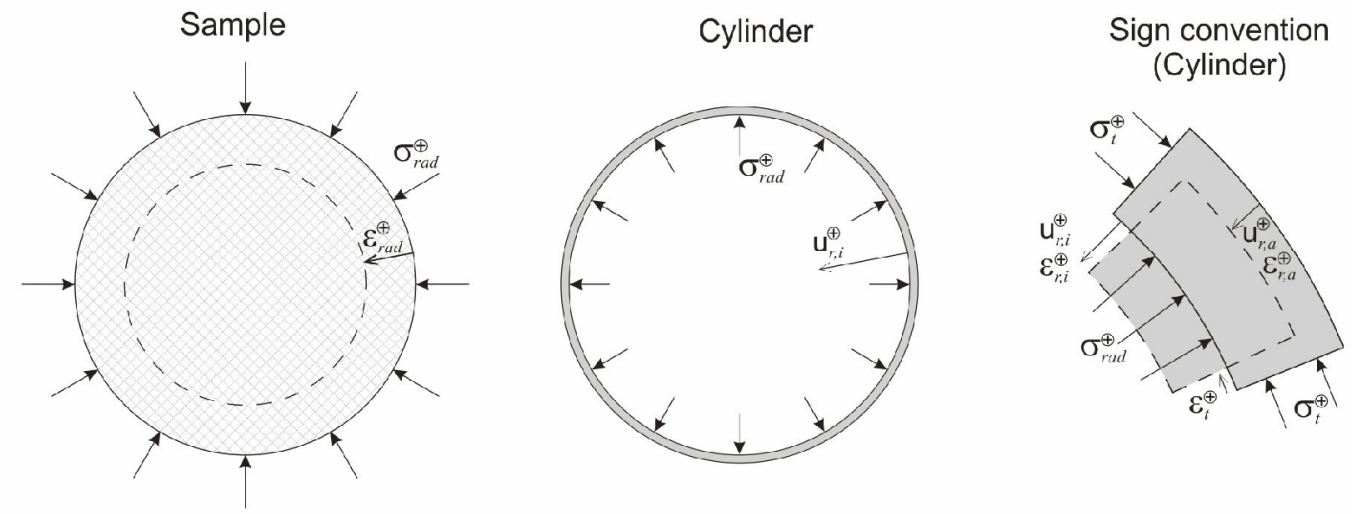

Figure 13-3: System of specimen and cylinder.

Radial and tangential stresses within the cylinder wall:

$$
\begin{aligned}
& \sigma_{r}(r)=\frac{r_{i}^{2} \sigma_{r a d}}{r_{a}^{2}-r_{i}^{2}}-\frac{1}{r^{2}} \frac{r_{i}^{2} r_{a}^{2} \sigma_{r a d}}{r_{a}^{2}-r_{i}^{2}} \\
& \sigma_{t}(r)=\frac{r_{i}^{2} \sigma_{r a d}}{r_{a}^{2}-r_{i}^{2}}+\frac{1}{r^{2}} \frac{r_{i}^{2} r_{a}^{2} \sigma_{r a d}}{r_{a}{ }^{2}-r_{i}^{2}}
\end{aligned}
$$

whereas $r_{a}$ and $r_{i}$ are the outer and inner radii of the cylinder.

Radial and tangential strains of the cylinder:

$$
\begin{gathered}
\varepsilon_{r}=\frac{d u}{d r}=\frac{1}{E_{c y l}} \cdot\left[\sigma_{r}-v_{c y l} \cdot \sigma_{t}\right] \\
\varepsilon_{t}=\frac{u}{r}=\frac{1}{E_{c y l}} \cdot\left[\sigma_{t}-v_{c y l} \cdot \sigma_{r}\right]
\end{gathered}
$$

$E_{c y l}$ and $v_{c y l}$ being the Young's modulus and Poisson ratio of the cylinder.

Thus the radial deformation of the cylinder:

$$
u(r)=\frac{1}{E_{c y l}} \cdot \frac{\sigma_{r a d} \cdot r_{i}^{2}}{r_{a}^{2}-r_{i}^{2}}\left[r \cdot\left(1-v_{c y l}\right)+\frac{1}{r} \cdot r_{a}^{2} \cdot\left(1+v_{c y l}\right)\right]
$$

at the outer surface of the cylinder (where the change in circumference is measured during the experiment):

$$
u\left(r_{a}\right)=\frac{1}{E_{c y l}} \cdot \frac{\sigma_{r a d} \cdot r_{i}^{2} \cdot r_{a} \cdot 2}{r_{a}^{2}-r_{i}^{2}}
$$


while at the inside of the cylinder (which corresponds to the deformation of the specimen):

$$
u\left(r_{i}\right)=\frac{1}{E_{c y l}} \cdot \frac{\sigma_{r a d} \cdot r_{i}^{2}}{r_{a}^{2}-r_{i}^{2}}\left[r_{i} \cdot\left(1-v_{c y l}\right)+\frac{r_{a}^{2}}{r_{i}} \cdot\left(1+v_{c y l}\right)\right]
$$

With $\Delta C_{c y l}=C_{c y l}-C_{0, c y l}=2 \pi\left(r_{a}+u_{\left(r_{a}\right)}\right)-2 \pi r_{a}=2 \pi u_{\left(r_{a}\right)}$ we get the radial stress acting from the specimen on the inside of the cylinder (from Equation $(\mathrm{H}-6)$ ):

$$
\sigma_{r a d}=\frac{\Delta C_{c y l} \cdot E_{c y l} \cdot\left(r_{a}^{2}-r_{i}^{2}\right)}{4 \pi \cdot r_{i}^{2} \cdot r_{a}}
$$

And thus the radial deformation (from Equation $(\mathrm{H}-7)$ )

$$
\Delta r=u\left(r_{i}\right)=\frac{\Delta C_{c y l}}{4 \pi \cdot r_{a}}\left[r_{i} \cdot\left(1-v_{c y l}\right)+\frac{r_{a}^{2}}{r_{i}} \cdot\left(1+v_{c y l}\right)\right]
$$

We assume that the stresses and strains acting in the specimen are constant throughout the crosssection of the specimen (i.e., we assume an element test under axisymmetric conditions), and therefore:

$$
\begin{aligned}
\varepsilon_{\text {rad }} & =\frac{\Delta r}{r_{\text {sample }}}=\frac{\Delta r}{r_{i}}=\frac{\Delta C_{c y l}}{4 \pi \cdot r_{a}}\left[\left(1-v_{c y l}\right)+\frac{r_{a}^{2}}{r_{i}^{2}} \cdot\left(1+v_{c y l}\right)\right] \\
& \left(\hat{=} \varepsilon_{t}\left(r_{i}\right)\right)
\end{aligned}
$$

Therefore, we get the following expressions for $\chi_{a x}, \chi_{\text {rad }}$ and $\chi$ :

$$
\begin{aligned}
\chi_{a x} & =\left(\frac{\partial \varepsilon_{a x}}{\partial m_{A}}+\frac{2 v}{E} \frac{\partial \sigma_{r a d}}{\partial m_{A}}\right) \cdot \rho_{A}=\left(\frac{\partial \varepsilon_{a x}}{\partial m_{A}}+\frac{2 v}{E} \cdot \frac{E_{c y l} \cdot\left(r_{a}^{2}-r_{i}^{2}\right)}{4 \pi \cdot r_{i}^{2} \cdot r_{a}} \frac{\partial C_{c y l}}{\partial m_{A}}\right) \cdot \rho_{A} \\
\chi_{r a d} & =\left(\frac{\partial \varepsilon_{r a d}}{\partial m_{A}}-\frac{(1-v)}{E} \frac{\partial \sigma_{r a d}}{\partial m_{A}}\right) \cdot \rho_{A} \\
& =\frac{\partial C_{c y l}}{\partial m_{A}} \frac{1}{4 \pi \cdot r_{a}}\left(\left(1-v_{c y l}\right)+\frac{r_{a}^{2}}{r_{i}^{2}} \cdot\left(1+v_{c y l}\right)-\frac{(1-v)}{E} E_{c y l} \cdot \frac{\left(r_{a}^{2}-r_{i}^{2}\right)}{r_{i}^{2}}\right) \cdot \rho_{A} \\
\chi & =\left(\frac{\partial \varepsilon_{a x}}{\partial m_{A}}+\frac{2 v}{(1-v)} \cdot \frac{\partial \varepsilon_{r a d}}{\partial m_{A}}\right) \cdot \rho_{A} \\
& =\left(\frac{\partial \varepsilon_{a x}}{\partial m_{A}}+\frac{2 v}{(1-v)} \cdot \frac{1}{4 \pi \cdot r_{a}} \cdot\left(\left(1-v_{c y l}\right)+\frac{r_{a}^{2}}{r_{i}^{2}} \cdot\left(1+v_{c y l}\right)\right) \cdot \frac{\partial C_{c y l}}{\partial m_{A}}\right) \cdot \rho_{A}
\end{aligned}
$$

By including the "fitting" pressure $\sigma_{0, f i t}$ from the calibration of the PVC cylinders (see Chapter 8.8.2), we get:

$$
\begin{gathered}
\sigma_{r a d}=\sigma_{0, f i t}+\frac{\Delta C_{c y l} \cdot E_{c y l, c a l} \cdot\left(r_{a}^{2}-r_{i}^{2}\right)}{4 \pi \cdot r_{i}^{2} \cdot r_{a}} \\
\Delta r=u\left(r_{i}\right)=\left[\frac{1}{E_{c y l, c a l}} \cdot \frac{\sigma_{0, f i t} \cdot r_{i}^{2}}{r_{a}^{2}-r_{i}^{2}}+\frac{\Delta C_{c y l}}{4 \pi \cdot r_{a}}\right] \cdot\left[r_{i} \cdot\left(1-v_{c y l}\right)+\frac{r_{a}^{2}}{r_{i}} \cdot\left(1+v_{c y l}\right)\right]
\end{gathered}
$$




$$
\begin{aligned}
\varepsilon_{\text {rad }} & =\frac{\Delta r}{r_{\text {sample }}}=\frac{\Delta r}{r_{i}}=\left[\frac{1}{E_{c y l, c a l}} \cdot \frac{\sigma_{0, f i} \cdot r_{i}^{2}}{r_{a}^{2}-r_{i}^{2}}+\frac{\Delta C_{c y l}}{4 \pi \cdot r_{a}}\right] \cdot\left[\left(1-v_{c y l}\right)+\frac{r_{a}^{2}}{r_{i}^{2}} \cdot\left(1+v_{c y l}\right)\right] \\
& \left(\hat{=} \varepsilon_{t}\left(r_{i}\right)\right)
\end{aligned}
$$

Since the "fitting" pressure is a constant value, the derivatives of $\sigma_{\text {rad }}$ with respect to $m_{A}$ are independent of it, and thus $\chi_{a x}, \chi_{\text {rad }}$ and $\chi$ are the same as in Equations $(H-11)$ to $(H-13)$. 



\section{Analysis of specimen composition (TGA, XRD)}

Figure I-1 and Figure I-2 show the results of TGA analyses performed on oedometer specimens described in Chapters 8.4.2 and 8.5. As described in Chapter 3.1, the drop in mass between $90^{\circ} \mathrm{C}$ and $140^{\circ} \mathrm{C}$ can be attributed solely to the dehydration of gypsum in the samples. Note, that the drop at a temperature higher than $450^{\circ} \mathrm{C}$ occurs due to dihydroxylation of kaolin (cf. Bontle and Nadiye-Tabbiruka, 2007) and is not of further interest in this work.

From the TGA measurements, the gypsum and anhydrite contents of the specimens post oedometer test can be calculated based on the mass balances according to Equation (2 - 9) (since the specimens did not contain any gypsum initially).

$$
\begin{gathered}
M_{G, \text { end }}=\Delta \omega \cdot M_{\text {tot }, \text { end }} \cdot \frac{172[\mathrm{~g} / \mathrm{mol}]}{36[\mathrm{~g} / \mathrm{mol}]} \\
M_{A, \text { end }}=M_{A, \text { prior }}-\Delta \omega \cdot M_{t o t, \text { end }} \cdot \frac{136[\mathrm{~g} / \mathrm{mol}]}{36[\mathrm{~g} / \mathrm{mol}]}
\end{gathered}
$$

where $M_{G, \text { end }}, M_{A, \text { end }}$ and $M_{\text {tot,end }}$ denote the masses of gypsum and anhydrite in the specimen and total dry mass of the specimen post test. $\Delta \omega$ corresponds to the measured change in mass in [wt\%] according to the TGA analysis. From these total masses, the masses per unit volume can be derived (as used, e.g., in Figure 8-21 and Figure 8-25):

$$
\begin{gathered}
m_{G, \text { end }}=\frac{M_{G, \text { end }}}{V_{\text {tot, end }}} \\
m_{A, \text { end }}=\frac{M_{A, \text { end }}}{V_{\text {tot }, \text { end }}}
\end{gathered}
$$

whereas $V_{\text {tot,end }}$ corresponds to the total volume of the specimen post test (calculated from measurements).

The progress of the AGT process within a specimen can be estimated by the following ratio:

$$
\vartheta=1-\frac{M_{A, \text { end }}}{M_{A, \text { prior }}}
$$




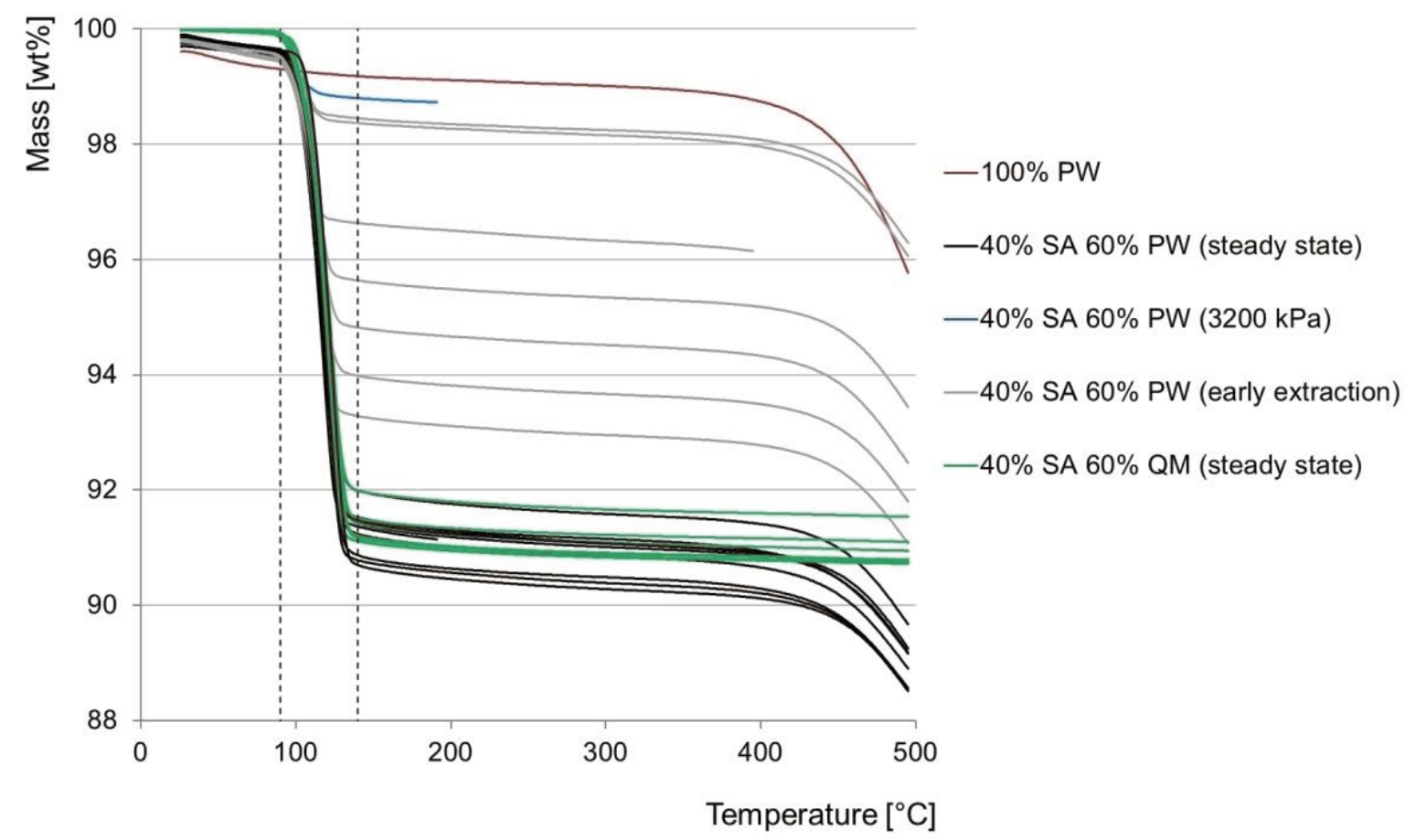

Figure l-1: $\quad$ TGA results of oedometer tests with $\sigma_{a x}>3 \mathrm{kPa}$.

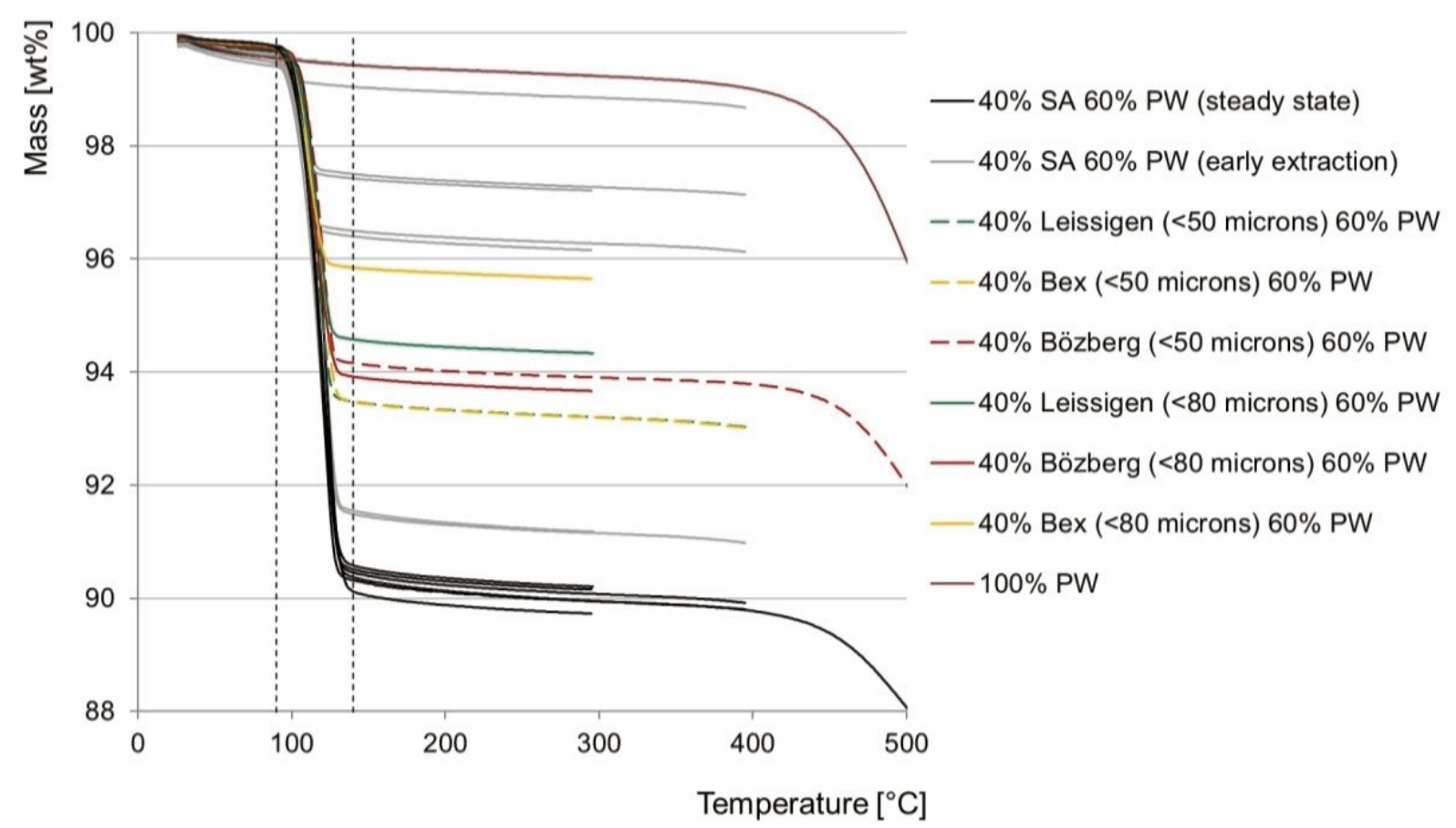

Figure l-2: $\quad$ TGA results of oedometer tests with $\sigma_{a x}=3 \mathrm{kPa}$.

In order to verify the reliability of the TGA results, XRD analysis was performed on three of the tested specimens from Figure I-2 (i.e., 1_XRD, 2_XRD, 3a_XRD and 3d_XRD in Figure I-3) as well as on a reference sample containing only the used kaolin (4_XRD). The results are shown in Figure I-3, where the mineralogical compositions of the specimens according to the XRD analysis are compared to the back-calculated results from TGA performed on samples of the same oedometer-specimens (e.g., comparison of "1_XRD" to "1_TGA"). Since the different minerals in the kaolin were not distinguished via TGA (as opposed to XRD, where each mineral is shown in a 
different color in Figure I-3), the kaolin is shown as one component in the results from TGA (dark red pillars in Figure I-3).

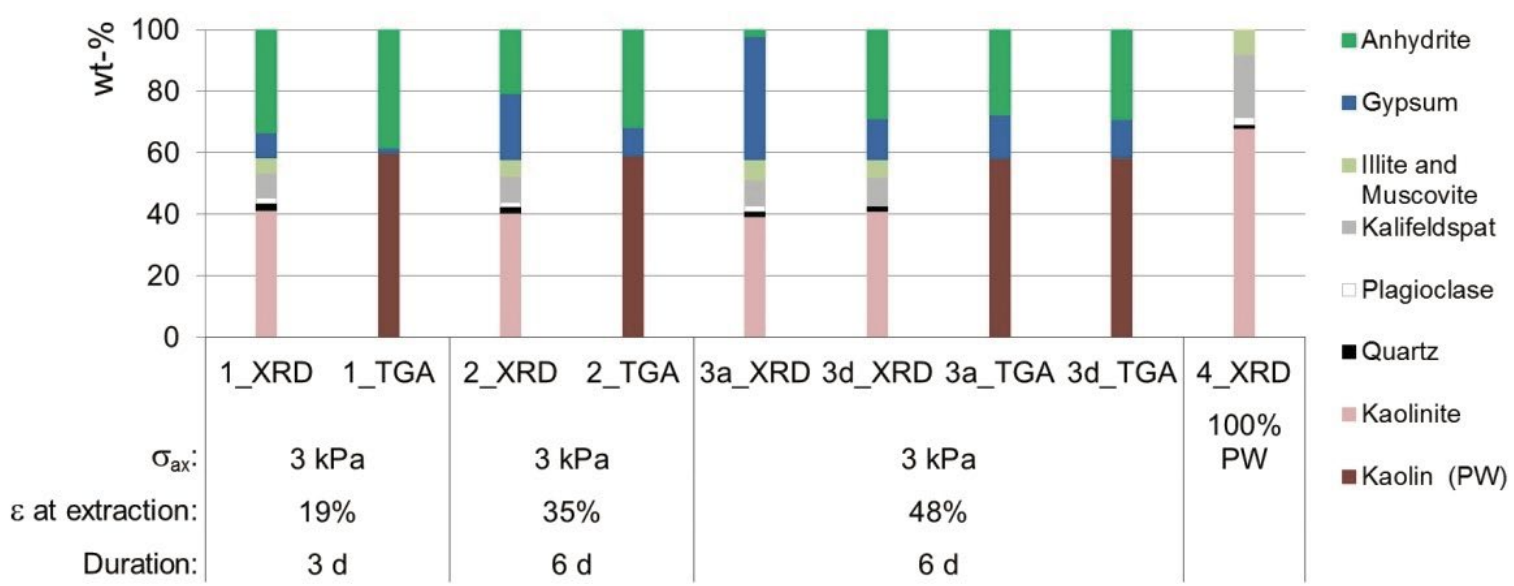

Figure I-3: Composition of three specimens post oedometer test (comparison between results from X-ray diffraction analysis and thermogravimetric analysis) and mineralogical composition of the kaolin based on X-ray diffraction analysis (pillar on the far right).

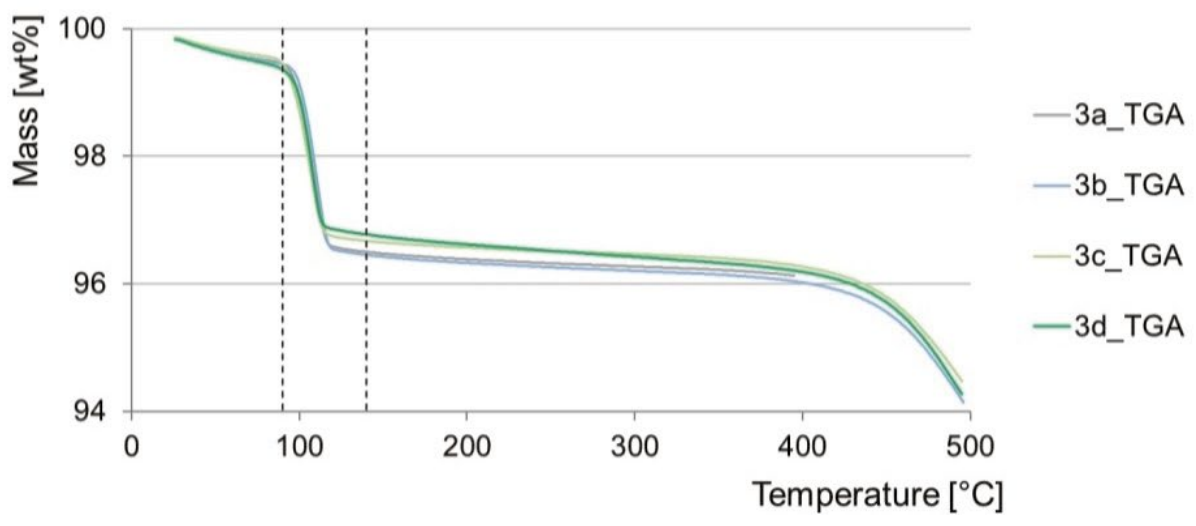

Figure 1-4: $\quad$ TGA repetition of a specimen.

One observation that can be made from Figure I-3 is that the analysis via TGA delivered generally higher anhydrite contents compared to the XRD analysis. This discrepancy was probably due to faulty sample preparation (further gypsum may have precipitated during air-drying of samples 1_XRD, 2_XRD and 3a_XRD at room temperature and humidity) because almost the same result was achieved as via TGA upon repetition of the X-ray analysis on one of the samples (3d_XRD, which was dried in an oven at $40^{\circ} \mathrm{C}$ ). Furthermore, repetition of TGA on that same specimen (3a_TGA to 3d_TGA in Figure I-4) showed that the TGA results are very consistent concerning reproducibility. Therefore, the TGA results can be considered reliable and sufficiently accurate for the analysis of the oedometer tests.

The determination of the specimen composition with XRD analysis was not always straight forward, which can be attributed to faulty sample preparation, as was also the case in the example described above. Another example for this is the occurrence of a significant amount of bassanite (up to $30 \%$ ) in the XRD results of some of the investigated specimens described in Chapters 8.4.2 and 11 . Bassanite is a hemihydrate $\left(\mathrm{CaSO}_{4} \cdot 0.5 \mathrm{H}_{2} \mathrm{O}\right)$ and can be produced by heating the dihydrate (gypsum, $\mathrm{CaSO}_{4} \cdot 2 \mathrm{H}_{2} \mathrm{O}$ ), cf., e.g., van't Hoff et al. (1903). It is strongly assumed to have been produced only after the tests during drying of the specimens at too high temperatures $\left(>60^{\circ} \mathrm{C}\right)$. The $\mathrm{XRD}$ results that showed bassanite were therefore corrected by assuming that all bassanite 
was gypsum prior to drying the specimens. This was considered in the results given in Figure 11-5 and Figure 11-7 (specimens marked with an asterisk).

This correction can be verified with the following example (specimen X26 from Belchen SB6 1.401.56): The first results from the XRD analysis are shown in the pillar on the left in Figure I-5 (X26_1). Upon repetition of the $\mathrm{X}$-ray analysis, where the sample was air-dried at room temperature (as opposed to the oven at $65^{\circ}$ ) no bassanite was detected in the specimen (right pillar in Figure $1-5$, X26_2). When using the results from X26_1 to calculate the amount of gypsum corresponding to the amount of bassanite, thus correcting the results (with Equations $(I-6)$ and $I-7)$ ), the pillar in the middle in Figure I-5 (X26_1*) is obtained. These corrected results correspond very well with the repeated XRD analysis (X26_2), thus the correction of the XRD results containing bassanite is acceptable. Therefore, the following equations were used for the corrections of the content of gypsum and other minerals of all results containing bassanite:

$$
\begin{gathered}
\omega_{G}^{*}=\frac{\omega_{G}+\omega_{B} \cdot \frac{172[\mathrm{~g} / \mathrm{mol}]}{145[\mathrm{~g} / \mathrm{mol}]}}{1+\omega_{B} \cdot\left(\frac{172[\mathrm{~g} / \mathrm{mol}]}{145[\mathrm{~g} / \mathrm{mol}]}-1\right)} \\
\omega_{\text {Component }}^{*}=\frac{\omega_{\text {Component }}}{1+\omega_{B} \cdot\left(\frac{172[\mathrm{~g} / \mathrm{mol}]}{145[\mathrm{~g} / \mathrm{mol}]}-1\right)}
\end{gathered}
$$

where $\omega_{G}, \omega_{B}$ and $\omega_{\text {Component }}$ are the contents (in wt $\%$ ) of gypsum, bassanite and other components of the specimen according to the XRD results while the asterisk indicates the corrected values.

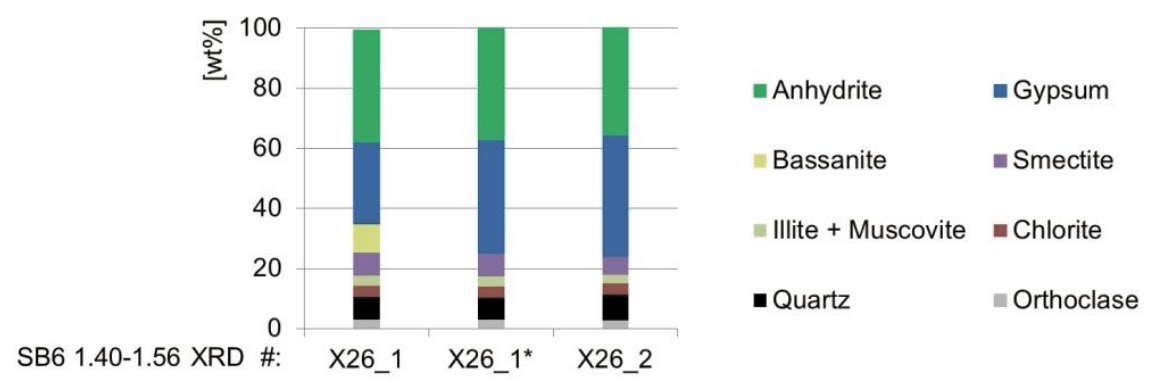

Figure 1-5: $\quad X R D$ results of $X 26 \_1$ (dried at $65{ }^{\circ} \mathrm{C}$ during specimen preparation) and correction of bassanite $\left(X 26 \_1^{*}\right)$ and $X R D$ results of $X 26 \_2$ (air-dried at room temperature during specimen preparation).

The same procedure was used on some of the specimens from Chapter 8.4.2, where different kinds of anhydrite were investigated in oedometer tests with $\sigma_{a x}=3 \mathrm{kPa}$. One specimen of each type of anhydrite was investigated with XRD in addition to the TGA analysis (of which the results are displayed in Figure I-2). The analysis of the specimen composition is shown in Figure I-6, for the original and corrected XRD results as well as the results obtained via TGA. It can be seen that a very good correlation exists between the corrected XRD results and the TGA results, thus it is again confirmed that the bassanite was produced during the preparation of the XRD specimens. 


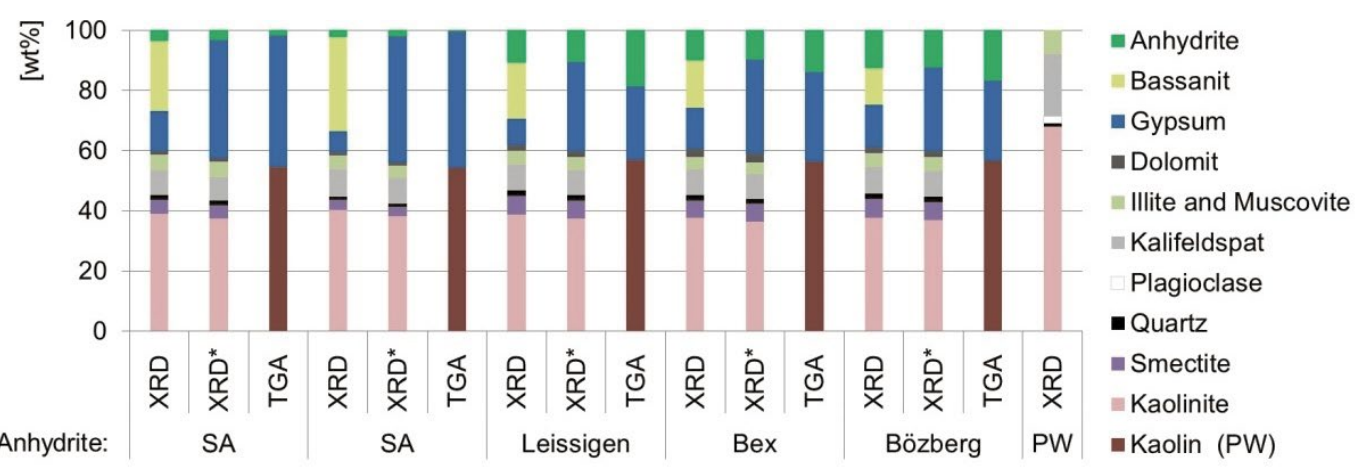

Figure l-6: $\quad$ Results from XRD and TGA analysis with correction of bassanite in the XRD results (marked *). 



\section{J. Specimen properties}

The properties of specimens from all swelling experiments are listed in the following tables.

The chemo-mechanical experiments described in Chapters 8.4.1, 8.4.2 and 8.5-8.8 are summarized in Table $\mathrm{J}-1$ to Table $\mathrm{J}-6$. The specimens are sorted by their components, axially applied stress and duration of experiment. The specimens marked with an asterisk $\left({ }^{*}\right)$ indicate reference specimens that were not subjected to water.

The XRD data and results from free swelling tests on rocks from Belchen (as well as investigations of the water chemism, cf. Chapter 11) are summarized in Table J-7 to Table J-9.

In some cases the tests are still ongoing (indicated by the grey fields in the tables). 
Table J-1: $\quad$ Specimen properties free powder swelling tests (Chapter 8.4.1), sorted by composition.

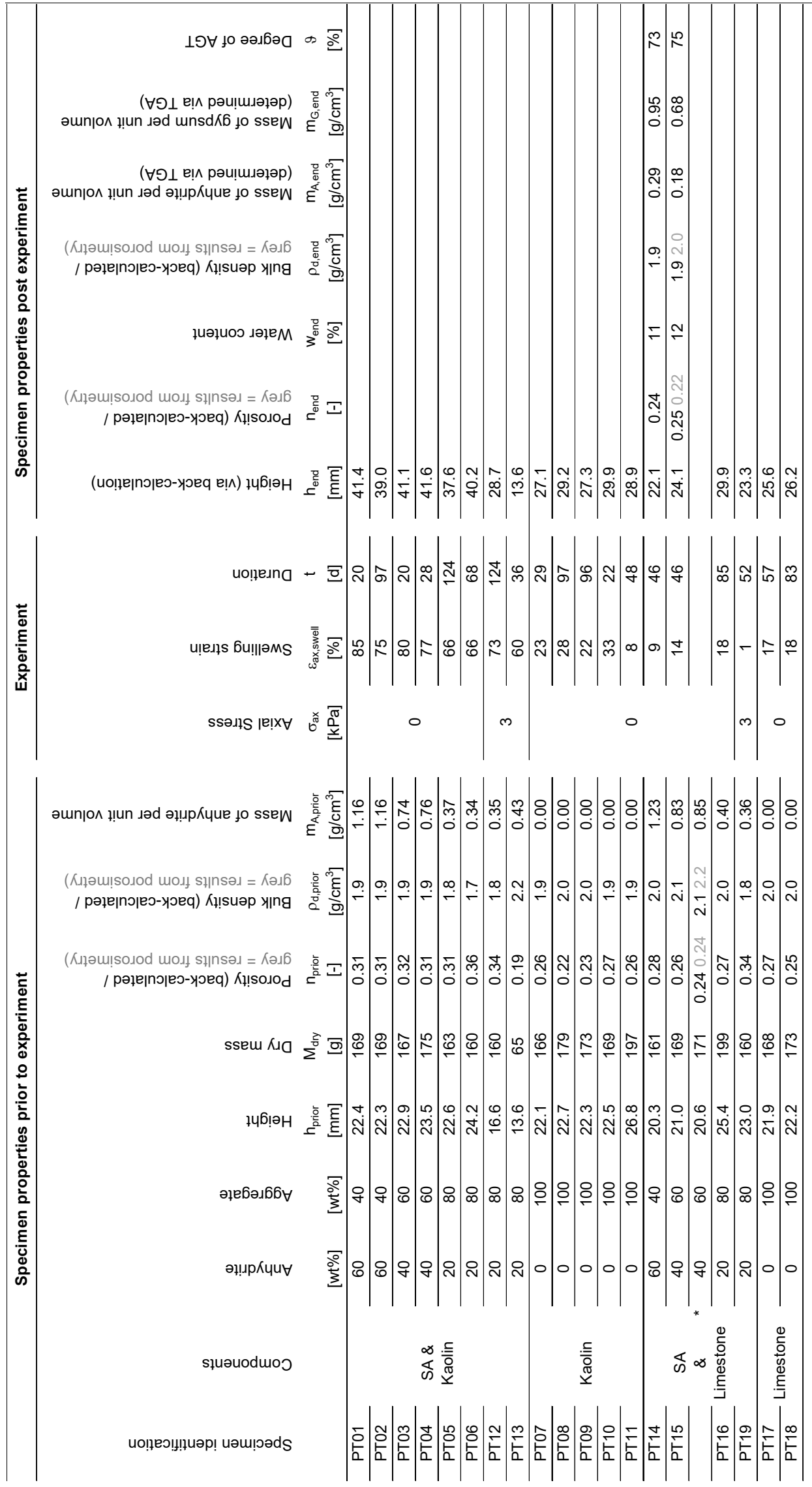


Table J-2: $\quad$ Specimen properties oedometer tests with an axial load of 3kPa (Chapters 8.4.2, 8.4.3 and 8.5), sorted by composition and degree of $A G T(\vartheta)$.

\begin{tabular}{|c|c|c|c|c|c|c|c|c|c|c|c|c|c|c|c|c|c|c|c|c|}
\hline \multirow[b]{2}{*}{ 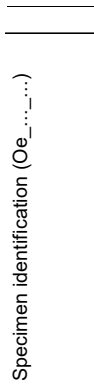 } & \multicolumn{7}{|c|}{ Specimen properties prior to experiment } & \multicolumn{6}{|c|}{ Experiment } & \multicolumn{7}{|c|}{ Specimen properties post experiment } \\
\hline & 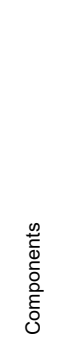 & 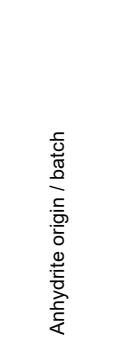 & $\begin{array}{l}\frac{\vec{J}}{\bar{D}} \\
\frac{D}{\mathbb{T}} \\
\text { I }\end{array}$ & 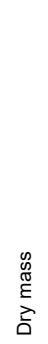 & 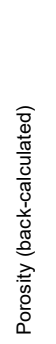 & 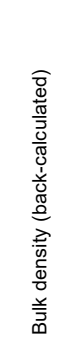 & 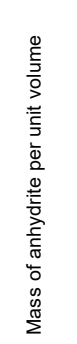 & 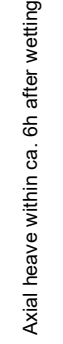 & 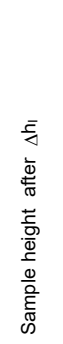 & 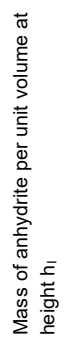 & 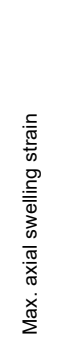 & 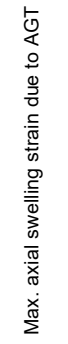 & 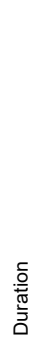 & 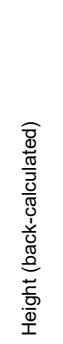 & 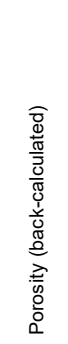 & 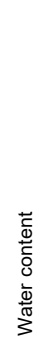 & 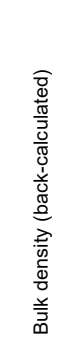 & 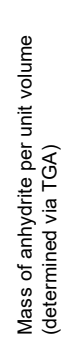 & 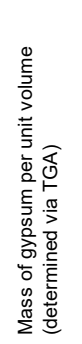 & 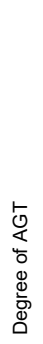 \\
\hline & & & $\begin{array}{c}\mathrm{h}_{\text {prior }} \\
{[\mathrm{mm}]}\end{array}$ & $\begin{array}{c}M_{\mathrm{dry}} \\
{[\mathrm{g}]}\end{array}$ & $\begin{array}{c}n_{\text {prior }} \\
{[-]}\end{array}$ & $\begin{array}{c}\rho_{\mathrm{d}, \text { prior }} \\
{\left[\mathrm{g} / \mathrm{cm}^{3}\right]}\end{array}$ & $\begin{array}{l}m_{\text {A,prior }} \\
{\left[\mathrm{g} / \mathrm{cm}^{3}\right]}\end{array}$ & $\begin{array}{c}\Delta \mathrm{h}_{1} \\
{[\mathrm{~mm}]}\end{array}$ & $\begin{array}{c}\mathrm{h}_{1} \\
{[\mathrm{~mm}]}\end{array}$ & $\begin{array}{c}\mathrm{m}_{\mathrm{A}, \mathrm{l}} \\
{\left[\mathrm{g} / \mathrm{cm}^{3}\right]}\end{array}$ & $\begin{array}{c}\varepsilon_{\mathrm{ax}, \mathrm{swell}} \\
{[\%]}\end{array}$ & $\begin{array}{c}\varepsilon_{\mathrm{ax}, \mathrm{AGT}} \\
{[\%]}\end{array}$ & $\begin{array}{c}\mathrm{t} \\
{[\mathrm{d}]}\end{array}$ & $\begin{array}{c}\mathrm{h}_{\text {end }} \\
{[\mathrm{mm}]}\end{array}$ & $\begin{array}{c}\mathrm{n}_{\text {end }} \\
{[-]}\end{array}$ & $\begin{array}{l}\mathrm{w}_{\text {end }} \\
{[\%]}\end{array}$ & $\begin{array}{c}\rho_{\mathrm{d}, \text { end }} \\
{\left[\mathrm{g} / \mathrm{cm}^{3}\right]}\end{array}$ & $\begin{array}{l}m_{\text {Aend }} \\
{\left[\mathrm{g} / \mathrm{cm}^{3}\right]}\end{array}$ & $\begin{array}{l}\mathrm{m}_{\mathrm{G}, \text { end }} \\
{\left[\mathrm{g} / \mathrm{cm}^{3}\right]}\end{array}$ & $\begin{array}{c}9 \\
{[\%]}\end{array}$ \\
\hline AA_1 & \multirow{30}{*}{ 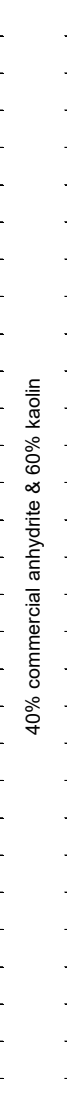 } & AA & 20.6 & 99 & 0.29 & 1.9 & 0.77 & 3 & 23.5 & 0.68 & 16 & 2 & 19 & 24.0 & 0.39 & 23 & 1.6 & 0.658 & 0.01 & 1 \\
\hline AA_2 & & AA & 19.9 & 99 & 0.27 & 2.0 & 0.80 & 3 & 22.8 & 0.70 & 17 & 2 & 90 & 23.3 & 0.38 & 24 & 1.7 & 0.67 & 0.01 & 1 \\
\hline 14_1 & & SA 1 & 20.8 & 97 & 0.31 & 1.9 & 0.75 & 2 & 22.8 & 0.69 & 12 & 2 & 0.2 & 23.2 & 0.38 & 20 & 1.7 & 0.665 & 0.01 & 1 \\
\hline AA_3 & & AA & 20.4 & 99 & 0.29 & 2.0 & 0.78 & 3 & 23.7 & 0.67 & 20 & 3 & 48 & 24.4 & 0.40 & 25 & 1.6 & 0.64 & 0.01 & 2 \\
\hline SA3_1 & & SA 3 & 20.4 & 98 & 0.29 & 1.9 & 0.77 & 3 & 23.0 & 0.69 & 15 & 2 & 26 & 23.5 & 0.38 & 23 & 1.7 & 0.65 & 0.03 & 3 \\
\hline $11 \_2$ & & SA 1 & 21.0 & 97 & 0.32 & 1.9 & 0.74 & 3 & 24.1 & 0.65 & 19 & 4 & 3 & 25.1 & 0.43 & 23 & 1.6 & 0.60 & 0.03 & 3 \\
\hline SA2_1 & & SA 2 & 20.5 & 99 & 0.29 & 1.9 & 0.78 & 3 & 23.2 & 0.69 & 25 & 10 & 30 & 25.6 & 0.42 & 26 & 1.6 & 0.58 & 0.05 & 7 \\
\hline $12 \_3$ & & SA 1 & 20.9 & 97 & 0.32 & 1.9 & 0.75 & 3 & 23.7 & 0.66 & 35 & 19 & 6 & 28.2 & 0.47 & 33 & 1.4 & 0.45 & 0.13 & 19 \\
\hline 11_1 & & SA 1 & 20.6 & 98 & 0.30 & 1.9 & 0.76 & 3 & 23.3 & 0.68 & 39 & 23 & 6 & 28.6 & 0.47 & 32 & 1.4 & 0.43 & 0.15 & 21 \\
\hline 13_3 & & SA 1 & 20.7 & 96 & 0.31 & 1.9 & 0.75 & 3 & 23.7 & 0.65 & 48 & 29 & 6 & 30.7 & 0.51 & 35 & 1.3 & 0.36 & 0.19 & 29 \\
\hline $13 \_1$ & & SA 1 & 21.0 & 100 & 0.30 & 1.9 & 0.76 & 2 & 22.6 & 0.71 & 38 & 28 & 7 & 28.9 & 0.46 & 34 & 1.4 & 0.39 & 0.21 & 30 \\
\hline 0_22 & & SA 3 milled & 20.2 & 100 & 0.27 & 2.0 & 0.80 & 4 & 24.0 & 0.67 & 49 & 26 & 13 & 30.2 & 0.47 & 33 & 1.4 & 0.33 & 0.25 & 38 \\
\hline 0_19 & & SA 2 & 19.8 & 94 & 0.30 & 1.9 & 0.77 & 3 & 22.6 & 0.67 & 40 & 23 & 50 & 27.8 & 0.44 & 31 & 1.4 & 0.24 & 0.38 & 55 \\
\hline 0_21 & & SA 3 milled & 20.5 & 100 & 0.28 & 2.0 & 0.78 & 4 & 24.3 & 0.66 & 53 & 29 & 15 & 31.3 & 0.46 & 33 & 1.3 & 0.16 & 0.45 & 70 \\
\hline 13_2 & & SA 1 & 20.6 & 98 & 0.30 & 1.9 & 0.76 & 2 & 23.0 & 0.68 & 57 & 40 & 9 & 32.3 & 0.47 & 35 & 1.3 & 0.084 & 0.51 & 83 \\
\hline $12 \_1$ & & SA 1 & 20.9 & 97 & 0.32 & 1.9 & 0.75 & 3 & 23.4 & 0.67 & 56 & 39 & 13 & 32.6 & 0.48 & 39 & 1.3 & 0.080 & 0.50 & 83 \\
\hline SA3_2 & & SA 3 & 19.7 & 99 & 0.26 & 2.0 & 0.81 & 3 & 23.0 & 0.69 & 65 & 41 & 126 & 32.5 & 0.46 & 35 & 1.3 & 0.056 & 0.55 & 88 \\
\hline $0 \_13$ & & SA 2 milled & 20.3 & 99 & 0.28 & 2.0 & 0.78 & 3 & 23.2 & 0.69 & 64 & 44 & 54 & 33.4 & 0.47 & 37 & 1.3 & 0.048 & 0.54 & 90 \\
\hline $0 \_7$ & & SA 2 & 20.4 & 99 & 0.29 & 2.0 & 0.78 & 3 & 23.0 & 0.69 & 64 & 45 & 75 & 33.5 & 0.48 & 37 & 1.3 & 0.043 & 0.55 & 91 \\
\hline $0 \_6$ & & SA 1 & 20.8 & 98 & 0.30 & 1.9 & 0.76 & 4 & 24.3 & 0.65 & 61 & 38 & 19 & 33.5 & 0.48 & 36 & 1.3 & 0.038 & 0.55 & 92 \\
\hline $0 \_20$ & & SA 3 milled & 20.5 & 99 & 0.29 & 1.9 & 0.78 & 4 & 24.2 & 0.66 & 69 & 43 & 64 & 34.6 & 0.49 & 38 & 1.3 & 0.034 & 0.54 & 93 \\
\hline PC_1 & & PC & 20.2 & 99 & 0.28 & 2.0 & 0.79 & 4 & 24.3 & 0.66 & 55 & 28 & 183 & 31.2 & 0.43 & 31 & 1.4 & 0.037 & 0.60 & 93 \\
\hline PC_2 & & PC & 19.7 & 99 & 0.26 & 2.0 & 0.81 & 3 & 23.0 & 0.69 & 58 & 35 & 210 & 31.0 & 0.43 & 31 & 1.4 & 0.036 & 0.60 & 93 \\
\hline $0 \_8$ & & SA 2 & 20.3 & 99 & 0.28 & 2.0 & 0.78 & 3 & 23.0 & 0.69 & 59 & 41 & 63 & 32.4 & 0.45 & 34 & 1.3 & 0.026 & 0.59 & 95 \\
\hline $15 \_1$ & & SA 1 & 20.5 & 98 & 0.30 & 1.9 & 0.77 & 2 & 22.2 & 0.71 & 55 & 43 & 44 & 31.7 & 0.45 & 33 & 1.4 & 0.023 & 0.60 & 95 \\
\hline $25 \_0$ & & SA 1 & 21.0 & 97 & 0.32 & 1.9 & 0.75 & 2 & 22.9 & 0.69 & 54 & 42 & 35 & 32.5 & 0.46 & 34 & 1.3 & 0.0223 & 0.58 & 95 \\
\hline 11_0 & & SA 1 & 20.3 & 93 & 0.33 & 1.8 & 0.75 & 2 & 22.0 & 0.69 & 49 & 37 & 33 & 30.1 & 0.45 & 31 & 1.4 & 0.0224 & 0.60 & 95 \\
\hline $12 \_2$ & & SA 1 & 20.9 & 98 & 0.31 & 1.9 & 0.76 & 3 & 23.8 & 0.66 & 51 & 33 & 29 & 31.5 & 0.44 & 32 & 1.4 & 0.0224 & 0.60 & 96 \\
\hline $15 \_0$ & & SA 1 & 17.2 & 98 & 0.16 & 2.3 & 0.92 & 3 & 19.8 & 0.80 & 73 & 50 & 25 & 29.8 & 0.41 & - & 1.4 & 0.014 & 0.65 & 97 \\
\hline 24_0 & & SA 1 & 20.3 & 98 & 0.29 & 1.9 & 0.78 & 2 & 22.1 & 0.71 & 59 & 45 & 49 & 32.2 & 0.45 & 36 & 1.3 & -0.001 & 0.62 & 100 \\
\hline Lei_80 & \multirow{6}{*}{ 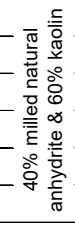 } & Leissigen & 19.2 & 97 & 0.26 & 2.0 & 0.81 & 3 & 21.8 & 0.72 & 60 & 41 & 56 & 30.7 & 0.48 & 37 & 1.3 & 0.25 & 0.33 & 51 \\
\hline Lei_50 & & Leissigen & 18.6 & 94 & 0.25 & 2.0 & 0.84 & 4 & 22.2 & 0.70 & 69 & 42 & 27 & 31.5 & 0.50 & 37 & 1.3 & 0.18 & 0.38 & 63 \\
\hline BB_50 & & Bözberg & 19.2 & 96 & 0.26 & 2.0 & 0.81 & 4 & 23.2 & 0.68 & 62 & 34 & 25 & 31.1 & 0.49 & - & 1.3 & 0.22 & 0.35 & 55 \\
\hline BB_80 & & Bözberg & 19.5 & 97 & 0.27 & 2.0 & 0.80 & 3 & 22.7 & 0.69 & 63 & 40 & 56 & 31.8 & 0.49 & 38 & 1.3 & 0.21 & 0.36 & 58 \\
\hline Bex_80 & & Bex & 19.0 & 96 & 0.26 & 2.0 & 0.82 & 4 & 22.7 & 0.69 & 56 & 32 & 49 & 29.8 & 0.48 & 36 & 1.4 & 0.32 & 0.25 & 38 \\
\hline Bex_50 & & Bex & 17.9 & 95 & 0.22 & 2.1 & 0.87 & 3 & 21.0 & 0.74 & 68 & 44 & 34 & 30.1 & 0.47 & 35 & 1.4 & 0.19 & 0.41 & 63 \\
\hline PW & $100 \%$ & kaolin & 22.0 & 97 & 0.32 & 1.8 & 0.00 & 3 & 25.0 & 0.00 & 16 & 2 & 13 & 25.5 & 0.41 & - & - & 0.00 & 0.00 & 0 \\
\hline
\end{tabular}


Table J-3: $\quad$ Specimen properties from oedometer tests with various axial loads (Chapter 8.5), sorted by composition, axial load and degree of $A G T(\vartheta)$.

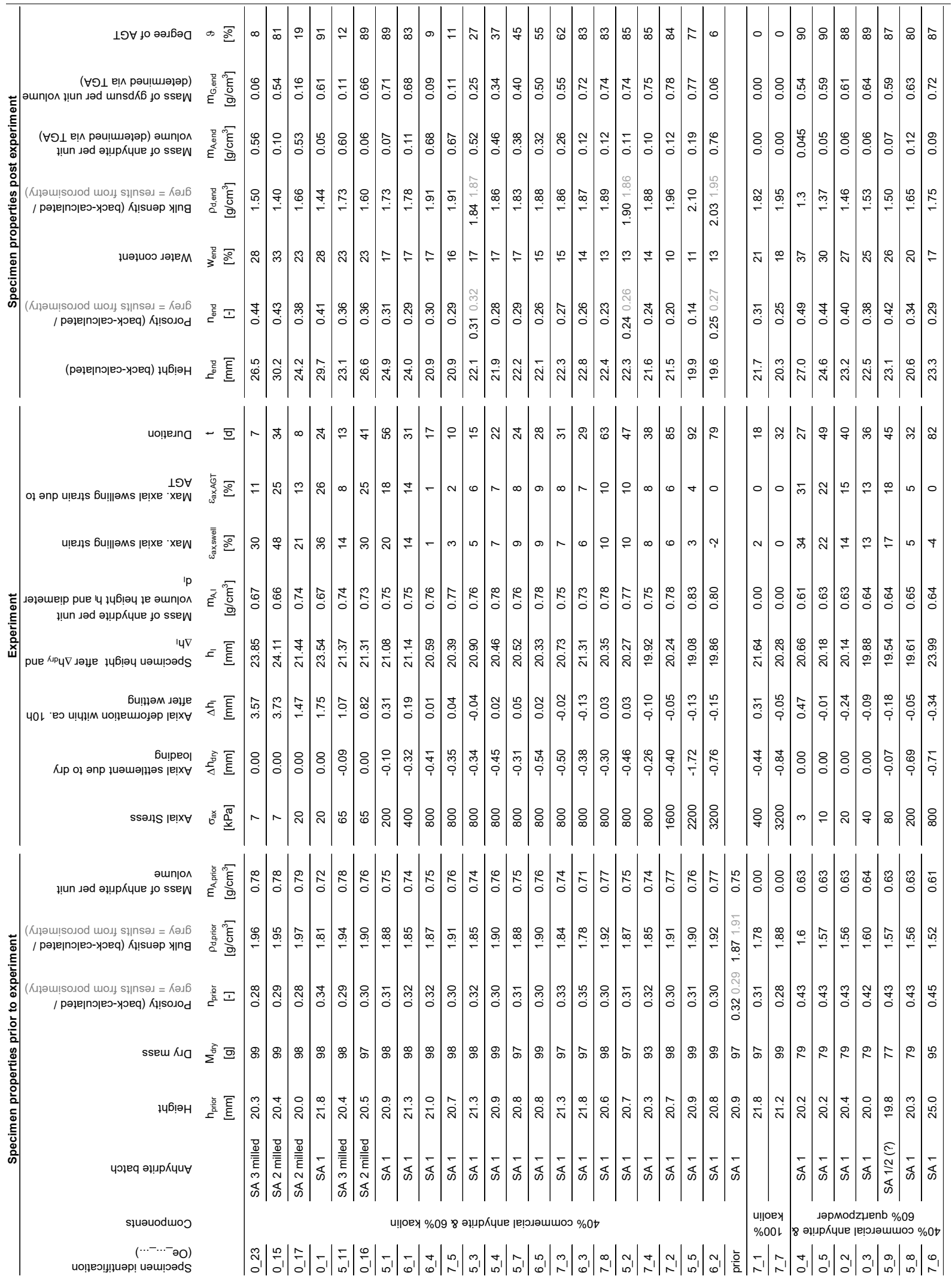


Table J-4: $\quad$ Specimen properties (complete constraint tests), sorted by the reached axial stress.

\begin{tabular}{|c|c|c|c|c|c|c|c|c|c|c|c|c|c|c|c|c|c|c|}
\hline \multirow{3}{*}{ 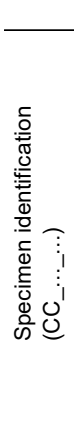 } & \multirow{3}{*}{ 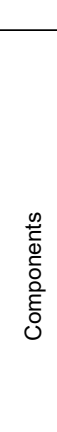 } & \multicolumn{7}{|c|}{ Specimen properties prior to experiment } & \multicolumn{3}{|c|}{ Experiment } & \multicolumn{7}{|c|}{ Specimen properties post experiment } \\
\hline & & 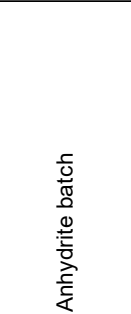 & $\begin{array}{l}\frac{\vec{J}}{.0} \\
\frac{.0}{\mathbb{1}} \\
\frac{1}{I}\end{array}$ & 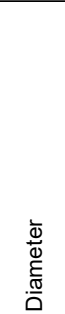 & 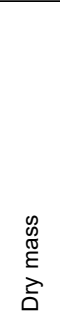 & 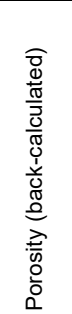 & 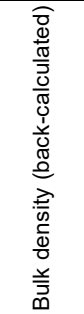 & 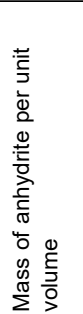 & 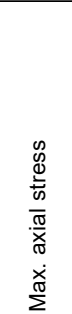 & 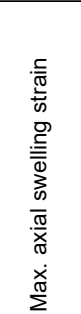 & 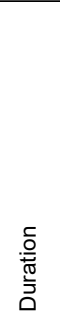 & 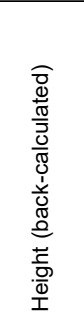 & 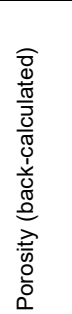 & 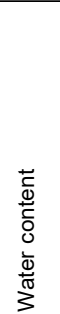 & 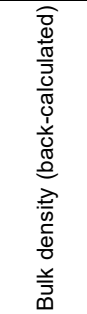 & 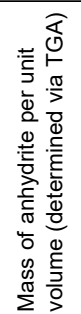 & 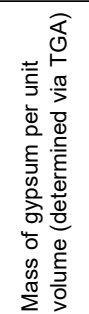 & 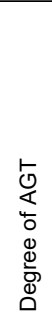 \\
\hline & & & $\begin{array}{l}h_{\text {prior }} \\
{[\mathrm{mm}]}\end{array}$ & $\begin{array}{l}d_{\text {prior }} \\
{[\mathrm{mm}]}\end{array}$ & $\begin{array}{c}M_{\mathrm{dry}} \\
{[\mathrm{g}]}\end{array}$ & $\begin{array}{c}\mathrm{n}_{\text {prior }} \\
{[-]}\end{array}$ & $\begin{array}{c}\rho_{\text {d,prior }} \\
{\left[\mathrm{g} / \mathrm{cm}^{3}\right]}\end{array}$ & $\begin{array}{l}\mathrm{m}_{\mathrm{A} \text {,prior }} \\
{\left[\mathrm{g} / \mathrm{cm}^{3}\right]}\end{array}$ & $\begin{array}{r}\sigma_{\text {axt,tot }} \\
{[\mathrm{MPa}]}\end{array}$ & $\begin{array}{c}\varepsilon_{\text {ax,swell }} \\
{[\%]}\end{array}$ & $\begin{array}{c}\mathrm{t} \\
\text { [d] }\end{array}$ & $\begin{array}{c}\mathrm{h}_{\text {end }} \\
{[\mathrm{mm}]}\end{array}$ & $\begin{array}{c}n_{\text {end }} \\
{[-]}\end{array}$ & $\begin{array}{l}\mathrm{w}_{\text {end }} \\
{[\%]}\end{array}$ & $\begin{array}{c}\rho_{\mathrm{d}, \text { end }} \\
{\left[\mathrm{g} / \mathrm{cm}^{3}\right]}\end{array}$ & $\begin{array}{c}m_{A, \text { end }} \\
{\left[\mathrm{g} / \mathrm{cm}^{3}\right]}\end{array}$ & $\begin{array}{c}\mathrm{m}_{\mathrm{G}, \text { end }} \\
{\left[\mathrm{g} / \mathrm{cm}^{3}\right]}\end{array}$ & $\begin{array}{c}9 \\
{[\%]}\end{array}$ \\
\hline 1 1_05 & & SA3 milled & 20.4 & 56 & 96 & 0.31 & 1.9 & 0.76 & 0.77 & 1.0 & 120 & 20.6 & 0.30 & 14 & 1.89 & 0.69 & 0.07 & 8 \\
\hline 2 2_02 & & SA2 milled & 20.4 & 56 & 99 & 0.29 & 2.0 & 0.78 & 1.03 & 2.2 & 41 & 20.8 & 0.28 & 16 & 1.92 & 0.66 & 0.13 & 14 \\
\hline 2_03 & & SA2 milled & 25.8 & 70 & 198 & 0.27 & 2.0 & 0.80 & 1.24 & 2.3 & 102 & 26.4 & 0.26 & 15 & 1.93 & 0.63 & 0.19 & 20 \\
\hline 3_01 & & SA2 & 20.3 & 56 & 97 & 0.30 & 1.9 & 0.76 & 1.43 & 1.0 & 386 & 20.5 & 0.26 & 19 & 1.98 & 0.52 & 0.30 & 31 \\
\hline 4 4_02 & & SA3 milled & 20.5 & 56 & 96 & 0.31 & 1.9 & 0.75 & 1.46 & 7.8 & 488 & 22.0 & 0.33 & 13 & 1.83 & 0.56 & 0.17 & 20 \\
\hline 1_03 & $\overline{\bar{g}}$ & $\mathrm{SA} 2$ milled & 20.3 & 56 & 98 & 0.29 & 1.9 & 0.78 & 1.88 & 2.3 & 124 & 20.8 & 0.23 & 12 & 1.98 & 0.42 & 0.44 & 45 \\
\hline 3_02 & $\therefore$ & SA2 milled & 20.4 & 56 & 99 & 0.29 & 1.9 & 0.78 & 1.90 & 2.6 & 290 & 21.0 & 0.20 & 9 & 2.03 & 0.26 & 0.63 & 65 \\
\hline 2 2_04 & $\infty$ & SA2 milled & 20.4 & 56 & 99 & 0.29 & 2.0 & 0.78 & 2.06 & 1.1 & 175 & 20.6 & 0.22 & 13 & 2.01 & 0.43 & 0.43 & 44 \\
\hline 1_04 & 苑 & SA2 milled & 20.3 & 56 & 99 & 0.29 & 2.0 & 0.78 & 2.50 & 1.9 & 116 & 20.7 & 0.21 & 10 & 2.00 & 0.33 & 0.55 & 57 \\
\hline 2_05 & है & SA3 milled & 20.5 & 56 & 98 & 0.29 & 1.9 & 0.77 & 2.60 & 2.1 & 360 & 20.9 & 0.19 & 13 & 1.95 & 0.17 & 0.74 & 78 \\
\hline 1_01 & $\circ$ & SA1 & 25.5 & 70 & 195 & 0.27 & 2.0 & 0.79 & 3.07 & 0.7 & 258 & 25.6 & 0.17 & 11 & 2.07 & 0.28 & 0.65 & 65 \\
\hline 1_06 & & SA3 milled & 20.5 & 56 & 96 & 0.31 & 1.9 & 0.76 & 3.11 & 2.0 & 436 & 20.9 & 0.23 & 10 & 1.96 & 0.30 & 0.56 & 60 \\
\hline 1 1_02 & & SA1 & 25.5 & 70 & 195 & 0.27 & 2.0 & 0.79 & 3.36 & 1.2 & 161 & 25.8 & 0.22 & 12 & 2.06 & 0.48 & 0.39 & 39 \\
\hline 2 2_01 & & SA1 & 25.7 & 70 & 198 & 0.27 & 2.0 & 0.80 & 3.51 & 0.8 & 622 & 25.9 & 0.14 & 9 & 2.08 & 0.16 & 0.81 & 80 \\
\hline 4_01 & & $\mathrm{SA} 1 / \mathrm{SA} 2$ & 20.4 & 56 & 96 & 0.31 & 1.9 & 0.76 & 3.54 & 1.3 & 623 & 20.6 & 0.19 & 10 & 2.06 & 0.15 & 0.76 & 80 \\
\hline 3_03 & & SA3 milled & 20.5 & 56 & 99 & 0.29 & 1.9 & 0.77 & 2.86 & 1.0 & 356 & (ongoin & & & & & & \\
\hline
\end{tabular}


Table J-5: $\quad$ Specimen properties (isotropic compression tests), sorted by the applied stress and degree of $A G T(\vartheta)$.

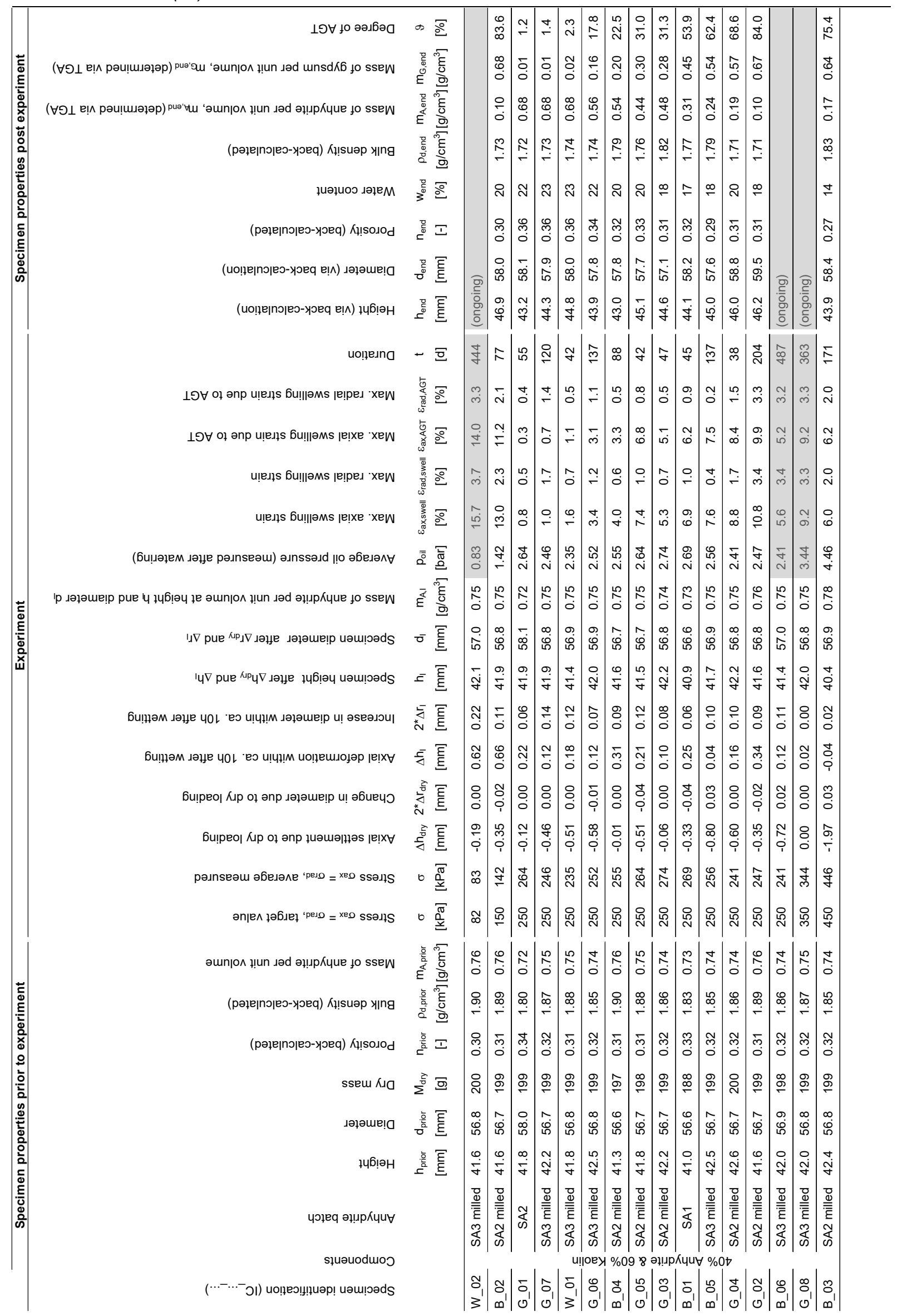


Table J-6: $\quad$ Specimen properties (flexible oedometer tests), sorted by axial load and degree of AGT ( $\vartheta$ ).

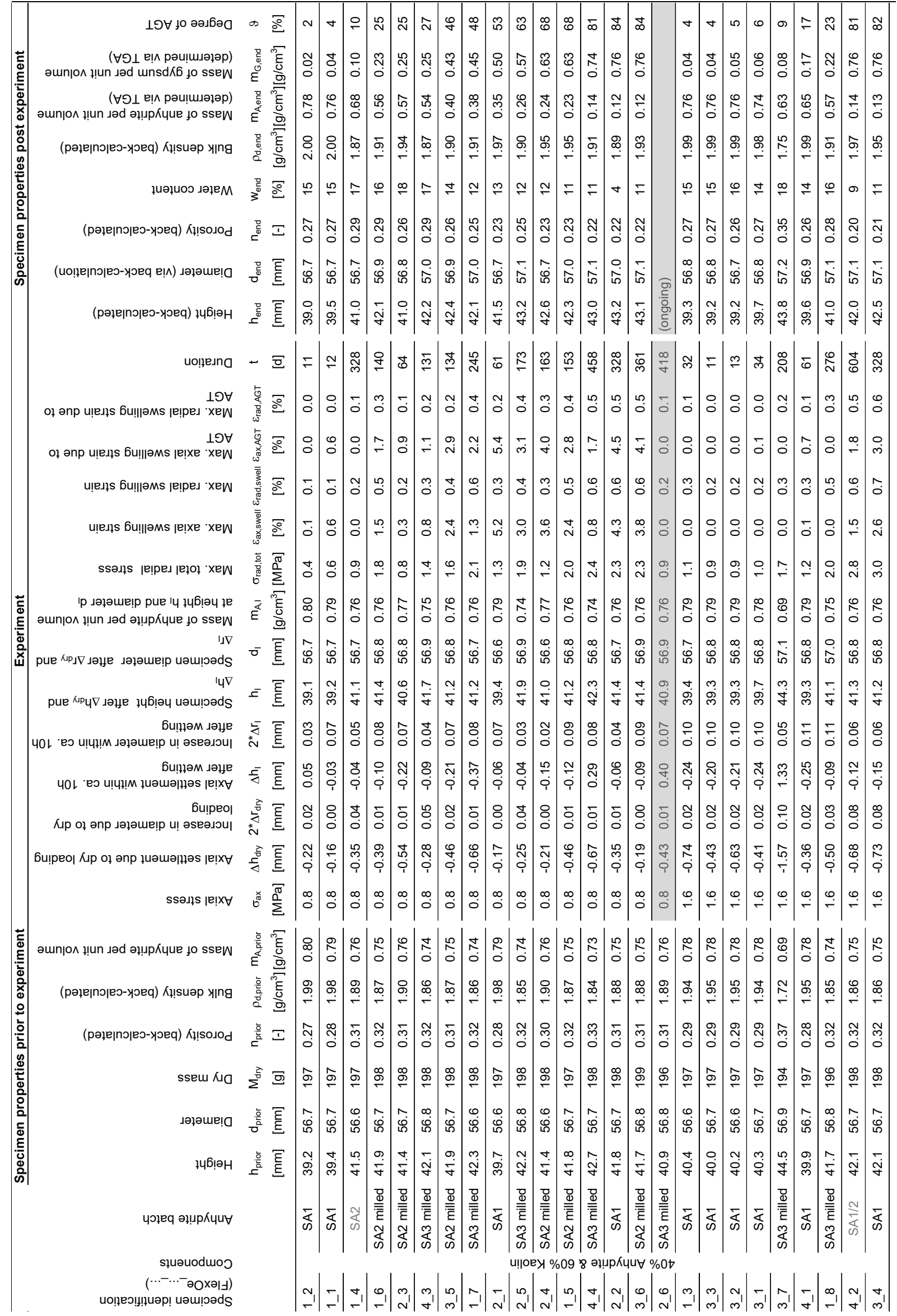


Table J-7: $\quad$ XRD results performed on rock specimens from Belchen (cf. Chapter 11). Grey fields indicate ongoing tests.

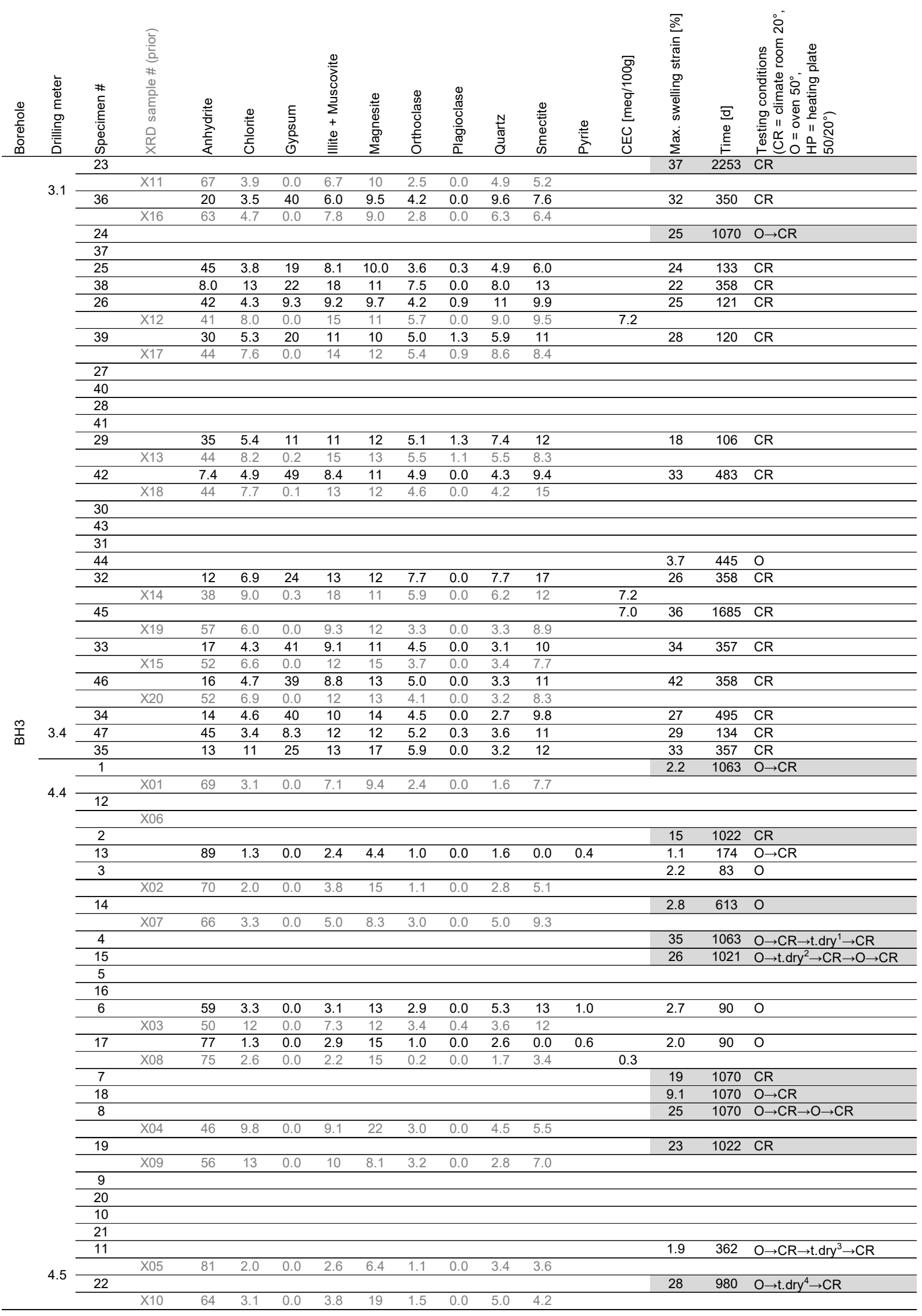


(Table J-7 continued)

\begin{tabular}{|c|c|c|c|c|c|c|c|c|c|c|c|c|c|c|c|c|c|}
\hline $\begin{array}{l}\frac{0}{0} \\
\frac{0}{0} \\
\frac{0}{0} \\
\infty\end{array}$ & 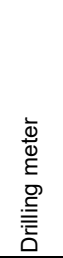 & 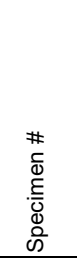 & 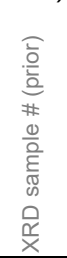 & 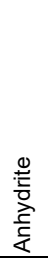 & 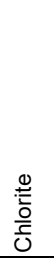 & $\begin{array}{l}E \\
\text { E } \\
\text { D } \\
\text { D. }\end{array}$ & 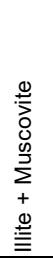 & 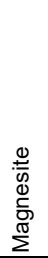 & 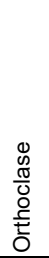 & $\begin{array}{l}0 \\
0 \\
\frac{\pi}{0} \\
\frac{0}{9} \\
\frac{\pi}{2} \\
\frac{\pi}{2}\end{array}$ & $\begin{array}{l}\stackrel{N}{\mathbb{N}} \\
\stackrel{2}{0}\end{array}$ & 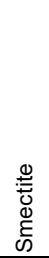 & 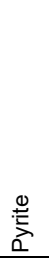 & 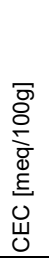 & 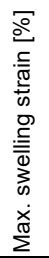 & 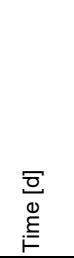 & 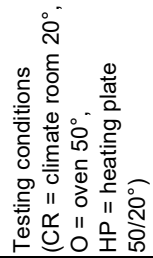 \\
\hline \multirow{12}{*}{$\begin{array}{l}0 \\
\stackrel{0}{\omega}\end{array}$} & \multirow[t]{4}{*}{1.25} & & $\mathrm{X} 21$ & 72 & 0.0 & 11 & 2.6 & 0.0 & 1.0 & 0.0 & 4.8 & 8.8 & & & & & \\
\hline & & 50 & & & & & & & & & & & & & 15 & 2024 & CR \\
\hline & & 51 & & & & & & & & & & & & & 13 & 2024 & CR \\
\hline & & 52 & & & & & & & & & & & & & 11 & 2024 & CR \\
\hline & \multirow{7}{*}{$\frac{1.38}{1.4}$} & & $\mathrm{X} 22$ & 55 & 0.0 & 21 & 3.2 & 0.0 & 2.2 & 0.0 & 7.3 & 11 & & & & & \\
\hline & & & $\times 25^{*}$ & 73 & 1.3 & 17 & 1.2 & 0.0 & 1.2 & 0.0 & 2.7 & 3.5 & & & & & \\
\hline & & 54 & & & & & & & & & & & & & 6.2 & 1861 & CR \\
\hline & & 55 & & & & & & & & & & & & & 6.3 & 1861 & CR \\
\hline & & & $\mathrm{X} 26^{*}$ & 37 & 3.7 & 38 & 3.4 & 0.0 & 3.0 & 0.0 & 7.4 & 7.6 & & & & & \\
\hline & & & $\mathrm{X} 27$ & & & & & & & & & & & & & & \\
\hline & & 56 & & & & & & & & & & & & & 8.0 & 1860 & $\mathrm{CR}$ \\
\hline & 1.56 & & $\mathrm{X} 28^{*}$ & 32 & 5.2 & 38 & 5.8 & 0.0 & 3.7 & 0.0 & 4.2 & 12 & & & & & \\
\hline \multirow{12}{*}{$\begin{array}{l}\mathbb{N} \\
\stackrel{1}{R} \\
\xi\end{array}$} & \multirow[t]{9}{*}{2.3} & & $\mathrm{X} 1$ & 51 & 3.4 & & 8.3 & 21 & 5.6 & & 2.9 & 7.6 & 0.5 & 7.6 & & & \\
\hline & & BA1 & & & & & & & & & & & & & 4.8 & 29 & $\mathrm{O} \rightarrow \mathrm{CR}$ \\
\hline & & BA2 & & 68 & 2.7 & 0.3 & 4.5 & 10 & 4.0 & & 2.5 & 6.9 & 0.3 & & 11 & 74 & $\mathrm{CR} \rightarrow \mathrm{O} \rightarrow \mathrm{CR}$ \\
\hline & & BA3 & & 64 & 3.4 & & 4.3 & 12 & 3.9 & & 2.8 & 8.6 & 0.4 & & 6.3 & 70 & $\mathrm{O} \rightarrow \mathrm{CR}$ \\
\hline & & BA4 & & 65 & 3.2 & & 4.8 & 13 & 4.2 & & 2.6 & 7.7 & 0.4 & & 6.2 & 69 & $\mathrm{O}$ \\
\hline & & BA5 & & 66 & 1.4 & 3.5 & 4.7 & 12 & 4.0 & & 3.2 & 4.6 & 0.3 & & 13 & 74 & $\mathrm{CR}$ \\
\hline & & BA6 & & & & & & & & & & & & & 42 & 583 & $\mathrm{HP} \rightarrow \mathrm{CR}$ \\
\hline & & BA7 & & & & & & & & & & & & & 5.5 & 582 & $\mathrm{O} \rightarrow \mathrm{CR}$ \\
\hline & & BA8 & & & & & & & & & & & & & 48 & 589 & CR \\
\hline & 2.5 & $\mathrm{P}^{*}$ & $\mathrm{X} 2$ & 62 & 2.5 & & 5.6 & 13 & 5.0 & & 2.4 & 9.0 & 0.5 & & & & \\
\hline & \multirow[t]{2}{*}{2.7} & BA9 & & & & & & & & & & & & & 16 & 581 & \\
\hline & & BA10 & & & & & & & & & & & & & 8.9 & 554 & \\
\hline
\end{tabular}

Grey fields: tests still on-going

$\mathrm{P}^{*}$ : Rock from this section was milled for oedometer tests

${ }^{1}$ Temporary drying of specimen 4: extraction of surrounding water in CR, dried in CR for 2d, in oven for 1d, re-wetting in CR with same water

${ }^{2}$ Temporary drying of specimen 15: extraction of surrounding water in oven, dried in oven for $6 \mathrm{~d}$, re-wetting in CR; ca. 120d later: switch to oven and back

${ }^{3}$ Temporary drying of specimen 11: extraction of surrounding water in CR, dried in CR for $2 \mathrm{~d}$, in oven for 1d, re-wetting in CR with fresh water

${ }^{4}$ Temporary drying of specimen 22: extraction of surrounding water in $\mathrm{O}$, dried in $\mathrm{O}$ for $3 \mathrm{~d}$, re-wetting in $\mathrm{CR}$ with same water 
Table J-8: $\quad$ Specimen properties (oedometer tests with milled and compressed rock from Belchen), sorted by the bore core and degree of $A G T(\vartheta)$. All specimens had a diameter of $56.3 \mathrm{~mm}$ and were axially loaded with $3 \mathrm{kPa}$.

\begin{tabular}{|c|c|c|c|c|c|c|c|c|c|c|c|c|c|c|c|c|}
\hline \multicolumn{6}{|c|}{ Specimen properties prior to experiment } & \multicolumn{6}{|c|}{ Experiment } & \multicolumn{5}{|c|}{ Specimen properties post experiment } \\
\hline 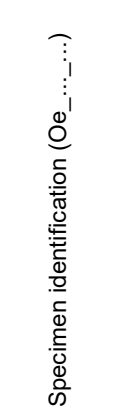 & 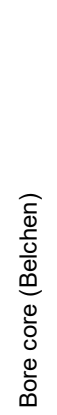 & $\begin{array}{l}\frac{\overrightarrow{\mathrm{t}}}{\mathrm{O}} \\
\frac{\mathrm{\omega}}{\mathrm{I}}\end{array}$ & \begin{tabular}{l}
$\mathscr{D}$ \\
$\mathbb{D}$ \\
$\mathbb{\varpi}$ \\
\multirow{2}{\Delta}{}
\end{tabular} & 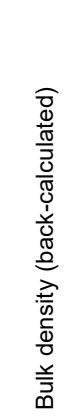 & 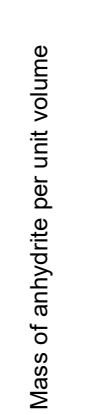 & 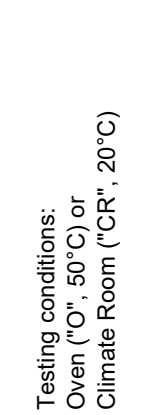 & 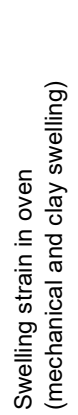 & 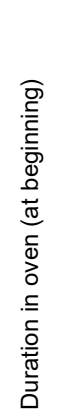 & 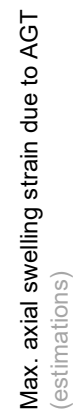 & 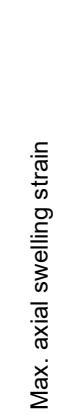 & 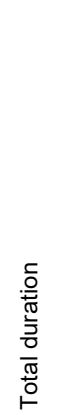 & 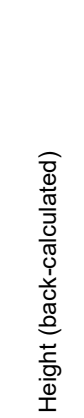 & 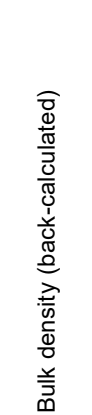 & 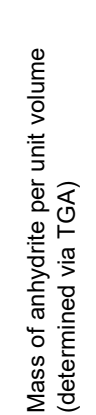 & 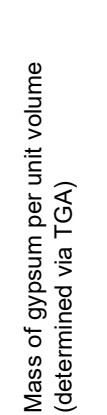 & 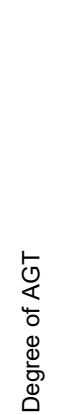 \\
\hline & & $\begin{array}{c}\mathrm{h}_{\text {prior }} \\
{[\mathrm{mm}]}\end{array}$ & $\begin{array}{c}M_{\text {dry }} \\
\text { [g] }\end{array}$ & $\begin{array}{c}\rho_{\mathrm{d}, \text { prior }} \\
{\left[\mathrm{g} / \mathrm{cm}^{3}\right]}\end{array}$ & $\begin{array}{l}m_{\text {A,prior }} \\
{\left[\mathrm{g} / \mathrm{cm}^{3}\right]}\end{array}$ & & $\begin{array}{l}\varepsilon_{\mathrm{ax}, \mathrm{l}} \\
{[\%]}\end{array}$ & $\begin{array}{l}t_{\text {oven }} \\
\text { [d] }\end{array}$ & $\begin{array}{c}\varepsilon_{\mathrm{ax}, \mathrm{AGT}} \\
{[\%]}\end{array}$ & $\begin{array}{c}\varepsilon_{\text {ax,swell }} \\
{[\%]}\end{array}$ & $\begin{array}{c}\mathrm{t} \\
\text { [d] }\end{array}$ & $\begin{array}{c}\mathrm{h}_{\text {end }} \\
{[\mathrm{mm}]}\end{array}$ & $\begin{array}{c}\rho_{\mathrm{d}, \text { end }} \\
{\left[\mathrm{g} / \mathrm{cm}^{3}\right]}\end{array}$ & $\begin{array}{c}m_{\mathrm{A}, \text { end }} \\
{\left[\mathrm{g} / \mathrm{cm}^{3}\right]}\end{array}$ & $\begin{array}{c}\mathrm{m}_{\mathrm{G}, \text { end }} \\
{\left[\mathrm{g} / \mathrm{cm}^{3}\right]}\end{array}$ & $\begin{array}{c}9 \\
{[\%]}\end{array}$ \\
\hline$\overline{\text { BA16_3 }}$ & \multirow{4}{*}{ 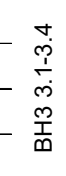 } & 17.5 & 99 & 2.28 & 1.04 & O & 18.7 & 74 & & 19 & 74 & 21.2 & 1.84 & 0.84 & 0.02 & 2 \\
\hline BA16_4 & & 18.8 & 100 & 2.13 & 0.94 & O-CR & 18.0 & 18 & 63 & 81 & 78 & 33.7 & 1.28 & 0.09 & 0.55 & 83 \\
\hline BA16_2 & & 17.7 & 101 & 2.29 & 1.04 & $\mathrm{CR}$ & & & 67 & 85 & 250 & 31.7 & 1.35 & 0.09 & 0.62 & 84 \\
\hline $\begin{array}{l}\text { BA16_5 } \\
\end{array}$ & & 20.9 & 100 & 1.92 & 0.84 & CR & & & 61 & 79 & 71 & 35.9 & 1.20 & 0.06 & 0.54 & 87 \\
\hline BA16_13 & \multirow{4}{*}{ 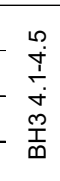 } & 17.6 & 100 & 2.28 & 1.38 & CR & & & 45 & 66 & 17 & 29.3 & 1.49 & 0.29 & 0.68 & 65 \\
\hline$\overline{\text { BA16_10 }}$ & & 18.0 & 100 & 2.23 & 1.35 & O-CR-O-CR & 21.3 & 32 & 44 & 65 & 67 & 29.6 & 1.46 & 0.27 & 0.69 & 67 \\
\hline$\overline{\text { BA16_12 }}$ & & 17.5 & 100 & 2.30 & 1.39 & CR & & & 50 & 71 & 45 & 30.0 & 1.50 & 0.13 & 0.85 & 83 \\
\hline$\overline{\text { BA16_11 }}$ & & 18.2 & 100 & 2.21 & 1.33 & CR & & & 50 & 71 & 67 & 32.3 & 1.39 & 0.10 & 0.82 & 86 \\
\hline BA17_5 & \multirow{9}{*}{ 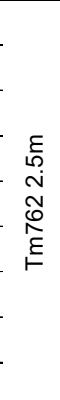 } & 18.6 & 100 & 2.16 & 1.35 & $\mathrm{CR}$ & & & 0 & 15 & 0.3 & 20.7 & 1.92 & 1.18 & 0.04 & 2 \\
\hline$\overline{\text { BA17_9 }}$ & & 18.7 & 99 & 2.14 & 1.33 & $\mathrm{CR}$ & & & 11 & 29 & 2 & 23.7 & 1.69 & 0.92 & 0.17 & 13 \\
\hline BA17_8 & & 18.8 & 100 & 2.13 & 1.33 & CR & & & 27 & 45 & 4 & 26.8 & 1.52 & 0.74 & 0.25 & 21 \\
\hline BA17_6 & & 19.7 & 100 & 2.03 & 1.27 & O-CR & 17.7 & 15 & 31 & 49 & 24 & 28.0 & 1.45 & 0.68 & 0.26 & 23 \\
\hline BA17_2 & & 18.1 & 99 & 2.20 & 1.37 & $\mathrm{CR}$ & & & 36 & 53 & 7 & 28.0 & 1.45 & 0.65 & 0.30 & 27 \\
\hline BA17_3 & & 18.5 & 100 & 2.17 & 1.35 & CR & & & 44 & 62 & 18 & 29.9 & 1.42 & 0.42 & 0.53 & 50 \\
\hline BA17_4 & & 19.0 & 99 & 2.10 & 1.31 & $\mathrm{CR}$ & & & 49 & 66 & 33 & 30.9 & 1.39 & 0.30 & 0.63 & 62 \\
\hline$\overline{\text { BA17_7 }}$ & & 18.1 & 99 & 2.21 & 1.38 & $\mathrm{CR}$ & & & 50 & 68 & 47 & 31.3 & 1.39 & 0.23 & 0.71 & 70 \\
\hline BA17_1 & & 18.0 & 101 & 2.26 & 1.41 & CR & & & 62 & 80 & 62 & 32.2 & 1.38 & 0.21 & 0.72 & 73 \\
\hline
\end{tabular}


Table J-9: $\quad$ Results from ICP and AAS measurements on selected water specimens from free-swell tests on rock specimens from Belchen.

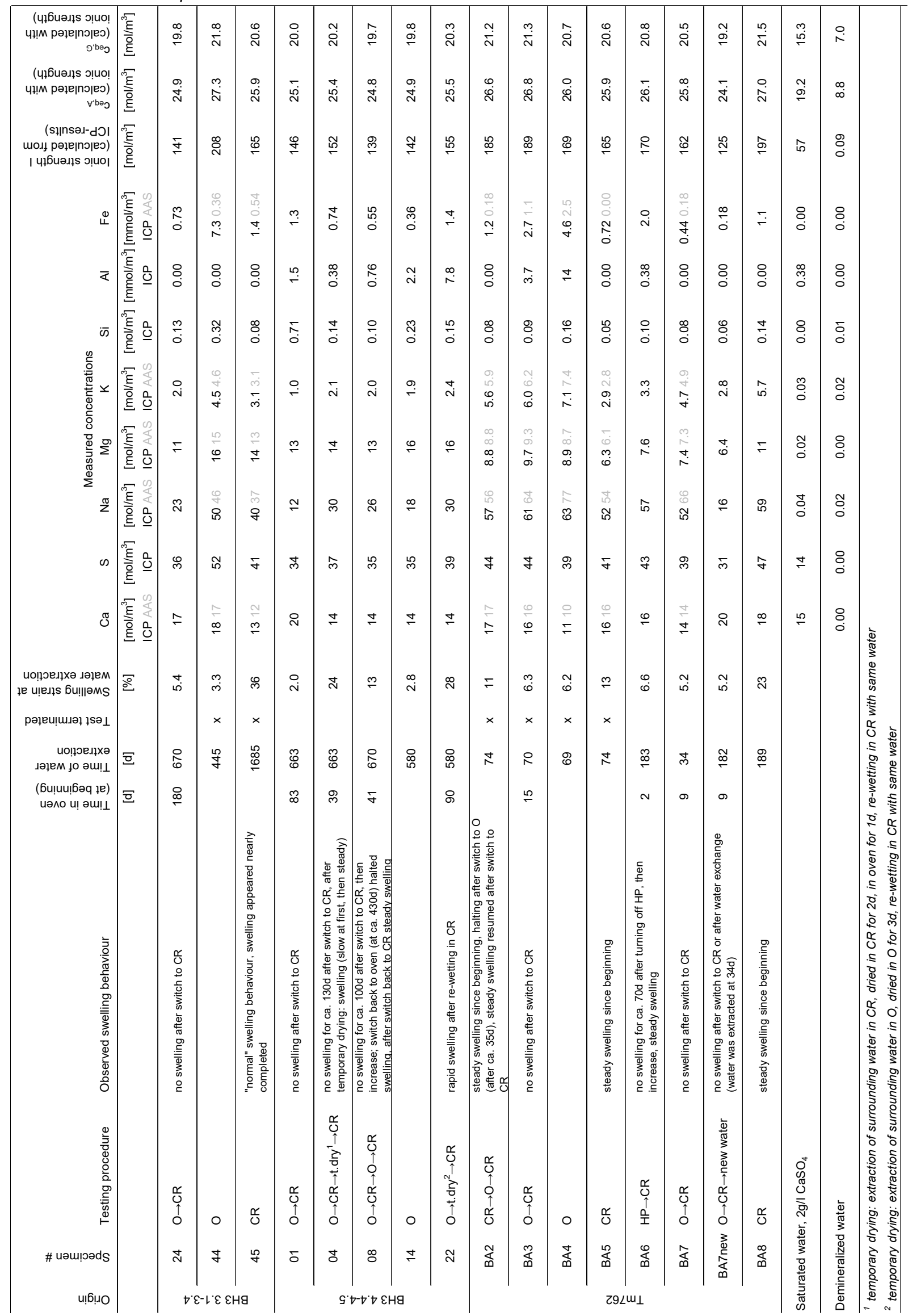



NOTATION 

Abbreviations

A anhydrite

AA anhydrite powder from Alfa Aesar

AAS atomic absorption spectroscopy

AGT anhydrite to gypsum transformation

BB Bözberg

BET surface area measurements based on the theory of Brunauer, Emmett and Teller

BSE backscattered electrons

CC complete constraint

C-M chemo-mechanical

EDTA ethylenediaminetetraacetic acid

EDX energy-dispersive X-ray spectroscopy

G gypsum

HMC hydraulical mechanical chemical coupled processes

IC isotropic compression

ICP-OES inductively coupled plasma - optical emission spectrometry

KM limestone powder (Kalkmehl)

MIP mercury-intrusion porosimetry

NAS new anhydrite surface

OAS original anhydrite surface

Oe oedometer

$P \quad$ pores

PC anhydrite powder from ProChem

PT preliminary test

PTFE polytetrafluoroethylene

PVC polyvinyl chloride

PW Polwhite E Chinaclay (kaolin)

QM quartz flour (Quarzmehl)

$\mathrm{RH} \quad$ relative humidity

SA anhydrite powder from Sigma Aldrich

SE secondary electrons

SEM scanning electron microscopy

TGA thermogravimetric analysis

XRD X-ray diffraction analysis

\section{Latin lower case letters}

a shape factor of parellelepipedic anhydrite particles (Chapter 5)

material specific coupling parameter for anhydrite dissolution (Chapter 7)

parameter describing the swelling law (Chapter 8)

radius of a cavity (Appendix $G$ )

$a_{1}, a_{2} \quad$ function constants for an approximation of experimental data (Chapter 8)

$a_{a x} \quad$ material specific coupling parameter for anhydrite dissolution (axial component)

$a_{\mathrm{Ca}^{2+}, c} \quad$ ionic activity of calcium at a concentration $c$ in solution (Chapter 2)

$a_{k l} \quad$ material specific coupling tensor for anhydrite dissolution 


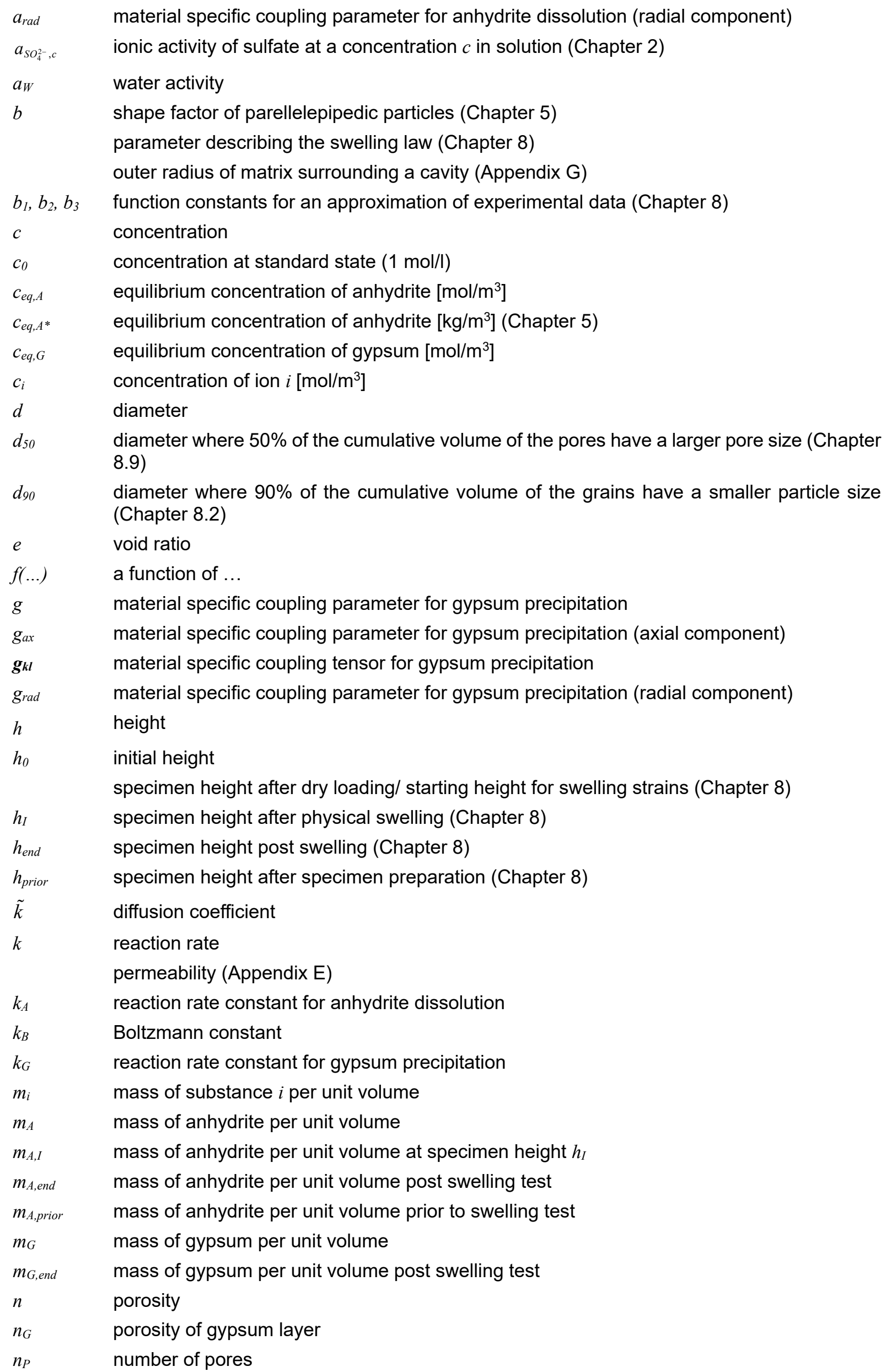




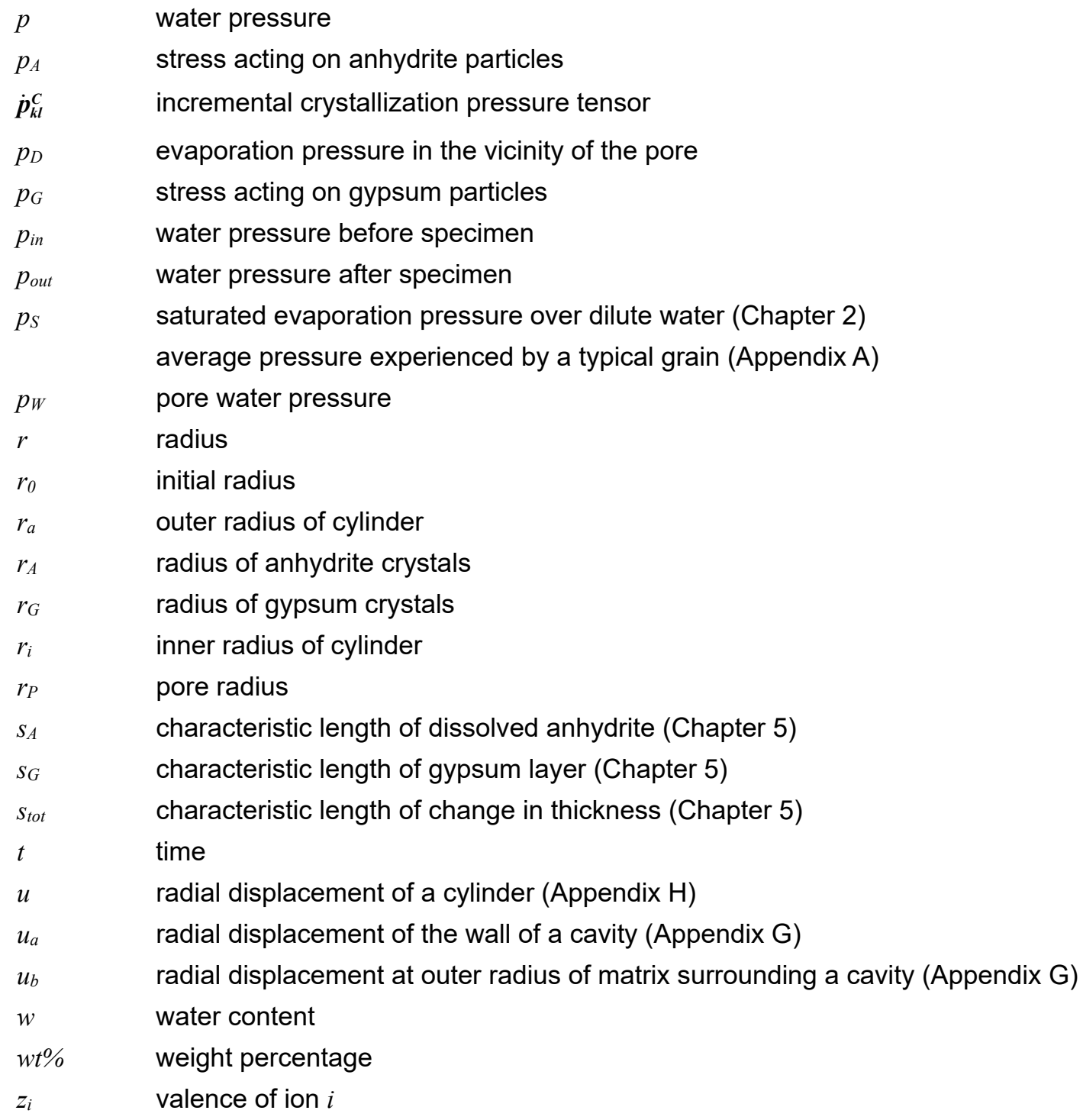

\section{Latin upper case letters}

A surface area

coefficient used in Davies equation (Appendix A)

$A_{A} \quad$ surface area of anhydrite

$A_{P} \quad$ pore area (in a cross section)

$A t \% \quad$ atomic percentage

$A_{\text {tot }} \quad$ total surface area

$C_{c y l} \quad$ circumference of PVC cylinder (Chapter 8.8)

$D \quad$ effective diffusion coefficient (Chapter 5)

diameter of specimen (Chapter 8)

$D_{i j k l} \quad$ stiffness tensor

$D_{\text {Triax }} \quad$ elasticity tensor for axisymmetric boundary conditions (Appendix D)

E Young's modulus

$E_{c y l} \quad$ Young's modulus of PVC cylinder (Chapter 8.8)

$E_{c y l, c a l} \quad$ Young's modulus of PVC cylinder, estimated from calibration tests (Chapter 8.8)

$F_{A} \quad$ specific surface area of anhydrite 
$F_{G} \quad$ specific surface area of gypsum

$F_{S} \quad$ specific surface area of inert solid

I ionic strength

$I_{A} \quad$ ionic strength at equilibrium of anhydrite

$I_{G} \quad$ ionic strength at equilibrium of gypsum

$I_{\text {other ions }} \quad$ increase of ionic strength due to other ions (addend to ionic strength)

$K \quad$ solubility product (Chapter 2 )

$M_{A} \quad$ total mass of anhydrite

$M_{A, 0} \quad$ initial mass of anhydrite

$M_{G} \quad$ total mass of gypsum

$M_{i} \quad$ total mass of a substance $i$

$Q \quad$ flow rate (Chapter 7$)$

ionic product (Chapter 2)

$R \quad$ universal gas constant $(8.314 \mathrm{~J} / \mathrm{K} / \mathrm{mol})$

$R_{0} \quad$ radius of diffusing particle

$R^{2} \quad$ coefficient of determination

RH relative humidity

$S_{A} \quad$ thickness of anhydrite particle (Chapter 5)

$S_{A 0} \quad$ initial thickness of anhydrite particle (Chapter 5)

$S_{G, A} \quad$ thickness of anhydrite particle with a gypsum layer (Chapter 5)

$\mathrm{Sr} \quad$ degree of saturation

$T \quad$ temperature

$T_{0} \quad$ temperature at standard state $(298 \mathrm{~K})$

$T_{e q} \quad$ transition temperature

$T_{\text {ext }} \quad$ temperature outside the cell

$T_{G} \quad$ tortuosity of the gypsum layer

$T_{\text {int }} \quad$ temperature inside the cell / temperature of the specimen

V volume

$V_{0} \quad$ initial volume

$V_{A} \quad$ volume of anhydrite

$V_{A}^{0} \quad$ molar volume of anhydrite at standard state $\left(45.94 \mathrm{~cm}^{3} / \mathrm{mol}\right)$

$V_{G} \quad$ volume of gypsum

$V_{G}^{0} \quad$ molar volume of gypsum at standard state $\left(74.30 \mathrm{~cm}^{3} / \mathrm{mol}\right)$

$V_{P} \quad$ pore volume

$V_{S} \quad$ volume of inert material

$V_{\text {tot }} \quad$ total volume (of the regarded system)

$V_{W} \quad$ molar volume of water $\left(18 \mathrm{~cm}^{3} / \mathrm{mol}\right.$, Appendices A and $\left.\mathrm{G}\right)$

volume of water (in the regarded system; Chapter 7 )

\section{Greek lower case letters}

$\gamma_{ \pm} \quad$ mean activity coefficient (Chapter 2)

$\gamma_{A C, A} \quad$ activity coefficient at equilibrium of anhydrite (Appendix A)

$\gamma_{A C, G} \quad$ activity coefficient at equilibrium of gypsum (Appendix $\mathrm{A}$ ) 


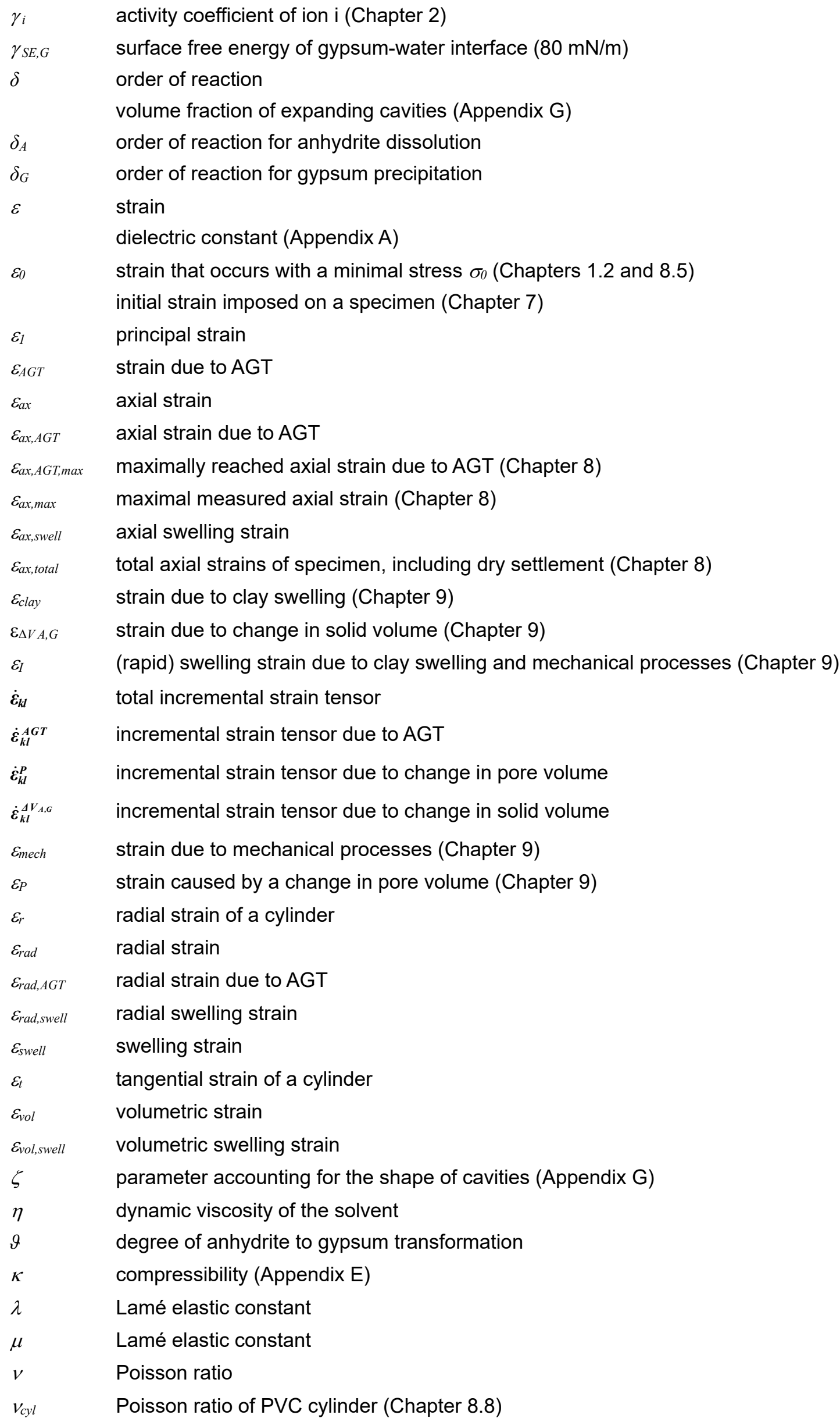




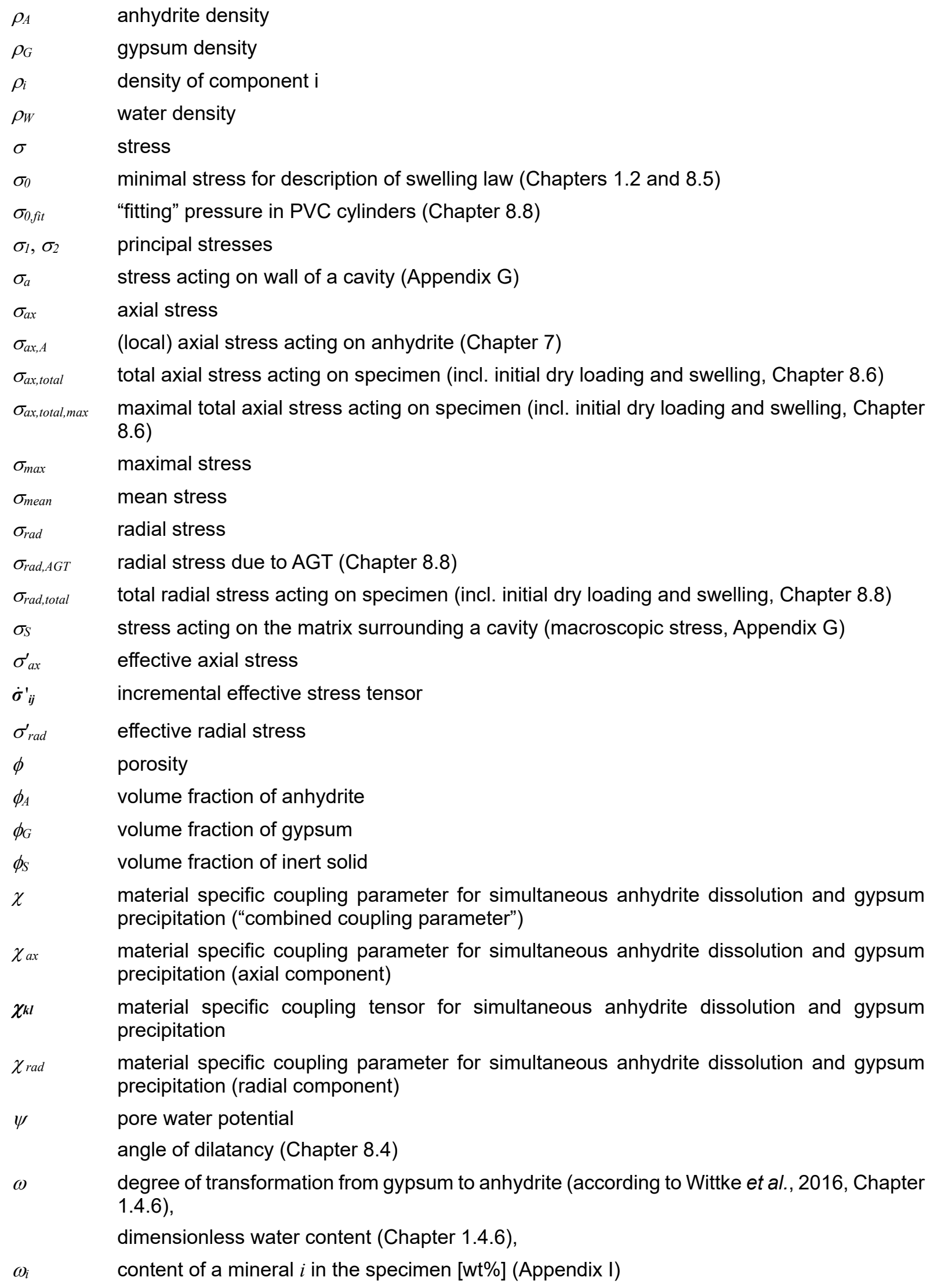




\section{Greek upper case letters}

$\Delta c_{e q} \quad$ difference between the equilibrium concentrations of gypsum and anhydrite

$\Delta C_{c y l} \quad$ change in circumference of PVC cylinder (Chapter 8.8)

$\Delta h \quad$ change in height

$\Delta h_{A G T} \quad$ deformation due to AGT (Chapter 8)

$\Delta h_{\text {clay }} \quad$ deformation due to clay swelling (Chapter 8)

$\Delta h_{d r y} \quad$ measured settlement from dry loading (Chapter 8)

$\Delta h_{I} \quad$ "initial" deformation due to physical swelling (Chapter 8)

$\Delta h_{\text {mech }} \quad$ deformation due to mechanical processes (Chapter 8)

$\Delta h_{P} \quad$ deformation due to change in pore volume (Chapter 8)

$\Delta h_{\text {swell }} \quad$ deformation measured after wetting the specimen (Chapter 8)

$\Delta h_{\text {total }} \quad$ total measured deformation (Chapter 8)

$\Delta h_{V A, G} \quad$ deformation due to change in solid volume (Chapter 8)

$\Delta r \quad$ change in radius

$\Delta_{r, A} G^{0} \quad$ standard Gibbs energy of anhydrite dissolution $(23680 \mathrm{~J} / \mathrm{mol})$

$\Delta_{r, A} S^{0} \quad$ standard entropy of anhydrite dissolution (-139.7 J/K/mol)

$\Delta_{r, A} V^{0} \quad$ standard volume of anhydrite dissolution $\left(-42.72 \mathrm{~cm}^{3} / \mathrm{mol}\right)$

$\Delta_{r, G A} G^{0} \quad$ standard Gibbs energy of the transformation of anhydrite to gypsum $(-1250 \mathrm{~J} / \mathrm{mol})$

$\Delta_{r, G A} S^{0} \quad$ standard entropy of anhydrite hydration (-52.42 J/K/mol)

$\Delta_{r, G A} V^{0} \quad$ standard volume of the transformation of anhydrite to gypsum $\left(-7.64 \mathrm{~cm}^{3} / \mathrm{mol}\right)$

$\Delta_{r, G} G^{0} \quad$ standard Gibbs energy of gypsum dissolution $(24930 \mathrm{~J} / \mathrm{mol})$

$\Delta_{l, G} S^{0} \quad$ standard entropy of gypsum dissolution (-87.28 J/K/mol)

$\Delta_{l, G} V^{0} \quad$ standard volume of gypsum dissolution $\left(-42.72 \mathrm{~cm}^{3} / \mathrm{mol}\right)$

$\Delta V_{A} \quad$ change in volume of anhydrite

$\Delta V_{G} \quad$ change in volume of gypsum

$\Delta V_{S} \quad$ change in solid volume

$\Delta V_{W} \quad$ change in volume of water

$\Delta \omega \quad$ change in mass measured with TGA [wt\%]

$\Psi \quad$ pore water potential 

REFERENCES 

Abell, A. B., Willis, K. L. and Lange, D. A. (1999). Mercury Intrusion Porosimetry and Image Analysis of Cement-Based Materials. In: Journal of Colloid and Interface Science, Vol. 211(1); pp. 39-44.

Alimi, F. and Gadri, A. (2004). Kinetics and morphology of formed gypsum. In: Desalination, Vol. 166; pp. 427-434.

Alonso, E. E., Berdugo, I., Tarragó, D. and Ramon, A. (2007). Tunnelling in sulphate claystones. 14th European Conference on Soil Mechanics and Geotechnical Engineering, Madrid, Spain.

Alonso, E. E., Berdugo, I. R. and Ramon, A. (2013). Extreme expansive phenomena in anhydriticgypsiferous claystone: the case of Lilla tunnel. In: Géotechnique, Vol. 63(7); pp. 584-612.

Alonso, E. E. and Olivella, S. (2008). Modelling Tunnel Performance in Expansive Gypsum Claystone. 12th International Conference of IACMAG, Goa, India.

Alonso, E. E. and Ramon, A. (2013). Heave of a railway bridge induced by gypsum crystal growth: field observations. In: Géotechnique, Vol. 63(9); pp. 707-719.

Amann, F., Ündül, Ö., Löw, S. and Kaiser, P. K. (2013). Fracture Processes and In-situ Fracture Observations in Gipskeuper. Forschungsauftrag ASTRA2011/006. Eidgenössisches Departement für Umwelt, Verkehr, Energie und Kommunikation UVEK, Bundesamt für Strassen.

Amstad, C. and Kovári, K. (2001). Untertagbau in quellfähigem Fels. ETHZ Forschungsauftrag 52/94 auf Antrag des Bundesamtes für Strassen (ASTRA). IGT, ETH Zürich.

Anagnostou, G. (1992). Untersuchungen zur Statik des Tunnelbaus in quellfähigem Gebirge. Doctoral Thesis. Supervisor: Kovari, K., ETH Zürich.

Anagnostou, G. (2007). Design Uncertainties in Tunnelling through Anhydritic Swelling Rocks. In: Felsbau, Vol. 25(4); pp. 48-56.

Anagnostou, G., Pimentel, E. and Serafeimidis, K. (2010). Swelling of sulphatic claystones - some fundamental questions and their practical relevance / Quellen von sulfatführenden Tonsteinen - Themen der Grundlagenforschung und ihre praktische Bedeutung. In: Geomechanics and Tunnelling, Vol. 3(5); pp. 567-572.

Anagnostou, G., Serafeimidis, K., Pimentel, E., Wanninger-Huber, T. and Vrakas, A. (2015). Modelling of anhydritic swelling claystones. Eidgenössisches Departement für Umwelt, Verkehr, Energie und Kommunikation UVEK, Bundesamt für Strassen, Bern.

Anagnostou, G., Serafeimidis, K. and Vrakas, A. (2014). On the Occurrence of Anhydrite in the Sulphatic Claystones of the Gypsum Keuper. In: Rock Mechanics and Rock Engineering, Vol. 48(1); pp. $1-13$.

Anderson, G. M. (1996). Thermodynamics of Natural systems. In: University of Toronto, John Wiley and Sons, Inc.

Appelo, C. A. J. and Postma, D. (2005). Geochemistry, groundwater and pollution. 2nd Ed. A. A. Balkema, Rotterdam.

ASTM International (2004). Standard Test Method for Consolidated Undrained Triaxial Compression Test for Cohesive Soils. In D4767-04.

ASTM International (2007a). Standard Terminology Relating to Soil, Rock, and Contained Fluids. In Designation: D653-07f.

ASTM International (2007b). Standard Test Method for Unconsolidated-Undrained Triaxial Compression Test on Cohesive Soils. In D2850-03a.

Atkins, P. and De Paula, J. (2006). Physical Chemistry. 8th Ed. Oxford University Press.

Azimi, G. and Papangelakis, V. G. (2011). Mechanism and kinetics of gypsum-anhydrite transformation in aqueous electrolyte solutions. In: Hydrometallurgy, Vol. 108(1-2); pp. 122-129.

Barton, A. F. M. and Wilde, N. M. (1971). Dissolution rates of polycrystalline samples of gypsum and orthorhombic forms of calcium sulphate by a rotating disc method. In: Transactions of the Faraday Society, Vol. 67(588); pp. 3590-3597.

Bary, B. (2008). Simplified coupled chemo-mechanical modeling of cement pastes behavior subjected to combined leaching and external sulfate attack. In: International Journal for Numerical and Analytical Methods in Geomechanics, Vol. 32(14); pp. 1791-1816. 
Bell, F. G. (1994). A survey of the engineering properties of some anhydrite and gypsum from the north and midlands of England. In: Engineering Geology, Vol. 38(1); pp. 1-23.

Berdugo, I. R. (2007). Tunnelling in sulphate-bearing rocks - expansive phenomena. Doctoral Thesis. Supervisor: Alonso, E. E. and Romero, E., UPC Barcelona, Spain.

Berdugo, I. R., Alonso, E. E., Romero, E. E., Gens, A. and Albis, M. (2009). A Review of Expansive Phenomena in Wagenburg North Tunnel. In: Revista de la Academia Colombiana de Ciencias Exactas, Físicas y Naturales (Bogotá), Vol. 33(129); pp. 455-468.

Berner, D. (1991). Die Geologie des Freudensteintunnels. In: Ingenieurbauwerke - DB Neubaustrecke Mannheim-Stuttgart: Der Freudensteintunnel, Vol. 7; pp. 58-116.

Bildstein, O., Worden, R. H. and Brosse, E. (2001). Assessment of anhydrite dissolution as the ratelimiting step during thermochemical sulfate reduction. In: Chemical Geology, Vol. 176(1-4); pp. 173-189.

Blight, G. E. (2013). Unsaturated soil mechanics in geotechnical practice. CRC PRESS, London.

Blount, C. W. and Dickson, F. W. (1973). Gypsum-Anhydrite equilibria in systems CaSO4-H2O and CaCO3-NaCl-H2O. In: Am. Mineralogist, Vol. 58; pp. 323-331.

Bock, E. (1961). On the solubility of anhydrous calcium sulphate and of gypsum in concentrated solutions of sodium chloride at $25^{\circ} \mathrm{C}, 30^{\circ} \mathrm{C}, 40^{\circ} \mathrm{C}$, and $50^{\circ} \mathrm{C}$. In: Canadian Journal of Chemistry, Vol. 39(9); pp. 1746-1751.

Bontle, M. and Nadiye-Tabbiruka, M. S. (2007). Chemical and Thermal Characterization of a Clayey Material Found Near Gaborone Dam. In: Journal of Applied Sciences and Environmental Management, Vol. 11(4); p. 4.

Bossart, P., Jaeggi, D. and Nussbaum, C. (2017). Experiments on thermo-hydro-mechanical behaviour of Opalinus Clay at Mont Terri rock laboratory, Switzerland. In: Journal of Rock Mechanics and Geotechnical Engineering, Vol. 9(3); pp. 502-510.

Bowles, J. E. (1996). Foundation Analysis and Design. 5th Ed. McGraw-Hill Companies, Inc.

Brezesinski, G. and Mögel, H.-J. (1993). Grenzflächen und Kolloide. Spektrum Akademischer Verlag, Heidelberg.

Brunauer, S., Emmett, P. H. and Teller, E. (1938). Adsorption of Gases in Multimolecular Layers. In: Journal of the American Chemical Society, Vol. 60(2); pp. 309-319.

Bulut, R. and Leong, E. (2009). Indirect Measurement of Suction. In: Laboratory and Field Testing of Unsaturated Soils. Tarantino, A., Romero, E. and Cui, Y.-J. (eds.). Springer Netherlands.

Butscher, C., Einstein, H. H. and Huggenberger, P. (2011). Effects of tunneling on groundwater flow and swelling of clay-sulfate rocks. In: Water Resources Research, Vol. 47(11).

Butscher, C., Einstein, H. H. and Huggenberger, P. (2015). Darcy flux as hydrological indicator for the swelling potential of clay-sulfate rocks in tunneling. In: Engineering Geology, Vol. 197; pp. 11-19.

Butscher, C., Huggenberger, P. and Zechner, E. (2011). Impact of tunneling on regional groundwater flow and implications for swelling of clay-sulfate rocks. In: Engineering Geology, Vol. 117(3-4); pp. 198-206.

Butscher, C., Huggenberger, P., Zechner, E. and Einstein, H. H. (2011). Relation between hydrogeological setting and swelling potential of clay-sulfate rocks in tunneling. In: Engineering Geology, Vol. 122(3-4); pp. 204-214.

Butscher, C., Mutschler, T. and Blum, P. (2016). Swelling of Clay-Sulfate Rocks: A Review of Processes and Controls. In: Rock Mechanics and Rock Engineering, Vol. 49(4); pp. 1533-1549.

Carrier, W. D. and Beckman, J. F. (1984). Correlations between index tests and the properties of remoulded clays. In: Géotechnique, Vol. 34(2); pp. 211-228.

Cheng, A. H.-D. (2016). Poroelasticity. Vol. 27. Springer International Publishing Switzerland.

Coussy, O. (2006). Deformation and stress from in-pore drying-induced crystallization of salt. In: Journal of the Mechanics and Physics of Solids, Vol. 54(8); pp. 1517-1547. 
Dai, Z., Shi, W., Kan, A. T., Zhang, N. and Tomson, M. B. (2014). Improvement of Thermodynamic Modeling of Calcium Carbonate and Calcium Sulfates at High Temperature and High Pressure in Mixed Electrolytes.

Dao, V. N. T., Morris, P. H. and Dux, P. F. (2008). On equations for the total suction and its matric and osmotic components. In: Cement and Concrete Research, Vol. 38(11); pp. 1302-1305.

Decagon Devices Inc. (2003). WP4 Dewpoint PotentiaMeter, Operator's Manual.

Delage, P. (2015). Thermo-hydro-mechanical issues in claystones: application to radioactive waste storage at great depth. In: Geotechnical Engineering for Infrastructure and Development.

Delage, P., Cui, Y. J. and Tang, A. M. (2010). Clays in radioactive waste disposal. In: Journal of Rock Mechanics and Geotechnical Engineering, Vol. 2(2); pp. 111-123.

Derjaguin, B. and Landau, L. (1941). Theory of the stability of strongly charged lyophobic sols and of the adhesion of strongly charged particles in solutions of electrolytes. In: Progress in Surface Science, Vol. 43(1-4); pp. 30-59.

Dewers, T. and Ortoleva, J. P. (1989). Mechano-chemical coupling in stressed rocks. In: Geochimica et Cosmochimica Acta, Vol. 53; pp. 1243-1258.

Durney, D. W. (1976). Pressure-Solution and Crystallization Deformation. In: Philosophical Transactions of the Royal Society of London. Series A, Mathematical and Physical Sciences, Vol. 283(1312); pp. 229-240.

Engesser, W., Ruch, C. and Wirsing, G. (2010). Geologische Untersuchungen von Baugrundhebungen im Bereich des Erdwärmesondenfeldes beim Rathaus in der historischen Altstadt von Staufen im Breisgau Sachstandbericht Az.:94-4763//10-563. Landesamt für Geologie, Rohstoffe und Bergbau (LGRB).

Eshel, G., Levy, G. J., Mingelgrin, U. and Singer, M. J. (2004). Critical Evaluation of the Use of Laser Diffraction for Particle-Size Distribution Analysis. In: Soil Science Society of America Journal, Vol. 68; pp. 736-743.

Espinosa-Marzal, R. M. and Scherer, G. W. (2010). Mechanisms of damage by salt. In: Geological Society, London, Special Publications, Vol. 331(1); pp. 61-77.

Fagerlund, G. (1973). Determination of specific surface by the BET method. In: Matériaux et Construction, Vol. 6(3); pp. 239-245.

Fecker, E. (1996). Untersuchung von Schwellvorgängen und Erprobung von Auskleidungskonzepten beim Freudensteintunnel. In: Tunnelbau Taschenbuch 1996; pp. 165-182.

Flatt, R. J. (2002). Salt damage in porous materials: how high supersaturations are generated. In: Journal of Crystal Growth, Vol. 242; pp. 435-454.

Flatt, R. J. (2012). Swelling inhibitors for anhydritic clastones - Quell-Inhibitoren für anhydritführende Tonsteine. ASTRA Proposal FGU 2012/001. ETH Zurich.

Flatt, R. J., Caruso, F., Sanchez, A. M. A. and Scherer, G. W. (2014). Chemo-mechanics of salt damage in stone. In: Nature Communications, Vol. 5; p. 4823.

Flatt, R. J., Wangler, T. and Shahab, A. (2017). Swelling inhibitors for anhydritic claystones. Forschungsprojekt FGU 2012/001 auf Antrag der Arbeitsgruppe Tunnelforschung (AGT). ETH Zürich, Institut für Baustoffe.

Fredlund, D. G. and Rahardjo, H. (1993). Soil mechanics for unsaturated soils. John Wiley \& Sons, Inc., New York.

Gattermann, J. H. (1998). Theorie und Modellversuch für ein Abdichtungsbauwerk aus hochverdichteten Bentonitformsteinen. Vol. 33. Aachen.

Geotechnisches Institut AG and Pfirter Nyfeler + Partner AG (2010). Sanierungstunnel Belchen STB Bohrkampagne 2009 Laboruntersuchungen.

Giesche, H. (2006). Mercury porosimetry: A general (practical) overview. In: Particle \& Particle Systems Characterization, Vol. 23(1); pp. 9-19.

Goldstein, J., Newbury, D. E., Joy, D. C., Lyman, C. E., Echlin, P., Llfshin, E., Sawyer, L. and R., M. J. (2003). Scanning electron microscopy and X-ray microanalysis. 3rd Ed. Springer Science + Business Media, New York. 
Götz, H. P. (1972). Zur Frage der Sohlhebungen im Gipskeuper. Internationales Symposium für Untertagbau, Luzern.

Grob, H. (1972). Schwelldruck im Belchentunnel - Swelling Pressure Illustrated with the Example of the Belchen Tunnel. Internationales Symposium für Untertagbau, Luzern.

Haines, P. J. (2002). Principles of thermal analysis and calorimetry. Royal society of chemistry.

Hauber, L., Jordan, P., Madsen, F., Nüesch, R. and Vögtli, B. (2005). Tonminerale und Sulfate als Ursache für druckhaftes Verhalten von Gesteinen. Forschungsauftrag ASTRA 1996/039 auf Antrag des Bundesamtes für Strassen.

Haynes, J. M. (1973). Pore size analysis according to the Kelvin equation. In: Materials and Structures - Matériaux et Constructions, Vol. 6(3); pp. 209-213.

Hill, A. E. (1937). The Transition Temperature of Gypsum to Anhydrite. In: Journal of the American Chemical Society, Vol. 59(11); pp. 2242-2244.

HORIBA (2015). www.horiba.com, Accessed 13.11.15.

Huber, T., Pimentel, E. and Anagnostou, G. (2015). Experimental Investigations for the Modelling of Chemo-mechanical Processes in Anhydritic Rock. In: Energy Procedia, Vol. 76; pp. 87-95.

Huder, J. and Amberg, G. (1970). Quellung in Mergel, Opalinuston und Anhydrit. In: Schweizerische Bauzeitung, Vol. 88(43); pp. 975-980.

Hueckel, T. (1997). Chemo-plasticity of clays subjected to stress and flow of a single contaminant. In: International Journal for numerical and analytical methods in geomechanics, Vol. 21; pp. 43-72.

Hueckel, T. and Baldi, G. (1990). Thermoplasticity of saturated clays: experimental constitutive study. In: Journal of Geotechnical Engineering, Vol. 116(12); pp. 17781796.

Huggenberger, P. and Butscher, C. (2012). Einfluss der Grundwasserströmung auf das Quellverhalten des Gipskeupers im Chienbergtunnel. In: Berichte der Forschung im Strassenwesen Research Project ASTRA / FGU 2008-004. Eidgenössisches Departement für Umwelt, Verkehr, Energie und Kommunikation UVEK, Bundesamt für Strassen.

Huggenberger, P., Butscher, C., Dresmann, H. and S., S. (2016). Einfluss von geologisch-hydrogeologischen Randbedingungen und baulichen Massnahmen auf das Quellen von Ton-SulfatGesteinen am Belchentunnel. In: Berichte der Forschung im Strassenwesen. Eidgenössisches Departement für Umwelt, Verkehr, Energie und Kommunikation UVEK, Bundesamt für Strassen.

Huggenberger, P., Zechner, E., Dresmann, H. and Vogt, R. (2012). Einfluss der Grundwasserströmung auf das Quellverhalten des Gipskeupers im Belchentunnel. In: Berichte der Forschung im Strassenwesen Eidgenössisches Departement für Umwelt, Verkehr, Energie und Kommunikation UVEK, Bundesamt für Strassen.

Imerys Performance \& Filtration Minerals (2008). Polwhite E. Data sheet.

Innorta, G., Rabbi, E. and Tomadin, L. (1980). The gypsum-anhydrite equilibrium by solubility measurements. In: Geochimica et Cosmochimica Acta, Vol. 44(12); pp. 1931-1936.

James, A. N. and Lupton, A. R. R. (1978). Gypsum and anhydrite in foundations of hydraulic structures. In: Géotechnique, Vol. 28(3); pp. 249-272.

Jasmund, K. and Lagaly, G. (1993). Tonminerale und Tone: Struktur, Eigenschaften, Anwendungen, und Einsatz in Industrie und Umwelt. Steinkopff, Darmstadt.

Jeschke, A. (2002). Lösungskinetik von Gips und Anhydrit. Doctoral Thesis; Fachbereich Physik, Elektrotechnik, Bremen.

Jost, C. (2016). Versiegelung von Anhydrit. Bachelor Thesis. Supervisor: Wanninger, T., Pimentel, E. and Anagnostou, G.; Institute for Geotechnical Engineering, ETH Zurich.

Kaiser, A. (2017). Quellverhalten von Gesteinen aus Anhydrit und Ton. Bachelor Thesis. Supervisor: Wanninger, T., Pimentel, E. and Anagnostou, G.; Institute for Geotechnical Engineering, ETH Zurich.

Kalkfabrik Netstal AG (2015). KFN Technical Data Sheet nekafill 15. 
Katzenbach, R., Bergmann, C. and Leppla, S. (2010). Langzeituntersuchungen zum Schwell- und Quellverhalten von Anhydrit. In: Geotechnik, Vol. 85(3); pp. 113-117.

Kiehl, J. R. (1990). Ein dreidimensionales Quellgesetz und seine Anwendung auf den Felshohlraumbau. 9. Nationales Felsmechanik Symposium, Aachen.

Kirschke, D. (1987). Laboratory and in situ swelling tests for the Freudenstein tunnel. 6th International Congress on Rock Mechanics, Montréal.

Kirschke, D. (1992). Neue Versuchstechniken und Erkenntnisse zum Anhydritschwellen. 10. Nationales Felsmechanik Symposium, Aachen, DE.

Kirschke, D. (1996). Neue Versuchstechniken und Erkenntnisse zum Anhydritschwellen. In: Tunnelbau 1996. DGGT - Deutsche Gesellschaft für Geotechnik e.V. (ed.). Verlag Glückauf GmbH, Essen.

Kirschke, D. (2010). Approaches to technical solutions for tunnelling in swellable ground / Lösungsansätze für den Tunnelbau in quellund schwellfähigem Gebirge. In: Geomechanics and Tunnelling, Vol. 3(5); pp. 547-556.

Kirschke, D., Kovári, K. and Prommersberger, G. (1991). Bemessungsgrundlagen und Konstruktion der Sohle des Freudensteintunnels. In: Ingenieurbauwerke - DB Neubaustrecke Mannheim-Stuttgart: Der Freudensteintunnel, Vol. 7; pp. 40-57.

Klimchouk, A. (2000). Dissolution and conversions of gypsum and anhydrite. In: Speleogenesis: Evolution of Karst Aquifers. Klimchouk, A. B., Ford, D. C., Palmer, A. N. and Dreybrodt, W. (eds.). Natlional Speleological Society, Huntsville, Alabama.

Kontrec, J., Kralj, D. and Brečević, L. (2002). Transformation of anhydrous calcium sulphate into calcium sulphate dihydrate in aqueous solutions. In: Journal of Crystal Growth, Vol. 240(1-2); pp. 203211.

Kunz, M. (2014). Untersuchungen zum Quellverhalten von Anhydrit. Bachelor Thesis. Supervisor: Wanninger, T., Pimentel, E. and Anagnostou, G.; Institute for Geotechnical Engineering, ETH Zurich.

Kunz, M. (2016). Die Eigenschaften verschiedener Anhydritpulver und ihr Einfluss auf die Reaktionskinetik und das Quellverhalten. Project Thesis. Supervisor: Wanninger, T., Pimentel, E. and Anagnostou, G.; Institute for Geotechnical Engineering, ETH Zurich.

Lang, H. J., Huder, J., Amann, P. and Puzrin, A. (2007). Bodenmechanik und Grundbau: Das Verhalten von Böden und Fels und die wichtigsten grundbaulichen Konzepte. 8th Ed. Springer Verlag, Berlin Heidelberg.

Lecampion, B. (2010). Stress-induced crystal preferred orientation in the poromechanics of in-pore crystallization. In: Journal of the Mechanics and Physics of Solids, Vol. 58(10); pp. 1701-1715.

Lippmann, F. (1976). Corrensite, a swelling clay mineral, and its influence on floor heave in tunnels in the Keuper formation. In: Bulletin of the International Association of Engineering Geology Bulletin de l'Association Internationale de Géologie de l'Ingénieur, Vol. 13; pp. 65-70.

Liu, S.-T. and Nancollas, G. H. (1970). The kinetics of crystal growth of calcium sulfate dihydrate. In: Journal of Crystal Growth, Vol. 6(3); pp. 281-289.

Madsen, F. T. (1976). Quelldruckmessung an Tongesteinen und Berechnung des Quelldrucks nach der DLVO - Theorie. In Mitteilungen des Institutes für Grundbau und Bodenmechanik ETH Zürich.

Madsen, F. T., Flückiger, A., Hauber, L., Jordan, P. and Voegtli, B. (1995). New investigations on swelling rocks in the Belchen tunnel, Switzerland. Proceedings for the 8th International Congress on Rock Mechanics, Tokyo, Japan.

Madsen, F. T. and Nüesch, R. (1990). Langzeitquellenverhalten von Tongesteinen und tonigen Sulfatgesteinen. Technischer Bericht 90-17. Nagra.

Madsen, F. T. and Nüesch, R. (1991). The Swelling Behaviour of Clay-sulfate Rocks. 7th International Congress on Rock Mechanics.

Manning, T. J. and Grow, W. R. (1997). Inductively Coupled Plasma - Atomic Emission Spectrometry. In: The Chemical Educator, Vol. 2(1); pp. 1-19.

Mantellato, S., Palacios, M. and Flatt, J. R. (2015). Reliable specific surface area measurements on anhydrous cements. In: Cement and Concrete Research, Vol. 67; pp. 286-291. 
Marsal, D. (1952). Der Einfluss des Druckes auf das System CaSO4-H2O. In: Heidelberger Beiträge zur Mineralogie and Petrographie, Vol. 3; pp. 289-296.

Mettler Toledo Intl. Inc. (2015). SevenMulti, Operating Instructions.

Meunier, A. (2005). Clays. Springer, Berlin; New York.

micrometrics (2014). ACCUPYC II gas displacement pycnometry system.

mindat.org (2019). Anhydrite. https://www.mindat.org/min234.html, Accessed 22.07.2019.

Mitchell, J. K. (1993). Fundamentals of Soil Behavior. 2nd Ed. John Wiley \& Sons Inc., New York.

Mullin, J. W. (2001). Crystallization. 4th Ed. Butterworth-Heinemann.

NASA (2007). Systems Engineering Handbook. In: NASA/SP-2007-6105. National Aeronautics and Space Administration, Washington, D.C.

Nesse, W. D. (1986). Introduction to optical mineralogy. Oxford University Press, New York.

Nüesch, R. and Ko, S. C. (2000). Influence of mineralogical composition to experimental swelling behaviour of shaly anhydrite rocks. In: Applied Mineralogy. Rammlmair, D. (ed.). Vol. 2. Balkema, Rotterdam.

Obert, L. and Duvall, W. I. (1967). Rock mechanics and the design of structures in rock. Wiley, New York.

Oldecop, L. and Alonso, E. (2012). Modelling the degradation and swelling of clayey rocks bearing calcium-sulphate. In: International Journal of Rock Mechanics and Mining Sciences, Vol. 54; pp. 90-102.

Parkhurst, D. L. (1995). User's guide to PHREEQC - a computer program for speciation, reaction-path, advective-transport, and inverse geochemical calculations. U.S. Geological survey, WaterResources Investigations Report 95-4227.

Partridge, E. P. and White, A. H. (1929). The solubility of calcium sulfate from 0 to $200^{\circ}$. In: Journal of the American Chemical Society, Vol. 51(2); pp. 360-370.

PerkinEImer (2008). Atomic Spectroscopy - A Guide to Selecting the Appropriate Technique and System.

Pimentel, E. (1996). Quellverhalten von diagenetisch verfestigtem Tonstein. Doctoral Thesis. Supervisor: Gudehus, G. and Natau, O., University of Karlsruhe.

Pimentel, E. (2003). Swelling behaviour of sedimentary rocks under consideration of micromechanical aspects and its consequences on structure design. In: Geotechnical measurements and modelling. Natau, O. (ed.).

Pimentel, E. (2007a). A laboratory testing technique and a model for the swelling behavior of anhydritic rock. The second half century of rock mechanics - 11th Congress of the International Society for Rock Mechanics (ISRM), Lisbon, Portugal.

Pimentel, E. (2007b). Quellverhalten von Gesteinen - Erkenntnisse aus Laboruntersuchungen. Quellprobleme in der Geotechnik, Fribourg.

Pimentel, E. (2015). Existing Methods for Swelling Tests - A Critical Review. In: European Geosciences Union General Assembly 2015, EGU, Wien, Österreich, Vol. 76; pp. 96-105.

Pimentel, E. and Anagnostou, G. (2010). Langzeitquellversuche an anhydritführenden Gesteinen. Forschungsauftrag FGU 2006/001 auf Antrag des Bundesamtes für Strassen (ASTRA).

Pimentel, E. and Anagnostou, G. (2013). New Apparatus and Experimental Setup for Long-Term Swelling Tests on Sulphatic Claystones. In: Rock Mechanics and Rock Engineering.

Pimentel, E. and Anagnostou, G. (2016). Langzeitquellversuche an anhydritführenden Gesteinen, Folgebericht Nr. 3. Forschungsauftrag FGU 2006/001 auf Antrag des Bundesamtes für Strassen (ASTRA).

Pimentel, E. and Wanninger, T. (2016). Expertise on the damages occurring in the community of Lochwiller (Alsace, France). Bericht 164201. ETH, Zurich.

Posnjak, E. (1938). The system CaSO4. In: American Journal of Science, 5th Edition, Vol. 35-A; pp. 247-272. 
Pregl, O., Fuchs, M., Müller, H., Petschl, G., Riedmüller, G. and Schwaighofer, B. (1980). Dreiaxiale Schwellversuche an Tongesteinen. In: Geotechnik, Vol. 1; pp. 1-7.

Pusch, R., Karnland, O. and Hoekmark, H. (1990). GMM - a general microstructural model for qualitative and quantitative studies of smectite clays.

Quantachrome Instruments (2007). Quantachrome Autosorb-1 Series - surface area, pore size and chemisorption.

Ramon, A. (2014). Expansion mechanisms in sulphated rocks and soils. Doctoral Thesis. Supervisor: Alonso, E.; Departament d'Enginyeria del Terreny, Cartogràfica i Geofísica, Universitat Politècnica de Catalunya.

Ramon, A. and Alonso, E. E. (2013). Heave of a railway bridge: modelling gypsum crystal growth. In: Géotechnique, Vol. 63(9); pp. 720-732.

Ramon, A., Alonso, E. E. and Olivella, S. (2017). Hydro-chemo-mechanical modelling of tunnels in sulfated rocks. In: Géotechnique, Vol. 67(11); pp. 968-982.

Ramsdell, L. S. and Partridge, E. P. (1929). The crystal forms of calcium sulphate. In: American Mineralogist, Vol. 14(2); pp. 59-74.

Rauh, F. (2009). Untersuchungen zum Quellverhalten von Anhydrit und Tongesteinen im Tunnelbau. Vol. B. Pfeil, München.

Rauh, F., Spaun, G. and Thuro, K. (2006). Assessment of the swelling potential of anhydrite in tunnelling projects. 10th congress of the International Association for Engineering Geology and the Environment.

Rauh, F. and Thuro, K. (2006). Why do pure anhydrites differ in their swelling capacity? 3rd Colloquium Rock Mechanics - Theory and Practice Vienna.

Rauh, F. and Thuro, K. (2007). Investigations On the Swelling Behavior of Pure Anhydrites. 1st CanadaUS Rock Mechanics Symposium, Vancouver, Canada.

Richard Baker Harrison LTD (2011). Polwhite E China Clay Data sheet.

Riley, C. M. and Byrne, J. V. (1961). Genesis of primary structures in anhydrite. In: Journal of Sedimentary Research, Vol. 31(4); pp. 553-559.

Rogenmoser, V. (2016). Quellverhalten von Mischungen aus Anhydrit und Ton. Bachelor Thesis. Supervisor: Wanninger, T., Pimentel, E. and Anagnostou, G.; Institute for Geotechnical Engineering, ETH Zurich.

Romero, E., Villar, M. V. and Lloret, A. (2005). Thermo-hydro-mechanical behaviour of two heavily overconsolidated clays. In: Engineering Geology, Vol. 81(3); pp. 255-268.

Sahores, J. (1962). Contribution à l'étude des phénomenes mécaniques accompagnant l'hydratation de l'anhydrite. Doctoral Thesis, Université de Toulouse.

Scherer, G. W. (2000). Stress from crystallization of salt in pores. In: Proceedings of the 9th International Congress on Deterioration and Conservation of Stone. Fassina, V. (ed.). Elsevier Science B.V., Amsterdam.

Scherer, G. W. (2002). Factors affecting crystallization pressure. International RILEM TC 186-ISA Workshop on Internal Sulfate Attack and Delayed Ettringite Formation, Villars, Switzerland.

Serafeimidis, K. (2014). On the dissolution, precipitation and transport processes in sulphatic swelling rocks. Doctoral Thesis. Supervisor: Anagnostou, G.; Veröffentlichungen des Instituts für Geotechnik (IGT) der ETH Zürich, vdf Hochschulverlag AG an der ETH Zürich.

Serafeimidis, K. and Anagnostou, G. (2012a). On the kinetics of the chemical reactions underlying the swelling of anhydritic rocks. Eurock, Stockholm.

Serafeimidis, K. and Anagnostou, G. (2012b). Simultaneous anhydrite dissolution and gypsum precipitation in a closed swelling rock system. 46th US Rock Mechanics / Geomechanics Symposium, Chicago, IL, USA.

Serafeimidis, K. and Anagnostou, G. (2013a). On the Time-Development of Sulphate Hydration in Anhydritic Swelling Rocks. In: Rock Mechanics and Rock Engineering, Vol. 46(3); pp. 619-634. 
Serafeimidis, K. and Anagnostou, G. (2013b). On the Solubilities of Anhydrite and Gypsum. In: Constitutive Modeling of Geomaterials: Advances and New Applications. Yang, Q., Zhang, J.-M., Zheng, H. and Yao, Y. (eds.). Springer Berlin Heidelberg, Berlin, Heidelberg.

Serafeimidis, K. and Anagnostou, G. (2014a). On the crystallisation pressure of gypsum. In: Environmental Earth Sciences, Vol. 72(12); pp. 4985-4994.

Serafeimidis, K. and Anagnostou, G. (2014b). The Solubilities and Thermodynamic Equilibrium of Anhydrite and Gypsum. In: Rock Mechanics and Rock Engineering, Vol. 48(1); pp. 15-31.

Serafeimidis, K., Anagnostou, G. and Vrakas, A. (2015). Scale effects in relation to swelling pressure in anhydritic claystones. International Symposium on Geomechanics from Micro to Macro (IS-Cambridge), Cambridge, UK.

Seufert, S., Hesse, C., Goetz-Neunhoeffer, F. and Neubauer, J. (2009a). Discrimination of bassanite and anhydrite III dehydrated from gypsum at different temperatures. In: Zeitschrift für Kristallographie Supplements, Vol. 2009(30); pp. 447-452.

Seufert, S., Hesse, C., Goetz-Neunhoeffer, F. and Neubauer, J. (2009b). Quantitative determination of anhydrite III from dehydrated gypsum by XRD. In: CEMCON Cement and Concrete Research, Vol. 39(10); pp. 936-941.

Sibelco Benelux (2009). Sikron M600 Technical Data.

Smith, B. R. and Sweett, F. (1971). Crystallization of calcium sulfate dihydrate. In: Journal of Colloid and Interface Science, Vol. 37(3); pp. 612-618.

Spaun, G. (1974). Über die Ursachen von Sohlhebungen in Tunneln des Gipskeupers. In: Festschrift Leopold Müller-Salzburg zum 65. Geburtstag. Fecker, E., Götz, H.-P., Sauer, G. and Spaun, G. (eds.). Widmann, Karlsruhe.

Sposito, G., Skipper, N. T., Sutton, R., Park, S.-H., Soper, A. K. and Greathouse, J. A. (1999). Surface geochemistry of the clay minerals. In: Proceedings of the National Academy of Sciences of the United States of America, Vol. 96(7); pp. 3358-3364.

TA Instruments (2015). Thermal Analysis.

Tang, A.-M., Cui, Y.-J. and Barnel, N. (2008). Thermo-mechanical behaviour of a compacted swelling clay. In: Géotechnique, Vol. 58(1); pp. 45-54.

Tarantino, A., Romero, E. and Cui, Y.-J. (2009). Laboratory and Field Testing of Unsaturated Soils. In.: Springer Netherlands.

Terzaghi, K. (1943). Theoretical soil mechanics. John Wiley \& Sons, Inc.

Thom, R., Sivakumar, R., Sivakumar, V., Murray, E. J. and Mackinnon, P. (2007). Pore size distribution of unsaturated compacted kaolin: the initial states and final states following saturation. In: Géotechnique, Vol. 57(5); pp. 469-474.

Thuro, K. (1993). Der Pulver-Quellversuch - ein neuer Quellhebungsversuch. In: Geotechnik, Vol. 16; pp. 101-106.

van Driessche, A. E. S., Stawski, T. M., Benning, L. G. and Kellermeier, M. (2017). Calcium Sulfate Precipitation Throughout Its Phase Diagram. In: New Perspectives on Mineral Nucleation and Growth: From Solution Precursors to Solid Materials. Van Driessche, A. E. S., Kellermeier, M., Benning, L. G. and Gebauer, D. (eds.). Springer International Publishing, Cham.

van Olphen, H. and Fripiat, J. (1979). Data handbook for clay materials and other non-metallic minerals. 1st Ed. Pergamon Press, Oxford, England.

van't Hoff, J. H., Armstrong, E. F., Hinrichsen, W., Weigert, F. and Just, G. (1903). Gips und Anhydrit. In: Zeitschrift für Physikalische Chemie, Vol. 45; pp. 257-306.

Vermeer, P. A. and de Borst, R. (1984). Non-associated plasticity for soils, concrete and rock. Heron, Delft.

Verwey, E. J. W. and Overbeek, J. T. G. (1948). Theory of the Stability of Lyophobic Colloids. Elsevier publishing company inc.

Villar, M. V., Gómez-Espina, R. and Lloret, A. (2010). Experimental investigation into temperature effect on hydro-mechanical behaviours of bentonite. In: Journal of Rock Mechanics and Geotechnical Engineering, Vol. 2(1); pp. 71-78. 
Villar, M. V. and Lloret, A. (2004). Influence of temperature on the hydro-mechanical behaviour of a compacted bentonite. In: Applied Clay Science, Vol. 26(1); pp. 337-350.

Wanninger, T., Pimentel, E. and Anagnostou, G. (2017). Experimental Investigations on the Self-Sealing of Anhydritic Rock. 51st U.S. Rock Mechanics/Geomechanics Symposium, San Francisco, California, USA.

Washburn, E. W. (1921). The Dynamics of Capillary Flow. In: Physical Review, Vol. 17(3); pp. 273-283.

Washburn, E. W. (1926-1933). International critical tables of numerical data, physics, chemistry and technology. Published for the National Research Council by McGraw-Hill, New York.

Weiss, A. (1958). Über äquimolaren Kationenaustausch bei niedrig geladenen Inonenaustauschern. In: Kolloid-Zeitschrift, Vol. 158(1); pp. 22-28.

Werlen, D. (2015). Untersuchungen zum Quellverhalten von Anhydrit. Bachelor Thesis. Supervisor: Wanninger, T., Pimentel, E. and Anagnostou, G.; Institute for Geotechnical Engineering, ETH Zurich.

Wirsching, F. (2000). Calcium Sulfate. In: Ullmann's Encyclopedia of Industrial Chemistry. Wiley-VCH Verlag $\mathrm{GmbH} \& \mathrm{Co} . \mathrm{KGaA}$.

Wittke-Gattermann, P. (1998). Verfahren zur Berechnung von Tunnels in quellfähigem Gebirge und Kalibrierung an einem Versuchsbauwerk. In: Geotechnik in Forschung und Praxis.

Wittke, M. (2004a). Bemessung von Tunneln im quellfähigen Gebirge unter Berücksichtigung der Selbstabdichtung. In: Geotechnik, Vol. 27(2); pp. 136-141.

Wittke, W. (1978). Grundlagen für die Bemessung und Ausführung von Tunnels in quellendem Gebirge und ihre Anwendung beim Bau der Wendeschleife der S-Bahn Stuttgart. Vol. 6. Aachen.

Wittke, W. (2004b). Planung, Bau und Überwachung von Tunneln in quellfähigem Gipskeuper. In: Geotechnik; pp. 104-111.

Wittke, W. and Rissler, P. (1976). Bemessung der Auskleidung von Hohlräumen in quellendem Gebirge nach der Finite-Element-Methode. In: Veröffentlichungen des Institutes für Grundbau, Bodenmechanik, Felsmechanik und Verkehrswasserbau der RWTH Aachen, Vol. 2; pp. 7-46.

Wittke, W., Wittke, M. and Wahlen, R. (2004). Zum Quellgesetz für den anhydritführenden, unausgelaugten Gipskeuper. In: Geotechnik, Vol. 27(2); pp. 112-117.

Wittke, W., Wittke, M. and Wittke-Gattermann, P. (2016). Tunnelvortrieb im anhydritführenden Gebirge. In: Taschenbuch für den Tunnelbau 2016. Deutsche Gesellschaft für Geotechnik e. V. (ed.). Wilhelm Ernst \& Sohn, Verlag für Architektur und technische Wissenschaften GmbH \& Co. KG.

Woodburn, J. A., Holden, J. C. and Peter, P. (1993). The Transistor Psychrometer: A New Instrument for Measuring Soil Suction. Unsaturated soils, New York.

Wu, R. and Boyd, C. E. (1990). Evaluation of Calcium Sulfate for Use in Aquaculture Ponds. In: The Progressive Fish-Culturist, Vol. 52(1); pp. 26-31.

Young, R. A. (1995). The Rietveld Method. Young, R. A. (ed.). Oxford university press. 



\section{Veröffentlichungen des Instituts für Geotechnik (IGT) der ETH Zürich}

Band 220: Georg Anagnostou, Kalman Kovári: The Stability of Tunnels in Grouted Fault Zones 2003, 168 Seiten, broschiert, ISBN 978-3-7281-2874-4

Band 221: Carlo Scapozza: Entwicklung eines dichte- und temperaturabhängigen Stoffgesetzes zur Beschreibung des visko-elastischen Verhaltens von Schnee 2004, 264 Seiten, broschiert, ISBN 978-3-7281-2931-4

Band 222: Sven Köhler: Auswahl und Einsatz von eisenhaltigen Füllmaterialien für Permeable Reaktive Barrieren (PRB) zur in situ Grundwassersanierung am Beispiel eines Chromatschadenfalls 2004, 244 Seiten, broschiert, ISBN 978-3-7281-2953-6

Band 223: Jolanda Luisa Trausch-Giudici: Stress-strain Characterisation of Seebodenlehm 2005, 250 Seiten, broschiert, ISBN 978-3-7281-3003-7

Band 224: Sarah M. Springman, Rita Hermanns Stengele, Rolf Katzenbach, Lisa Martinenghi, Stephan Semprich, Arno Thut, Markus von Moos: Festkolloquium zur Verabschiedung von Prof. Dr. Peter Amann: Aktuelle Probleme der Geotechnik 2006, 96 Seiten, broschiert, ISBN 978-3-7281-3072-3

Band 225: Sophie Messerklinger: Non-linearity and small strain behaviour in lacustrine clay 2006, 478 Seiten, broschiert, ISBN 978-3-7281-3083-9

Band 226: Philippe Nater: Belastungs- und Verformungsverhalten von geschichteten Bodensystemen unter starren Kreisfundationen

2007, 330 Seiten, broschiert, ISBN 978-3-7281-3138-6

Band 227: Ravikiran Chikatamarla: Optimisation of cushion materials for rockfall protection galleries 2007, Band 1: 278 Seiten, Band 2: 200 Seiten, broschiert, ISBN 978-3-7281-3164-5

Band 228: Philipp Teysseire: Geotechnische Eigenschaften von Moränen 2007, 330 Seiten, broschiert, ISBN 978-3-7281-3138-6

Band 229: $\quad$ Anja Heinz: Modifizierte Bentonitsuspensionen für geotechnische Bauverfahren in Böden hoher Durchlässigkeit

2007, 160 Seiten, broschiert, ISBN 978-3-7281-3112-6

Band 230: Martin Vogelhuber: Modifizierte Bentonitsuspensionen für geotechnische Bauverfahren in Böden hoher Durchlässigkeit

2007, 326 Seiten, broschiert, ISBN 978-3-7281-3177-5

Band 231: Andrea Thielen: Einfluss der Bodensättigung auf die Stabilität von Hängen 2008, 348 Seiten, broschiert, ISBN 978-3-7281-3165-2

Band 232: Thomas Weber: Modellierung der Baugrundverbesserung mit Schottersäulen 2008, 296 Seiten, broschiert, ISBN 978-3-7281-3167-9

Band 233: $\quad$ Erich Saurer: Shear Band Propagation in Soils and Dynamics of Tsunamigenic Landslides 2010, 190 Seiten, broschiert, ISBN 978-3-7281-3317-5

Band 234: Anton Sres: Theoretische und experimentelle Untersuchungen zur künstlichen Bodenvereisung im strömenden Grundwasser

2010, 168 Seiten, broschiert, ISBN 978-3-7281-3307-6

Band 235: Stefan Bergamin: Die Stabilität der Felsfundamente von Staumauern 2010, 270 Seiten, broschiert, ISBN 978-3-7281-3306-9

Band 236: Marco Ramoni: On the feasibility of TBM drives in squeezing ground and the risk of shield jamming 2010, 216 Seiten, broschiert, ISBN 978-3-7281-3363-2 


\section{Veröffentlichungen des Instituts für Geotechnik (IGT) der ETH Zürich}

Band 237: Carlo Rabaiotti: Analysis in Road Geotechnics

2011, 244 Seiten, broschiert, ISBN 978-3-7281-3274-1

Band 238: $\quad$ Linard Cantieni: Spatial Effects in Tunnelling Through Sqeezing Ground

2011, 188 Seiten, broschiert, ISBN 978-3-7281-3438-7

Band 239: Michael Iten: Novel Applications of Distributed Fiber-optic Sensing in Geotechnical Engineering 2012, 282 Seiten, broschiert, ISBN 978-3-7281-3454-7

Band 240: Juliane A. Buchheister: Verflüssigungspotenzial von reinem und siltigem Sand unter multiaxialer Belastung

2012, 334 Seiten, broschiert, ISBN 978-3-7281-3305-2

Band 241: $\quad$ Bernd Imre: Micromechanical Analyses of Sturzstroms (Rock Avalanches) on Earth and Mars 2012, 172 Seiten, broschiert, ISBN 978-3-7281-3331-1

Band 242: André Arnold: Tragverhalten von nicht starren Flachfundationen unter Berücksichtigung der lokalen Steifigkeitsverhältnisse

2012, 332 Seiten, broschiert, ISBN 978-3-7281-3400-4

Band 243: Yuko Yamamoto: Instabilities in alpine permafrost: strength and stiffness in a warming regime 2014, 514 Seiten, broschiert, ISBN 978-3-7281-3640-4

Band 244: Konstantinos Serafeimidis: On the dissolution, precipitation and transport processes in sulphatic swelling rocks

2014, 248 Seiten, broschiert, ISBN 978-3-7281-3646-6

Band 245: Pierre André Mayor: Verhalten eines Flussdammes unter wiederholter Hochwasserbelastung 2014, 244 Seiten, broschiert, ISBN 978-3-7281-3648-0

Band 246: Emma Jane Pooley: Centrifuge modelling of ground improvement for double porosity clay 2015, 268 Seiten, broschiert, ISBN 978-3-7281-3651-0

Band 247: Wilmer Ferney Morales Peñuela: River dyke failure modeling under transient water conditions 2015, 434 Seiten, broschiert, ISBN 978-3-7281-3630-5

Band 248: $\quad$ Amin Askarinejad: Failure mechanisms in unsaturated silty sand slopes triggered by rainfall 2015, 364 Seiten, broschiert, ISBN 978-3-7281-3676-3

Band 249: Sara Zingg: Static effects and aspects of feasibility and design of drainages in tunnelling 2017, 228 Seiten, broschiert, ISBN 978-3-7281-3819-4

Band 250: Weijie Dong: On the role of constitutive behaviour in the response of squeezing ground to tunnelling 2017, 202 Seiten, broschiert, ISBN 978-3-7281-3860-6

Band 251: Roberto Schuerch: On the delayed failure of geotechnical structures in low permeability ground 2018, 226 Seiten, broschiert, ISBN 978-3-7281-3856-9

Band 252: Jean Nicolas François-Xavier Gautray: Influence of smear and compaction zones on the performance of stone columns in lacustrine clay

2019, 408 Seiten, broschiert, ISBN 978-3-7281-3797-5

Band 253: Alexandru Marin: Dynamic non-linear soil behaviour in alpine areas 2019, 202 Seiten, broschiert, ISBN 978-3-7281-3889-7

Band 254: Florence Mezger: On the variability of squeezing behaviour in tunnelling 2020, 356 Seiten, broschiert, ISBN 978-3-7281-4005-0 
ISBN: 978-3-7281-4011-1 (Printversion)

ISBN: 978-3-7281-4012-8 (E-Book)

www.vdf.ethz.ch 